ALESSANDRO LUGLI NASCIMENTO

ANÁLISE DE ESTABILIDADE DE CONTENÇÕES, VIA MEF, CONSIDERANDO A INTERAÇÃO SOLO-ESTRUTURA 


\section{ANÁLISE DE ESTABILIDADE DE CONTENÇÕES, VIA MEF, CONSIDERANDO A INTERAÇÃO SOLO-ESTRUTURA}

Dissertação apresentada à Escola Politécnica da Universidade de São Paulo para obtenção do título de Mestre em Engenharia 


\section{ANÁLISE DE ESTABILIDADE DE CONTENÇÕES, VIA MEF, CONSIDERANDO A INTERAÇÃO SOLO-ESTRUTURA}

Dissertação apresentada à Escola Politécnica da Universidade de São Paulo para obtenção do título de Mestre em Engenharia

Área de concentração: Interação SoloEstrutura

Orientador: Prof. Dr. Marcos Aurélio de Marques Noronha 


\section{Este exemplar foi revisado e alterado em relação à versão original, sob}

responsabilidade única do autor e com a anuência de seu orientador.

São Paulo, 24 de janeiro de 2012.

Assinatura do autor

Assinatura do orientador Manes Aurélio Maques Nororke

FICHA CATALOGRÁFICA

Nascimento, Alessandro Lugli

Análise de estabilidade de contenções via MEF considerando a

interação solo-estrutura / A.L. Nascimento. -- ed.rev. -- São Paulo, 2011. $273 \mathrm{p}$.

Dissertação (Mestrado) - Escola Politécnica da Universidade de São Paulo. Departamento de Engenharia de Estruturas e Geotécnica.

1. Estabilidade de contenções 2. Método dos elementos finitos 3 .Concreto armado 4. Diagrama momento-normal-curvatura 5. Análise probabilística 6.Modelagem computacional 7.Interação solo-estrutura I. Universidade de São Paulo. Escola Politécnica. Departamento de Engenharia de Estruturas e Geotécnica II. t. 


\section{AGRADECIMENTOS}

À Deus pela dádiva da vida e pela oportunidade de cumprir mais esta etapa. À Patrícia pelo apoio e dedicação.

Ao Prof. Marcos Noronha pela orientação, amizade e confiança.

À Banca examinadora pelas valiosas sugestões na qualificação.

À minha mãe e minha sogra pelas orações.

Ao longo da minha vida profissional, muitas pessoas contribuíram para o seu crescimento e amadurecimento e influenciaram na realização deste trabalho de forma direta ou indireta. Cito algumas delas, correndo o risco de cometer injustiças:

O Edevaldo pelos primeiros ensinamentos sobre o que é concreto armado, o Ricardo e o Luis, da Rausse \& Benvenga Engenharia, por sua paixão pela profissão de engenheiros de estruturas, o Marcos Dalcin pela postura e ética na condução de equipes, o Cláudio pelo incentivo ao aprimoramento profissional, o Jorge Takahashi pela paciência e boa vontade em compartilhar um pouco de sua experiência, ensinando e aconselhando, o Marcos, o Paulo e o Willian pelas nossas reflexões e discussões técnicas tão valiosas, o Paulo e o Edson pela boa vontade em me ajudar com a revisão do texto.

À Planservi Engenharia pelo incentivo na forma de flexibilidade no trabalho para que houvesse conciliação com os estudos.

À Rocsciense Inc. por terem sido tão prestativos em fornecer uma licença temporária para uso do software Phase 2 e os artigos sobre análise estatística nos quais o software é baseado.

Finalmente, a todos muito obrigado! 


\section{RESUMO}

Este trabalho tem a finalidade de estudar a influência da parede de concreto na análise de estabilidade de contenções atirantadas bem como discutir sobre segurança nestas análises. Para isto foram elaborados modelos em estado plano de deformação por meio do método dos elementos finitos, MEF, para análise. A parede de concreto foi modelada com variações de rigidez e modelos reológico, com o fim de se enteder sua influência no fator de segurança. Por fim foi realizado um breve estudo sobre a utilização dos métodos estatísticos na análise de estabilidade de contenções.

\section{PALAVRAS CHAVE}

Estabilidade de contenções; Método dos elementos finitos; Concreto armado; Interação solo-estrutura; Diagrama momento-normal-curvatura, Métodos estatísticos na análise de estabilidade de contenções. 


\begin{abstract}
This work has the purpose of study the influence of the concrete wall in the stability analysis of tieback retaining walls and to discuss these safety analysis. Models were developed using plane strain state via the finite element method, FEM, for analysis. The concrete wall was modeled with variations of stiffness and rheological models, in order to bore its influence on the safety factor. Finally a brief study was conducted on the use of statistical methods in stability analysis of retaining walls.
\end{abstract}

\title{
KEYWORDS
}

Stability of retaining walls; Finite element method; Reinforced concrete, soilstructure interaction; Diagram-normal-moment curvature, Statistical methods in stability analysis of retaining walls. 


\section{LISTA DE SÍMBOLOS}

\section{LETRAs LATINAS MaIÚsCULAS}

B Matriz de deformação

$\mathbf{B}^{m} \quad$ Matriz de deformação do elemento $m$

C Tensor direito de Cauchy-Green

[C] Matriz de elasticidade ou matriz dos módulos de rigidez elástica

$C^{\mathrm{ep}}$ Matriz dos módulos elastoplásticos de rigidez tangente

[D] Matriz de flexibilidade.

E Tensor das deformações de Green-Lagrange

E Modelo elástico

EI Rigidez a flexão

E Módulo de elasticidade

$E_{c s}$ Módulo de elasticidade secante do concreto, é o módulo de elasticidade do aço

$E_{c i} \quad$ Módulo de elasticidade tangente inicial do concreto

$E_{c 1} \quad$ Módulo secante

E Energia

F Gradiente da transformação

FS Fator de segurança

$F_{d} \quad$ Valor de projeto das ações

$G \quad$ Módulo de elasticidade transversal

$G_{c} \quad$ Módulo de elasticidade transversal do concreto

$G_{s} \quad$ Módulo de elasticidade transversal do aço

H Função de interpolação

I Momento de inércia

$I_{1} \quad$ Invariante linear

$I_{2}$ Invariante quadrático

$I_{3}$ Invariante cúbico

$J_{1}, J_{2}, J_{3}$ Invariantes do tensor antiesférico das tensões

$\mathbf{K}^{m} \quad$ Matriz de rigidez 
L Gradiente dos deslocamentos

Pf Probabilidade de falha ou ruína

$R \quad$ Modelo plástico

R Vetor dos esforços nodais equivalentes

$\mathbf{R}_{B}^{m} \quad$ Vetor dos esforços nodais

$\mathbf{R}_{S}^{m} \quad$ Vetor dos esforços nodais

$\mathbf{R}_{0}^{m} \quad$ Vetor dos esforços nodais

$R_{d} \quad$ Valor de projeto da resistência

$R_{m} \quad$ Valor médio da resistência

$\mathbb{R}^{3} \quad$ Espaço vetorial euclidiano

$\left(\mathbf{s}_{1}, \mathbf{s}_{2}, \mathbf{s}_{3}\right) \quad$ Autovalores do tensor antiesférico

T Tensor das tensões

$\mathbf{T}^{\mathrm{e}}$ Tensor esférico ou hidrostático

$\mathbf{T}^{\mathrm{a}}$ Tensor antiesférico ou desviador

$U$ Energia de deformação interna

$U_{0}^{*} \quad$ Energia de deformação específica

$U_{0} \quad$ Energia de deformação armazenada

$\checkmark$ Coeficiente de variação

\section{Letras Latinas MaIÚsculas}

b Campo de forças de volume

c Coesão

e Base do espaço vetorial

$f_{c d} \quad$ Resistência de cálculo a compressão

$f_{c k}$ Resistência característica a compressão

$f_{c m}$ Resistência média a compressão

$f_{c m d}$ Valor reduzido para a resistência do concreto à compressão

$f_{c t k}$ Resistência característica a tração do concreto

$f_{c t, m}$ Resistência à tração média do concreto

$f_{c t \text {, inf }}$ Resistência à tração, característica inferior do concreto

$f_{c t k, s u p}$ Resistência à tração, característica superior do concreto 
$f_{y d}$ Resistência de cálculo ao escoamento do aço

$f_{y m} \quad$ Valor médio da resistência ao escoamento do aço

$f_{y k}$ Resistência característica ao escoamento do aço

$f_{t}$ Tensão última de ruptura do aço

$f_{y}$ Tensão de escoamento do aço

n Versor normal

$n_{\text {oct }}$ Tensão normal octaédrica

t Largura unitária, vetor tensão

$\overline{\mathbf{t}} \quad$ Campo de forças de superfície

$W$ Trabalho

u, u Campo de deslocamentos

u Poro pressão

\section{Letras GRegas MaIúsculas}

$\Delta$ incremento

$\Delta E_{d}$ Deformação desviadora incremental

$\Delta \varepsilon_{V}$ Deformação volumétrica incremental

$\Delta \boldsymbol{\varepsilon}^{p}$ Incremento de deformação plástica

$\Delta p$ Incremento de carga

$\Delta W$ Trabalho incremental

$\Pi \quad$ Energia potencial total

\section{Letras GRegas Minúsculas}

$\alpha_{E} \quad$ Fator de correção

$\beta \quad$ Índice de confibilidade

$\gamma_{i j}$ Distorção do corpo no plano

$\gamma_{R d} \quad$ Fator de incerteza do modelo.

$\delta_{i j} \quad$ Delta de kronecker

$\delta \Pi$ Variação do funcional de energia potencial 


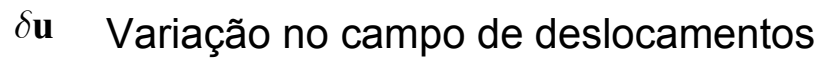

$\left[\partial_{\varepsilon}\right]$ Operador diferencial

$\varepsilon \quad$ Deformação total

$\varepsilon^{\mathrm{e}} \quad$ Parcela de deformação elástica

$\varepsilon_{c l}$ Deformação correspondente a tensão máxima de compressão

$\varepsilon_{c, \text { lim }}$ Deformação limite

$\varepsilon^{\mathrm{p}} \quad$ Parcela de deformação plástica

$\varepsilon_{B}, \varepsilon_{C}$ Representa a deformação nos pontos B e C

$\varepsilon_{m} \quad$ Deformação normal octaédrica ou média

$\varepsilon_{y} \quad$ Valor do alongamento ou encurtamento máximo do aço

$\varepsilon_{y d}$ Início do escoamento do aço

$\varepsilon_{y l} \quad$ Máximo de encurtamento do aço

$\varepsilon_{V} \quad$ Deformação volumétrica

$\varepsilon_{u k} \quad$ Alongamento total característico do aço para a carga máxima

$\varepsilon_{u d} \quad$ Alongamento total de cálculo do aço para a carga máxima

$\gamma_{o c t}$ Deformação tangencial octaédrica

$\mu \quad$ Valor médio

$\xi \quad$ Vetor deformação

$p^{\prime}$ Tensão efetiva média pela notação de Potts e Zdravkovic

$\nu_{i j} \quad$ Coeficiente de Poisson

$v$ Coeficiente de poisson

б Tensor condensado das tensões

$\sigma$ Tensão, desvio padrão

$\boldsymbol{\sigma}_{0} \quad$ Vetor tensões iniciais

$\sigma_{\mathrm{c}}$ Tensão do concreto

$\sigma_{y} \quad$ Tensão de plastificação

$\left(\sigma_{1}, \sigma_{2}, \sigma_{3}\right)$ Tensões principais no sistema tridimensional

$\sigma$ 'Tensão efetiva

$\sigma_{m}$ Tensão normal media

$\tau \quad$ Tensões de cisalhamento 
$\tau_{c}$ Redução da resistência ao cisalhamento

$\tau_{\text {oct }}$ Tensão tangencial octaédrica

$\phi \quad$ Ângulo de atrito interno do material

$\varphi \quad$ Dilatância do material

$\Phi$ Função de distribuição acumulada da distribuição normal

$\Omega \quad$ Energia potencial das cargas externas

Outros Caracteres

$\nabla \quad$ Gradiente (nabla) 


\section{SUMÁRIO}

1. INTRODUÇÃO

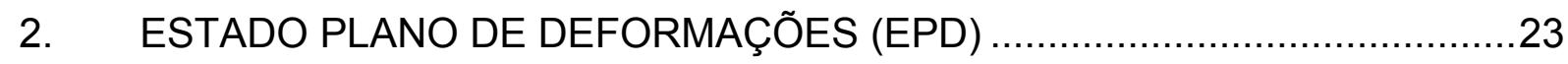

2.1 COMPATIBILIDADE DE DEFORMAÇÕES E DESLOCAMENTOS …........24

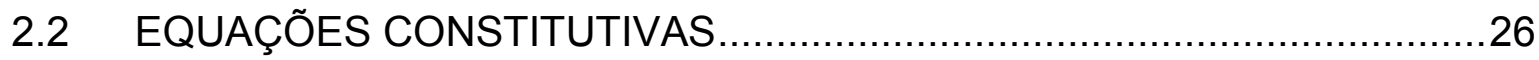

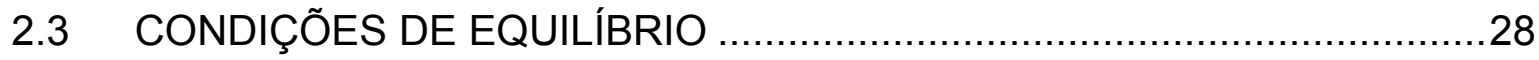

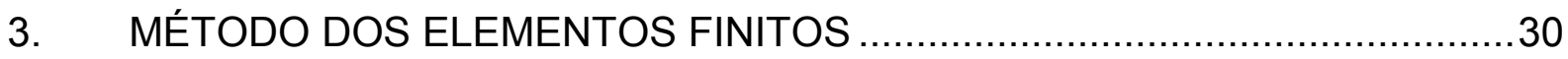

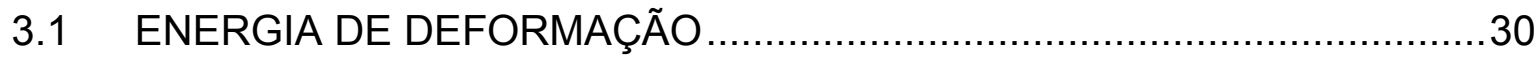

3.2 PRINCÍPIO DA MÍNIMA ENERGIA POTENCIAL ....................................30

3.3 FORMULAÇÃO DO MEF PARA ELASTICIDADE PLANA …......................34

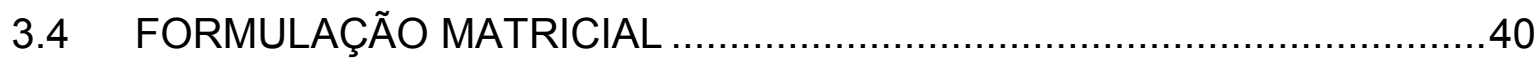

3.5 ELEMENTOS FINITOS TRIANGULARES........................................... 41

3.6 ELEMENTOS FINITOS QUADRILATERAIS ........................................45

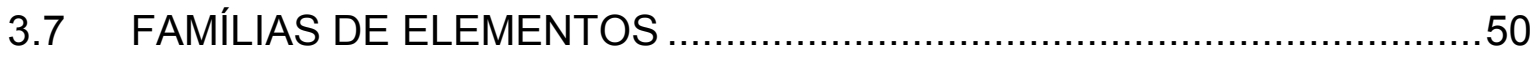

3.8 ANÁLISE NÃO-LINEAR E CRITÉRIOS DE CONVERGÊNCIA ..................52

3.9 COMPARAÇÃO DE RESULTADOS ENTRE MODELOS COM VARIAÇÃO

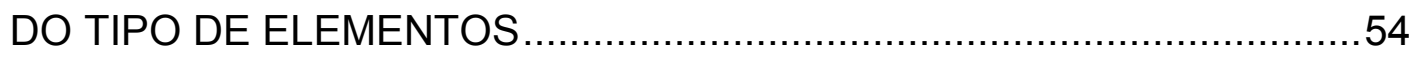

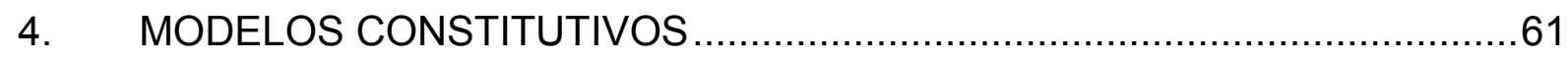

4.1 MODELOS CONSTITUTIVOS ELASTOPLÁSTICOS UNIAXIAIS ...............62

4.2 MODELOS CONSTITUTIVOS ELASTOPLÁSTICOS MULTIAXIAIS ..........66

4.2.1 TENSÕES PRINCIPAIS E INVARIANTES DE TENSÃO ......................66

4.2.2 DEFORMAÇÕES PRINCIPAIS E INVARIANTES DE DEFORMAÇÃO .73

4.2.3 CONCEITOS BÁSICOS PARA FORMULAÇÃO ...................................77

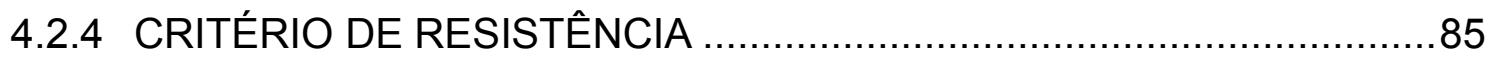

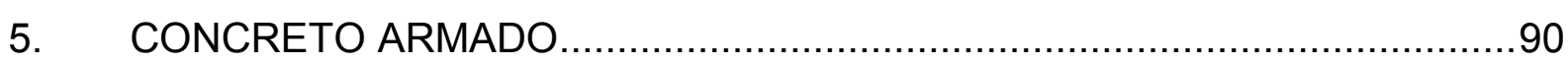

5.1 CONCRETO

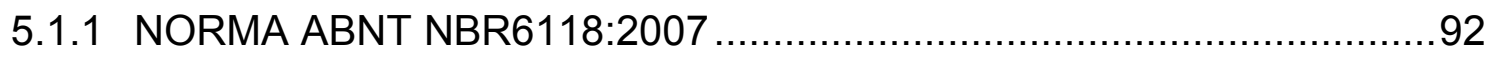

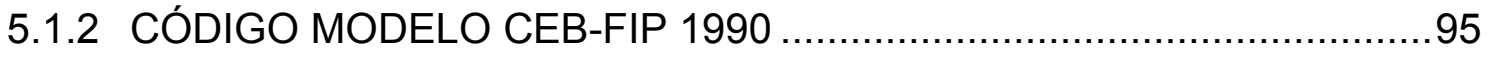


5.1.3 CÓDIGO MODELO CEB-FIB 2010 101

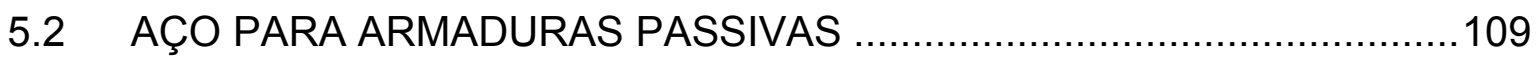

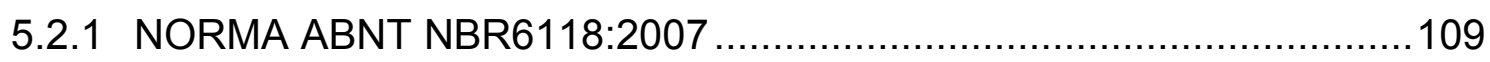

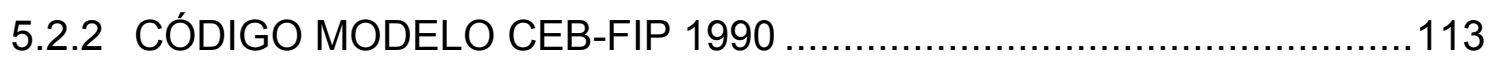

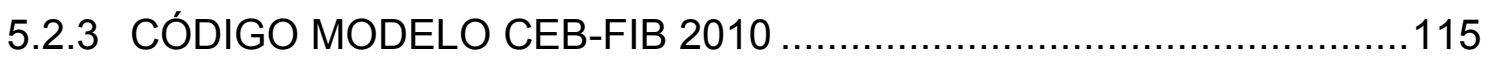

5.3 COMPARAÇÃO ENTRE A NORMA E OS CÓDIGOS MODELOS E COMENTÁRIOS ADICIONAIS ............................................................117

5.3.1 CONCRETO

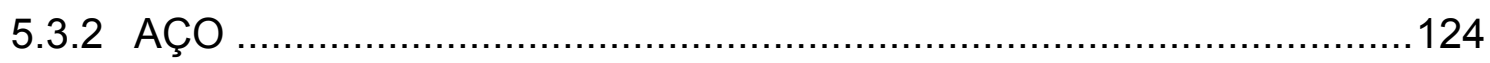

5.4 CONSIDERAÇÕES SOBRE PARÂMETROS DOS MATERIAIS E SEGURANÇA......

5.5 RIGIDEZ A FLEXÃO E FLEXO-COMPRESSÃO DE ELEMENTOS LINEARES DE CONCRETO ARMADO..

6. ANÁLISE DE ESTABILIDADE VIA MÉTODO DOS ELEMENTOS FINITOS143

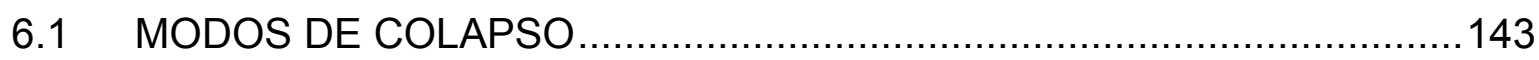

6.2 SENSIBILIDADE DE PARÂMETROS ................................................145

6.3 DEFINIÇÃO DE FATORES DE SEGURANÇA PARA ANÁLISE DE ESTABILIDADE 147

6.4 MÉTODOS ESTATÍSTICOS PARA VERIFICAÇÃO DA SEGURANÇA NA ANÁLISE DE ESTABILIDADE............................................................150

6.4.1 INCERTEZAS EM PROBLEMAS DE ENGENHARIA …....................150

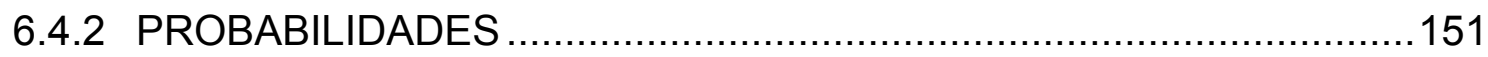

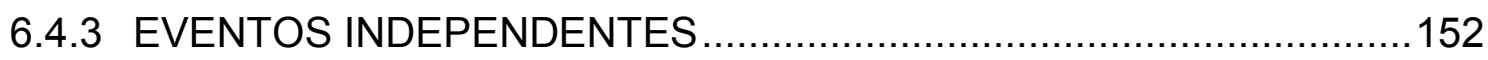

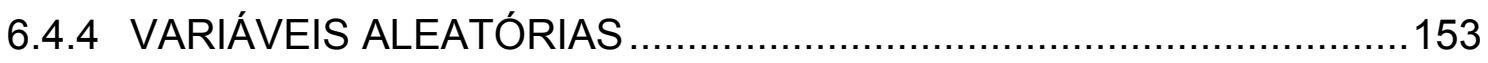

6.4.5 FUNÇÃO DENSIDADE DE PROBABILIDADE E FUNÇÃO DE DISTRIBUIÇÃO ACUMULADA DE PROBABILIDADES .....................153

6.4.6 PARÂMETROS E MOMENTOS DE UMA VARIÁVEL ALEATÓRIA ....154 6.4.7 MODELOS ANALÍTICOS DE FENÔMENOS ALEATÓRIOS ...............155 


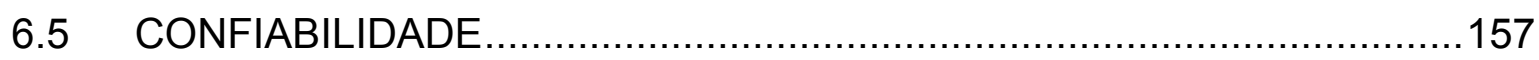

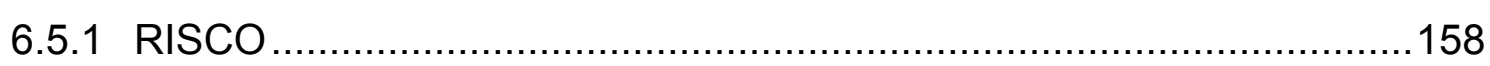

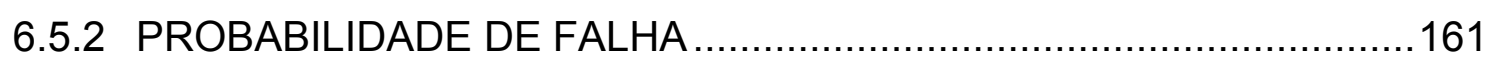

6.5.3 EQUAÇÕES DE ESTADO LIMITE E ÍNDICE DE CONFIABILIDADE..162

6.6 APLICAÇÃO DOS MÉTODOS ESTATÍSTICOS NA ANÁLISE DE

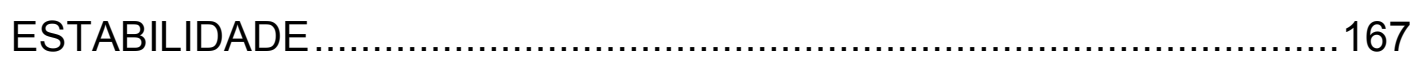

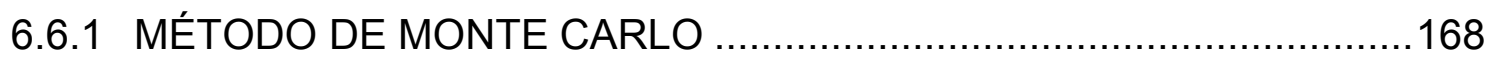

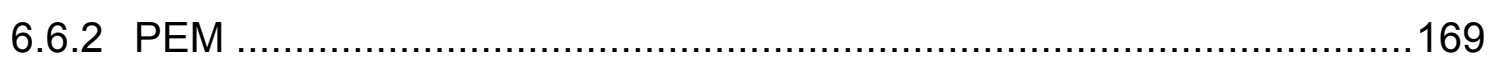

6.6.3 DADOS ESTATÍSTICOS PARA COESÃO E ÂNGULO DE ATRITO ...171

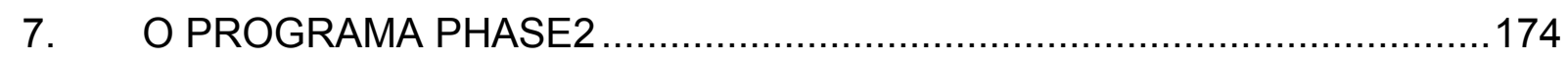

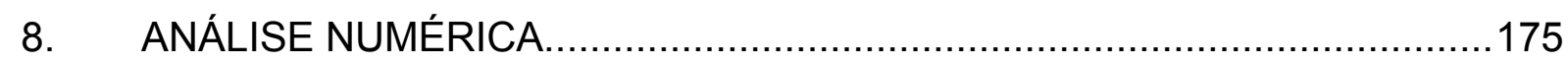

8.1 VALIDAÇÃO DA MALHA E ESFORÇOS NA PAREDE, NA FASE FINAL DE ESCAVAÇÃO 179

8.2 ANÁLISE DE ESTABILIDADE COM MODELO ELÁSTICO LINEAR PARA A RIGIDEZ DA PAREDE

8.3 ANÁLISE DE ESTABILIDADE COM MODELO ELASTOPLÁSTICO PERFEITO PARA A RIGIDEZ DA PAREDE 200

8.4 ANÁLISE DE ESTABILIDADE CONSIDERANDO A RIGIDEZ TANGENTE DO DIAGRAMA M-N-1/R, COM DIAGRAMA TENSÃO DEFORMAÇÃO PARABÓLICO-RETANGULAR E OS LIMITES DA ABNT NBR6118:2007

8.5 ANÁLISE DE ESTABILIDADE CONSIDERANDO A RIGIDEZ TANGENTE DO DIAGRAMA M-N-1/R, COM DIAGRAMA TENSÃO DEFORMAÇÃO PARABÓLICO-RETANGULAR E OS LIMITES DO CEB-FIB 2010. 228

8.6 ANÁLISE DE ESTABILIDADE COM MODELO ELÁSTICO LINEAR PARA A RIGIDEZ DA PAREDE, CONSIDERANDO A VARIAÇÃO DOS PARÂMETROS DO SOLO (ANÁLISE ESTATÍSTICA). .232

8.7 ANÁLISE DE ESTABILIDADE COM MODELO ELASTOPLÁSTICO PERFEITO PARA A RIGIDEZ DA PAREDE, CONSIDERANDO O 
DIAGRAMA BILINEAR INDICADO PELO CEB-FIB 2010 E A VARIAÇÃO DOS PARÂMETROS DO SOLO (ANÁLISE ESTATÍSTICA) ...................244

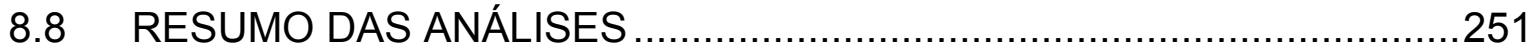

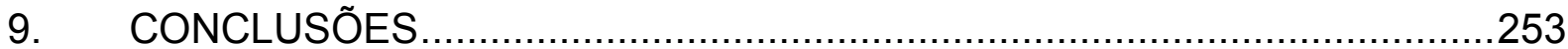

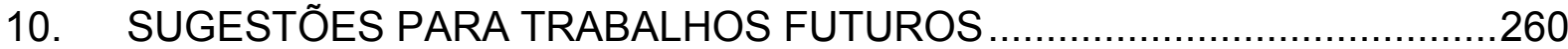

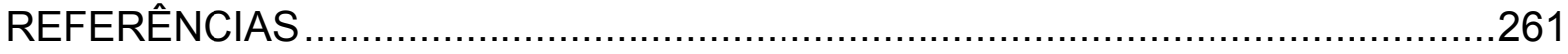

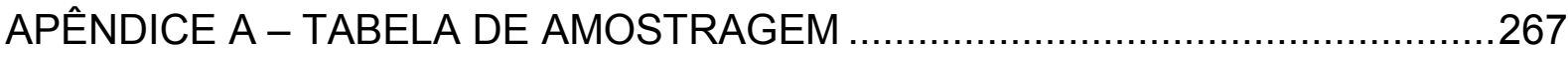




\section{INTRODUÇÃO}

Em engenharia civil, cada vez mais, procura-se entender o comportamento das estruturas nas suas interfaces com o meio, afinal com o funcionamento conjunto, são interdependentes. Este é o campo de estudos da interação soloestrutura, no qual este trabalho se situa. O tipo de obra estudada neste trabalho, cortinas atirantadas, é presença comum em estradas e encostas. Seu princípio básico é fazer com que a própria massa a ser contida trabalhe em sua estabilidade.

Para chegar a este fim é necessária a inclusão de dois elementos, os tirantes e o paramento de concreto, no caso de cortinas atirantadas, que forma um sistema composto por três agentes interdependentes; o solo, que é o maciço a ser contido e que contribui fundamentalmente para a estabilidade, a parede de concreto que reúne os esforços provenientes da tendência do maciço mover-se no sentido de sua descompressão e os tirantes que transferem estes esforços para as regiões mais resistentes do maciço.

Neste conjunto o elemento mais importante é o próprio maciço a ser contido, pois a ele serão transferidos, por fim, os esforços e cabe a ele dissipá-lo no meio. $\mathrm{O}$ conhecimento da reologia do solo é objeto de infindáveis estudos, que cada vez mais aperfeiçoam os modelos constitutivos as serem aplicados.

Os tirantes apresentam um funcionamento simples e um comportamento complexo, simples no sentido de ser um elemento linear que transfere a carga de um lugar para o outro, e complexo na forma como esta carga é transferida para o maciço, pois ela é transferida pela interface entre o solo e o bulbo injetado que é influenciado pelo método construtivo, pressão de injeção, etc.

O paramento de concreto armado, igualmente aos tirantes, apresenta um funcionamento simples e um comportamento complexo, neste caso é simples por que funciona como anteparo do maciço, contendo a carga e a transferindo aos tirantes e complexo por conta de sua reologia não-linear e a influência da interface junto ao maciço que modificam os esforços.

O objetivo deste trabalho é estudar o efeito do paramento de concreto armado como contribuinte para estabilidade do conjunto, ou seja, a análise de estabilidade considerando influência do paramento de concreto armado e também a análise de estabilidade considerando a variação estatística dos parâmetros do 
maciço e interface entre maciço e paramento de concreto. Não é objetivo deste trabalho estudar o comportamento dos tirantes, pois devido a abrangência do tema seriam necessárias outras dissertações e teses.

A justificativa é contribuir para o entendimento do significado do fator de segurança em contenções. Tradicionalmente a análise de estabilidade é realizada pelos métodos de equilíbrio limite, em que se consideram somente os parâmetros do maciço e a força dos tirantes e tem como resultado um fator de segurança que é comparado a um fator se segurança de referência. $O$ valor do fator de segurança de referência foi estabelecido com base em experiências empíricas e não traz os conceitos probabilidade de falha ou ruína tampouco considera o efeito da rigidez do paramento de concreto, portanto ao se observar somente o fator de segurança de referência, não é possível medir o grau de segurança envolvido.

Aoki (2008), em um artigo sobre fatores de segurança em estacas diz o seguinte:

[...] O profissional de engenharia civil experiente sabe que fator de segurança maior que um nada significa, e não garante que a obra não venha a ruir [...].

O problema é que não se ensina, adequadamente, como estabelecer a relação entre a probabilidade de ruína decorrente de fatores aleatórios, e o fator de segurança prescrito nas normas. $A$ probabilidade de ruína e o fator de segurança não podem ser tratados independentemente: são formas diferentes de prover margem de segurança adequada para a obra. $\mathrm{Na}$ verdade existe uma relação direta entre os dois parâmetros. (grifo do autor).

A metodologia adotada tem as seguintes etapas:

- Revisões bibliográficas em teses, dissertações e artigos que tratem o tema cortinas atirantadas;

- Revisão teórica em modelagem computacional pelo método dos elementos finitos;

- Separar os elementos constituintes da contenção, no caso a estrutura de concreto e o maciço e estudar por meio de literatura técnica seus modelos reológicos;

- Revisão teórica sobre métodos estatísticos e confiabilidade; 
- Aplicação em modelos por meio do método dos elementos finitos.

Nas revisões bibliográficas sobre o assunto não foram encontrados trabalhos que tratem da influência da rigidez do paramento de concreto na estabilidade de cortinas atirantadas. A seguir são apresentados alguns resumos e comentários da bibliografia básica analisada nos temas cortinas atirantadas, taludes, análise de estabilidade e análise estatística da estabilidade. Eles estão ordenados por ordem cronológica.

Hachich (1978) faz uma introdução aos conceitos de segurança em projetos de geotecnia e conceitua a questão do uso de probabilidade e estatística como critério de tomada de decisão. Faz uma crítica aos métodos tradicionais de introdução a segurança (fatores de segurança interno e externo) adotados em alguns métodos de análise, enquanto incapazes de refletir as incertezas nos valores de resistência e solicitações. Este trabalho sinaliza a necessidade da adoção de uma abordagem estatística como método racional e que para tanto há a necessidade de mais estudos sobre a variabilidade das características de interesse dos materiais envolvidos e suas eventuais correlações.

Nota-se que decorridos mais de trinta anos, na prática corriqueira da elaboração de projetos, ainda se adotam os mesmos métodos tradicionais em questão de segurança. Considerando o avanço deste período na área da computação, tanto em hardware quanto em software, e que seu uso está completamente disseminado nas atividades diárias da eleboração de projetos, não há impedimento para que se começe a adotar, ainda que pelos métodos mais simples, os conceitos de probabilidade de ruína, índice de segurança e risco.

Neste trabalho, Hachich (1978), faz algumas asserções que são apresentadas e discutidas adiante.

Em relação a contenções estroncadas ou atirantas quanto ao seu comportamento mecânico, coloca que não há, a rigor, interação solo-estrutura, a não ser uma estrutura mista, composta de diversos materiais (solo, concreto e aço) com problemas de interação entre eles. O comportamento como uma única estrutura mista, de fato, ocorre para estabilidade, de forma geral, considerando que cada componete constituinte contribui para tal e que há uma interdependência entre eles. Quanto ao uso do termo "interação solo-estrutura" julga-se que é uma questão semântica. Estrutura pode ter um sentido amplo, como aquilo que é, ou foi 
construído e ainda obra de construção (Novo Dicionário Eletrônico Aurélio versão 5.0), sendo assim obras de terra podem ser consideradas como estruturas, como barragens e contenções em terra armada, no entanto no uso corrente o termo significa interação entre o solo e os outros materiais constituintes da estrutura, portanto quando empregado com este significado considera-se que ele atinge o objetivo fundamental que é a transmissão e entendimento da mensagem que se quer passar.

Em relação a estados limites de utilização (estados limites de serviço) para contenções e obras enterradas:

[...] não são comuns verificações explícitas da segurança contra estados limites de utilização [...]. A razão histórica para tal procedimento é que os deslocamentos só poderiam ser calculados a partir de modelos cuja análise apresentava dificuldades aparantemente intransponíveis até o surgimento dos computadores digitais [...]. Deve haver, então, uma explicação para o fato de, apesar dessa limitação, ter sido possível construir obras que apresentaram comportamento satisfatório, isto é, não atingiram a ruína. Conclui-se que houve um ajuste empírico dos valores dos coeficientes de segurança a serem adotados, para que eles garantissem uma dequada margem de segurança contra o estadolimite condicionante, qualquer que ele fosse, de acordo com o tipo de estrutura. (HACHICH, 1978, p. 2.21 e 22, grifo do autor).

Como comentado anteriormente já não há a limitação computacional. É viável nas atividades diárias de projeto, portanto, o emprego de modelos por meio dos quais se obtenha os deslocamentos e se realize o atendimento ao estado limite de serviço. O que há são discussões e questionamentos quanto a qual método numérico, modelo reológio e critério de resistência representa melhor uma determinada situação de projeto. Quanto ao uso dos coeficientes de segurança ajustados empiricamente só pode-se afirmar que seriam válidos para obras que apresentem condições idênticas de geometria, materiais empregados na estrutura e condições de suporte, mas ainda assim somente se desprezarmos a variabilidade intrinseca das propriedades dos materiais.

Em relação a aplicação dos métodos estatísticos na análise de segurança: 
O que se observa, particularmente em geotecnia, é que os engenheiros que pesquisam novos modelos de análise de segurança - ou seja, que trabalham em nível científico de teorização - se esquecem por vezes de que, conforme já observado por Langejan (1965) em um dos primeiros trabalhos sobre o assunto, é preciso passar dos princípios a métodos aplicáveis a diferentes problemas práticos. Os projetistas, por sua vez, tendem a subestimar o valor dos novos modelos pois os prováveis benefícios se encontram em geral um pouco além das necessidades dos projetos de rotina, os quais geraram uma tradição de realizações úteis baseadas em modelos determinísticos. (HACHICH, 1978, p. 4,7).

Para alguns problemas de engenharia já há uma farta quantidade de publicações e pesquisas e até programas comerciais desenvolvidos. Para o problemas da estabilidade de taludes, por exemplo citam-se os trabalhos: Cherubini, Garrasi e Petrolla (1992), Hammah et al. (2005), Fabrício (2006) e Ribeiro (2008); o programa Slide 6.0 da Rocscience Inc. que oferece diversos métodos de análise de estabilidade por equilíbrio limite e análise estatística. Faltam pesquisas sobre a variabilidade dos parâmetros do solo, suas correlações, a variabilidade com a profundidade e regional. Neste sentido as pesquisas no assunto poderiam fornecer mapas regionais com tais informações. O fato dos projetistas subestimarem o valor dos modelos que consideram a variabilidade estatística reside no desconhecimento no assunto e na falsa crença de que o fator de segurança é suficiente para garantir a segurança.

Marzionna (1979), discorre sobre os métodos empíricos e semiempíricos de cálculo de contenções em valas. São abordados os temas: estabilidade geral, estabilidade de fundo, estabilidade local e deslocamentos. Quanto a segurança introduzida por meio de fatores de segurança, pondera que a adoção de um valor mínimo de fator de segurança parece desprovido de justificativa e seria mais razoável aceitar como estável e segura valas com com fator de segurança maior que 1 e argumenta que mesmo que uma determinada análise resultar em um fator de segurança menor que 1 , não quer dizer que este será o mecanismo de ruptura da estrutura, pois podriam existir outros mecanismos em piores condições de estabilidade. Comenta-se que isto está associado ao método de análise adotado, 
método do equilíbrio limite, em que deve-se admitir um determinado mecanismo de ruptura para só então calcular seu equilíbrio.

Nimir (1979), discorre sobre o dimensionamento e construtução de contenções de valas de metrô. Conceitua os diverso métodos de cálculo, empírico, semiempírico e analítico e fornece tabelas para prédimensionamento de contenções, elaboradas por meio de um programa de análise unidimensional evolutivo.

Meyerhof (1982) apresenta um estudo sobre os estados limites em engenharia geotécnica analisando a magnitude dos fatores de segurança parciais e totais utilizados em projetos de aterros, estruturas de contenção e fundações, a luz dos conceitos de confiabilidade e probabilidade de ruína. No caso de contenções, para adoção de fatores de segurança totais entre os valores 1,5 a 2 conclui que a probabilidade de ruína correspondente é aproximadamente $0,1 \%$.

Gimenes (1988), estuda um método para obtenção de parâmetros estatísticos de medições geotécnicas irregularmente espaçadas. Este método deriva de um modelo de interpolação linear de pontos regularmente espaçados associado a metodologia de Vanmarcke (1977). Ele foi utilizado para determinação da escala de flutuação, que foi confrontada com valores simulados por um processo aleatório correlacionado, com resultados satisfatórios.

Clough e O'Rourke (1990) fazem uma revisão bibliográfica sobre deslocamentos em paredes escoradas e um estudo paramétrico por meio de modelos numéricos para avaliar os efeitos de cada componente da estrutura separadamente (rigidez da parede, profundidade da escavação); como resultado de interesse é apresenta um gráfico em que o deslocamento máximo da parede é obtido em função da rigidez da parede e fator segurança para estabilidade.

Cherubini, Garrasi e Petrolla (1992) avaliam a confiabilidade quanto à estabilidade local de uma cortina de estacas prancha atirantada com tirante único, e engastada em solo não coesivo (areias), por meio de dois modelos analíticos em que se consideram os empuxos passivo e ativo por meio do equilíbrio limite. Como variáveis aleatórias foram consideradas o ângulo de atrito, o peso do solo, sem correlação entre eles, e o ângulo de atrito na interface entre a cortina sendo que este último foi admitido como função do ângulo de atrito do solo. Para obtenção da probabilidade de falha e índice de confiabilidade utilizou o Point-Estimate Method (PEM) proposto por Rosenblueth (1975). Os resultados indicaram que a 
variabilidade do peso do solo afetou pouco a estabilidade; Um resultado interessante foi que a probabilidade de ruína foi maior para valores maiores de ângulo de atrito na interface e também para valores maiores de ângulo de atrito do maciço.

Trondi (1993) desenvolve um programa para o cálculo de paredes de contenção através de um método unidimensional evolutivo considerando a parede como uma viga de largura unitária calculada através do método dos elementos finitos. O solo é considerado como um conjunto de molas e para o calculo de plastificação destas molas é utilizado o método de Newton-Raphson modificado.

More (2003) estudou o comportamento de cortinas atirantadas como um todo, em análise numérica, incluindo as análises de estabilidades por equilíbrio limite, ambos de forma determinística. Neste trabalho há um capítulo dedicado aos tirantes. Porém como se trata de um estudo geral, a influência do paramento de concreto na estabilidade foi estudada superficialmente e apenas para modelos com rigidez constante do paramento.

Aun (2004), estuda a influência da largura da vala na determinação do empuxo passivo na região da ficha. Conclui que para uma relação aproximada entre a lagura da vala pelo comprimento da ficha maior ou igual a dois os coeficientes de empuxo passivo são próximos aos das teorias clássicas.

Fabrício (2006) aborda a análise probabilística de probabilidades em taludes e contenções do tipo muro de gravidade. Compara dois métodos probabilísticos, o PEM e segundo momento. Em ambos os casos foi adotado o método do equilíbrio limite para o cáculo da estabilidade.

Tacitano (2006), desenvolve um programa de análise que utiliza o método unidimensional evolutivo. Neste método o paramento é representada por uma viga com rigidez constante, as estroncas ou os tirantes por molas e o solo por molas distribuidas ao longo da contenção de forma isolada uma das outras (hipótese de Winkler) com comportamento elastoplástico com histerese.

Flores (2008) também aborda a análise probabilística de probabilidades em taludes e compara dois métodos probabilísticos, O PEM e segundo momento. Adicionalmente considera a variabilidade espacial do solo.

Ribeiro (2008) realiza uma revisão bibliográfica de conceitos básicos de probabilidade e estatística, mostrando alguns avanços da aplicação desses conceitos na engenharia geotécnica. 
Bilgin (2010) estuda os efeitos dos métodos construtivos para contenções com estacas prancha quanto a deslocamentos, distrubuição de empuxos horizontais, esforços na estaca prancha e no tirante, por meio de modelos em estado plano de deformações analisados com o método dos elementos finitos. O objetivo é avaliar as diferenças nestes resultados, já que os métodos tradicionais de dimensionamento não fazem distinção entre os métodos construtivos empregados. Para isto são avaliados dois métodos construtivos, cravação da cortina e escavação e cravação da cortina (no trecho da ficha) e aterro a montante, também são analisados os resultados consdiderando a variação do tipo de solo e da altura da contenção. Os resultados das análises mostraram que houve um diferença mínima quanto a empuxos horizontais totais (faz-se o comentário de que nesta análise a estaca prancha tem rigidez pequena quando comparada com a rigidez do maciço, o que leva o leva a um estado "ativo", assim poderia ser explicada a indistinção nestes resultados), os deslocamentos e momentos fletores para contenção construída com aterro a montante foram significamente maiores (54\% e $34 \%$ respectivamente).

Zevgolis e Bourdeau (2010) fizeram um estudo estatístico sobre análise de estabilidade externa de muros de flexão considerando modos de falha correlacionados (para um determinado valor de parâmetros a probabilidade de ocorrencia de ao menos um dos três modos de falha). Os resultados mostrarm que a probabilidade de falha do sistema não é uma função linear dos valores dos fatores de segurança. 


\section{ESTADO PLANO DE DEFORMAÇÕES (EPD)}

Seja um espaço vetorial definido em $\mathbb{R}^{3}$ de base e e um sistema de coordenadas $X$ com um corpo contido neste espaço e que uma das dimensões deste corpo seja muito maior que as demais, neste caso $x_{3} \gg x_{1}, x_{2}$ como mostrado na figura 1:

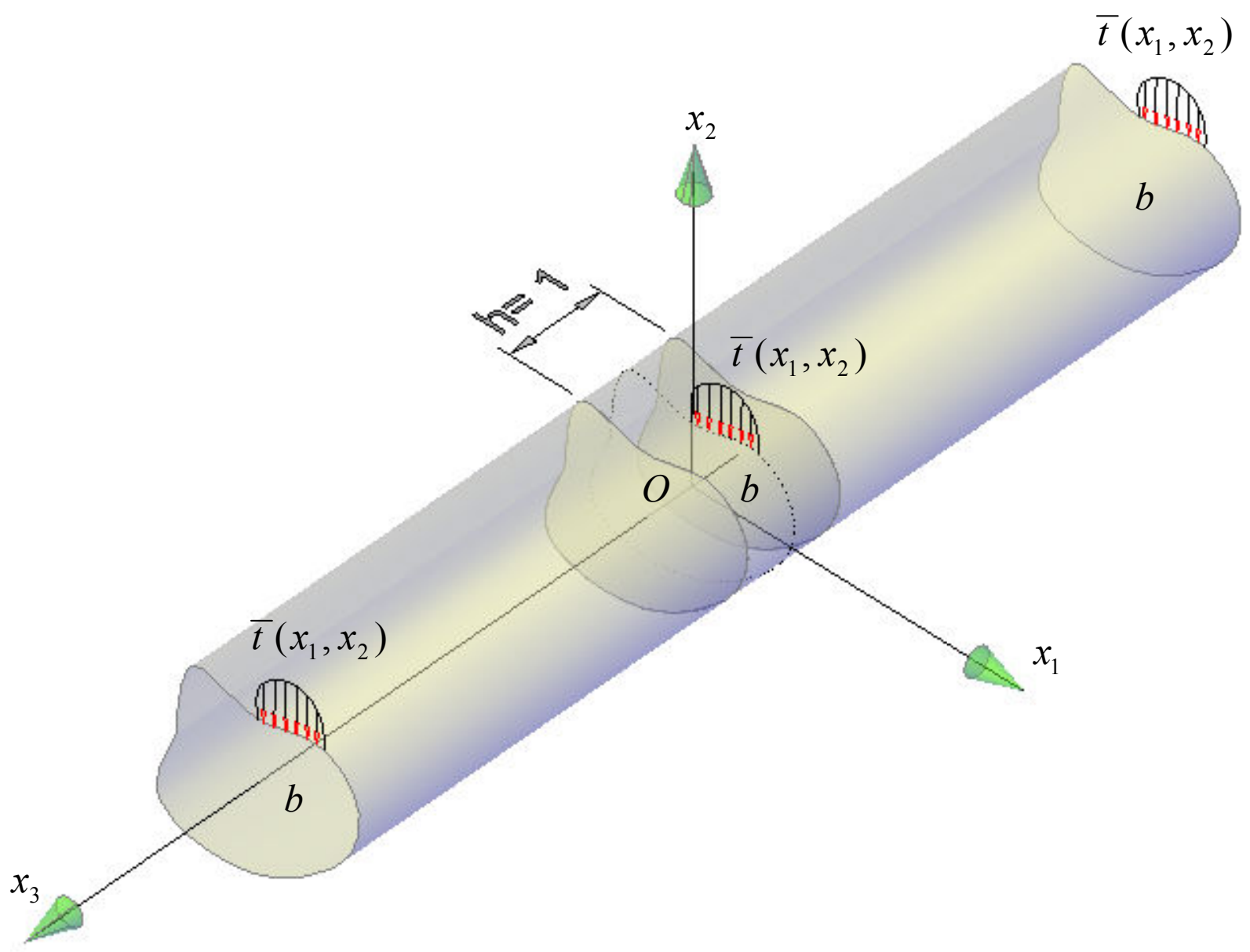

Figura 1 - Estado plano de deformações

Em que, t é a largura unitária e que o corpo seja constituído de material elástico linear.

$$
\left\{e_{i}\right\}=\left[\begin{array}{l}
e_{1} \\
e_{2} \\
e_{3}
\end{array}\right] \text {, é uma base ortonormal. }
$$




$$
[X]=\left[\begin{array}{l}
x_{1} \\
x_{2} \\
x_{3}
\end{array}\right] \text {, é um sistema cartesiano ortogonal. }
$$

\subsection{COMPATIBILIDADE DE DEFORMAÇÕES E DESLOCAMENTOS}

Admitindo-se um campo de deslocamentos $\mathbf{u}=u_{j}\left(x_{i}\right)$, independente de $x_{3} \mathrm{e}$ com o vetor dos deslocamentos $u_{3}$ de valor nulo, teremos:

$$
\{\mathbf{u}\}=\left[\begin{array}{c}
u_{1}\left(x_{1}, x_{2}\right) \\
u_{2}\left(x_{1}, x_{2}\right) \\
\cdot
\end{array}\right]
$$

Assim o gradiente dos deslocamentos, $\mathbf{L}$, fica definido por:

$$
\mathbf{L}=\nabla \mathbf{u}
$$

$$
[\mathbf{L}]=u_{i, j}=\left[\begin{array}{ccc}
u_{1,1} & u_{1,2} & \cdot \\
u_{2,1} & u_{2,1} & \cdot \\
\cdot & \cdot & \cdot
\end{array}\right]
$$

O gradiente da transformação, $\mathbf{F}$ :

$$
\begin{aligned}
& \mathbf{F}=\mathbf{L}+\mathbf{I} \\
& {[\mathbf{F}]=\left[\begin{array}{ccc}
u_{1,1} & u_{1,2} & \cdot \\
u_{2,1} & u_{2,1} & \cdot \\
\cdot & \cdot & \cdot
\end{array}\right]+\left[\begin{array}{ccc}
1 & \cdot & \cdot \\
\cdot & 1 & \cdot \\
\cdot & \cdot & 1
\end{array}\right]=\left[\begin{array}{ccc}
F_{11} & F_{12} & \cdot \\
F_{21} & F_{22} & \cdot \\
\cdot & \cdot & 1
\end{array}\right]}
\end{aligned}
$$

O tensor direito de Cauchy-Green, $\mathbf{C}$ :

$$
\begin{aligned}
\mathbf{C} & =\mathbf{F}^{\mathbf{T}} \mathbf{F} \\
{[\mathbf{C}] } & =\left[\begin{array}{ccc}
F_{11} & F_{21} & \cdot \\
F_{12} & F_{22} & \cdot \\
\cdot & \cdot & 1
\end{array}\right] \cdot\left[\begin{array}{ccc}
F_{11} & F_{12} & \cdot \\
F_{21} & F_{22} & \cdot \\
\cdot & \cdot & 1
\end{array}\right]=\left[\begin{array}{ccc}
C_{11} & C_{12} & \cdot \\
C_{21} & C_{22} & \cdot \\
\cdot & \cdot & 1
\end{array}\right]
\end{aligned}
$$


Com o exposto acima se pode obter o tensor das deformações de GreenLagrange, $\mathbf{E}$ :

$$
\begin{aligned}
& \mathbf{E}=\frac{1}{2}(\mathbf{C}-\mathbf{I})=\frac{\mathbf{1}}{\mathbf{2}}\left(\mathbf{L}+\mathbf{L}^{\mathrm{T}}+\mathbf{L}^{\mathrm{T}} \mathbf{L}\right) \\
& {[\mathbf{E}]=\frac{1}{2} \cdot\left(\left[\begin{array}{ccc}
C_{11} & C_{12} & \cdot \\
C_{21} & C_{22} & \cdot \\
\cdot & \cdot & 1
\end{array}\right]-\left[\begin{array}{ccc}
1 & \cdot & \cdot \\
\cdot & 1 & \cdot \\
\cdot & \cdot & 1
\end{array}\right]\right)=\left[\begin{array}{ccc}
E_{11} & E_{12} & \cdot \\
E_{21} & E_{22} & \cdot \\
\cdot & \cdot & \cdot
\end{array}\right]}
\end{aligned}
$$

Para pequenas deformações, $\mathbf{L}^{\mathrm{T}} \mathbf{L} \approx 0$, pois $\|u\|$ é muito pequeno.

$$
u_{k, i} \cdot u_{k, j} \approx 0
$$

Neste caso o tensor das deformações fica definido por:

$$
\begin{aligned}
& \mathbf{E}=\frac{1}{2}\left(\mathbf{L}+\mathbf{L}^{\mathbf{T}}\right) \approx \boldsymbol{\varepsilon} \\
& {[\mathbf{E}]=\left[\begin{array}{ll}
\varepsilon_{11} & \varepsilon_{12} \\
\varepsilon_{21} & \varepsilon_{22}
\end{array}\right]}
\end{aligned}
$$

Na forma compacta:

$$
\{\boldsymbol{\varepsilon}\}=\left\{\begin{array}{c}
\varepsilon_{11} \\
\varepsilon_{22} \\
2 \varepsilon_{12}
\end{array}\right\}=\left\{\begin{array}{c}
\varepsilon_{11} \\
\varepsilon_{22} \\
\gamma_{12}
\end{array}\right\}
$$

Em que $\gamma_{12}$ é a distorção do corpo no plano $\left(x_{1}, x_{2}\right)$.

De (2.4) e (2.15) e por meio do operador diferencial $\left[\partial_{\varepsilon}\right]$, obtêm-se:

$$
\{\boldsymbol{\varepsilon}\}=\left[\partial_{\varepsilon}\right]\{\mathbf{u}\} \Rightarrow\left\{\begin{array}{l}
\varepsilon_{11} \\
\varepsilon_{22} \\
\gamma_{12}
\end{array}\right\}=\left[\begin{array}{ll}
\frac{\partial}{\partial x_{1}} & \cdot \\
\cdot & \frac{\partial}{\partial x_{2}} \\
\frac{\partial}{\partial x_{2}} & \frac{\partial}{\partial x_{1}}
\end{array}\right]\left\{\begin{array}{l}
u_{1} \\
u_{2}
\end{array}\right\}
$$




\subsection{EQUAÇÕES CONSTITUTIVAS}

O tensor das tensões, $\mathbf{T}$, é definido por:

$$
\mathbf{T}=\mathbb{C} \mathbf{E}
$$

$$
\text { Fazendo: } \mathbb{C}^{-1}=\mathbb{D}
$$

$$
\mathbf{E}=\mathbb{D} \mathbf{T}
$$

$\mathbb{C}$ é o tensor dos módulos elásticos rigidez e $\mathbb{D}$ o tensor dos módulos elásticos de flexibilidade.

$\mathrm{Na}$ forma compacta, por meio do tensor condensado das tensões, $\boldsymbol{\sigma}$ :

$$
\begin{aligned}
& \{\boldsymbol{\sigma}\}=[C]\{\boldsymbol{\varepsilon}\} \\
& \text { Fazendo } C^{-1}=D \\
& \{\boldsymbol{\varepsilon}\}=[D]\{\boldsymbol{\sigma}\}
\end{aligned}
$$

$[C]$ é a matriz de elasticidade ou matriz dos módulos de rigidez elástica e $[D]$ a matriz de flexibilidade.

Supondo ortotropia do material, com módulo de elasticidade $E_{i}$ e coeficiente de Poisson, $\nu_{i j}$, diferente para cada direção:

$$
\begin{aligned}
& \varepsilon_{11}=\frac{T_{11}}{E_{1}}-\frac{\nu_{21} \cdot T_{22}}{E_{2}}-\frac{\nu_{31} \cdot T_{33}}{E_{3}} \\
& \varepsilon_{22}=-\frac{\nu_{12} \cdot T_{11}}{E_{1}}+\frac{T_{22}}{E_{2}}-\frac{\nu_{32} \cdot T_{33}}{E_{3}} \\
& \varepsilon_{33}=-\frac{\nu_{13} \cdot T_{11}}{E_{1}}-\frac{\nu_{23} \cdot T_{22}}{E_{2}}+\frac{T_{33}}{E_{3}}
\end{aligned}
$$

Para o estado plano de deformações (EPD), tem-se que $\varepsilon_{33}=0$, assim: 


$$
T_{33}=E_{3}\left(\frac{\nu_{13} \cdot T_{11}}{E_{1}}+\frac{\nu_{23} \cdot T_{22}}{E_{2}}\right)
$$

Para material isotrópico:

$$
\begin{aligned}
& T_{33}=\nu\left(T_{11}+T_{22}\right) \\
& \varepsilon_{11}=\frac{\left(1-\nu^{2}\right)}{E} \cdot T_{11}-\frac{\nu \cdot\left(1-\nu^{2}\right)}{E} \cdot T_{22} \\
& \varepsilon_{22}=\frac{\left(1-\nu^{2}\right)}{E} \cdot T_{22}-\frac{\nu \cdot\left(1-\nu^{2}\right)}{E} \cdot T_{11}
\end{aligned}
$$

Lembrando-se que:

$$
\gamma_{12}=\frac{T_{12}}{G}
$$

$G$ é o módulo de elasticidade transversal, e para materiais elásticos e isotrópicos é definido por:

$$
G=\frac{E}{2 \cdot(1+\nu)}
$$

Com isso $[D]$ pode ser definida por:

$$
[D]=\frac{1+\nu}{E}=\left[\begin{array}{ccc}
1-\nu & -\nu & \cdot \\
-\nu & 1-\nu & \cdot \\
\cdot & \cdot & 2
\end{array}\right]
$$

Considerando-se (2.20):

$$
[C]=\frac{E}{(1+\nu) \cdot(1-2 \nu)}=\left[\begin{array}{ccc}
1-\nu & -\nu & \cdot \\
-\nu & 1-\nu & \cdot \\
\cdot & \cdot & \frac{1-2 \nu}{2}
\end{array}\right]
$$




\subsection{CONDIÇÕES DE EQUILÍBRIO}

Para um determinado campo de forças de volume, $\mathbf{b}$ :

$$
\begin{aligned}
& \nabla \cdot \mathbf{T}+\mathbf{b}=0 \\
& \nabla \cdot \mathbf{T}=T_{i j, j} \\
& \mathbf{b}=b_{i}
\end{aligned}
$$

Para o EPD:

$$
\begin{aligned}
& b_{3}=0 \\
& T_{13}=T_{23}=T_{31}=T_{32}=0 \\
& T_{33}=f\left(T_{11}, T_{22}\right)
\end{aligned}
$$

Assim:

$$
\begin{aligned}
& T_{11,1}+T_{12,2}+b_{1}=0 \\
& T_{21,1}+T_{22,2}+b_{2}=0
\end{aligned}
$$

Para um determinado campo de forças de superfície, $\overline{\mathbf{t}}$ :

$$
\mathbf{t}=\mathbf{T n}=\overline{\mathbf{t}}
$$

t é o vetor tensão e n o versor normal ao ponto de aplicação de $\mathbf{t}$.

Para superfície lateral:

$$
\{\mathbf{n}\}=\left[\begin{array}{c}
n_{1} \\
n_{2} \\
\cdot
\end{array}\right]
$$




$$
\left\{\begin{array}{l}
t_{1}=T_{11} \cdot n_{1}+T_{12} \cdot n_{2}=\bar{t}_{1} \\
t_{2}=T_{21} \cdot n_{1}+T_{22} \cdot n_{2}=\bar{t}_{2} \\
t_{3}=0
\end{array}\right.
$$

Para superfície de topo:

$$
\begin{gathered}
\left\{e_{3}\right\}=\left[\begin{array}{l}
\cdot \\
\cdot \\
1
\end{array}\right] \\
\left\{\begin{array}{l}
t_{1}=0 \\
t_{2}=0 \\
t_{3}=T_{33}
\end{array}\right.
\end{gathered}
$$




\section{MÉTODO DOS ELEMENTOS FINITOS}

\subsection{ENERGIA DE DEFORMAÇÃO}

No desenvolvimento do método dos elementos finitos (MEF) os teoremas baseados no princípio da conservação da energia têm grande importância, como exemplo cita-se o fato da formulação ser baseada na resolução de sistemas de integrais que permitem que o domínio seja subdivido em subdomínios e que as funções integradas sejam contínuas apenas nos subdomínios.

Proença (2003, p. 373) faz uma explanação sobre os princípios físicos dos teoremas de energia, neste texto tais princípios estão apresentados abaixo de forma resumida.

Sobre um sólido deformável, diferentes formas de energia podem ser caracterizadas, de natureza mecânica são potenciais de posição, forças atuantes sobre ele, a energia cinética e térmica. A primeira lei da termodinâmica postula um balanço entre as variações de energia no sistema e introduz a energia interna, como função do trabalho das tensões nas deformações do corpo.

$$
E_{\text {interma }}+E_{\text {cinética }}=W_{\text {trabahlho }}+Q_{\text {térmica }}
$$

No desenvolvimento que será apresentado admiti-se que a variação da energia potencial de posição e da energia cinética seja nula considerando-se que a grandeza dos deslocamentos seja pequena, não haja movimento inicial e o carregamento seja aplicado de forma gradual num regime quase-estático. Também que não há energia térmica a ser considerada, levando-se em conta que o processo de carregamento e deformação é adiabático e isotérmico.

$$
E_{\text {interna }}=W_{\text {trabalho }}
$$

\subsection{PRINCÍPIO DA MÍNIMA ENERGIA POTENCIAL}

Inicialmente podemos definir energia potencial total $(\Pi)$ como $\circ$ trabalho total realizado para deslocar a estrutura de seu estado deformado para o indeformado. A energia potencial total pode ser definida pela seguinte expressão: 


$$
\Pi=U+\Omega
$$

$U$ é a energia de deformação interna e $\Omega$ é a energia potencial das cargas externas. O MEF pode ser formulado a partir da variação do funcional de energia potencial:

$$
\delta \Pi=\delta(U+\Omega)
$$

O princípio da mínima energia potencial total pode ser definido por:

$$
\delta \Pi=0
$$

O princípio da mínima energia potencial estacionária define que em um sistema conservativo, dentre todas as configurações de deformadas admissíveis, aquela que torna a energia potencial estacionária com respeito a pequenas variações de deslocamentos e satisfaz as equações de equilíbrio, leva $\Pi$ a uma condição de extremo. No caso do funcional energia potencial total, a condição de estacionariedade é de mínimo.

Em outras palavras: "Entre todos os campos de deslocamentos cinematicamente compatíveis, o que corresponde à configuração de equilíbrio do sólido, é o que torna estacionária a energia potencial total." (Sánchez, 2000, p. 245)

A verificação do estado de equilíbrio é realizada por meio da segunda variação da energia potencial total (Sánchez, 2000; Savassi, 1996):

$$
\begin{aligned}
& \delta^{2} \Pi>0 \text {, equilíbrio estável } \\
& \delta^{2} \Pi=0 \text {, equilíbrio indiferente } \\
& \delta^{2} \Pi<0 \text {, equilíbrio instável }
\end{aligned}
$$

Júnior et al. (2007, p.36,37) mostra a aplicação do princípio da energia potencial estacionária para o cálculo do deslocamento causado pela aplicação de uma força na extremidade de uma mola: 

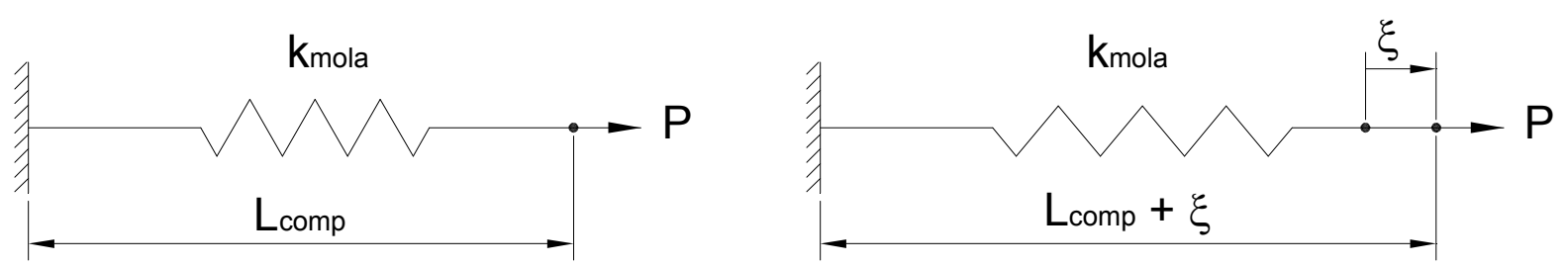

Figura 2 - Mola com carregamento na extremidade (modificado de Júnior et al. 2007)

A energia de deformação armazenada na mola e a energia potencial das cargas externas são respectivamente:

$$
\begin{aligned}
& U=\frac{1}{2} \cdot k_{\text {mola }} \cdot \xi^{2} \\
& \Omega=-P \cdot \xi
\end{aligned}
$$

A energia potencial das cargas externas corresponde à energia necessária para carga retornar a posição inicial. Neste caso a energia potencial é:

$$
\Pi=\frac{1}{2} \cdot k_{m o l a} \cdot \xi^{2}-P \cdot \xi
$$

Aplicando o princípio da mínima energia potencial total e da mínima energia potencial estacionária:

$$
\begin{aligned}
& \delta \Pi=\frac{\partial \Pi}{\partial \xi} \delta \xi=0 \\
& \frac{\partial\left(\frac{1}{2} \cdot k_{\text {mola }} \cdot \xi^{2}-P \cdot \xi\right)}{\partial \xi} \delta \xi=\left(k_{\text {mola }} \cdot \xi-P\right) \delta \xi=0
\end{aligned}
$$

Considerando a variação $\delta \xi$ nula:

$$
\left\{\begin{array}{l}
k_{\text {mola }} \cdot \xi-P=0 \\
\xi=\frac{P}{k_{\text {mola }}}
\end{array}\right.
$$


Demonstrando graficamente:

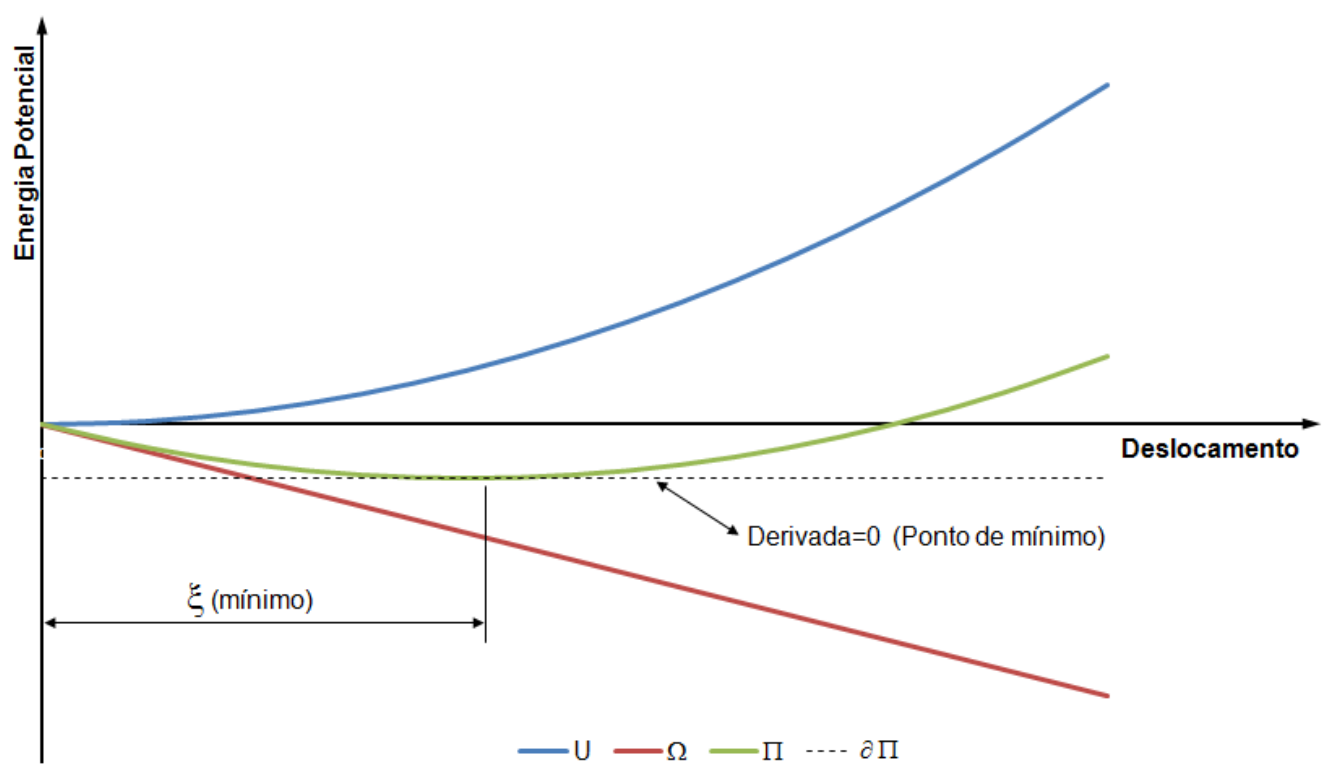

Figura 3 - Energia Potencial x Deslocamento (modificado de Júnior et al. 2007)

A verificação da condição de equilíbrio pode ser feita por:

$$
\delta^{2} \Pi=\frac{\partial^{2}\left(\frac{1}{2} \cdot k_{\text {mola }} \cdot \xi^{2}-P \cdot \xi\right)}{\partial \xi^{2}} \delta^{2} \xi=k_{\text {mola }} \therefore \text { Equilíbrio estável }
$$

Para resolução de problemas com vários graus de liberdade a energia potencial total e sua variação são estabelecidas, respectivamente, por:

$$
\begin{gathered}
\Pi=\Pi_{i} \\
\delta \Pi=\delta \Pi_{i}
\end{gathered}
$$

Em se tratando do MEF, Soriano (2003, p. 10) define:

No método dos elementos finitos, a solução aproximada de deslocamentos é arbitrada em cada subdomínio, denominado elemento finito, em função dos deslocamentos dos seus pontos nodais, deslocamentos esses que são determinados com a referida condição de mínimo [A condição de mínimo a que ele se refere é do funcional energia potencial total]. 


\subsection{FORMULAÇÃO DO MEF PARA ELASTICIDADE PLANA}

Em Savassi (1996, p. 105) o desenvolvimento do MEF é realizado a partindo-se da energia de deformação específica, $U_{0}^{*}$, para obtenção da energia de deformação interna, $U$ :

$$
U_{0}^{*}=\frac{1}{2} \cdot\{\boldsymbol{\sigma}\}^{T}\{\boldsymbol{\varepsilon}\}
$$

Neste ponto cabe a observação de que a deformação específica como apresentada acima é formulada para materiais com relações constitutivas lineares, para o caso de materiais com relações constitutivas não lineares é necessário metodologia para que a matriz de rigidez seja atualizada. Em modelos constitutivos e análise não-linear e critérios de convergência, este tema será novamente abordado. A seguir será apresentado, como exemplo, um método de carregamento incremental que nos leva a um problema tangente.

Em um problema tangente a relação entre tensão e deformação pode ser apresentada por:

$$
\begin{aligned}
& \dot{\mathbf{T}}=\mathbb{C} \dot{\mathbf{E}} \\
& \mathbb{C}=\frac{\partial \mathbf{T}}{\partial \mathbf{E}}
\end{aligned}
$$

Em que se indica por um ponto superposto a derivada temporal de uma grandeza para um mesmo ponto material, neste caso cada instante $t_{i+1}$ corresponde a um incremento desta mesma grandeza, que pode ser resultado de um incremento de carga $\Delta p$. Para ilustrar o problema tangente recorre-se ao caso uniaxial em que:

$$
\begin{aligned}
& \dot{\sigma}=E \dot{\varepsilon} \\
& E=\frac{d \sigma}{d \varepsilon}
\end{aligned}
$$




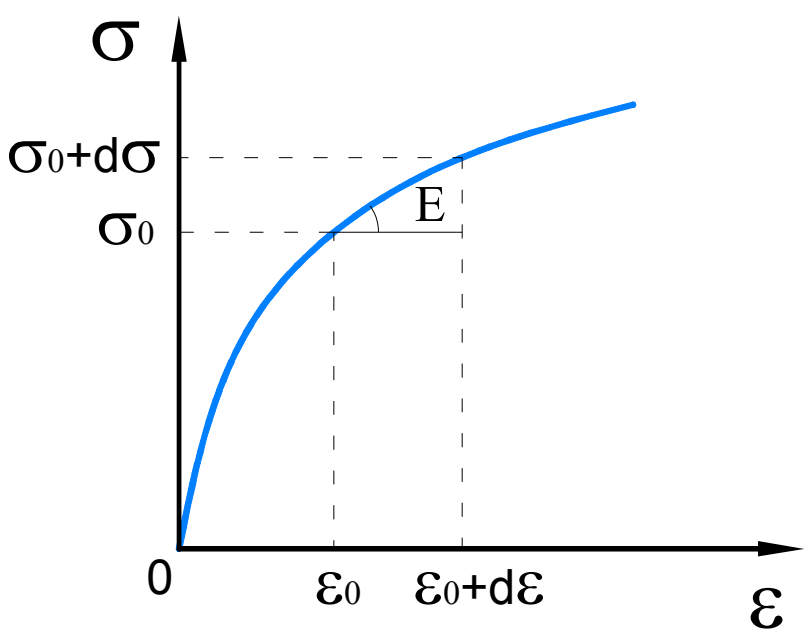

Figura 4 - Problema tangente para o caso uniaxial

Considerando-se a existência de tensões iniciais, representadas pelo vetor tensões iniciais, $\boldsymbol{\sigma}_{0}$, a energia de deformação armazenada é modificada, neste caso para que não haja confusão de notação chamou-se esta outra energia de deformação de $U_{0}$ em que $U_{0}^{*}$ é um caso particular de $U_{0}$ que fica como função de:

$$
\begin{aligned}
& U_{0}=f\left(\boldsymbol{\sigma}, \boldsymbol{\sigma}_{0}, \boldsymbol{\varepsilon}\right) \\
& U_{0}=U_{0}^{*} \text { para } \boldsymbol{\sigma}_{0}=0
\end{aligned}
$$

O carregamento pode ser divido em $\mathrm{n}$ partes e aplicado de forma iterativa (incremental) sobre o domínio, neste caso a energia de deformação armazenada também fica dividida em $\mathrm{n}$ partes.

$$
U=U_{0}^{i}=\sum_{i=1}^{n} \Delta U_{0}^{i}
$$

Desta forma a cada incremento de carga se obtêm um novo campo de deformações e a matriz de rigidez pode ser recalculada para atender as relações constitutivas. Neste método, dentro de uma iteração, as relações constitutivas são mantidas lineares e após todas as iterações resolve-se um problema de função não linear por meio de uma série de funções lineares. 

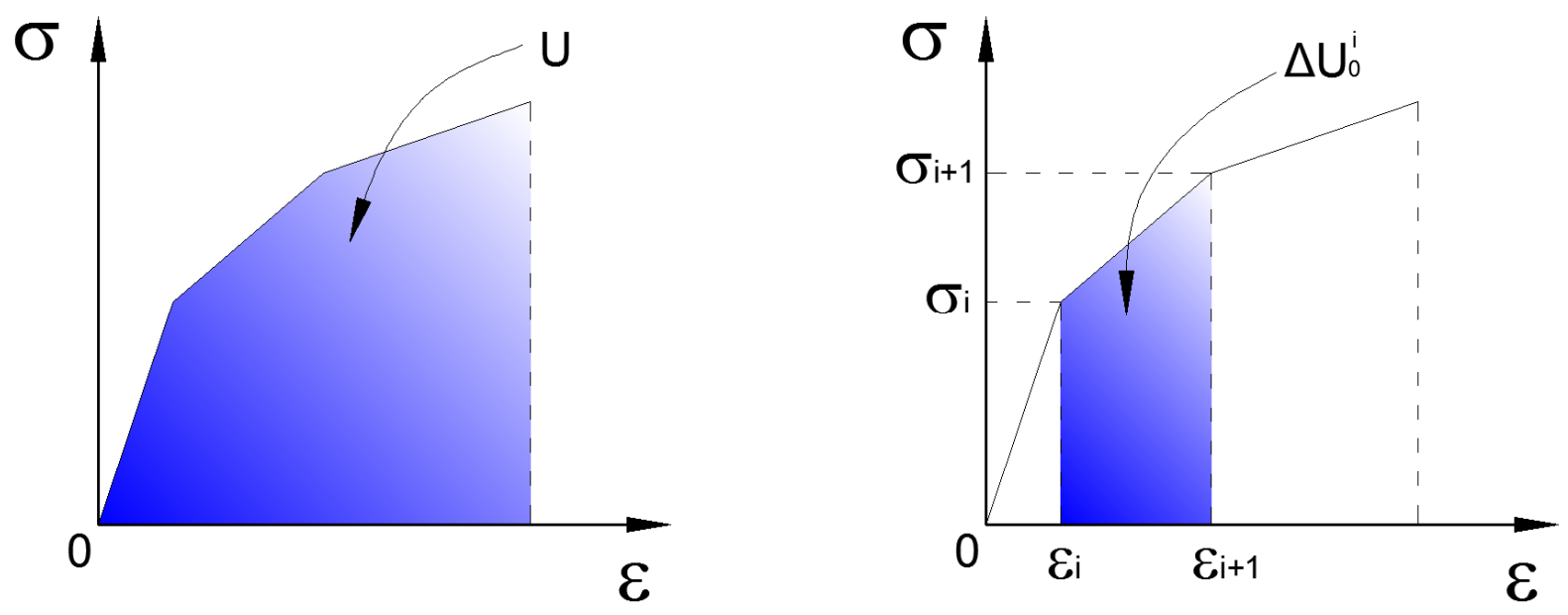

Figura 5 - Partição da energia de deformação

Para facilitar os cálculos, a cada iteração, durante a resolução do problema, utiliza-se de uma nova base em que o campo de deformações anterior é considerado nulo e no final é somado aos os anteriores. O gráfico abaixo ilustra o método para o caso uniaxial.

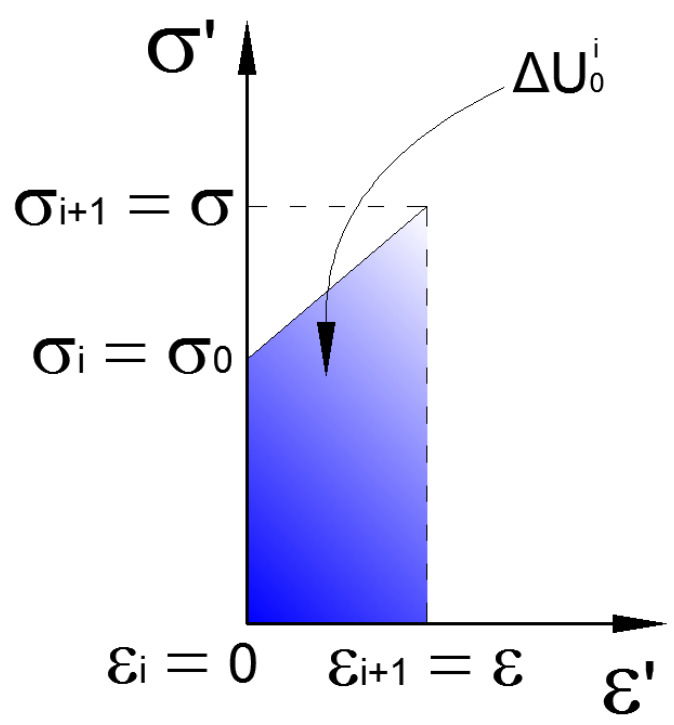

Figura 6 - Obtenção de parte da energia de deformação em uma iteração

Obtêm-se $\Delta U_{0}^{i}$ pela seguinte integral: 


$$
\left\{\begin{array}{l}
\Delta U_{0}^{i}=\int_{0}^{\varepsilon}\left(E \varepsilon+\sigma_{0}\right) d \varepsilon=\frac{1}{2} E \varepsilon^{2}+\sigma_{0} \varepsilon \\
\sigma=E \varepsilon \\
\Delta U_{0}^{i}=\frac{1}{2} \sigma \varepsilon+\sigma_{0} \varepsilon
\end{array}\right.
$$

Para o EPD:

$$
\Delta U_{0}^{i}=\frac{1}{2} \cdot\{\boldsymbol{\sigma}\}^{T}\{\boldsymbol{\varepsilon}\}+\left\{\boldsymbol{\sigma}_{0}\right\}^{T}\{\boldsymbol{\varepsilon}\}
$$

Em cada iteração a resolução do problema não linear por meio do MEF é similar ao problema linear. Considerando isto, o desenvolvimento a seguir é apresentado como para um problema linear, sem a necessidade de índices que indiquem iteração.

A partir de (3.27) pode-se calcular a energia de deformação interna:

$$
U=\int_{V} U_{0} d V=\frac{1}{2} \cdot \int_{V}\left(\{\boldsymbol{\sigma}\}^{T}\{\boldsymbol{\varepsilon}\}+2 \cdot\left\{\boldsymbol{\sigma}_{0}\right\}^{T}\{\boldsymbol{\varepsilon}\}\right) d V
$$

Para o EPD a largura é unitária, assim:

$$
U=\frac{1}{2} \cdot \int_{A}\left(\{\boldsymbol{\sigma}\}^{T}\{\boldsymbol{\varepsilon}\}+2 \cdot\left\{\boldsymbol{\sigma}_{0}\right\}^{T}\{\boldsymbol{\varepsilon}\}\right) d A
$$

Supondo que já se conheça a função do campo de deslocamentos, u, a energia potencial das cargas externas é determinada por:

$$
\Omega=-\left(\int_{A}\left(\{\mathbf{u}\}^{T}\{\mathbf{b}\}\right) d A+\int_{S}\left(\{\mathbf{u}\}^{T}\{-\overline{\mathbf{t}}\}\right) d S\right)
$$

Somando (3.29) e (3.30) pode-se formar o funcional energia potencial total:

$$
\Pi=U+\Omega=\frac{1}{2} \cdot \int_{A}\left(\{\boldsymbol{\sigma}\}^{T}\{\boldsymbol{\varepsilon}\}+2 \cdot\left\{\boldsymbol{\sigma}_{0}\right\}^{T}\{\boldsymbol{\varepsilon}\}\right) d A-\left(\int_{A}\left(\{\mathbf{u}\}^{T}\{\mathbf{b}\}\right) d A+\int_{S}\left(\{\mathbf{u}\}^{T}\{\overline{\mathbf{t}}\}\right) d S\right)
$$

Com (2.16) e (2.19):

$$
\{\boldsymbol{\sigma}\}=[C]\left[\partial_{\varepsilon}\right]\{\mathbf{u}\}
$$


Aplicando-se variação no campo de deslocamentos, $\delta \mathbf{u}$, e introduzindo na equação (2.16):

$$
\{\delta \boldsymbol{\varepsilon}\}=\left[\partial_{\varepsilon}\right]\{\delta \mathbf{u}\}
$$

Obtêm-se:

$\delta \Pi=\frac{1}{2} \cdot \int_{A}\left(\{\delta \mathbf{u}\}^{T}\left[\partial_{\varepsilon}\right]^{T}[C]\left[\partial_{\varepsilon}\right]\{\mathbf{u}\}+2 \cdot\left\{\boldsymbol{\sigma}_{0}\right\}^{T}\left[\partial_{\varepsilon}\right]\{\delta \mathbf{u}\}\right) d A-\left(\int_{A}\left(\{\delta \mathbf{u}\}^{T}\{\mathbf{b}\}\right) d A+\int_{S}\left(\{\delta \mathbf{u}\}^{T}\{\overline{\mathbf{t}}\}\right) d S\right)$

$$
\delta \Pi=0
$$

$\frac{1}{2} \cdot \int_{A}\left(\{\delta \mathbf{u}\}^{T}\left[\partial_{\varepsilon}\right]^{T}[C]\left[\partial_{\varepsilon}\right]\{\mathbf{u}\}+2 \cdot\{\delta \mathbf{u}\}^{T}\left[\partial_{\varepsilon}\right]^{T}\left\{\boldsymbol{\sigma}_{0}\right\}^{T}\right) d A=\int_{A}\left(\{\delta \mathbf{u}\}^{T}\{\mathbf{b}\}\right) d A+\int_{S}\left(\{\delta \mathbf{u}\}^{T}\{\overline{\mathbf{t}}\}\right) d S$

Não há um método para se determinar de forma direta o campo de deslocamentos que satisfaça a equação acima. Para isso impõe-se que os deslocamentos tenham uma pré-determinada variação funcional e aproveitando-se de (2.16) e (2.17) é possível aplicar o MEF para resolução do problema.

Bucalem et al. (2008) faz uma descrição objetiva das unidades elementares que compõe o domínio quando do uso do MEF, o texto abaixo é baseado nesta descrição.

No MEF o domínio é dividido em uma série de subdomínios, denominados elementos e em cada elemento é definido um conjunto de pontos denominado pontos nodais ou nós. Como resultado da partição do domínio em elementos e nós, obtêm-se uma malha que representa a discretização do domínio. A figura 7 representa graficamente o que descrito: 

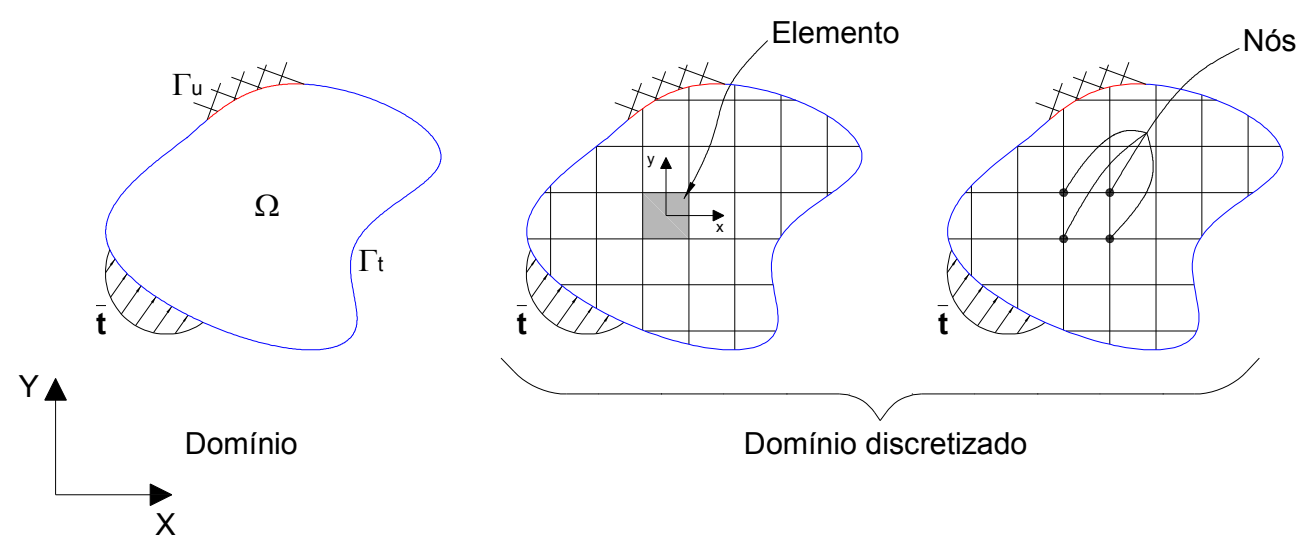

Figura 7 - Discretização do domínio

$\mathrm{Na}$ figura 7 os eixos grafados em letras maiúsculas representam o sistema global de coordenadas e os em letras minúsculas o sistema local de coordenadas associado a um determinado elemento. A discretização apresentada adota elementos retangulares, no entanto outros tipos de elementos podem ser utilizados. Os elementos, em geral, partilham os nós, desta forma observa-se intuitivamente que qualquer deformação experimentada por algum elemento é transmitida aos elementos adjacentes, portanto, na resolução do problema deve haver compatibilidade de deslocamentos.

Supondo que para certo elemento finito, $m$, já se tenha a expressão que forneça o campo de deslocamentos $\mathbf{u}^{m}$, e que os parâmetros nodais ou função aproximadora seja $\hat{\mathbf{u}}$, por meio das funções de interpolação ${ }^{1} \mathbf{H}$, em coordenadas globais (do domínio) e de (2.16) e (2.19), faz-se a seguinte correlação:

$$
\left\{\mathbf{u}^{m}\right\}=[\mathbf{H}]\{\hat{\mathbf{u}}\}
$$

Para a função de interpolação em coordenadas locais (do elemento) utilizase o índice $m$, como em $\mathbf{H}^{m}$.

A equação abaixo apresenta, por exemplo, a função aproximadora para um elemento triangular de três nós:

\footnotetext{
${ }^{1}$ Processo em que se determina o valor duma função num ponto interno dum intervalo a partir dos valores da função nas fronteiras desse intervalo. (Novo Dicionário Eletrônico Aurélio versão 5.0). Pode ser chamada de funções de forma.
} 


$$
\{\hat{\mathbf{u}}\}^{T}=\left\{\begin{array}{llllll}
u_{1} & v_{1} & u_{2} & v_{2} & u_{3} & v_{3}
\end{array}\right\}^{T}
$$

A função de interpolação depende do tipo de elemento adotado e também do número de nós que o compõe. Ela tem grande importância para a qualidade da solução obtida, como será visto mais adiante.

\subsection{FORMULAÇÃO MATRICIAL}

Costa (2008) apresenta a formulação matricial para o MEF, sem considerar as tensões iniciais, a partir do equacionamento do problema pelo princípio dos trabalhos virtuais. A formulação abaixo será baseada em seu trabalho:

A matriz de rigidez $\mathbf{K}^{m}$, de um elemento é definida por:

$$
\left[\mathbf{K}^{m}\right]=\int_{V^{m}}\left[\mathbf{B}^{m}\right]^{T}[C]\left[\mathbf{B}^{m}\right] d V
$$

Pode-se também:

Para o EPD:

$$
\left[\mathbf{K}^{m}\right]=\int_{A^{m}}\left[\mathbf{B}^{m}\right]^{T}[C]\left[\mathbf{B}^{m}\right] d A
$$

Em que $\mathbf{B}^{m}$, representa a matriz de deformação do elemento $m$.

A matriz de rigidez da estrutura, $\mathbf{K}$, é definida por:

$$
[\mathbf{K}]=\sum\left[\mathbf{K}^{m}\right]
$$

As forças de volume na formulação matricial geram o vetor dos esforços nodais, $\mathbf{R}_{B}^{m}$, de um elemento definida por:

$$
\left\{\mathbf{R}_{B}^{m}\right\}=\int_{A^{m}}\left[\mathbf{H}^{m}\right]^{T}\left\{\mathbf{b}^{m}\right\} d A
$$

As forças de superfície na formulação matricial geram o vetor dos esforços nodais, $\mathbf{R}_{S}^{m}$, de um elemento definida por:

$$
\left\{\mathbf{R}_{S}^{m}\right\}=\int_{A^{m}}\left[\mathbf{H}^{m}\right]^{T}\left\{\overline{\mathbf{t}}_{\boldsymbol{m}}\right\} d A
$$


As tensões iniciais na formulação matricial geram o vetor dos esforços nodais, $\mathbf{R}_{0}^{m}$, de um elemento definida por:

$$
\left\{\mathbf{R}_{0}^{m}\right\}=\int_{A^{m}}\left[\mathbf{B}^{m}\right]^{T}\left\{\boldsymbol{\sigma}_{0}^{m}\right\} d A
$$

O vetor dos esforços nodais equivalentes, $\mathbf{R}$, é definido por:

$$
\left\{\begin{array}{l}
\left\{\mathbf{R}_{B}\right\}=\sum\left\{\mathbf{R}_{B}^{m}\right\} \\
\left\{\mathbf{R}_{S}\right\}=\sum\left\{\mathbf{R}_{S}^{m}\right\} \\
\left\{\mathbf{R}_{0}\right\}=\sum\left\{\mathbf{R}_{0}^{m}\right\} \\
\{\mathbf{R}\}=\left\{\mathbf{R}_{B}\right\}+\left\{\mathbf{R}_{S}\right\}-\left\{\mathbf{R}_{0}^{m}\right\}
\end{array}\right.
$$

Definindo-se $\mathbf{U}$ como o vetor do campo de deslocamentos e considerando (3.36), obtêm-se o seguinte sistema de equações algébricas:

$$
\delta \mathbf{U}([\mathbf{K}]\{\mathbf{U}\}-\{\mathbf{R}\})=0
$$

Dado que $\delta \mathbf{U}$ é arbitrário, pode-se fazer:

$$
\left\{\begin{array}{l}
{[\mathbf{K}]\{\mathbf{U}\}-\{\mathbf{R}\}=0} \\
{[\mathbf{K}]\{\mathbf{U}\}=\{\mathbf{R}\}}
\end{array}\right.
$$

\subsection{ELEMENTOS FINITOS TRIANGULARES}

Serão apresentadas as funções de interpolação para dois tipos de elementos, o elemento triangular de três nós (linear) e o elemento triangular de seis nós (quadrático). Serão omitidas as deduções para obtenção de tais funções que podem ser encontradas em Costa (2008), Soriano (2003), Savassi (1996) e Bathe (1996). Na apresentação a seguir será adotada a notação utilizada por Costa (2008).

Seja o elemento triangular como o apresentado abaixo: 


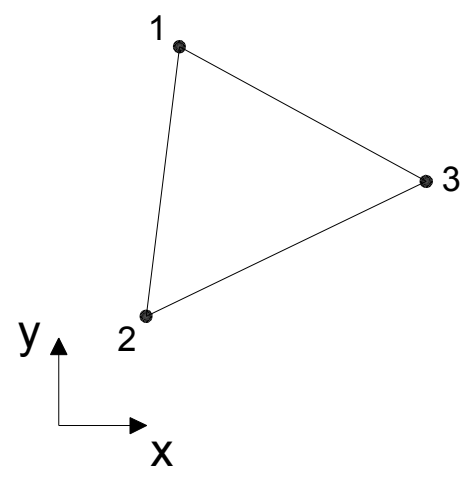

Figura 8 - Elemento triangular de três nós linear

A função de interpolação é expressa por um polinômio completo do $1^{\circ} \mathrm{grau}$ :

$$
h_{i}=A+B x+C y
$$

Em que para se obter seus coeficientes, podem-se impor as condições:

$$
\left\{\begin{array}{l}
h_{i}=a_{j} \\
i=j, a_{j}=1 \\
i \neq j, a_{j}=0
\end{array}\right.
$$

Como ilustração, considere-se função de interpolação, $h_{1}(x, y)$, representada graficamente pela figura 9:

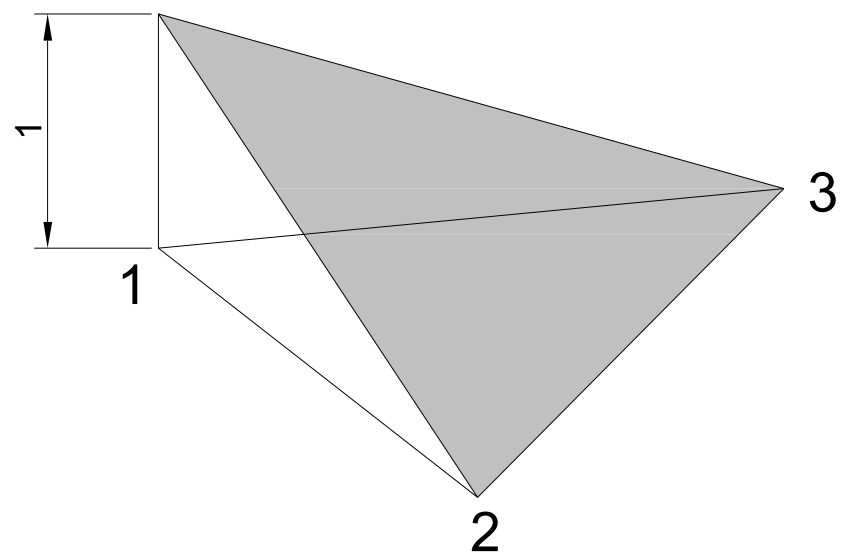

Figura 9 - Função de interpolação $h_{1}$ representada graficamente

Seja:

$$
[\mathbf{B}]=[L][\mathbf{H}]
$$




$$
\begin{gathered}
{[\mathbf{B}]=\left[\begin{array}{ll}
\frac{\partial}{\partial x} & \cdot \\
\cdot & \frac{\partial}{\partial y} \\
\frac{\partial}{\partial y} & \frac{\partial}{\partial x}
\end{array}\right]\left[\begin{array}{cccccc}
h_{1} & \cdot & h_{2} & \cdot & h_{3} & \cdot \\
\cdot & h_{1} & \cdot & h_{2} & \cdot & h_{3}
\end{array}\right]=\left[\begin{array}{llllll}
\frac{\partial h_{1}}{\partial x} & \cdot & \frac{\partial h_{2}}{\partial x} & \cdot & \frac{\partial h_{3}}{\partial x} & \cdot \\
\cdot & \frac{\partial h_{1}}{\partial y} & \cdot & \frac{\partial h_{2}}{\partial y} & \cdot & \frac{\partial h_{3}}{\partial y} \\
\frac{\partial h_{1}}{\partial y} & \frac{\partial h_{1}}{\partial x} & \frac{\partial h_{2}}{\partial y} & \frac{\partial h_{2}}{\partial x} & \frac{\partial h_{3}}{\partial y} & \frac{\partial h_{3}}{\partial x}
\end{array}\right]} \\
{[\mathbf{B}]=\frac{1}{2 \Delta}\left[\begin{array}{ccccccc}
b_{1} & \cdot & b_{2} & \cdot & b_{3} & \cdot \\
\cdot & c_{1} & \cdot & c_{2} & \cdot & c_{3} \\
c_{1} & b_{1} & c_{2} & b_{2} & c_{3} & b_{3}
\end{array}\right]}
\end{gathered}
$$

Em que, $\left(a_{i}, b_{i}, c_{i}\right)$ são coeficientes de $h_{i}$ e são funções lineares de $\left(x_{i}, y_{i}\right)$, $\Delta$ é um determinante, função de $\left(x_{i}, y_{i}\right)$ e geometricamente representa o dobro da área do elemento e $L$ é um operador diferencial.

Inserindo (2.37) em (2.16) e adotando-se $L$ como operador diferencial:

$$
\left\{\boldsymbol{\varepsilon}^{m}\right\}=[L]\left\{\mathbf{u}^{m}\right\}=[L][\mathbf{H}]\{\hat{\mathbf{u}}\}=[\mathbf{B}]\{\hat{\mathbf{u}}\}
$$

Outra forma de apresentação das funções de interpolação dos elementos triangulares é por meio coordenadas homogêneas, como apresentado por Savassi (1996, p. 120,121) e Soriano (2003, p. 118,119), neste último a mesma formulação é apresentada com o nome de coordenadas triangulares ou coordenadas triangulares normalizadas ou ainda coordenadas naturais de triângulo.

Neste caso são estabelecidas a funções $\xi_{i}$, que geometricamente representam relações entre parte da área do elemento e a área do elemento, $A_{e}$.

Algebricamente:

$$
\left\{\begin{array}{l}
\xi_{1}=\frac{1}{2 A_{e}}\left[\left(y_{2}-y_{3}\right) x+\left(x_{3}-x_{2}\right) y+x_{2} y_{3}-x_{3} y_{2}\right] \\
\xi_{2}=\frac{1}{2 A_{e}}\left[\left(y_{3}-y_{1}\right) x+\left(x_{1}-x_{3}\right) y+x_{3} y_{1}-x_{1} y_{3}\right] \\
\xi_{3}=\frac{1}{2 A_{e}}\left[\left(y_{1}-y_{2}\right) x+\left(x_{2}-x_{1}\right) y+x_{1} y_{2}-x_{2} y_{1}\right]
\end{array}\right.
$$

Matricialmente: 


$$
\left\{\begin{array}{l}
\xi_{1} \\
\xi_{2} \\
\xi_{3}
\end{array}\right\}=\frac{1}{2 A_{e}}\left[\begin{array}{ccc}
x_{2} y_{3}-x_{3} y_{2} & y_{2}-y_{3} & x_{3}-x_{2} \\
x_{3} y_{1}-x_{1} y_{3} & y_{3}-y_{1} & x_{1}-x_{3} \\
x_{1} y_{2}-x_{2} y_{1} & y_{1}-y_{2} & x_{2}-x_{1}
\end{array}\right]\left\{\begin{array}{l}
1 \\
x \\
y
\end{array}\right\}
$$

Para o elemento triangular de três nós, linear, as funções interpolação, ou de forma são obtidas por:

$$
h_{i}=\xi_{i}
$$

De (2.42)

$[\mathbf{B}]=\frac{1}{2 A_{e}}\left[\begin{array}{cccccc}\left(y_{2}-y_{3}\right) & \cdot & \left(y_{3}-y_{1}\right) & \cdot & \left(y_{1}-y_{2}\right) & \cdot \\ \cdot & \left(x_{3}-x_{2}\right) & \cdot & \left(x_{1}-x_{3}\right) & \cdot & \left(x_{2}-x_{1}\right) \\ \left(x_{3}-x_{2}\right) & \left(y_{2}-y_{3}\right) & \left(x_{1}-x_{3}\right) & \left(y_{3}-y_{1}\right) & \left(x_{2}-x_{1}\right) & \left(y_{1}-y_{2}\right)\end{array}\right]$

Com (2.44) e (2.48) observa-se que, para o elemento triangular linear, as deformações são constante ao longo do elemento.

Seja o elemento triangular como o apresentado abaixo:

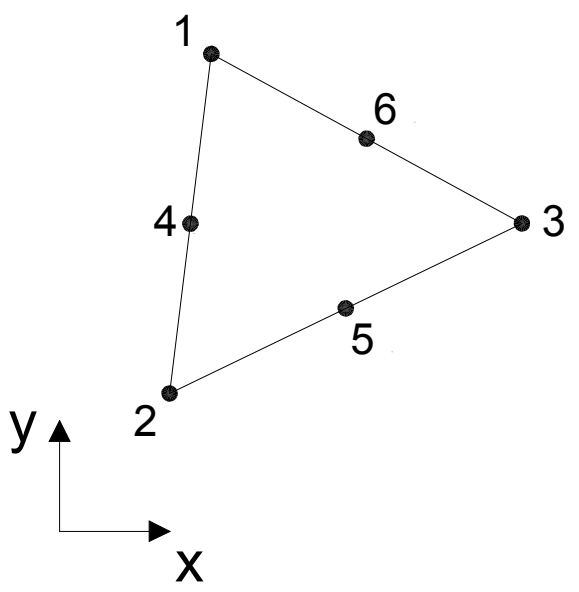

Figura 10 - Elemento triangular de seis nós quadrático

Para o elemento triangular de seis nós, quadrático, as funções interpolação, ou de forma são obtidas por: 


$$
\left\{\begin{array}{l}
h_{1}=\xi_{1}\left(2 \xi_{1}-1\right) \\
h_{2}=\xi_{2}\left(2 \xi_{2}-1\right) \\
h_{3}=\xi_{3}\left(2 \xi_{3}-1\right) \\
h_{4}=4 \xi_{1} \xi_{2} \\
h_{5}=4 \xi_{2} \xi_{3} \\
h_{6}=4 \xi_{3} \xi_{1}
\end{array}\right.
$$

Fazendo $(x, y)=\left(x_{1}, x_{2}\right)$ e por meio de $L$ :

$$
\begin{aligned}
& {[L]=\left[\frac{\partial}{\partial x_{i}}\right]} \\
& \frac{\partial \mathbf{H}_{j}}{\partial x_{i}}=\sum_{k=1}^{3} \frac{\partial \mathbf{H}_{j}}{\partial \xi_{k}} \frac{\partial \xi_{k}}{\partial x_{i}}
\end{aligned}
$$

Pode-se assim calcular B . como em (2.41).

A título de exemplo, para $B_{11}$ :

$$
\left\{\begin{array}{l}
B_{11}=\frac{\partial \mathbf{H}_{1}}{\partial \xi_{1}} \frac{\partial \xi_{1}}{\partial x}+\frac{\partial \mathbf{H}_{1}}{\partial \xi_{2}} \frac{\partial \xi_{2}}{\partial x}+\frac{\partial \mathbf{H}_{1}}{\partial \xi_{3}} \frac{\partial \xi_{3}}{\partial x} \\
=\left(y_{2}-y_{3}\right)\left(\frac{2}{A_{e}}\left|\left(y_{2}-y_{3}\right) x+\left(x_{3}-x_{2}\right) y+x_{2} y_{3}-x_{3} y_{2}\right|-1\right)
\end{array}\right.
$$

Com (2.51) observa-se que, para o elemento triangular quadrático, as deformações são lineares ao longo do elemento.

\subsection{ELEMENTOS FINITOS QUADRILATERAIS}

Serão apresentadas as funções de interpolação para o elemento quadrilateral de quatro nós bilinear isoparamétrico e o de oito nós biquadrático isoparamétrico. A definição simples para transformação isoparamétrica é que dado um elemento quadrilateral distorcido obtém-se funções de forma que servirão para interpolar tanto deslocamentos, quanto coordenadas no elemento. A importância, deste elemento, reside na capacidade de se modelar domínios de geometria complexa com um número menor de elementos. Atualmente os principais códigos comerciais de MEF utilizam elementos isoparamétricos. As deduções para obtenção 
de funções de interpolação em elementos isoparamétricos podem ser encontradas na mesma bibliografia citada para elementos triangulares.

A seguir é apresentada a formulação para o elemento quadrilateral de quatro nós linear isoparamétrico. Esta será baseada em Costa (2008).

A partir de um elemento quadrilateral distorcido, faz-se a transformação de coordenadas que leva do sistema auxiliar de coordenadas $(r, s)$ ao sistema local de coordenadas $(x, y)$. A figura 11 ilustra a transformação:
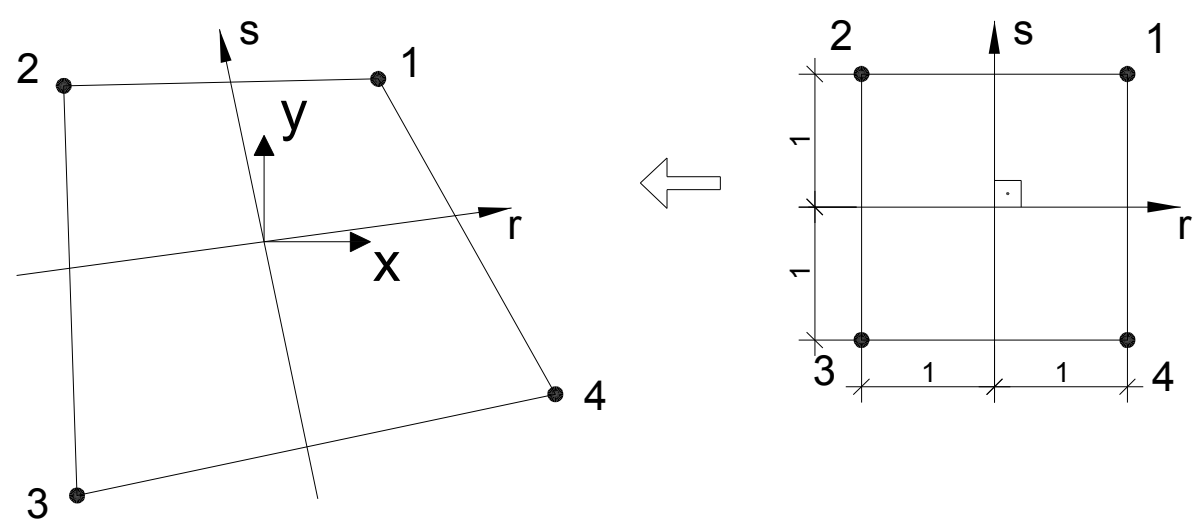

Figura 11 - Elemento quadrilateral de quatro nós bilinear isoparamétrico (modificado de Costa, 2008)

$\mathrm{Na}$ transformação utilizam-se as funções de interpolação $\mathbf{H}$, do elemento, definidas no sistema auxiliar:

$$
\left\{\begin{array}{l}
x(r, s)=\sum_{i=1}^{4} h_{i}(r, s) x_{i} \\
y(r, s)=\sum_{i=1}^{4} h_{i}(r, s) y_{i}
\end{array}\right.
$$

Matricialmente:

$$
\{x\}=[\mathbf{H}]\{c\}
$$

Deste modo, podem-se obter as coordenadas cartesianas de um ponto qualquer no interior do elemento por meio de $\mathbf{H}$.

As funções de interpolação são definidas no sistema auxiliar por: 


$$
\left\{\begin{array}{l}
h_{1}=\frac{1}{4}(1+r)(1+s) \\
h_{2}=\frac{1}{4}(1-r)(1+s) \\
h_{3}=\frac{1}{4}(1-r)(1-s) \\
h_{4}=\frac{1}{4}(1+r)(1-s)
\end{array}\right.
$$

Pela matriz jacobiana da transformação:

$$
\begin{aligned}
& \left\{\begin{array}{l}
\frac{\partial \varphi}{\partial r} \\
\frac{\partial \varphi}{\partial s}
\end{array}\right\}=[J]\left[\begin{array}{l}
\frac{\partial \varphi}{\partial x} \\
\frac{\partial \varphi}{\partial y}
\end{array}\right\} \\
& {[J]=\left[\begin{array}{ll}
\frac{\partial x}{\partial r} & \frac{\partial y}{\partial r} \\
\frac{\partial x}{\partial s} & \frac{\partial y}{\partial s}
\end{array}\right]=\left[\begin{array}{ll}
J_{11} & J_{12} \\
J_{22} & J_{22}
\end{array}\right]}
\end{aligned}
$$

Obtêm-se a transformação:

$$
\left\{\begin{array}{l}
J_{11}=\frac{\partial x}{\partial r}=\sum_{i=1}^{4} \frac{\partial h_{i}}{\partial r} x_{i}=\frac{1}{4}\left[(1+s) x_{1}-(1+s) x_{2}-(1-s) x_{3}+(1-s) x_{4}\right] \\
J_{12}=\frac{\partial y}{\partial r}=\sum_{i=1}^{4} \frac{\partial h_{i}}{\partial r} y_{i}=\frac{1}{4}\left[(1+s) y_{1}-(1+s) y_{2}-(1-s) y_{3}+(1-s) y_{4}\right] \\
J_{21}=\frac{\partial x}{\partial s}=\sum_{i=1}^{4} \frac{\partial h_{i}}{\partial s} x_{i}=\frac{1}{4}\left[(1+r) x_{1}+(1-r) x_{2}-(1-r) x_{3}-(1+r) x_{4}\right] \\
J_{22}=\frac{\partial y}{\partial s}=\sum_{i=1}^{4} \frac{\partial h_{i}}{\partial s} y_{i}=\frac{1}{4}\left[(1+r) y_{1}+(1-r) y_{2}-(1-r) y_{3}-(1+r) y_{4}\right]
\end{array}\right.
$$

Invertendo (2.64) e pela regra da cadeia:

$$
\left.\left\{\begin{array}{l}
\frac{\partial \varphi}{\partial x} \\
\frac{\partial \varphi}{\partial y}
\end{array}\right\}=[J]^{-1}\left\{\begin{array}{l}
\frac{\partial \varphi}{\partial r} \\
\frac{\partial \varphi}{\partial s}
\end{array}\right\}=\left[\begin{array}{ll}
\frac{\partial x}{\partial r} & \frac{\partial y}{\partial r} \\
\frac{\partial x}{\partial s} & \frac{\partial y}{\partial s}
\end{array}\right]\left\{\begin{array}{c}
\frac{\partial \varphi}{\partial r} \\
\frac{\partial \varphi}{\partial s}
\end{array}\right\} \Rightarrow\left\{\begin{array}{c}
\frac{\partial \varphi}{\partial x} \\
\frac{\partial \varphi}{\partial y}
\end{array}\right\}=[\Gamma]\right]\left[\begin{array}{c}
\frac{\partial \varphi}{\partial r} \\
\frac{\partial \varphi}{\partial s}
\end{array}\right\}
$$




$$
[\Gamma]=[J]^{-1}=\left[\begin{array}{ll}
\frac{\partial r}{\partial x} & \frac{\partial s}{\partial x} \\
\frac{\partial r}{\partial y} & \frac{\partial s}{\partial y}
\end{array}\right]=\frac{1}{|J|}\left[\begin{array}{cc}
J_{22} & -J_{12} \\
-J_{21} & J_{11}
\end{array}\right]
$$

A matriz de deformação, $\mathbf{B}$, pode ser obtida por:

$$
[\mathbf{B}]=\left[\begin{array}{cccc}
\Gamma_{11} & \Gamma_{12} & \cdot & \cdot \\
\cdot & \cdot & \Gamma_{21} & \Gamma_{22} \\
\Gamma_{21} & \Gamma_{22} & \Gamma_{11} & \Gamma_{12}
\end{array}\right][\mathbf{H}]
$$

A título de exemplo, para $B_{11}$ :

$$
\left\{\begin{array}{l}
B_{11}=\frac{1}{|J|} J_{22} \frac{\partial h_{1}}{\partial r}-\frac{1}{|J|} J_{12} \frac{\partial h_{1}}{\partial s} \\
=\frac{1}{4|J|} J_{22}(1+s)-\frac{1}{4|J|} J_{12}(1+r)
\end{array}\right.
$$

Em (2.69) e (2.70) observa-se que, para o elemento quadrilateral bilinear, as deformações são lineares ao longo do elemento.

Baseado em (2.40), tem-se:

$$
[\mathbf{k}]=\int_{A}[\mathbf{B}]^{T}[C][\mathbf{B}] d A
$$

E por meio de:

$$
d A=|\overrightarrow{d r} \wedge \overrightarrow{d s}|=|J| d r d s
$$

Obtêm-se

$$
[\mathbf{k}]=\int_{A}[\mathbf{B}]^{T}[C][\mathbf{B}] d A=\int_{-1}^{1} \int_{-1}^{1}[\mathbf{B}]^{T}[C][\mathbf{B}]|J| d r d s
$$

Costa (2008) faz a seguinte observação:

Para que a transformação de coordenas definida por [3.61] seja biunívoca, é preciso que o determinante da matriz jacobiana não se anule em nenhum ponto do domínio do elemento [...] que ele seja sempre do mesmo sinal. Isso estará garantido se a distorção não for exagerada. [Para o elemento apresentado] [...] basta assegurar que 
nenhum ângulo interno do elemento distorcido seja maior que 180 graus. [...] constata-se que os elementos da matriz $[\Gamma]$ são frações nas quais, tanto o numerador, quanto o denominador são polinômios que dependem das variáveis auxiliares $r$ e $s$. Esse fato trará importantes conseqüências, dificultando sobremaneira a integração exata das expressões subseqüentes, tornado quase obrigatório o uso de integração numérica. [Por exemplo, a quadratura de Gauss].

A seguir é apresentada a formulação para o elemento quadrilateral de oito nós biquadrático isoparamétrico. Esta será baseada em Soriano (2003).
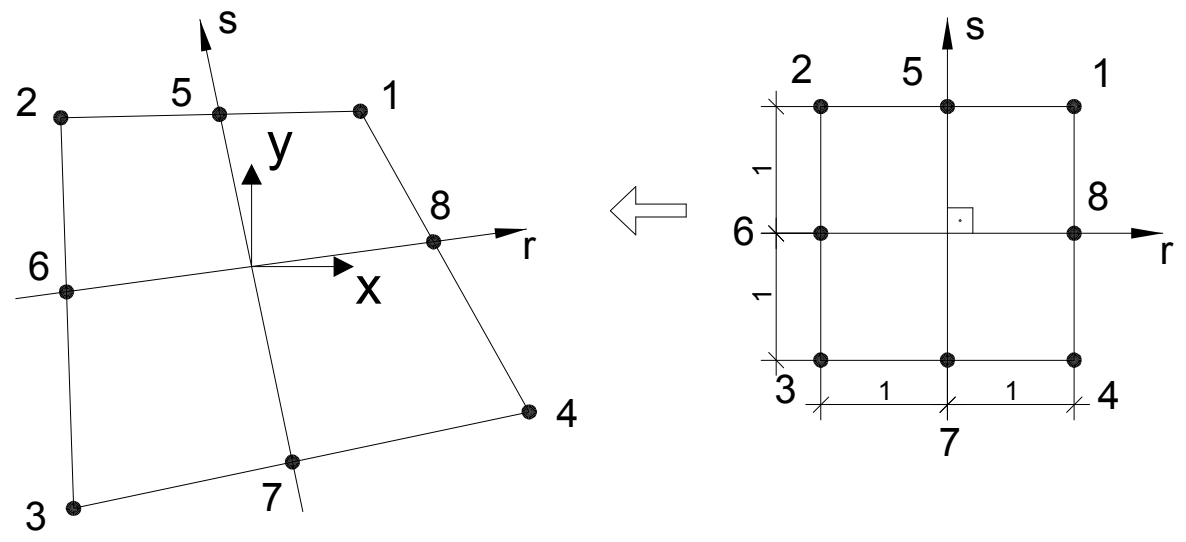

Figura 12 - Elemento quadrilateral de oito nós biquadrático isoparamétrico

A transformação é feita do mesmo modo que para o elemento bilinear, a não ser pelas funções de interpolação, $\mathbf{H}$, que ficam:

Para os nós i = 1,2,3 e 4:

$$
h_{i}=\frac{1}{4}\left(1+r_{i}\right)\left(1+s_{i}\right)\left(r_{i}+s_{i}-1\right)
$$

Para os nós i = 5 e 7:

$$
h_{i}=\frac{1}{2}\left(1-r^{2}\right)\left(1+s_{i}\right)
$$

Para os nós i $=6$ e 8 :

$$
h_{i}=\frac{1}{2}\left(1+r_{i}\right)\left(1-s^{2}\right)
$$


Em que o índice i em $\left(r_{i}, s_{i}\right)$ denota o sinal do nó em que a função está estabelecida. Por exemplo, para o nó 2:

$$
h_{2}=\frac{1}{4}(1-r)(1+s)(-r+s-1)
$$

Neste elemento a função de interpolação, $\mathbf{H}$, têm elementos quadráticos, e considerando o exposto em (2.66), (2.70) e (2.77), observa-se que a deformações são quadráticas ao longo do elemento

\subsection{FAMÍLIAS DE ELEMENTOS}

Os elementos mostrados nos itens anteriores podem ser classificados em famílias de elementos. Serão apresentadas duas famílias que representam estes elementos, a família Lagrange e a família Serendipity. Para isto far-se-á uso do triângulo de Pascal ou triângulo de monômios:

Aplicado ao MEF o triângulo de Pascal é uma apresentação geométrica do crescimento de binômios. Por meio dele pode-se determinar o grau do polinômio a ser utilizado em determinado elemento.

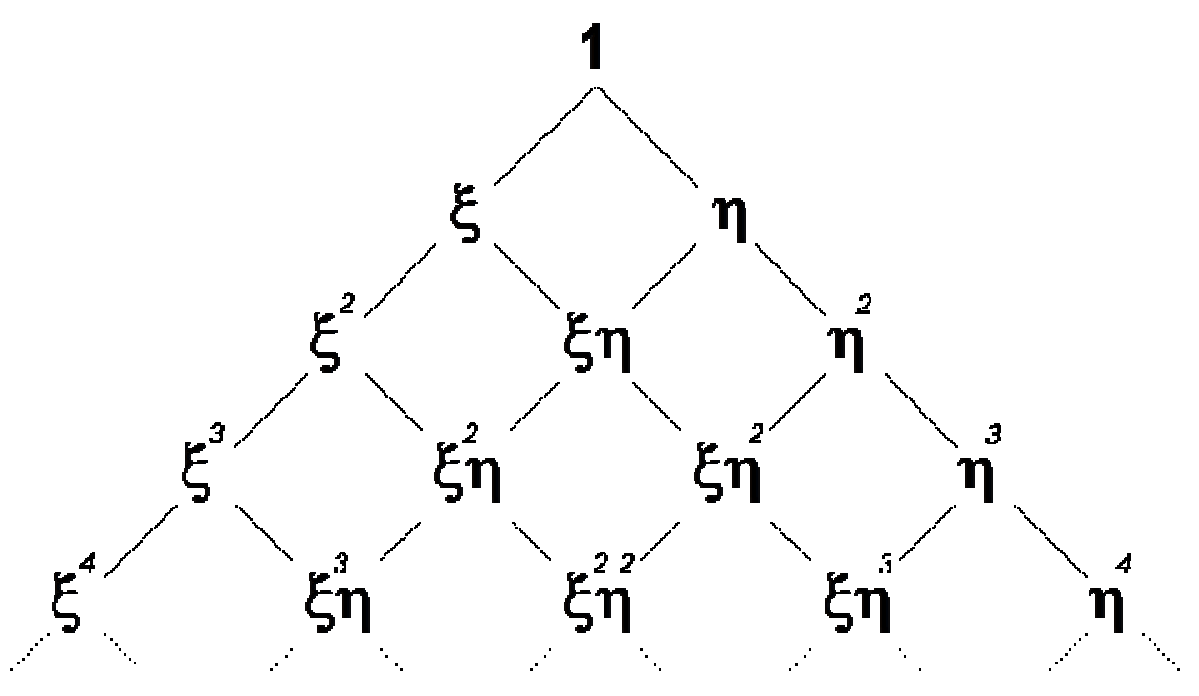

Figura 13 - Triângulo de Pascal

$\mathrm{Na}$ família Lagrange as funções de interpolação de grau superior são obtidas multiplicando-se funções lineares entre si, inclusive em coordenadas distintas. $\mathrm{Na}$ família Serendipity as funções de interpolação são obtidas com base nas funções 
lineares, de forma que com o crescimento do grau da função sejam introduzidos outros monômios para corresponder a uma determinada condição do contorno.

Os elementos triangulares apresentados anteriormente, de três e seis nós, podem ser classificados tanto como da família Lagrange quanto da família Serendipity e por meio do triângulo de pascal podem-se obter os monômios que compõe a função de interpolação:

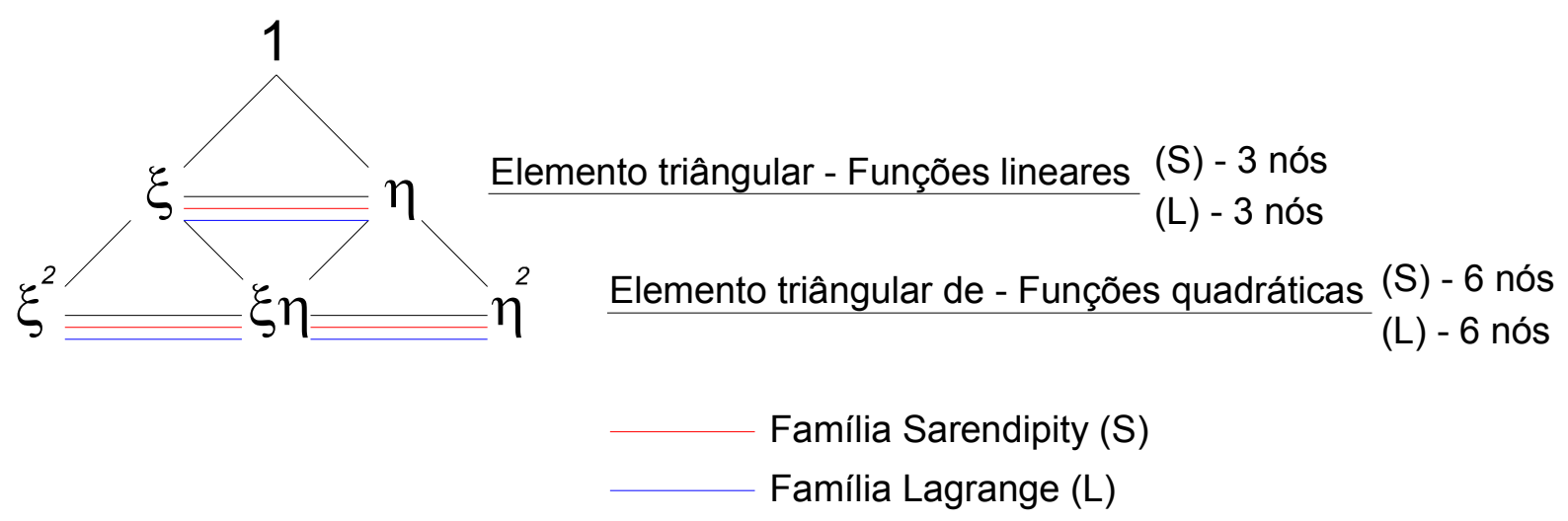

Figura 14 - Obtenção de monômios para elemento triangular

O elemento quadrilateral bilinear de quatro nós apresentado anteriormente pode ser classificado tanto como da família Lagrange quanto da família Serendipity o elemento quadrilateral biquadrático de oito nós pode ser classificado como da família Serendipity. Por meio do triângulo de pascal podem-se obter os monômios que compõe a função de interpolação:

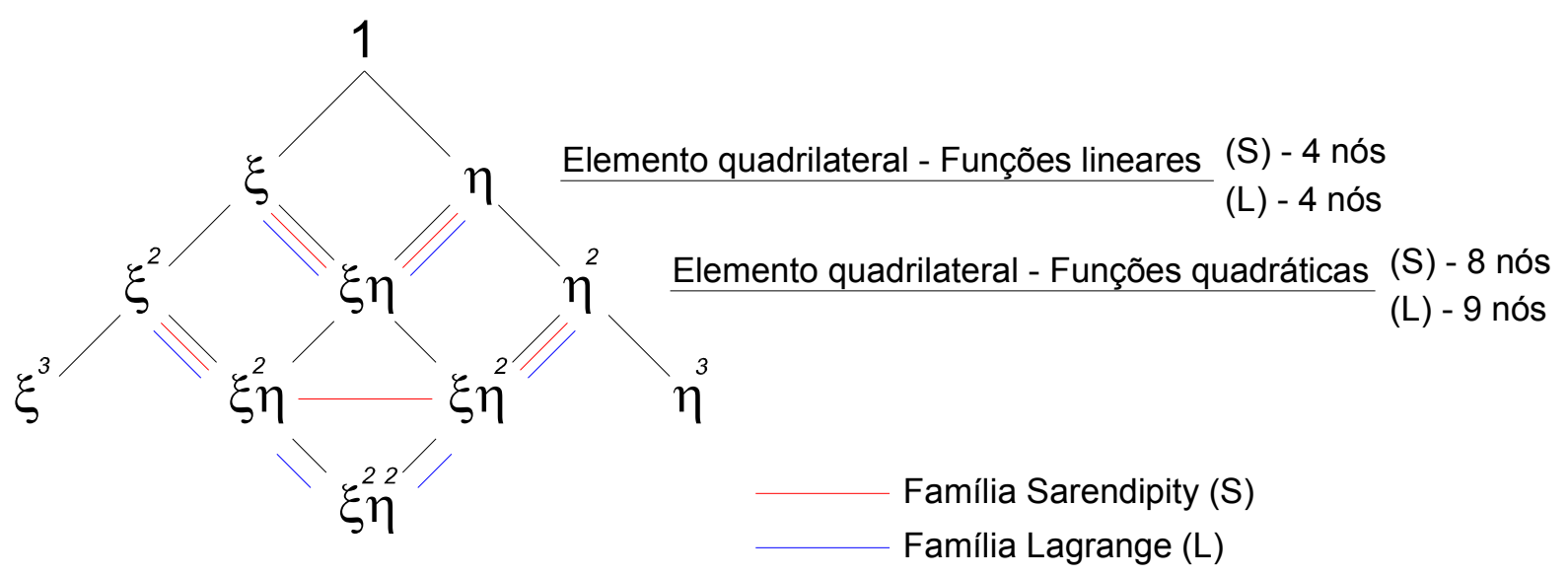

Figura 15 - Obtenção de monômios para elemento quadrilateral 
O elemento quadrilateral biquadrático da família Lagrange tem nove nós, três por face e um nó central com o monômio $\xi \eta$, além disto, tem também o monômio $\xi^{2} \eta^{2}$ em um vértice.

\subsection{ANÁLISE NÃO-LINEAR E CRITÉRIOS DE CONVERGÊNCIA}

Para análise estática de elementos finitos, por meio de (2.46), considerando o vetor do campo de deslocamentos incremental $\Delta \mathbf{U}$ e vetor dos esforços nodais equivalentes, $\mathbf{R}$, decomposto em vetor das forças nodais aplicadas, $\mathbf{P}$, e vetor das forças internas, $\mathbf{F}$ :

$$
\left\{\begin{array}{l}
{[\mathbf{K}]\{\Delta \mathbf{U}\}=\{\mathbf{R}\}} \\
{[\mathbf{K}]\{\Delta \mathbf{U}\}=\{\mathbf{P}\}-\{\mathbf{F}\}}
\end{array}\right.
$$

Em análise não-linear o vetor $\mathbf{P}$ pode ser aplicado em uma série de incrementos ou etapas, de forma que:

$$
\mathbf{P}=P_{1}+P_{2}, \ldots,+P_{n}
$$

A solução é obtida em cada etapa, com um incremento de $\mathbf{P}$.

$$
[\mathbf{K}]\{\Delta \mathbf{U}\}_{i+1}=\{\mathbf{P}\}_{i+1}-\{\mathbf{F}\}_{i} \text { para } i=0,1,2 \ldots n
$$

Para apresentação do critério de convergência considere-se, por simplicidade, a mola da figura 2 com rigidez não-linear, $K$, e com um carregamento axial na ponta, $P$ :

$$
K U=P
$$

A rigidez não-linear da mola é função do deslocamento, $K=K(U)$.

Considere-se que o carregamento incremental $P_{n}$, corresponda ao deslocamento $U_{n}$, e que se deseja obter o deslocamento correspondente ao próximo carregamento incremental, $P_{n+1}$. A resistência interna da mola, $F_{0}$, está em equilíbrio com a força externa $P_{n}$. Antes de aplicar o próximo incremento de carregamento, avalia-se a rigidez, $K_{0}$, que é tangente ao ponto $\left(F_{0}, P_{n}\right)$ na curva força-deslocamento e em seguida, calcula-se o próximo deslocamento incremental.

Com o deslocamento incremental atual e atualiza-se a solução: 


$$
\begin{aligned}
& \left\{\begin{array}{l}
K_{0} \Delta U_{1}=P_{n+1}-F_{0} \\
\Delta U_{1}=K_{0}^{-1}\left(P_{n+1}-F_{0}\right)
\end{array}\right. \\
& U_{n+1}=U_{n}+\Delta U_{1}
\end{aligned}
$$

A partir do deslocamento atual, podemos calcular a força interna, $F_{l}$, na mola, como mostrado na figura 16 :

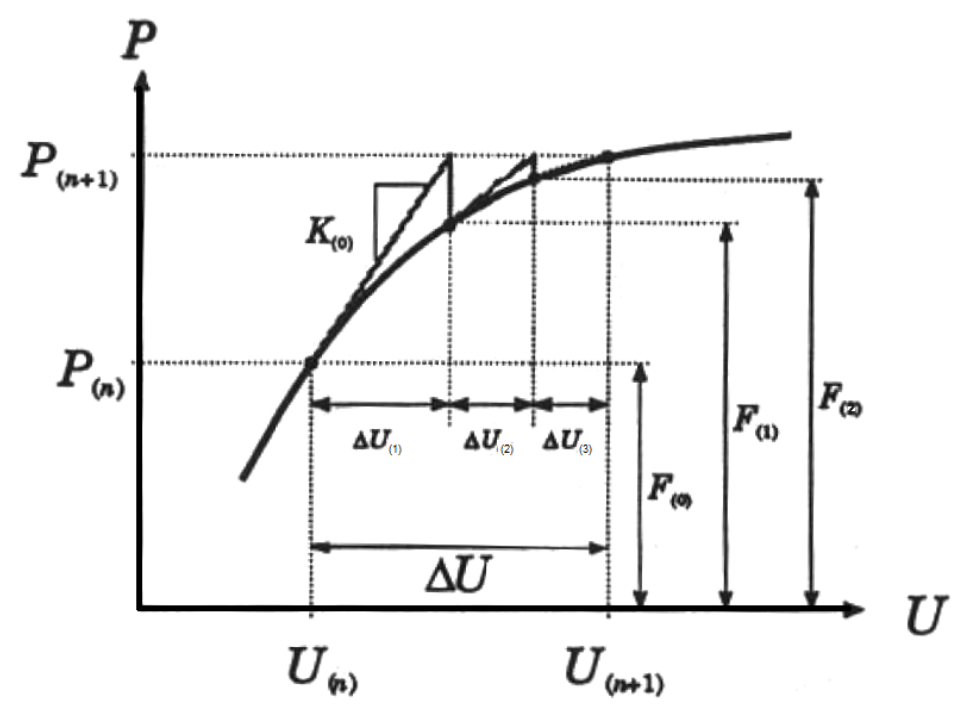

Figura 16 - Gráfico para força-deslocamento em uma mola não linear, com carregamento incremental (Rocscience - Manual Teórico)

Nesta fase, o erro força atual ou desequilíbrio do carregamento, $\left(P_{n+1}-F_{1}\right)$, é muito grande, mas o objetivo das iterações é reduzir o desequilíbrio de carregamento para zero, ou pelo menos, para um número muito pequeno. Para a próxima iteração, há uma nova e mais precisa estimativa do deslocamento, $U_{n+1}$, assim aplica-se o mesmo carregamento incremental, $P_{n+l}$.

Ao continuar a iterações, não só o desequilíbrio de carregamento, mas também os incrementos de deslocamento se aproximam de zero, e as atualizações de $U_{n+1}$ a aproxima da solução correta. O fim das iterações ocorre há convergência para o resultado, ou seja quando, o resultado estiver suficientemente próximo do correto, de acordo com algum critério de parada.

Uma forma de se aplicar um critério de parada é controlar a convergência da energia do sistema, que pode ser feito de duas formas: 
Critério da energia absoluta:

$$
\left\|\frac{\Delta U_{i}^{T}\left(P_{n}-F_{i}\right)}{\Delta U_{0}^{T}\left(P_{n}-F_{0}\right)}\right\|<\text { Erro Tolerado }
$$

Critério da razão quadrática da energia:

$$
\sqrt{\frac{\left[\Delta U_{i}^{T}\left(P_{n}-F_{i}\right)\right]^{2}}{\left[\Delta U_{0}^{T}\left(P_{n}-F_{0}\right)\right]^{2}}}<\text { Erro Tolerado }
$$

Pode-se, ainda, controlar o desequilíbrio entre a força atual e a força total aplicada (critério de forças).

$$
\left|\frac{\left(P_{n+1}\right)^{2}}{\left(F_{n}\right)^{2}}\right|<\text { Erro Tolerado }
$$

Ou controlar o tamanho do incremento atual, que tende a tornar-se torna-se uma pequena fração do deslocamento inicial.

$$
\left|\frac{\left(\Delta U_{1}-\Delta U_{n}\right)^{2}}{\left(\Delta U_{1}\right)^{2}}\right|<\text { Erro Tolerado }
$$

\subsection{COMPARAÇÃO DE RESULTADOS ENTRE MODELOS COM VARIAÇÃO DO TIPO DE ELEMENTOS}

Em Savassi (1996, p. 143 apud Brebbia e Connor, 1973) é apresentado uma aplicação do MEF para uma viga em balanço (estado plano de tensões, EPT) em que são comparados os resultados utilizando-se diversos tipos de elementos e diversas densidades de malhas. Reproduz-se abaixo a estrutura analisada: 


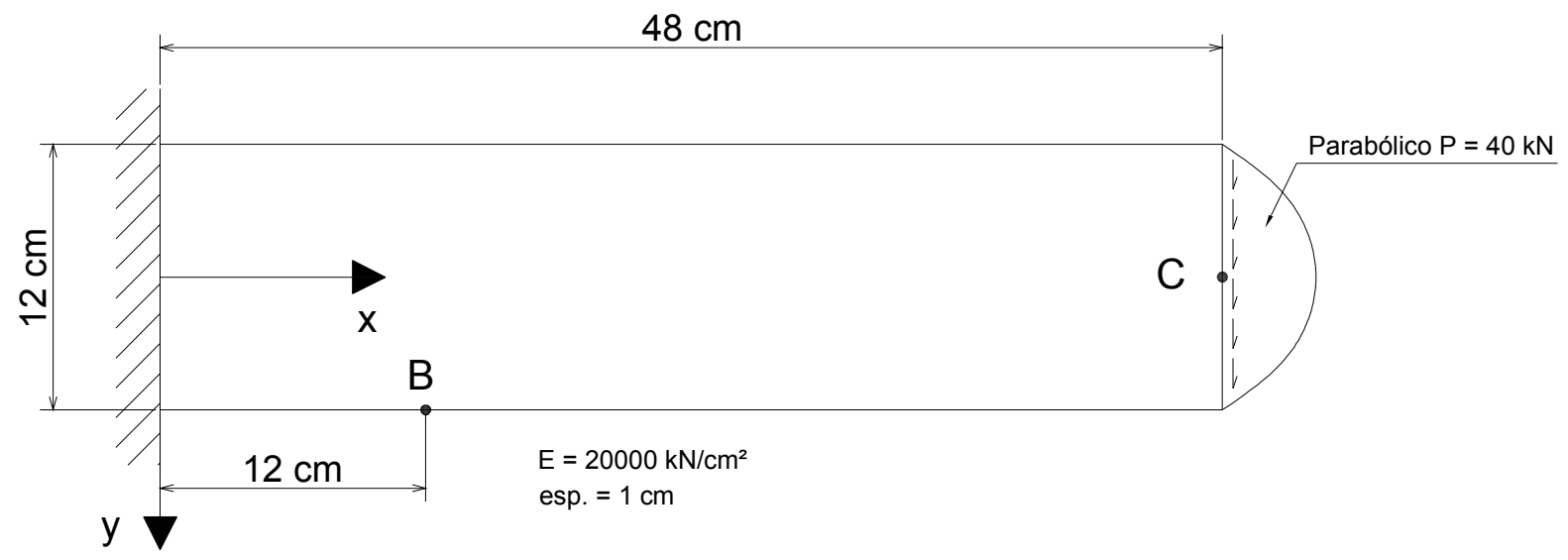

Figura 17 - Viga em balanço (Savassi, 1996)

Considerando as seguintes discretizações e resolvendo-se via MEF:

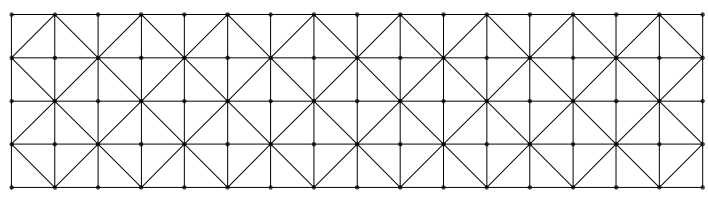

128 ELEMENTOS TRIÂNGULARES DE 3 NÓS - TL1

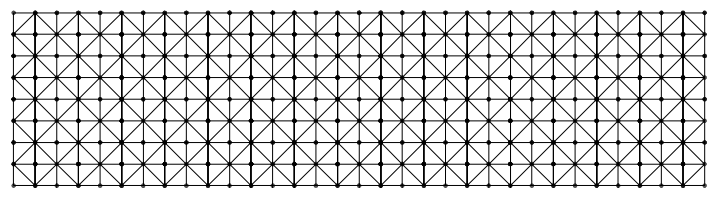

512 ELEMENTOS TRIÂNGULARES DE 3 NÓS - TL2

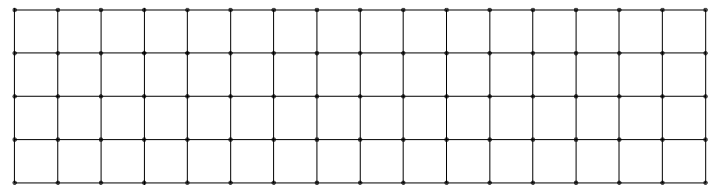

64 ELEMENTOS QUADRILATERAIS DE 4 NÓS - QL1

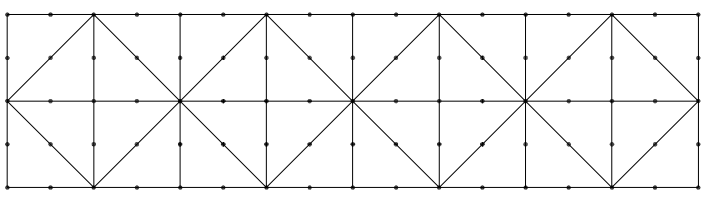

32 ELEMENTOS TRIÂNGULARES DE 6 NÓS - TQ1

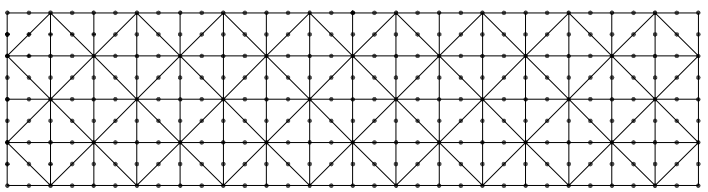

128 ELEMENTOS TRIÂNGULARES DE 6 NÓS - TQ2

Figura 18 - Viga em balanço - modelos (modificado de Savassi, 1996) 
A tabela abaixo apresenta os resultados da solução via MEF:

Tabela 1 - Resultados da comparação (modificado de Savassi, 1996)

\begin{tabular}{|c|c|c|c|c|c|}
\hline $\begin{array}{c}\text { TIPO DE } \\
\text { ELEMENTO }\end{array}$ & $\begin{array}{l}\text { NÚMERO DE } \\
\text { ELEMENTOS }\end{array}$ & $\begin{array}{c}\text { FLECHA EM C } \\
(\mathrm{cm})\end{array}$ & DIFERENÇA (\%) & $\sigma_{x}\left(\mathrm{~N} / \mathrm{cm}^{2}\right)(\mathrm{em} \mathrm{B})$ & DIFERENÇA (\%) \\
\hline TL1 & 128 & 0,458369 & $14,1 \%$ & 51,2224 & $14,6 \%$ \\
\hline TL2 & 512 & 0,512811 & $3,9 \%$ & 57,3427 & $4,4 \%$ \\
\hline TQ1 & 32 & 0,531750 & $0,4 \%$ & 59,9892 & $0,02 \%$ \\
\hline TQ2 & 128 & 0,533393 & $0,1 \%$ & 60,0011 & $0,002 \%$ \\
\hline QL1 & 64 & 0,539693 & $1,1 \%$ & 60,7803 & $1,3 \%$ \\
\hline $\begin{array}{l}\text { TEORIA DE } \\
\text { VIGAS }\end{array}$ & & 0,533740 & & 60,0000 & \\
\hline
\end{tabular}

Fonte: Savassi, 1996.

Nota: Acrescentou-se a coluna com número de elementos e a alterou-se a nomenclatura dos tipos de elementos.

Observa-se por meio da tabela acima que para o elemento triangular de três nós, mesmo com o adensamento da malha, ainda houve diferença significativa entre o resultado analítico e o resultado numérico, isso se deve ao fato do campo de deformações, resultante da primeira derivada da função de interpolação, ser constante no elemento. Observa-se também que para o elemento triangular quadrático, mesmo com poucos elementos, o resultado foi bastante satisfatório também quando comparado ao resultado do elemento quadrilateral.

Para comparar os resultados de malhas por meio do programa Phase2, será utilizado um exemplo resolvido analiticamente. Em Timoshenko e Goodier (1970, p.39) é apresentada a resolução da viga acima, em EPT, por meio da teoria da elasticidade para obtenção das tensões internas. Neste caso fez-se uso das funções de Airy para estabelecer o campo de tensões e a função adotada foi um polinômio do quarto grau:

$$
\phi_{4}=\frac{a_{4}}{12} x^{4}+\frac{b_{4}}{6} x^{3} y+\frac{c_{4}}{2} x^{2} y^{2}+\frac{d_{4}}{6} x y^{3}+\frac{e_{4}}{12} y^{4}
$$

Esta equação satisfaz a condição da equação biarmônica:

$$
\frac{\partial^{4} \phi}{\partial x^{4}}+2 \frac{\partial^{4} \phi}{\partial x^{2} \partial y^{2}}+\frac{\partial^{4} \phi}{\partial y^{4}}=0
$$

E pôde-se então determinar o campo de tensões: 


$$
\left\{\begin{array}{l}
\sigma_{x}=\frac{\partial^{2} \phi}{\partial y^{2}}=-\frac{3 P}{2 c^{3}} x y \\
\sigma_{y}=\frac{\partial^{2} \phi}{\partial x^{2}}=0 \\
\tau_{x y}=-\frac{\partial^{2} \phi}{\partial x \partial y}=-\frac{3 P}{4 c}\left(1-\frac{y^{2}}{c^{2}}\right)
\end{array}\right.
$$

O significado dos coeficientes de (3.91) são mostrados abaixo:

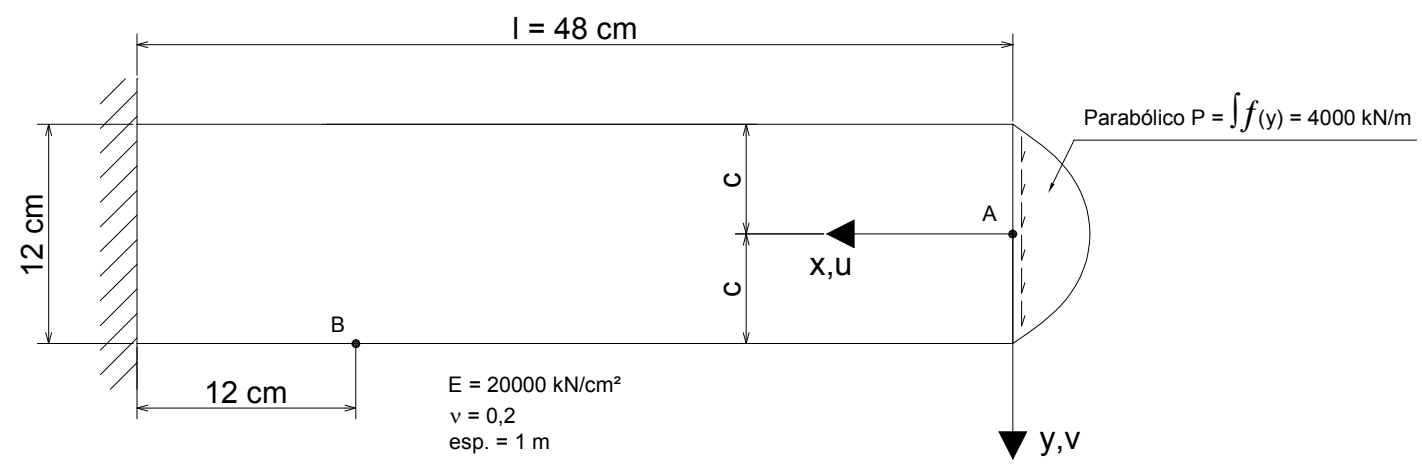

Figura 19 - Viga em balanço exemplo

No EPT e EPD a distribuição de tensões no plano $(x, y)$ da estrutura é mesma, pois o equilíbrio neste plano é regido pelas mesmas equações. Com isso poderemos usar as equações de (2.80) para representar o campo de tensões no EPD. Os deslocamentos no EPT e EPD são diferentes, pois no EPD ocorre um confinamento do plano $(x, y)$ exercido por $\sigma_{z} \neq 0$ com $\varepsilon_{z}=0$, que modifica o campo de deslocamentos.

Deformações no EPT:

$$
\left\{\begin{array}{l}
\varepsilon_{x}=\frac{1}{E}\left(\sigma_{x}-\nu \sigma_{y}\right) \\
\varepsilon_{y}=\frac{1}{E}\left(\sigma_{y}-\nu \sigma_{x}\right) \\
\gamma_{x y}=\frac{1}{G} \tau_{x y}
\end{array}\right.
$$

Deformações no EPD: 


$$
\left\{\begin{array}{l}
\varepsilon_{x}=\frac{1}{E}\left[\left(1-\nu^{2}\right) \sigma_{x}-\nu(1+\nu) \sigma_{y}\right] \\
\varepsilon_{y}=\frac{1}{E}\left[\left(1-\nu^{2}\right) \sigma_{y}-\nu(1+\nu) \sigma_{x}\right] \\
\gamma_{x y}=\frac{1}{G} \tau_{x y}
\end{array}\right.
$$

Para determinação dos deslocamentos fez-se a integração das deformações por meio das equações:

$$
\left\{\begin{array}{l}
\varepsilon_{x}=\frac{\partial u}{\partial x} \\
\varepsilon_{y}=\frac{\partial v}{\partial y} \\
\gamma_{x y}=\frac{\partial u}{\partial y}+\frac{\partial v}{\partial x}
\end{array}\right.
$$

Assim determinaram-se os deslocamentos no EPD:

$$
\left\{\begin{array}{l}
u=-\frac{3 P a x^{2} y}{4 c^{3}}-\frac{3 P a y^{3}}{12 c^{3}}(b-d)+\frac{3 P a l^{3} x}{4 c^{3}}-\frac{3 P a l^{4}}{4 c^{3}} \\
v=-\frac{3 P b x y^{2}}{4 c^{3}}+\frac{3 P a x^{3}}{12 c^{3}}-\frac{3 P a l^{2} x}{4 c^{3}}-\frac{P a l^{3}}{2 c^{3}}
\end{array}\right.
$$

Em que:

$$
\left\{\begin{array}{l}
a=\frac{\left(1-v^{2}\right)}{E} \\
b=\frac{v(1+v)}{E} \\
d=\frac{2(1+v)}{E}
\end{array}\right.
$$

No caso do exemplo da fig. 17 , o deslocamento no ponto A (48,0) é:

$$
\left\{\begin{array}{l}
u=0 \\
v=-\frac{P a l^{3}}{2 c^{3}}=0,492 \mathrm{~cm}
\end{array}\right.
$$

E a tensão $\sigma_{x}$ em B $(36,-6)$ é: 


$$
\sigma_{x}=-\frac{3 P}{2 c^{3}} x y=600.000 \mathrm{kN} / \mathrm{m}^{2}
$$

No Phase2 foram feitos oito modelos, com a discretização mostrada abaixo:

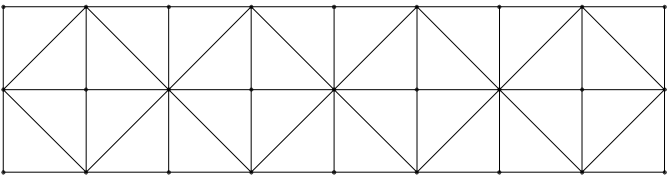

32 ELEMENTOS TRIÂNGULARES DE 3 NÓS - TL1

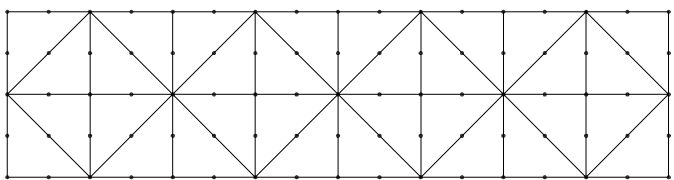

32 ELEMENTOS TRIÂNGULARES DE 6 NÓS - TQ1

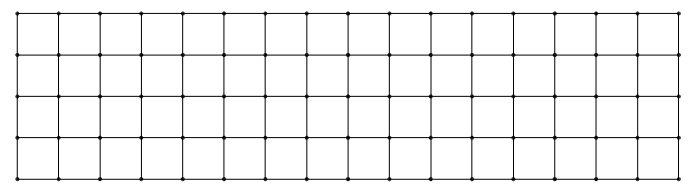

64 ELEMENTOS QUADRILATERAIS DE 4 NÓS - QL1

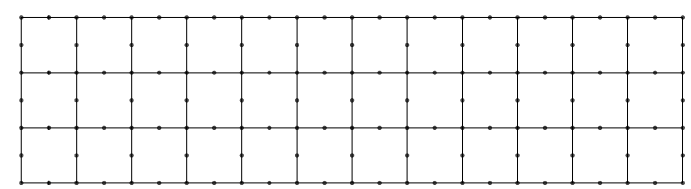

36 ELEMENTOS QUADRILATERAIS DE 8 NÓS - QQ1

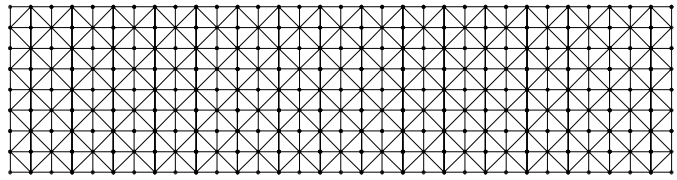

512 ELEMENTOS TRIÂNGULARES DE 3 NÓS - TL2

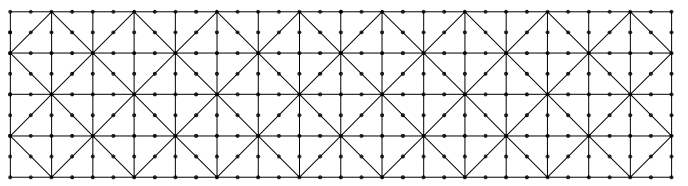

128 ELEMENTOS TRIÂNGULARES DE 6 NÓS - TQ2

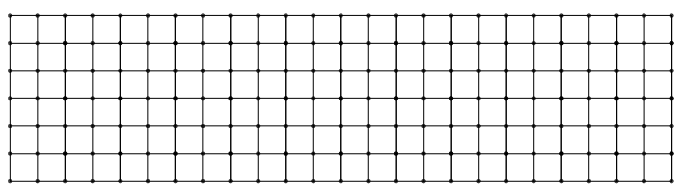

144 ELEMENTOS QUADRILATERAIS DE 4 NÓS - QL2

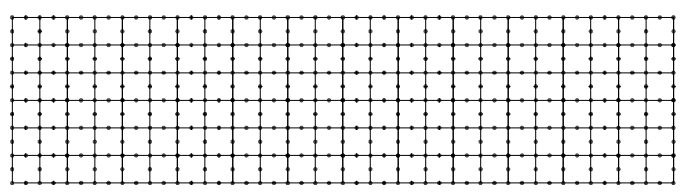

144 ELEMENTOS QUADRILATERAIS DE 8 NÓS - QQ2

Figura 20 - Viga em balanço - modelos Phase2 EPD

A tabela abaixo apresenta os resultados da solução via MEF: 
Tabela 2 - Resultados dos modelos

\begin{tabular}{|c|c|c|c|c|c|}
\hline $\begin{array}{c}\text { TIPO DE } \\
\text { ELEMENTO }\end{array}$ & $\begin{array}{l}\text { NÚMERO DE } \\
\text { ELEMENTOS }\end{array}$ & FLECHA EM A $(\mathrm{cm})$ & DIFERENÇA (\%) & $\sigma_{\mathrm{X}}\left(\mathrm{kN} / \mathrm{m}^{2}\right)$ & DIFERENÇA (\%) \\
\hline TL1 & 32 & 0,3194 & $35,0 \%$ & 184934,5 & $69,2 \%$ \\
\hline TL2 & 512 & 0,4931 & $0,3 \%$ & 505252,5 & $15,8 \%$ \\
\hline TQ1 & 32 & 0,5112 & $4,0 \%$ & 599925,0 & $0,01 \%$ \\
\hline TQ2 & 128 & 0,5124 & $4,3 \%$ & 599932,5 & $0,01 \%$ \\
\hline QL1 & 64 & 0,4964 & $1,0 \%$ & 437240,0 & $27,1 \%$ \\
\hline QL2 & 144 & 0,5051 & $2,8 \%$ & 493585,0 & $17,7 \%$ \\
\hline QQ1 & 36 & 0,5120 & $4,2 \%$ & 600160,0 & $0,03 \%$ \\
\hline QQ2 & 144 & 0,5125 & $4,3 \%$ & 599960,0 & $0,01 \%$ \\
\hline \multicolumn{2}{|c|}{ TEORIA DA ELASTICIDADE } & 0,4915 & & 600000,0 & \\
\hline
\end{tabular}

Fonte: Elaborado pelo autor com base nos resultados dos modelos.

Analisando-se a tabela acima se verifica que os resultados foram semelhantes aos apresentados por Savassi (1996, p. 143 apud Brebbia e Connor, 1973) em que os modelos com função de interpolação quadrática apresentaram resultados melhores mesmo nos modelos menos discretizados. Cabe a observação de que os resultados obtidos analiticamente podem não ser os exatos, pois foi admitido um campo de tensões por meio das funções de Airy, no entanto os resultados entre o modelo analítico e os numéricos com função de interpolação quadrática diferem pouco. Observa-se também a diferença nas tensões apresentadas pelos modelos lineares, que mesmo com o aumento do número de elementos apresentaram diferenças significativas indicando que a convergência para os resultados esperados demandaria um aumento maior na discretização. Os modelos quadráticos com elementos triangulares e quadrilaterais mostraram resultados parecidos para quantidades de elementos semelhantes. 


\section{MODELOS CONSTITUTIVOS}

Modelos constitutivos, matematicamente, podem ser entendidos como funções ou operadores que correlacionam determinadas grandezas. Em mecânica do contínuo estas grandezas são tensões e deformações e as funções que fazem as correlações são suas propriedades reológicas. Estas propriedades são complexas e para problemas práticos impedem sejam usadas em sua totalidade. Para seu uso em engenharia são feitas simplificações, em que se consideram os aspectos mais relevantes. Finalmente em engenharia modelos constitutivos podem ser entendidos como a correlação entre tensões (ou função de tensões) e deformações (ou função de deformações) com resultados observáveis experimentalmente.

Neste trabalho será apresentado o modelo constitutivo: elastoplástico linear, isotrópico, que servirá como modelo constitutivo para simular o comportamento do solo e interface solo-concreto (parede) nos modelos numéricos estudados adiante.

Em geotecnia é necessário que seja feita a distinção das tensões atuantes em um ponto do meio contínuo em tensões totais, $\sigma$, poro pressões, $u$, e tensões efetivas, $\sigma$ ', e a relação entre elas:

$$
\sigma^{\prime}=\sigma-u
$$

No caso do modelo constitutivo elastoplástico com critério de resistência de Mohr-Coulomb aplicado a análise de estabilidade usualmente as tensões verificadas são as efetivas. Bueno e Vilar (2004, p. 83) e Massad (2003, p. 56) enfatizam que o uso de tensões efetivas em análise de estabilidade é mais correto conceitualmente e em Pinto (2002, p. 89) encontra-se a seguinte asserção, sobre tensões efetivas:

A tensão efetiva é responsável pelo comportamento mecânico do solo, e só mediante uma análise através de tensões efetivas se consegue estudar cientificamente os fenômenos de resistência e deformação dos solos.

Nas formulações a seguir será suprimido o apóstrofo (') para não sobrecarregá-las e será mostrado apenas quando necessário, para fazer alguma distinção ou caracterizar notação adotada por algum autor. 


\subsection{MODELOS CONSTITUTIVOS ELASTOPLÁSTICOS UNIAXIAIS}

Apesar deste trabalho se basear em modelos bidimensionais $\mathrm{e}$ tridimensionais, os modelos unidimensionais são úteis para o entendimento daqueles e para o paramento $^{2}$ de concreto de concreto que no modelo é representada por elementos de barra.

Em Pimenta (2007, p.196) é apresentado o modelo elastoplástico de PrandtlReuss que consiste numa associação em série do modelo elástico de Hooke e o modelo plástico de Saint-Venant:
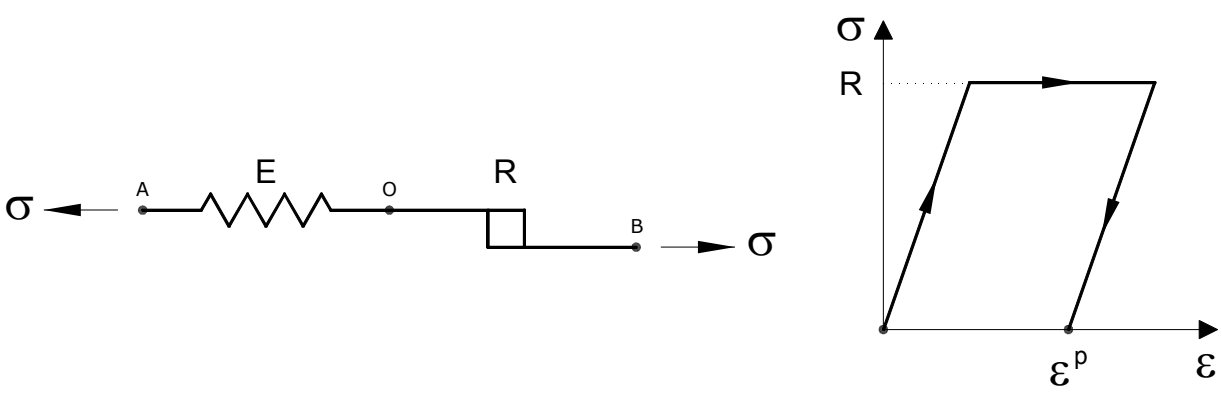

Figura 21 - Modelo elastoplástico de Prandtl-Reuss (modificado de Pimenta, 2007)

$\mathrm{Na}$ associação acima os dois elementos, $E$ (elástico) e $R$ (plástico) estão sujeitos a mesma tensão $\sigma$, porém a deformação total $\varepsilon$, corresponde à soma da parcela de deformação elástica $\varepsilon^{\mathrm{e}}$, com a parcela de deformação plástica $\varepsilon^{p}$.

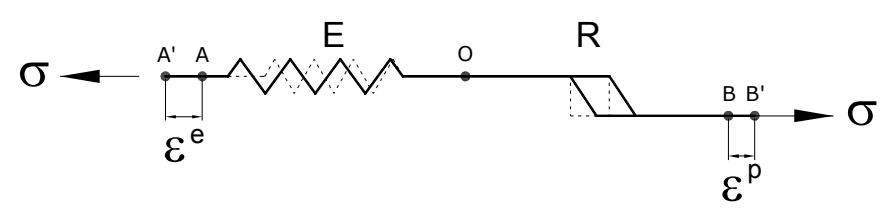

Figura 22 - Deformação no modelo elastoplástico de Prandtl-Reuss

$$
\begin{aligned}
& \varepsilon=\varepsilon^{e}+\varepsilon^{p} \\
& \varepsilon^{p}>0 \text { para } \sigma>R
\end{aligned}
$$

A deformação plástica acontece somente se a tensão $\sigma$, ultrapassar a tensão de plastificação $R$.

${ }^{2}$ Por paramento de concreto entendem-se os elementos de contenção estacas justapostas e cortinas ou paredes-diafragma. 
Em Potts e Zdravkovic (1999, p.133) e Pedro França (2009, p.44) são drescritos três modelos de barras sujeitas a carregamentos uniaxiais com comportamentos e leis constitutivas elastoplásticas distintas. A seguir serão mostrados os três modelos juntamente com as descrições dos comportamentos, baseadas nas bibliografias supracitadas. O primeiro modelo é o elástico linear perfeitamente plástico:
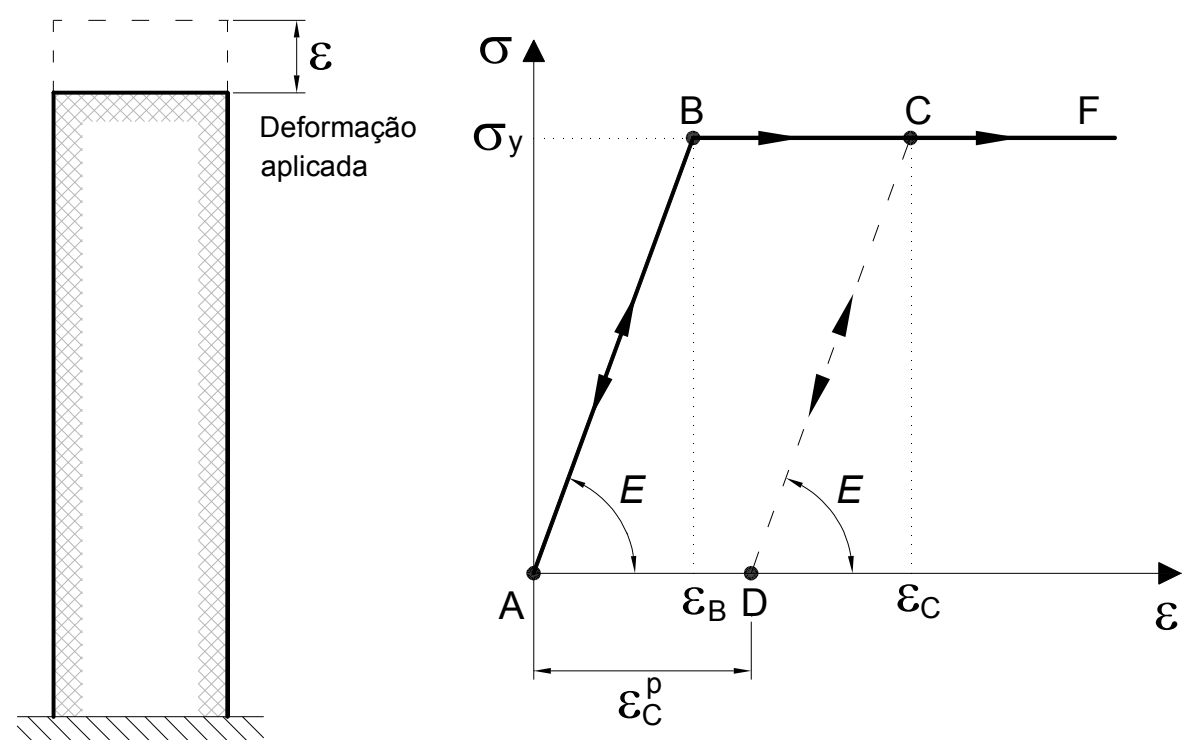

Figura 23 - Deformação uniaxial de material elástico linear perfeitamente plástico (modificado de Potts e Zdravkovic, 1999)

Aplicando-se a deformação $\varepsilon$ a barra apresenta comportamentos distintos a medida que a deformação aumenta. Entre os pontos A e B o comportamento é elástico linear com módulo de elasticidade $E$, até o ponto $\mathrm{B}$ o comportamento é reversível sem que ocorram deformações permanentes, a tensão é obtida pela função $\sigma(\varepsilon)=E \varepsilon$ e a deformação em $B$ é $\varepsilon_{B}$. No ponto $B$ a barra atinge a tensão de plastificação $\sigma_{y}$ e a deformação passa a ser constante para qualquer incremento, assim entre os pontos $\mathrm{B}$ e $\mathrm{C}$ não há aumento de tensão, somente de deformação que no ponto $C$ corresponde a $\varepsilon_{C}$ e a função $\sigma(\varepsilon)=\sigma_{y}$. Se no ponto $C$ a barra for completamente descarregada chegará ao ponto $\mathrm{D}$ e neste caso aparecerá uma deformação permanente dada pela função $\varepsilon_{C}^{p}=\varepsilon_{C}-\varepsilon_{B}$ e durante o descarregamento a tensão é obtida pela função $\sigma(\varepsilon)=E\left(\varepsilon-\varepsilon_{C}{ }^{p}\right)$. Se a barra sofrer nova deformação, entre os pontos $\mathrm{D}$ e $\mathrm{C}$ comportamento voltará a ser elástico linear com módulo de elasticidade $E$ e a tensão volta a obedecer a função $\sigma(\varepsilon)=E\left(\varepsilon-\varepsilon_{C}{ }^{p}\right)$ até atingir 
novamente a tensão de plastificação $\sigma_{y}$ no ponto $C$, com deformação $\varepsilon_{c}$. Entre os pontos C e $\mathrm{F}$ a tensão volta a ser constante com função $\sigma(\varepsilon)=\sigma_{y}$ e a deformação permanente sofrerá acréscimo $\varepsilon_{C}^{p}>\varepsilon_{C}-\varepsilon_{B}$.

O segundo modelo é o elastoplástico com endurecimento (hardening) como mostrado abaixo:
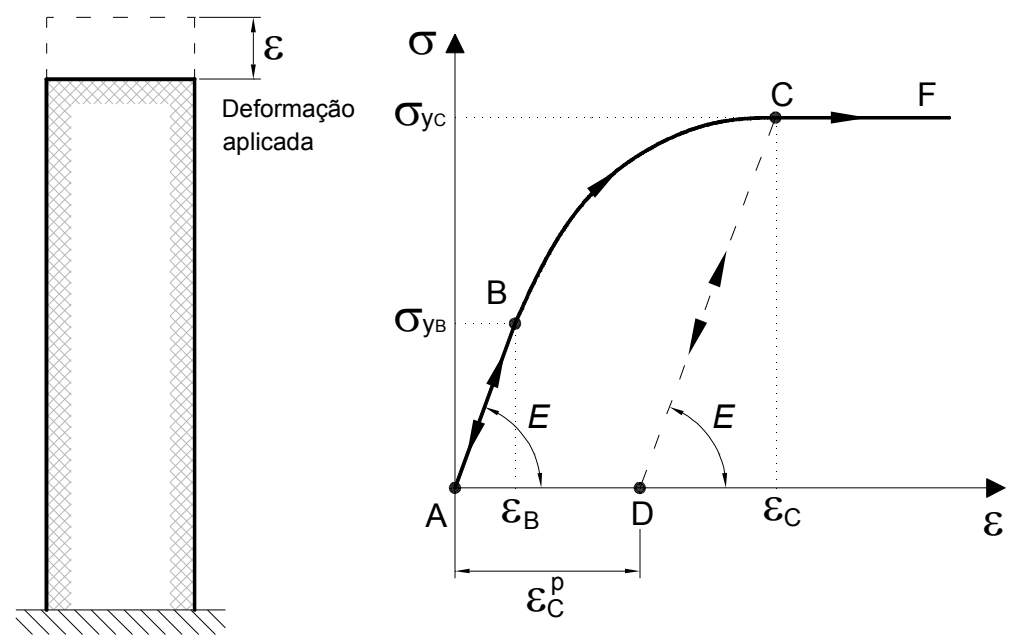

Figura 24 - Deformação uniaxial de material elastoplástico com endurecimento (hardening) (modificado de Potts e Zdravkovic, 1999)

Aplicando-se a deformação $\varepsilon$ a barra apresenta comportamentos distintos a medida que a deformação aumenta. Entre os pontos A e B o comportamento é elástico linear com módulo de elasticidade $E$, até o ponto $\mathrm{B}$ o comportamento é reversível sem que ocorram deformações permanentes, a tensão é obtida pela função $\sigma(\varepsilon)=E \varepsilon$ e a deformação em $\mathrm{B}$ é $\varepsilon_{\mathrm{B}}$. No ponto $\mathrm{B}$ a barra atinge o início da tensão de plastificação $\sigma_{\mathrm{yB}}$, com deformação $\varepsilon_{\mathrm{B}}$ e a lei constitutiva passa a ser não linear plástica até o ponto $\mathrm{C}$, a função $\sigma(\varepsilon)$ não é mais linear e pode ser qualquer função injetora crescente. No ponto C a barra atinge o final da tensão de plastificação $\sigma_{y c}$ em que $\sigma_{y c}>\sigma_{y B}$ e a deformação passa a ser constante para qualquer incremento, desta forma haverá somente aumento de deformação e não de tensão, que no ponto $C$ corresponde a $\varepsilon_{C}$ e a função $\sigma(\varepsilon)=\sigma_{y C}$. Se no ponto $C$ a barra for completamente descarregada chegará ao ponto $D$ e neste caso aparecerá uma deformação permanente dada pela função $\varepsilon_{C}{ }^{p}=\varepsilon_{C}-\varepsilon_{B}$ e durante o descarregamento a tensão é obtida pela função $\sigma(\varepsilon)=E\left(\varepsilon-\varepsilon_{C}^{p}\right)$. Se a barra sofrer nova deformação, entre os pontos $\mathrm{D}$ e C o comportamento voltará a ser elástico linear com módulo de 
elasticidade $E$ e a tensão volta a obedecer a função $\sigma(\varepsilon)=E\left(\varepsilon-\varepsilon_{C}^{\mathrm{p}}\right)$ até atingir novamente a tensão de plastificação $\sigma_{y c}$ no ponto $C$, com deformação $\varepsilon_{c}$. Entre os pontos $\mathrm{C}$ e $\mathrm{F}$ a tensão fica constante com função $\sigma(\varepsilon)=\sigma_{y c}$ e a deformação permanente sofrerá acréscimo $\varepsilon_{C}{ }^{p}>\varepsilon_{C}-\varepsilon_{B}$.

O terceiro modelo é o elastoplástico com amolecimento (softening) como mostrado abaixo:
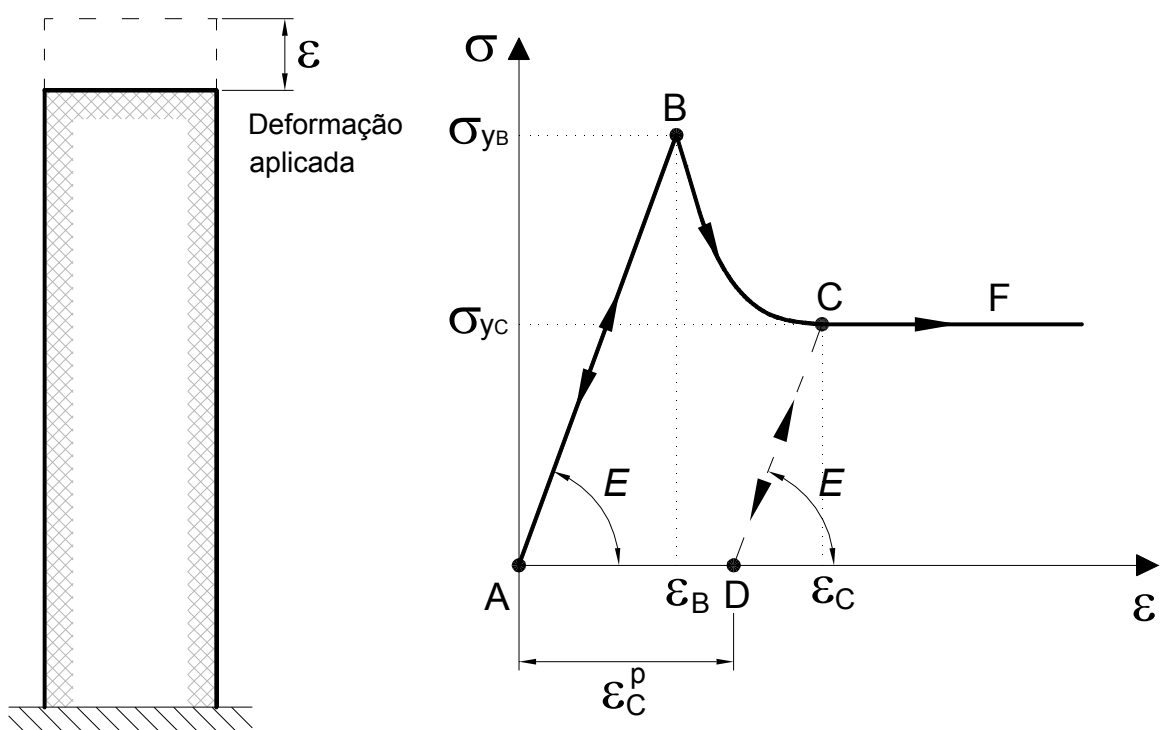

Figura 25 - Deformação uniaxial de material elastoplástico com amolecimento (softening) (modificado de Potts e Zdravkovic, 1999)

Aplicando-se a deformação $\varepsilon$ a barra apresenta comportamentos distintos a medida que a deformação aumenta. Entre os pontos A e B o comportamento é elástico linear com módulo de elasticidade $E$, até o ponto $\mathrm{B}$ o comportamento é reversível sem que ocorram deformações permanentes, a tensão é obtida pela função $\sigma(\varepsilon)=E \varepsilon$ e a deformação em $\mathrm{B}$ é $\varepsilon_{\mathrm{B}}$. No ponto $\mathrm{B}$ a barra atinge $\mathrm{o}$ início da tensão de plastificação $\sigma_{y B}$, com deformação $\varepsilon_{B}$ e a lei constitutiva passa a ser não linear plástica até o ponto $C$, a função $\sigma(\varepsilon)$ não é mais linear e pode ser qualquer função injetora decrescente. No ponto $C$ a barra atinge $O$ final da tensão de plastificação $\sigma_{y c}$ em que $\sigma_{y c}<\sigma_{y B}$ e a deformação passa a ser constante para qualquer incremento, desta forma haverá somente aumento de deformação e não de tensão, que no ponto $C$ corresponde a $\varepsilon_{C}$ e a função $\sigma(\varepsilon)=\sigma_{y c}$. Se no ponto $C$ a barra for completamente descarregada chegará ao ponto $\mathrm{D}$ e neste caso aparecerá uma 
deformação permanente dada pela função $\varepsilon_{C}{ }^{p}=\varepsilon_{C}-\varepsilon_{B}$ e durante o descarregamento a tensão é obtida pela função $\sigma(\varepsilon)=E\left(\varepsilon-\varepsilon_{C}^{p}\right)$. Se a barra sofrer nova deformação, entre os pontos D e C o comportamento voltará a ser elástico linear com módulo de elasticidade $E$ e a tensão volta a obedecer a função $\sigma(\varepsilon)=E\left(\varepsilon-\varepsilon_{C}{ }^{p}\right)$ até atingir novamente a tensão de plastificação $\sigma_{y c}$ no ponto $C$, com deformação $\varepsilon_{C}$. Entre os pontos C e $\mathrm{F}$ a tensão fica constante com função $\sigma(\varepsilon)=\sigma_{\mathrm{yc}}$ e a deformação permanente sofrerá acréscimo $\varepsilon_{C}^{p}>\varepsilon_{C}-\varepsilon_{B}$.

Pedro França (2009, p. 47 apud Potts e Zdravkovic, 1999, p.134) com relação a este último modelo:

Do ponto de vista da engenharia, um material que se comporta dessa maneira merece atenção especial, pois quando solicitado sob tensão inicial de plastificação, a tensão de plastificação reduz juntamente com a resistência a solicitação.

Em outras palavras, neste tipo de material quando representar o comportamento de um solo, ao atingir-se o início da plastificação, a perda da resistência imediatamente posterior pode significar a ruína de uma estrutura nele estiver apoiado.

Pode-se afirmar que os modelos apresentados por Potts e Zdravkovic (1999, p.133) e Pedro França (2009) seguem os princípios do modelo elastoplástico de Prandtl-Reuss.

\subsection{MODELOS CONSTITUTIVOS ELASTOPLÁSTICOS MULTIAXIAIS}

\subsubsection{TENSÕES PRINCIPAIS E INVARIANTES DE TENSÃO}

Para que sejam desenvolvidos, adequadamente, os conceitos relacionados ao estado multiaxiais de tensões, é necessário que sejam introduzidos os conceitos de tensões principais e invariantes.

Segundo Sánchez (2000, p.50) as tensões principais definidas por $\left(\sigma_{1}, \sigma_{2}, \sigma_{3}\right)$, em um sistema tridimensional, representam a tensões normais máximas conjugadas a tensões tangenciais nulas em um ponto deste sistema, vinculados a um determinado plano cujo versor normal é $\mathbf{n}$.

Em mecânica dos sólidos é usual adotar-se a seguinte convenção: 


$$
\sigma_{1} \geq \sigma_{2} \geq \sigma_{3}
$$

Em Pimenta (2007, p.174) e Almeida Neto (2008):

A tensão normal atuante em uma determinada superfície é dada por:

$$
\sigma=\mathbf{t} \cdot \mathbf{n}
$$

Em que $\mathbf{t}$ é o vetor tensão, lembrando de (2.62) e aplicando-a ao caso tridimensional:

$$
\sigma=\mathbf{n} \cdot \mathbf{T n}
$$

Como o tensor das tensões, T, é um operador simétrico e um tensor de $2^{\circ}$ ordem, ele possui três autovalores que são exatamente as tensões principais $\left(\sigma_{1}, \sigma_{2}, \sigma_{3}\right)$. Se os três autovalores forem distintos, os autovetores associados serão triortogonais e formarão uma base ortonormal.

Como demonstração da obtenção dos autovalores:

Considerando (2.42) e fazendo:

$$
\begin{aligned}
& \mathbf{T n}=\sigma \mathbf{n} \\
& (\mathbf{T}-\sigma \boldsymbol{\delta}) \mathbf{n}=0
\end{aligned}
$$

Primeira solução, $\mathbf{n}=0$. Lembrando que $\mathbf{n}$ é um versor normal:

$$
\begin{aligned}
& n_{1}^{2}+n_{2}^{2}+n_{3}^{2}=1 \\
& \therefore \mathbf{n} \neq 0
\end{aligned}
$$

Pelo exposto em (4.7) a primeira solução não é possível. Para que haja outras soluções o sistema deverá ser indeterminado, assim a segunda solução:

$$
\begin{aligned}
& \left|T_{i j}-\sigma \delta_{i j}\right|=0 \\
& \left|\begin{array}{ccc}
\left(T_{11}-\sigma\right) & T_{12} & T_{13} \\
T_{12} & \left(T_{22}-\sigma\right) & T_{23} \\
T_{13} & T_{23} & \left(T_{33}-\sigma\right)
\end{array}\right|=0 \\
& \sigma^{3}-I_{1} \sigma^{2}+I_{2} \sigma-I_{3}=0
\end{aligned}
$$


Em que $I_{1}, I_{2}$ e $I_{3}$ são denominados invariantes principais do tensor das tensões, pois as tensões principais independem do sistema de coordenadas adotado.

Invariante linear, $I_{1}$ :

$$
I_{1}=T_{11}+T_{22}+T_{33}
$$

Invariante quadrático, $I_{2}$ :

$$
\begin{aligned}
& I_{2}=\left|\begin{array}{ll}
T_{11} & T_{12} \\
T_{12} & T_{22}
\end{array}\right|+\left|\begin{array}{ll}
T_{22} & T_{23} \\
T_{23} & T_{33}
\end{array}\right|+\left|\begin{array}{ll}
T_{11} & T_{13} \\
T_{13} & T_{33}
\end{array}\right| \\
& I_{2}=T_{11} T_{22}+T_{22} T_{33}+T_{33} T_{11}-T_{12}^{2}-T_{23}^{2}-T_{31}^{2}
\end{aligned}
$$

Invariante cúbico, $I_{3}$ :

$$
\begin{aligned}
I_{3} & =\left|\begin{array}{lll}
T_{11} & T_{12} & T_{13} \\
T_{21} & T_{22} & T_{23} \\
T_{31} & T_{32} & T_{33}
\end{array}\right| \\
I_{3} & =T_{11} T_{22} T_{33}+2 T_{12} T_{23} T_{31}-T_{11} T_{23}^{2}-T_{22} T_{31}^{2}-T_{33} T_{12}^{2}
\end{aligned}
$$

Outra forma de apresentação dos invariantes definidos acima é mostrada em Caputo (2011, p.116) que define os invariantes em função das tensões principais: Invariante linear, $I_{1}$ :

$$
I_{1}=\sigma_{1}+\sigma_{2}+\sigma_{3}
$$

Invariante quadrático, $I_{2}$ :

$$
I_{2}=\sigma_{1} \sigma_{2}+\sigma_{1} \sigma_{3}+\sigma_{2} \sigma_{3}
$$

Invariante cúbico, $I_{3}$ :

$$
I_{3}=\sigma_{1} \sigma_{2} \sigma_{3}
$$

A tensão normal media é definida por:

$$
\sigma_{m}=\frac{1}{3} I_{1}
$$

Calculando-se (4.17) de acordo com (4.14): 


$$
\sigma_{m}=\sigma_{o c t}=\frac{1}{3}\left(\sigma_{1}+\sigma_{2}+\sigma_{3}\right)
$$

(4.18) também é chamada de tensão hidrostática, tensão normal octaédrica ou "tensão efetiva média" (Potts e Zdravkovic, 1999, p. 115, tradução nossa), neste último é adotada a seguinte notação:

$$
p^{\prime}=\frac{1}{3}\left(\sigma_{1}^{\prime}+\sigma_{2}^{\prime}+\sigma_{3}^{\prime}\right)
$$

Como tensor das tensões é simétrico, ele pode ser decomposto em outros dois tensores: o tensor esférico ou hidrostático, $\mathbf{T}^{\mathrm{e}}$, e o tensor antiesférico ou desviador, $\mathbf{T}^{\mathrm{a}}$.

$$
\begin{aligned}
& \mathbf{T}=\mathbf{T}^{e}+\mathbf{T}^{a} \\
& \mathbf{T}^{e}=\sigma_{m} \mathbf{I}=\left[\begin{array}{ccc}
\sigma_{m} & \cdot & \cdot \\
\cdot & \sigma_{m} & \cdot \\
\cdot & \cdot & \sigma_{m}
\end{array}\right] \\
& \mathbf{T}^{a}=\mathbf{T}-\mathbf{T}^{e}=\left[\begin{array}{ccc}
T_{11}-\sigma_{m} & T_{12} & T_{13} \\
T_{21} & T_{22}-\sigma_{m} & T_{23} \\
T_{31} & T_{32} & T_{33}-\sigma_{m}
\end{array}\right]
\end{aligned}
$$

O tensor antiesférico possui três autovalores $\left(\mathrm{s}_{1}, \mathrm{~s}_{2}, \mathrm{~s}_{3}\right)$, que são denominados tensões desviadoras principais, Sánchez (2000, p.82), e fornece um segundo conjunto de invariantes, denominados invariantes do tensor antiesférico das tensões, obtidos por meio de sua equação característica, similar a (4.10)

$$
s^{3}-J_{1} s^{2}+J_{2} s-J_{3}=0
$$

Invariantes do tensor antiesférico das tensões:

$$
\begin{aligned}
& J_{1}=0 \\
& J_{2}=\frac{1}{3} I_{1}^{2}-I_{2}
\end{aligned}
$$




$$
J_{3}=\frac{2}{27} I_{1}^{3}-\frac{1}{3} I_{1} I_{2}+I_{3}
$$

Assim como os invariantes principais do tensor das tensões, os invariantes do tensor antiesférico das tensões principais independem do sistema de coordenadas adotado.

Por meio de (4.25) pode-se calcular a tensão tangencial octaédrica:

$$
\tau_{o c t}=\sqrt{\frac{2}{3} J_{2}}
$$

A tensão normal octaédrica e a tensão tangencial octaédrica são as tensões obtidas em um plano definido no espaço tridimensional formado pelas tensões principais $\left(\sigma_{1}, \sigma_{2}, \sigma_{3}\right)$ em que seu vetor normal no primeiro quadrante possui os seguintes componentes:

$$
\left\{n_{\text {oct }}\right\}=\left(\frac{\sqrt{3}}{3}\right)\left[\begin{array}{l}
1 \\
1 \\
1
\end{array}\right]
$$

Geometricamente:
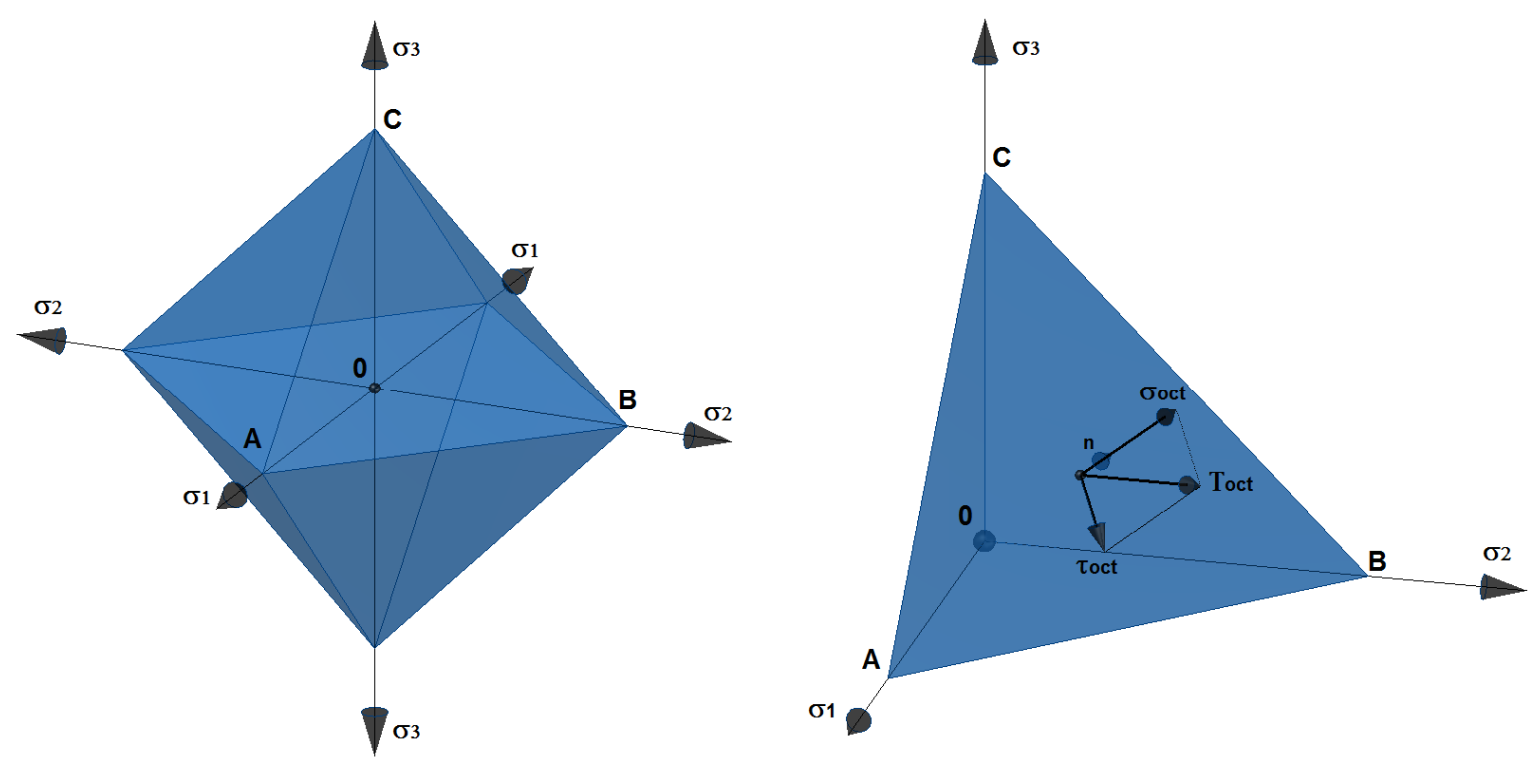

Figura 26 - Planos octaédricos e tensões octaédricas (modificado de Sánchez, 2000)

Uma utilidade das tensões octaédricas está na aplicação dos critérios de resistência. Considerando o espaço tridimensional formado pelas tensões principais, 
pode-se construir um eixo hidrostático $\left(\sigma_{1}=\sigma_{2}=\sigma_{3}\right)$, que passa pela origem e tem direção e sentido de $\mathbf{n}_{\text {oct }}$ em que o estado de tensões representado pelo ponto $P$ $\left(\sigma^{\mathrm{p}}, \sigma^{\mathrm{p}}{ }_{2}, \sigma^{\mathrm{p}}\right)$ corresponde a:

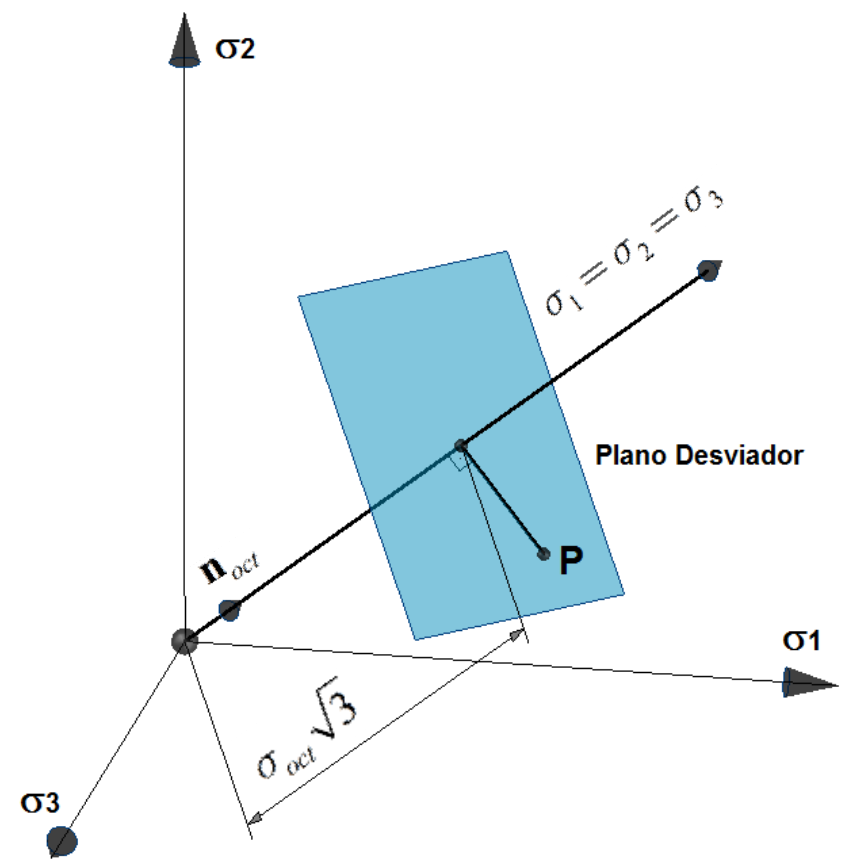

Figura 27 - Espaço das tensões principais (modificado de Potts e Zdravkovic, 1999)

O plano desviador ou antiesférico é o plano que contém a tensão desviadora, o versor deste plano é $\mathbf{n}_{\text {oct. }}$. Uma simplificação da representação do estado de tensões $\mathrm{P}$ projetado no plano desviador é vê-lo de topo de forma que o referencial seja projetado sobre ele. 


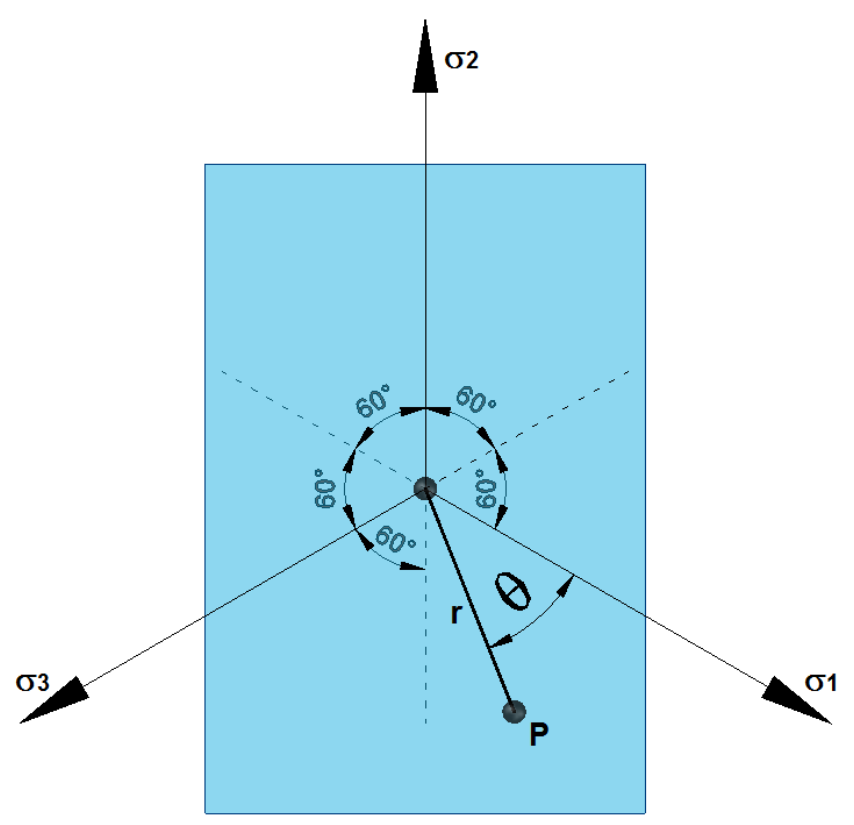

Figura 28 - Plano desviador (modificado de Sánchez, 2000)

$\mathrm{Na}$ figura 28, $\theta$ e $r$ são invariantes e geometricamente $r$ representa a distância do centro do referencia ao ponto $\mathrm{P}$ e $\theta$ o ângulo entre $\mathrm{r}$ e o eixo $\sigma_{1}$.

$$
\begin{aligned}
& r=\sqrt{2 J_{2}}=\tau_{o c t} \sqrt{3} \\
& \theta=\frac{1}{3} \arccos \left(\frac{J_{3} 3 \sqrt{3}}{2 \sqrt{J_{2}^{3}}}\right), 0 \leq \theta \leq 60^{\circ}
\end{aligned}
$$

As tensões principais podem ser colocadas em função de (3.29) e (3.30):

$$
\left\{\begin{array}{l}
\sigma_{1} \\
\sigma_{2} \\
\sigma_{3}
\end{array}\right\}=\frac{I_{1}}{3}\left\{\begin{array}{l}
1 \\
1 \\
1
\end{array}\right\}+\frac{r \sqrt{6}}{3}\left\{\begin{array}{c}
\cos \theta \\
\cos \left(60^{\circ}-\theta\right) \\
\cos \left(60^{\circ}+\theta\right)
\end{array}\right\}
$$

Potts e Zdravkovic (1999, p.115) faz uso de outra notação para os invariantes definidos em (4.29) e (4.30) e para (4.31). Os invariantes abaixo são chamados de "tensão desviadora" e "Ângulo de Lode" respectivamente (Potts e Zdravkovic, 1999, p. 115, tradução nossa):

$$
J=\frac{\sqrt{6}}{6} \sqrt{\left(\sigma_{1}^{\prime}-\sigma_{2}^{\prime}\right)^{2}+\left(\sigma_{2}^{\prime}-\sigma_{3}^{\prime}\right)^{2}+\left(\sigma_{3}^{\prime}-\sigma_{1}^{\prime}\right)^{2}}
$$




$$
\begin{aligned}
& r=J \sqrt{2} \\
& \theta=\tan ^{-1}\left[\frac{1}{\sqrt{3}}\left(2 \frac{\left(\sigma_{2}^{\prime}-\sigma_{3}^{\prime}\right)}{\left(\sigma_{1}^{\prime}-\sigma_{3}^{\prime}\right)}-1\right)\right], \quad-30^{\circ} \leq \theta \leq 30^{\circ}
\end{aligned}
$$

As tensões principais colocadas em função de (4.19), (4.32) e (4.34):

$$
\left\{\begin{array}{l}
\sigma_{1}^{\prime} \\
\sigma_{2}^{\prime} \\
\sigma_{3}^{\prime}
\end{array}\right\}=p^{\prime}\left\{\begin{array}{l}
1 \\
1 \\
1
\end{array}\right\}+\frac{2}{\sqrt{3}} J\left\{\begin{array}{c}
\operatorname{sen}\left(\theta+\frac{2 \pi}{3}\right) \\
\operatorname{sen} \theta \\
\operatorname{sen}\left(\theta-\frac{2 \pi}{3}\right)
\end{array}\right\}
$$

\subsubsection{DEFORMAÇÕES PRINCIPAIS E INVARIANTES DE DEFORMAÇÃO}

Considerando a deformação $\varepsilon$, segundo a direção do versor $\mathbf{n}$, com o vetor deformação $\xi$ :

$$
\varepsilon=\xi \cdot \mathbf{n}
$$

Por meio do tensor das deformações:

$$
\varepsilon=\mathbf{n} \cdot \mathbf{E n}
$$

Fazendo

$$
\begin{aligned}
& \mathbf{E n}=\varepsilon \mathbf{n} \\
& (\mathbf{E}-\boldsymbol{\delta} \varepsilon) \mathbf{n}=0
\end{aligned}
$$

Como no caso das tensões, considerando $\mathbf{n} \neq 0$ :

$$
\begin{aligned}
& \left|E_{i j}-\delta_{i j} \varepsilon\right|=0 \\
& \left|\begin{array}{ccc}
\left(\varepsilon_{11}-\varepsilon\right) & \varepsilon_{12} & \varepsilon_{13} \\
\varepsilon_{12} & \left(\varepsilon_{22}-\varepsilon\right) & \varepsilon_{23} \\
\varepsilon_{13} & \varepsilon_{23} & \left(\varepsilon_{33}-\varepsilon\right)
\end{array}\right|=0
\end{aligned}
$$




$$
\varepsilon^{3}-I_{1}^{\prime} \varepsilon^{2}+I_{2}^{\prime} \varepsilon-I_{3}^{\prime}=0
$$

Em que $I_{1}^{\prime}, I_{2}^{\prime}$ e $I^{\prime}{ }_{3}$ são os invariantes principais do tensor das deformações, e $\varepsilon_{1}, \varepsilon_{2}$ e $\varepsilon_{3}$, os autovalores de (4.40) que representam as deformações principais.

Em Sánchez (2000, p.163)

Invariante linear, $I^{\prime}{ }_{1}$ :

$$
I_{1}^{\prime}=\varepsilon_{11}+\varepsilon_{22}+\varepsilon_{33}
$$

Invariante quadrático, $I_{2}^{\prime}$ :

$$
\begin{aligned}
I_{2}^{\prime} & =\left|\begin{array}{ll}
\varepsilon_{11} & \varepsilon_{12} \\
\varepsilon_{12} & \varepsilon_{22}
\end{array}\right|+\left|\begin{array}{cc}
\varepsilon_{22} & \varepsilon_{23} \\
\varepsilon_{23} & \varepsilon_{33}
\end{array}\right|+\left|\begin{array}{cc}
\varepsilon_{11} & \varepsilon_{13} \\
\varepsilon_{13} & \varepsilon_{33}
\end{array}\right| \\
I_{2}^{\prime} & =\varepsilon_{11} \varepsilon_{22}+\varepsilon_{22} \varepsilon_{33}+\varepsilon_{33} \varepsilon_{11}-\varepsilon_{12}^{2}-\varepsilon_{23}^{2}-\varepsilon_{31}^{2}
\end{aligned}
$$

Invariante cúbico, $I^{\prime}{ }_{3}$ :

$$
\begin{aligned}
I_{3}^{\prime} & =\left|\begin{array}{lll}
\varepsilon_{11} & \varepsilon_{12} & \varepsilon_{13} \\
\varepsilon_{21} & \varepsilon_{22} & \varepsilon_{23} \\
\varepsilon_{31} & \varepsilon_{32} & \varepsilon_{33}
\end{array}\right| \\
I_{3}^{\prime} & =\varepsilon_{11} \varepsilon_{22} \varepsilon_{33}+2 \varepsilon_{12} \varepsilon_{23} \varepsilon_{31}-\varepsilon_{11} \varepsilon_{23}^{2}-\varepsilon_{22} \varepsilon_{31}^{2}-\varepsilon_{33} \varepsilon_{12}^{2}
\end{aligned}
$$

Definindo-se os invariantes do tensor das deformações em função das deformações principais:

Invariante linear, $I^{\prime}{ }_{1}$ :

$$
I_{1}^{\prime}=\varepsilon_{1}+\varepsilon_{2}+\varepsilon_{3}
$$

Invariante quadrático, $I_{2}^{\prime}$ :

$$
I_{2}^{\prime}=\varepsilon_{1} \varepsilon_{2}+\varepsilon_{1} \varepsilon_{3}+\varepsilon_{2} \varepsilon_{3}
$$

Invariante cúbico, $I^{\prime} 3$ :

$$
I_{3}^{\prime}=\varepsilon_{1} \varepsilon_{2} \varepsilon_{3}
$$

Assim como as tensões octaédricas, pode-se definir as deformações octaédricas considerando o espaço tridimensional formado pelas deformações principais e uma fibra definida pelo versor (4.28): 
Deformação normal octaédrica ou média:

$$
\varepsilon_{m}=\varepsilon_{o c t}=\frac{1}{3} I_{1}^{\prime}=\frac{1}{3}\left(\varepsilon_{1}+\varepsilon_{2}+\varepsilon_{3}\right)
$$

Deformação tangencial octaédrica:

$$
\gamma_{o c t}=\frac{2 \sqrt{2}}{3}\left(I_{1}^{\prime 2}-3 I_{2}^{\prime}\right)=\frac{2}{3} \sqrt{\left(\varepsilon_{1}-\varepsilon_{2}\right)^{2}+\left(\varepsilon_{2}-\varepsilon_{3}\right)^{2}+\left(\varepsilon_{3}-\varepsilon_{1}\right)^{2}}
$$

A decomposição do tensor das deformações, $\mathbf{E}$, em um tensor esférico ou hidrostático, $\mathbf{E}^{\mathrm{e}}$, e um tensor antiesférico ou desviador, $\mathbf{E}^{\mathrm{a}}$ pode ser feito de maneira semelhante ao tensor das tensões $\mathbf{T}$, e fornece um segundo conjunto de invariantes, denominados invariantes do tensor antiesférico ou desviador das deformações:

$$
\begin{aligned}
& J_{1}^{\prime}=0 \\
& J_{2}^{\prime}=\frac{1}{3} I_{1}^{\prime 2}-I_{2}^{\prime} \\
& J_{3}^{\prime}=\frac{2}{27} I_{1}^{\prime 3}-\frac{1}{3} I_{1}^{\prime} I_{2}^{\prime}+I_{3}^{\prime}
\end{aligned}
$$

Por meio de (3.50) pode-se calcular a tensão tangencial octaédrica:

$$
\gamma_{o c t}=2 \sqrt{\frac{2}{3} J_{2}^{\prime}}
$$

Sánchez (2000, p. 171) descreve a uma interpretação geométrica para (4.48): Considerando um cubo elementar de volume unitário e admitindo o caso de pequenas deformações, a deformação volumétrica (ou volúmica) é dada por:

$$
\varepsilon_{V}=\varepsilon_{1}+\varepsilon_{2}+\varepsilon_{3}=I^{\prime}{ }_{1}
$$



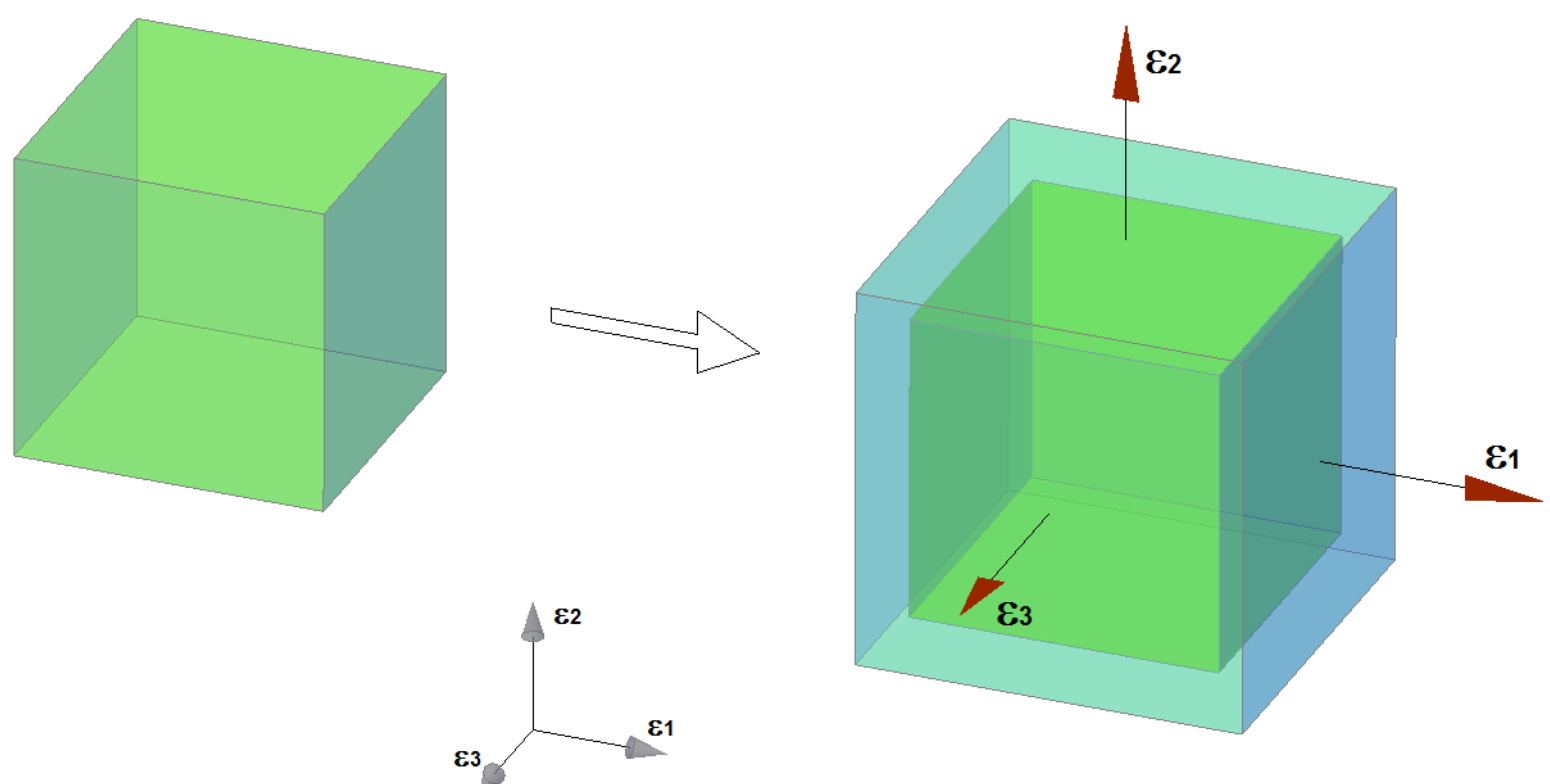

Figura 29 - Deformação volumétrica

Em que ocorre a variação do volume sem mudança de forma e $\varepsilon v$ é proporcional a $\varepsilon_{\mathrm{m}}$.

Segundo Potts e Zdravkovic (1999, p.116) apenas dois invariantes de deformações são usualmente utilizados:

A "deformação volumétrica incremental" (FRANÇA, P., 2009, p. 31):

$$
\Delta \varepsilon_{V}=\Delta \varepsilon_{1}+\Delta \varepsilon_{2}+\Delta \varepsilon_{3}
$$

E a "deformação desviadora incremental" (Potts e Zdravkovic, 1999, p. 117, tradução nossa):

$$
\Delta E_{d}=\frac{2}{\sqrt{6}} \sqrt{\left(\Delta \varepsilon_{1}-\Delta \varepsilon_{2}\right)^{2}+\left(\Delta \varepsilon_{2}-\Delta \varepsilon_{3}\right)^{2}+\left(\Delta \varepsilon_{3}-\Delta \varepsilon_{1}\right)^{2}}
$$

Pedro França $(2009$, p. 31) traduz o nome de (4.56) como deformação cisalhante (ou distorção) incremental.

A justificativa para a escolha dos invariantes supracitados é o fato deles serem usados para obtenção do trabalho incremental:

$$
\Delta W=\left\{\boldsymbol{\sigma}^{\prime}\right\}^{T}\{\Delta \boldsymbol{\varepsilon}\}=p^{\prime} \Delta \varepsilon_{V}+J \Delta E_{d}
$$

A adição do delta na expressão, reresentando o incremento, está ligado a forma de resolução do problema no MEF, similarmente ao apresentado no capítulo 3 
e pela deformação não se comportar de maneira monotônica obrigatoriamente, como exemplificado abaixo.
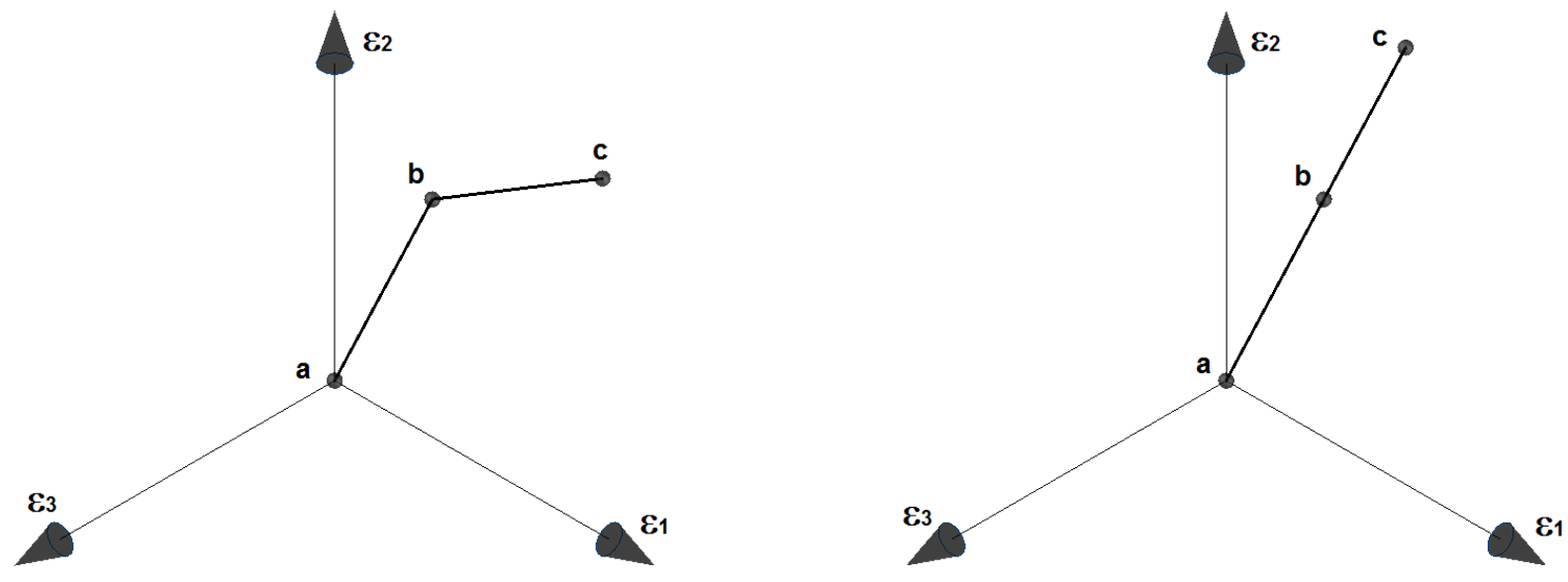

Figura 30 - Plano desviador de deformações - (a) Mudança de direção da deformação; (b) Deformação monotônica (modificado de Potts e Zdravkovic, 1999)

Velloso, Maria, e Lopes (1998, p. 177) indicam que seja utilizada a abordagem de incrementos de deformações (análise incremental), considerando a dependência entre deformações plásticas e o caminho de carregamento. Desta forma as deformações totais são obtidas pelo somatório dos incrementos de deformações.

Quanto a análise incremental de problemas inelásticos, Bathe (1996, p. 595) cita três condições cinemáticas possíveis: pequenas deformações e deslocamentos; pequenas deformações com grandes deslocamentos e rotações; grandes deslocamentos e rotações. Para pequenas deformações e deslocamentos a formulação para o material pode ser dividida em duas partes, uma para a parte elástica e outra para parte inelástica. Isto implica em mudança da matriz de rigidez, e ao formular-se o problema com incrementos de deformações pode-se corrigi-la a cada passo.

\subsubsection{CONCEITOS BÁSICOS PARA FORMULAÇÃO}

Pedro França (2009, p. 48 apud Potts e Zdravkovic, 1999, p.136) e Martins (2008, p.61) citam os conceitos básicos para formulação de modelos constitutivos elastoplásticos:

1. Coincidência de eixos: 
Assume-se que as direções das tensões principais e das deformações incrementais plásticas são coincidentes.

2. Função de plastificação:

Existe uma função escalar definida como função de plastificação que diferencia o comportamento elástico e o comportamento elastoplástico. No caso uniaxial esta função é definida por constantes como a tensão de plastificação $\sigma_{y}$, e no caso multiaxial por uma superfície, denominada superfície de plastificação. Ela é caracterizada por:

$$
F(\{\sigma\},\{k\})=0
$$

Em que $\{\sigma\}$ e $\{k\}$ denotam que a função de plastificação depende do estado de tensões aplicado num ponto e de seus parâmetros de estado respectivamente. Os parâmetros de estado assumem valores diferentes de acordo com o tipo de plastificação representada. No caso de modelos constitutivos elastoplásticos perfeitos os parâmetros de estado são constantes e representam os valores das tensões de plastificação do material, no caso de modelos constitutivos elastoplásticos com endurecimento ou amolecimento os parâmetros de estado variam juntamente as deformações plásticas representando a mudança no estado de tensões na plastificação.

A função de plastificação pode ser definida como função dos invariantes $F\left(I_{1}, J_{2}, J_{3}\right)$ para materiais isotrópicos (PACHÁS, 2009, p. 27).

A figura 31 representa a curva de plastificação e a superfície de platificação. 

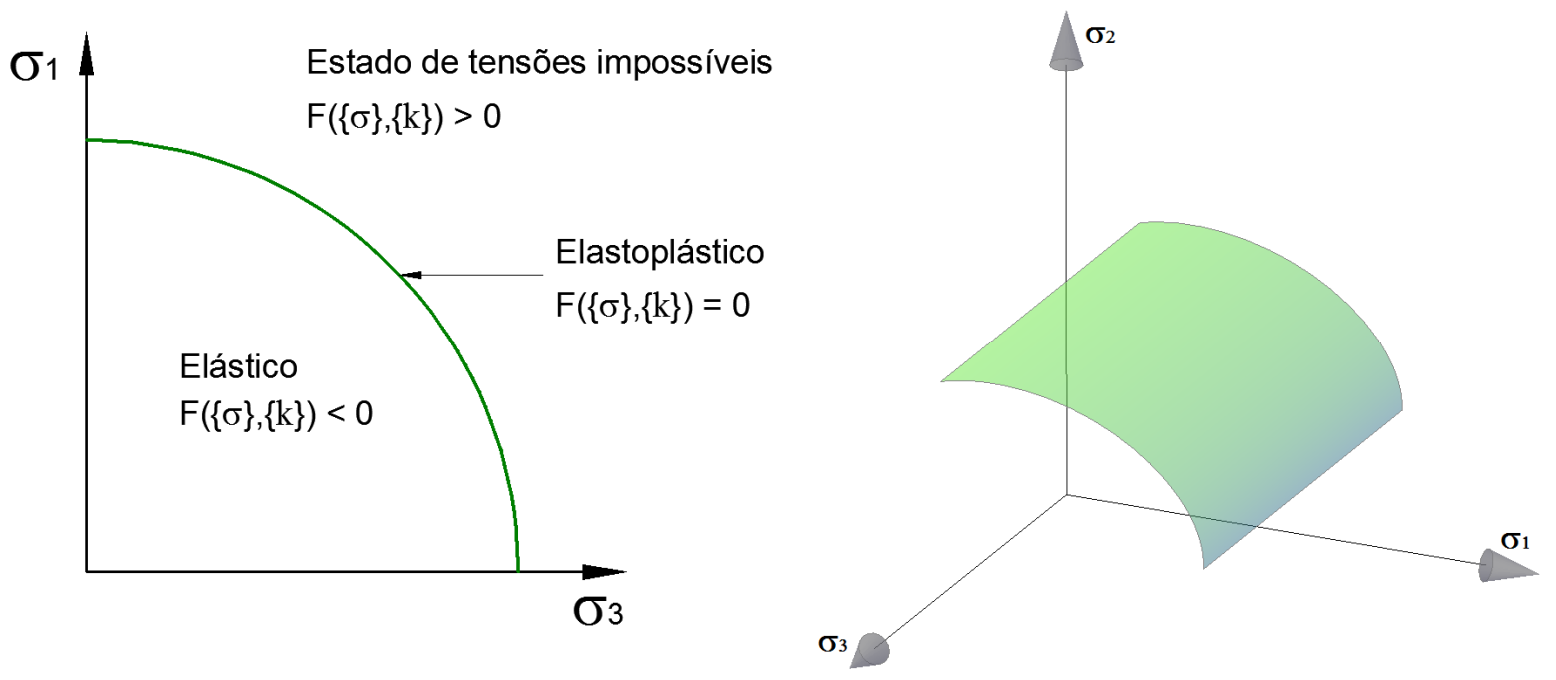

Figura 31 - (a) Curva de plastificação; (b) Trecho de superfície de plastificação (Potts e Zdravkovic, 1999)

Velloso, Maria, e Lopes (1998, p.175) conjugam modelos uniaxiais, representando ensaios de tração, com modelo biaxiais, representando os critérios de escoamento do materiais: 


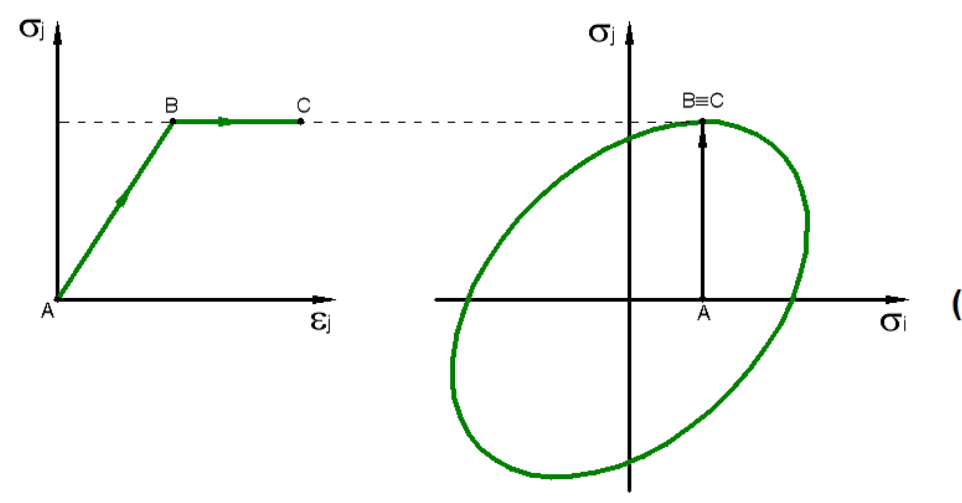

(A)

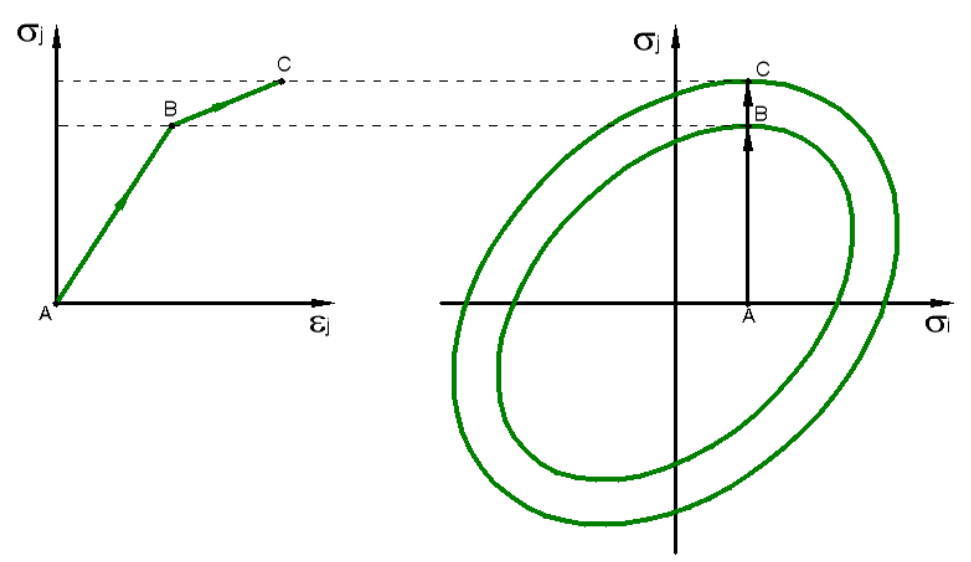

(B)

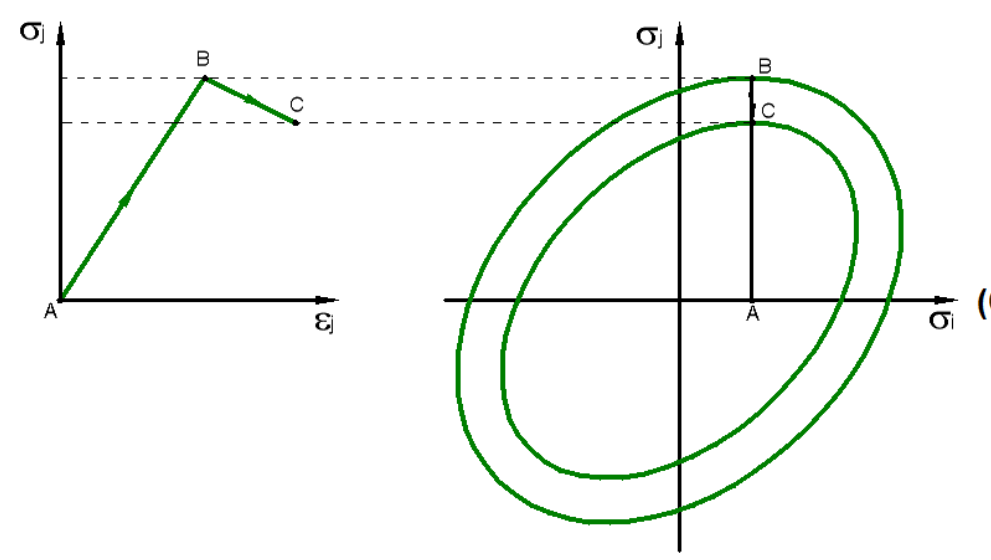

Figura 32 - Curva de escoamento - (A) Material elastoplástico perfeito; (B) Material elastoplástico com endurecimento; (C) Material elastoplástico com amolecimento (modificado de Velloso, Maria, e Lopes, 1998)

3. Função de potencial plástico:

Existe uma função vetorial definida como função de potencial plástico que direciona a deformação de um ponto quando este atinge a superfície de plastificação. No caso uniaxial fica evidente que a direção da deformação plástica tem mesma direção das tensões atuantes, no caso multiaxial esta situação não é mais evidente, pois tensor das tensões e o tensor das deformações tem seis 
componentes cada. No caso multiaxial é necessário estabelecer uma lei de fluxo para a plastificação. Esta função é caracterizada por:

$$
P(\{\sigma\},\{m\})=0
$$

Em que $\{\sigma\}$ e $\{m\}$ denotam que a função de potencial plástico depende do estado de tensões aplicado num ponto e de seu vetor de parâmetros de estado respectivamente. O vetor de parâmetros de estado é definido sobre a superfície de plastificação e quando é normal a esta superfície, diz-se que obedece a lei da normalidade.

Pimenta (2007, p.345) apresenta a lei da normalidade para o vetor de parâmetros de estado:

Seja o vetor normal a superfície de plastificação:

$$
\mathbf{n}=\nabla F
$$

m obedece à lei de normalidade quando:

$$
\mathbf{m}=\mathbf{n}
$$

Em que:

$$
\dot{\boldsymbol{\varepsilon}}^{p}=\dot{\alpha} \mathbf{m}
$$

$\alpha$ é um escalar. Considerando incrementos de deformações:

$$
\Delta \boldsymbol{\varepsilon}^{p}=\alpha \mathbf{m}
$$

O vetor definido em (4.63) pode ser definido como incremento de deformação plástica. Velloso, Maria, e Lopes (1998, p.176) adotam a terminologia "vetor acréscimo de deformação plástica".

Graficamente: 


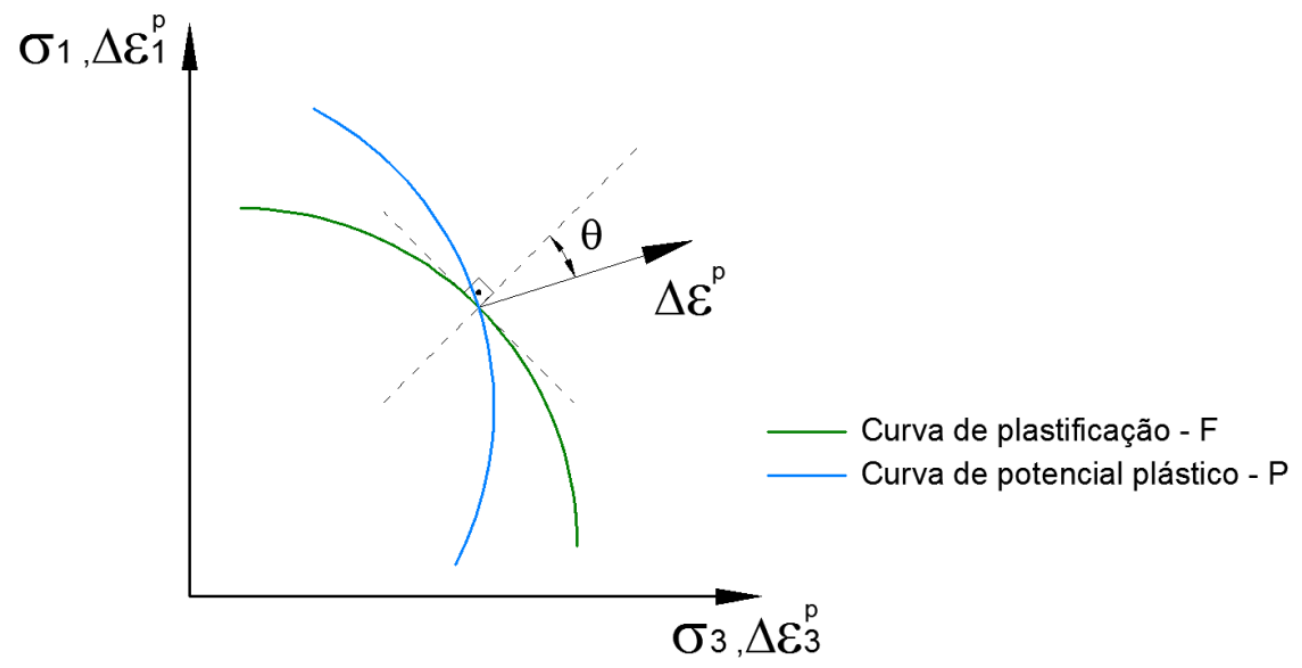

Figura 33 - Curvas de potencial plástico e plastificação (adaptado de Velloso, Maria, e Lopes, 1998)

Tem-se a condição de normalidade quando $\mathrm{F}=\mathrm{P}$ e $\theta=0$. Esta condição também é chamada de lei de escoamento associada ou lei de fluxo associado. No caso do material elastoplástico com endurecimento com lei de fluxo associada:

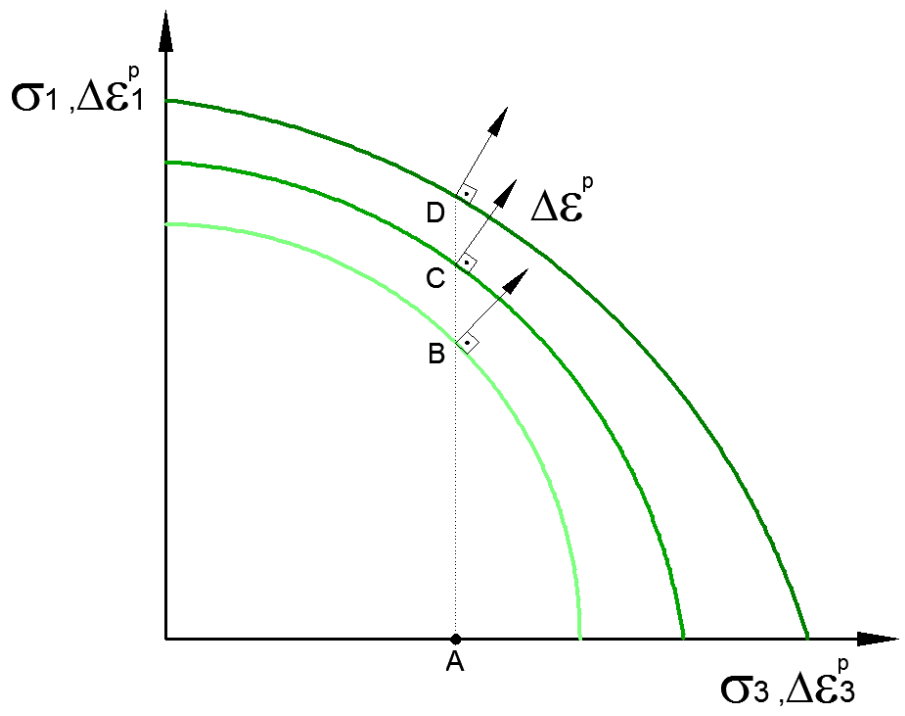

Figura 34 - Curvas de potencial plástico e plastificação para o material elastoplástico com endurecimento (adaptado de Potts e Zdravkovic, 1999)

Tridimensionalmente: 


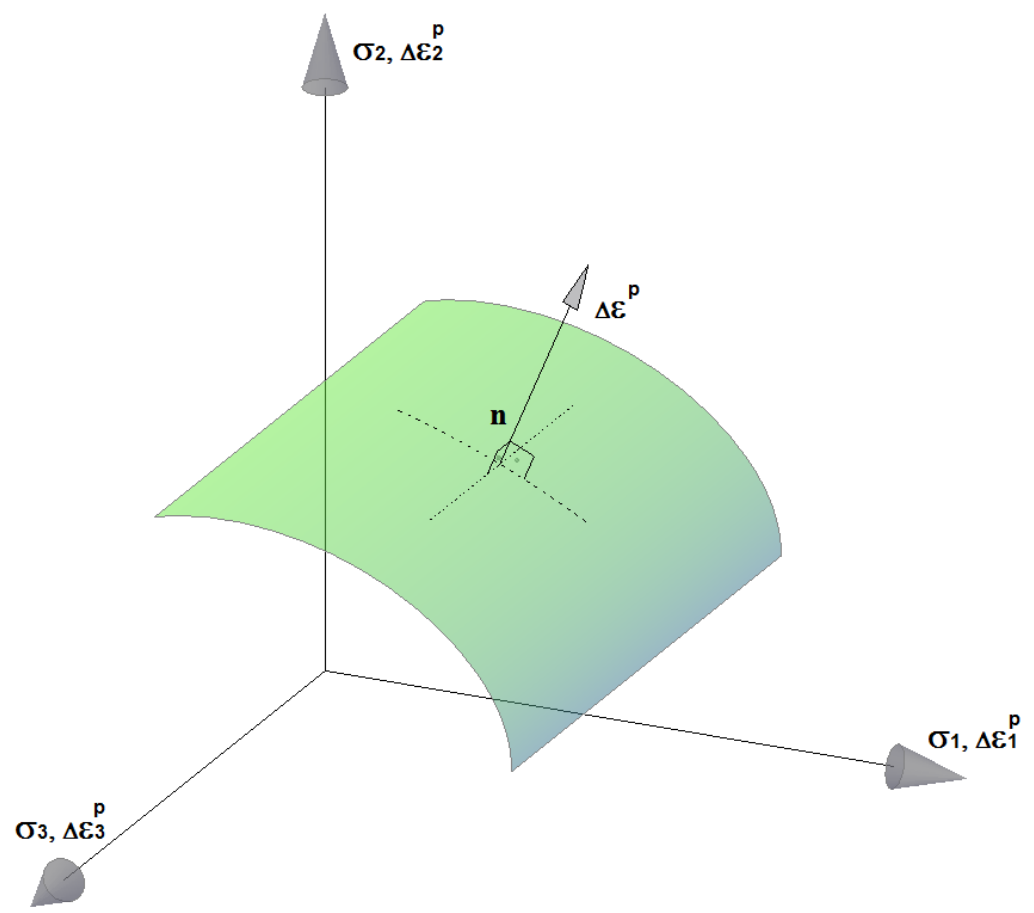

Figura 35 - Trecho de superfície de plastificação e vetor parâmetros de estado (modificado de Potts e Zdravkovic, 1999)

Sobre o ângulo $\theta$, Velloso, Maria, e Lopes $(1998$, p.176) fazem a seguinte asserção:

"[...] é extremamente conveniente admitir-se, no modelo de análise, que $\theta$ é nulo."

A conveniência citada deve-se a matriz constitutiva (matriz dos módulos de rigidez) e a matriz de rigidez global serem simétricas para a lei de fluxo associado e não simétricas para lei de fluxo não associado (POTTS \& ZDRAVKOVIC, 1999, p. 138).

A lei de fluxo governa o efeito da dilatância do material (deformação volumétrica plástica).

As seguir serão apresentadas as formulações para obtenção da matriz dos módulos elastoplásticos de rigidez tangente $C^{\mathrm{ep}}$, que correlaciona o vetor incremento de tensões e o vetor de incremento de deformação total:

$$
\{\Delta \boldsymbol{\sigma}\}=\left[C^{e p}\right]\{\Delta \boldsymbol{\varepsilon}\}
$$

Estas formulações forão baseadas nas apresentadas Bathe (1996), Potts e Zdravkovic (1999) e Pimenta (2007). Faz-se uma observação quanto a notação 
adotada representar incremento: Em Bathe (1996) é usado "d" e para indicar incremento, em Potts e Zdravkovic (1999) é usado " $\Delta$ " para indicar incremento e em Pimenta (2007) é usada a derivada temporal, que dá um formato generalista.

Para as formulações a seguir adotar-se-á " $\Delta$ ", por denotarem incremento fazendo distinção da notação de derivada " $d$ ".

Por meio do modelo elastoplástico de Prandtl-Reuss, como o definido em (4.2), pode-se estabelecer as seguintes relações incrementais:

$$
\begin{aligned}
& \{\Delta \boldsymbol{\varepsilon}\}=\left\{\Delta \boldsymbol{\varepsilon}^{e}\right\}+\left\{\Delta \boldsymbol{\varepsilon}^{p}\right\} \\
& \{\Delta \boldsymbol{\sigma}\}=[C]\left(\{\Delta \boldsymbol{\varepsilon}\}-\left\{\Delta \boldsymbol{\varepsilon}^{p}\right\}\right)
\end{aligned}
$$

Em que $C$ é matriz dos módulos de rigidez elástica como definido no capítulo 2 para o EPD.

Pela equação de consistência de Prager:

$$
F=0 \quad \therefore \quad \partial F=0
$$

Assim:

$$
\begin{aligned}
& \partial F=\{\mathbf{n}\}^{T}\{\Delta \boldsymbol{\sigma}\}+\left\{\mathbf{n}_{k}\right\}^{T}\{\Delta \mathbf{k}\}=0 \\
& \{\Delta \boldsymbol{\sigma}\}=-\frac{\left\{\mathbf{n}_{k}\right\}^{T}\{\Delta \mathbf{k}\}}{\{\mathbf{n}\}^{T}}
\end{aligned}
$$

Substituitndo (4.63) em (4.66) e combinando com (4.69):

$$
\begin{aligned}
& \{\Delta \boldsymbol{\sigma}\}=[C]\{\Delta \boldsymbol{\varepsilon}\}-\alpha[C]\{\mathbf{m}\} \\
& \alpha=-\frac{\left\{\mathbf{n}_{k}\right\}^{T}[C]\{\Delta \boldsymbol{\varepsilon}\}}{\{\mathbf{n}\}^{T}[C]\{\mathbf{m}\}+A}
\end{aligned}
$$

Em que:

$$
A=-\frac{1}{\alpha}\left\{\mathbf{n}_{k}\right\}^{T}\{\Delta \mathbf{k}\}
$$


Substituitndo (4.71) em (4.70):

$$
\begin{aligned}
& \{\Delta \boldsymbol{\sigma}\}=[C]\{\Delta \boldsymbol{\varepsilon}\}-\frac{[C]\{\mathbf{m}\}\{\mathbf{n}\}^{T}[C]\{\Delta \boldsymbol{\varepsilon}\}}{\{\mathbf{n}\}^{T}[C]\{\mathbf{m}\}+A} \\
& \{\Delta \boldsymbol{\sigma}\}=\left([C]-\frac{[C]\{\mathbf{m}\}\{\mathbf{n}\}^{T}[C]}{\{\mathbf{n}\}^{T}[C]\{\mathbf{m}\}+A}\right)\{\Delta \boldsymbol{\varepsilon}\}
\end{aligned}
$$

Comparando-se (4.73) com (4.64):

$$
\left[C^{e p}\right]=[C]-\frac{[C]\{\mathbf{m}\}\{\mathbf{n}\}^{T}[C]}{\{\mathbf{n}\}^{T}[C]\{\mathbf{m}\}+A}
$$

Para o caso elastoplástico perfeito, os parâmetros de estado são constantes assim, $A=0$.

$$
\left[C^{e p}\right]=[C]-\frac{[C]\{\mathbf{m}\}\{\mathbf{n}\}^{T}[C]}{\{\mathbf{n}\}^{T}[C]\{\mathbf{m}\}}
$$

Para o caso de lei de fluxo associada, $\mathbf{m}=\mathbf{n}$ :

$$
\left[C^{e p}\right]=[C]-\frac{[C]\{\mathbf{n}\}\{\mathbf{n}\}^{T}[C]}{\{\mathbf{n}\}^{T}[C]\{\mathbf{n}\}}
$$

Em Potts e Zdravkovic (1999) a matriz dos módulos elastoplásticos de rigidez tangente, definida em (4.74), é apresentada como função de (4.59) e (4.58):

$$
\left[C^{e p}\right]=[C]-\frac{[C]\left\{\frac{\partial P(\{\sigma\},\{m\})}{\partial \sigma}\right\}\left\{\frac{\partial F(\{\sigma\},\{k\})}{\partial \sigma}\right\}^{T}[C]}{\left\{\frac{\partial F(\{\sigma\},\{k\})}{\partial \sigma}\right\}^{T}[C]\left\{\frac{\partial P(\{\sigma\},\{m\})}{\partial \sigma}\right\}+A}
$$

\subsubsection{CRITÉRIO DE RESISTÊNCIA}

O critério de resistência utilizado nos modelos deste trabalho para representar a resistência do solo e interface de solo-concreto será o critério de resistência de Mohr-Coulomb. Ele é o caso particular do critério de Mohr, em que a 
variação da tensão de cisalhamento limite é linear e é um modelo elastoplástico perfeito.

Neste critério admiti-se que um material não suporte determinadas tensões de cisalhamento seja qual for o plano de aplicação. A tensão de cisalhamento limite é estabelecida como função da tensão normal atuante e a função de plastificação tem a forma abaixo:

$$
F=\tau-f(\sigma)
$$

Uma aplicação de (4.78) é a equação de Coulomb, normalmente usada para representar o limite de resistência em ensaios de compressão triaxiais:

$$
F=\tau-\sigma \tan (\phi)-c
$$

Em que c é a coesão e $\phi$ o ângulo de atrito interno do material, $\tau$ e $\sigma$ são as tensões de cisalhamento e normal respectivamente, no plano de falha. Como se trata de um critério elastoplástico perfeito, os parâmetros de estado (c, $\phi$ ) são constantes.

Graficamente:

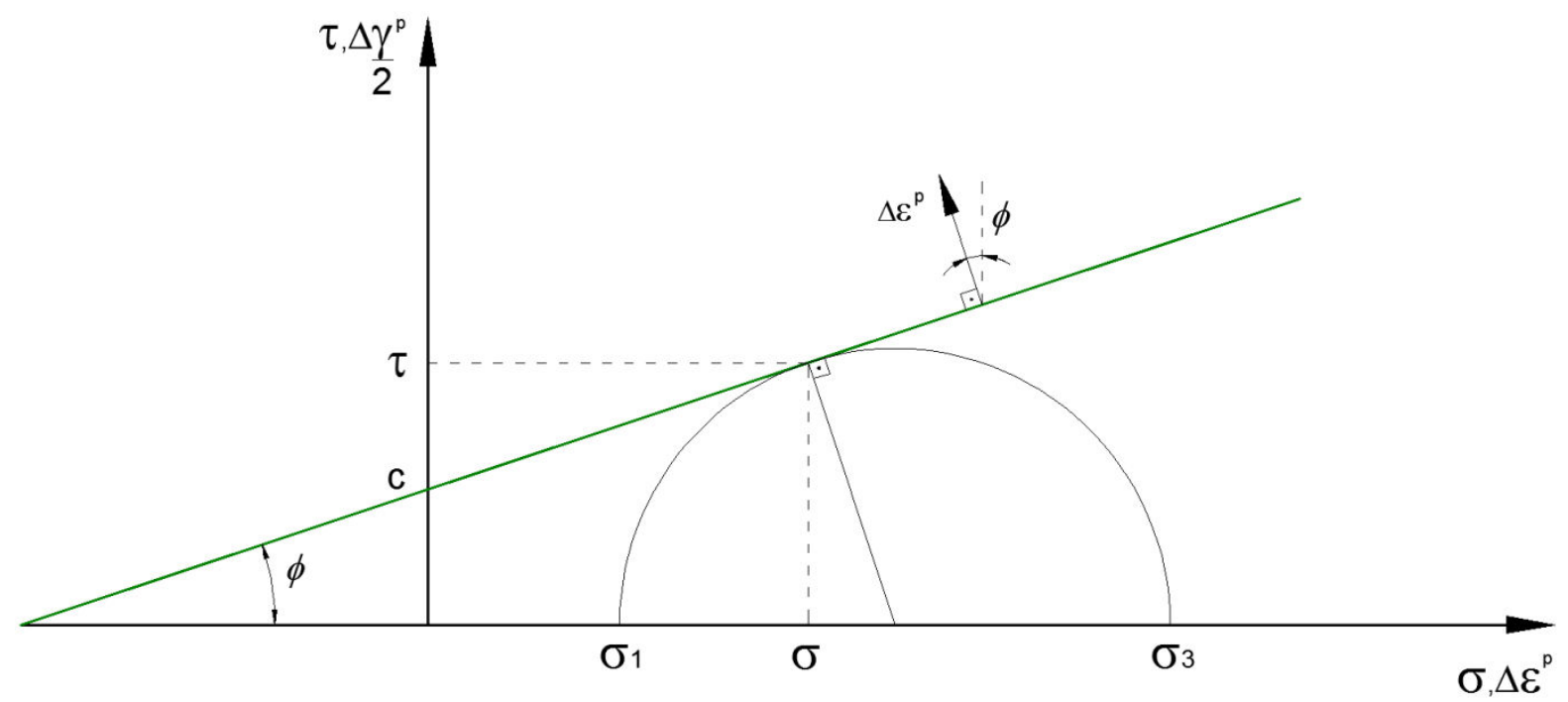

Figura 36 - Circulo e envoltória de Mohr (modificado de Potts e Zdravkovic, 1999)

A equação (4.78) pode ser reescrita em função das tensões principais e lembrando-se de (4.58): 


$$
\sigma_{1}-\sigma_{3}=2 c \cos (\phi)+\left(\sigma_{1}+\sigma_{3}\right) \operatorname{sen}(\phi)
$$

Abaixo é apresentada a função de plastificação em função dos invariantes principais, do tensor das tensões e dos invariantes do tensor antiesférico das deformações:

$$
F=\sqrt{J_{2}}\left(\frac{2 \cos ^{2} \phi-1}{\cos \phi}\right) \operatorname{sen}\left(\theta+\frac{\pi}{3}\right)-\frac{\operatorname{tg} \phi}{3}\left(I_{1}+\sqrt{3 J_{2}} \cos \left(\theta+\frac{\pi}{3}\right)\right)-c
$$

A função de plastificação do critério de Mohr-Coulomb, geometricamente é representada pela superfície de um cone hexagonal no espaço das tensões principais e um hexágono no plano desviador:

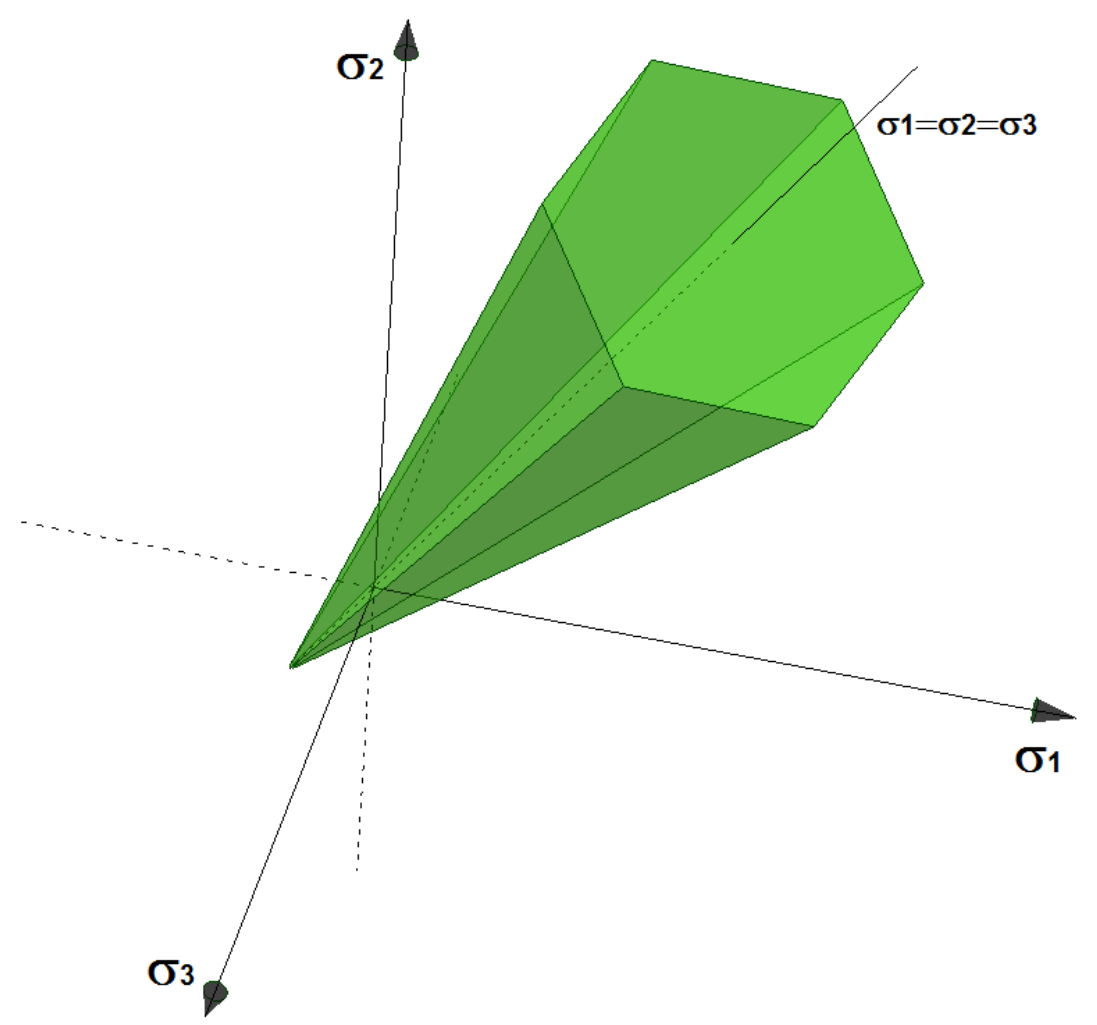

Figura 37 - Superfície de plastificação de Mohr-Coulomb no espaço das tensões principais 


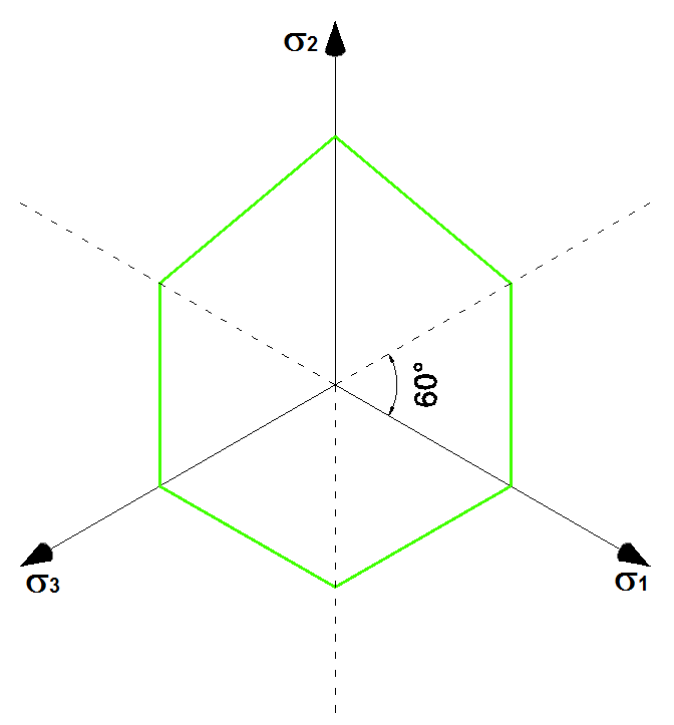

Figura 38 - Superfície de plastificação de Mohr-Coulomb no plano desviador

Potts e Zdravkovic (1999, p. 152) apresenta as funções de plastificação e de potencial plástico do critério de Mohr-Coulomb obtidas como função da tensão efetiva média, da tensão desviadora e do ângulo de Lode:

$$
F=J-\left(\frac{c^{\prime}}{\tan \phi^{\prime}}+p^{\prime}\right) g(\theta)
$$

Em que:

$$
g(\theta)=\frac{3 \operatorname{sen} \phi^{\prime}}{3 \cos \theta+\sqrt{3} \operatorname{sen} \theta \operatorname{sen} \phi^{\prime}}
$$

$\mathrm{Na}$ função de potencial plástico abaixo os índices "c" indicam valores do estado de tensões tomados sobre a superfície de plastificação:

$$
P=J-\left[\left(\frac{c^{\prime}}{\tan \phi^{\prime}}+p_{c}{ }^{\prime}\right) \frac{g(\theta)}{g_{p p}(\theta)}-p_{c}{ }^{\prime}+p^{\prime}\right] g_{p p}(\theta)
$$

Em que:

$$
g_{p p}(\theta)=\frac{3 \operatorname{sen} \varphi}{3 \cos \theta+\sqrt{3} \operatorname{sen} \theta \operatorname{sen} \varphi}
$$

O ângulo $\varphi$ é a dilatância do material. Para lei de fluxo associada, a dilatância é igual ao ângulo de atrito interno, $\varphi=\phi$, para lei de fluxo não associada, a 
dilatância é menor que ângulo de atrito interno, $\varphi<\phi$. A lei de fluxo associada simplifica o equacionamento, pois iguala as funções de plastificação e potencial plástico e faz com que a matriz dos módulos de rigidez seja simétrica. No entando aumenta-se a deformação volumétrica plástica, e de acodo com Potts e Zdravkovic (1999, p. 153) a magnitude desta deformação fica muito maior do que o observado em que há uma dilatância (aumento da deformação volumétrica) inicial na região da superfície de plastificação e logo após, a deformação continua a volume constante. 


\section{CONCRETO ARMADO}

A estrutura de concreto armado é parte importante da contenção, pois sua rigidez influencia os deslocamentos e consequentemente a distribuição de empuxos.

O objetivo deste capítulo é apresentar uma revisão bibliográfica sobre concreto armado, referente a modelos reológicos, e também uma metodologia para obtenção da rigidez à flexo-compressão de estruturas de concreto armado modeladas como estruturas lineares para aplicação na análise de estabilidade de contenções.

O paramento de concreto armado, de estruturas de contenção, é caracterizado estruturalmente como elemento de superfície. No entanto no caso de contenções longas em que se pode utilizar o EPD como modelo para o maciço, adota-se o modelo de estrutura linear com largura unitária para o paramento de concreto. Tal simplificação decorre da distribuição de empuxos ao longo do comprimento horizontal da contenção tender a ser constante, a não ser nas faixas dos tirantes que impõe uma carga localizada no paramento, portanto com efeito tridimensional. No estudo do efeito da rigidez do paramento de concreto na estabilidade do sistema de contenção, adotou-se a rigidez média do paramento de concreto nas faixas horizontais que contêm os tirantes, considerando que para a estabilidade do sistema a rigidez média do paramento é representativa.

Para obtenção dessa rigidez é necessário conhecer a reologia do concreto e do aço e estabelecer seu funcionamento conjunto. Entende-se como rigidez a flexão e flexo-compressão para um elemento estrutural o produto do módulo de elasticidade no qual o material é formado $(E)$ com o momento de inércia da seção transversal do elemento estrutural (I), representado neste texto por "El". A rigidez do concreto armado não é constante e tem um comportamento complexo perante a intensidade da solicitação da peça, passando por diversas fases até a ruína. Uma forma simples de classificar estas fases é apresentada pela norma ABNT NBR6118:2007, em que são definidos estádios ${ }^{3}$, iniciando com um comportamento linear e não fissurado e terminando com um comportamento não-linear e fissurado. Um item complexo de se determinar que influencia na rigidez é o mecanismo que

${ }^{3}$ Fase, período, época, estação. (Novo Dicionário Eletrônico Aurélio versão 5.0). Na ABNT NBR6118:2007, os estádios representam os tipos de esforços internos na seção de concreto de acordo com determinado nível de solicitação. 
governa a formação de fissuras e a resistência do concreto fissurado que torna a rigidez variável em função dos esforços internos. Para a aplicação pretendida, na análise de estabilidade de contenções, pode ser usada uma rigidez média para cada trecho (considerando uma barra discretizada em $n$ trechos), pois a principal influência do paramento de concreto na estabilidade é exercida sobre o campo de deslocamentos e portanto a rigidez média é adequada.

A obtenção do valor da rigidez pode ser feita por meio dos diagramas momento-normal-curvatura, que atendam as condições de compatibilidade e as leis constitutivas dos materiais (BUCHAIM, 2001, p. 101). Para obtenção de tais diagramas são utilizados modelos reológicos elástoplásticos tanto para o concreto quanto para o aço.

A seguir é apresentada uma revisão bibliográfica, referente aos modelos reológicos indicados pela norma brasileira ABNT NRB6118:2007, e pelos códigos modelo CEB-FIP MODEL CODE 1990 - DESIGN CODE (1993), que será representado neste trabalho por CEB-FIP 1990 e o CEB-FIB MODEL CODE 2010 Volumes 1 e 2 (2010) que serão representados neste trabalho como CEB-FIB 2010. Destaca-se que o código modelo CEB-FIB 2010, encontra-se na condição de first complete draft (portanto está aberto para comentários, que serão recebidos e analisados por comissões designadas, para então ser apresentada a versão final para aprovação em assembléia geral). A norma brasileira também está em processo de revisão, no texto base do projeto de revisão, que será designado neste trabalho por ABNT NBR6118 (2011) (em fase de elaboração) ${ }^{4}$, as alterações relevantes quanto as questões abordadas neste trabalho, serão pontuadas no decorrer da revisão bibliográfica.

O Eurocode 2 (2004) também foi analisado e foi constatado que as relações constitutivas para o concreto e o aço são similares as do CEB-FIB 2010, assim optou-se por não se apresentar o Eurocode 2 (2004).

${ }^{4}$ ABNT NBR6118 (2011) a ser editado pela Associação Brasileira de Normas Técnicas, 2012. 


\subsection{CONCRETO}

\subsubsection{NORMA ABNT NBR6118:2007}

Os modelos reológicos apresentados a seguir são válidos para concretos de das classes $\mathrm{C} 10$ a C50. O concreto apresenta uma relação tensão-deformação nãolinear. A ABNT NBR6118:2007 (p. 20) apresetenta um diagrama idealizado, parabólico-retangular para tensões de compressão, mostrado na figura 39:

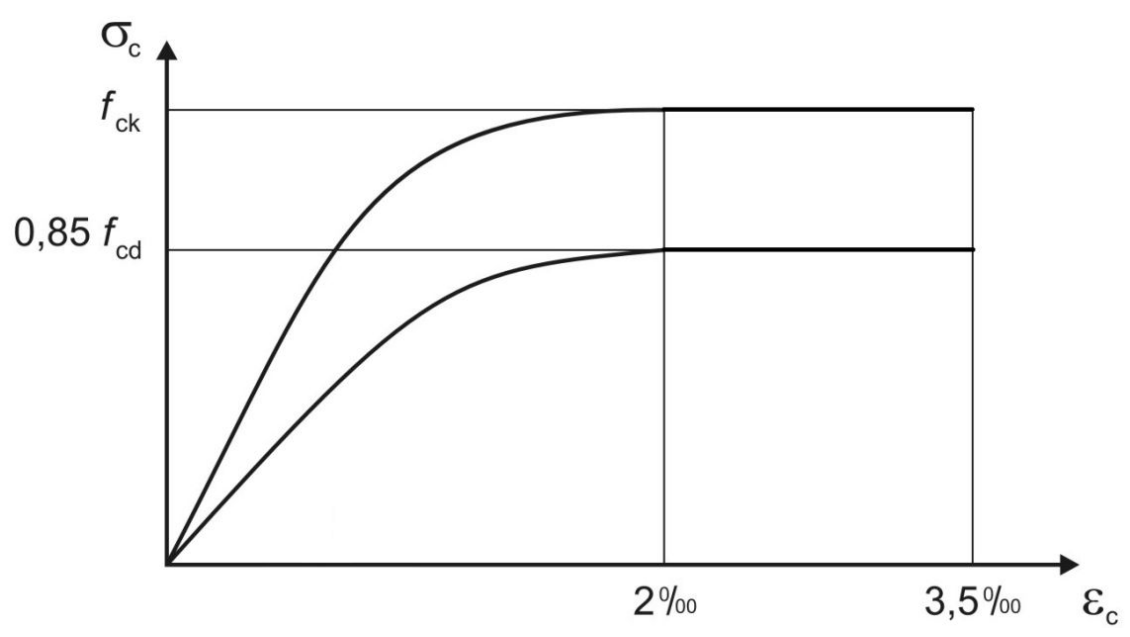

Figura 39 - Diagrama tensão-deformação, para tensões de compressão (modificado da ABNT NBR6118:2007)

Para o trecho parabólico limitado a tensão de compressão $0,85 \cdot f_{c d}$, a relação tensão-deformação é dada por:

$$
\sigma_{\mathrm{c}}=0,85 \mathrm{f}_{\mathrm{cd}}\left[1-\left(1-\frac{\varepsilon_{c}}{0,002}\right)^{2}\right]
$$

A equação 5.1 pode ser adotada para outros limites de compressão, bastando substituir o termo $0,85 \cdot f_{c d}$. No projeto de revisão da ABNT NBR6118 (2011) foram ampliadas as classes de concreto que serão atendidas pela norma, que poderá ser até $\mathrm{C} 90$. No entanto para classes superiores ao C50 o expoente da equação 5.1 será uma função de fck e não mais o valor constante 2 .

Para tensões de tração, com o concreto não fissurado, a ABNT NBR6118:2007 (p. 21) apresenta um diagrama idealizado, bilinear, como mostrado na figura 40: 


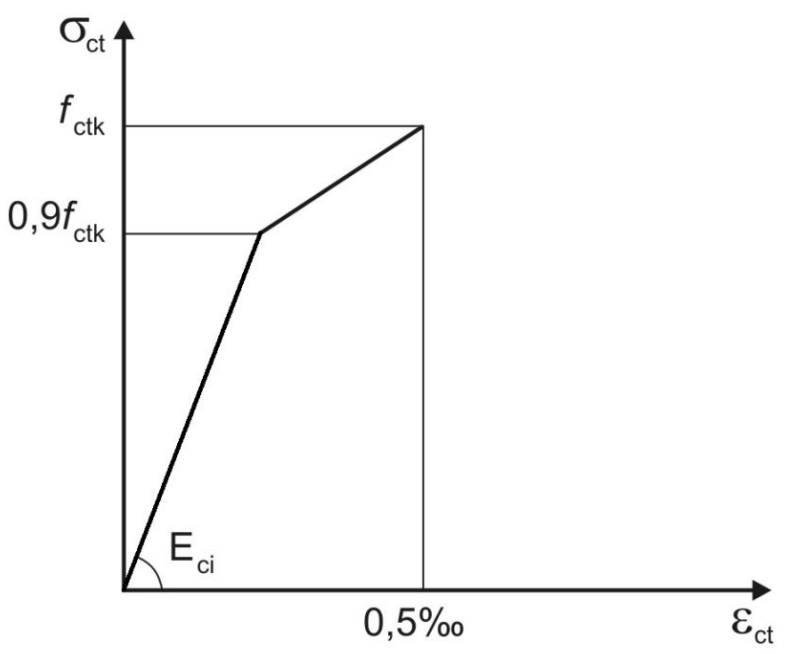

Figura 40 - Diagrama tensão-deformação, para tensões de tração (modificado da ABNT NBR6118:2007)

No projeto de revisão da ABNT NBR6118 (2011) a deformação limite de tração no concreto foi ampliada para 0,015\%.

No diagrama apresentado na figura $39, f_{c k}$ é a resistência característica a compressão do concreto correspondente ao quantil de $5 \%$ de distribuição de resistências; $f_{c d}$ é a resistência de cálculo a compressão, ou seja, a resistência característica a compressão dividida por um coeficiente de ponderação. Na figura 40 $f_{c t k}$ é a resistência característica a tração, que pode ser determinada como função da resistência característica à compressão. Nas equações 5.2 à 5.4 são apresentadas as relações para obtenção das resistências à tração média, característica inferior e superior, respectivamente:

$$
\begin{aligned}
& f_{c t, m}=0,3 \sqrt[3]{\left(f_{c k}\right)^{2}} \quad[\mathrm{MPa}] \\
& f_{c k, \text { inf }}=0,7 f_{c t, m} \quad[\mathrm{MPa}] \\
& f_{c k k, \text { sup }}=1,3 f_{c t, m} \quad[\mathrm{MPa}]
\end{aligned}
$$

O fator 0,85 , que multiplica o termo $f_{c d}$, convencionalmente chamado de efeito Rüsh, é o produto de três outros fatores, (Fusco, 2008, p. 86):

$$
\mathrm{k}_{\text {mod }}=\mathrm{k}_{\text {mod, } 1} \cdot \mathrm{k}_{\text {mod, }, 2} \cdot \mathrm{k}_{\text {mod, } 3}=1,2 \cdot 0,95 \cdot 0,75 \cong 0,85
$$


O fator $\mathrm{k}_{\mathrm{mod}, 1}$ representa o crescimento da resistência após os 28 dias de idade; $k_{\text {mod,2 }}$ representa o efeito da superestimação da resistência no ensaio com corpo de prova cilíndrico, adotado para aferir a resistência, gerado pelo atrito do corpo de prova com as pratos da prensa e pelo efeito escala, considerando que corpos de prova maiores teriam resistência menores; $k_{\text {mod,3 }}$ representa o efeito da diminuição da resistência pela ação dos carregamentos de longa duração.

O módulo de elasticidade utilizado em análises lineares do comportamento global das estruturas é o módulo de elasticidade tangente inicial, $E_{c i}$ :

$$
E_{c i}=5600 \sqrt{f_{c k}} \quad[\mathrm{MPa}]
$$

O módulo de elasticidade utilizado em análises elásticas lineares de projeto para determinação de esforços é o módulo de elasticidade secante, $E_{c s}$, função do módulo de elasticidade tangente inicial, $E_{c i}$ :

$$
E_{c s}=0,85 E_{c i}
$$

A redução do módulo de elasticidade deve-se ao fato de que seu valor efetivo é menor nas regiões em que as tensões estejam em torno de $40 \%$ a $50 \%$ do valor do $f_{c k}$ (IBRACON, 2007, p. 39).

No projeto de revisão da ABNT NBR6118 (2011) o fator 0,85 que multiplica o módulo de elasticidade tangente inicial para obtenção do módulo de elasticidade secante foi alterado para o valor 0,95, também foram acrescentados fatores de correção para o módulo de elasticidade conforme o tipo de agregado utilizado no concreto. Estes fatores são os mesmos apresentados em IBRACON (2007, p. 40), conforme tabela 3.

Tabela 3 - Coeficientes de correção para o módulo de elasticidade do concreto conforme a natureza do agregado.

\begin{tabular}{|c|c|}
\hline Natureza do agregado graúdo & $\mathbf{a}_{1}$ \\
\hline Basalto, diabásio e calcário sedimentar denso & 1,1 a 1,2 \\
\hline Granito e gnaisse & 1,0 \\
\hline Calcário metamórfico, e metasedimento & 0,9 \\
\hline Arenito & 0,7 \\
\hline
\end{tabular}

Fonte: IBRACON (2007) 
No entanto outro multiplicador do módulo de elasticidade que considera a consistência do concreto no seu lançamento, apresentado também em IBRACON (2007, p. 40) não foi incorporado ao projeto de revisão da ABNT NBR6118 (2011).

Tabela 4 - Coeficientes de correção para o módulo de elasticidade do concreto conforme sua consistência em estado fresco.

\begin{tabular}{|c|c|}
\hline \multicolumn{1}{|c|}{ Consistência do concreto fresco ${ }^{1)}$} & $a_{2}$ \\
\hline \multicolumn{1}{|c|}{ fluida } & 0,9 \\
\hline \multicolumn{1}{|c|}{ plástica } & 1,0 \\
\hline \multicolumn{1}{|c|}{ seca } & 1,1 \\
\hline $\begin{array}{l}\text { 1) Consistência obtida pela NBR NM 67 sem o uso de aditivos, especialmente } \\
\text { superplastificantes. }\end{array}$ \\
\hline
\end{tabular}

Fonte: IBRACON (2007)

Esta diferença entre os módulos de elasticidade do concreto de acordo com a consistência surge para concretos dosados para obtenção de uma mesma resistência, mas com slumps diferentes, como na comparação de concretos bombeados que necessitam de uma consistência mais fluida, portanto com maior teor de argamassa e não bombeados (informação verbal) ${ }^{5}$.

Para tensões de compressão menores que $0,5 \cdot f_{c}$ e tensões de tração menores que $f_{c t}$, o coeficiente de poisson, $v$, e o módulo de elasticidade transversal $G_{c}$ podem ser tomados como:

$$
\begin{aligned}
& \nu=0,2 \\
& G_{c}=0,4 E_{c s}
\end{aligned}
$$

\subsubsection{CÓDIGO MODELO CEB-FIP 1990}

Os modelos reológicos apresentados a seguir são válidos para concretos de das classes C12 a C80. O CEB-FIP 1990 (p. 40), na parte referente a entrada de dados de projeto, item propriedade dos materiais, apresetenta um diagrama idealizado, para tensões de compressão, conforme mostrado na figura 41 :

${ }^{5}$ Deformações nas estruturas de edifícios de concreto armado; fissuração, fluência e influência do processo construtivo. Palestra proferida pelo Prof. Dr. Eng. Ricardo Leopoldo e Silva França no dia 17/09/2009 no Instituto de Engenharia de São Paulo. 


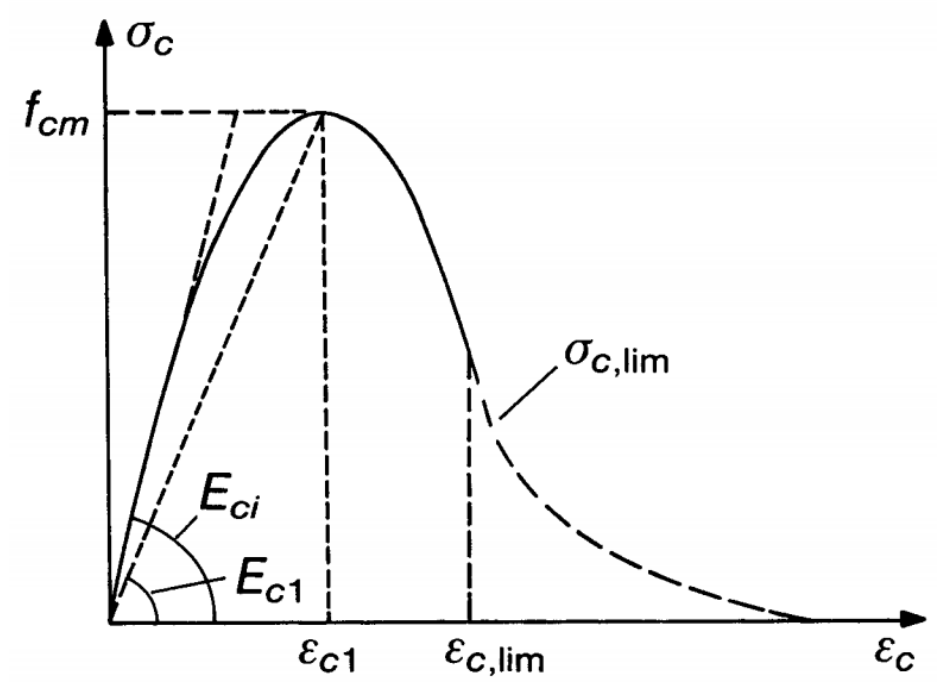

Figura 41 - Diagrama tensão-deformação, para tensões de compressão (CEB-FIP 1990)

Para a primeira parte do diagrama que passa pela tensão de compressão média, $f_{c m}$, a relação tensão-deformação é dada por:

$$
\sigma_{\mathrm{c}}=\left[\frac{\frac{E_{c i}}{E_{c 1}} \frac{\varepsilon_{c}}{\varepsilon_{c 1}}-\left(\frac{\varepsilon_{c}}{\varepsilon_{c 1}}\right)^{2}}{1+\left(\frac{E_{c i}}{E_{c 1}}-2\right) \frac{\varepsilon_{c}}{\varepsilon_{c 1}}}\right] f_{c m} \quad \text { para }\left|\varepsilon_{c}\right|<\left|\varepsilon_{c, \text { lim }}\right|
$$

O diagrama da figura 41 é conhecido como diagrama de Grasser, por ser este seu autor (FRANÇA R. L., 1991, p. 3.7). A equação 5.10 pode ser adotada para outros limites de compressão que não sejam a tensão media, bastando substituir $f_{c m}$, $E_{c i}$ e $E_{c l}$, pelos valores correspondentes a tensão resistente requerida. $\varepsilon_{c l}$ é a deformação correspondente a tensão máxima de compressão e é convencionada ao valor constante:

$$
\varepsilon_{\mathrm{c} 1}=0,0022
$$

$\varepsilon_{c, \text { lim }}$ é a deformação limite convencionada, e pode ser obtida pela relação:

$$
\frac{\varepsilon_{c, \mathrm{lim}}}{\varepsilon_{c 1}}=\frac{1}{2}\left(\frac{1}{2} \frac{E_{c i}}{E_{c 1}}+1\right)+\sqrt{\left[\frac{1}{4}\left(\frac{1}{2} \frac{E_{c i}}{E_{c 1}}+1\right)^{2}-\frac{1}{2}\right]} \text { para } \sigma_{c, \lim }=0,5 f_{c m}
$$

$\sigma_{c, \text { lim }}$ é a tensão correspondente a deformação $\varepsilon_{c, \text { lim. }}$. Na seção de comentários do CEB-FIP 1990 (p. 41) é apresentada uma equação para o trecho 
tracejado do diagrama tensão-deformação, em que $\varepsilon_{c}>\varepsilon_{c, \text { lim }}$, a utilização deste trecho é opcional.

$$
\sigma_{\mathrm{c}}=\left[\left(\frac{1}{\frac{\varepsilon_{c, \mathrm{lim}}}{\varepsilon_{c 1}}} \xi-\frac{2}{\left(\frac{\varepsilon_{c, \mathrm{lim}}}{\varepsilon_{c 1}}\right)^{2}}\right)\left(\frac{\varepsilon_{c}}{\varepsilon_{c 1}}\right)^{2}+\left(\frac{4}{\frac{\varepsilon_{c, \mathrm{lim}}}{\varepsilon_{c 1}}}-\xi-\right) \frac{\varepsilon_{c}}{\varepsilon_{c 1}}\right]^{-1} f_{c m} \quad \text { para }\left|\varepsilon_{c}\right|>\left|\varepsilon_{c, \lim }\right|
$$

Onde que $\xi$ corresponde à seguinte relação:

$$
\xi=\frac{4\left[\left(\frac{\varepsilon_{c, \text { lim }}}{\varepsilon_{c 1}}\right)^{2}\left(\frac{E_{c i}}{E_{c 1}}-2\right)+2 \frac{\varepsilon_{c, \lim }}{\varepsilon_{c 1}}-\frac{E_{c i}}{E_{c 1}}\right]}{\left[\frac{\varepsilon_{c, \lim }}{\varepsilon_{c 1}}\left(\frac{E_{c i}}{E_{c 1}}-2\right)+1\right]}
$$

O diagrama tensão-deformação para diversas classes de concreto, considerando (5.16) e (5.17) é apresentado na figura 42:

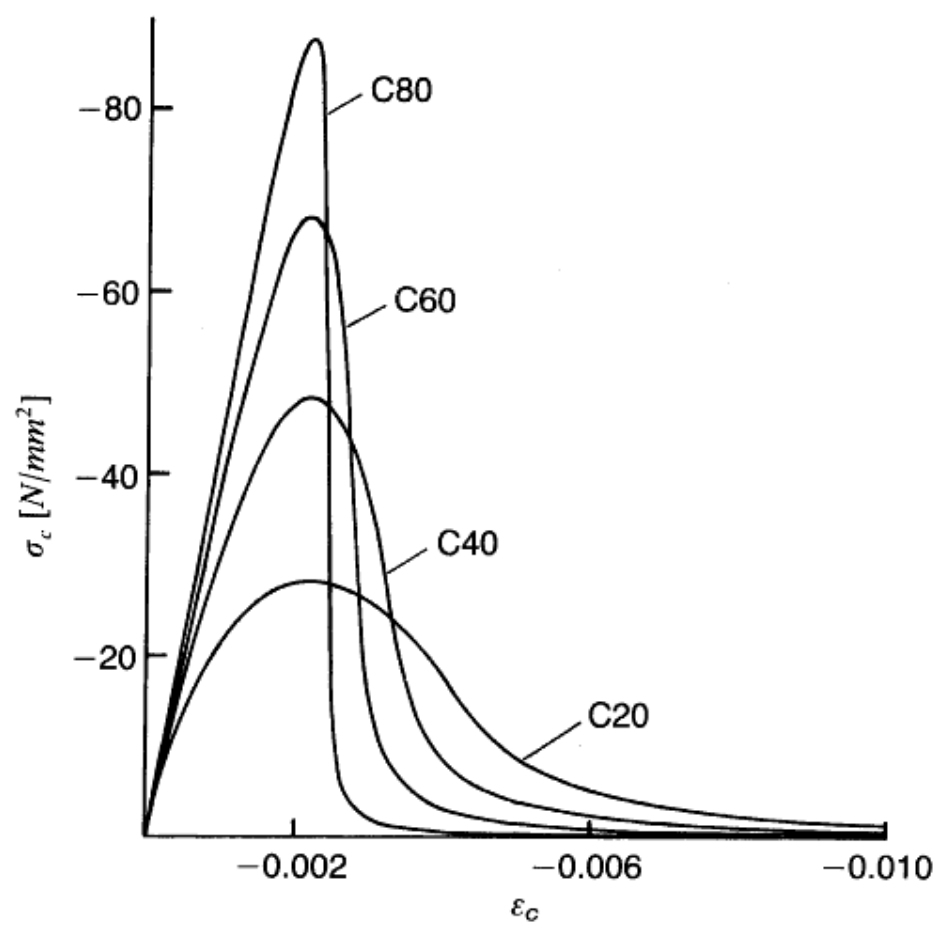

Figura 42 - Diagrama tensão-deformação completo, para tensões de compressão (CEB-FIP 1990) $E_{c l}$ é o módulo secante obtido pela relação: 


$$
E_{\mathrm{cl}}=\frac{f_{c m}}{0,0022}
$$

$E_{c i}$ é o módulo de elasticidade tangente inicial para o concreto aos 28 dias de idade:

$$
E_{\mathrm{ci}}=E_{\mathrm{co}} \sqrt[3]{\frac{f_{c m}}{f_{c m o}}}=2,15 \cdot 10^{4} \sqrt[3]{\frac{f_{c m}}{10}} \quad[\mathrm{MPa}]
$$

O módulo de elasticidade utilizado em análises elásticas lineares é o módulo de elasticidade reduzido, $E_{c}$, que considera a deformação plástica inicial causada por deformações irreversíveis e é obtido como função do módulo de elasticidade tangente inicial, $E_{c i}$ :

$$
E_{\mathrm{c}}=0,85 E_{\mathrm{ci}}
$$

Este módulo pode ser corrigido, por um fator de correção, $\alpha_{E}$, em função do tipo de agregado utilizado, na tabela abaixo são apresentados os valores para $\alpha_{E}$.

Tabela $5-\alpha \mathrm{E}$

\begin{tabular}{c|c}
\hline Tipos de agregados & $\alpha_{E}$ \\
\hline Basalto e calcários densos & 1.2 \\
Quartizitos & 1.0 \\
Calcários & 0.9 \\
Arenitos & 0.7 \\
\hline
\end{tabular}

Fonte: CEB-FIP 1990

Nos procedimentos de projeto, o CEB-FIP 1990 (p. 148, item verificação de estados limites últimos) fornece duas alternativas de modelos constitutivos simplificados para aplicação em estados limites últimos. Uma alternativa é um diagrama parabólico-retangular e a outra um diagrama linear (tensões uniformes). $O$ equacionamento para o diagrama parabólico-retangular é similar ao apresentado pela ABNT NBR6118:2007, considerando classes de concreto até C50. Na figura 43 são apresentadas as relações para o diagrama parabólico-retangular: 


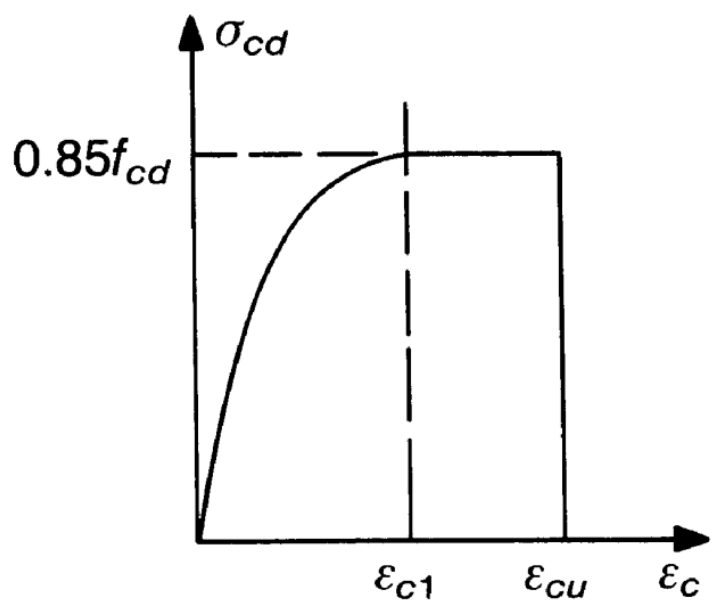

Figura 43 - Diagrama tensão-deformação parabólico-retangular (CEB-FIP 1990)

$$
\left.\begin{array}{lr}
\sigma_{\mathrm{cd}}=0,85 \mathrm{f}_{\mathrm{cd}}\left[1-\left(1-\frac{\varepsilon_{c}}{\varepsilon_{c 1}}\right)^{2}\right] & \text { para } \varepsilon_{c}<\varepsilon_{c 1} \\
\sigma_{\mathrm{cd}}=0,85 \mathrm{f}_{\mathrm{cd}} & \text { para } \varepsilon_{c 1} \leq \varepsilon_{c} \leq \varepsilon_{c u} \\
\sigma_{\mathrm{cd}}=0 & \text { para } \varepsilon_{c u}<\varepsilon_{c} \\
\varepsilon_{c 1}=0,002 &
\end{array}\right\}
$$

Em flexão:

$$
\left.\begin{array}{l}
\varepsilon_{c u}=0,0035 \quad \text { para } f_{c k} \leq 50 \mathrm{MPa} \\
\varepsilon_{c u}=0,0035\left(\frac{50}{f_{c k}}\right) \quad \text { para } 50 \mathrm{MPa}<f_{c k} \leq 80 \mathrm{MPa}
\end{array}\right\}
$$

Em compressão uniaxial:

$$
\varepsilon_{c u}=0,002
$$

Para tensões de tração, com o concreto não fissurado, o CEB-FIP 1990 (p. 42) apresenta um diagrama idealizado, bilinear, como mostrado abaixo: 


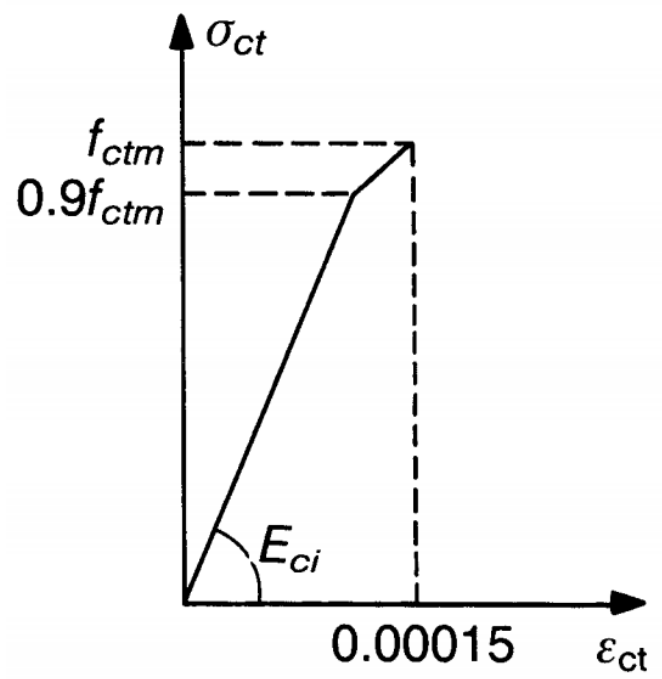

Figura 44 - Diagrama tensão-deformação, para tensões de tração (CEB-FIP 1990)

Nos diagramas das figuras 43 e 44, $f_{c m}$ é a resistência média a compressão; $f_{c t m}$ é a resistência média a tração do concreto, que pode ser obtida como função da resistência característica a compressão, inferior e superior:

$$
f_{c t m}=f_{c k t o, m} \sqrt[3]{\left(\frac{f_{c k}}{f_{c k o}}\right)^{2}}=1,4 \sqrt[3]{\left(\frac{f_{c k}}{10}\right)^{2}}=0,302 \sqrt[3]{\left(f_{c k}\right)^{2}} \quad[\mathrm{MPa}]
$$

Por meio de $f_{\text {ctm }}$ podem ser obtidas as resistências características a tração inferior e superior:

$$
\begin{aligned}
& f_{c k t, \text { min }}=f_{c k t o, \text { min }} \sqrt[3]{\left(\frac{f_{c k}}{f_{c k o}}\right)^{2}}=0,95 \sqrt[3]{\left(\frac{f_{c k}}{10}\right)^{2}}=0,205 \sqrt[3]{\left(f_{c k}\right)^{2}}=0,679 f_{c t m} \quad[\mathrm{MPa}] \\
& f_{c k t, \max }=f_{c k s, \text { max }} \sqrt[3]{\left(\frac{f_{c k}}{f_{c k o}}\right)^{2}}=1,85 \sqrt[3]{\left(\frac{f_{c k}}{10}\right)^{2}}=0,399 \sqrt[3]{\left(f_{c k}\right)^{2}}=1,32 f_{c t m} \quad[\mathrm{MPa}]
\end{aligned}
$$

Para tensões de compressão menores que $0,5 \cdot f_{c k}$ e tensões de tração menores que $f_{c t k}$, o coeficiente de poisson, $v$, pode ser tomado no intervalo:

$$
0,1 \leq \nu \leq 0,2
$$


O CEB-FIP 1990 não determina o módulo de elasticidade transversal, $G_{c}$, a ser adotado. No entanto para o intervalo de tensões proposto para o coeficiente de poisson pode ser adotado o módulo fornecido pela teoria da elasticidade:

$$
G=\frac{E_{c}}{2(1+v)}
$$

\subsubsection{CÓDIGO MODELO CEB-FIB 2010}

Os modelos reológicos apresentados a seguir são válidos para concretos de das classes C12 a C90. O CEB-FIB 2010 (p. 120) apresetenta um diagrama idealizado para tensões de compressão, mostrado na figura 45 :

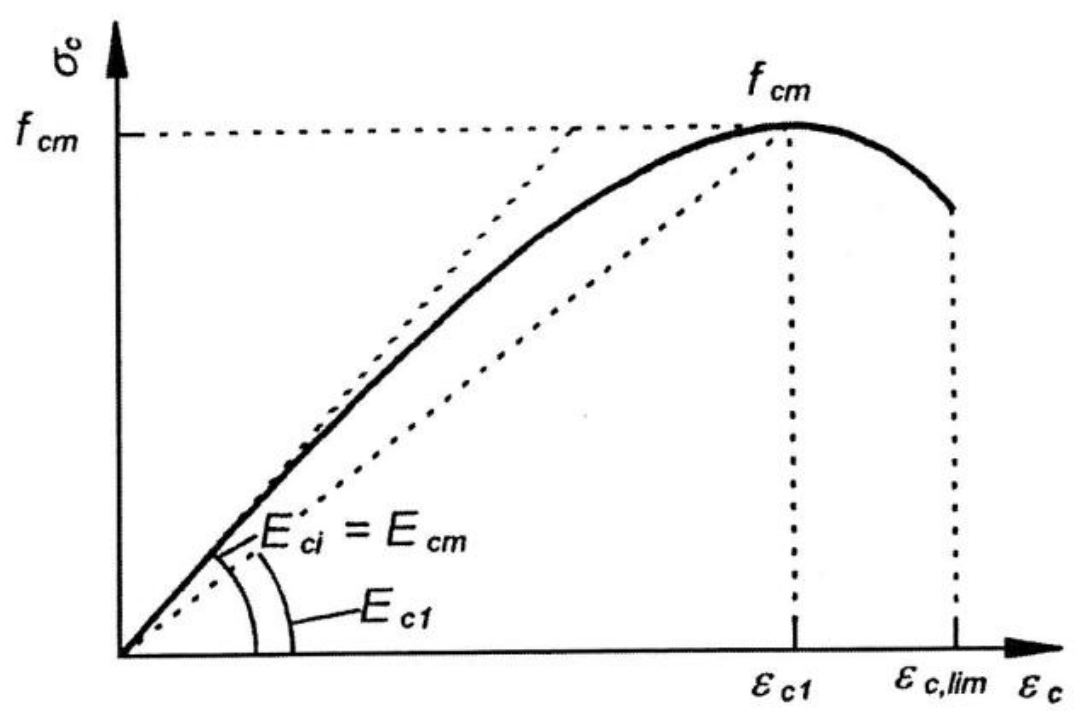

Figura 45 - Diagrama tensão-deformação, para tensões de compressão (CEB-FIB 2010)

A formulação que representa a relação tensão-deformação, que tem como tensão limite o $f_{c m}$, é apresentada abaixo:

$$
\sigma_{\mathrm{c}}=\left[\frac{k \cdot \eta-\eta^{2}}{1+(k-2) \eta}\right] f_{c m} \quad \text { para } \quad\left|\varepsilon_{c}\right|<\left|\varepsilon_{c, \lim }\right|
$$

Em que:

$$
k=\frac{E_{c i}}{E_{c 1}}
$$




$$
\eta=\frac{\varepsilon_{c}}{\varepsilon_{c 1}}
$$

No diagrama acima, $f_{c m}$ é a resistência média a compressão aos 28 dias de idade.

Os valores para deformação correspondente a tensão máxima de compressão, $\varepsilon_{c l}$, juntamente com o módulo secante, $E_{c l}$, módulo de elasticidade tangente inicial para o concreto aos 28 dias de idade, $E_{c i}$, a relação entre módulos, $k$, e a deformação limite convencionada $\varepsilon_{c, \text { lim }}$ são apresentados na tabela abaixo para diversas classes de resistência.

Tabela 6 - Deformações $\varepsilon_{\mathrm{c} 1}$ e $\varepsilon_{\mathrm{c}, \mathrm{lim}}$, módulos $\mathrm{E}_{\mathrm{c} 1}, \mathrm{E}_{\mathrm{ci}}$, e relação entre módulos, $\mathrm{k}$, para concreto comum

\begin{tabular}{c|c|c|c|c|c|}
\hline Classes de concreto & $\mathbf{C 1 2}$ & $\mathbf{C 2 0}$ & $\mathbf{C 3 0}$ & $\mathbf{C 4 0}$ & $\mathbf{C 5 0}$ \\
\hline$E_{c i}[\mathrm{GPa}]$ & 27.1 & 30.3 & 33.6 & 36.3 & 38.6 \\
$E_{c 1}[\mathrm{GPa}]$ & 11.1 & 13.3 & 16.5 & 20.0 & 23.2 \\
$\varepsilon_{c 1}[\%]$ & -1.8 & -2.1 & -2.3 & -2.4 & -2.5 \\
$\varepsilon_{c, \text { lim }}[\%]$ & -3.5 & -3.5 & -3.5 & -3.5 & -3.4 \\
$k$ & 2.44 & 2.28 & 2.04 & 1.82 & 1.66 \\
\hline \multicolumn{5}{|l}{} \\
\hline Classes de concreto & $\mathbf{C 8 0}$ & $\mathbf{C 9 0}$ & $\mathbf{C 1 0 0}$ & $\mathbf{C 1 1 0}$ & $\mathbf{C 1 2 0}$ \\
\hline$E_{c i}[\mathrm{GPa}]$ & 44.4 & 46.0 & 47.5 & 48.9 & 50.3 \\
$E_{c 1}[\mathrm{GPa}]$ & 31.4 & 33.8 & 36 & 39.3 & 42.7 \\
$\varepsilon_{c 1}[\%]$ & -2.8 & -2.9 & -3.0 & -3.0 & -3.0 \\
$\varepsilon_{c, \text { lim }}[\%]$ & -3.1 & -3.0 & -3.0 & -3.0 & -3.0 \\
$k$ & 1.41 & 1.36 & 1.32 & 1.24 & 1.18 \\
\hline
\end{tabular}

Fonte: CEB-FIB 2010

$\mathrm{Na}$ tabela acima o fator que corresponde ao tipo de agregado utilizado foi tomado como $\alpha_{E}=1$.

A equação (5.23) pode ser adotada para outros limites de compressão que não os médios, bastando substituir $f_{c m}, E_{c i}$ e $E_{c l}$, pelos valores correspondentes a resistência requerida.

O módulo de elasticidade tangente inicial para o concreto aos 28 dias de idade, $E_{c i}$, cujos valores são mostrados na tabela 1 , são obtidos pela equação 
abaixo, como função da resistência média a compressão do concreto e do tipo de agregado utilizado, $\alpha_{E}$ :

$$
E_{\mathrm{ci}}=E_{\mathrm{co}} \alpha_{E} \sqrt[3]{\frac{f_{c m}}{10}}=2,15 \cdot 10^{4} \alpha_{E} \sqrt[3]{\frac{f_{c m}}{10}} \quad[\mathrm{MPa}]
$$

Tabela 7 - Fator $\alpha_{E}$

\begin{tabular}{c|c|c}
\hline Tipos de agregados & $\alpha_{E}$ & $\begin{array}{l}E_{c 0} \cdot \alpha_{E} \\
{[\mathrm{MPa}]}\end{array}$ \\
\hline Basalto e calcários densos & 1.2 & 25800 \\
Quartizitos & 1.0 & 21500 \\
Calcários & 0.9 & 19400 \\
Arenitos & 0.7 & 15100 \\
\hline
\end{tabular}

Fonte: CEB-FIB 2010

O módulo de elasticidade utilizado em análises elásticas lineares é o módulo de elasticidade reduzido, $E_{c}$, que considera a deformação plástica inicial causada por deformações irreversíveis. Ele pode ser obtido como função do módulo de elasticidade tangente inicial, $E_{c i}$, e do fator de correção $\alpha_{i}$.

$$
E_{\mathrm{c}}=\alpha_{i} E_{\mathrm{ci}}
$$

Este fator pode ser obtido pela equação ou tabela abaixo:

$$
\alpha_{i}=0,8+0,2 \frac{f_{c m}}{88} \leq 1
$$


Tabela 8 - Fator $\alpha_{i}$

\begin{tabular}{c|c|c|c|c|c|c|c}
\hline $\begin{array}{c}\text { Classes de } \\
\text { concreto }\end{array}$ & C12 & C20 & C30 & C40 & C50 & C60 & C70 \\
\hline$E_{c i}[\mathrm{GPa}]$ & 27.1 & 30.3 & 33.6 & 36.3 & 38.6 & 40.7 & 42.6 \\
$E_{c}[\mathrm{GPa}]$ & 22.9 & 26.2 & 29.7 & 33.0 & 36.0 & 38.9 & 41.7 \\
$\alpha_{i}$ & 0.845 & 0.864 & 0.886 & 0.909 & 0.932 & 0.955 & 0.977 \\
\hline
\end{tabular}

\begin{tabular}{c|c|c|c|c|c}
\hline $\begin{array}{c}\text { Classes de } \\
\text { concreto }\end{array}$ & $\mathbf{C 8 0}$ & $\mathbf{C 9 0}$ & $\mathbf{C 1 0 0}$ & $\mathbf{C 1 1 0}$ & $\mathbf{C 1 2 0}$ \\
\hline$E_{c i}[\mathrm{GPa}]$ & 44.4 & 46.0 & 47.5 & 48.9 & 50.3 \\
$E_{c}[\mathrm{GPa}]$ & 44.4 & 46.0 & 47.5 & 48.9 & 50.3 \\
$\alpha_{i}$ & 1.0 & 1.0 & 1.0 & 1.0 & 1.0 \\
\hline
\end{tabular}

Fonte: CEB-FIB 2010

No diagrama tensão-deformação o módulo de elasticidade reduzido é definido como coeficiente angular da reta secante que passa pelo ponto correspondente a tensão máxima em serviço de $0,4 \cdot f_{\mathrm{cm}}$.

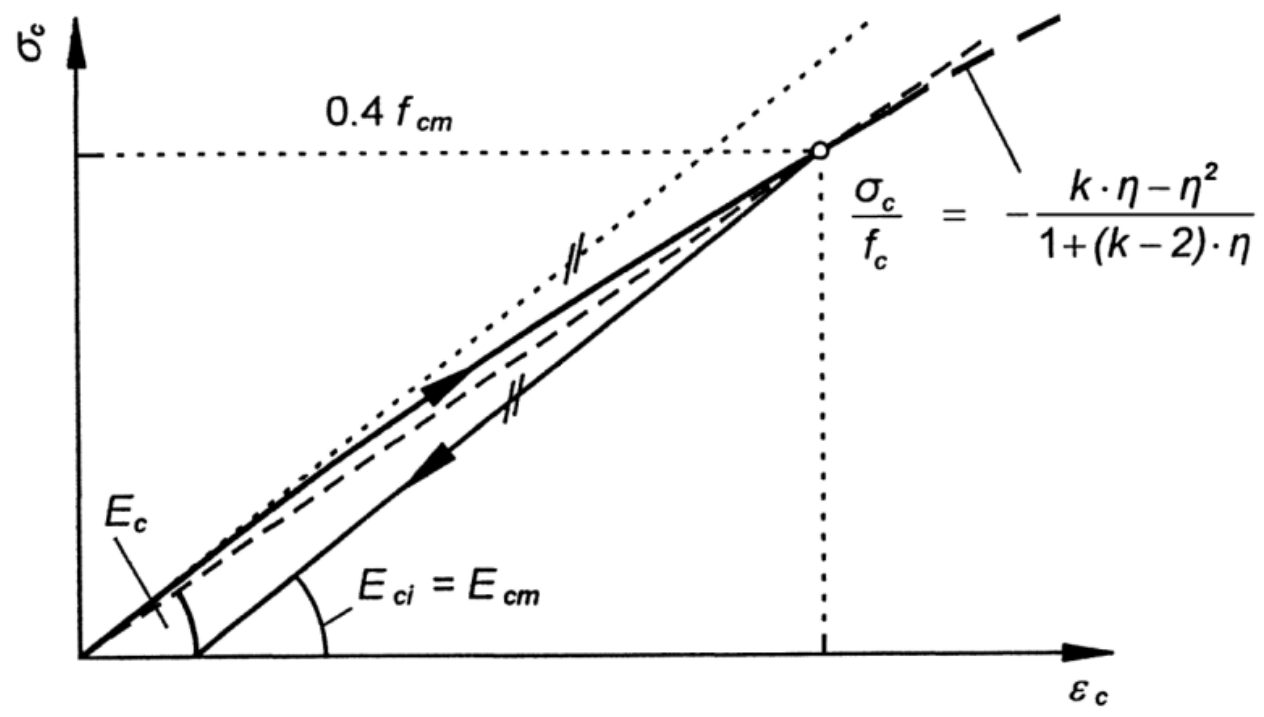

Figura 46 - Representação gráfica de $E_{c}$ (modificado do CEB-FIB 2010)

No item 7.2.3 do CEB-FIB 2010 (p. 16), na parte referente a valores a serem adotados em projeto, são indicados outros três diagramas tensão-deformação; o diagrama de Grasser para análise não-linear, similar ao mostrado na figura 45, e outros dois para dimensionamento de seções em estado limite último, em que um é 
- diagrama parabólico-retangular, similar aos apresentados pela ABNT NBR6118:2007 e pelo CEB-FIP 1990 e outro um diagrama bilinear.

Para análise não-linear:

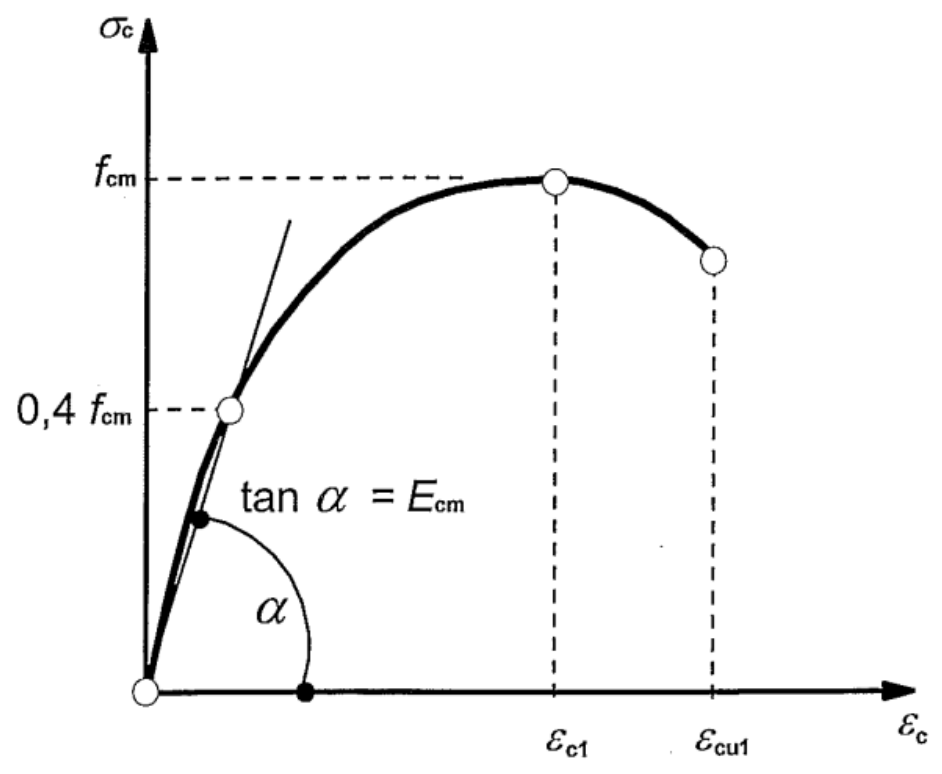

Figura 47 - Diagrama tensão-deformação para análise não-linear em projeto (CEB-FIB 2010) ${ }^{6}$

O equacionamento apresentado em (5.26) e (5.28) serve para o diagrama acima contanto que:

$$
\left.\begin{array}{l}
\varepsilon_{c u 1}=\varepsilon_{c, \text { lim }} \\
\varepsilon_{c u 1}=0,0035 \quad \text { para } f_{c k} \leq 50 \mathrm{MPa} \\
\varepsilon_{c u 1}=2,8+27\left(\frac{98-f_{c m}}{100}\right)^{4} \text { para } 50 \mathrm{MPa}<f_{c k} \leq 90 \mathrm{MPa} \quad[\% 0]
\end{array}\right]
$$

A relação, $k$, é tomada por:

$$
k=\frac{1,05 E_{c m} \varepsilon_{c 1}}{f_{c m}}
$$

${ }^{6}$ O Eurocode 2 (2004) adota o mesmo diagrama com equacionamento similar. 
Em que:

$$
E_{c m}=\left(\frac{f_{c m}}{10}\right)^{0,3}
$$

O cálculo do módulo de elasticidade pela equação (5.35) apresenta valores incoerentes com a tabela 6 e 8 e também com a tabela 7.2-1 do CEB-FIB 2010, portanto desconsidera-se este equacionemento. No caso de um concreto classe C30 pela tabela 7.2-1 teríamos $\mathrm{E}_{\mathrm{cm}}=32 \mathrm{GPa}$ e pela equação (5.35), $\mathrm{E}_{\mathrm{cm}}=1,49 \mathrm{MPa}$.

Para o diagrama parabólico-retangular:

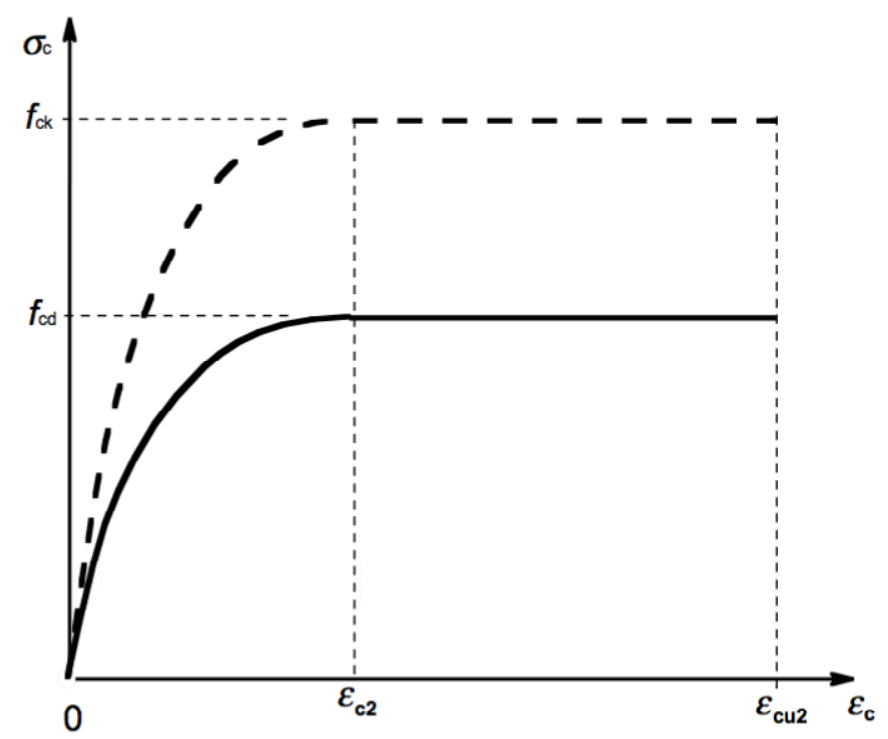

Figura 48 - Diagrama tensão-deformação parabólico-retangular (CEB-FIB 2010)

O fator 0,85 foi incorporado ao $f_{c d}$.

$$
\left.\begin{array}{ll}
\sigma_{c d}=f_{c d}\left[1-\left(1-\frac{\varepsilon_{c}}{\varepsilon_{c 2}}\right)^{n}\right] & \text { para } \varepsilon_{c}<\varepsilon_{c 2} \\
\sigma_{c d}=f_{c d} & \text { para } \varepsilon_{c 2} \leq \varepsilon_{c} \leq \varepsilon_{c u 2}
\end{array}\right\}
$$




$$
\begin{aligned}
& \text { Para } f_{c k} \leq 50 \mathrm{MPa} \\
& n=2 \\
& \varepsilon_{c 2}=0,002 \\
& \varepsilon_{c u 2}=0,0035 \\
& \left.\begin{array}{l}
\text { Para } 50 \mathrm{MPa}<f_{c k} \leq 90 \mathrm{MPa} \\
n=1,4+23,4\left(\frac{90-f_{c k}}{100}\right)^{4} \\
\varepsilon_{c 2}=2,0+0,085\left(f_{c k}-50\right)^{0,53} \\
\varepsilon_{c u 2}=2,6+35\left(\frac{90-f_{c k}}{100}\right)^{4}
\end{array}\right\}
\end{aligned}
$$

\section{Para o diagrama bilinear:}

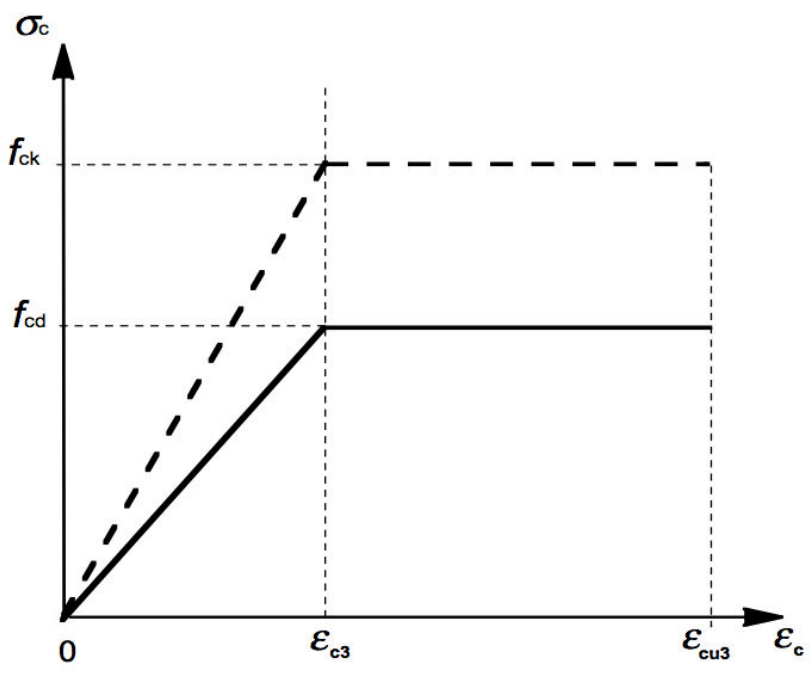

Figura 49 - Diagrama tensão-deformação bilinear (CEB-FIB 2010) 
Para $f_{c k} \leq 50 \mathrm{MPa}$

$\varepsilon_{c 3}=0,00175$

$\varepsilon_{c u 3}=0,0035$

Para $50 \mathrm{MPa}<f_{c k} \leq 90 \mathrm{MPa}$

$\varepsilon_{c 3}=1,75+0,55\left(\frac{f_{c k}-50}{40}\right)$

$\varepsilon_{c u 3}=2,6+35\left(\frac{90-f_{c k}}{100}\right)^{4}$

Para tensões de tração, com o concreto não fissurado, o CEB-FIB 2010 (p. 122) apresenta um diagrama idealizado, bilinear, como mostrado abaixo:

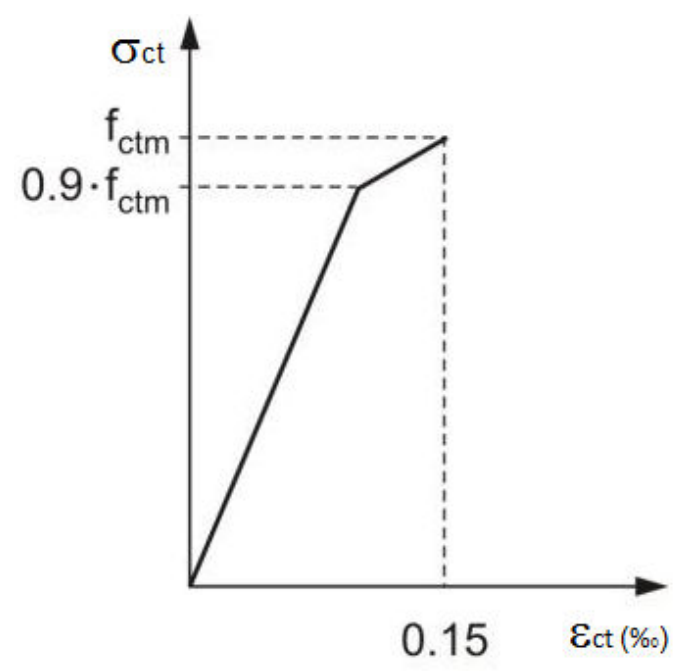

Figura 50 - Diagrama tensão-deformação, para tensões de tração (CEB-FIB 2010)

No diagrama acima, $f_{c t m}$ é a resistência média a tração do concreto, que pode ser obtida como função da resistência característica a compressão, $f_{c k}$ :

$$
\begin{array}{r}
f_{c t m}=0,3 \sqrt[3]{\left(f_{c k}\right)^{2}} \text { para classes de concreto } \leq C 50 \quad[\mathrm{MPa}] \\
f_{c t m}=2,12 \ln \left(1+0,1 f_{c m}\right) \text { para classes de concreto }>C 50 \quad[\mathrm{MPa}]
\end{array}
$$

Por meio de $f_{c t m}$ podem ser obtidas as resistências características a tração inferior, $f_{c t k \text { min }}$, e superior, $f_{c t k, \text { max }}$ : 


$$
\begin{aligned}
& f_{c k t \text { min }}=0,7 f_{c t m} \\
& f_{c t k \text {,max }}=1,3 f_{c t m}
\end{aligned}
$$

Para $\sigma_{c t}<0,9 f_{c t m}$ pode ser adotado como coeficiente angular, o módulo de elasticidade tangente $E_{c i}$.

Para tensões de compressão menores que $0,6 \cdot f_{c k}$ e tensões de tração menores que $0,6 \cdot f_{c t k}$, o coeficiente de poisson, $v$, pode ser tomado no intervalo:

$$
0,14 \leq \nu \leq 0,24
$$

O CEB-FIB 2010 não determina o módulo de elasticidade transversal, $G_{c}$, a ser adotado, no entanto para o mesmo intervalo de tensões proposto para o coeficiente de poisson, pode ser adotado o módulo fornecido pela teoria da elasticidade:

$$
G=\frac{E_{c}}{2(1+v)}
$$

\subsection{AÇO PARA ARMADURAS PASSIVAS}

\subsubsection{NORMA ABNT NBR6118:2007}

A ABNT NBR6118:2007 (p. 22) apresenta como modelo reológico para o aço das armaduras passivas um diagrama tensão-deformação idealizado elastoplástico perfeito em que enquadram-se os aços das categorias CA-25, CA-50 e CA-60 que são classificados de acordo com a norma de aços destinados a armaduras para concreto armado, a ABNT NBR7480:2007. Entre as categorias de aço, além das diferenças entre resistências, há também diferenças entre os processos de produção e produto obtido. As barras de aço são produzidas com laminação a quente nas categorias CA-25 e CA-50 e os fios de aço são produzidas com laminação a frio na categoria CA-60. 


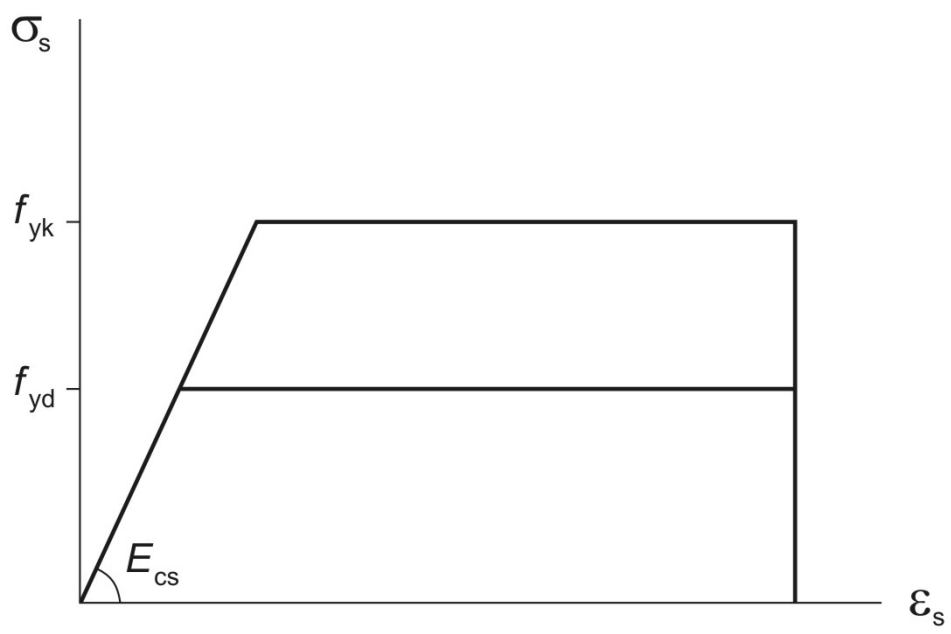

Figura 51 - Diagrama tensão-deformação para armaduras passivas; válido para tração e compressão (ABNT NBR6118:2007)

No diagrama acima, $f_{y k}$ é a resistência característica ao escoamento do aço correspondente ao quantil de $5 \%$ de distribuição de resistências; $f_{y d}$ é resistência de cálculo ao escoamento, ou seja, a resistência característica ao escoamento dividida por um coeficiente de ponderação; $E_{c s}$ o módulo de elasticidade que pode ser admitido igual a:

$$
E_{c s}=210 \mathrm{GPa}
$$

Não é apresentado o valor do alongamento ou encurtamento máximo permitido, $\varepsilon_{y}$, nem do início do escoamento, $\varepsilon_{y d}$, no entanto para o alongamento máximo e o encurtamento máximo a serem adotados em projeto ficam implícitos os valores determinados pelos domínios de deformação: 


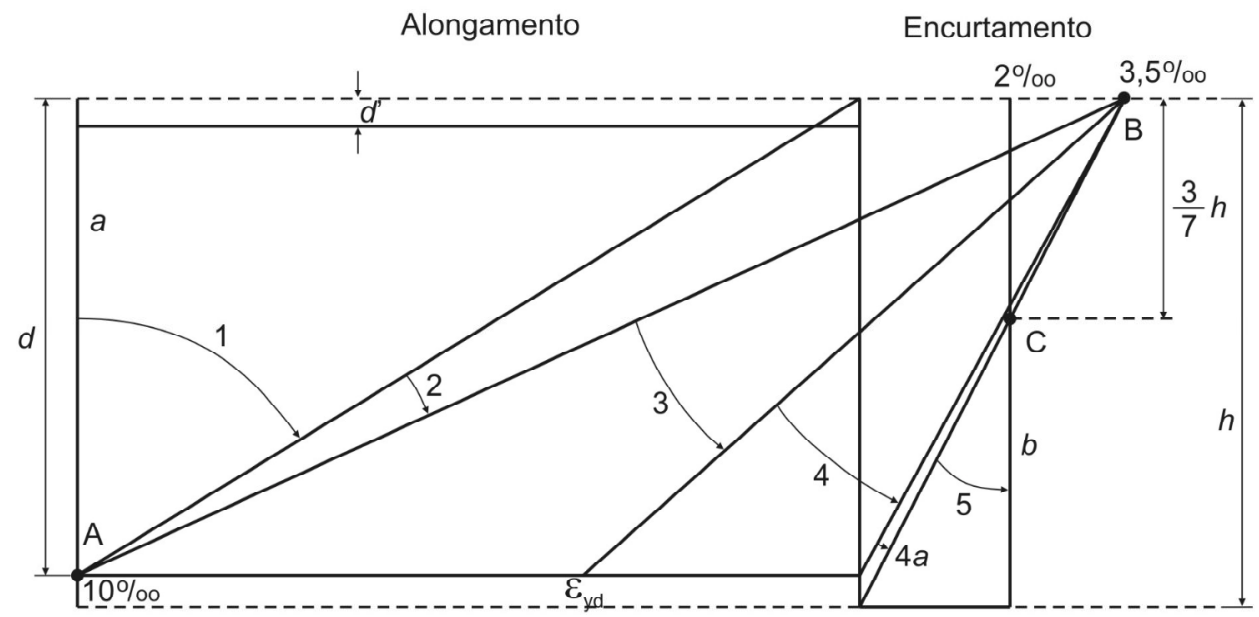

Figura 52 - Domínios de deformação (ABNT NBR6118:2007)

Assim, $\varepsilon_{y l}$ é adotado como o valor máximo de alongamento permitido:

$$
\varepsilon_{y l}=0,01
$$

$\mathrm{E} \varepsilon_{y e}$ é adotado como o valor máximo de encurtamento permitido (teórico):

$$
\varepsilon_{y e}=0,0035
$$

O alongamento ou encurtamento de início de escoamento, $\varepsilon_{y d}$ para $f_{y d}$ e $\varepsilon_{y k}$ para $f_{y k}$, pode ser obtido por meio do módulo de elasticidade e no caso do CA-50, por exemplo:

$$
\varepsilon_{y k}=\frac{f_{y k}}{E_{c s}}=\frac{500}{210000}=0,00238
$$

Considerando o coeficiente de ponderação para a resistência do aço, $\gamma_{s}$, pode-se obter $\varepsilon_{y d}$.

$$
\varepsilon_{y d}=\frac{\frac{f_{y k}}{\gamma_{s}}}{E_{c s}}=\frac{\frac{500}{1,15}}{210000}=0,00207
$$

Graficamente: 


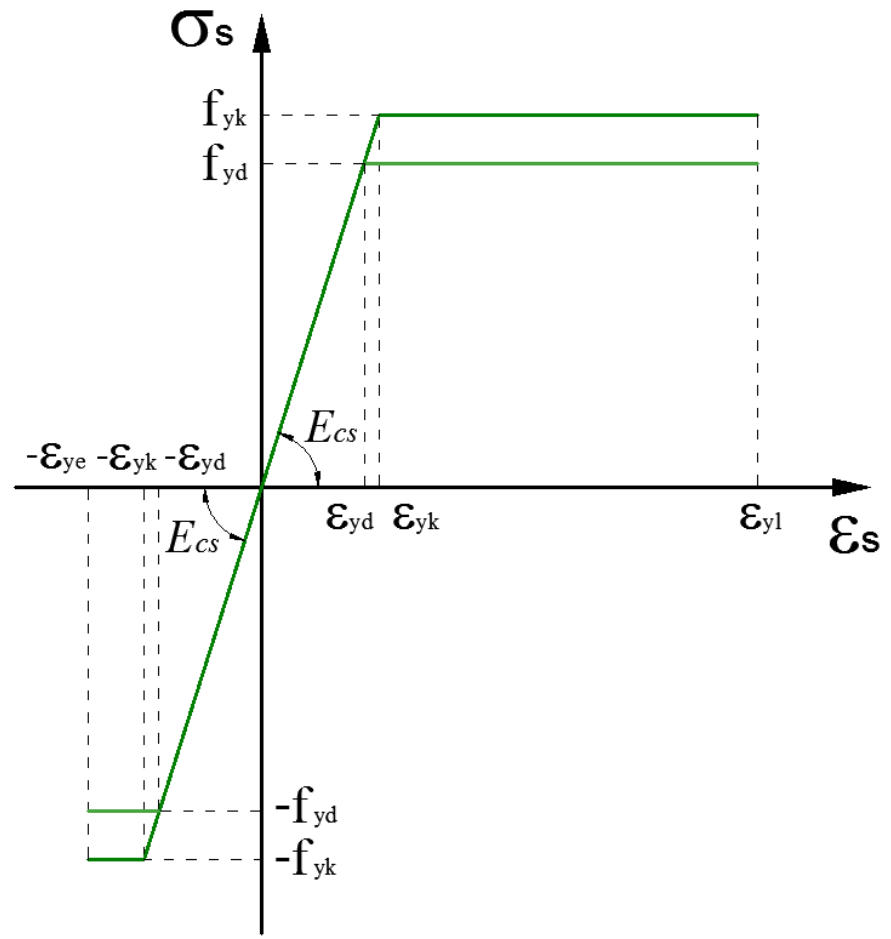

Figura 53 - Diagrama tensão-deformação para tração e compressão do aço CA-50 adotado em projeto

Vale frisar que o diagrama tensão-deformação elastoplástico perfeito para o aço apresentado pela ABNT NBR6118:2007 é convencionado, pois ocorre encruamento quando alongado acima de um determinado limite. A norma ABNT NBR7480:2007 determina que o aço CA-50 tenha um encruamento mínimo de 8\% em relação a tensão de escoamento $\left(1,08 \cdot f_{y}\right)$ e o alongamento mínimo de $8 \%$ em um comprimento de $10 . \varnothing$ ou $5 \%$ para o alongamento total na carga máxima. 0 diagrama abaixo, obtido em um ensaio de uma barra de CA-50 de diâmetro $\varnothing 6,3 \mathrm{~mm}$ ilustra o alongamento máximo e o encruamento: 


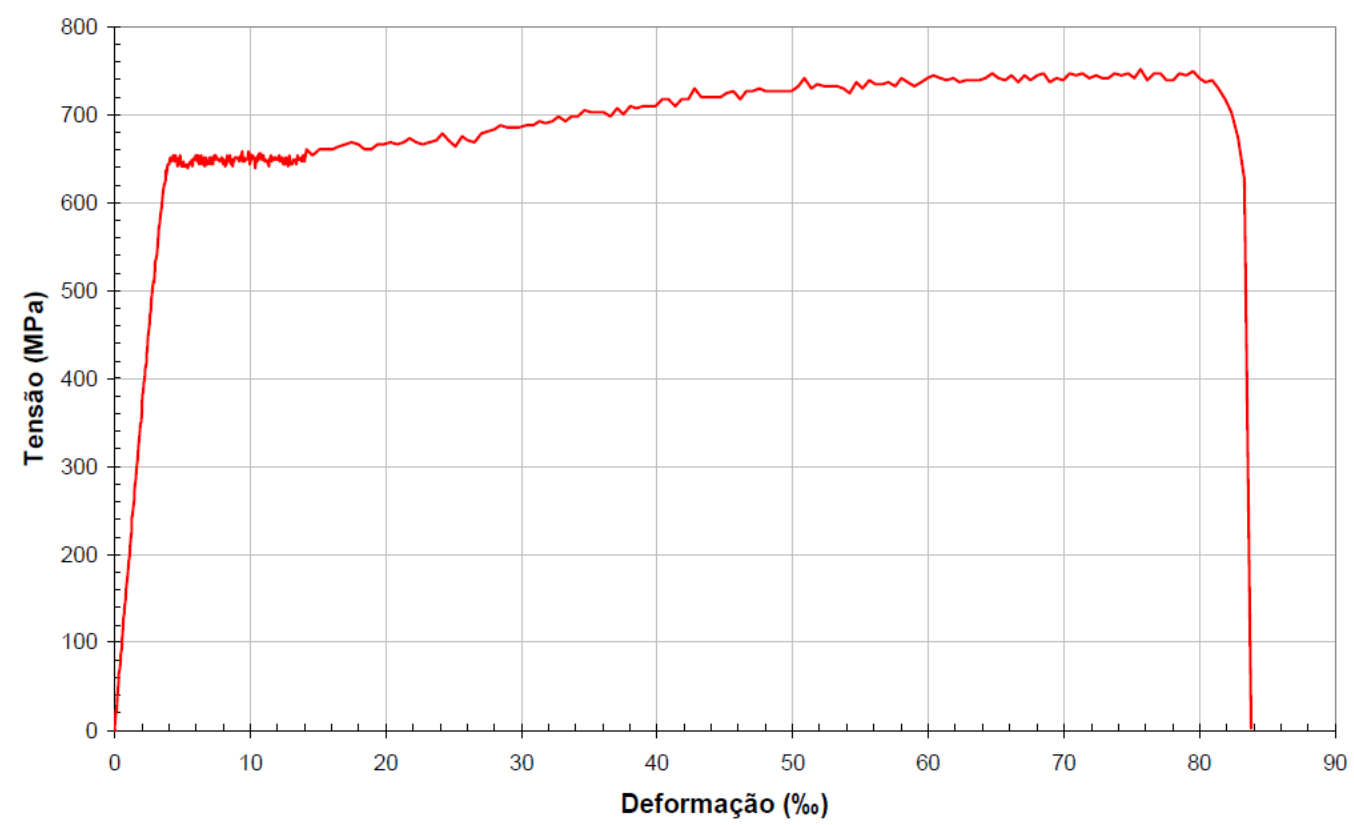

Figura 54 - Diagrama tensão-deformação para aço tratado a quente, obtido em ensaio (Pinheiro, 2005 apud Toshiaki Takeia)

No diagrama acima, nota-se que a tensão de escoamento obtida, $640 \mathrm{MPa}$, foi $28 \%$ maior que a nominal, $500 \mathrm{MPa}$, e o limite de resistência, $750 \mathrm{MPa}$ com um alongamento máximo de $8,4 \%$.

Normalmente não são utilizados o coeficiente de poisson, $v$, e módulo de elasticidade transversal, $G_{s}$, pois a armadura não tem volume representativo perante o volume de concreto e o efeito da distorção é desprezível para os casos usuais, mas para qualquer outra finalidade há como referência os valores indicados para o aço estrutural pela norma ABNT NBR8800:2008 (p. 23):

$$
\begin{aligned}
& \nu=0,3 \\
& G_{s}=77 \mathrm{GPa}
\end{aligned}
$$

\subsubsection{CÓDIGO MODELO CEB-FIP 1990}

O CEB-FIP 1990 (p. 74) permite que seja adotado como modelo reológico para o aço das armaduras passivas um diagrama tensão-deformação idealizado elastoplástico perfeito para aço das classes A, B e S. O que diferencia as classes é o mínimo requerido para a relação entre a tensão última de ruptura, $f_{t}$, e a tensão de 
escoamento, $f_{y}$, e o mínimo requerido para o alongamento total característico para a carga máxima, $\varepsilon_{u k}$.

Classe A: $\left(f_{t} / f_{y}\right)_{k} \geq 1,08$ e $\varepsilon_{u k} \geq 5 \%$

Classe B: $\left(f_{t} / f_{y}\right)_{k} \geq 1,05$ e $\varepsilon_{u k} \geq 2,5 \%$

Classe S: $\left(f_{t} / f_{y}\right)_{k} \geq 1,15$ e $\varepsilon_{u k} \geq 6 \%$

O aumento no valor da tensão última de ruptura em relação a tensão de escoamento é o encruamento. $O$ valor característico da razão $\left(f_{t} / f_{y}\right)_{k}$ corresponde ao quantil de $5 \%$ da relação entre a tensão última de ruptura e a tensão de escoamento. Os aços da classe $S$ são indicados para regiões em que os efeitos sísmicos sejam importantes, por isso a necessidade de maior dutilidade.

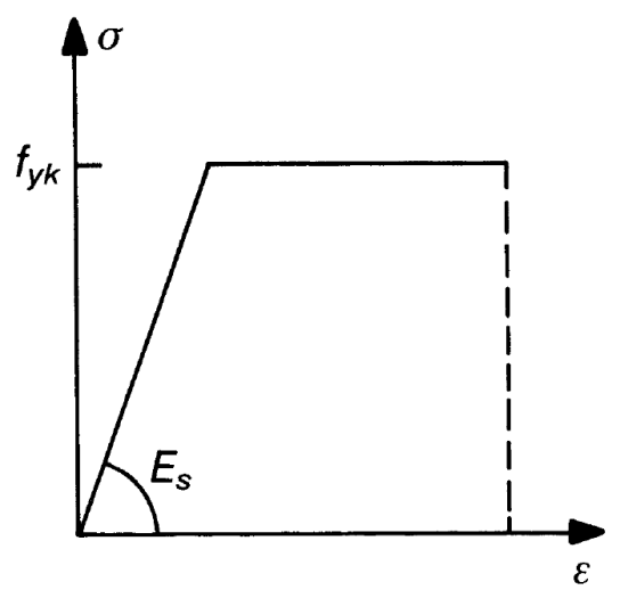

Figura 55 - Diagrama tensão-deformação idealizado para armaduras passivas (CEB-FIP 1990)

No diagrama acima, $f_{y k}$ é a resistência característica ao escoamento do aço correspondente ao quantil de $5 \%$ de distribuição de resistências e $E_{s}$ o módulo de elasticidade que pode ser admitido igual a:

$$
E_{s}=200 \mathrm{GPa}
$$

Não é apresentado o valor do alongamento ou encurtamento máximo permitido, $\varepsilon_{y}$, nem do início do escoamento, $\varepsilon_{y k}$, no entanto para o alongamento máximo e o encurtamento máximo a podem ser adotados os valores determinados pelos domínios de deformação: 


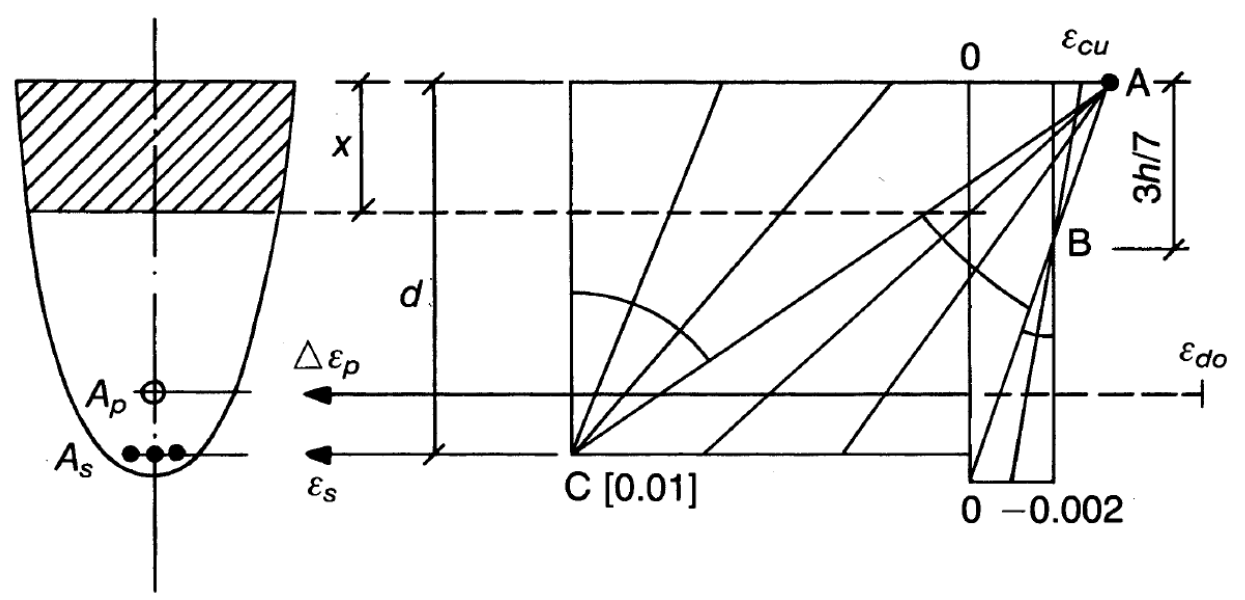

Figura 56 - Domínios de deformação (CEB-FIP 1990)

Assim, $\varepsilon_{y l}$ é adotado como o valor máximo de alongamento permitido:

$$
\varepsilon_{y l}=0,01
$$

E $\varepsilon_{y e}$ é adotado como o valor máximo de encurtamento permitido (teórico):

$$
\varepsilon_{y e}=\varepsilon_{c u}
$$

O alongamento ou encurtamento de início de escoamento, $\varepsilon_{y k}$ para $f_{y k}$, pode ser obtido por meio do módulo de elasticidade e no caso de $f_{y k}=500 \mathrm{MPa}$, por exemplo:

$$
\varepsilon_{y k}=\frac{f_{y k}}{E_{s}}=\frac{500}{200000}=0,0025
$$

Assim como na ABNT NBR6118:2007 não são indicados os valores do coeficiente de poisson, $v$, e do módulo de elasticidade transversal, $G_{s}$.

\subsubsection{CÓDIGO MODELO CEB-FIB 2010}

O CEB-FIB 2010 (p. 178) permite que seja adotado como modelo reológico para o aço das armaduras passivas um diagrama tensão-deformação idealizado elastoplástico perfeito para aços das classes A, B, C e D. O que diferencia as classes é o mínimo requerido para a relação entre a tensão última de ruptura, $f_{t}$, e a tensão de escoamento, $f_{y}$, e o mínimo requerido para o alongamento total característico na carga máxima, $\varepsilon_{u k}$. 
Classe A: $\left(f_{t} / f_{y}\right)_{k} \geq 1,05$ e $\varepsilon_{u k} \geq 2,5 \%$

Classe B: $\left(f_{t} / f_{y}\right)_{k} \geq 1,08$ e $\varepsilon_{u k} \geq 5 \%$

Classe C: $\left(f_{t} / f_{y}\right)_{k} \geq 1,15$ e $\leq 1,35$ e $\varepsilon_{u k} \geq 7 \%$

Classe D: $\left(f_{t} / f_{y}\right)_{k} \geq 1,25$ e $\leq 1,45$ e $\varepsilon_{u k} \geq 8 \%$

O aumento no valor da tensão última de ruptura em relação a tensão de escoamento é o encruamento. O valor característico da razão $\left(f_{t} / f_{y}\right)_{k}$ corresponde ao quantil de $5 \%$ da relação entre a tensão última de ruptura e a tensão de escoamento. Os aços das classes C e D são indicados para regiões em que os efeitos sísmicos sejam importantes, por isso a necessidade de maior dutilidade.

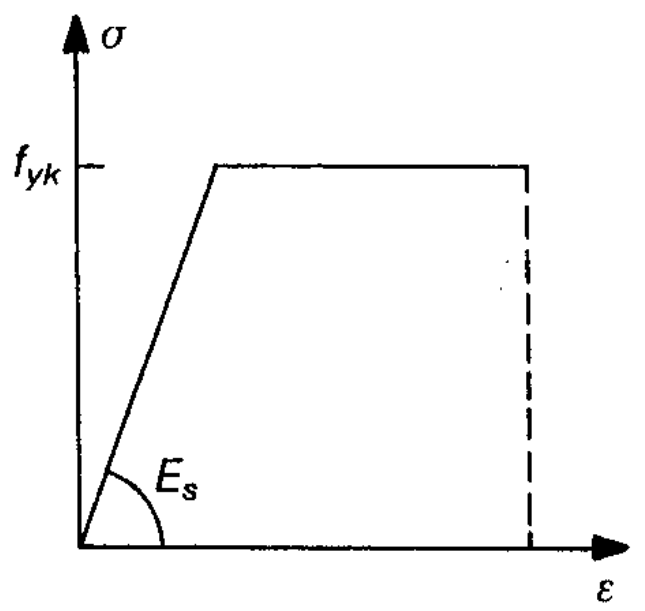

Figura 57 - Diagrama tensão-deformação idealizado para armaduras passivas (CEB-FIB 2010)

No diagrama acima, $f_{y k}$ é a resistência característica ao escoamento do aço correspondente ao quantil de $5 \%$ de distribuição de resistências e $E_{s}$ o módulo de elasticidade que pode ser admitido igual a:

$$
E_{s}=200 \mathrm{GPa}
$$

No item 7.2.3 do CEB-FIB 2010 (p. 25) na parte referente a projeto é indicado um diagrama tensão-deformação em que é permitido optar por um diagrama com encruamento ou sem encruamento: 


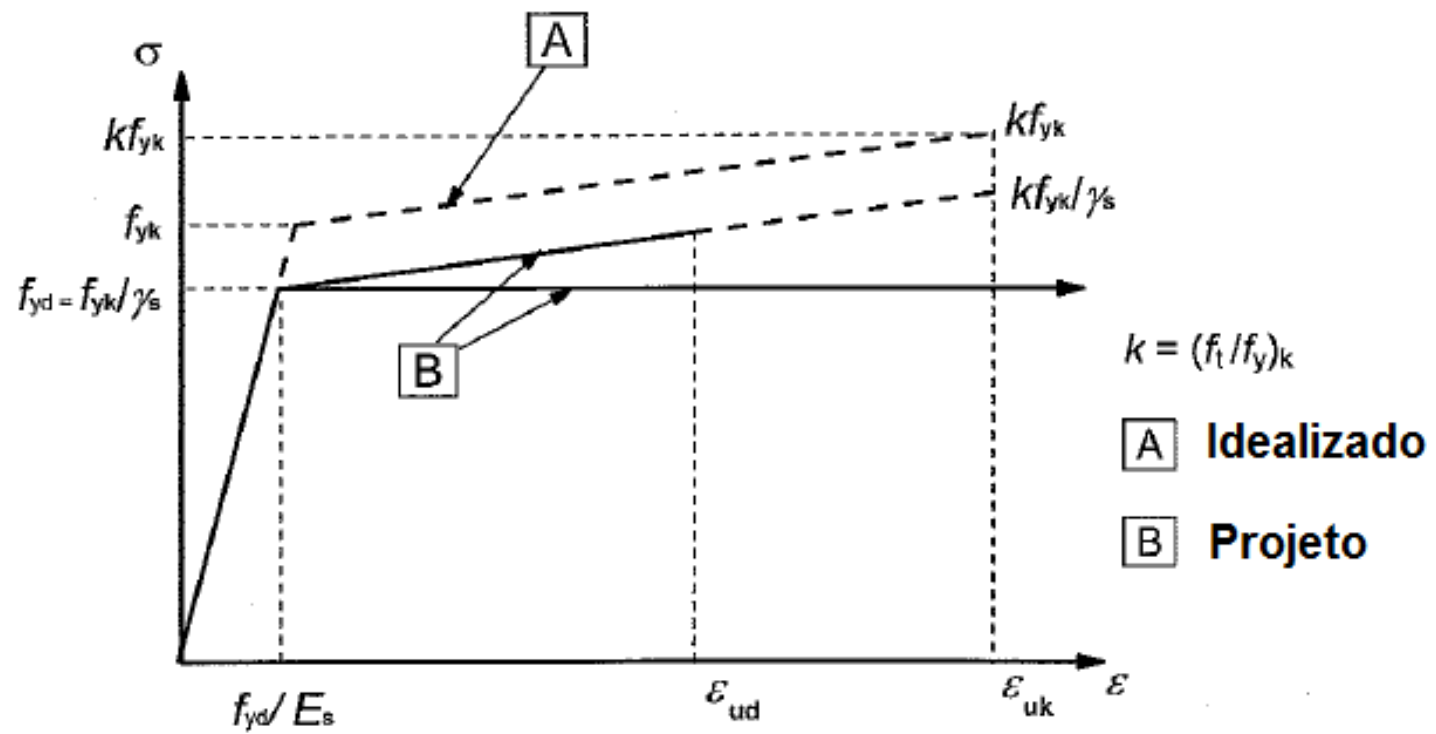

Figura 58 - Diagrama tensão-deformação idealizado com encruamento (CEB-FIB 2010)

No diagrama acima $f_{y d}$ é resistência de cálculo ao escoamento, ou seja, a resistência característica ao escoamento dividida por um coeficiente de ponderação e $\varepsilon_{u d}$ é o alongamento total de cálculo para a carga máxima. O CEB-FIB 2010 indica o valor para $\varepsilon_{u d}$ em apenas uma ocasião, que é no caso das deformações plásticas da estrutura terem relevância, considera-se apropriado utilizar o encruamento e neste caso a tensão máxima é:

$$
\sigma_{s}=k f_{c d}
$$

E a deformação máxima:

$$
\varepsilon_{u d}=0,9 \varepsilon_{u k}
$$

Assim como na ABNT NBR6118:2007 não são indicados os valores do coeficiente de poisson, $v$, e do módulo de elasticidade transversal, $G_{s}$.

\subsection{COMPARAÇÃO ENTRE A NORMA E OS CÓDIGOS MODELOS E COMENTÁRIOS ADICIONAIS}

\subsubsection{CONCRETO}

Há mais de 80 anos diversos pesquisadores do mundo vem se dedicando aos estudos sobre modelos reológicos à serem empregados para o concreto que representem melhor a realidade. 
Entre os diversos pesquisadores pode-se citar os trabalhos de $\mathrm{H}$. Rüsh sobre deformação lenta para o concreto (RÜSH, 1981), H. Rüsh e H. Kupfer sobre resistência em solicitações biaxiais (LEONHARDT E MÖNNIG, 1977) e também sobre o mesmo tema L. Nelissen (FUSCO, 1995), E. Grasser pelo diagrama tensãodeformação (RÜSH, 1981), W. F. Chen e Ottosen sobre critérios de resistência (CAMPOS FILHO, 2003), mais recentemente M. François sobre um novo critério de plastificação para concreto (FRANÇOIS, 2008).

De acordo com Langendonck (1959, p. 152) já na década de 30 havia estudos sobre equações para representar o diagrama tensão-deformação do concreto, entre elas a parabólica:

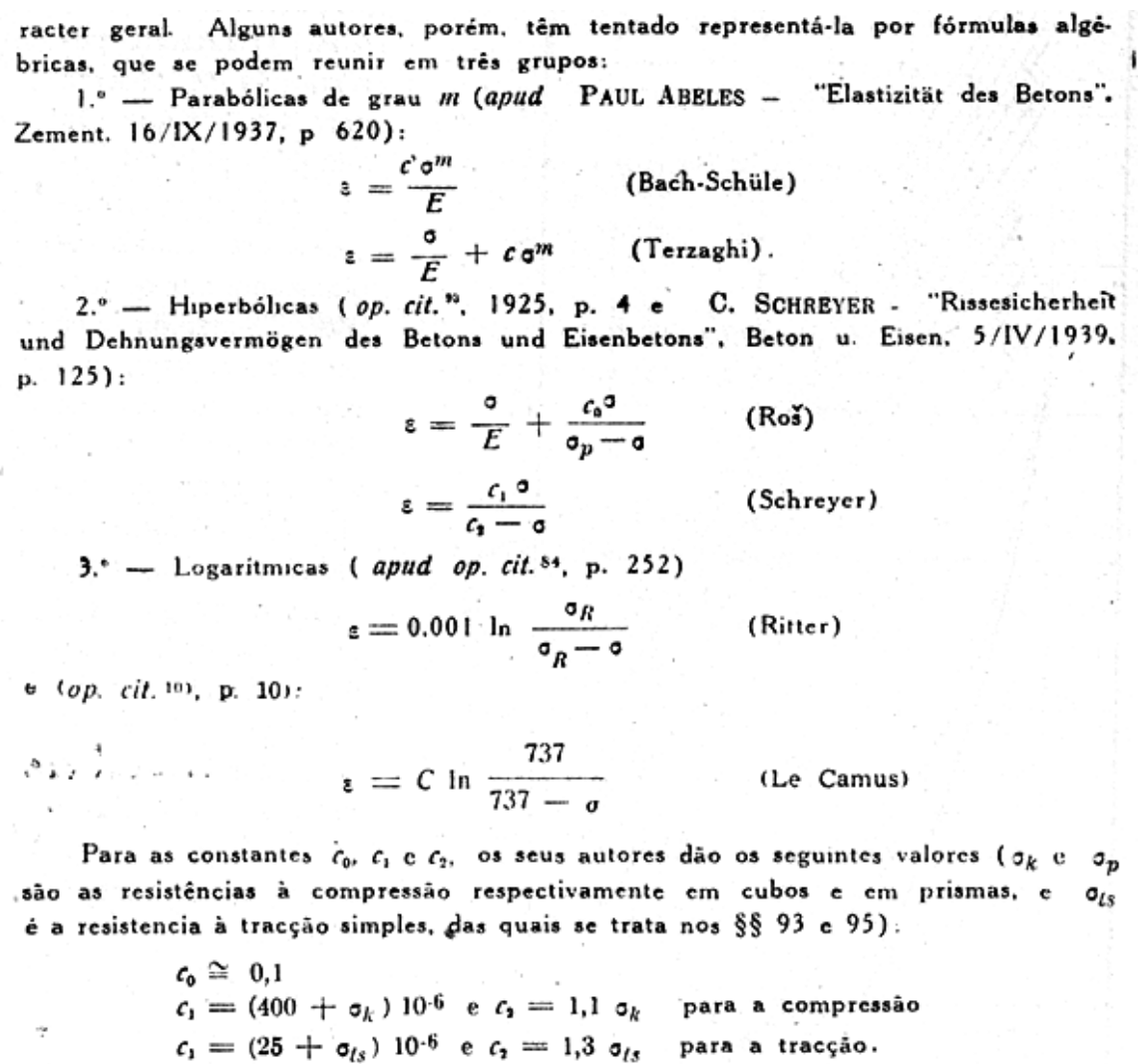

As tensôes são dadas $\mathrm{cm} \mathrm{kg} / \mathrm{cm}=\mathrm{e}{ }_{R}$ representa a tensâo de ruptura por compressảo. Outras leis de variação de $\varepsilon$ em função de $\sigma$ são citadas $\mathrm{em} \mathrm{A} \mathrm{VOELL.MY} \mathrm{-}$ "Zusammenhang zwischen Druck-, Biege- und Knick-Festigkeit von Beton und Eisenbeton". Schweizerische Bauzeitung, 17/1X/1949. cujo autor propõe uma fórmula parabólica do $2 .^{\circ}$ grau $\circ={ }^{\circ} \frac{\varepsilon}{\varepsilon_{0}}\left(2-\frac{\varepsilon}{\varepsilon_{0}}\right)$ válida atè $=\varepsilon_{0}$. e substituida dai por diante, até a ruptura, pelo valor constante $0=o_{R}$.

Figura 59 - Funções para o diagrama tensão-deformação (LANGENDONCK, 1959) 
Outras formas de distribuição têm sido sugeridas como se mostra na fig. 256 (vejam-se os trabalhos dos respectivos autores citados nas notas 435 e 438 , bem como Rudolf SALiger (Die neue Theorip des Stahlbetons auf Grund der Bildsamkeit im Bruchzustand», Viena, 19:-
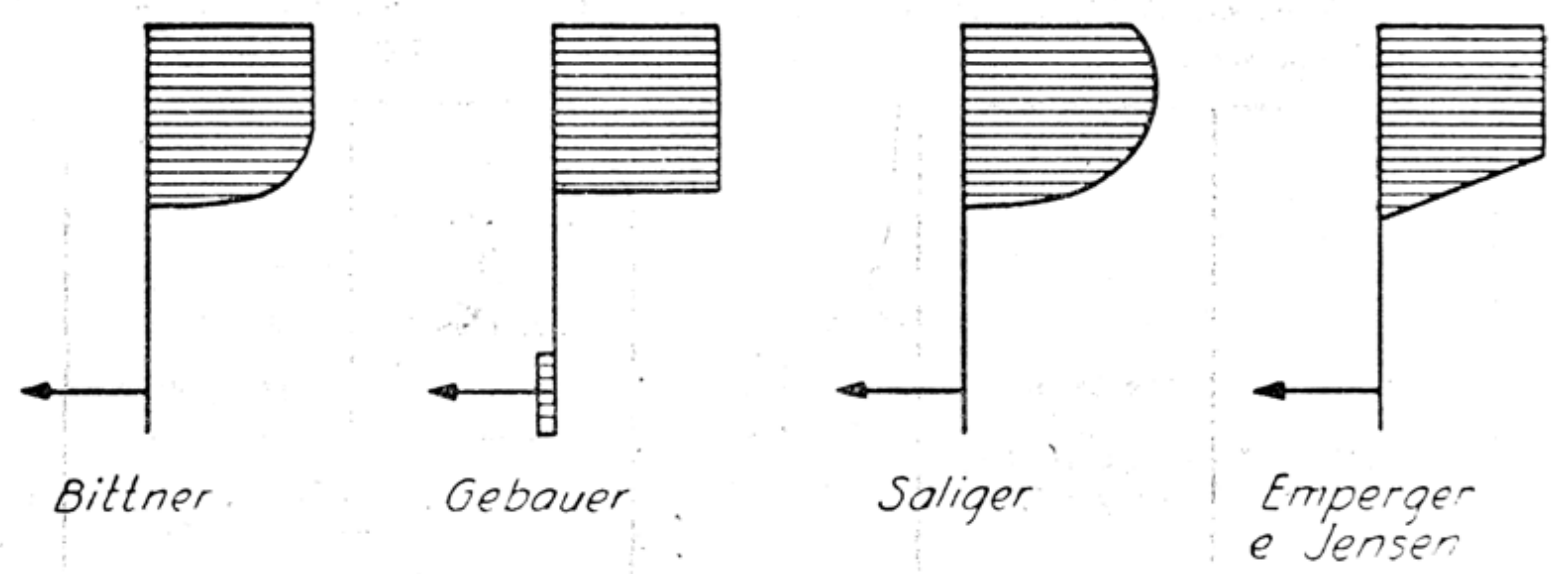

Figura 60 - Diagramas tensão-deformação para o concreto (LANGENDONCK, 1959)

$\mathrm{Na}$ figura 60 são mostrados os diversos diagramas de tensões propostos pelos autores indicados logo abaixo.

Fusco (2008, p. 144) faz um breve histórico sobre a evolução dos modelos de cálculo e dos diversos diagramas tensões adotados, destaca-se o trabalho de Bittner de 1936, o mesmo apresentado na figura 60 , em que foi utilizado um diagrama parabólico-retangular para representar a variação de tensões no trecho comprimido de uma peça fletida.

Em Rüsh (1981, p. 97) é mostrado um diagrama tensão-deformação parabólico-retangular e um bilinear recomendados pela norma alemã DIN 1045 de 1972 e de acordo com Fusco (1981, p. 351), o Manual de flambagem do CEB-FIP de 1977 também recomendava o diagrama parabólico-retangular.

Ao compararmos a norma ABNT NBR6118:2007 com os códigos modelos CEB-FIP 1990 e CEB-FIB 2010 a primeira diferença está no tipo de diagrama adotado para os diversos fins, que pela norma é o parabólico-retangular para análises não-lineares e dimensionamentos (verificação de estado limite último, ELU), nos códigos modelos é indicado em diagrama mais sofisticado para análises nãolineares e os mais simples como o parabólico-retangular para dimensionamento. $\mathrm{O}$ equacionamento do diagrama parabólico-retangular entre os três é o mesmo para classes de concreto até $\mathrm{C} 50$, o que indica que tenham a mesma origem. A vantagem 
no uso deste diagrama está na sua simplicidade pois ele depende apenas da resistência a compressão.

As equações indicadas para análise não-linear pelos códigos modelos são iguais, a não ser pela obtenção dos coeficientes, em que se destaca que no CEBFIB 2010 a deformação correspondente a tensão máxima de compressão, $\varepsilon_{c l}$, não é constante e varia em função da resistência a compressão. O CEB-FIP 1990 apresenta uma formulação específica para o trecho decrescente do diagrama tensão-deformação, além da deformação limite convencionada. Entende-se que sua aplicação seja feita em casos de verificação de estruturas existentes ou que entraram em colapso, pois sua consideração levaria a grandes deformações.

Quanto a resistência média a compressão, a ABNT NBR6118:2007 não indica o valor a ser adotado em projeto. O CEB-FIP 1990 e CEB-FIB 2010 fornecem os mesmos valores para obtenção da resistência média a compressão a ser adotada em projeto:

$$
\left\{\begin{array}{l}
f_{c m}=f_{c k}+\Delta f \\
\Delta f=8 M P a
\end{array}\right.
$$

O valor da resistência media a compressão também pode ser obtido considerando que a resistência característica a compressão é obtida por:

$$
f_{c k}=f_{c m}-1,645 \sigma_{c}
$$

Em que $\sigma_{c}$, neste caso, representa o desvio padrão. Em Fusco (2008, p. 71) é apresentado um gráfico esquemático do desvio padrão versus resistência cúbica média, medidos em mais de 800 obras. Deste gráfico foi obtido o desvio padrão médio de acordo com a resistência do concreto:

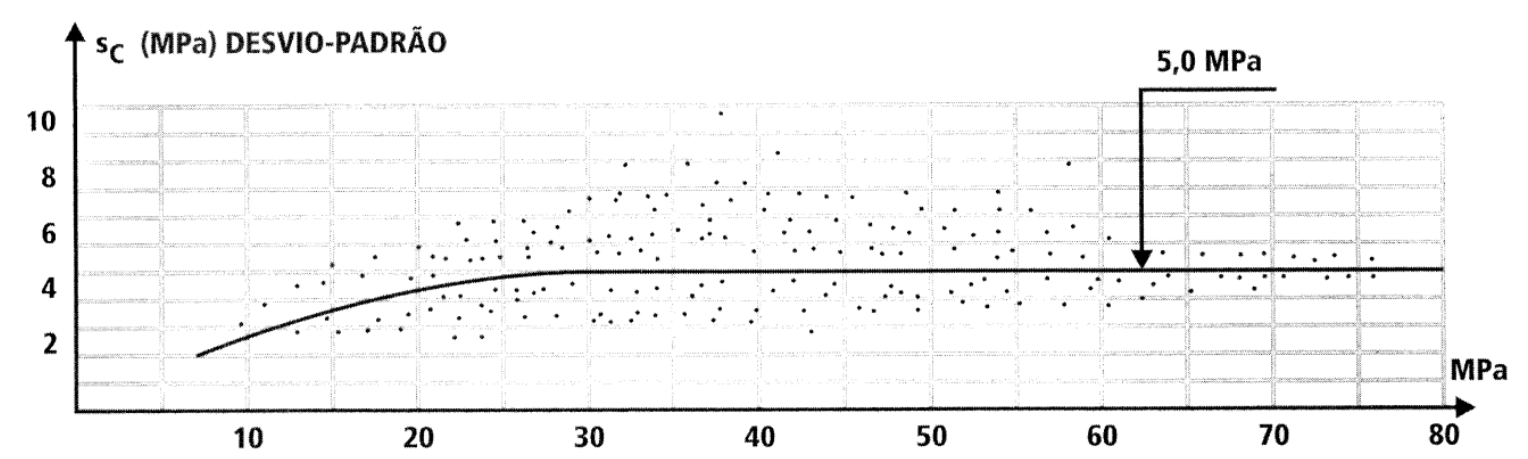

Figura 61 - Desvio padrão versus resistência cúbica média, esquemático (FUSCO, 2008) 
Pelo gráfico acima o desvio padrão para concretos com resistência acima de $25 \mathrm{MPa}$ apresentaram um devio padrão médio de $5 \mathrm{MPa}$, considerando (5.60):

$$
\begin{aligned}
& f_{c k}=f_{c m}-1,645 \cdot 5 \\
& f_{c m}=f_{c k}+8,225
\end{aligned}
$$

O acréscimo de tensão para se obter a resistência média apresentado em (5.61) é praticamente o mesmo que em (5.59).

Para a realidade brasileira atual existem dúvidas quantos aos valores a serem adotados para $\Delta f$ e consequentemente para o desvio padrão, que podem ser sensivelmente menores (informação verbal) ${ }^{7}$.

O CEB-FIB 2010 permite que seja usado um diagrama bilinear. Este diagrama comparado ao parabólico-retangular fica a favor de segurança para o dimensionamento. Abaixo os dois diagramas são apresentado no mesmo gráfico, considerando um concreto de classe $\mathrm{C} 30$, para que fique visível a diferença:

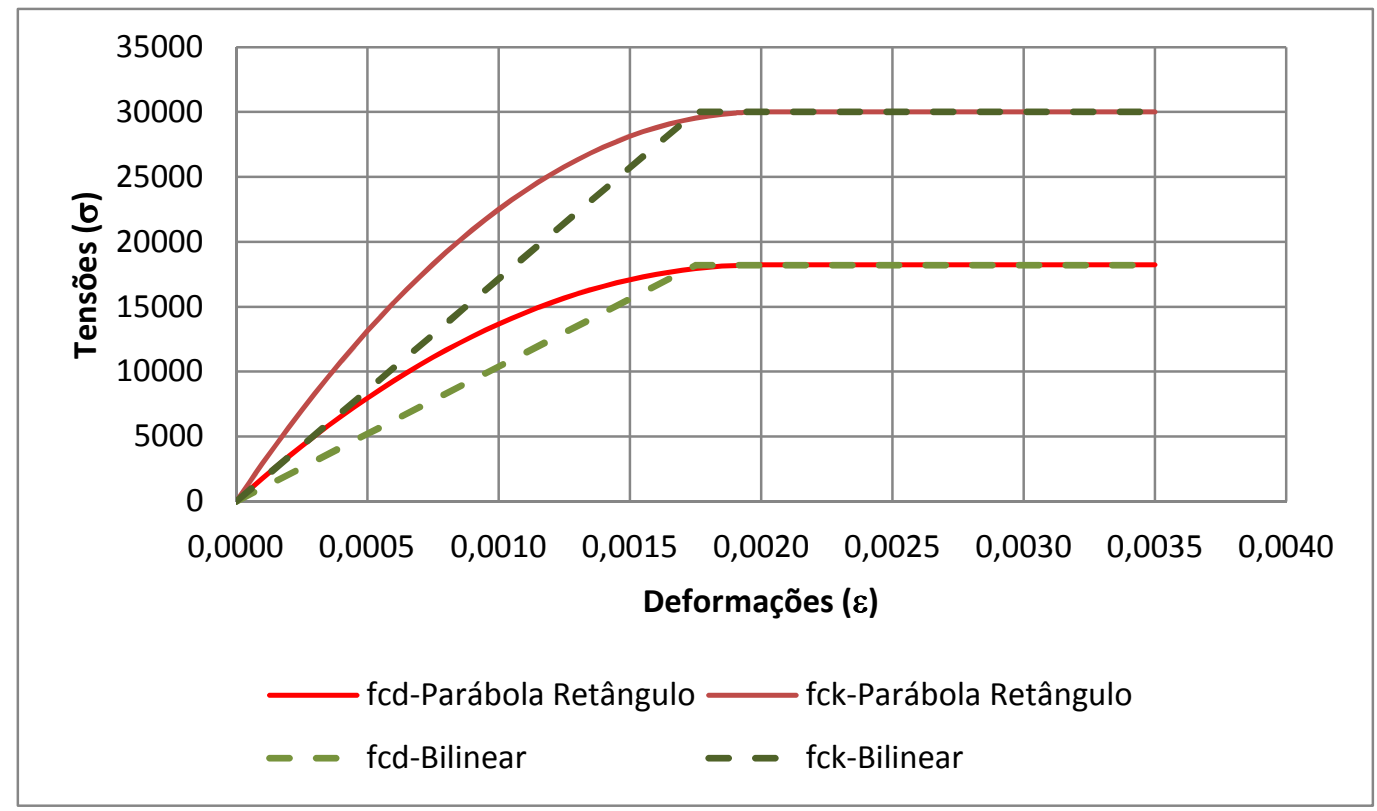

Figura 62 - Comparação dos diagramas parabólico-retangular e bilinear

Ao analisarmos o gráfico acima percebe-se que se integrarmos as tensões do diagrama parabólico-retangular a força resistente resultante será maior que no diagrama bilinear.

7 Deformações nas estruturas de edifícios de concreto armado; fissuração, fluência e influência do processo construtivo. Palestra proferida pelo Prof. Dr. Eng. Ricardo Leopoldo e Silva França no dia 17/09/2009 no Instituto de Engenharia de São Paulo. 
Um fator importante que causa diminuição na resistência do concreto e variação no diagrama tensão-deformação é o efeito das cargas de longa duração (tensões aplicadas por um longo período tempo, cujos valores quando acima de um determinado limite provocam a ruptura do concreto) . Nas análises estruturais, sejam lineares ou não-lineares esse efeito deve ser considerado. A figura 63 ilustra esse efeito:

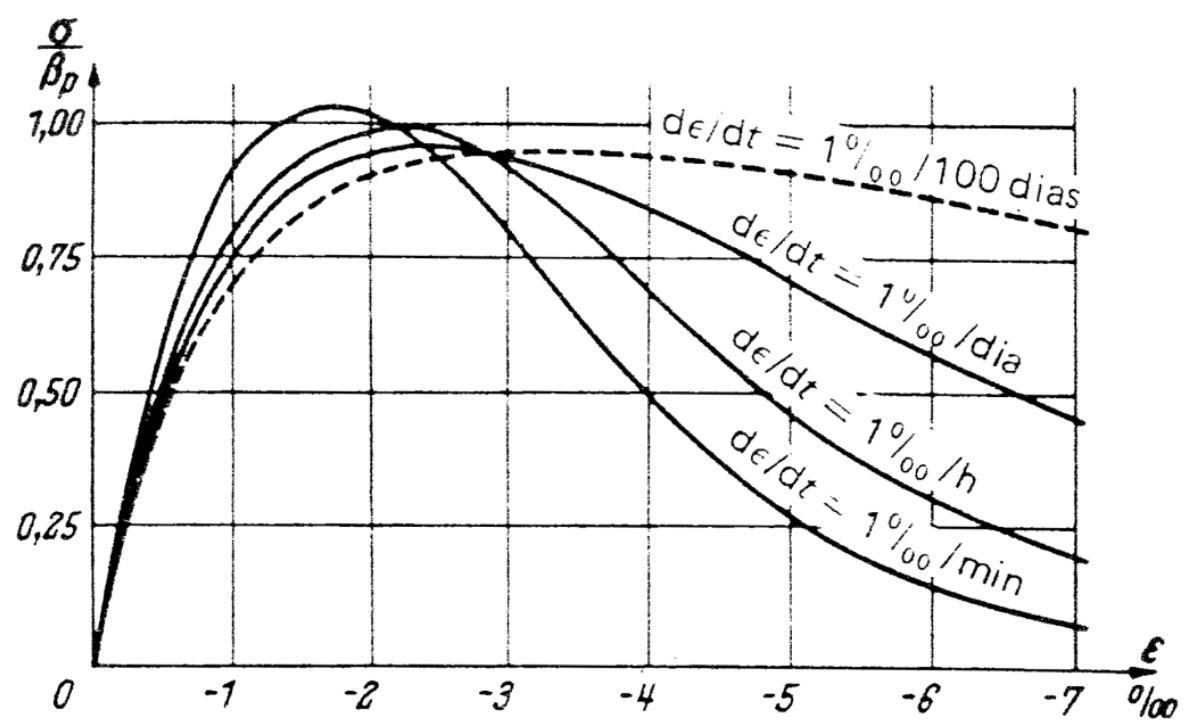

Figura 63 - Diagrama tensão-deformação considerando o efeito das cargas de longa duração (RÜSH, 1981)

Uma forma simples de considerar este efeito é utilizar um fator de correção para a resistência, o $\mathrm{k}_{\bmod , 3}$. Como já foi mostrado, ao multiplicarem-se todos os $\mathrm{k}_{\bmod }$ obtêm-se o coeficiente 0,85 , o efeito Rüsh. No projeto de revisão da ABNT NBR6118 (2011) o valor constante 0,85 , é variável em função de $f_{c k}$ para concretos de classes superiores C50.

Quanto a resistência a tração nota-se que as equações para obtenção das diversas resistências são praticamente as mesmas entre a norma e os códigos modelos, a única diferença é o limite de deformação que nos códigos modelos é três vezes maior que o limite apresentado pela norma ABNT NBR6118:2007. No projeto de revisão da ABNT NBR6118 (2011) este limite é idêntico ao dos códigos modelos.

O módulo de elasticidade utilizado para análises elásticas apresenta diferenças ao comparar-se a norma com os códigos modelos. Uma das diferenças é a consideração, pelos códigos modelos, de um fator de correção que é função do 
tipo de agregado, outra diferença é a formulação adotada. Se considerarmos, por exemplo, um concreto classe $\mathrm{C} 30$ e um fator de correção unitário:

Pela norma ABNT NBR6118:2007

$$
E_{c s}=0,85 \cdot 5600 \sqrt{30}=26072 \mathrm{MPa}
$$

Pelo código modelo CEB-FIP 1990

$$
E_{\mathrm{c}}=0,85 \cdot 2,15 \cdot 10^{4} \sqrt[3]{\frac{30+8}{10}}=28518 \mathrm{MPa}
$$

Pelo código modelo CEB-FIB 2010

$$
E_{\mathrm{c}}=\left[0,8+0,2 \frac{(30+8)}{88}\right] \cdot 2,15 \cdot 10^{4} \sqrt[3]{\frac{30+8}{10}}=29738 \mathrm{MPa}
$$

Entre a ABNT NBR6118:2007 e o CEB-FIP 1990 há um aumento de 9,4\% e entre ABNT NBR6118:2007 e o CEB-FIB 2010 há um aumento de 14,1\%.

Pelo projeto de revisão ABNT NBR6118 (2011):

$$
E_{c s}=0,95 \cdot 5600 \sqrt{30}=29139 \mathrm{MPa}
$$

Pela equação (5.65) vemos que um aumento de $11,7 \%$ com relação a (5.62), o que tornará o valor do módulo de elasticidade obtido pelo equacionamento da norma brasileira mais próximo dos códigos modelos. Para ilustrar as diferenças entre os equacionamentos é apresentado a figura 64 . 


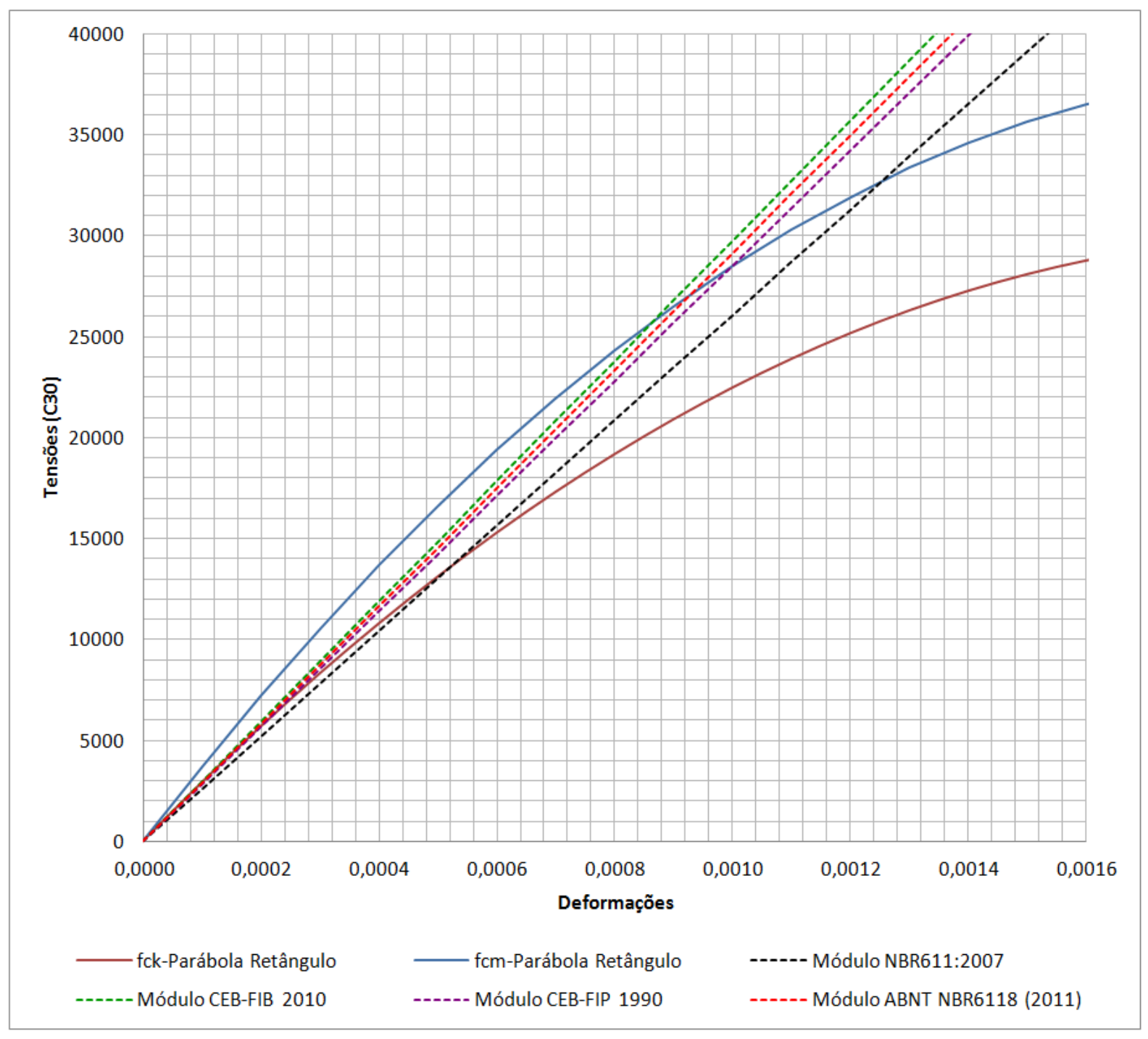

Figura 64 - Diagrama tensão-deformação parabólico-retangular e módulo de elasticidade

\subsubsection{AÇO}

Quanto ao aço tanto a norma quanto os códigos modelos indicam o diagrama idealizado elastoplástico perfeito para projeto, independentemente do tipo de análise. O CEB-FIB 2010, além do elastoplástico perfeito indica um diagrama elastoplástico com endurecimento, ou encruamento. Os diagramas indicados independem do processo de fabricação do aço. No caso da norma os limites de deformações a serem usados em projeto ficam determinados pelos domínios de deformação, no CEB-FIP 1990 podem ser usados os domínios de deformação e no CEB-FIB 2010 não há indicação dos limites a serem adotados em projeto, a não ser o alongamento máximo de acordo com a classe do aço e no caso das deformações plásticas da estrutura terem relevância. 
Quanto ao alongamento máximo da armadura estipulado em $1 \%$ pelos domínios de deformações, Fusco (2008, p. 174):

O alongamento último é convencional, não havendo precisão em sua definição. Para essa finalidade, o valor de $10 \times 10^{-3}$ é tão bom quanto o de $5 \times 10^{-3}$, pois a sensação de iminência de colapso é praticamente a mesma, quer existam 10 ou 5 fissuras de $1 \mathrm{~mm}$ de abertura por metro linear da peça.

Tanto o CEB-FIP 1990, quanto o CEB-FIB 2010 classificam o aço por classes que são determinadas pelo alongamento total característico para a carga máxima e, como pode-se chamar, pela razão de encruamento a relação $\left(f_{t} \mid f_{y}\right)_{k}$.

Observa-se que os valores para o alongamento total característico para a carga máxima e a razão de encruamento, determinados pela norma ABNT NBR7480:2007 para o aço CA-50 são os mesmos que para o aço da classe A no CEB-FIP 1990 e para o aço da classe B no CEB-FIB 2010.

Nos códigos modelos são classificados aços com grande dutilidade para uso em regiões em que o efeito sísmico seja relevante. Outras observações são que há uma pequena diferença, menor que $5 \%$, entre o módulo de elasticidade indicado pela norma e pelos códigos modelos e que tanto na norma quanto no códigos modelos não é indicado o valor da resistência média do aço, no entanto sabe-se que esse valor é muito próximo ao valor da resistência caracterísca, dada a pequena variabilidade da resistência.

\subsection{CONSIDERAÇÕES SOBRE PARÂMETROS DOS MATERIAIS E SEGURANÇA}

$\mathrm{Na}$ análise não-linear, para determinação de esforços, deve-se adotar a resistência compressão, de forma que a estrutura tenha a rigidez adequada (no caso do equacionamento em que a relação tensão-deformação é função da resistência a compressão). Em IBRACON (2007, p. 57) há a seguinte recomendação quanto a análise não-linear:

Deslocamentos, deformações, esforços internos e tensões na estrutura devem ser calculados com base em valores médios das propriedades dos materiais [...] Entretanto, devem ser adotados valores de cálculo para essas propriedades nas regiões críticas onde 
a resitência última precise ser calculada de acordo com os itens apropriados apresentados na NB-1.

Em Oliveira e Ricardo França (2000) são apresentadas as recomendações do CEB-FIP 1990, do Eurocode 2 e de França (R., 1991) quanto ao valor a ser adotado para resistência a compressão do concreto em análises não-lineares (física e geométrica):

O CEB-FIP 1990 no item 6.6.2.3 recomenda adotar:

$$
\begin{aligned}
& \alpha f_{c}=\alpha \frac{f_{c k}}{\gamma_{c}}=1 \frac{f_{c k}}{1,2}=0,833 f_{c k} \\
& E_{c d}=\frac{E_{c i}}{\gamma_{c}}=\frac{E_{c i}}{1,2}
\end{aligned}
$$

Se adotarmos $\alpha_{\text {Rüsh }}=0,85$ (efeito Rüsh):

$$
\alpha f_{c}=0,85 \frac{f_{c k}}{1,2}=0,708 f_{c k}
$$

O Eurocode $2^{8}$, apêndice 3 , recomenda adotar:

Considerando $\alpha=1$ e $\alpha_{E}=1$ :

$$
\alpha f_{c}=\alpha \cdot \alpha_{E} \frac{f_{c k}}{\gamma_{c}}=1,0 \cdot 1,0 \frac{f_{c k}}{1,35}=0,741 f_{c k}
$$

$$
E_{c d}=\frac{E_{c i, m}}{\gamma_{c}}=\frac{E_{c i, m}}{1,35}
$$

Se adotarmos $\alpha_{\text {Rüsh }}=0,85$ :

$$
\alpha f_{c}=\alpha \cdot \alpha_{E} \frac{f_{c k}}{\gamma_{c}}=0,85 \cdot 1,0 \frac{f_{c k}}{1,35}=0,630 f_{c k}
$$

Em França (R., 1991) é adotado:

$\overline{{ }^{8} \mathrm{Na} \text { versão atual do Eurocode } 2}$ (2004) não foi encontrado tal recomendação, mas que para o diagrama tensão-deformação poderiam ser adotadas as formulações (5.26-5.32 à 5.34), considerando o efeito da fluência e adotando um modelo que considere as incertezas do material. No caso de pilares devem ser adotados valor de cálculo, $f_{c d}$ e $f_{y d}$, para os diagramas tensão-deformação, na verificação da resistência. 


$$
\alpha f_{c}=0,85 \cdot 1,3 \cdot f_{c d}=0,85 \cdot 1,3 \frac{f_{c k}}{1,4}=0,789 f_{c k}
$$

Faz-se a observação de que os valores recomendados acima são para obtenção de esforços provenientes do efeito de $2^{\circ}$ ordem em pilares. Observa-se, também, que em todas as formulações, foi considerado um valor maior que o de cálculo para a resistência a compressão do concreto utilizado para verificação do ELU das seções. Isso se deve ao fato, como colocado por Oliveira e Ricardo França (2000), da ocorrência de valores baixos de resistência para toda a estrutura ou todas as seções, terem baixa probabilidade de ocontecer ${ }^{9}$.

Quanto ao aço o item 6.6.2.3 do CEB-FIP 1990 não deixa claro qual valor de para o escoamento deve ser adotado para obtenção dos esforços, mas indica que pode ser utilizado o item 2.2.4.3 que apresenta alguns diagramas para o aço em que é considerado o encruamento, na seção de comentários desse mesmo item é permitido o diagrama elastoplástico perfeito considerando a resistência característica ao escoamento, $f_{y k}$. Para o Eurocode 2, ver nota 8. Em França $(R ., 1991)$ é adotado a resistência de cálculo do aço, $f_{y d}$.

Em França (R., 1991), para a verificação da capacidade resistente última de uma determinada seção crítica são adotados os valores de cálculo das resistências, com os fatores não reduzidos, $\gamma_{c}=1,4$ e $\gamma_{s}=1,15$, igualmente o faz a norma ABNT NBR6118:2007.

No CEB-FIP 1990 para a verificação da capacidade resistente última de uma determinada seção crítica também deverá ser usado os fatores não reduzidos, $\gamma_{\mathrm{c}}=$ 1,5 e $\gamma_{\mathrm{s}}=1,15$. Quanto ao enrijecimento provocado pelo concreto tracionado, o CEBFIP 1990 comenta que só é significativo para seções com pequenas taxas de armaduras em que o ELU para instabilidade ocorra antes da armadura escoar. No item 5.4.1.4, que trata das leis constitutivas para análises não-lineares nos casos gerais, permite-se adotar os valores médios das propriedades dos materiais para obtenção dos esforços, neste caso a resistência a compressão pode ser adotada, considerando $\alpha_{\text {Rüsh }}=0,85$ :

\footnotetext{
${ }^{9}$ Neste trabalho não está sendo tratado o caso de pilares, nem de efeitos de $2^{\circ}$ ordem, a justificativa para a análise bibliográfica destes casos é que a maior parte da bibliografia que trata o assunto: análise não-linear por meio de diagramas $\mathrm{M}-\mathrm{N}-1 / \mathrm{r}$ ser para pilares, além disso, os estudos dos casos de pilares costumam ser mais aprofundados, por conta do efeito de $2^{\circ} \mathrm{ordem}$.
} 


$$
\begin{aligned}
& \alpha f_{c m}=0,85\left(f_{c k}+8\right) \text { para concreto C30: } \\
& \alpha f_{c m}=0,85\left(f_{c k}+\frac{4}{15} f_{c k}\right)=1,077 f_{c k(30)}
\end{aligned}
$$

O CEB-FIB 2010 comenta que o objetivo da análise não-linear é simular o comportamento da estrutura mais próximo do real e avaliar o valor representativo da capacidade resistente e que esta tarefa também pode ser formulada como uma previsão da resistência mais provável, que é o valor médio de resistência. Portanto, a resistência média pode ser escolhida como referência para avaliação de segurança pela análise não-linear. A incerteza devido à variação aleatória das propriedades dos materiais (e possivelmente a outros parâmetros de resistência) é descrita pela variação aleatória da resistência e, neste caso, um modelo de incerteza deve ser acrescentado.

Para resistência de projeto em análises não-lineares o CEB-FIB 2010 aplica um modelo de resistência global:

$$
F_{d} \leq R_{d}, R_{d}=\frac{R_{m}}{\gamma_{R}^{*} \cdot \gamma_{R d}}
$$

Em que, $F_{d}$ corresponde ao valor de projeto das ações, $R_{d}$ ao valor de projeto da resistência, $R_{m}$ é o valor médio da resistência, $\gamma^{*} \mathrm{R}$ é o fator de resistência global que considera as incertezas das propriedades dos materiais e $\gamma_{R d}$ é o fator de incerteza do modelo.

O fator de segurança global contas para as incertezas do modelo aleatório parâmetros, ou seja, das propriedades dos materiais

$\mathrm{O}$ valor de projeto da resistência, $R_{d}$, pode ser avaliada por vários métodos baseados em diferentes níveis de aplicação da teoria da probabilidade:

- método probabilístico para obtenção do índice de confiabilidade exigido ou probabilidade de falha da estrutura;

- método da resistência global;

- método dos coeficientes parciais de segurança.

Será apresentado abaixo a formulação para o método da resistência global, na obtenção do valor de projeto da resistência:

$$
R_{d}=\frac{r\left(f_{m, \ldots}\right)}{\gamma_{R} \cdot \gamma_{R d}}
$$


Em que:

$$
\begin{aligned}
\gamma_{R} & =1,2 \\
\gamma_{R d} & =\left\{\begin{array}{l}
1,0 \text { para modelos sem incertezas } \\
1,06 \text { para modelos em que as incertezas são pequenas } \\
1,10 \text { para modelos em que as incertezas são grandes }
\end{array}\right.
\end{aligned}
$$

E a função $r$ representa os valores de resistência obtidos na análise nãolinear, que está em função dos valores médios das propriedades dos materiais, na forma abaixo:

Para o concreto:

$$
f_{c m d}=1,1 f_{c k} \frac{\gamma_{s}}{\gamma_{c}}=1,1 f_{c k} \frac{1,15}{1,5}=1,1 f_{c k} 0,767=0,843 f_{c k}
$$

O código modelo faz o arredondamento:

$$
f_{c m d} \cong 0,85 f_{c k}
$$

Em que $f_{c m d}$ é o valor reduzido para a resistência do concreto à compressão devido à sua incerteza.

Para o aço:

$$
f_{y m}=1,1 f_{y k}
$$

Em que $f_{y m}$ é o valor médio da resistência ao escoamento do aço. $O$ multiplicador 1,1 de (5.78) e (5.80) é o fator que leva a resistência característica ao seu valor médio.

O equacionamento acima provêm da necessidade de obter-se um fator de segurança único para o concreto e o aço, no entanto é fato que os dois materiais tem variabilidade distinta, mas partindo dos fatores de segurança parciais que foram obtidos para uma mesma probabilidade de ruína:

Para o aço:

$$
\left\{\begin{array}{l}
f_{y d}=\frac{f_{y m}}{\gamma_{G L}^{A c o}} \rightarrow f_{y m}=f_{y d} \cdot \gamma_{G L}^{A c o}=f_{y d} \cdot 1,1 \cdot \gamma_{s} \\
\gamma_{G L}^{A c o}=1,1 \cdot \gamma_{s}=1,1 \cdot 1,15=1,27
\end{array}\right.
$$


Para o concreto:

$$
\left\{\begin{array}{l}
f_{c d}=\frac{f_{c m}}{\gamma_{G L}^{\text {Concreto }}} \rightarrow f_{c m}=f_{c d} \cdot \gamma_{G L}^{\text {Concreto }}=f_{c d} \cdot 1,1 \cdot \gamma_{c} \\
\gamma_{G L}^{\text {Concreto }}=1,1 \cdot \gamma_{c}=1,1 \cdot 1,5=1,65
\end{array}\right.
$$

Fazendo a imposição:

$$
\left\{\begin{array}{l}
\gamma_{G L}^{* \text { Concreto }}=1,27 \\
f_{c m}=f_{c d} \cdot \gamma_{G L}^{* \text { Concreto }}=\frac{f_{c k}}{\gamma_{c}} \cdot 1,1 \cdot \gamma_{s}=\frac{f_{c k}}{1,5} \cdot 1,1 \cdot 1,15=0,843 f_{c k} \cong 0,85 f_{c k}
\end{array}\right.
$$

Considerando:

$$
\begin{aligned}
& \gamma_{R}=1,2 \\
& \gamma_{R d}=1,06 \\
& \text { A ̧̧o } \rightarrow R_{d}=\frac{r\left(f_{m, \ldots}\right)}{\gamma_{R} \cdot \gamma_{R d}}=\frac{1,1 \cdot f_{y k}}{\gamma_{R} \cdot \gamma_{R d}}=\frac{1,1 \cdot f_{y k}}{1,2 \cdot 1,06}=0,865 \cdot f_{y k} \cong \frac{f_{y k}}{1,15} \text { ou } \frac{f_{y k}}{\gamma_{s}}(5.85) \\
& \text { Concreto } \rightarrow R_{d}=\frac{r\left(f_{m, \ldots}\right)}{\gamma_{R} \cdot \gamma_{R d}}=\frac{0,85 \cdot f_{c k}}{\gamma_{R} \cdot \gamma_{R d}}=\frac{0,85 \cdot f_{c k}}{1,2 \cdot 1,06}=0,668 \cdot f_{c k} \cong \frac{f_{c k}}{1,5} \text { ou } \frac{f_{c k}}{\gamma_{c}}
\end{aligned}
$$

Observa-se que (5.59) resulta em valores maiores de resistência a compressão que (5.79).

Neste método as propriedades médias dos materiais, para o cálculo das resistências, são considerados e também as diferentes incertezas do aço e do concreto.

Os valores para os modelos reológicos adotados para as ações podem ser os médios, sendo assim a formulação apresentada em (5.72) é válida também para o CEB-FIB 2010. No entanto pode-se adotar o valor reduzido para o concreto como apresentado em (5.79), considerando sua incerteza.

Nas formulações acima não estão explícitos os valores para $\alpha_{\text {Rüsh, no }}$ entanto no item 7.2.3.1.4 do CEB-FIB 2010, há o seguinte comentário quanto ao valor à ser adotado para resistência a compressão de cálculo:

Rüsch determinou para $\alpha_{c c}\left(\alpha_{\text {Rüsh }}\right)$ o valor 0,8 . No entanto, seus testes foram realizados em prismas de concreto que foram 
submetidos a cargas contínuas a uma idade de 28 dias. Normalmente, o concreto tem uma idade maior quando ele é carregado com um nível de carga substancial. Concretos com variados tipos de cimentos quanto ao endurecimento (lento, normal e rápido) mostram um aumento de resistência de $10 \%$ para $25 \%$ após três meses. A combinação dos dois efeitos dá uma gama de $\alpha_{\mathrm{cc}}=0,9$ à 1,0. O valor limite inferior é $\alpha_{c c}=0,85$. (CEB-FIB 2010, tradução nossa).

Não é comentado sobre o efeito da superestimação da resistência no ensaio com corpo de prova cilíndrico, $\mathrm{k}_{\bmod , 2}=0,95$.

No equaciomento apresentado em (5.73) a (5.86) está implícito $\alpha_{\text {Rüsh }}=1,0$, se considerarmos $\alpha_{\text {Rüsh }}=0,85$ :

$$
\alpha f_{c m d}=0,85 \cdot 0,85 \cdot f_{c k}=0,723 f_{c k}
$$

Em Fusco (1981, p. 352) há a sugestão de dois valores para a resistência do concreto, juntamente ao diagrama parabólico-retangular, a serem usados na obtenção de esforços e deslocamentos considerando o efeito de $2^{\circ}$ ordem em pilares:

Para pilares esbeltos $(\lambda>80)$ :

$$
f_{c}=\frac{f_{c k}}{1,2} \cong 0,85 f_{c k}
$$

Para pilares medianamente esbeltos $(\lambda<80)$ :

$$
f_{c}=\frac{f_{c m}}{\gamma_{c 1}}=\frac{f_{c m}}{1,2} \cong 0,85 f_{c m} \cong f_{c k}
$$

Nos valores acima não é explícito o valor para $\alpha_{\text {Rüsh }}$, se for adotarmos $\alpha_{\text {Rüsh }}$ = 1,0 as formulações acima são válidas.

Para o aço é adotado a resistência característica ao escoamento, $f_{y k}$. Para ELU, são adotados os valores de cálculo das resistâncias.

Abaixo os diversos fatores que multiplicam a resistência característica são apresentados graficamente: 


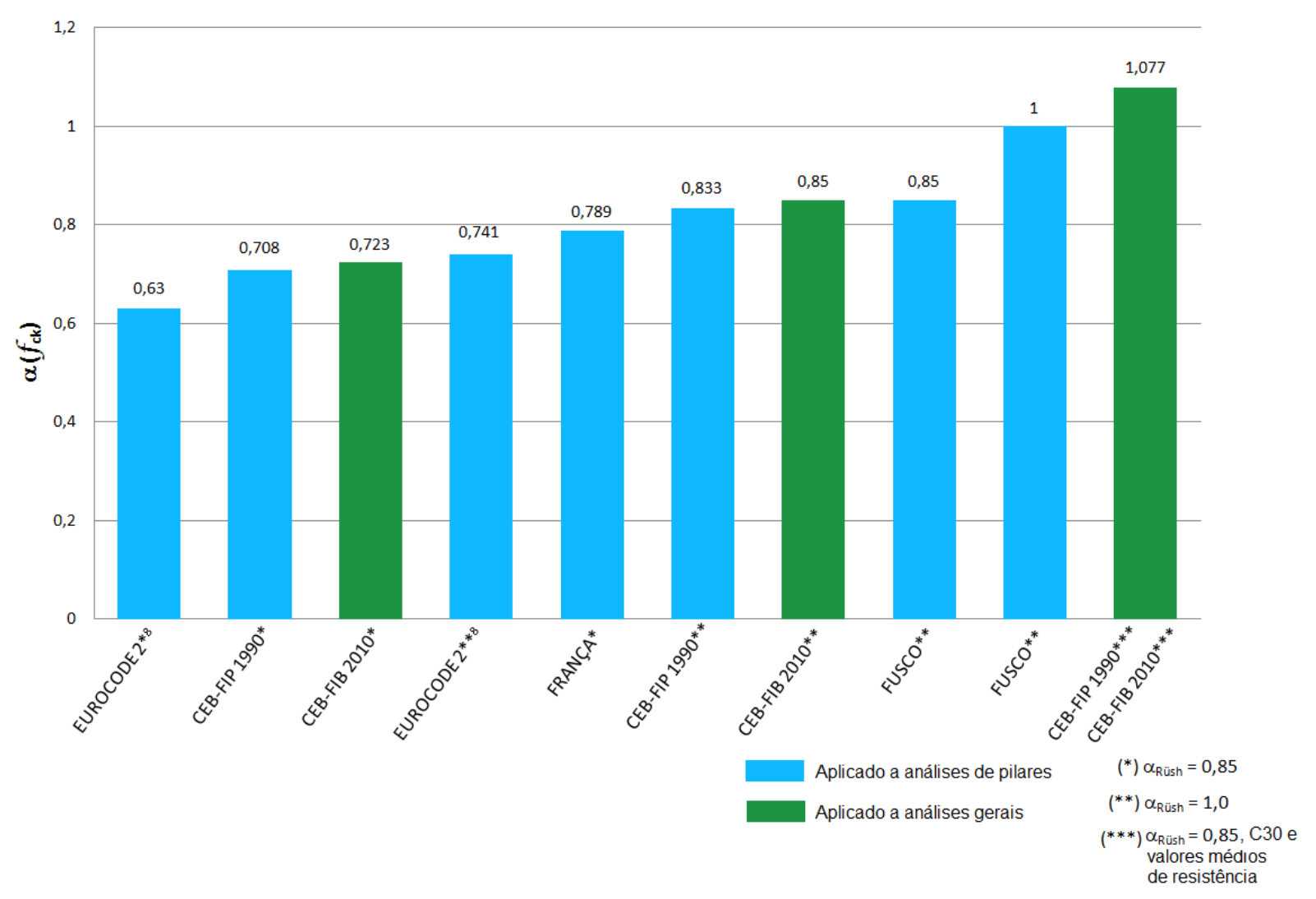

Figura 65 - Fatores para resistência característica do concreto em análises não-lineares

No caso de pilares isolados a única fonte de resistência ao esforço de colapso é a seção transversal da própria estrutura, já o caso uma contenção atirantada é mais complexo, pois envolve a resistência do paramento de concreto armado, a resistência do maciço, sua interação com o paramento e também a resistência dos tirantes, além disso, não se trata de uma barra, mas de uma parede, portanto se pode dizer que é um sistema mais robusto. Portanto julga-se que a segurança no caso do pilar possa ser maior que no caso do paramento de concreto, sobretudo quando comparado a pilares esbeltos.

Neste trabalho serão adotados dois valores para a resistência a compressão do concreto e escoamento do aço, que serão aplicados nos modelos desenvolvidos para análise de estabilidade: os valores propostos por França (R., 1991) e os valores propostos pelo CEB-FIB 2010 com parâmetros reduzidos e $\alpha_{\text {Rüsh }}=1,0$. Acredita-se que poderiam ser adotados valores maiores, porém este dois valores apresentam uma formulação consistente e no proposto por França (R., 1991) uma aplicação direta pela norma ABNT NBR6118:2007. 


\subsection{RIGIDEZ A FLEXÃO E FLEXO-COMPRESSÃO DE ELEMENTOS LINEARES DE CONCRETO ARMADO}

Como já foi abordado, seja qual for o método adotado para obtenção da rigidez do concreto armado, ele deverá obeder um determinado modelo constitutivo, promover compatibilidade com as deformoções na seção e garantir as condições de equilíbrio. Neste trabalho será adotado a utilização dos diagramas momento-normalcurvatura (M-N-1/r), como meio de obtenção da rigidez da seção transversal.

Para isso serão admitidas como válidas as seguintes hipóteses: Será considerado o elemento de barra de Bernouilli-Euler, em que as seções planas permanecem planas após a deformação, a rotação da seção transversal devido a esforços transversais (distorção) é nula; as deformações das barras de aço são as mesmas para o concreto do seu entorno, desde que este não se encontre tracionado, em que neste caso considera-se fissurado; os carregamentos são quase-estáticos, sem alternância e portanto sem histerese; os esforços são unidirecionais, ou seja considera-se a flexão em torno de apenas um eixo.

Quanto aos modelos reológicos adotados neste trabalho, para o concreto será adotada como tensão de referência a resistência a compressão média, em dois tipos de diagramas, o parabólico-retangular e da norma ABNT NBR6118:2007 e o de Grasser do código modelo CEB-FIB 2010 e para o aço será adotada como tensão de referência a resistência caracteristica ao escoamento, por não se dispor de dados sobre a resistência média e considerar-se que a variabilidade seja pequena, ou seja o valor do desvio padrão seja pequeno em relação ao tensão de escoamento média, o diagrama elastoplástico perfeito juntamente ao concreto com o diagrama parabólico-retangular e o diagrama elastoplástico com endurecimento juntamente ao concreto com o diagrama de Grasser. Quanto a adoção de uma resistência para o concreto em análises em que considera-se a não lineriadade geométrica para pilares, por meio dos diagramas M-N-1/r, Fusco (1981, p. 351) e Oliveira e Ricardo França (2000) comentam que a utilização da tensão do diagama tensão-deformação parabólico-retangular com a tensão máxima de compressão em $0,85 \cdot f_{c d}$ leva a uma deformabilidade exagerada para a estrutura.

Em Oliveira e Ricardo França (2000) é apresentado um gráfico que ilustra o efeito da variação do diagrama $\mathrm{M}-\mathrm{N}-1 / \mathrm{r}$ considerando a variação da resistência do concreto: 


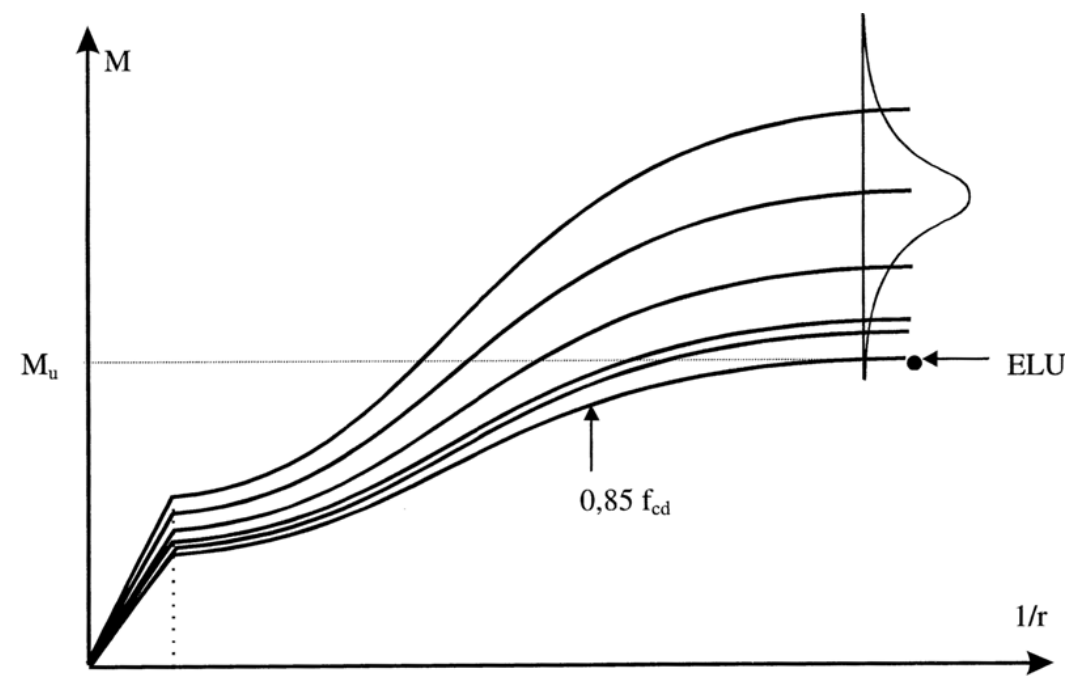

Figura 66 - Variabilidade do diagrama M-N-1/r em relação à resistência do concreto (OLIVEIRA e FRANÇA, R., 2000)

O diagrama $\mathrm{M}-\mathrm{N}-1 / \mathrm{r}$ completo, considerando-se todas as fases por que passa a seção de concreto armado ao sofrer a flexão, é apresentado abaixo:

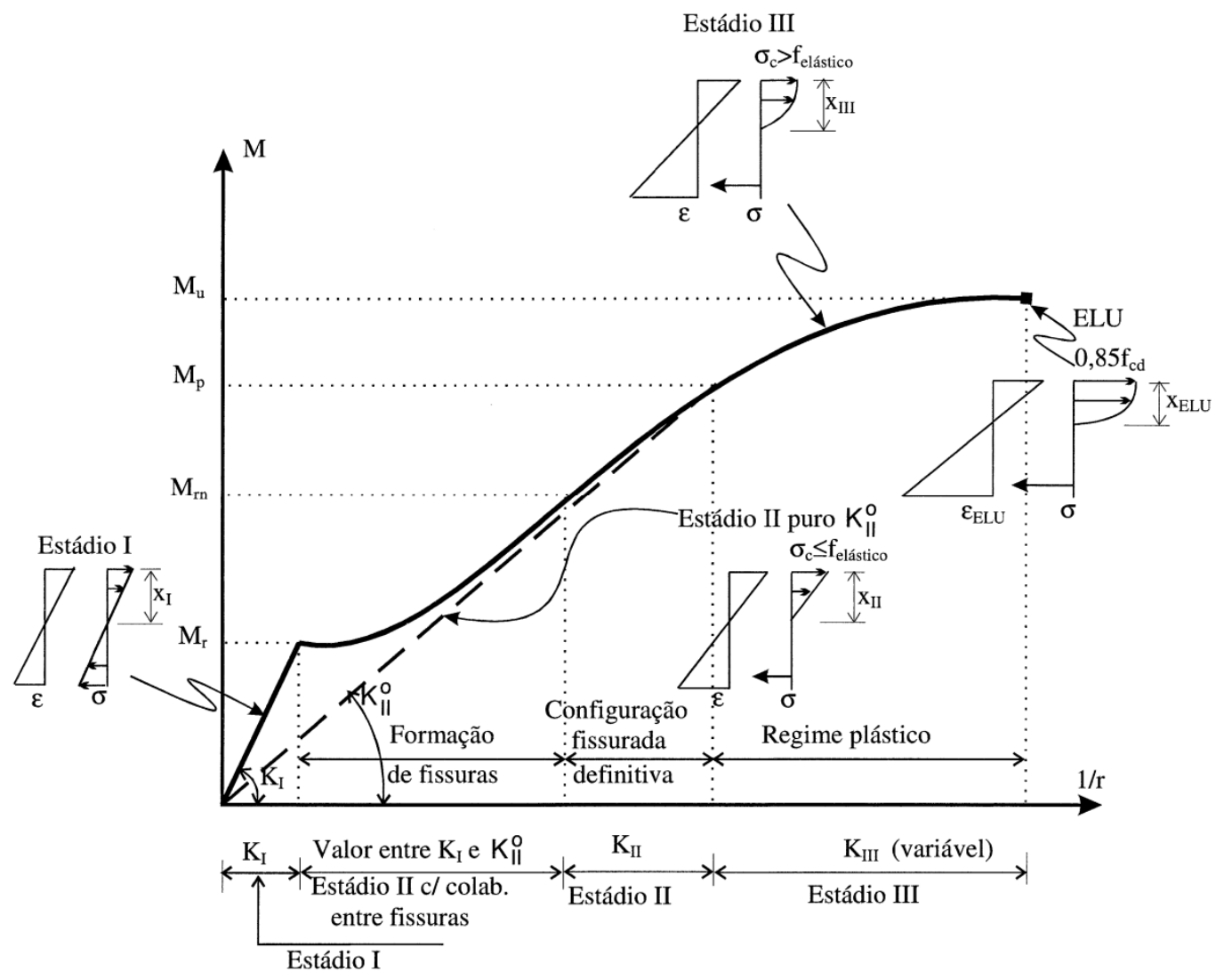

Figura 67 - Variação da rigidez da seção de concreto (OLIVEIRA e FRANÇA, R., 2000) 
O diagrama acima mostra que a rigidez da seção, antes da fissuração do concreto, é linear e que com o aumento do momento fletor aparece um ponto de quebra ${ }^{10}$, no diagrama que representa o início da fissuração, nota-se que não há um patamar horizontal após a fissuração, isto que significa que, considerando a curvatura média, há uma contribuição do concreto tracionado entre fissuras e na região tracionada acima da fissura, como exemplo de abordagem para esta situação cita-se a mecânica da fratura que utiliza os conceitos de energia:

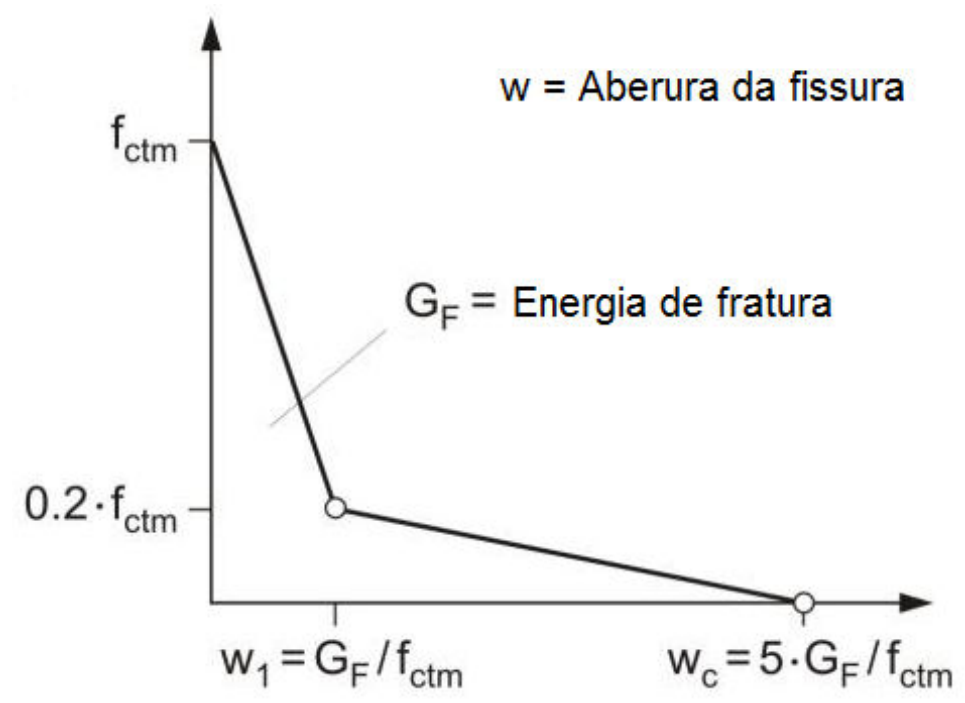

Figura 68 - Relação tensão-abertura de fissura (CEB-FIB 2010)

Continuando-se a aumentar o momento fletor chega-se a seção completamente fissurada e o digrama passa a tangenciar a reta tracejada que representa o estádio II puro, por fim chega-se ao estádio III, com ponto final no ELU.

Para usar do diagrama não-linear em qualquer análise numérica é necessário aplicar-se um método iterativo de forma que a rigidez possa ser atualizada a cada incremento de solicitação

No código modelo CEB-FIP 1990 é apresentado um método para obtenção do diagrama $\mathrm{M}-\mathrm{N}-1 / \mathrm{r}$ em que são considerados todos os estádios e a rigidez média, a figura 69 representa o diagrama:

${ }^{10}$ A quebra em um ponto do diagrama indica que a função que o representa é contínua, mas não diferenciável neste ponto. 


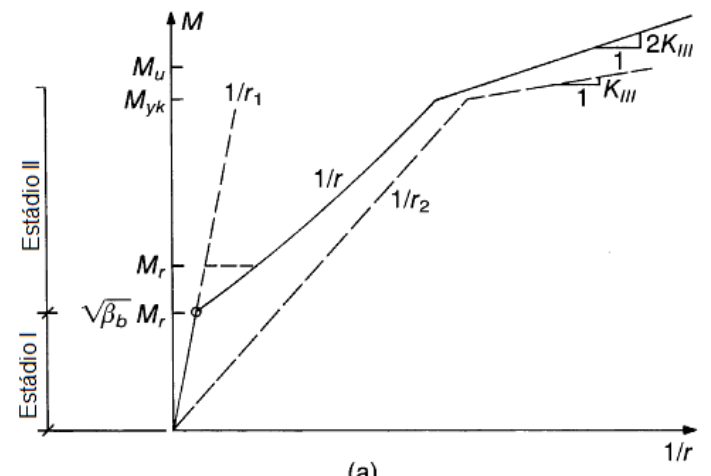

(a)

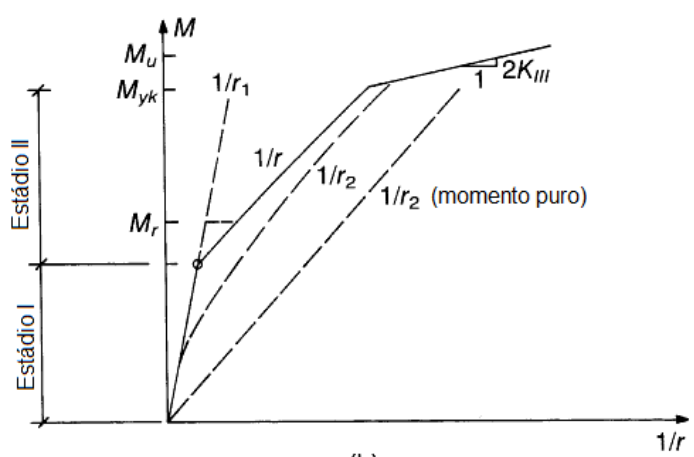

(b)

Figura 69 - Diagramas M-N-1/r - (a) Flexão simples; (b) Flexo-compressão (CEB-FIP 1990)

A dificuldade de construir o diagrama para flexo-compressão, como mostrado na figura 69(b) é estabelecer o ponto em que se inicia a fissura, e divide o digrama entre o estádio I e o estádio II, pois diferentemente da flexão simples, em que este ponto fica determinado pelo momento de fissuração reduzido, $\left(\sqrt{ } \beta_{b}\right) M_{r}$, na flexo-compressão, de acordo com o CEB-FIP 1990, não é possível obtê-lo por uma regra simples, neste caso indica-se que para aplicações práticas podem-se obter os valores para as curvaturas $1 / r_{1}$ e $1 / r_{2}$ no CEB Bulletin 158 (Manual sobre fissuras e deformações).

Outra forma de se obter o diagrama $\mathrm{M}-\mathrm{N}-1 / \mathrm{r}$ é desprezar completamente $\mathrm{o}$ concreto tracionado, considerado o concreto fissurado, deixando a cargo da armadura toda a resistência a tração, neste caso a maior diferença na rigidez seria para esforços que geram tensões de tração menores que a resistência a tração do concreto (estádio I), portanto poderia ser usado para situações em que uma deformabilidade maior leve a configurações que sejam a favor da segurança.

Uma forma mais simples de se utilizar o digrama $M-N-1 / r$ é fazer a linearização do diagrama por meio da rigidez secante, como proposto por Ricardo França (R., 1991) e adotado pela ABNT NBR6118:2007, para o cálculo do efeito de $2^{\circ}$ ordem em pilares. Sem que se esteja cometendo exagero, pode-se adotar a rigidez secante para o caso de dimensionamento ou verificação em que, assim como no caso anterior, a consideração de uma rigidez menor do que a real leva a estrutura a uma deformabilidade maior e que isto signifique situações que fiquem a favor da segurança. A figura 70 ilustra o método: 


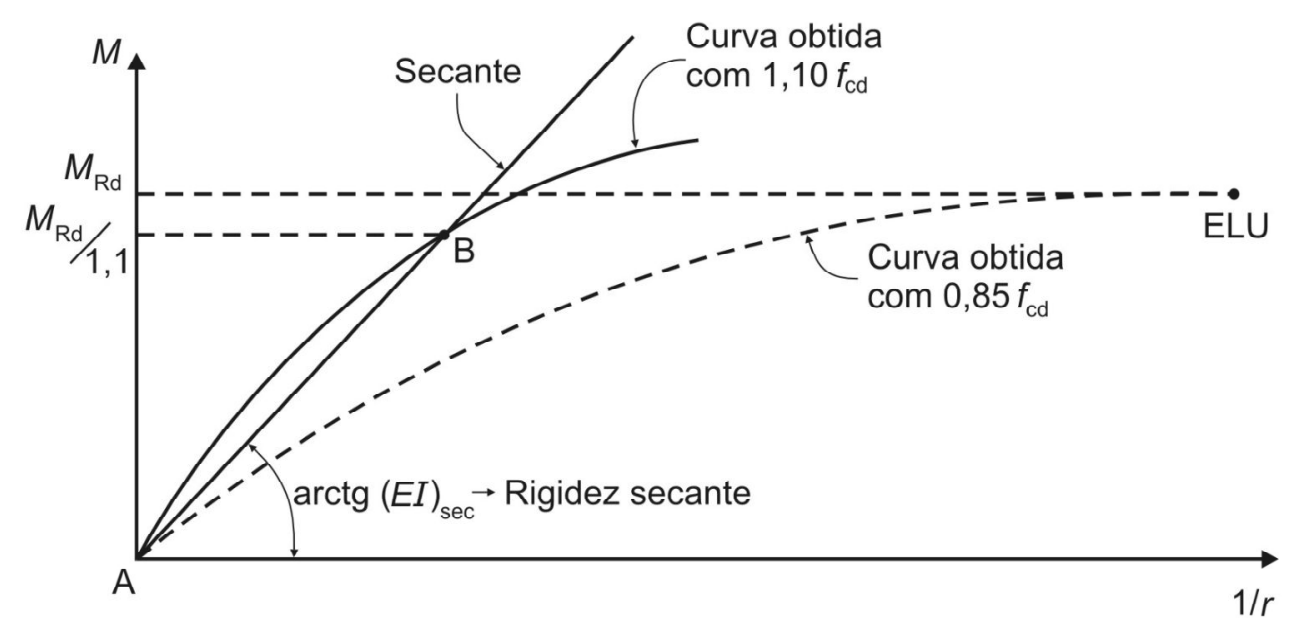

Figura 70 - Diagrama M-N-1/r com a rigidez secante (ABNT NBR6118:2007)

No diagrama acima a adoção da resistência a compressão de $1,1 \cdot f_{c d}$ considera que nem todas as seções do pilar estão em ELU, portanto o pilar tem uma rigidez maior e apresenta uma deformabilidade menor, o divisor 1,1 do momento $M_{R d}$ é o $\gamma_{f 3}$. Uma vantagem do diagrama linearizado é que para uma determinada força normal, obtêm-se uma rigidez constante, que independe do momento fletor atuante, o que facilita sua aplicação.

Neste trabalho o diagrama $\mathrm{M}-\mathrm{N}-1 / \mathrm{r}$ será aplicado de quatro formas diferentes, em duas será utilizado o diagrama em que se despreza o concreto tracionado e outras duas será utilizado o diagrama linearizado. Para cada diagrama serão adotados dois diagramas tensão-deformação conforme comentado anteriormente.

Para obtenção da rigidez será adotado a equação da curvatura aproximada. Abaixo é apresentada a diferença entre a curvatura aproximada e a exata:

A curvatura exata tem a seguinte relação:

$$
\frac{1}{r}=\frac{\frac{d^{2} y}{d x^{2}}}{\left[1+\left(\frac{d y}{d x}\right)^{2}\right]^{\frac{3}{2}}}
$$

No entanto pode-se adotar a curvatura aproximada, pois derivada da linha elástica elevada ao quadrado tem um efeito desprezível sobre ela.

A curvatura aproximada tem a seguinte relação: 


$$
\frac{1}{r} \cong \frac{d^{2} y}{d x^{2}}
$$

Para demonstrar, se considerarmos uma barra com uma linha elástica senoidal, como apresentada por Fusco (1981, p. 158):

$$
y=a \operatorname{sen} \frac{\pi}{\ell} x
$$

Em que $y$ é o deslocamento ao longo da barra, $x$ a posição ao longo da barra e $a$ o deslocamento máximo, no meio da barra.

Por meio (5.84), (5.85) e (5.86) obtêm-se:

Curvatura exata:

$$
\frac{1}{r}=\frac{-\left(\frac{\pi}{\ell}\right)^{2} y}{\left[1+\left(\frac{\pi}{\ell}\right)^{2}\left(a^{2}-y^{2}\right)\right]^{\frac{3}{2}}}
$$

Curvatura aproximada:

$$
\frac{1}{r}=-\left(\frac{\pi}{\ell}\right)^{2} y
$$

Considerando uma barra de $5 \mathrm{~m}$ e que deslocamento no meio dela seja 10 $\mathrm{cm}$, obteremos os seguintes valores: 
Tabela 9 - Comparação das curvaturas exata e aproximada

\begin{tabular}{|c|c|c|c|c|}
\hline \multirow{2}{*}{$\mathrm{x}(\mathrm{m})$} & \multirow{2}{*}{$\mathrm{y}(\mathrm{m})$} & \multicolumn{2}{|c|}{ Curvatura } & \multirow{2}{*}{ Diferença } \\
\cline { 3 - 4 } & & Exata & Aproximada & \\
\hline 0,00 & 0,00 & 0 & 0 & $0,00 \%$ \\
\hline 0,25 & 0,01 & 0,003925 & 0,003948 & $0,58 \%$ \\
\hline 0,50 & 0,02 & 0,007851 & 0,007896 & $0,57 \%$ \\
\hline 0,75 & 0,03 & 0,011780 & 0,011844 & $0,54 \%$ \\
\hline 1,00 & 0,04 & 0,015713 & 0,015791 & $0,50 \%$ \\
\hline 1,25 & 0,05 & 0,019652 & 0,019739 & $0,44 \%$ \\
\hline 1,50 & 0,06 & 0,023598 & 0,023687 & $0,38 \%$ \\
\hline 1,75 & 0,07 & 0,027552 & 0,027635 & $0,30 \%$ \\
\hline 2,00 & 0,08 & 0,031516 & 0,031583 & $0,21 \%$ \\
\hline 2,25 & 0,09 & 0,035491 & 0,035531 & $0,11 \%$ \\
\hline 2,50 & 0,10 & 0,039478 & 0,039478 & $0,00 \%$ \\
\hline 2,75 & 0,09 & 0,035491 & 0,035531 & $0,11 \%$ \\
\hline 3,00 & 0,08 & 0,031516 & 0,031583 & $0,21 \%$ \\
\hline 3,25 & 0,07 & 0,027552 & 0,027635 & $0,30 \%$ \\
\hline 3,50 & 0,06 & 0,023598 & 0,023687 & $0,38 \%$ \\
\hline 3,75 & 0,05 & 0,019652 & 0,019739 & $0,44 \%$ \\
\hline 4,00 & 0,04 & 0,015713 & 0,015791 & $0,50 \%$ \\
\hline 4,25 & 0,03 & 0,011780 & 0,011844 & $0,54 \%$ \\
\hline 4,50 & 0,02 & 0,007851 & 0,007896 & $0,57 \%$ \\
\hline 4,75 & 0,01 & 0,003925 & 0,003948 & $0,58 \%$ \\
\hline 5,00 & 0,00 & 0 & 0 & $0,00 \%$ \\
\hline
\end{tabular}

Fonte: Elaborado pelo autor

Pela tabela acima se observa que a diferença entre as relações de curvatura foi muito pequena, $<1 \%$, e isso com um valor exagerado para o deslocamento no meio da barra, quando comparado aos valores admitidos para as estruturas em geral.

O diagrama M-N-1/r pode ser obtido por diversas metodologias, a utilizada neste trabalho é esquematizada abaixo: 


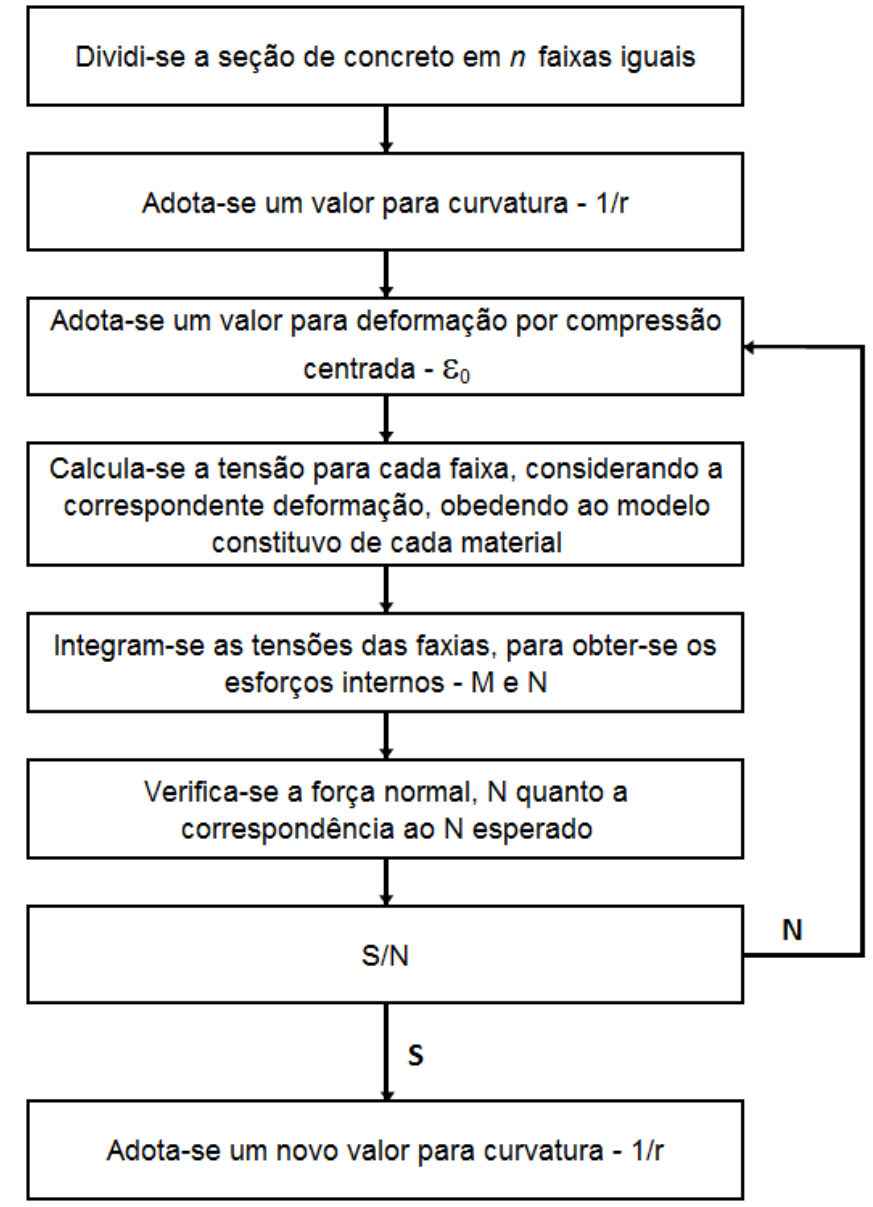

Figura 71 - Processo de obtenção do diagrama M-N-1/r (Adaptado de FRANÇA, R., 2009)

Por meio de uma planilha eletrônica pode-se programar o processo acima.

Esquematicamente, o cálculo dos esforços internos a partir da curvatura e da deformação centrada:

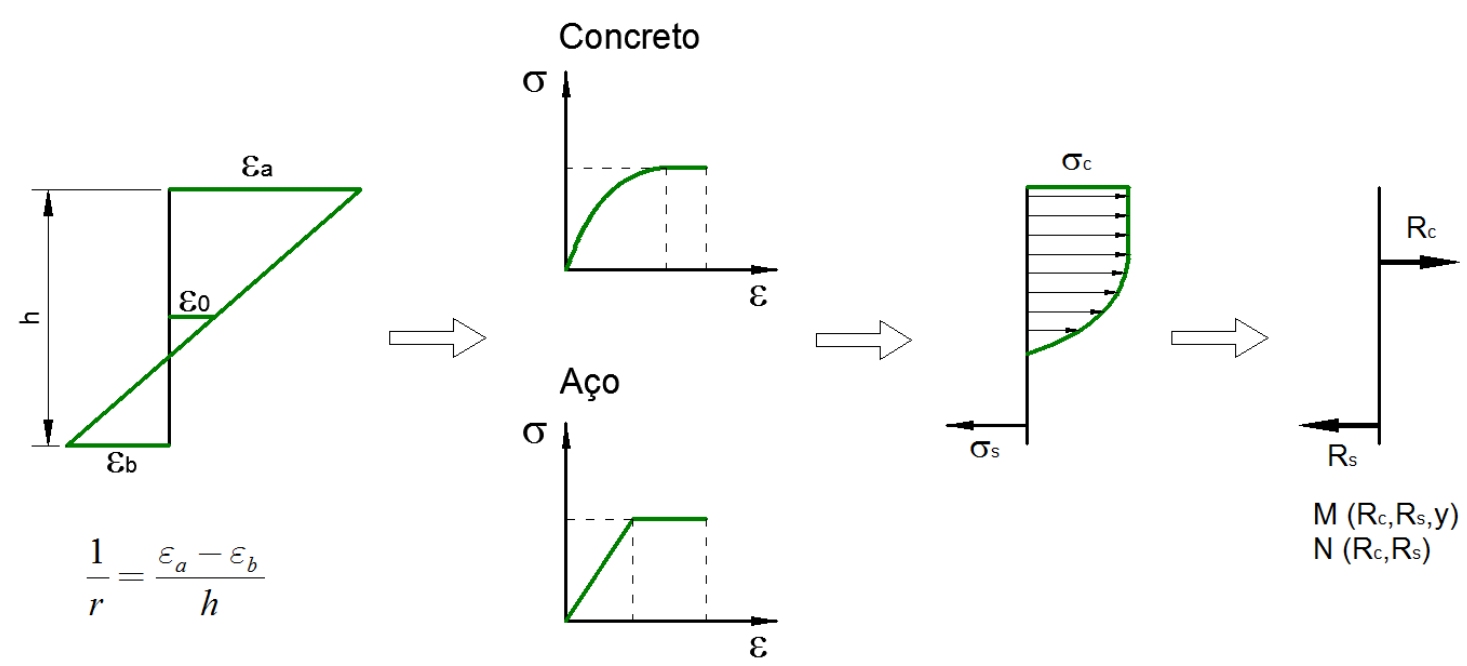

Figura 72 - Obtenção dos esforços por meio das relações de curvatura 
Para ilustrar o método foram elaborados três diagramas $M-N / 1 / r$, sendo que cada um dos três foi adotada um diagrama tensão deformação diferente.

Os dados são:

- Concreto C30 e aço CA-50;

- Tensão de compressão média para o concreto $f_{c m}=38 \mathrm{MPa}$;

- Tensão de escoamento média para o aço $f_{v m}=550 \mathrm{MPa}$;

- Seção retangular $100 \times 50 \mathrm{~cm}$, com As de $32,7 \mathrm{~cm}^{2}$ (Ø25 c/ 15) em cada face, $d^{\prime}=5 \mathrm{~cm}$;

- Força normal $\mathrm{N}_{\mathrm{d}}=1400 \mathrm{kN}$;

- Diagrama tensão-deformação bilinear conforme equação (5.38);

- Diagrama tensão-deformação parabólico-retangular conforme equação (5.1);

- Diagrama tensão-deformação de Grasser conforme equações (5.26) e (5.32) a (5.34).

Resultado:

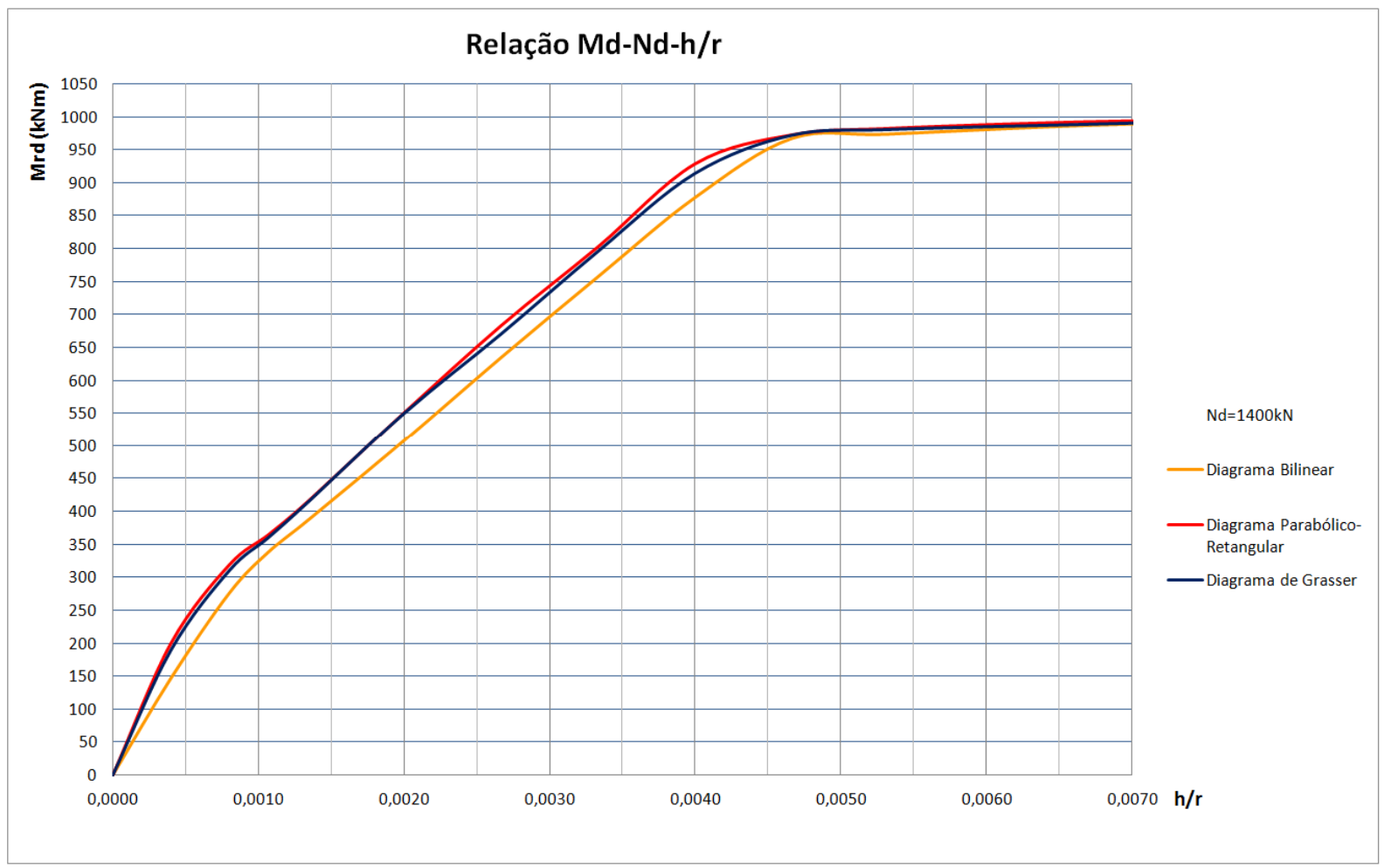

Figura 73 - Diagrama M-N-h/r considerando três diagramas tensão-deformação 
Observa-se pela figura 73 , que os diagramas $M-N-1 / r$ em que foram adotados os diagramas tensão-deformação parabólico-retangular e de Grasser não apresentaram diferença significativa entre si e o diagrama em que foi adotado o diagrama tensão-deformação bilinear mostrou-se mais abatido em relação aos demais, o que indica que a rigidez obtida por meio deste diagrama é menor que a obtida com os demais.

Considerando, por exemplo, o momento fletor de $550 \mathrm{kNm}$, obtêm-se, pelos diagramas parabólico-retangular e de Grasser:

$$
\begin{aligned}
& \frac{1}{r}=\frac{0,002}{h}=0,002 \\
& \frac{1}{r}=\frac{M}{E I} \rightarrow E I=\frac{M}{\frac{1}{r}}=\frac{550}{0,002}=275000,0 \mathrm{kNm}^{2}
\end{aligned}
$$

Pelo diagrama bilinear:

$$
\begin{aligned}
& \frac{1}{r}=\frac{0,00225}{h}=0,00225 \\
& \frac{1}{r}=\frac{M}{E I} \rightarrow E I=\frac{M}{\frac{1}{r}}=\frac{550}{0,00225}=244444,4 \mathrm{kNm}^{2}
\end{aligned}
$$

A diferença entre (5.96) e (5.98) é de $11,1 \%$ a menos em relação ao primeiro. 


\section{ANÁLISE DE ESTABILIDADE VIA MÉTODO DOS ELEMENTOS FINITOS}

\subsection{MODOS DE COLAPSO}

Em engenharia o equilíbrio é requisito básico de existência para qualquer tipo obra, e no caso de contenções a estabilidade (equilíbrio estático) não é diferente. Em uma contenção atirantada a estabilidade é dependente basicamente das três partes que a compõe: o solo, os tirantes e o paramento de concreto, portanto estas três partes devem ser analisadas quanto à estabilidade e capacidade resistente. A figura 74 resume os modos de falha de uma contenção atirantada:
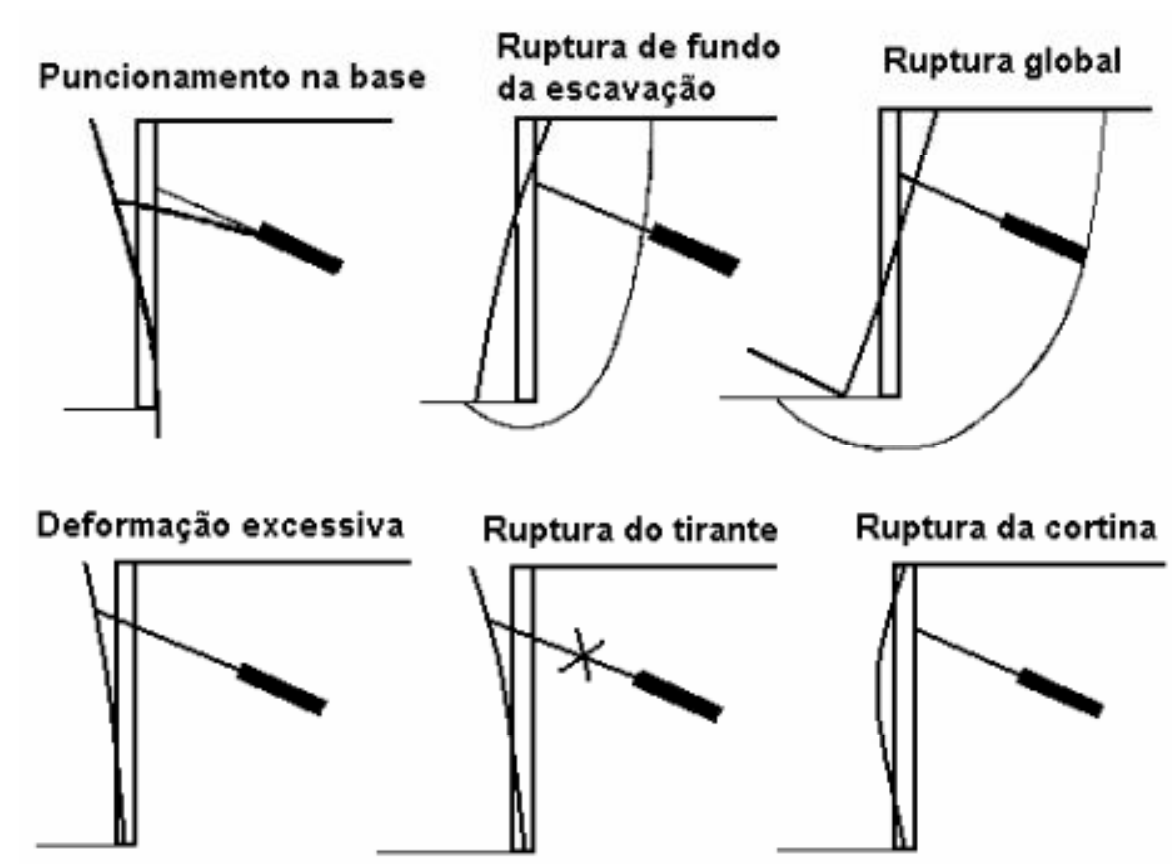

Figura 74 - Modos de colapso para contenções atirantadas (More, 2003 apud GeoRio, 2000)

Pelos métodos tradicionais de dimensionamento e verificação da estabilidade, cada modo de falha é verificado separadamente. As contenções por cortinas de concreto, paredes diafragmas, estacas justapostas, estacões com concreto projetado, perfil pranchado, entre outras, para o dimensionamento e verificação da estabilidade podem ser divididas em três tipos básicos: paredes em balanço, paredes com um nível de tirante e paredes multiatirantadas.

O quadro abaixo faz um resumo dos itens que devem ser verificados e dos métodos tradicionalmente adotados: 
Tabela 10 - Resumo de itens a serem verificados

\begin{tabular}{|c|c|c|c|c|c|c|}
\hline 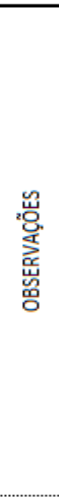 & 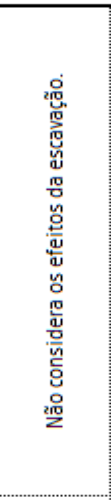 & 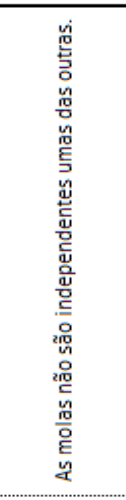 & 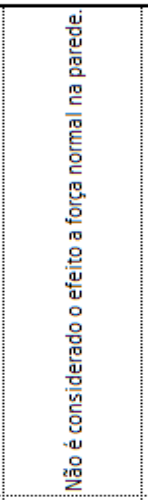 & 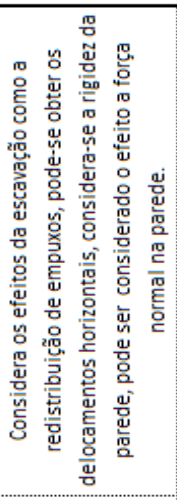 & 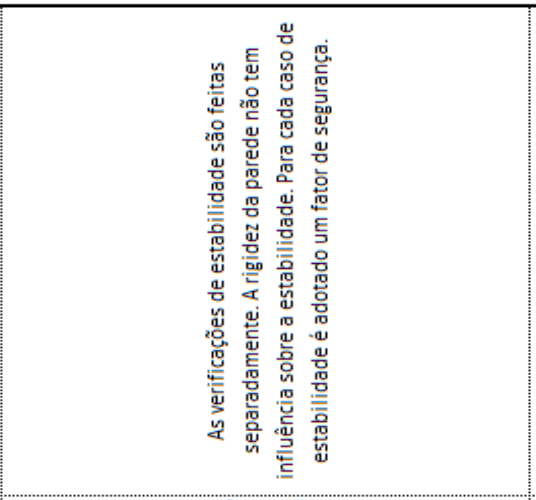 & 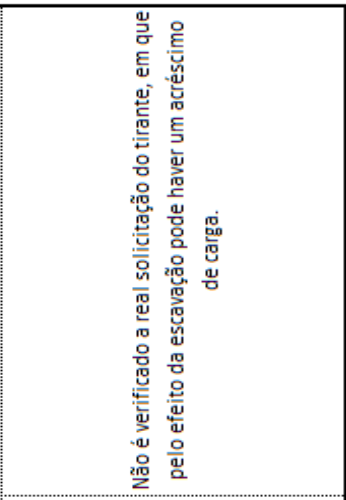 \\
\hline 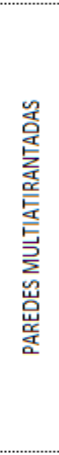 & 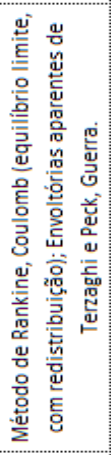 & 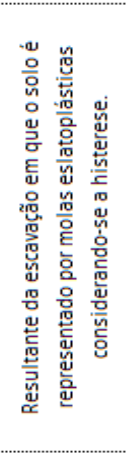 & 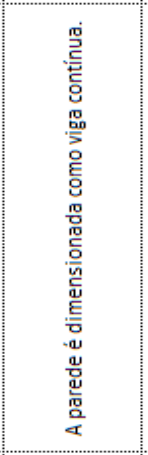 & 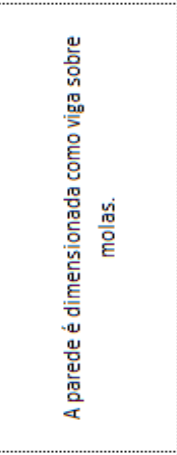 & 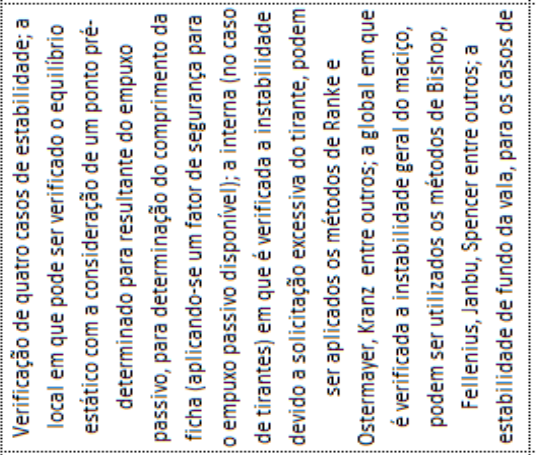 & 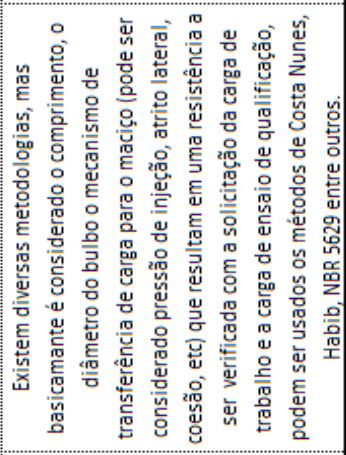 \\
\hline 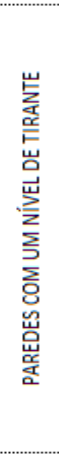 & 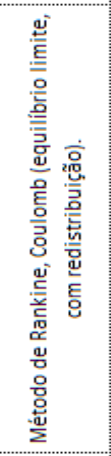 & 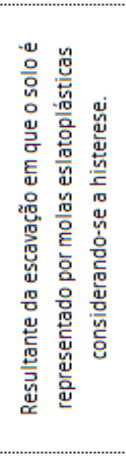 & 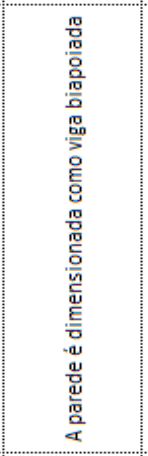 & 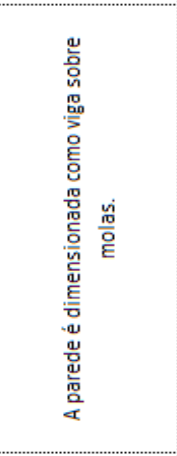 & 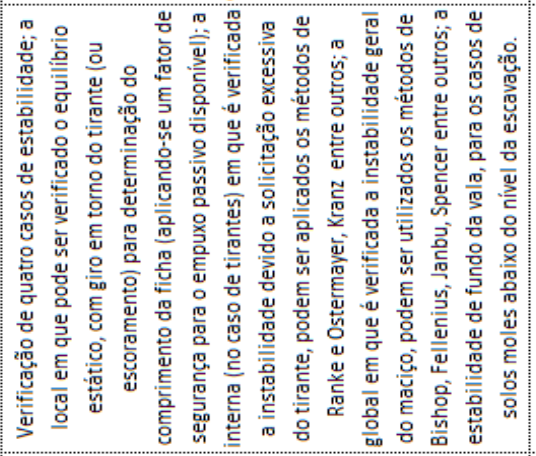 & 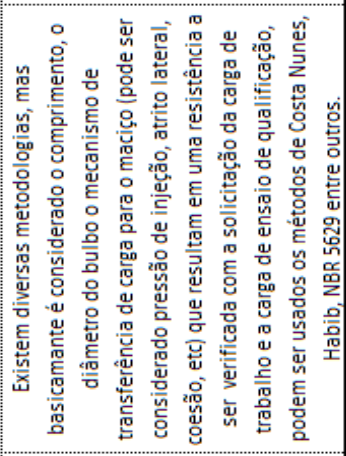 \\
\hline 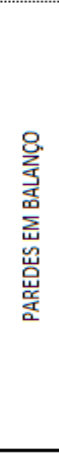 & 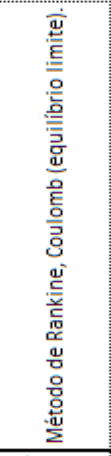 & 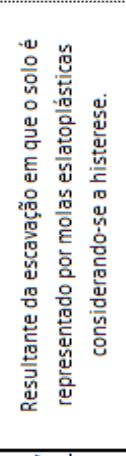 & 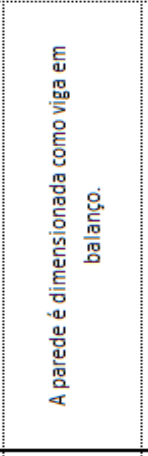 & 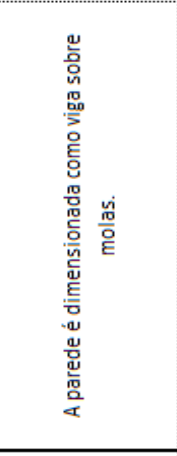 & 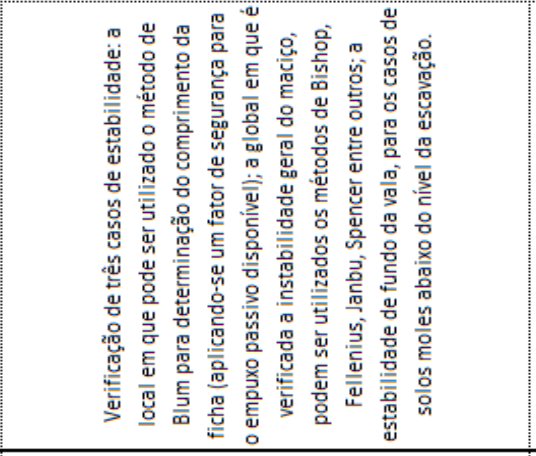 & \\
\hline & 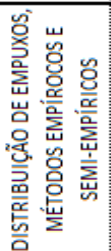 & 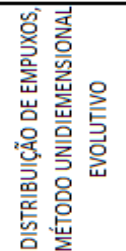 & 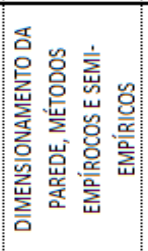 & 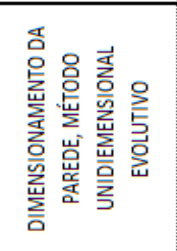 & 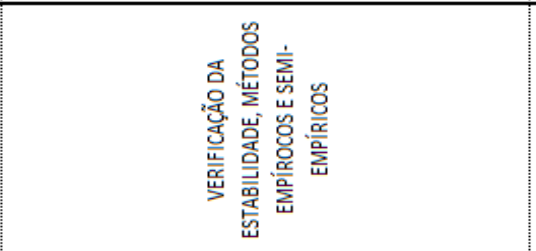 & 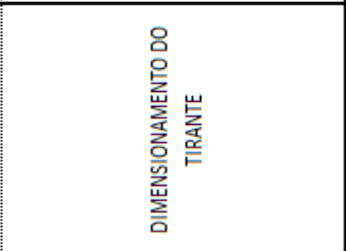 \\
\hline
\end{tabular}

Fonte: Elaborado pelo autor 
Por meio do MEF, dependendo da implementação, a verificações de estabilidade e dimensionamentos, relatados acima, podem ser feitos em um único modelo com a vantagem de se obter os campos de tensões e deslocamentos do maciço.

No caso da análise de estabilidade, como resultado da análise, via MEF, é obtido um fator de segurança global que está ligado ao mecanismo de ruptura em que este fator é menor. Desta forma, como vantagem do método, não é necessário impor uma superfície de deslizamento, pois a medida que ocorre a plastificação aparece naturalmente uma região plastificada cujo plano médio é a superfície de plastificação. Isto se torna interessante em casos complexos de contenções, barragens e taludamentos em que seria necessário fazer um grande número de análises e ainda assim sem a garantia, que de acordo com o método adotado, da obtenção do menor fator de segurança.

Uma desvantagem do método é a necessidade de parâmetros para os modelos, que nem sempre são possíveis de se obter nas obras correntes, como o módulo de deformabilidade e o coeficiente de poisson, e para utilizar o método, recorre-se a correlações com os resultados das investigações disponíveis, normalmente o SPT.

\subsection{SENSIBILIDADE DE PARÂMETROS}

Em Hammah et al. (2005) foram feitos teste de sensibilidade para o módulo de deformabilidade, o coeficiente de poisson e a dilatância, na análise de estabilidade via MEF. Foram feitos dois modelos de taudes com $24 \mathrm{~m}$ de altura e $39^{\circ}$ de inclinação, um dele foi cosiderado o maciço homogêneo e no outro três tipos de materiais em camadas horizontais, sendo que duas estão no talude. $O$ ângulo de atrito foi $35^{\circ}$ e a coesão $10,5 \mathrm{kPa}$.

Os resultados são apresentados nas tabela abaixo: 
Tabela 11 - Resultados do teste de sensibilidade de parâmetros para taludes homogêneos em análise de estabilidade via MEF

\begin{tabular}{|l|l|l|l|l|}
\hline \multirow{2}{*}{ No. } & \multicolumn{5}{|c|}{ Talude Homogêneo } \\
\cline { 2 - 5 } & $\mathbf{E ~ ( k P a )}$ & $\mu$ & $\psi^{\circ}$ & Fator de segurança \\
\hline 1 & 2,000 & 0.2 & 0 & 1.21 \\
\hline 2 & 2,000 & 0.48 & 0 & 1.18 \\
\hline 3 & 20,000 & 0.2 & 0 & 1.21 \\
\hline 4 & 20,000 & 0.48 & 0 & 1.18 \\
\hline 5 & 200,000 & 0.2 & 0 & 1.21 \\
\hline 6 & 200,000 & 0.48 & 0 & 1.18 \\
\hline 7 & 20,000 & 0.2 & 17.5 & 1.26 \\
\hline 8 & 20,000 & 0.2 & 35 & 1.25 \\
\hline 9 & 20,000 & 0.48 & 17.5 & 1.22 \\
\hline 10 & 20,000 & 0.48 & 35 & 1.27 \\
\hline
\end{tabular}

Fonte: Hammah, et al. 2005.

Tabela 12 - Resultados do teste de sensibilidade de parâmetros para taludes heterogêneos em análise de estabilidade via MEF

\begin{tabular}{|l|l|l|l|l|l|l|l|}
\hline \multirow{2}{*}{ No. } & \multicolumn{7}{|c|}{ Talude Composto por 3 Materiais } \\
\cline { 2 - 8 } & Material 1 & Material 2 & \multicolumn{2}{l|}{ Material 3 } & Fator de segurança \\
\hline & $\mathrm{E}(\mathrm{kPa})$ & $\mu$ & $\mathrm{E}(\mathrm{kPa})$ & $\mu$ & $\mathrm{E}(\mathrm{kPa})$ & $\mu$ & \\
\hline 1 & 20,000 & 0.2 & 20,000 & 0.2 & 20,000 & 0.2 & $1.19^{*}$ \\
\hline 2 & 2,000 & 0.2 & 20,000 & 0.2 & 200,000 & 0.2 & 1.15 \\
\hline 3 & 200,000 & 0.2 & 20,000 & 0.2 & 2,000 & 0.2 & 1.34 \\
\hline 4 & 20,000 & 0.2 & 2,000 & 0.2 & 200,000 & 0.2 & 1.16 \\
\hline 5 & 200,000 & 0.2 & 2,000 & 0.2 & 20,000 & 0.2 & 1.23 \\
\hline 6 & 200,000 & 0.2 & 2,000 & 0.2 & $2,000,000$ & 0.2 & 1.23 \\
\hline 7 & $2,000,000$ & 0.2 & 2,000 & 0.2 & 200,000 & 0.2 & 1.29 \\
\hline 8 & 20,000 & 0.48 & 20,000 & 0.3 & 20,000 & 0.2 & 1.19 \\
\hline 9 & 20,000 & 0.2 & 20,000 & 0.48 & 20,000 & 0.3 & 1.16 \\
\hline 10 & 20,000 & 0.2 & 2,000 & 0.3 & 200,000 & 0.48 & 1.17 \\
\hline
\end{tabular}

*A diferença de valor para o fator da tabela anterior á causada por diferença nas malhas adotadas

Fonte: Hammah, et al. 2005.

Pelas tabelas acima se observa que mesmo para grandes variações do módulo do deformabilidade, da ordem de $10^{3}$, as diferenças foram pequenas, o mesmo se observa para as outras varáveis. Quanto à dilatância se observa que há tendência de aumento no fator de segurança com a sua consideração. Ressalta-se que os resultados acima são válidos para modelos mais simples e que não foi considerado nenhum tipo de intervenção no maciço, como escavação ou introdução de reforços. Em Hammah et al. (2005) também foram comparados os resultados da análise de estabilidade, via equilíbrio limite, de 33 exemplos disponíveis na literatura e com a análise de estabilidade via MEF e obtiveram diferenças de resultado da ordem de $10 \%$. 


\subsection{DEFINIÇÃO DE FATORES DE SEGURANÇA PARA ANÁLISE DE ESTABILIDADE}

Os fatores de segurança, conforme citado por Brinkgreve e Bakker (1991), são definidos usualmente como o fator resultante da relação entre a carga de colapso e a carga de trabalho. No caso contenções de maciços de solo o carregamento principal é o peso próprio do solo desconfinado e o contraponto ao colapso é resistência dos materiais utilizados na contenção e no caso específico do maciço de solo a resistência é representada por suas propriedades, que por meio do critério de Mohr-Coulomb são traduzidas em coesão, $c$, e ângulo de atrito interno, $\phi$, assim o fator de segurança fica definido por:

$$
F S=\frac{\tau}{\tau_{c}}=\frac{c+\sigma^{\prime} \tan \phi}{c_{c}+\sigma^{\prime} \tan \phi_{c}}
$$

Em que $F S$ é fator de segurança, $\tau$ é resistência ao cisalhamento e o índice $c$ indica parâmetros críticos de resistência. Outra forma de se obter o fator de segurança é:

$$
\tau_{c}=\frac{\tau}{F S}=\frac{c}{F S}+\sigma^{\prime} \frac{\tan \phi}{F S}
$$

Em Ferreira e Farfán (2006) e Nian (et al. 2011) o fator de segurança é apresentado separadamente para $c$ e $\phi$ e é chamado de strength reduction ou shear strength reduction (SSR) (redução da resistência ao cisalhamento).

$$
\begin{aligned}
& c_{c}=\frac{c}{F S} \\
& \tan \phi_{c}=\frac{\tan \phi}{F S}
\end{aligned}
$$

O método utilizado na análise de estabilidade via MEF é o SSR.

Em Ou (2006, p. 126), é apresentado outro fator de segurança, o load factor method (método do fator de carga):

$$
F S=\frac{R}{D}
$$


Em que $R$ representa a força resistente e $D$ a força mobilizante. Este método é utilizado na maior parte das análises de estabilidade via equilíbrio limite (MEL), como por exemplo, o método de Bishop em que por meio de uma superfície de deslizamento circular é calculado o fator de segurança como o momento gerado pelas forças acima da superfície de deslizamento e o momento gerado pela resistência (cisalhamento) ao longo da superfície de deslizamento.

O SSR é similar a aplicação de fator de segurança para materiais como aço e concreto, pois ele é aplicado diretamente sobre a os agentes que geram incerteza na resistência enquanto o método do fator de carga é uma medida indireta da segurança.

A aplicação do SSR no MEF é feita de forma iterativa. Na primeira iteração são obtidos os campos de tensões e deformações naturais, devido ao peso próprio dos materiais, neste caso pode-se zerar as deformações; na próxima iteração é aplicado o fator de segurança maior que um por meio das equações (6.3) e (6.4), procede-se o cálculo e verifica-se se há convergência e os deslocamentos, obedecendo a um critério de parada; repete-se o procedimento partindo da solução anterior até que não haja convergência ou os deslocamentos sejam maiores que os estabelecidos pelo critério de parada.

Existem algumas publicações com recomendações para a adoção de valores para o fator de segurança aplicado como em (6.3) e (6.4) para diversos fins. Na publicação EM 1110-2-2504 (1994, p. 5-5) dos US Army Corps of Engineers são apresentados os fatores mínimos requeridos para o cálculo do empuxo passivo na verificação da estabilidade local: 
Tabela 13 - FS mínimo para empuxo passivo em contenções

Minimum Safety Factors for Determining the Depth of Penetration Applied to the Passive Pressures

\begin{tabular}{lll}
\hline Loading Case & Fine-Grain Soils & Free-Draining Soils \\
\hline Floodwalls & & \\
\hline Usual & $\begin{array}{l}1.50 \mathrm{Q} \text {-Case } \\
1.10 \mathrm{~S} \text {-Case }\end{array}$ & $1.50 \mathrm{~S}$-Case \\
Unusual & $\begin{array}{l}1.25 \mathrm{Q} \text {-Case } \\
1.10 \mathrm{~S} \text {-Case }\end{array}$ & $1.25 \mathrm{~S}$-Case \\
& $\begin{array}{l}1.10 \mathrm{Q} \text {-Case } \\
\text { Extreme }\end{array}$ & $1.10 \mathrm{~S}$-Case \\
\hline Retaining Walls & & \\
\hline Usual & $2.00 \mathrm{Q}$-Case & $1.50 \mathrm{~S}$-Case \\
& $1.50 \mathrm{~S}$-Case & \\
Unusual & $1.75 \mathrm{Q}$-Case & $1.25 \mathrm{~S}$-Case \\
& $1.25 \mathrm{~S}$-Case & \\
Extreme & $\begin{array}{l}1.50 \mathrm{Q} \text {-Case } \\
1.10 \mathrm{~S} \text {-Case }\end{array}$ & $1.10 \mathrm{~S}$-Case \\
\end{tabular}

Fonte: US Army Corps of Engineers, 1994

O Eurocode 7 (2004) fornece a tabela abaixo, com valores para o fator de segurança para análises de estabilidade por MEL, aplicado conforme (6.3) e (6.4).

Tabela 14 - FS mínimo para análise de estabilidade via MEL

\begin{tabular}{|l|c|c|}
\hline Soil parameter & Symbol & Value \\
\hline Angle of shearing resistance ${ }^{\mathrm{a}}$ & $\gamma_{\varphi^{\prime}}$ & 1,25 \\
\hline Effective cohesion & $\gamma_{\mathrm{c}^{\prime}}$ & 1,25 \\
\hline Undrained shear strength & $\gamma_{\mathrm{cu}}$ & 1,4 \\
\hline Unconfined strength & $\gamma_{\mathrm{qu}}$ & 1,4 \\
\hline Weight density & $\gamma_{\gamma}$ & 1,0 \\
\hline a This factor is applied to tan $\varphi^{\prime}$ & & \\
\hline
\end{tabular}

Fonte: Eurocode 7, 2004 


\subsection{MÉTODOS ESTATÍSTICOS PARA VERIFICAÇÃO DA SEGURANÇA NA ANÁLISE DE ESTABILIDADE}

Para conhecer a segurança, por meio de um método científico, em um problema de estabilidade é necessária a compreensão e obtenção das grandezas envolvidas no fenômeno assim como a quantificação de suas incertezas. Uma abordagem para este problema é a utilização de métodos estatísticos. Desta forma pode-se obter como resultado da análise, por exemplo, a probabilidade de falha e o fator de segurança médio. Assim, para quantificar as grandezas envolvidas é necessária que se conheçam as propriedades dos materiais, por exemplo, em seus valores médios e também sua a forma de variação.

A seguir serão apresentados alguns conceitos sobre estatística, probabilidade que servirão de base para os métodos de análise futuramente adotados.

\subsubsection{INCERTEZAS EM PROBLEMAS DE ENGENHARIA}

Em Beck (2011) os tipos de incertezas em problemas de engenharia são classificados em dois grupos: incerteza intrínseca e incerteza epistêmica.

Incerteza intrínseca é a que faz parte da gênese ou da natureza do processo e, portanto não pode ser eliminada. Um exemplo deste tipo de incerteza é a incerteza física das propriedades dos materiais como massa específica, capacidade resistente. As propriedades de interesse neste trabalho: Nos solos, peso específico, coesão, ângulo de atrito interno, no concreto a resistência a compressão e no aço o escoamento, podem ser classificadas com este tipo de incerteza.

Cita-se outro exemplo de incerteza intrínseca, a incerteza de previsão, que como o próprio nome diz refere-se a possibilidade de se prever a condição futura de um processo. As propriedades de interesse neste trabalho, já citadas, também podem ser classificadas com este tipo de incerteza, pois há variação ao longo do tempo, como por exemplo, a alteração da coesão dos solos de acordo com o grau de saturação, a fluência do concreto, entre outros. Em Guidicine e Nieble (1983) há o seguinte comentário:

"O processo de alteração por intemperismo leva a um enfraquecimento gradual do meio rochoso, ou terroso, no qual ocorre, pela remoção dos elementos solúveis constituintes dos 
próprios minerais, pela dissolução dos elementos com função de cimentação em solos ou rochas sedimentares, pelo desenvolvimento de uma rede de microfraturas num meio rochoso que não as possuía." (grifo nosso).

Este tipo de incerteza é de difícil previsão em solos, pois é depende de sua pedogênese. Neste trabalho não será abordado este tipo de incerteza nas análises.

Incerteza epistêmica é que está associada ao processo de inferência, obtenção e manipulação dos dados estatísticos. Um exemplo deste tipo de incerteza é a incerteza estatística em que, por exemplo, considera-se que as variáveis obedeçam a determinadas amostras de curvas de distribuição de probabilidades. Uma forma de se diminuir este tipo de incerteza é, por exemplo, aumentar a quantidade de amostras de um determinado evento. Outro exemplo deste tipo de incerteza é a incerteza de modelo que ocorre quando representamos fenômenos físicos por meio de modelos matemáticos. Este tipo de incerteza pode ser diminuída com a calibração dos modelos pelos ensaios experimentais. No caso de contenções há uma dificuldade de se reproduzir em um ensaio as condições reais que aparecem em campo e neste caso a instrumentação das obras in situ seria mais proveitosa.

\subsubsection{PROBABILIDADES}

Para a entendimento de probabilidades é necessário que antes sejam definidos fenômeno aleatório e espaço amostral. Em Magalhães e Lima (2002) fenômeno aleatório é definido como acontecimento em que os resultados não podem ser previstos com exatidão e espaço amostral como o conjunto de todos os resultados possíveis de um determinado fenômeno aleatório.

Existem diversas definições para probabilidade. Em Magalhães e Lima (2002) e Silva (2003) é apresentada a definição axiomática:

Seja o evento $A$, pertencente a um espaço amostral $\Omega$ e uma função $P(\cdot)$ que satisfaça as condições: 


$$
\left\{\begin{array}{l}
0 \leq P(A) \leq 1, \forall A \subset \Omega \\
P(\Omega)=1 \\
P\left(\bigcup_{i=1}^{n} A_{i}\right)=\sum_{i=1}^{n} P\left(A_{i}\right), \text { com } A_{i} \text { disjuntos. }
\end{array}\right.
$$

Esta função, $P(\cdot)$, é denominada probabilidade.

Em Beck (2011) são apresentadas outras definições, além da axiomática:

Pela definição clássica, probabilidade é entendida como a razão entre o número de resultados favoráveis a um determinado evento em relação ao total de resultados possíveis.

$$
P(A)=\frac{N_{\text {evento }}}{N_{\text {possiveis }}}
$$

Neste caso os resultados possíveis devem ser equiprováveis, ou seja ter a mesma probabilidade de ocorrência.

Pela definição frequentista, baseado em um grande número de observações, probabilidade é entendida como a razão entre o número de observações de um determinado evento e o número total de realizações de um experimento.

$$
P(A)=\lim _{n \rightarrow \infty} \frac{n_{A}}{n}
$$

Pela definição bayesiana, probabilidade é entendida como grau de confiança, ou seja, a probabilidade de que ocorra um determinado evento é o grau de confiança em relação a sua ocorrência.

\subsubsection{EVENTOS INDEPENDENTES}

Considerando dois eventos, $A$ e $B$, diz-se que são independentes se a ocorrência de $A$ não afetar a probabilidade de ocorrência de $B$ e vice-versa.

$$
P(A \cap B)=P(A) \cdot P(B)
$$


Utilizando o conceito de probabilidade condicional, dado que ocorreu o evento $B$ a probabilidade de ocorrência do evento $A$ é a mesma:

$$
P(A \mid B)=P(A)
$$

O conceito de eventos independentes é fundamental para a análise pretendida, pois se considera que os efeitos de cada parâmetro de resistência do solo (coesão e ângulo de atrito interno) sejam independentes entre si.

\subsubsection{VARIÁVEIS ALEATÓRIAS}

Beck (2011, p. 32) apresenta a seguinte definição para variável aleatória: "Uma variável aleatória real $X(w)$ é uma função real que atribui a cada ponto amostral $w$ de um espaço $\Omega$ um valor real $x$, tal que o conjunto $\{X \leq x\}$ é um evento para qualquer número real $x$ ". Como $X$ é uma variável aleatória sua ocorrência é determinada em termos de probabilidades. A variável aleatória pode ser do tipo discreta ou contínua. No caso de variáveis aleatórias discretas o domínio de sua função é formado por um número finito ou infinito contável de pontos. No caso de variáveis aleatórias contínuas o domínio de sua função é formado por um número infinito de pontos. As variáveis aleatórias estão diretamente associadas as distribuições de probabilidades pois são caracterizadas por estas.

\subsubsection{FUNÇÃO DENSIDADE DE PROBABILIDADE E FUNÇÃO DE DISTRIBUIÇÃO ACUMULADA DE PROBABILIDADES}

De acordo com Magalhães e Lima (2002), uma função $f(x)$ é chamada de função densidade de probabilidade para uma variável aleatória contínua $X$ se satisfizer as seguintes condições:

$$
\left\{\begin{array}{l}
f(x) \geq 0, \text { para todo } x \in(-\infty, \infty) \\
\text { A área definida por } f(x) \text { é igual a } 1 \rightarrow \int_{-\infty}^{\infty} f(x) d x=1
\end{array}\right.
$$

Para calcular uma determinada probabilidade por meio da função densidade de probabilidades, resolva-se a integral para o intervalo de interesse, por exemplo, 
para se calcular a probabilidade de que a variável aleatória esteja compreendida no intervalo $(a, b)$ :

$$
P(a \leq X \leq b)=\int_{a}^{b} f(x) d x
$$

A integral da função densidade de probabilidade define uma nova função chamada de função de distribuição acumulada de probabilidades, que para variáveis aleatórias contínuas é conhecida por:

$$
F_{x}(x)=\int_{-\infty}^{x} f(x) d x=P(X \leq x)
$$

\subsubsection{PARÂMETROS E MOMENTOS DE UMA VARIÁVEL ALEATÓRIA}

Em estatística, parâmetros e momentos de variáveis são medidas que definem o comportamento dos dados. Estas medidas podem ser de posição ou dispersão. Beck (2011) e Silva (2003) citam os mais importantes, apresentados abaixo.

Valor esperado, média ou momento de primeira ordem de uma variável aleatória:

$$
E(X)=\mu=\int_{-\infty}^{+\infty} x \cdot f(x) d x
$$

Nota-se que se a função densidade de probabilidade for simétrica em torno da origem do eixo $\mathrm{x}$, a média será nula. Ao fazer um paralelo com os conceitos da física, pode-se dizer que se a função densidade de probablidade representar a distribuição de massa no eixo, então a média será o centro de gravidade desta massa.

Mediana é o ponto divisor da distribuição de probabilidade em duas partes equiprováveis:

$$
F_{x}\left(x_{\text {med }}\right)=\frac{1}{2}
$$


Moda, ou valor mais provável é o ponto de máximo da função densidade de probabilidade.

$$
m_{0} \text { (moda) } \rightarrow f\left(m_{0}\right)=\text { máx } f(x)
$$

Variância, ou momento central de segunda ordem de uma variável aleatória é dado por:

$$
E\left[(X-\mu)^{2}\right]=\sigma^{2}(X)=\int_{-\infty}^{\infty}(x-\mu)^{2} f(x) d x
$$

Ela indica o quão longe estão os valores de uma determinada dispersão de dados, do valor esperado.

Desvio-padrão é a raiz quadrada da variância é têm a mesma desta, com a vantagem de ter a mesma unidade de medida da variável:

$$
\sigma(X)=\sqrt{E\left[(X-\mu)^{2}\right]}
$$

Coeficiente de variação é a razão entre o desvio padrão e a média.

$$
V=\frac{\sigma}{\mu}
$$

\subsubsection{MODELOS ANALÍTICOS DE FENÔMENOS ALEATÓRIOS}

Será apresentado o modelo de distribuição Normal ou de Gauss, que será utilizado nas análises posteriores. Este modelo é tem sua importância no fato de que as variáveis de muitos fenômenos físicos serem caracterizadas por ele, e também de ser uma distribuição limite, de acordo com o Teorema Central do Limite. Para se construir esta distribuição são necessários dois parâmetros, a média e o desviopadrão.

A função densidade de probabilidade da distribuição normal é apresentada abaixo:

$$
f(x)=\frac{1}{\sigma \sqrt{2 \pi}} \exp \left[-\frac{1}{2}\left(\frac{x-\mu}{\sigma}\right)^{2}\right],-\infty \leq x \leq \infty
$$

A função de distribuição acumulada de probabilidades é apresentada abaixo: 


$$
F_{x}(x)=\int_{-\infty}^{x} \frac{1}{\sigma \sqrt{2 \pi}} \exp \left[-\frac{1}{2}\left(\frac{x-\mu}{\sigma}\right)^{2}\right] d x,-\infty \leq x \leq \infty
$$

A notação de que uma variável aleatória contínua tem distribuição normal para a função densidade de probabilidade é apresentada abaixo:

$$
X \sim N\left(\mu, \sigma^{2}\right)
$$

A integral da equação (6.20) não possui solução analítica, para resolvê-la recorre-se a métodos numéricos ou utiliza-se uma tabela de referência, em que a equação foi previamente resolvida por método numérico, com resultados para determinados parâmetros, desta forma, os resultados desejados são obtidos por correlação entre parâmetros. O resultado da tabela de referência é apresentado de acordo com uma distribuição normal padrão, que é caracterizada por possuir média nula e desvio-padrão unitário.

A transformação de uma variável aleatória contínua com distribuição normal em uma variável normal padrão, $Y$ (variável com distribuição normal padrão), é dada por:

$$
Y=\frac{X-\mu}{\sigma}
$$

A função densidade de probabilidade e a função de distribuição acumulada de probabilidades da distribuição normal padrão, são respectivamente:

$$
\begin{aligned}
& f(y)=\phi(y)=\frac{1}{\sqrt{2 \pi}} \exp \left(-\frac{y^{2}}{2}\right),-\infty \leq x \leq \infty \\
& F_{y}(y)=\Phi(y)=\int_{-\infty}^{y} \phi(y) d y,-\infty \leq x \leq \infty
\end{aligned}
$$

Os valores da tabela de referência correspondem aos da função de distribuição acumulada de probabilidades da distribuição normal padrão, integrada para determinados limites. Para se obter os valores da função de distribuição acumulada de probabilidades considerando os parâmetros de interesse, faz-se a transformação: 


$$
F_{x}(x)=\Phi\left(\frac{x-\mu}{\sigma}\right)
$$

\subsubsection{TEOREMA CENTRAL DO LIMITE}

Este teorema afirma que a média de um número suficientemente grande de amostras de uma população com variáveis aleatórias independentes, em que cada amostra tem uma média e variância finita, tende a uma distribuição normal.

\subsection{CONFIABILIDADE}

Beck (2011, p.14) define confiabilidade como sendo o grau de confiança de que um sistema não falhe dentro do período de tempo destinado ao uso deste sistema, esta definição apresenta um conceito subjetivo. Dhillon (1999) define confiabilidade como a probabilidade de que um item irá desempenhar as suas atribuições de forma satisfatória para o período de tempo indicado, quando usado nas condições especificadas, por esta definição subtende-se que confiabilidade é o evento complementar da probabilidade de falha.

A confiabilidade de um sistema estrutural requer que sejam atendidos determinados requisitos que assegurem que ele cumpra sua função. Estes requisitos são de serviço, segurança, robustez, econômico e social. Abaixo são comentados dois deles:

O requisito de segurança determina que um sistema estrutural deva suportar determinados níveis de carregamentos (eventuais e repetitivos) sem entrar em colapso. O requisito de robustez determina que um sistema estrutural tenha uma reserva de capacidade estrutural de forma a não colapsar completamente frente a eventos extremos como por exemplo explosões, impactos, terremotos entre outros. No requisito de robustez a reserva de capacidade estrutral não significa essenciamente que seja necessário projetar um estrutura com com mais elementos estruturais ou material, mas principalmente que seja feito um detalhamento adequado prevendo a eventual ocorrência de eventos extremos. No caso de contenções cita-se como exemplo de robustez do sistema a perda de um ou alguns tirantes não causarem seu colapso, neste caso para proceder a verificação deste requisito seria necessário uma análise tridimensional de estabilidade. 


\subsubsection{RISCO}

Risco é a probabilidade de acontecer algum tipo de dano dentro de um período de tempo específico. Pode também ser definido em termos de custo de ocorrência, $C($.$) :$

$$
\left\{\begin{array}{l}
\text { Evento falha }=E \\
\text { risco }(E)=P(E) \cdot C(E)
\end{array}\right.
$$

$\mathrm{Na}$ figura 75 é apresentado um gráfico com a probabilidade de falha versus consequências de ruína em termos de perdas de vidas humanas e custo financeiro.

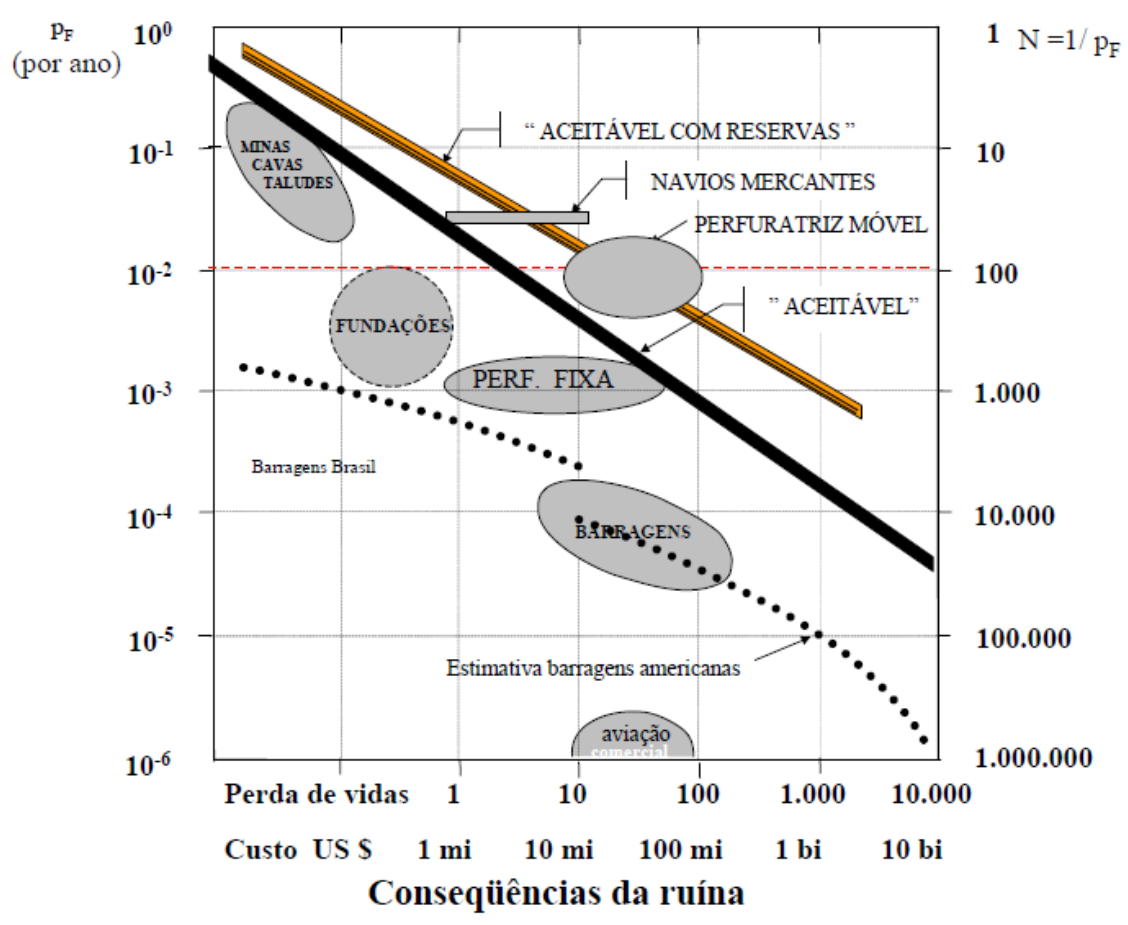

Figura 75 - Probabilidade de falha x Conseqüências (Beck, 2011 apud Whitman, 1984)

Observa-se na figura 75 que a probabilidade de ruína de taludes é relativamente grande (maior que $1 \mathrm{em} \mathrm{100)} \mathrm{quando} \mathrm{comparada} \mathrm{as} \mathrm{probabilidades} \mathrm{de}$ ruína de outras obras, no entanto o risco de perda de vidas é baixo.

Ao analisarmos o caso de contenções pode-se considerar quatro tipos de obras quanto ao risco de perda de vidas e custo financeiro:

1. Contenção provisória de taludes fora de áreas urbanas;

2. Contenção definitiva de taludes fora de áreas urbanas;

3. Contenção provisória de taludes em áreas urbanas; 
4. Contenção definitiva de taludes em áreas urbanas;

O primeiro tipo apresenta um custo financeiro baixo na ocorrência de uma eventual ruína, pois a obra é temporária (funcionará por um tempo muito inferior ao de uma obra definitiva), está mobilizada e pode interagir no sentido de conter ou minimizar as perdas neste evento, por este mesmo motivo apresenta risco de perda de vidas médio, pois há pessoas trabalhando diariamente ao redor dela.

O segundo tipo apresenta um custo financeiro médio na ocorrência de uma eventual ruína, pois no caso de uma estrada, por exemplo, além do custo da obra soma-se o custo de interdição do trecho afetado. O risco de perda de vidas é baixo considerando o tempo de exposição dos veículos nas proximidades da obra.

O terceiro tipo apresenta um custo financeiro alto na ocorrência de uma eventual ruína, pois afetaria outras estruturas e vias ao seu redor. O risco de perda de vidas é médio, pois haverá pessoas no seu entorno, mas a obra é temporária (funcionará por um tempo muito inferior ao de uma obra definitiva), está mobilizada e pode interagir no sentido de conter ou minimizar as perdas neste evento.

O quarto tipo, pelos mesmos motivos do terceiro, apresenta um custo financeiro alto na ocorrência de uma eventual ruína. O risco de perda de vidas é alto, pois haverá pessoas no seu entorno e a obra é definitiva.

A ABNT NBR11682:2009 que trata especificamente da estabilidade de encostas apresenta um método para obtenção dos fatores de segurança que varia de acordo com o nível de segurança contra perda de vidas humanas, danos materiais e ambientais. 
Tabela 15 - Nível de segurança contra perda de vidas humanas

\begin{tabular}{|c|l|}
\hline NíVEL DE SEGURANÇA & \multicolumn{1}{|c|}{ CRITÉRIOS } \\
\hline Alto & $\begin{array}{l}\text { Áreas com intensa movimentação e permanência de pessoas, como edificações } \\
\text { públicas, residenciais ou industriais, estádios, praças e demais locais, urbanos ou } \\
\text { não, com possibilidade de elevada concentração de pessoas. } \\
\text { Ferrovias e rodovias de tráfego intenso. }\end{array}$ \\
\hline Médio & $\begin{array}{l}\text { Áreas e edificaçôes com movimentação e permanência restrita de pessoas. } \\
\text { Ferrovias e rodovias de tráfego moderado }\end{array}$ \\
\hline Baixo & $\begin{array}{l}\text { Áreas e edificações com movimentação e permanência eventual de pessoas. } \\
\text { Ferrovias e rodovias de tráfego reduzido }\end{array}$ \\
\hline
\end{tabular}

Fonte: ABNT NBR11682:2009

Tabela 16 - Nível de segurança contra danos materiais e ambientais

\begin{tabular}{|c|l|}
\hline NíVEL DE SEGURANÇA & \multicolumn{1}{|c|}{ CRITÉRIOS } \\
\hline Alto & $\begin{array}{l}\text { Danos materiais: Locais próximos a propriedades de alto valor histórico, social ou } \\
\text { patrimonial, obras de grande porte e áreas que afetem serviços assenciais. } \\
\text { Danos ambientais: Locais sujeitos a acidentes ambientais graves, tais como nas } \\
\text { proximidades de oleodutos, barragens de rejeito e fábricas de produtos tóxicos. }\end{array}$ \\
\hline Médio & $\begin{array}{l}\text { Danos materiais: Locais próximos a propriedades de valor moderado } \\
\text { Danos ambientais: Locais sujeitos a acidentes ambientais moderados }\end{array}$ \\
\hline Baixo & $\begin{array}{l}\text { Danos materiais: Locais próximos a propriedades de valor reduzido } \\
\text { Danos ambientais: Locais sujeitos a acidentes ambientais reduzidos }\end{array}$ \\
\hline
\end{tabular}

Fonte: ABNT NBR11682:2009

Por meio do cruzamento dos níveis de segurança escolhidos de acordo com as tabelas acima, se obtém os fatores de segurança contra deslizamento da obra em análise: 
Tabela 17 - Fatores de segurança mínimos para deslizamentos

\begin{tabular}{|c|c|c|c|}
\hline NívEL DE SEGURANCAA CONTRA & Alto & Médio & Baixo \\
\hline Alto & 1,5 & 1,5 & 1,4 \\
\hline Médio & 1,5 & 1,4 & 1,3 \\
\hline Baixo & 1,4 & 1,3 & 1,2 \\
\hline
\end{tabular}

Fonte: ABNT NBR11682:2009

Nota: Foram suprimidas as notas.

Para contenções um sistema de avaliação dos riscos como o da ABNT NBR11682:2009 poderia ser adotado, neste caso os fatores de segurança a serem considerados deveriam ser calibrados para este tipo de obra.

\subsubsection{PROBABILIDADE DE FALHA}

Considerando duas curvas de densidade de probabilidade, sendo uma de resistência, $f_{R}(r)$, e outra de solicitação, $f_{S}(s)$, a probabilidade de falha ou ruína é definida como uma área abaixo da superposição das curvas.

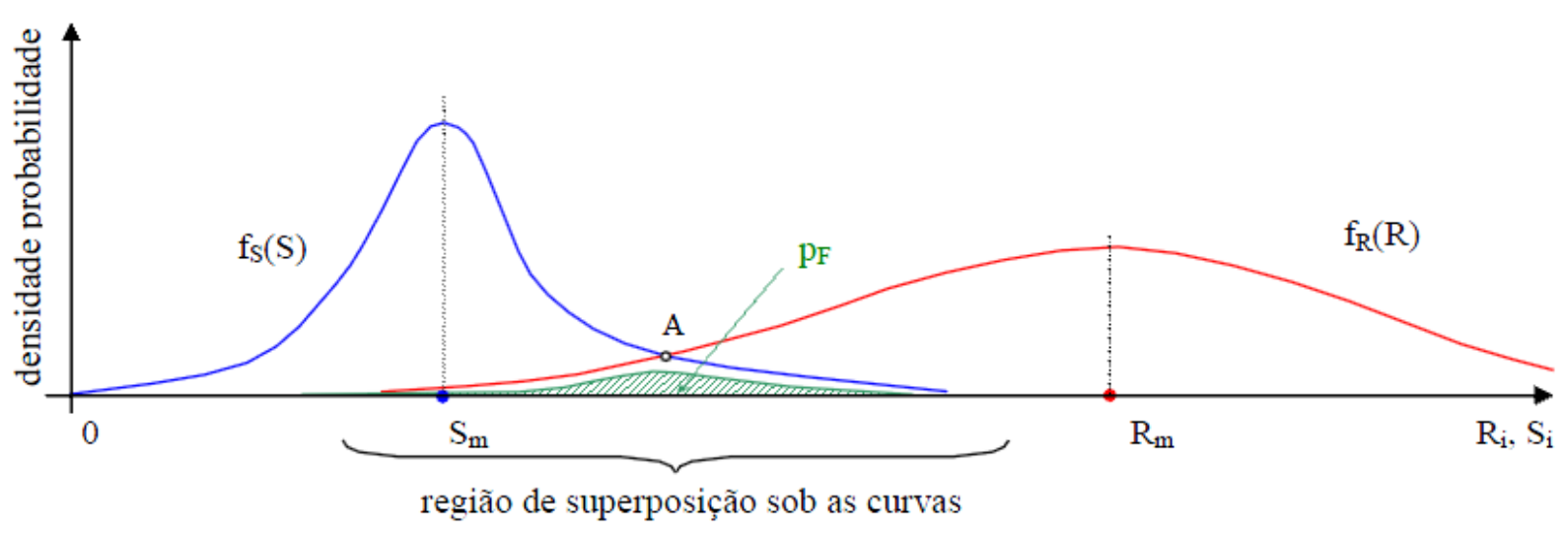

Figura 76 - Definição numérica de probabilidade de falha (Aoki, 2008)

A função probabilidade de falha é definida por: 


$$
P_{f}=\int_{-\infty}^{\infty} f_{S}(s)\left[\int_{-\infty}^{S} f_{R}(r) d r\right] d s=\int_{-\infty}^{\infty} f_{S}(s) F_{R}(s) d s
$$

\subsubsection{EQUAÇÕES DE ESTADO LIMITE E ÍNDICE DE CONFIABILIDADE}

De acordo com Beck (2011), os modos de falha de sistemas estruturais podem ser quantificados por meio de equações de estado limite que são escritas como função das variáveis de projetos.

$$
g(x)=g\left(x_{1}, x_{2}, \ldots, x_{n}\right)=0
$$

Por meio destas equações, a falha do sistema estrutural fica caracterizada por valores negativos ou nulos.

$$
\left\{\begin{array}{l}
D_{f=}\{x \mid g(x) \leq 0\} \\
D_{s=}\{x \mid g(x)>0\}
\end{array}\right.
$$

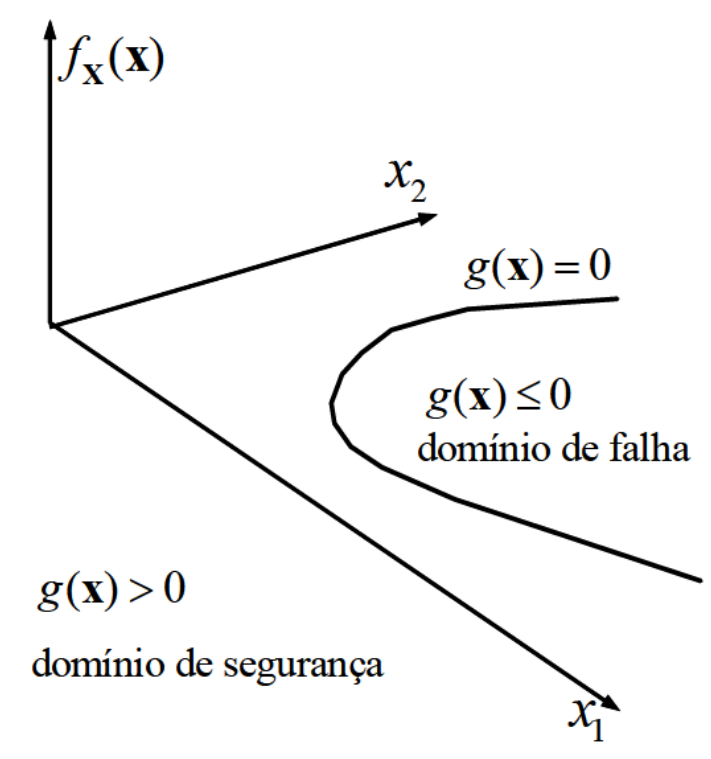

Figura 77 - Domínios da equação de estado limite (Beck, 2011)

No caso da equação de estado limite ser independente do tempo e envolver somente as variáveis aleatórias resistência $\mathrm{R}$ e solicitação $\mathrm{S}$ :

$$
g(R, S)=R-S=0
$$


A probabilidade de falha, considerando a equação de estado limite, fica definida como a probabilidade dela ser menor ou igual zero.

$$
P_{f}=P\{g(x) \leq 0\} \rightarrow P_{f}=P\{R-S \leq 0\}
$$

A equação de estado limite, como definida em (6.31), pode ser colocada como margem de segurança, $M$ :

$$
M=R-S
$$

E a probabilidade de falha:

$$
P_{f}=P\{M \leq 0\}=\int_{-\infty}^{0} f_{M}(m) d m=F_{M}
$$

A figura 78 ilustra graficamente a probabilidade de falha e a função densidade de probabilidade da margem de segurança, definida pela função (6.34):

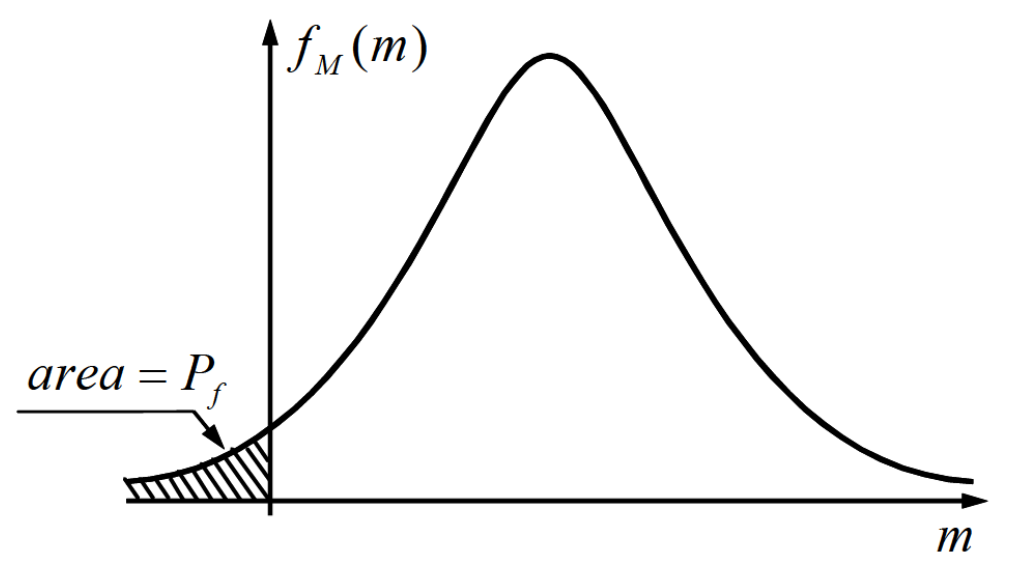

Figura 78 - Probabilidade de falha em função da margem de segurança (Beck, 2011)

Por meio da equação (6.33) podemos escrever a margem de segurança média em termos dos valores médios da resistência e solicitação, e considerando o caso de distribuições normais e variáveis independentes, o desvio padrão da margem de segurança:

$$
\begin{gathered}
\mu_{M}=\mu_{R}-\mu_{S} \\
\sigma_{M}=\sqrt{\sigma_{R}^{2}-\sigma_{S}^{2}}
\end{gathered}
$$


Considerando o valor médio da margem de segurança, Aoki (2008) apresenta o índice de confiabilidade, $\beta$, como o fator que multiplica o desvio padrão da margem de segurança na equação (6.37):

$$
\left\{\begin{array}{l}
\mu_{M}=\beta \cdot \sigma_{M} \\
\beta=\frac{\mu_{M}}{\sigma_{M}}=\frac{\mu_{R}-\mu_{S}}{\sqrt{\sigma_{R}^{2}-\sigma_{S}^{2}}}
\end{array}\right.
$$

Graficamente:

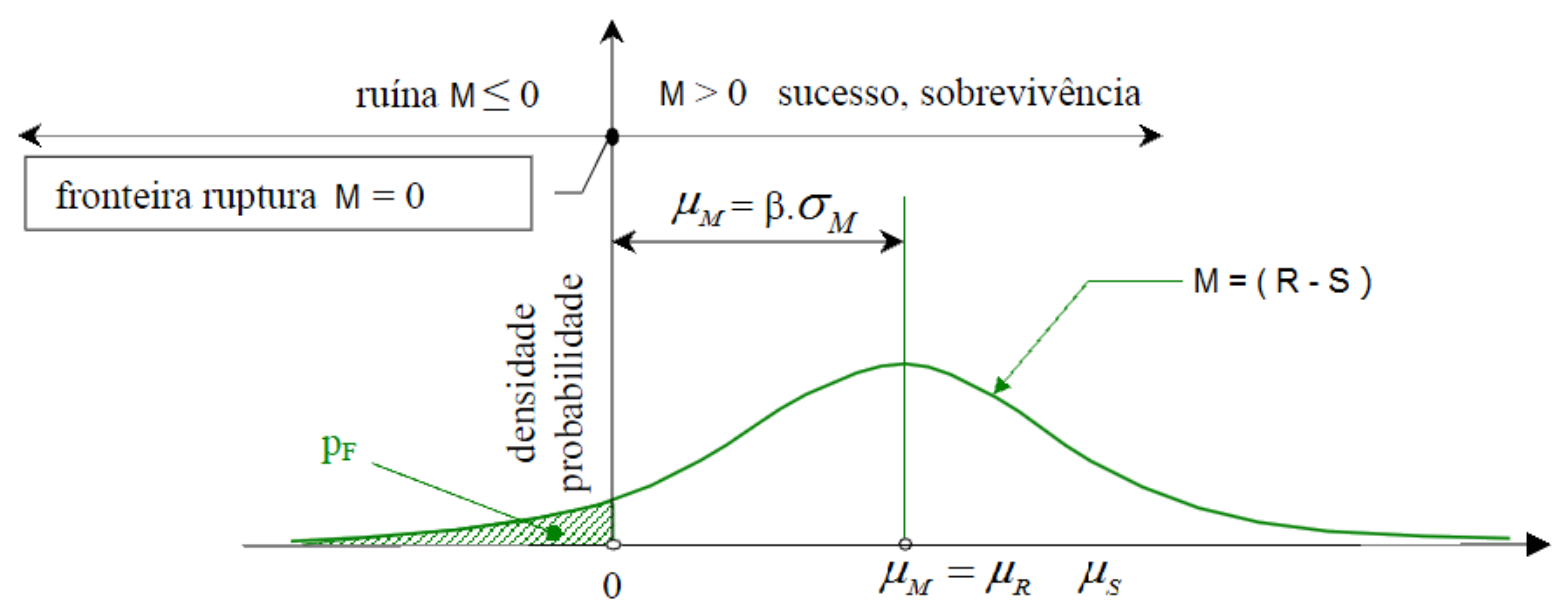

Figura 79 - Índice de confiabilidade em função da margem de segurança (Modificado de Aoki, 2008)

Beck (2011) apresenta o índice de confiabilidade por meio da variável $M$ transformada na variável normal padrão $Y$, que tem média nula e desvio padrão unitário. Esta transformação é conhecida como transformação de Hassofer e Lind.

$$
\left\{\begin{array}{l}
Y_{i}=\frac{X_{i}-\mu_{X_{i}}}{\sigma_{X_{i}}} \rightarrow Y=\frac{M-\mu_{M}}{\sigma_{M}} \\
P_{f}=P_{f}\{M \leq 0\}=P_{f}\left\{Y \leq-\frac{\mu_{M}}{\sigma_{M}}\right\}=\Phi\left(-\frac{\mu_{M}}{\sigma_{M}}\right)=\Phi(-\beta)=1-\Phi(\beta)
\end{array}\right.
$$

Graficamente: 

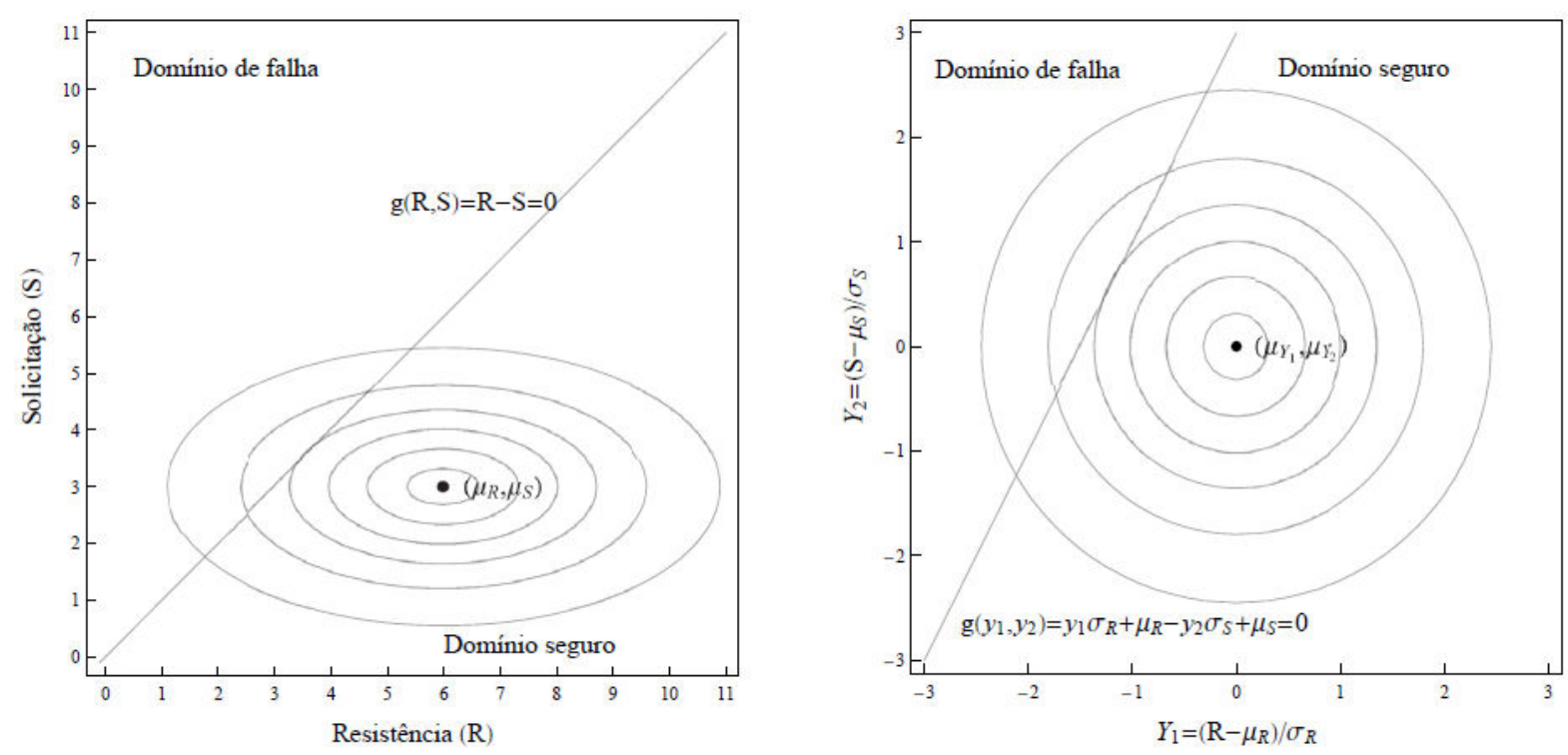

Figura 80 - Transformação das variáveis (Beck, 2011)

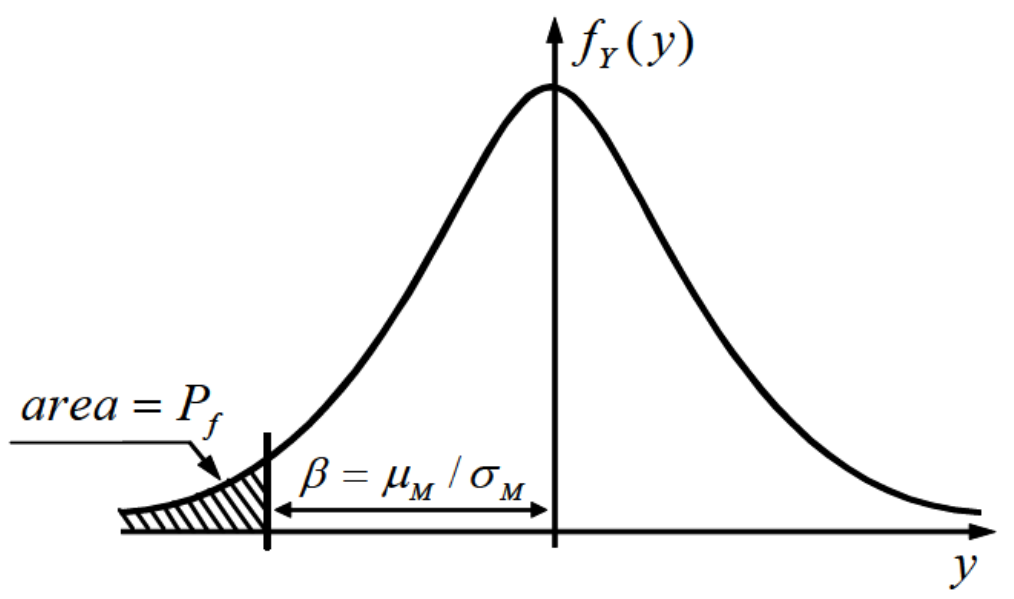

Figura 81 - Índice de confiabilidade em função da margem de segurança transformada (Beck, 2011)

Desta forma o índice de confiabilidade representa uma medida geométrica cujo módulo é a mínima distância entre o local geométrico em que a equação margem de segurança ou equação de estado limite é nula e o a origem do espaço normal padrão.

No caso da equação de estado limite ser aproximada por uma função linear, como mostrado na figura 81 , é necessário o conhecimento de momentos até segunda ordem (média e desvio-padrão), isso equivale a assumir que as variáveis aleatórias do problema tenham uma distribuição normal de probabilidades, isto é classificado como método de primeira ordem e segundo momento ou FOSM (First Order Second Moment). 
Para obtenção do índice de confiabilidade na aplicação da análise de estabilidade deve-se utliza-lo como função do fator se segurança. Se considerarmos que o fator de segurança obedece ao modelo de distribuição normal de probabilidades, o índice de confiabilidade pode ser obtido como função do valor médio e desvio-padrão do fator de segurança (CHERUBINI, GARRASI E PETROLLA, 1992, apud CHOWDHRY, 1988).

$$
\beta=\frac{\mu_{F S}-1}{\sigma_{F S}}
$$

A equação (6.39) pode ser obtida pelas relações a seguir:

O domínio da falha é estabelecido por:

$$
M \leq 0
$$

A condição limite para a ocorrência da falha é:

$$
X=1
$$

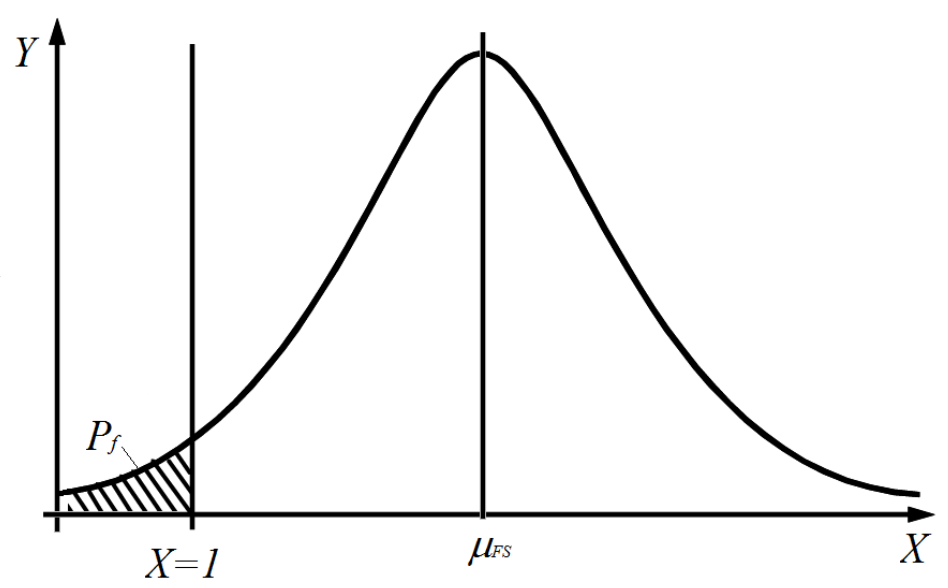

Figura 82 - Condição limite para ocorrência da falha.

$$
\left\{\begin{array}{l}
\mu_{F S} \leq 1 \\
\mu_{F S}-1 \leq 0
\end{array}\right.
$$

Considerando (6.41) a equação de estado limite e a margem de segurança são definidos abaixo:

$$
g(X)=M=\mu_{F S}-1
$$


Considerando (6.37):

$$
\left\{\begin{array}{l}
\mu_{M}=\beta \cdot \sigma_{M} \\
\mu_{M}=\mu_{F S}-1 \\
\sigma_{M}=\sigma_{F S} \\
\beta=\frac{\mu_{F S}-1}{\sigma_{F S}}
\end{array}\right.
$$

Como referência de valores para índice de confiabilidade para aplicações práticas, o Eurocode 0 (2004) apresenta os valores para a probabilidade de falha associada aos índice de confiabilidade para uma distribuição normal de probabilidades e também os índices de confiabilidade requeridos, de acordo com o estado limite e o tempo de durabilidade da obra.

Tabela 18 - Probabilidades de ruína e índices de confiabilidade

\begin{tabular}{|c|c|c|c|c|c|c|c|}
\hline$P_{\mathrm{f}}$ & $10^{-1}$ & $10^{-2}$ & $10^{-3}$ & $10^{-4}$ & $10^{-5}$ & $10^{-6}$ & $10^{-7}$ \\
\hline$\beta$ & 1,28 & 2,32 & 3,09 & 3,72 & 4,27 & 4,75 & 5,20 \\
\hline
\end{tabular}

Fonte: Eurocode 0, 2004

Tabela 19 - Índices de confiabilidade requeridos

\begin{tabular}{|l|c|c|}
\hline \multirow{2}{*}{ Limit state } & \multicolumn{2}{|c|}{ Target reliability index } \\
\cline { 2 - 3 } & 1 year & 50 years \\
\hline Ultimate & 4,7 & 3,8 \\
\hline Fatigue & & 1,5 to 3,8 \\
\hline Serviceability (irreversible) & 2,9 & 1,5 \\
\hline
\end{tabular}

Fonte: Eurocode 0, 2004

De acordo com Meyerhof (1982), para o caso de estabilidade em contenções com adoção de fatores de segurança entre 1,5 e 2 a probabilidade de ruína é aproximadamente $10^{-3}$.

\subsection{APLICAÇÃO DOS MÉTOdOS ESTATÍSTICOS NA ANÁLISE DE ESTABILIDADE}

Existem diversos métodos que podem ser adotados, cita-se o método de Monte Carlo e o Point-Estimate Method (PEM) proposto por Rosenblueth (1975). 


\subsubsection{MÉTODO DE MONTE CARLO}

Pelo método de Monte Carlo, são tomadas amostras aleatórias das variáveis de entrada, no caso do problema ter mais de uma variável são geradas combinações aleatórias destas variáveis. Estas combinações de variáveis são usadas para executar os cálculos de forma determinística, assim pode-se obtem-se como resultado a distribuição de probabilidades e os momentos estatísticos (média, variância, etc) da variável resposta, que para análise de estabilidade é a probalidade de ruína e o fator de segurança.

Hammah, Yacoub e Curran (2006) citam como vantagem do método a flexibilidade na incorporação de uma grande variedade de distribuições de probabilidade, sem muita aproximação e a capacidade se fazer, de maneira simples, correlações entre variáveis. E como desvantagem a necessidade de fazer muitas simulações para se alcançar uma boa precisão, o que computacionalmente pode demendar muito tempo principalmente para aplicações em análise de estabilidade via MEF.

Esta desvantagem tem início pela geração das amostras das variáveis de entrada. Elas podem ser geradas de forma aleatória a partir da função conjunta de densidade de probabilidades (amostragem simples), no entanto para se obter um resultado satisfatório é necessário um grande número de amostras de variáveis. Para contornar este problema pode-se utilizar técnicas de amostragem que otimizam a geração de variáveis de forma a se obter resultados melhores que a amostragem simples e com menos quantidade de análises.

Cita-se como técnica de amostragem o Latin Hipercube Sampling (LHS), que consiste basicamente em dividir a distribuição da variável em intervalos e fazer uma seleção aleatória dentro de cada intervalo, sendo que estes intervalos são não sobrepostos e tem probabilidades iguais. No caso de duas variáveis, os $n$ valores obtidos para a variável $X 1$ são combinados de forma aleatória com os $n$ valores de X2. Para mais de duas variáveis procede-se da mesma forma, ou seja obtêm-se $n$ valores para a nova variável e faz-se a combinação com as demais. Como exemplo são apresentadas duas amostragens com 1000 valores cada, sendo que em uma foi adotada a amostragem simples e na outra o LHS: 

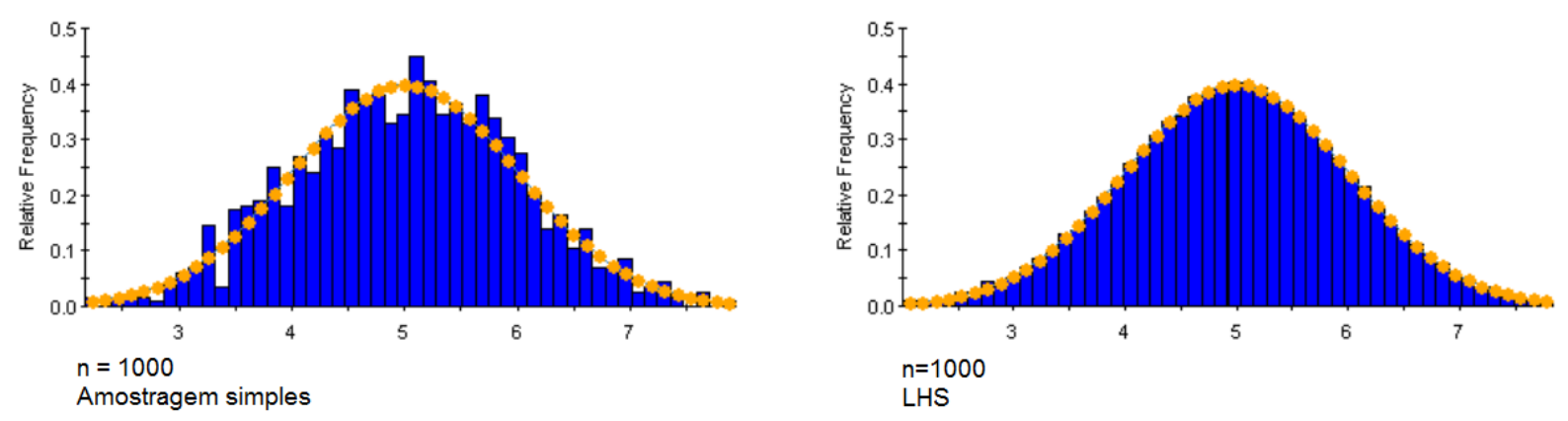

Figura 83 - Comparação entre amostragem simples e a técnica LHS (Rocscience Inc - Slide 6.0 Probabilistic Analysis).

\subsubsection{PEM}

O PEM é uma alternativa mais eficiente que o método de Monte-Carlo para o caso do MEF, que dependendo do modelo elaborado tem um gasto computacional grande (em termos de tempo de processamento). O princípio do PEM é calcular soluções em diversos pontos estimados da distribuição de probabilidade das variáveis de entrada e combiná-los com a ponderação adequada, a fim de se obter uma aproximação da distribuição da solução. Desta forma é necessário que se adote um método para propagação de erros. Em Rosenblueth (1975) é utilizada série de Taylor para fazer a propagação de erros em soluções analíticas. No entanto, esta abordagem exige que seja possível extrair uma derivada parcial da função solução. Valley e Duff (2011) comentam que esta forma de esta solução para fica impossível quando o método é aplicado em um problema de métodos numéricos como o MEF pelo fato de ser necessário se extrair a derivada parcial da função solução. Para aplicação em métodos numéricos utiliza-se o two-point estimate (ROSENBLUETH, 1981). Abaixo o método é apresentado de forma sucinta:

Dada a distribuição de probabilidades de variáveis aleatórias de entrada, serão geradas $2^{n}$ soluções para avalição em que $n$ é número de variáveis aleatórias de entrada. A função solução é dada por:

$$
y=f\left(x_{1}, x_{2}, \ldots, x_{n}\right)
$$

Em que $x_{n}$ é a variável aleatória de entrada. A distribuição para a solução aproximada é dada por: 


$$
\bar{y}=\sum_{i=1}^{2^{n}} w f_{i}
$$

Em que $w$ são os pesos das funções e são obtidos por:

$$
w=\frac{1}{2^{n}}
$$

Para cada variável aleatória de entrada são tomados dois valores da distribuição de probabilidades, assim pode-se ter $2^{n}$ combinações de soluções:

$$
y_{( \pm, \pm)(i)}=f_{i}\left(x_{1}^{ \pm}, x_{2}^{ \pm}, \ldots, x_{n}^{ \pm}\right), \text {para } i=2^{n}
$$

E por meio de uma função de distribuição como a Normal, por exemplo, pode-se calcular o valor médio $\bar{x}_{n}$, e o desvio padrão, $\sigma_{\mathrm{x}}$.

A figura 84 mostra esquematicamente o método, considerando duas variáveis de entrada:

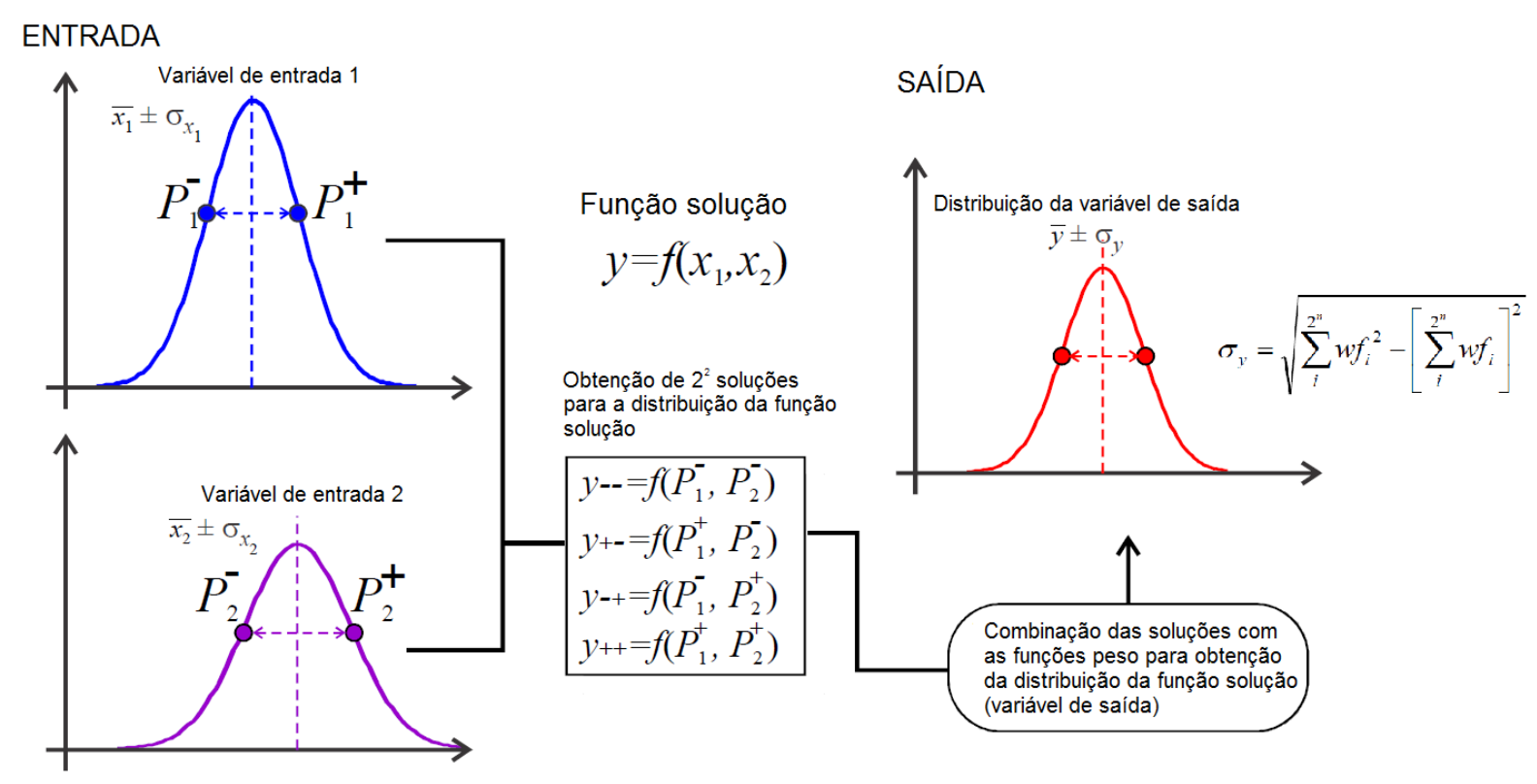

Figura 84 - llustração da obtenção da distribuição da função solução (adaptado de VALLEY e DUFF, 2011)

No programa Phase2, desenvolvido pela Rocsciense Inc, foi implementado o PEM para aplicações diversas, em que se permite a entrada de variáveis com distribuição normal de probabilidades, não correlacionadas, e se obtém a variável de saída também com distribuição normal de probabilidade. 


\subsubsection{DADOS ESTATÍSTICOS PARA COESÃO E ÂNGULO DE ATRITO}

Para aplicação dos métodos estatísticos são necessários os dados estatísticos dos materiais, como valor médio e desvio padrão. Para obtê-los pode-se recorrer a ensaios ou adotar os valores disponíveis na literatura técnica.

Abaixo são apresentadas duas tabelas, uma com os coeficientes de variação das propriedades dos solos e outra com valores para o desvio padrão:

Tabela 20 - Coeficientes de variação das propriedades dos solos

\begin{tabular}{|c|c|c|}
\hline $\begin{array}{l}\text { Property or in situ test } \\
\text { result } \\
\text { (1) }\end{array}$ & $\begin{array}{c}\text { Coefficient } \\
\text { of variation } \\
-V \\
(\%) \\
(2)\end{array}$ & $\begin{array}{l}\text { Source } \\
\text { (3) }\end{array}$ \\
\hline Unit weight $(\gamma)$ & $3-7 \%$ & $\begin{array}{l}\text { Harr (1984), Kulhawy } \\
(1992)\end{array}$ \\
\hline Buoyant unit weight $\left(\gamma_{b}\right)$ & $0-10 \%$ & $\begin{array}{l}\text { Lacasse and Nadim (1997), } \\
\text { Duncan }(2000)^{a}\end{array}$ \\
\hline $\begin{array}{l}\text { Effective stress friction an- } \\
\text { gle }\left(\phi^{\prime}\right)\end{array}$ & $2-13 \%$ & $\begin{array}{l}\text { Harr (1984), Kulhawy } \\
(1992)\end{array}$ \\
\hline $\begin{array}{l}\text { Undrained shear strength } \\
\left(S_{u}\right)\end{array}$ & $13-40 \%$ & $\begin{array}{l}\text { Harr }(1984), \text { Kulhawy } \\
\text { (1992), Lacasse and Na- } \\
\operatorname{dim}(1997), \text { Duncan } \\
(2000)^{a}\end{array}$ \\
\hline $\begin{array}{l}\text { Undrained strength ratio } \\
\left(S / \sigma^{\prime}\right)\end{array}$ & $5-15 \%$ & $\begin{array}{l}\text { Lacasse and Nadim (1997), } \\
\text { Duncan }(2000)^{a}\end{array}$ \\
\hline Compression index $\left(C_{c}\right)$ & $10-37 \%$ & $\begin{array}{l}\text { Harr (1984), Kulhawy } \\
\quad(1992), \text { Duncan }(2000)^{a}\end{array}$ \\
\hline $\begin{array}{l}\text { Preconsolidation pressure } \\
\left(p_{p}\right)\end{array}$ & $10-35 \%$ & $\begin{array}{l}\text { Harr (1984), Lacasse and } \\
\text { Nadim (1997), Duncan } \\
(2000)^{a}\end{array}$ \\
\hline $\begin{array}{l}\text { Coefficient of permeability } \\
\text { of saturated clay }(k)\end{array}$ & $68-90 \%$ & $\begin{array}{l}\text { Harr }(1984), \text { Duncan } \\
(2000)^{x}\end{array}$ \\
\hline $\begin{array}{l}\text { Coefficient of permeability } \\
\text { of partly saturated clay } \\
\text { (k) }\end{array}$ & $130-240 \%$ & $\begin{array}{l}\text { Harr (1984), Benson et al. } \\
\text { (1999) }\end{array}$ \\
\hline $\begin{array}{l}\text { Coefficient of consolida- } \\
\text { tion }\left(c_{v}\right)\end{array}$ & $33-68 \%$ & Duncan $(2000)^{2}$ \\
\hline $\begin{array}{l}\text { Standard penetration test } \\
\text { blow count }(N)\end{array}$ & $15-45 \%$ & $\begin{array}{l}\text { Harr (1984), Kulhawy } \\
(1992)\end{array}$ \\
\hline $\begin{array}{l}\text { Electric cone penetration } \\
\text { test }(q)\end{array}$ & $5-15 \%$ & Kulhawy (1992) \\
\hline $\begin{array}{l}\text { Mechanical cone penetra- } \\
\text { tion test }(q)\end{array}$ & $15-37 \%$ & $\begin{array}{l}\text { Harr (1984), Kulhawy } \\
(1992)\end{array}$ \\
\hline $\begin{array}{l}\text { Dilatometer test tip resis- } \\
\text { tance }\left(q_{0 \mathrm{a} / \pi}\right)\end{array}$ & $5-15 \%$ & Kulhawy (1992) \\
\hline $\begin{array}{l}\text { Vane shear test undrained } \\
\text { strength }(S,)\end{array}$ & $10-20 \%$ & Kulhawy (1992) \\
\hline
\end{tabular}

Fonte: Duncan, 2000

Por meio do coeficiente de variação, $V$, e do valor médio da propriedade, pode-se obter o desvio padrão: 


$$
\left\{\begin{array}{l}
V=\frac{\sigma}{\bar{x}} \\
\sigma=V \cdot \bar{x}
\end{array}\right.
$$

Tabela 21 - Desvio padrão para propriedades dos solos

\begin{tabular}{|l||l|}
\hline Soil property & $\begin{array}{l}\text { Standard deviation } \\
{[\% \text { of expected mean value }]}\end{array}$ \\
\hline \hline Unit weight $\left[\mathrm{kN} / \mathrm{m}^{3}\right]$ & $5-10 \%$ \\
\hline $\begin{array}{l}\text { Internal Friction } \tan \left(\varphi^{\prime}\right) \\
(\text { drained })\end{array}$ & $10-20 \%$ \\
\hline Drained Cohesion $\left[\mathrm{kN} / \mathrm{m}^{2}\right]$ & $10-50 \%$ \\
\hline $\begin{array}{l}\text { Undrained Shearing Strength } \\
{\left[\mathrm{kN} / \mathrm{m}^{2}\right]}\end{array}$ & $10-40 \%$ \\
\hline Stiffness $\left[\mathrm{MN} / \mathrm{m}^{2}\right]$ & $20-100 \%$ \\
\hline
\end{tabular}

Fonte: Joint Committe on Structural Fafety - JCSS - 2006

A obtenção do ângulo de atrito entre a contenção e o maciço, $\delta$, pode ser feita por meio de ensaios, em que deve-se levar em conta a tensão média atuante, ou adotar valores recomendados pela literatura técnica. Em Bowles (1996, p. 619), é indicado, para interface entre solo e paredes de concreto, o ângulo de atrito estar entre 0,6 a 0,8 $\phi$ (ângulo de atrito interno do solo), também é apresentada uma tabela com valores para o ângulo de atrito entre diversos tipos de contenção e diversos tipos de solo. A coesão para os casos comuns pode ser desprezada. 
Tabela 22 - Tabela para valores de ângulo de atrito entre contenção e solo

\begin{tabular}{ll}
\multicolumn{1}{c}{ Interface materials } & $\begin{array}{c}\text { Friction angle, } \\
\boldsymbol{\delta}, \text { degrees }\end{array}$ \\
\hline Mass concrete or masonry on the following: & $35^{\circ}$ \\
Clean sound rock & $\boldsymbol{\phi}$ \\
Clean gravel, gravel-sand mixtures, coarse sand & $\boldsymbol{\phi}$ \\
Clean fine to medium sand, silty medium to coarse sand, silty or clayey gravel & $\boldsymbol{\phi}$ \\
Clean fine sand, silty or clayey fine to medium sand & $\boldsymbol{\phi}$ \\
Fine sandy silt, nonplastic silt & $\boldsymbol{\phi}$ \\
Very stiff and hard residual or preconsolidated clay & $\boldsymbol{}$ \\
Medium stiff and stiff clay and silty clay & $22^{\circ}$ \\
Steel sheet piles against the following: & 17 \\
Clean gravel, gravel-sand mixture, well-graded rock fill with spalls & 14 \\
Clean sand, silty sand-gravel mixture, single-size hard rock fill & 11 \\
Silty sand, gravel, or sand mixed with silt or clay & \\
Fine sandy silt, nonplastic silt & $22-26$ \\
Formed concrete or concrete sheetpiling against the following: & $17-22$ \\
Clean gravel, gravel-sand mixtures, well-graded rock fill with spalls & 17 \\
Clean sand, silty sand-gravel mixture, single-size hard rock fill & 14 \\
Silty sand, gravel, or sand mixed with silt or clay & \\
Fine sandy silt, nonplastic silt & \\
Various structural materials & $35^{\circ}$ \\
Masonry on masonry, igneous and metamorphic rocks: & 33 \\
Dressed soft rock on dressed soft rock & 29 \\
Dressed hard rock on dressed soft rock & 26 \\
Dressed hard rock on dressed hard rock & 17 \\
Masonry on wood (cross grain) & $14-16$ \\
Steel on steel at sheet-pile interlocks & \\
Wood on soil &
\end{tabular}

Fonte: Bowles, 1996 


\section{O PROGRAMA PHASE2}

O PHASE2, versão 8.0, da empresa canadense Rocsciense Inc, é um programa de elementos finitos aplicado a problemas de engenharia da área de geotecnia e interação solo-estrutura.

Foi implementado com as formulações para:

- Modelos em estado plano de deformação e axissimétricos;

- Materiais isotrópicos, ortotrópicos e trasnversalmente isotrópicos;

- Quatro tipos de elementos bidimensionais, T3, T6, Q4, e Q8;

- Barras com formulação de Bernoulli e Timoshenko;

- Modelos constitutivos elastoplásticos: Mohr-Coulomb, Hoek-Brown, Hoek-Brown generalizado, Cam-Clay, Cam-Clay modificado, DruckerPrager, lei de fluxo-associado e não-associado;

- Modelo constitutivo elastoplástico perfeito para barras, no caso de concreto armado considera as armaduras (sem escorregamento entre o aço e o concreto);

- Elemento de interface, com critério de Mohr-Coulomb;

- Diversos elementos para tipos específicos de reforço do maciço, como tirantes (considerando o elemento de interface), pregagens, etc;

- Etapas de escavação, aterro e aplicação dos reforços, com a retirada de elementos, alteração das propriedades, inserção de tirantes, etc;

- Consideração da poro-pressão;

- Análise de estabilidade (SSR);

- Análise estatística (PEM);

- Solver com eliminação de Gauss e gradiente conjugado;

- Convergência por critérios de energia. 


\section{ANÁLISE NUMÉRICA}

Para análise numérica utilizou-se o programa Phase2, com modelos em estado plano de deformação. O modelo básico consiste em uma escavação com 15 $\mathrm{m}$ de profundidade em que são realizadas 15 etapas de escavação com $1 \mathrm{~m}$ de avanço. O maciço é composto por duas camadas horizontais de solo não-saturado $(u=0)$, em que a primeira vai até o fundo da escavação (altura de $15 \mathrm{~m}$ ), e a segunda infinita.

Para os materiais do maciço adotou-se: areia argilosa medianamente compacta para a primeira camada e areia argilosa compacta para a segunda camada, ambas com o critério de resistência de Mohr-Coulomb. Os parâmetros foram baseados nos valores indicados na NC-03 do METRÔ (1980) e são apresentados na figura 85.

O empuxo em repouso foi obtido pela fórmula de Jaky:

$$
\left\{\begin{array}{l}
k_{0}=1-\operatorname{sen} \phi \\
k_{0-\text { camada } 1}=1-\operatorname{sen} 30^{\circ}=0,5 \\
k_{0-\text { camada } 2}=1-\operatorname{sen} 35^{\circ}=0,43
\end{array}\right.
$$

O topo do terreno e o fundo da escavação são planos e horizontais. Considerou-se que a contenção seja comprida o suficiente para que se possam utilizar modelos em estado plano de deformação. 


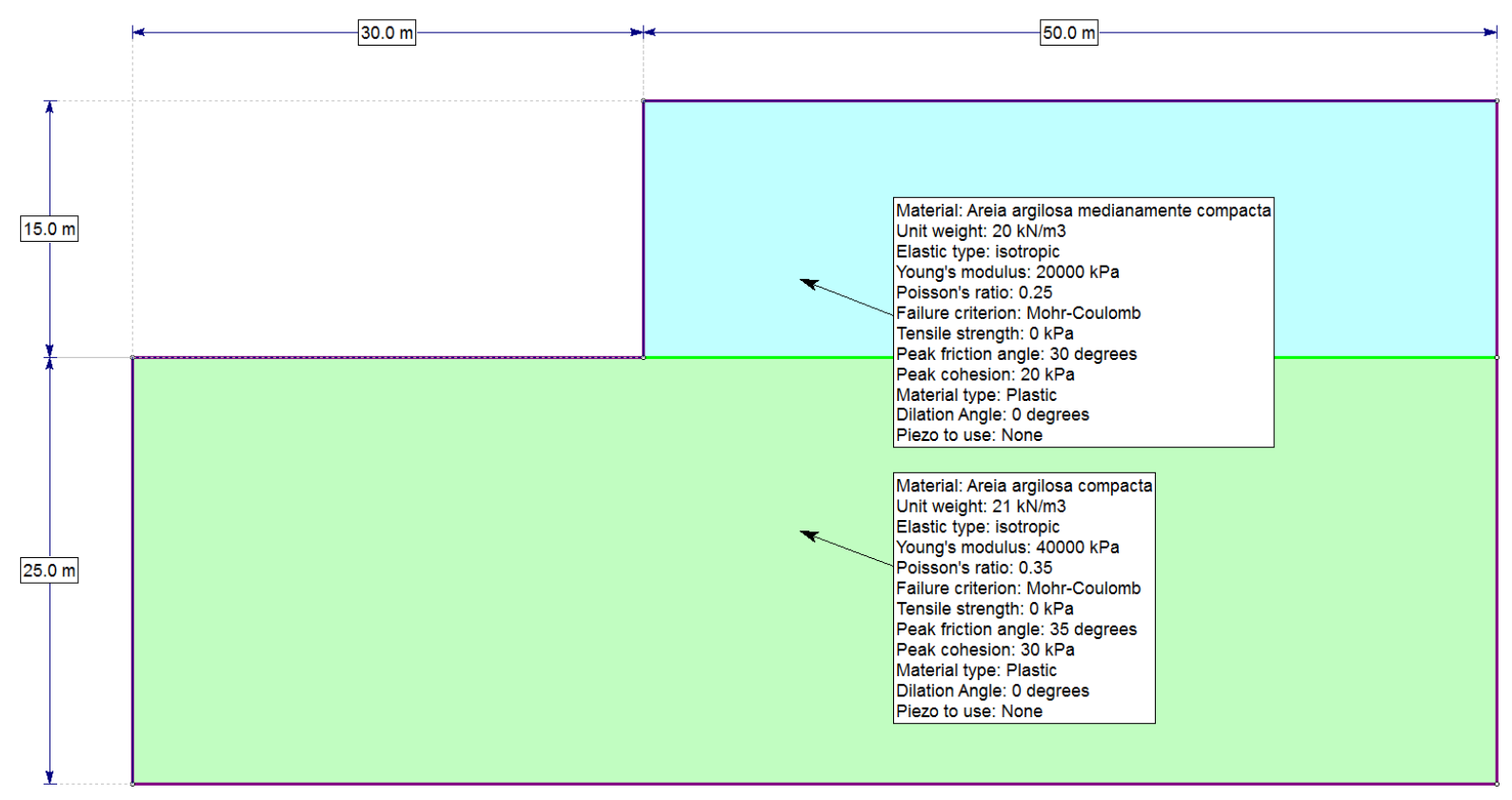

Figura 85 - Modelo base

A contenção consiste em: uma parede de concreto armado, C30 e aço CA50 , com $40 \mathrm{~cm}$ de espessura, atirantada, composta por 2 tirantes prédimensionados. Considerou-se a parede executada como parede diafragma (incorporada ao terreno antes da escavação) e embutimento (ficha) de $4 \mathrm{~m}$. Para o pré-dimensionamento dos tirantes foi considerado que a carga gerada pelo empuxo ativo é a carga de trabalho dos tirantes.

O coeficiente de empuxo ativo para o cálculo dos tirantes foi obtido pelos valores indicados na NC-03 do METRÔ (1980):

$$
k_{a-\text { camada } 1}=0,3
$$

E o empuxo ativo, $E$ :

$$
\left\{\begin{array}{l}
E=\frac{k_{a} \gamma h^{2}}{2}=\frac{k_{a} \gamma\left(h-z_{0}\right)^{2}}{2}=\frac{k_{a} \gamma\left[h-\left(\frac{2 c}{\gamma \sqrt{k_{a}}}\right)\right]^{2}}{2} \\
E=\frac{0,3 \cdot 20\left[15-\left(\frac{2 \cdot 20}{20 \sqrt{0,3}}\right)\right]^{2}}{2}=386,4 \mathrm{kN}
\end{array}\right.
$$

Considerando que o espaçamento horizontal entre tirantes é $3 \mathrm{~m}$ : 


$$
F_{T}=\frac{386,4 \cdot 3}{2} \cong 600 \mathrm{kN}
$$

Em que:

$\gamma$ é o peso específico do solo $\left(k N / \mathrm{m}^{3}\right)$;

$h$ é a altura da escavação $(m)$;

$c$ é a coesão $\left(k N / \mathrm{m}^{2}\right)$;

$z_{0}$ é a altura em que as tensões horizontais se anulam $\left(k N / \mathrm{m}^{2}\right)$;

Para o dimensionamento dos bulbos de ancoragem será utilizado a formulação sugerida por Costa Nunes (YASSUDA e DIAS, 1998, p. 626):

$$
\left\{\begin{array}{l}
L_{s}=\frac{\gamma_{E} \cdot F_{T}}{\left\{\pi \cdot D_{d} \cdot[c+(\gamma \cdot h+\Delta p) \cdot \operatorname{tg} \phi]\right\}} \\
L_{s}=\frac{1,75 \cdot 600}{\left\{\pi \cdot 0,1 \cdot\left[20+(20 \cdot 5+10 \cdot 20 \cdot 5) \cdot \operatorname{tg} 30^{\circ}\right]\right\}} \cong 6 \mathrm{~m}
\end{array}\right.
$$

Em que:

$L_{s}$ é comprimento do bulbo $\left(k N / m^{3}\right)$;

$h$ é a altura média de solo sobre o bulbo $(m)$;

$\phi$ é o ângulo de atrito de solo $\left({ }^{\circ}\right)$;

$c$ é a coesão $\left(k N / m^{2}\right)$;

$D_{d}$ é o diâmetro do bulbo $(m)$;

$\gamma_{E}$ é o fator para carga de ensaio;

$\Delta p$ é a parcela de aumento de pressão normal devido a pressão residual de injeção (5 a 10 vezes o valor de $\gamma \cdot h)\left(\mathrm{kN} / \mathrm{m}^{2}\right)$;

O primeiro tirante a $4 \mathrm{~m}$ da superfície com comprimento total de $20 \mathrm{~m}$ e o segundo a $10 \mathrm{~m}$ da superfície com comprimento total de $15 \mathrm{~m}$, ambos com inclinação de $15^{\circ}$ e 10 cordoalhas $\varnothing 12,7$.

Para ângulo de atrito entre o solo e a parede, $\delta$, foi adotado um valor intermediário entre os indicados no capítulo 6 , com uma relação entre o ângulo de atrito residual igual a unidade, $\delta_{R E S}$,:

$$
\delta=\delta_{R E S}=0,7 \cdot \phi=0,7 \cdot 30^{\circ}=21^{\circ}
$$


A parede foi dimensionada em regime elástico linear, com os esforços obtidos em análise numérica, de acordo com a ABNT NBR6118:2007, para obtenção das armaduras utilizadas na análise não linear.

A análise numérica foi feita em 7 etapas:

1. Validação da malha e verificação de esforços na parede, na fase final de escavação;

2. Análise de estabilidade com modelo elástico linear para a rigidez da parede;

3. Análise de estabilidade com modelo elastoplástico perfeito para a rigidez da parede, considerando o diagrama bilinear indicado pelo CEB-FIB 2010;

4. Análise de estabilidade considerando a rigidez tangente do diagrama $\mathrm{M}-\mathrm{N}-1 / \mathrm{r}$, com diagrama tensão-deformação parabólico-retangular e os limites da ABNT NBR6118:2007;

5. Análise de estabilidade considerando a rigidez tangente do diagrama M-N-1/r, com diagrama tensão-deformação de Grasser e os limites do CEB-FIB 2010;

6. Análise de estabilidade com modelo elástico linear para a rigidez da parede, considerando a variação dos parâmetros do solo (análise estatística).

7. Análise de estabilidade com modelo elastoplástico perfeito para a rigidez da parede, considerando o diagrama bilinear indicado pelo CEB-FIB 2010 e a variação dos parâmetros do solo (análise estatística). 


\subsection{VALIDAÇÃO DA MALHA E ESFORÇOS NA PAREDE, NA FASE FINAL DE ESCAVAÇÃO}

Aproveitando-se dos resultados do capítulo 3 , serão adotados apenas elementos com função de interpolação quadrática.

Foram feitos 12 modelos, 6 com o elemento tipo T6 (triângular de 6 nós) e 6 com o elemento tipo Q8 (quadrilateral de 8 nós), com aumento gradativo do número de elementos para verificação da convergência de resultados. A melhor forma de fazer esta verificação seria dividir os elementos progressivamente, no entanto isto não é possível no programa PHASE2, a não ser modelos com geometria muito simples, assim a verificação foi feita gerando uma nova malha, mais refinada, em cada etapa. Foi escolhido, como resultado, o deslocamento horizontal da parede diafragma em que criou-se um gráfico deslocamento versus altura da parede para cada modelo e reuniu-se para cada grupo de elementos. Abaixo são apresentados os modelos e os gráficos para o elemento T6:

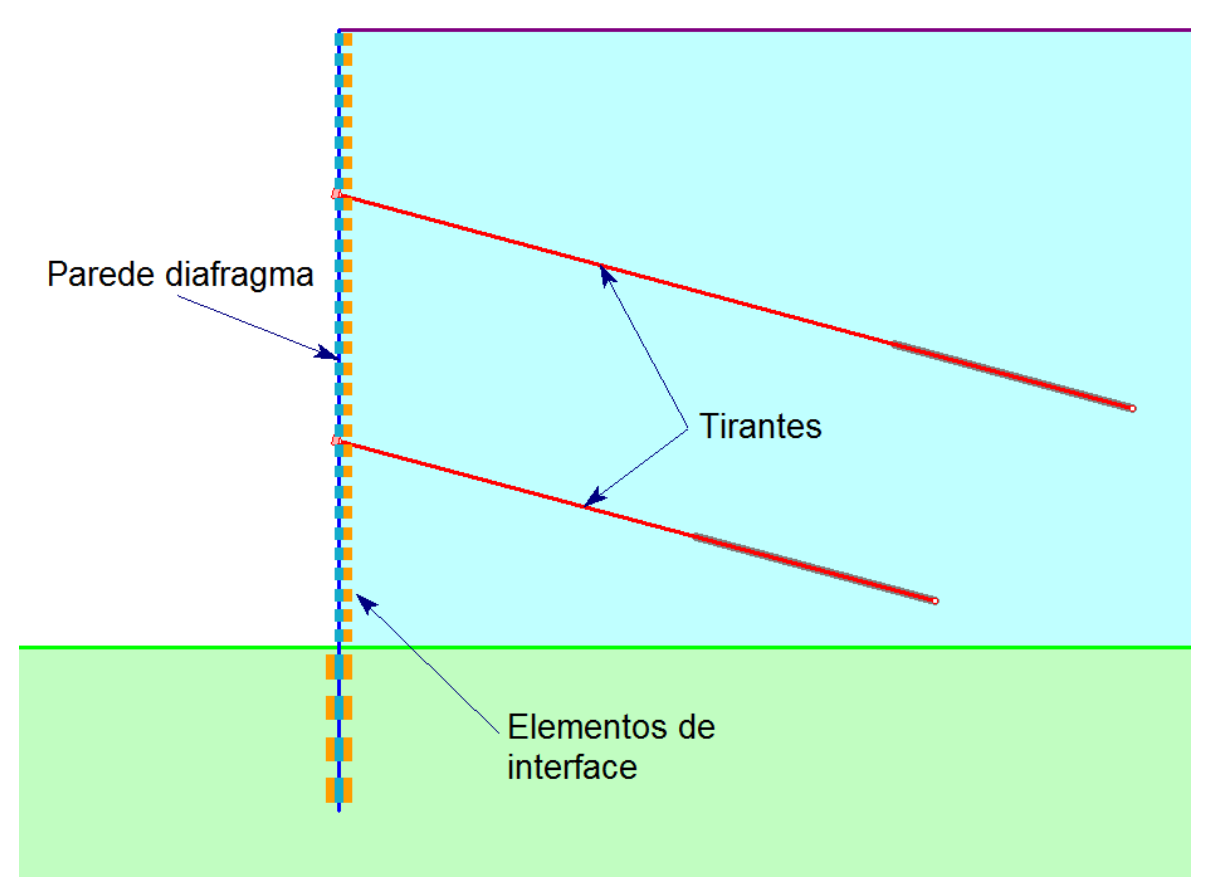

Figura 86 - Elementos componentes dos modelos 
15 etapas de

escavação $(1 \mathrm{~m})$

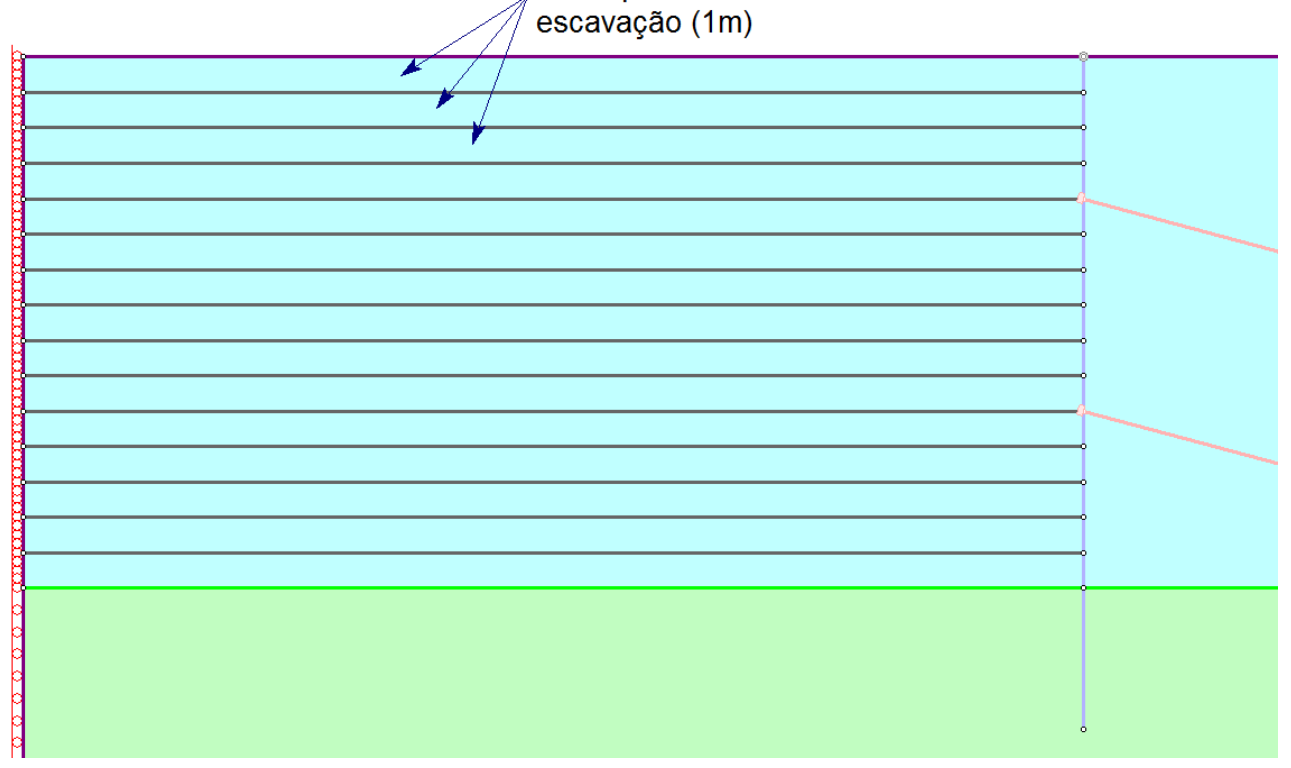

Figura 87 - Etapas de escavação dos modelos

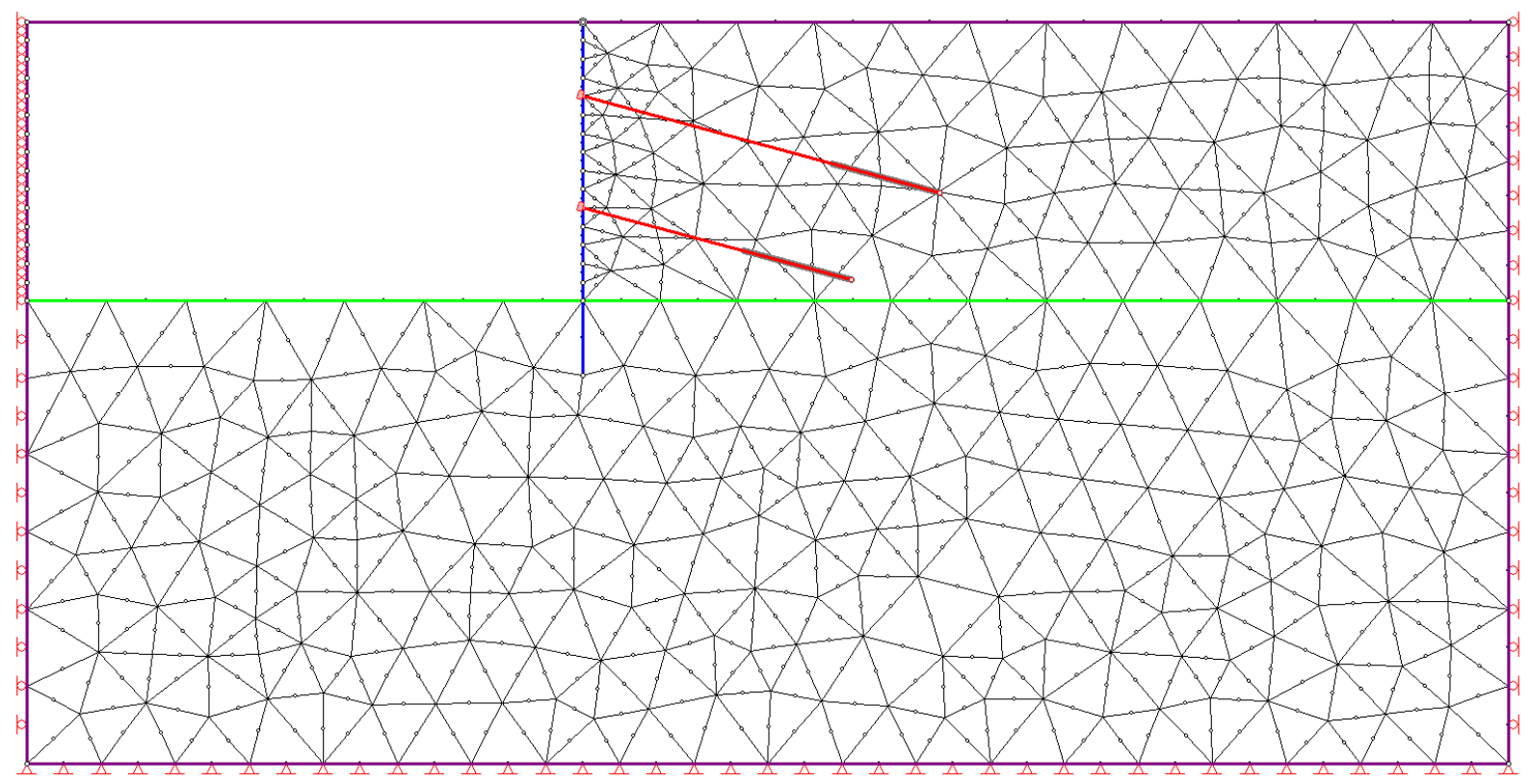

Figura 88 - 802 Elementos T6 


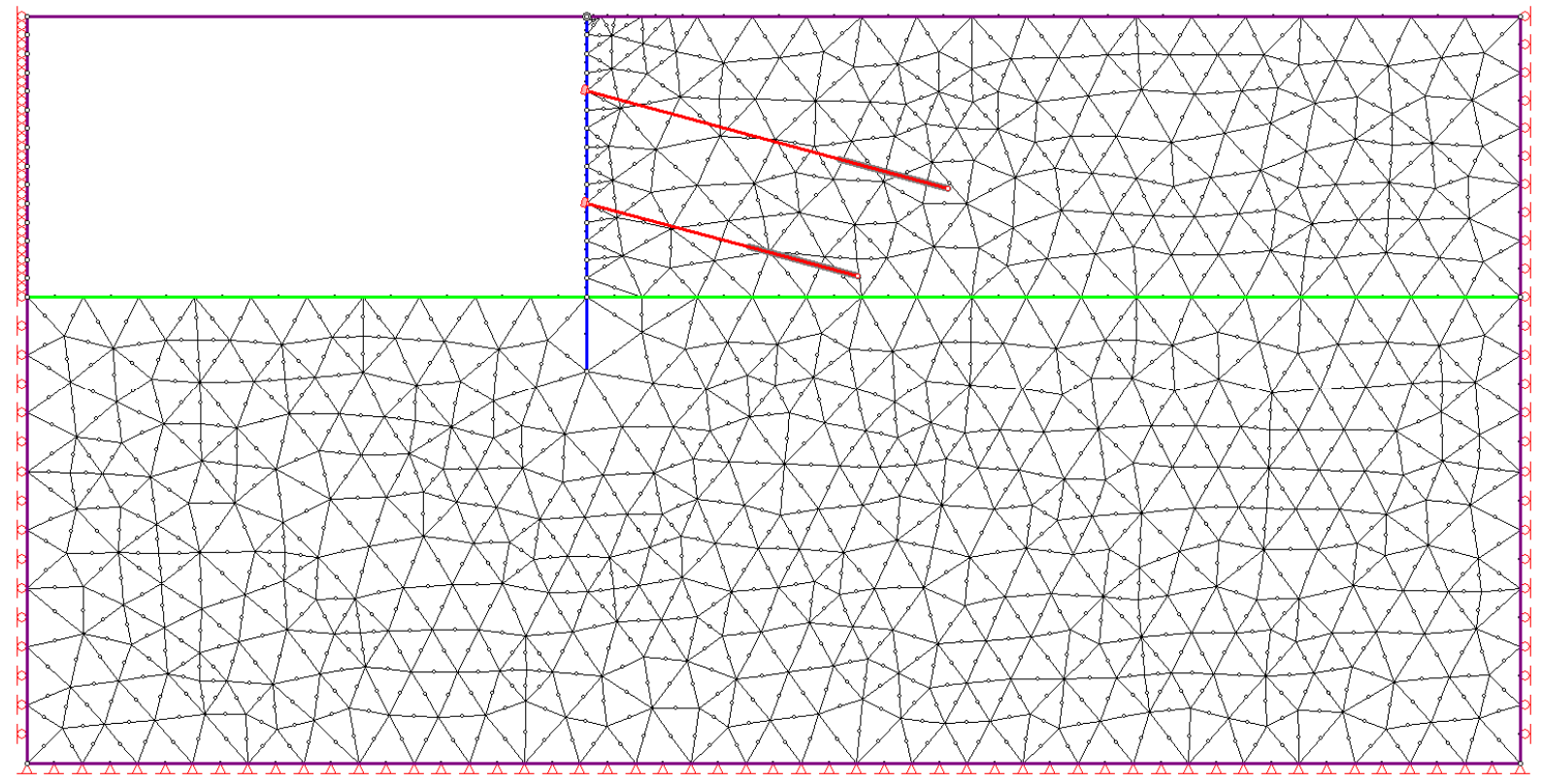

Figura 89 - 1381 Elementos T6

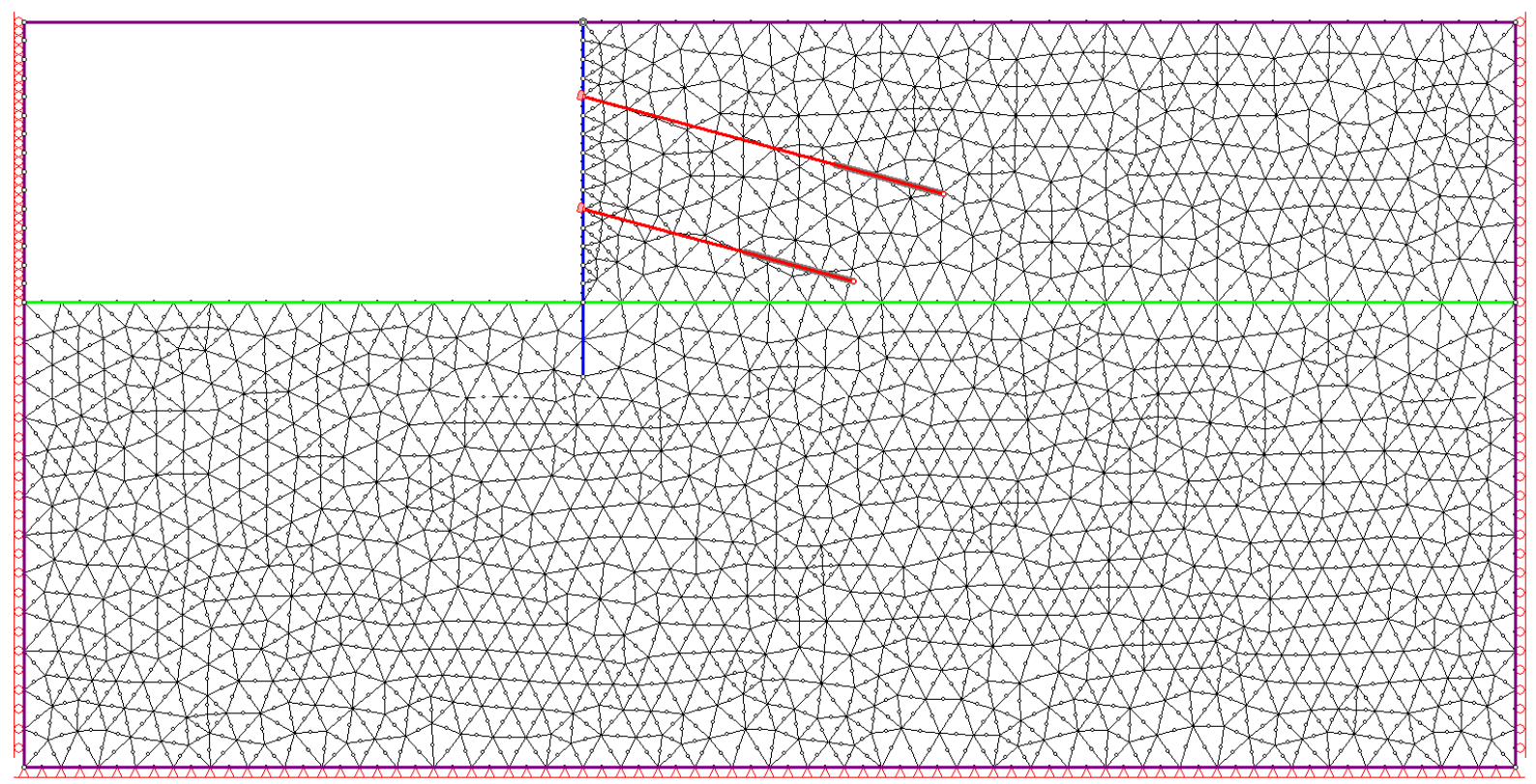

Figura 90 - 2746 Elementos T6 


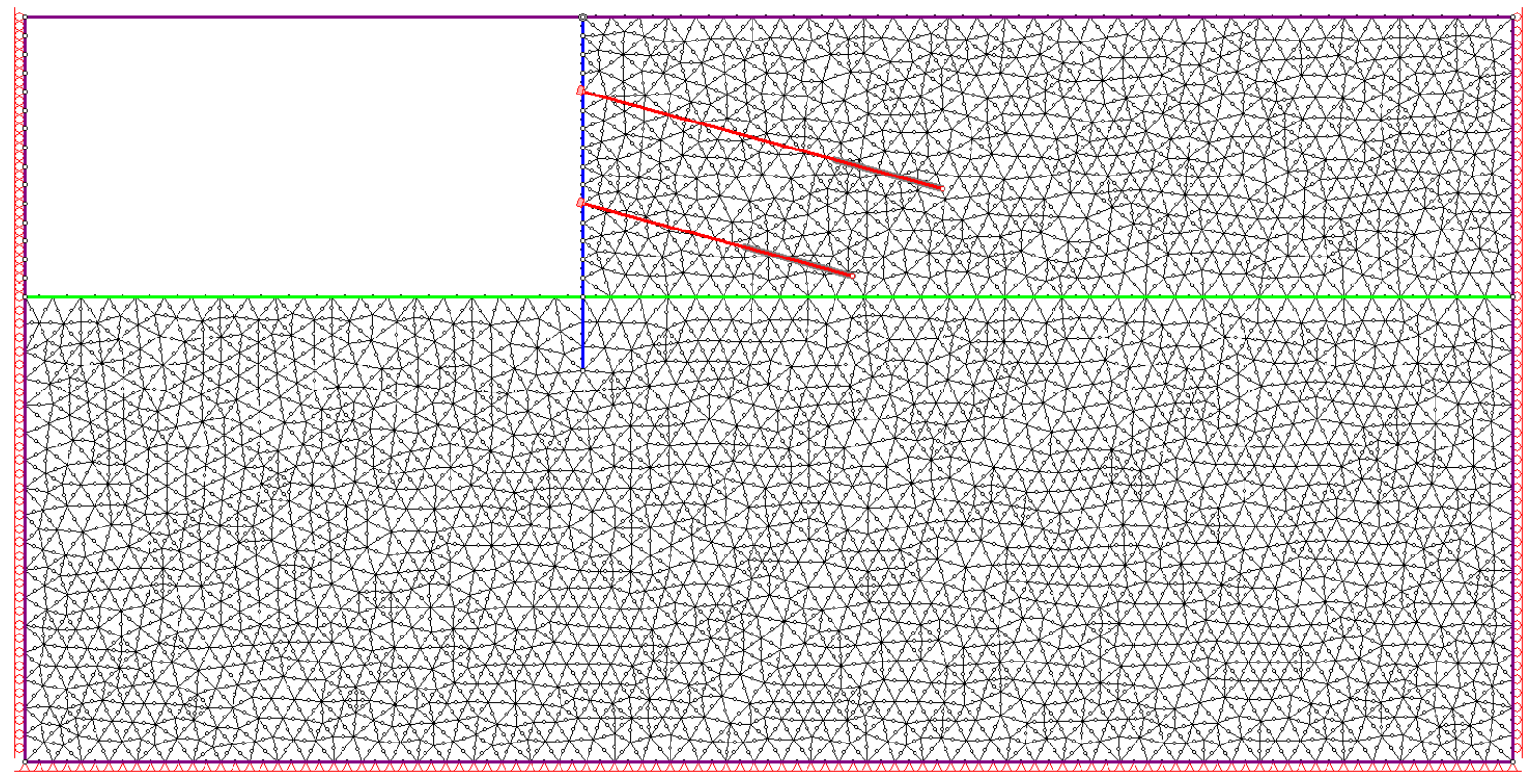

Figura 91 - 5317 Elementos T6

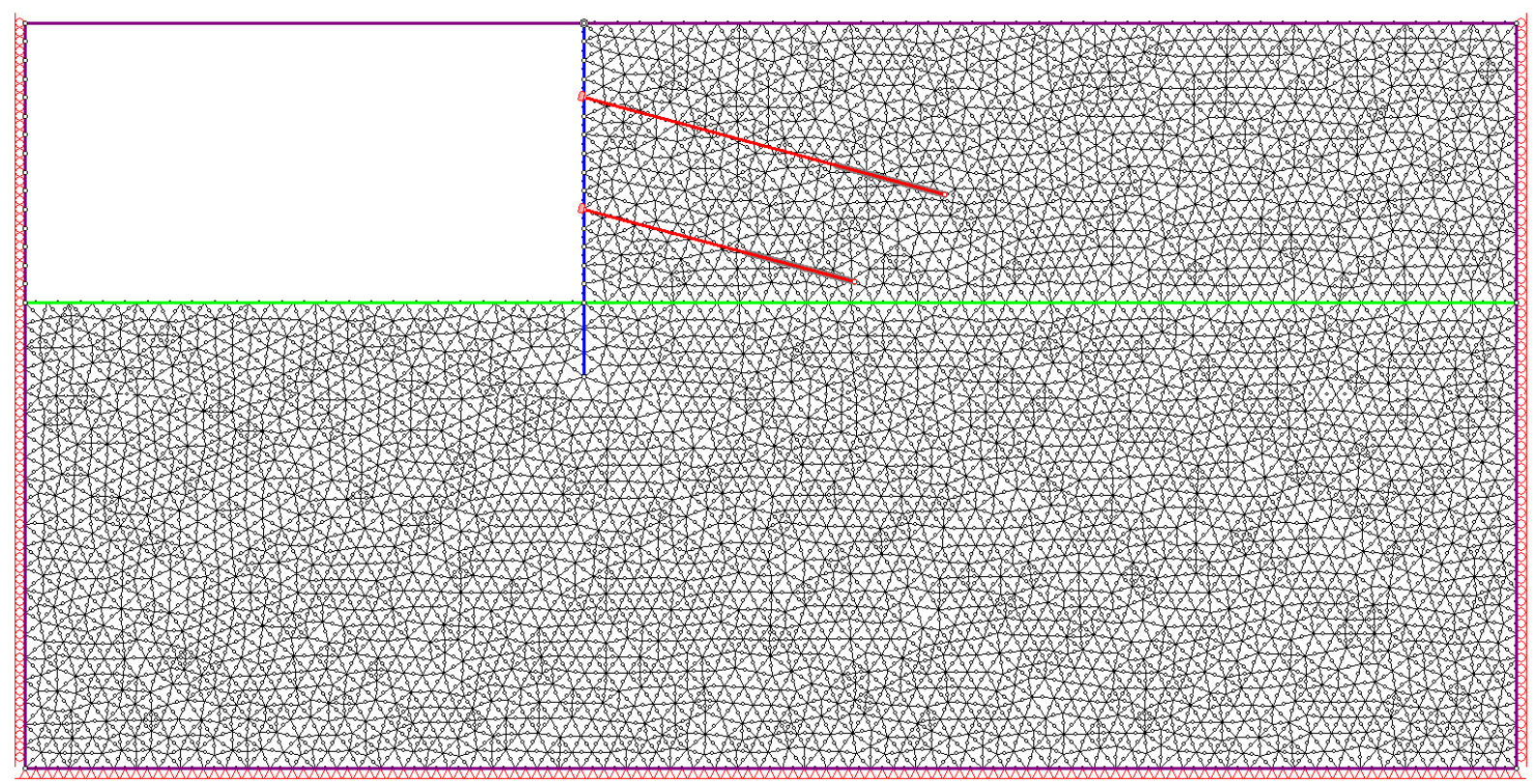

Figura 92 - 7907 Elementos T6 


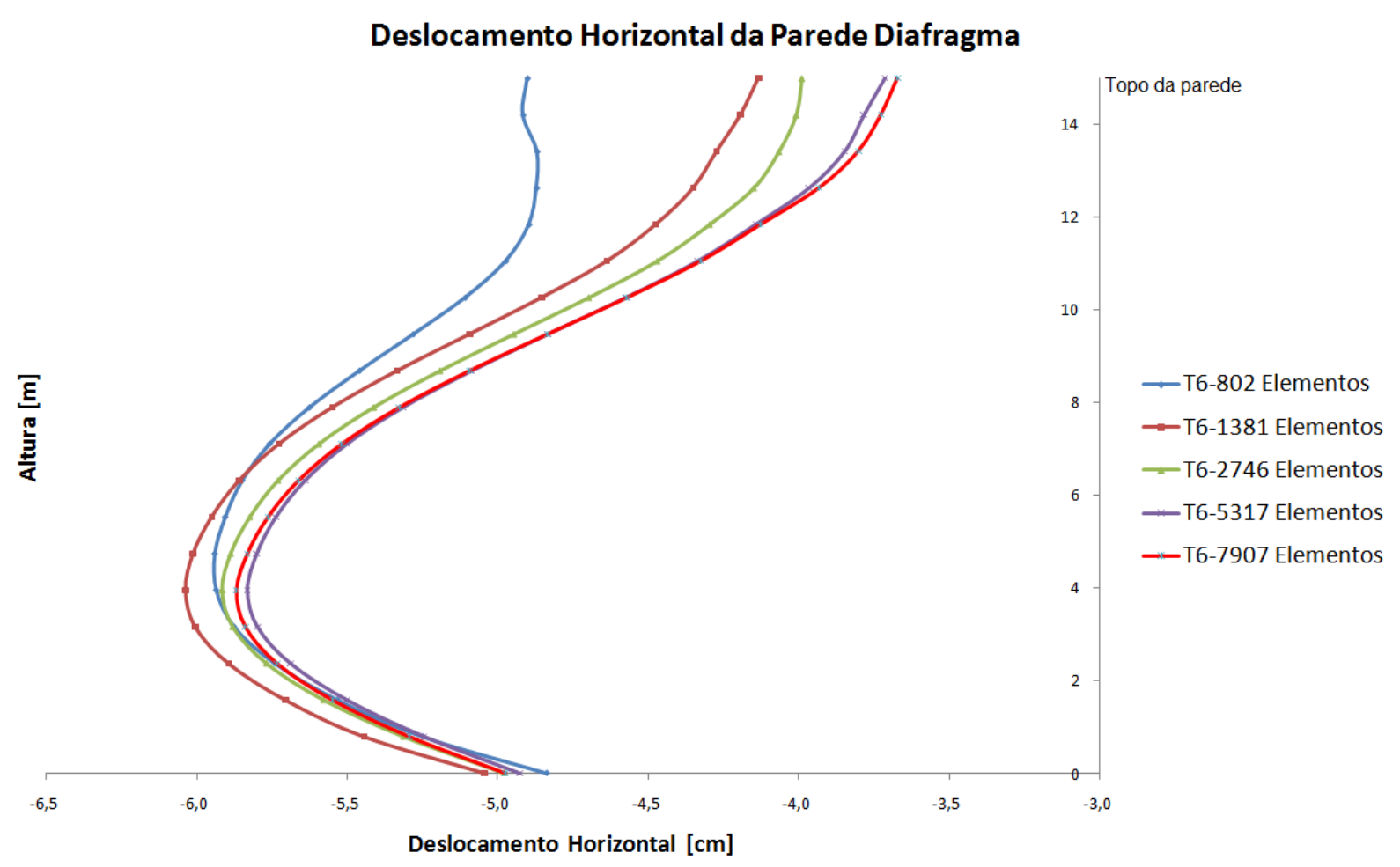

Figura 93 - Deslocamento horizontal da parede diafragma de 5 modelos com elementos T6

Pelo gráfico acima, a não ser pelo modelo com 802 elementos, a diferença absoluta entre os deslocamentos foi pequena, e também a convergência foi alcançada a partir do modelo com 5317 elementos.

Adicionalmente fez-se um modelo em que a malha foi adensada somente na região de influência da parede e dos tirantes, adotou-se, igualmente aos anteriores o elemento T6, com 2918 elementos. 


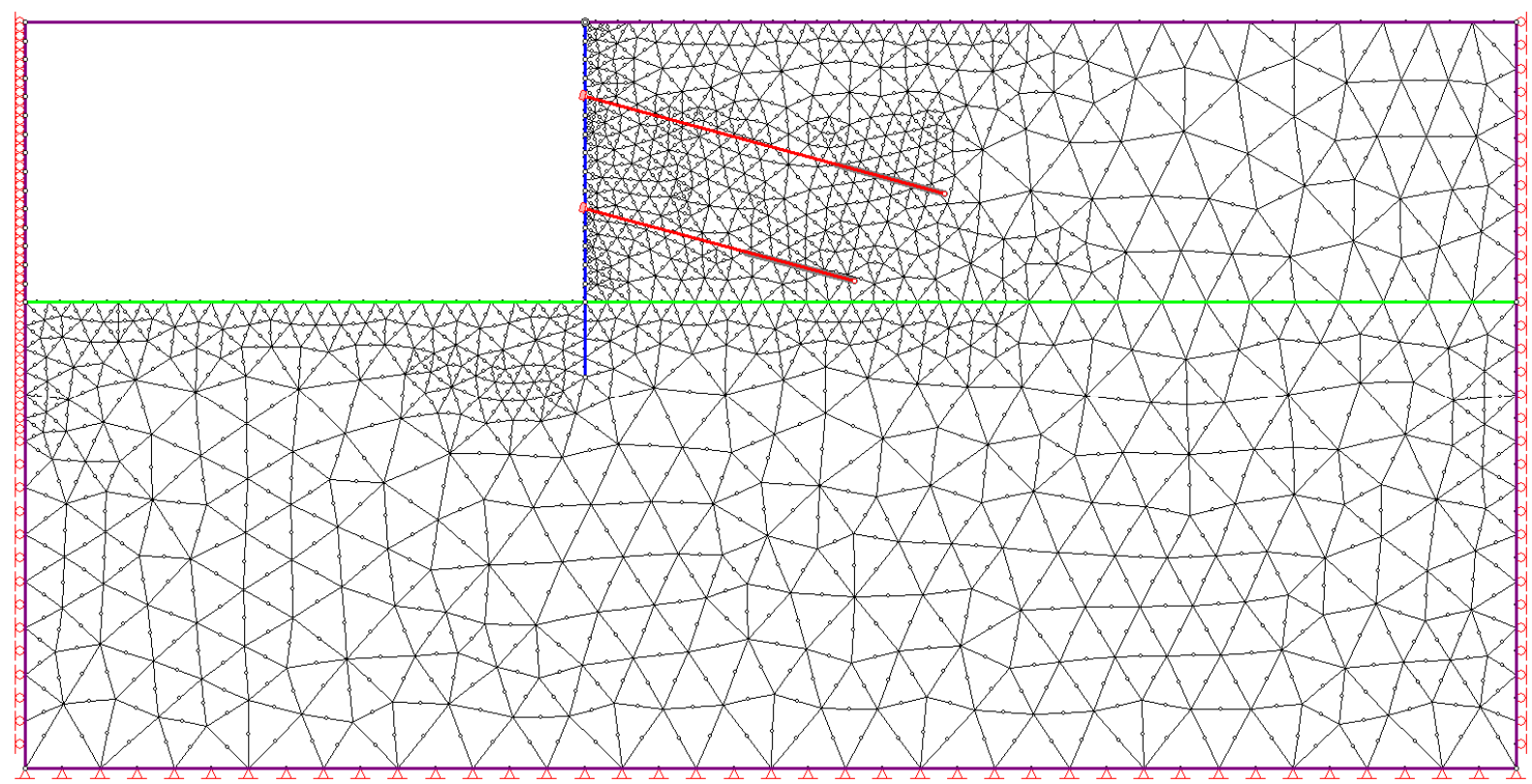

Figura 94 - 2918 Elementos T6 (Modelo com malha adensada na região da parede e tirantes)

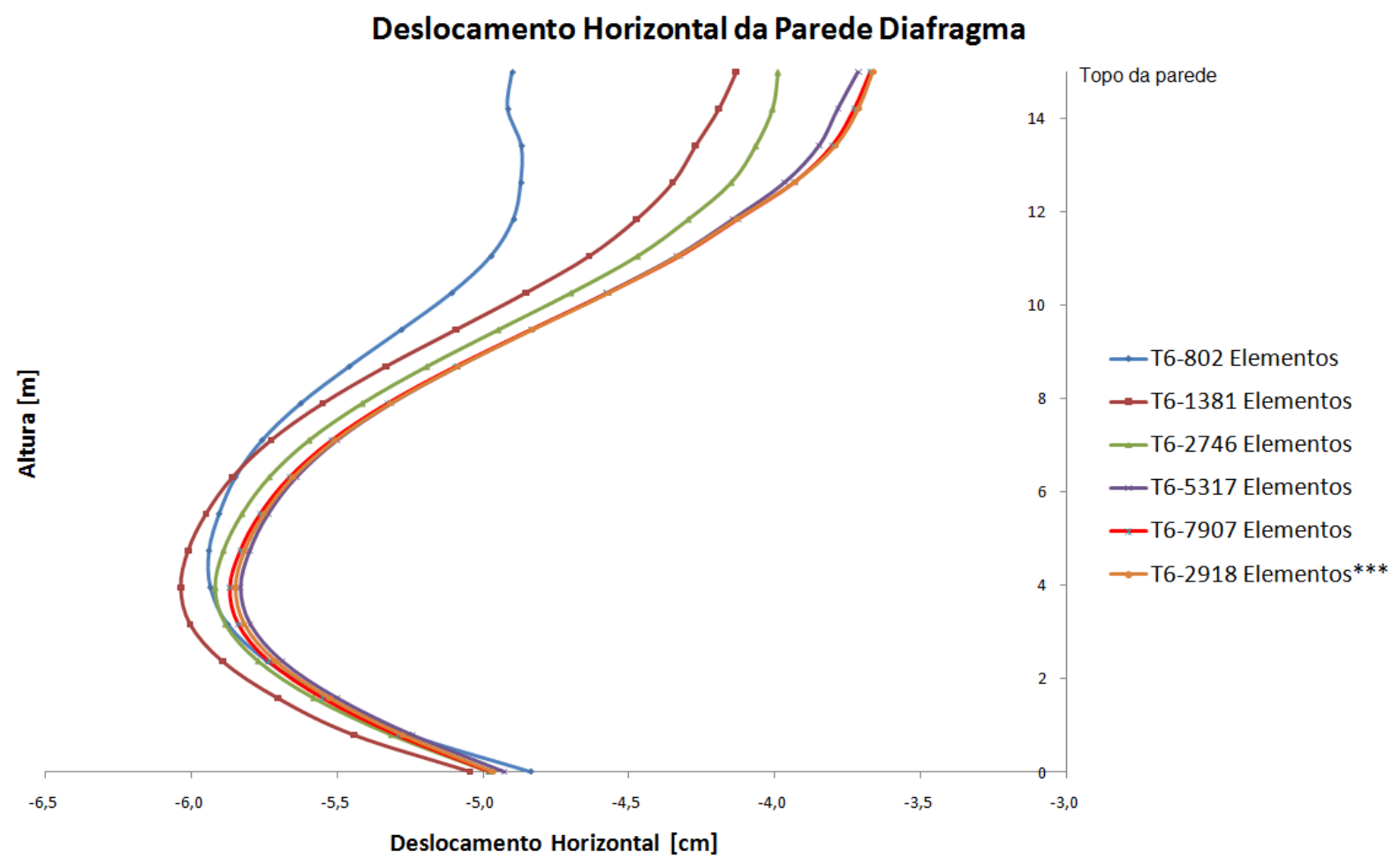

Figura 95 - Deslocamento horizontal da parede diafragma de 6 modelos com elementos T6

Observa-se pelo gráfico acima que o modelo com adensamento de malha gerou resultados próximos aos dos modelos com mais de 5000 elementos.

Abaixo são apresentados os modelos e o gráficos para o elemento Q8: 


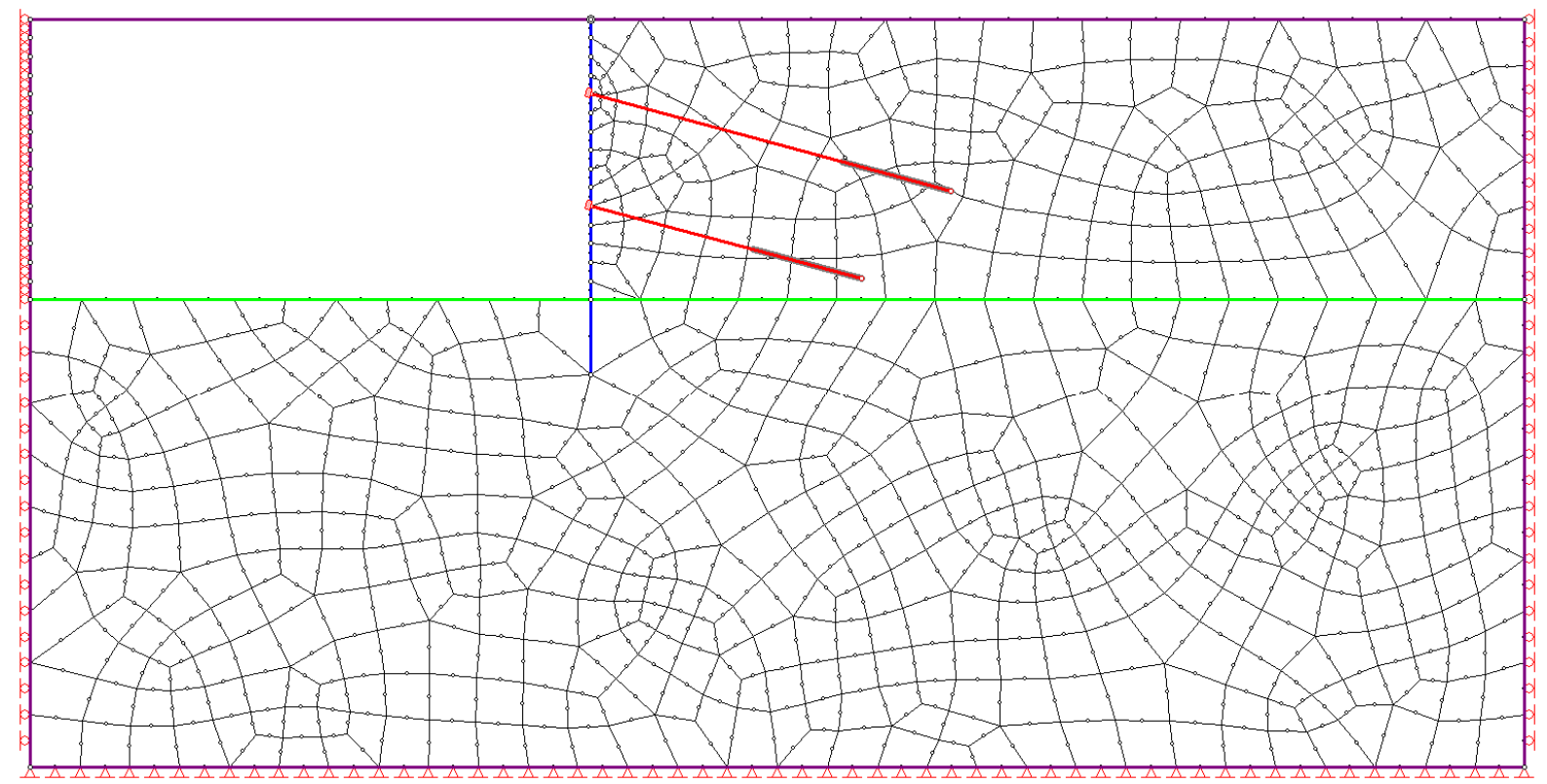

Figura 96 - 800 Elementos Q8

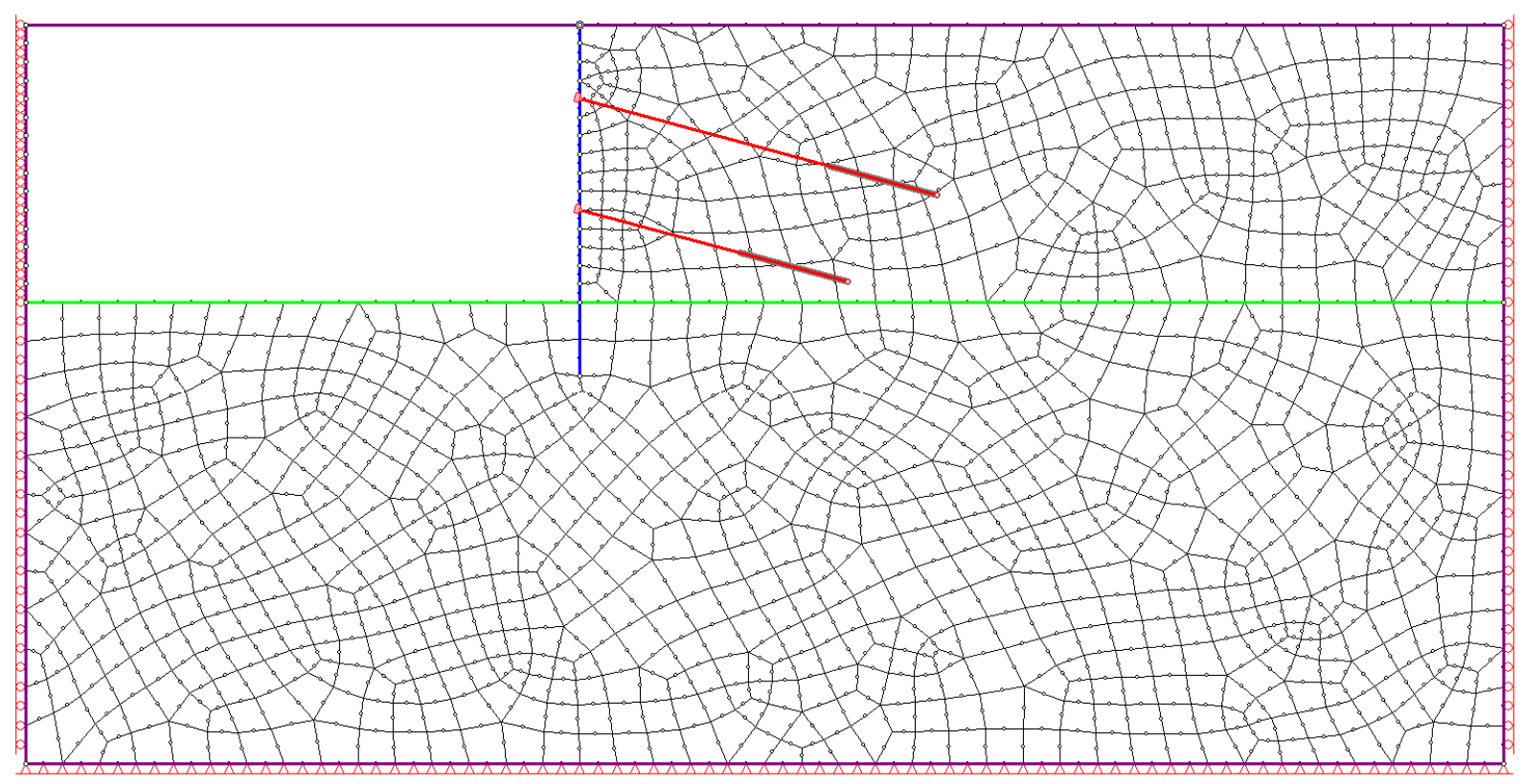

Figura 97 - 1268 Elementos Q8 


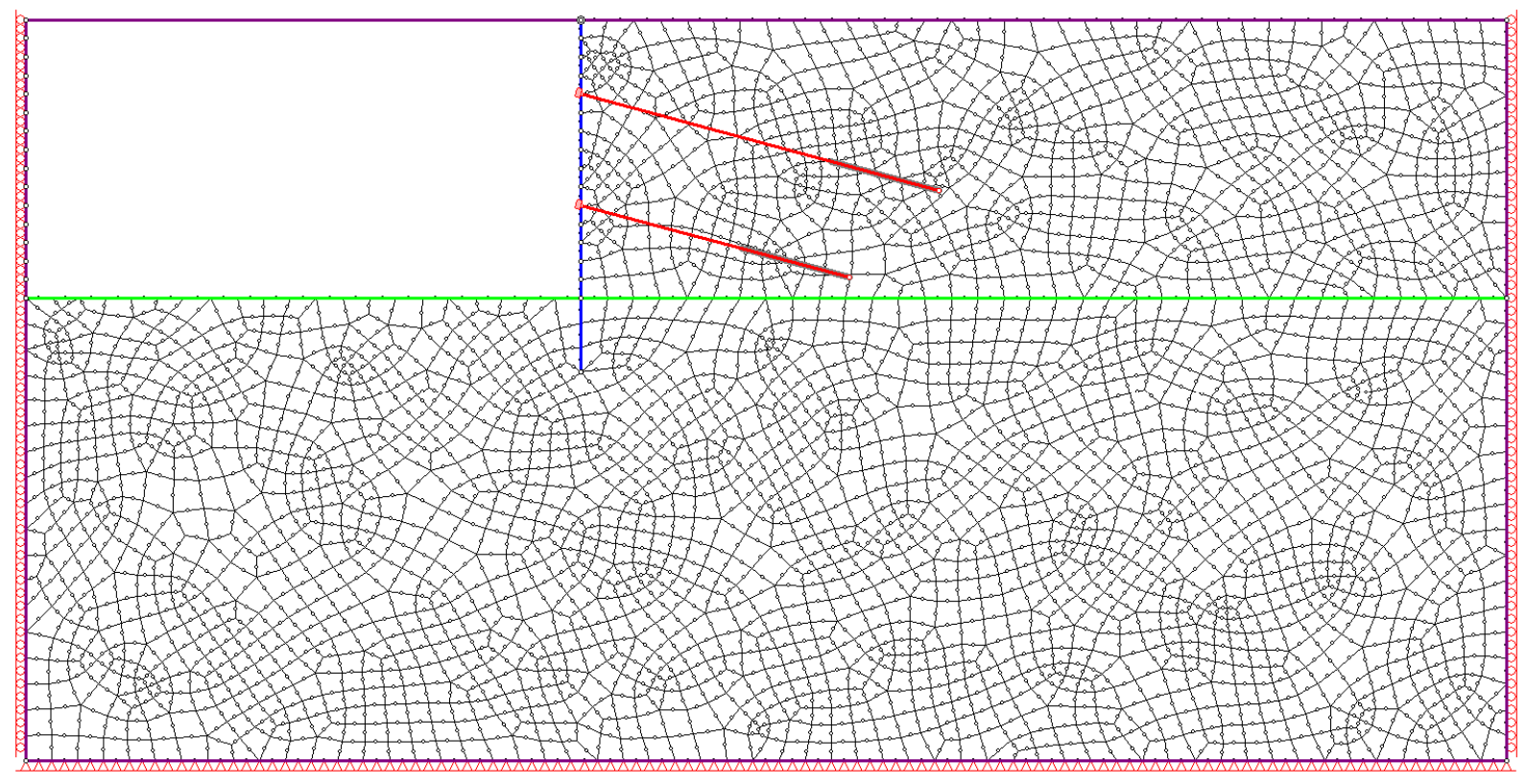

Figura 98 - 2799 Elementos Q8

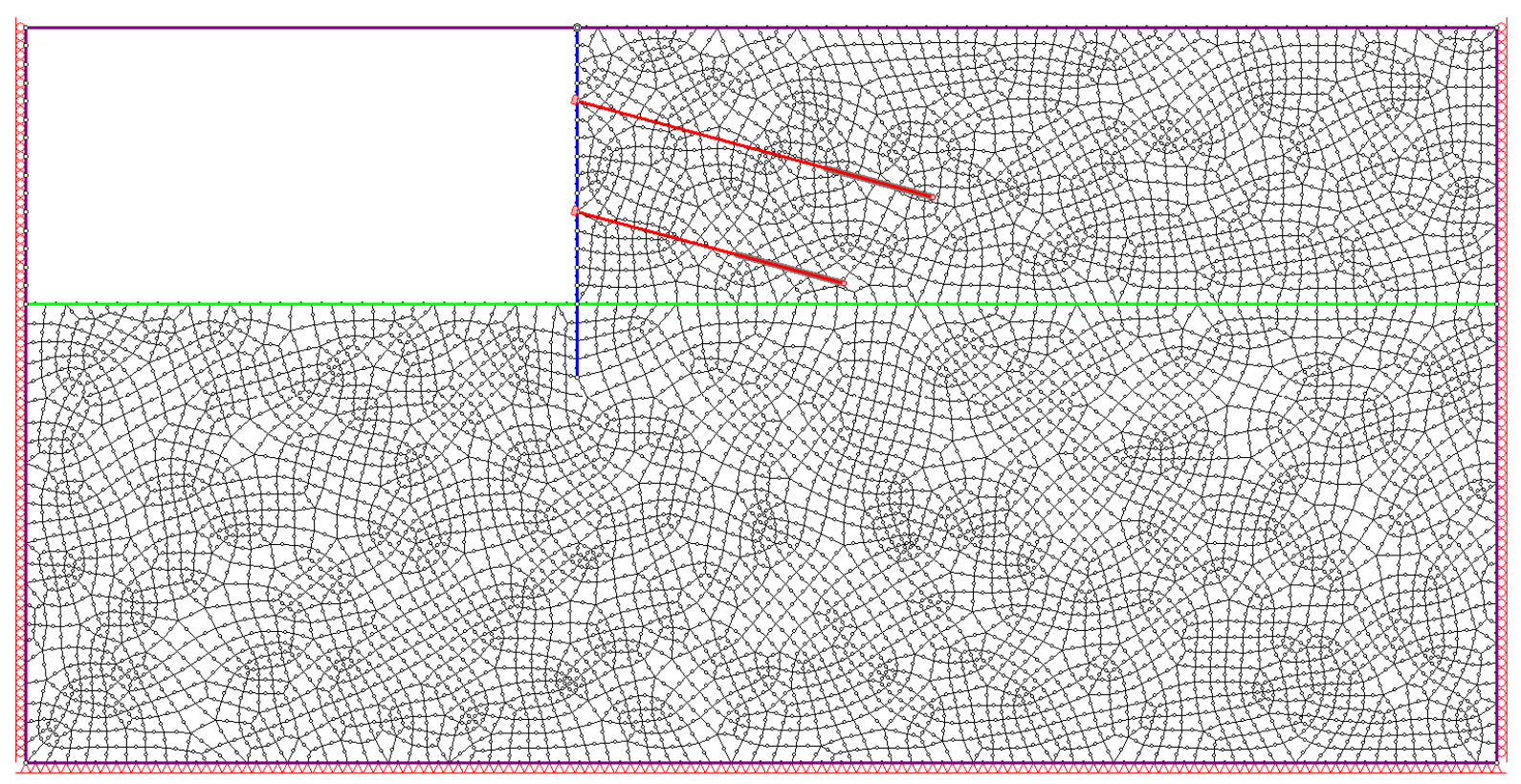

Figura 99 - 4435 Elementos Q8 


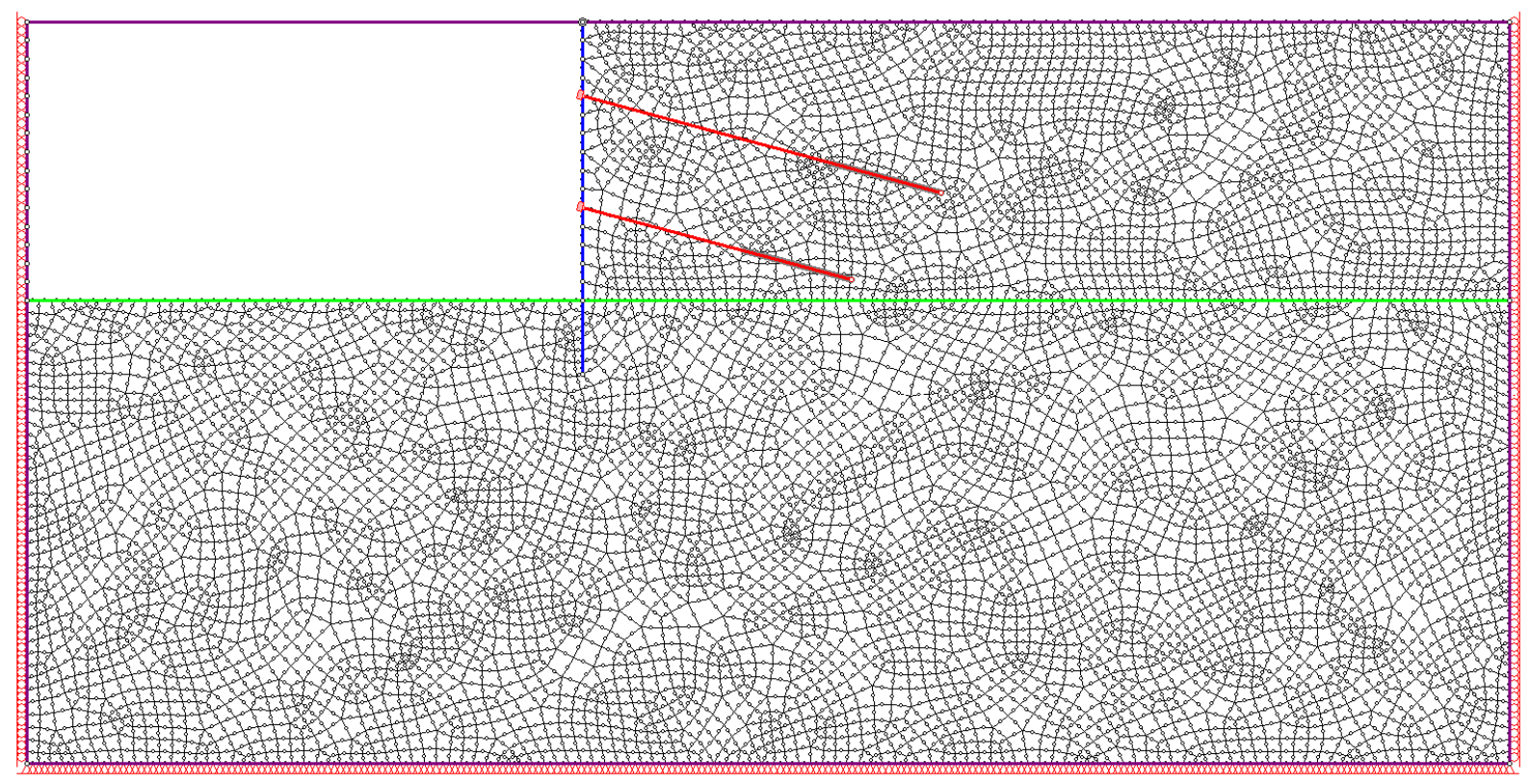

Figura 100 - 5891 Elementos Q8

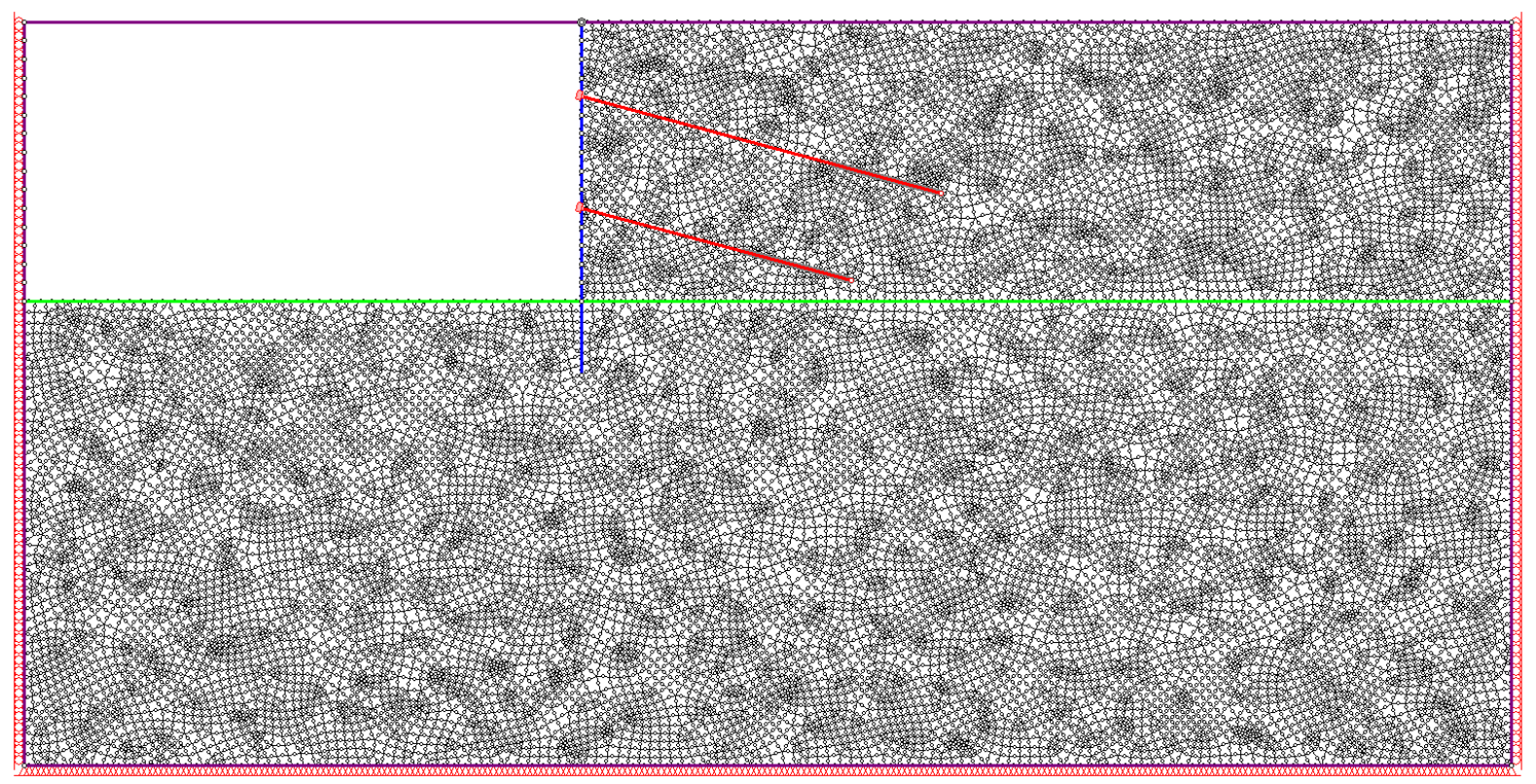

Figura 101 - 15456 Elementos Q8 


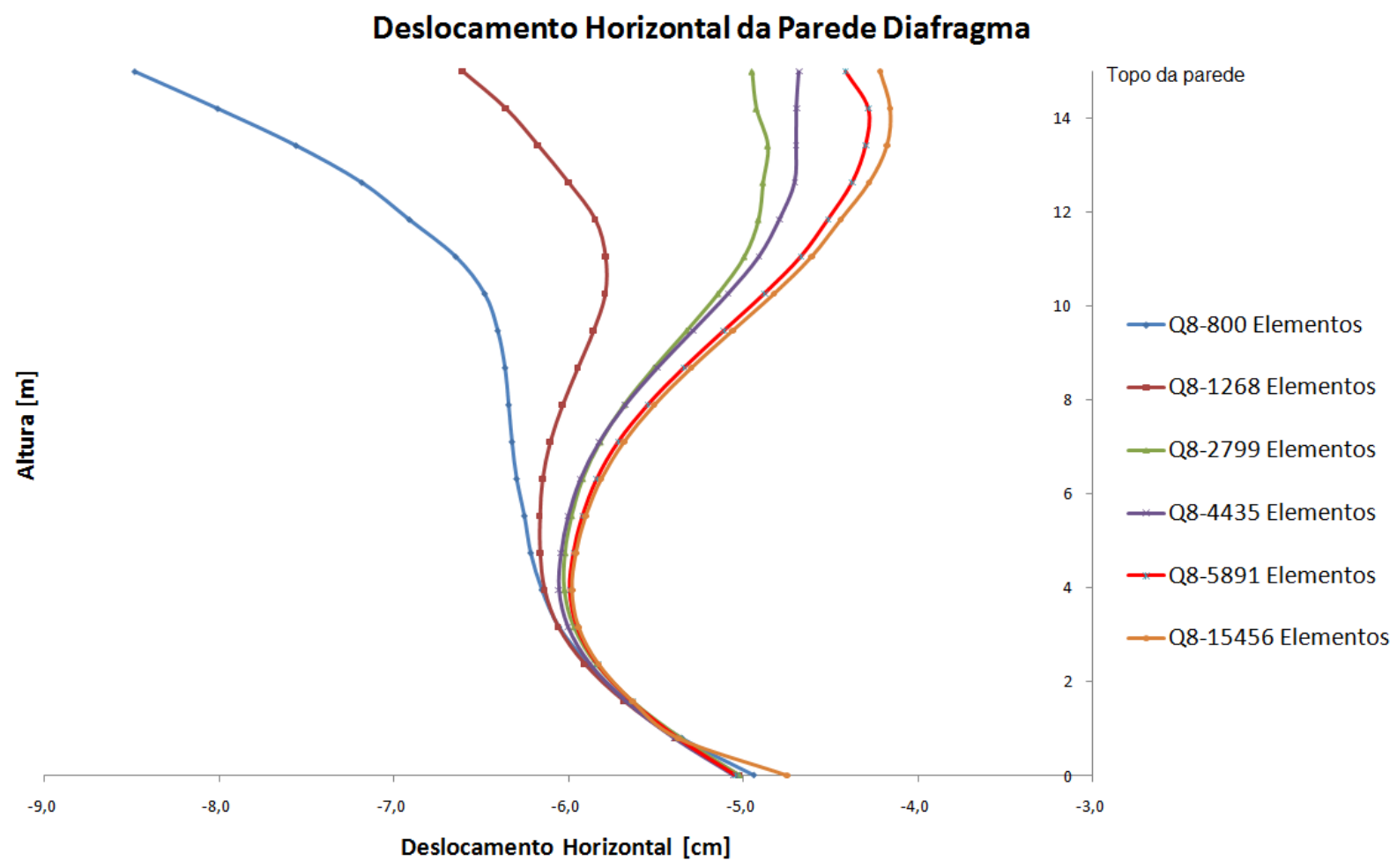

Figura 102 - Deslocamento horizontal da parede diafragma de 5 modelos com elementos Q8

Observa-se pelo gráfico que diferença absoluta entre os deslocamentos foi grande para os modelos com menos de 2000 elementos, e também que a convergência foi alcançada a partir do modelo com 5817 elementos.

Os resultados dos deslocamentos da parede nos modelos Q8-15456 e T67907 foram comparados pelo gráfico abaixo: 


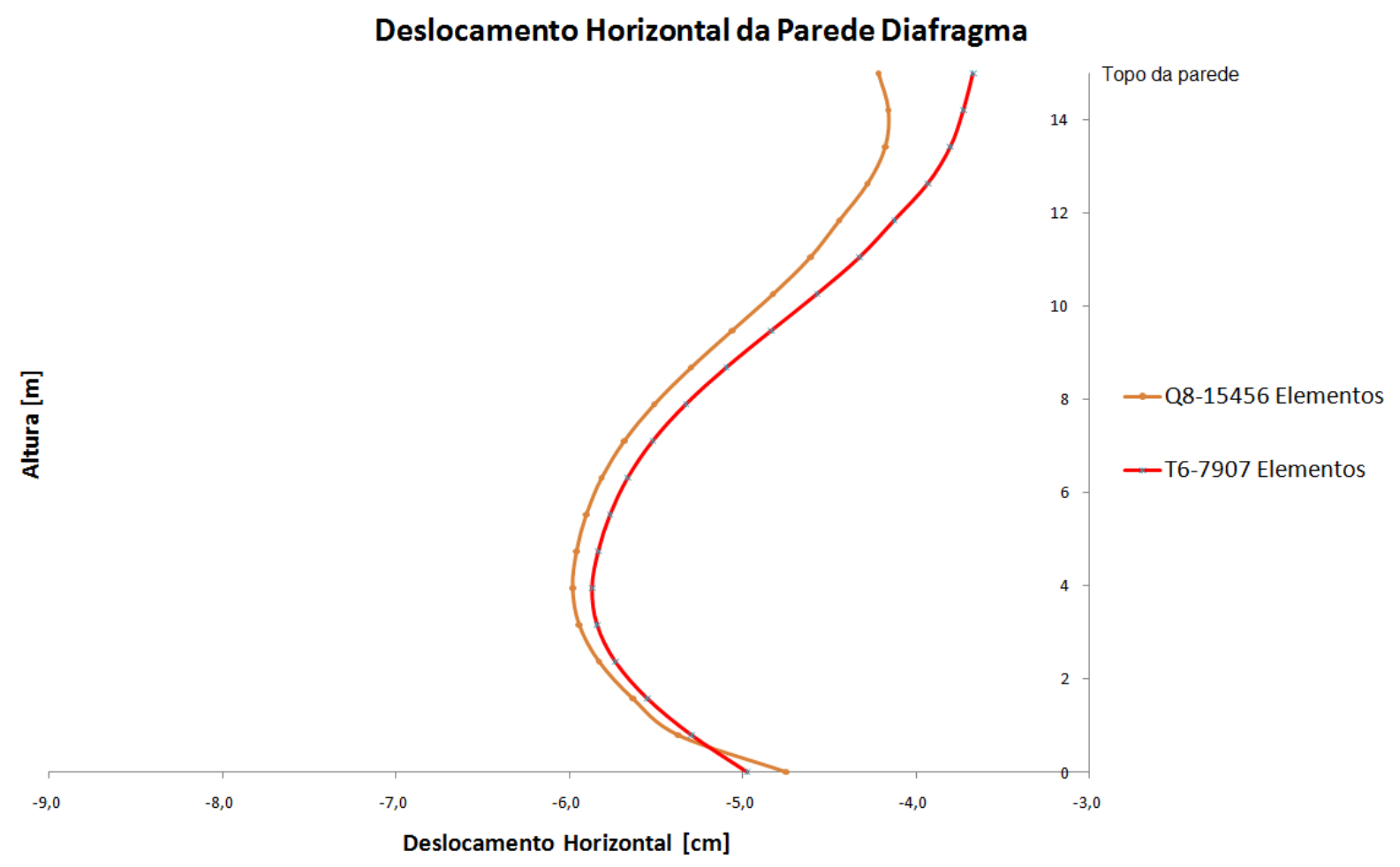

Figura 103 - Deslocamento horizontal da parede nos modelos Q8-15456 e T6-7907

Tabela 23 - Comparação dos deslocamentos nas paredes dos modelos Q8-15456 e T6-7907

\begin{tabular}{|c|c|c|c|c|}
\hline \multirow{2}{*}{$\begin{array}{c}\text { Dist. (m) } \\
\text { (0 - topo) }\end{array}$} & \multicolumn{2}{|c|}{ Deslocamento horizontal (cm) } & \multirow{2}{*}{ Dif. absoluta (cm) } \\
\hline 0,0 & 4,2 & 3,7 & $14,9 \%$ & 0,5 \\
\hline 0,8 & 4,2 & 3,7 & $11,6 \%$ & 0,4 \\
\hline 1,6 & 4,2 & 3,8 & $9,9 \%$ & 0,4 \\
\hline 2,4 & 4,3 & 3,9 & $8,9 \%$ & 0,3 \\
\hline 3,2 & 4,4 & 4,1 & $7,7 \%$ & 0,3 \\
\hline 3,9 & 4,6 & 4,3 & $6,6 \%$ & 0,3 \\
\hline 4,7 & 4,8 & 4,6 & $5,5 \%$ & 0,3 \\
\hline 5,5 & 5,1 & 4,8 & $4,7 \%$ & 0,2 \\
\hline 6,3 & 5,3 & 5,1 & $4,0 \%$ & 0,2 \\
\hline 7,1 & 5,5 & 5,3 & $3,4 \%$ & 0,2 \\
\hline 7,9 & 5,7 & 5,5 & $3,0 \%$ & 0,2 \\
\hline 8,7 & 5,8 & 5,7 & $2,7 \%$ & 0,2 \\
\hline 9,5 & 5,9 & 5,8 & $2,4 \%$ & 0,1 \\
\hline 10,3 & 6,0 & 5,8 & $2,2 \%$ & 0,1 \\
\hline 11,1 & 6,0 & 5,9 & $1,9 \%$ & 0,1 \\
\hline 11,8 & 5,9 & 5,8 & $1,8 \%$ & 0,1 \\
\hline 12,6 & 5,8 & 5,7 & $1,7 \%$ & 0,1 \\
\hline 13,4 & 5,6 & 5,5 & $1,5 \%$ & 0,1 \\
\hline 14,2 & 5,4 & 5,3 & $1,5 \%$ & 0,1 \\
\hline 15,0 & 4,8 & 5,0 & $4,7 \%$ & 0,2 \\
\hline
\end{tabular}

Fonte: Elaborado pelo autor com base nos resultados dos modelos

Observa-se pelo gráfico e tabela acima um comportamento mais rígido do modelo com elementos triangulares, que fica evidenciado por apresentar 
deslocamentos menores ao longo de praticamente toda a altura e pela diferença maior $(14,9 \%)$ estar na região menos rígida, o topo da parede que fica em balanço. A maior diferença absoluta foi pequena $(0,5 \mathrm{~cm})$, se considerarmos que se trata de uma contenção com $15 \mathrm{~m}$ de altura. Na região de maior deslocamento a diferença foi pequena, em torno de $2 \%$ com diferença absoluta de $0,1 \mathrm{~cm}$.

Abaixo são apresentados os esforços obtidos na fase final da escavação, para os dois modelos:

Momento Fletor

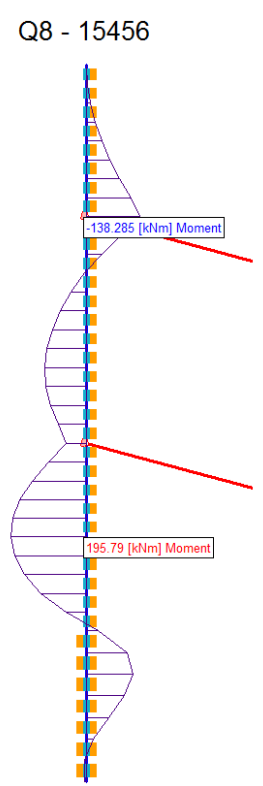

Força Normal

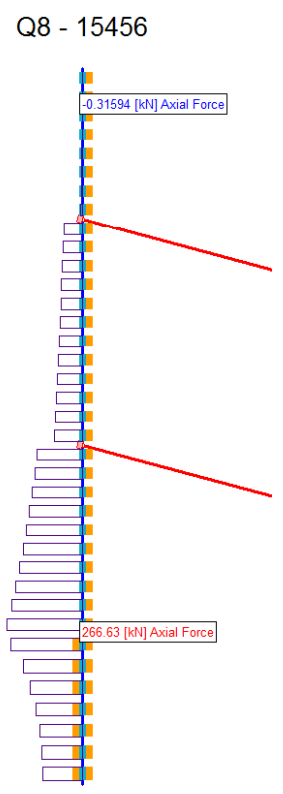

T6 - 7907

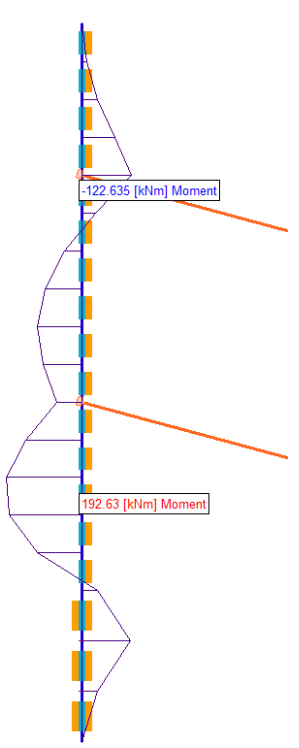

T6 - 7907

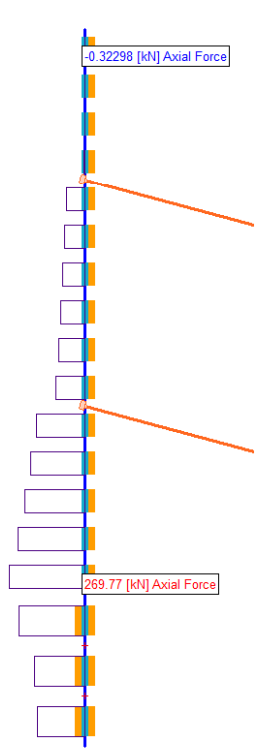

Força Cortante

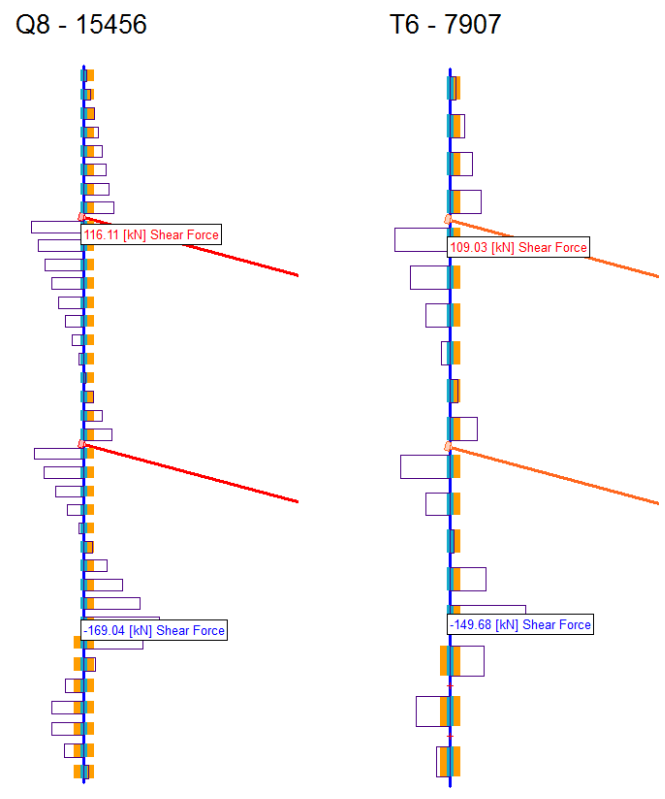


Para o momento fletor e força normal a diferença foi pequena, considerando os valores máximos, 1,6\% para o momento fletor e 1,2\% para a força normal, no caso da força cortante a diferença foi maior, $12,9 \%$ se considerarmos as incertezas inerentes aos modelos, valores em torno de $10 \%$ são tolerados. No entanto, para investigar se a diferença na força cortante é devida a discretização da malha em torno da parede, foi elaborado outro modelo adensando a malha neste local, que ficou com 8687 elementos.

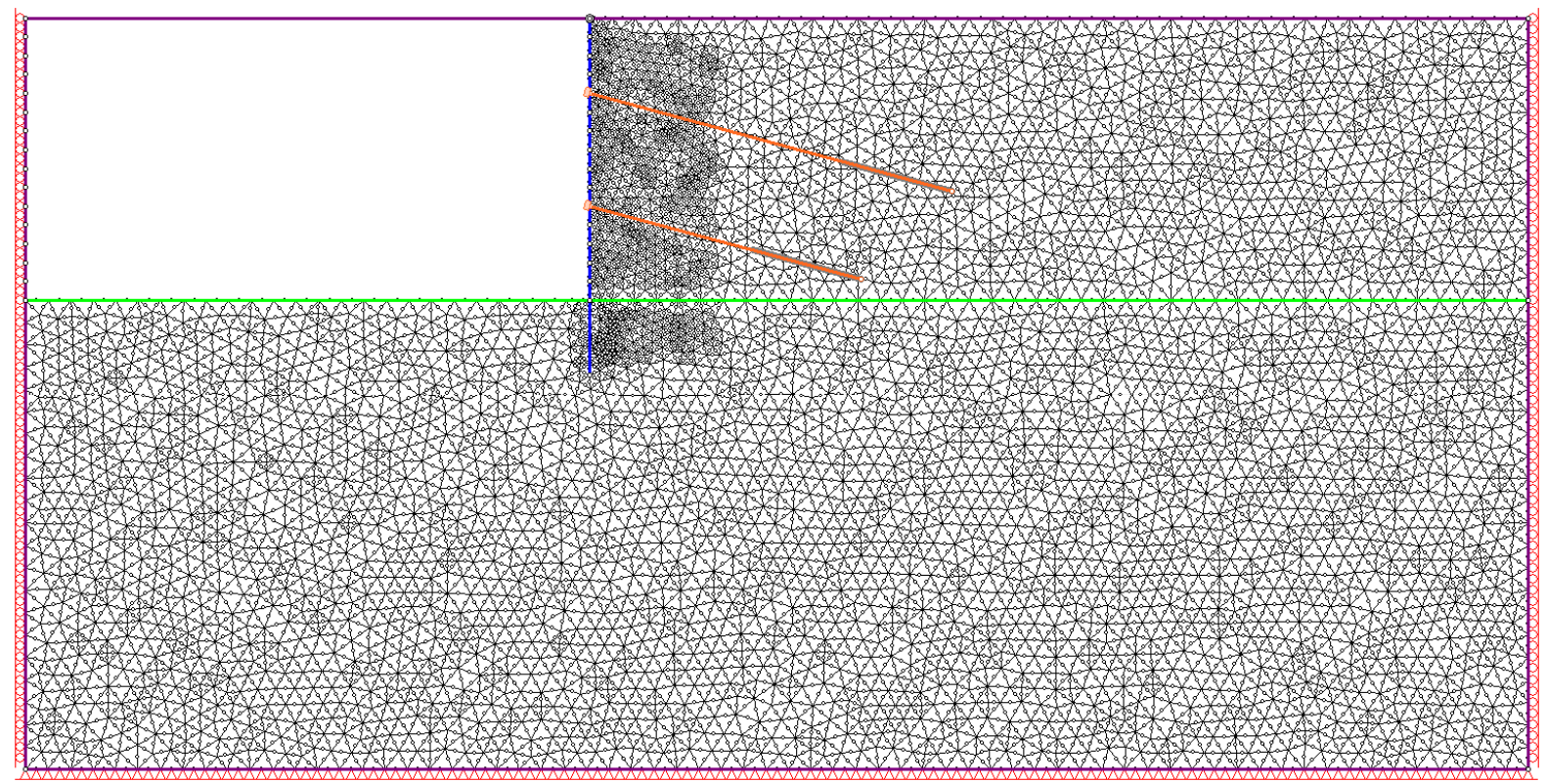

Figura 105 - 8687 Elementos T6 


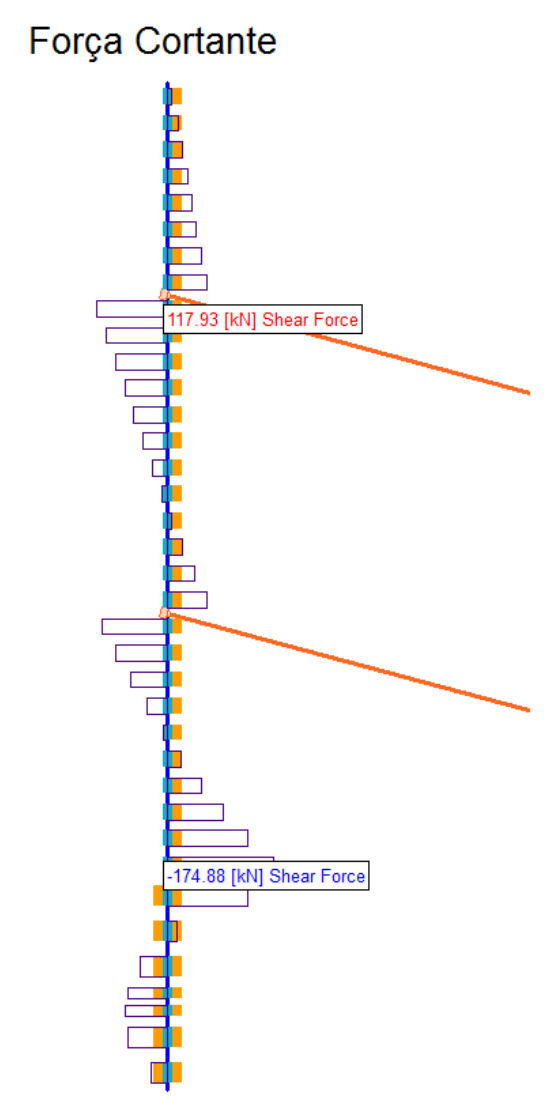

Figura 106 - Força cortante na parede do modelo T6-8687

Observa-se que a diferença entre a força cortante do modelo com adensamento e o modelo Q8-15456 foi pequena, 3,5\%.

Pelo observado nas comparações, os modelos com elemento T6 apresentam resultados satisfatórios, tomando-se os cuidados com a discretização da malha na região da parede.

Para os demais modelos deste trabalho foram adotados malhas com elementos T6. As análises de estabilidade para modelos com muitos elementos podem ser demoradas, e a região que realmente é afetada pela análise de estabilidade é uma parcela do modelo total, portanto será adotado o modelo T62918 para as próximas análises. Os esforços da parede, obtidos neste modelo na fase final de escavação são apresentados abaixo: 


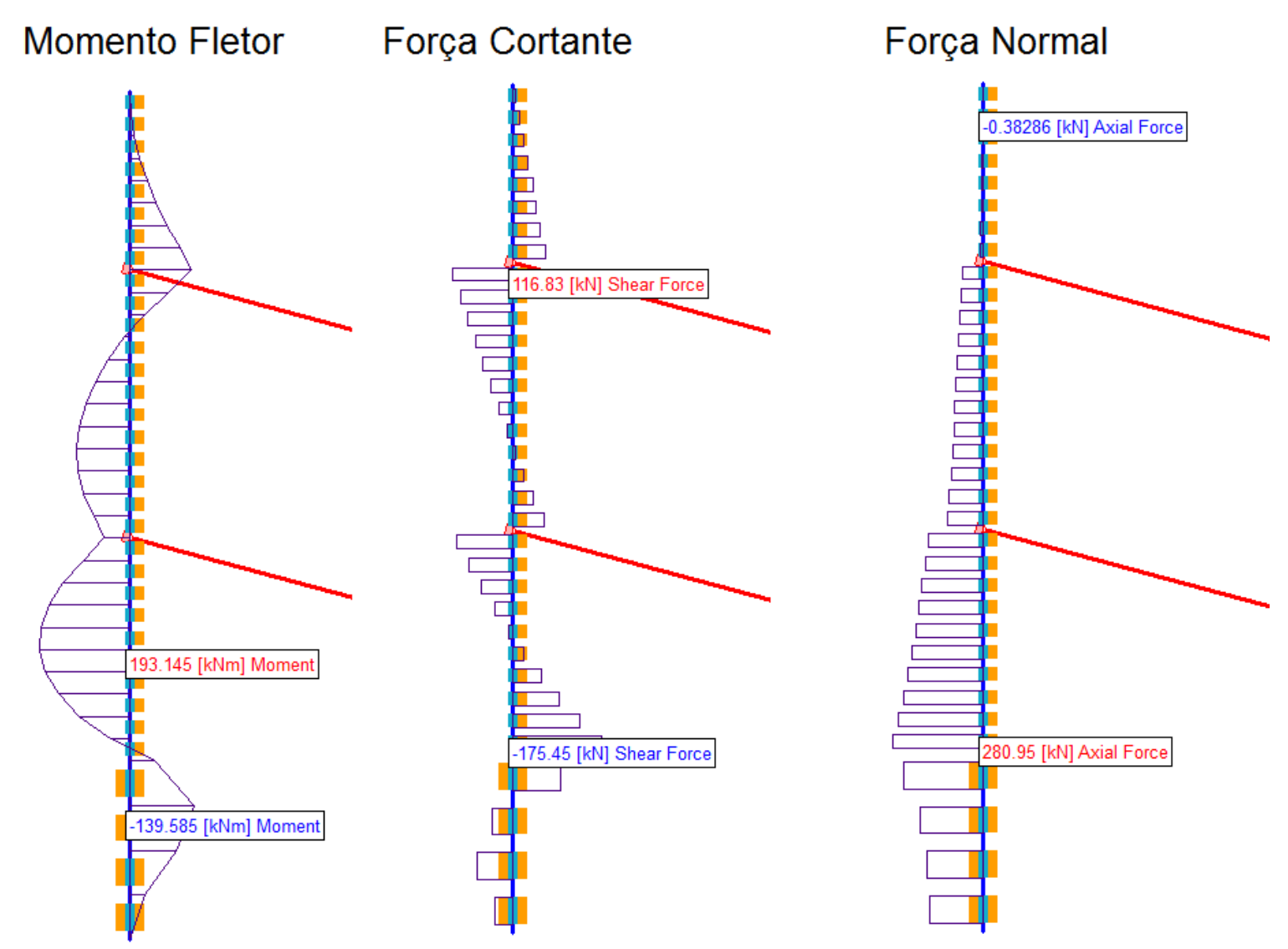

Figura 107 - Esforços na parede do modelo T6-2918

Comparando os esforços do modelo T6-2918 com os obtidos no modelo Q815456 as diferenças foram pequenas, para o momento fletor máximo a diferença foi pequena, $1,4 \%$, a força normal, $5,4 \%$ e a força cortante $3,8 \%$.

Os esforços acima foram adotados para o dimensionamento da parede que será usado nos modelos não-lineares:

Desconsiderando a força normal, haja vista que a força normal aplicada é pequena perante a capacidade resistente $\left(\nu_{d}=7286 \mathrm{kN}\right)$, por meio das tabelas para flexão simples (PINHEIRO; NASCIMENTO e MOREIRA, 2006):

$k_{c}=\frac{b \cdot d^{2}}{M_{d}}=\frac{100 \cdot 35^{2}}{1,4 \cdot 100 \cdot 200}=4,4 \Rightarrow A_{s}=\frac{M_{d} \cdot k_{s}}{d}=\frac{28000 \cdot 0,025}{35}=20 \mathrm{~cm}^{2} / \mathrm{m}$

Adotado, portanto, $\varnothing 20 \mathrm{c} / 15\left(21 \mathrm{~cm}^{2} / \mathrm{m}\right)$.

As demais verificações não serão feitas, por não fazerem parte do escopo do trabalho. 


\subsection{ANÁLISE DE ESTABILIDADE COM MODELO ELÁSTICO LINEAR PARA A RIGIDEZ DA PAREDE}

Os dados principais do modelo foram apresentados anteriormente, abaixo é apresentado o módulo de elasticidade adotado:

$$
E_{c i}=1000 \cdot 0,85 \cdot 5600 \cdot \sqrt{30}=26071594 \mathrm{kN} / \mathrm{m}^{2} \text { - Módulo de elasticidade }
$$

ABNT NBR6118:2007;

O fator de segurança obtido é apresentado abaixo, juntamente ao gráfico de convergência fornecido pelo programa:

Shear Strength Reduction - Critical SRF: 2 at Displacement: 1.237 m

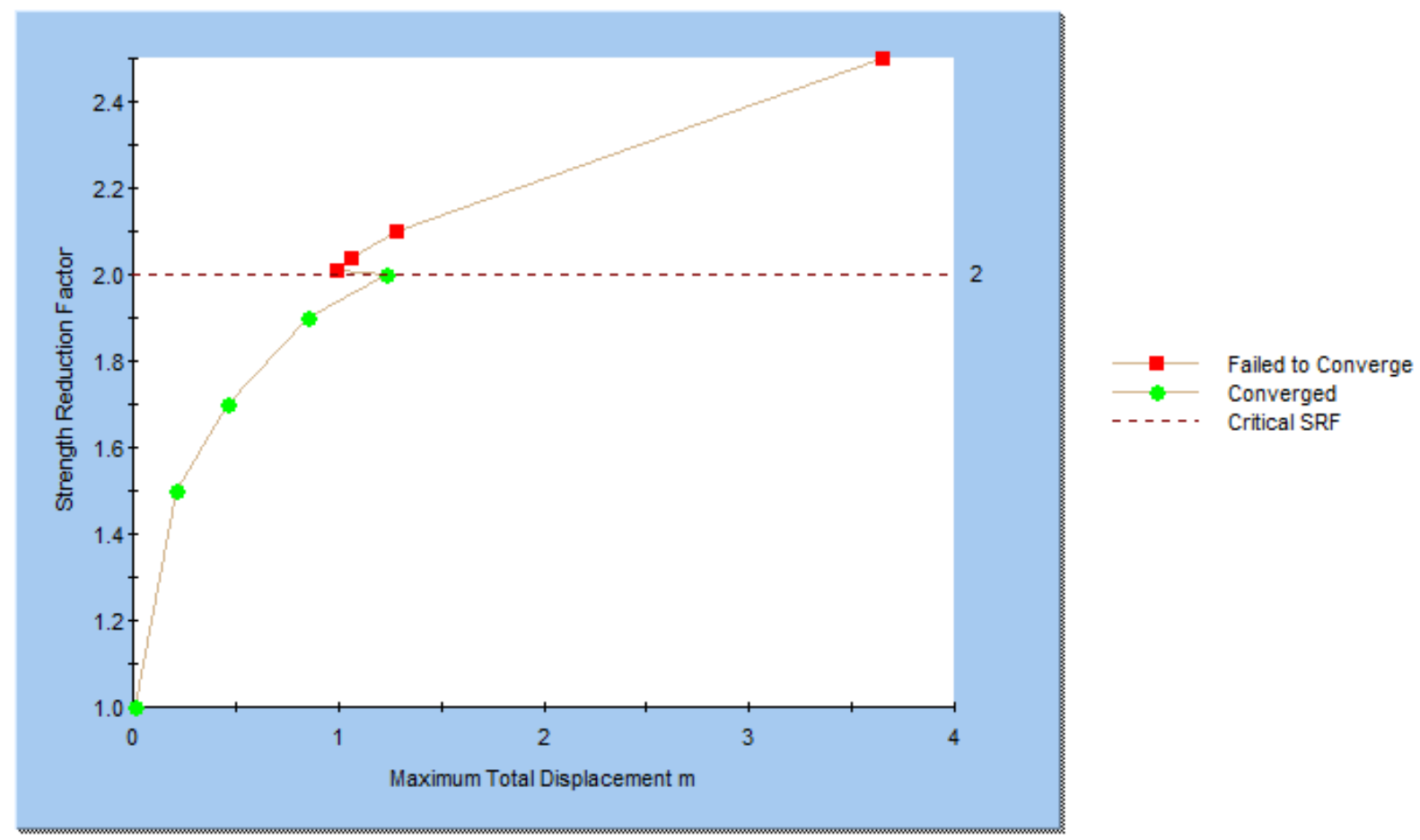

Figura 108 - SSR gráfico de convergência, parede com material elástico linear - (FS = 2) - Modelo 1.2

O resultado da análise mostrou que o fator de segurança para o modelo analisado foi $F S=2,0$. Os pontos do gráfico de convergência, fornecido pelo programa, indicam o fator aplicado versus máximo deslocamento máximo obtido na análise. Observa-se que a curva obtida foi praticamente contínua, a não ser próximo ao ponto de instabilidade. 
Abaixo são apresentados os deslocamento horizontais para a fase final da escavação, $F S=1$, e o acréscimo de deslocamentos horizontais e totais obtidos na análise, $\mathrm{FS}=2$, e também os vetores de deslocamento:

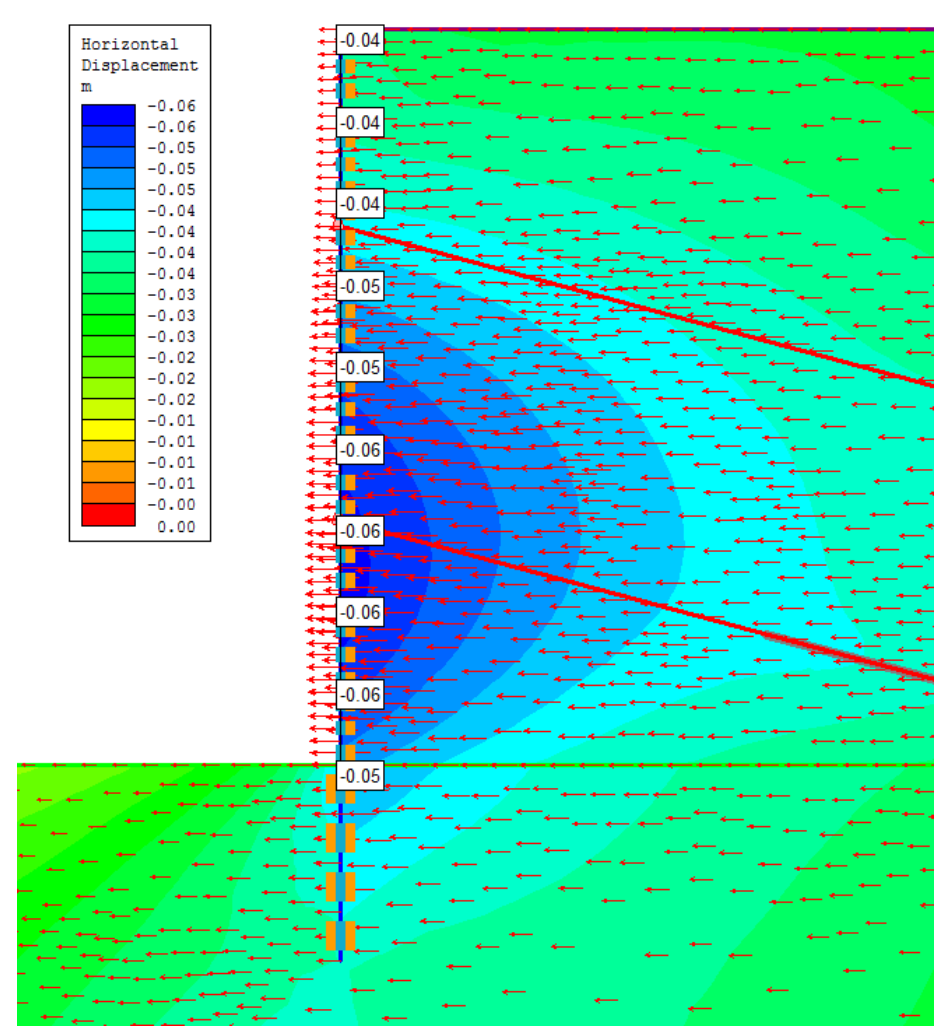

Figura 109 - Deslocamentos horizontais FS $=1-$ Modelo 1.2 


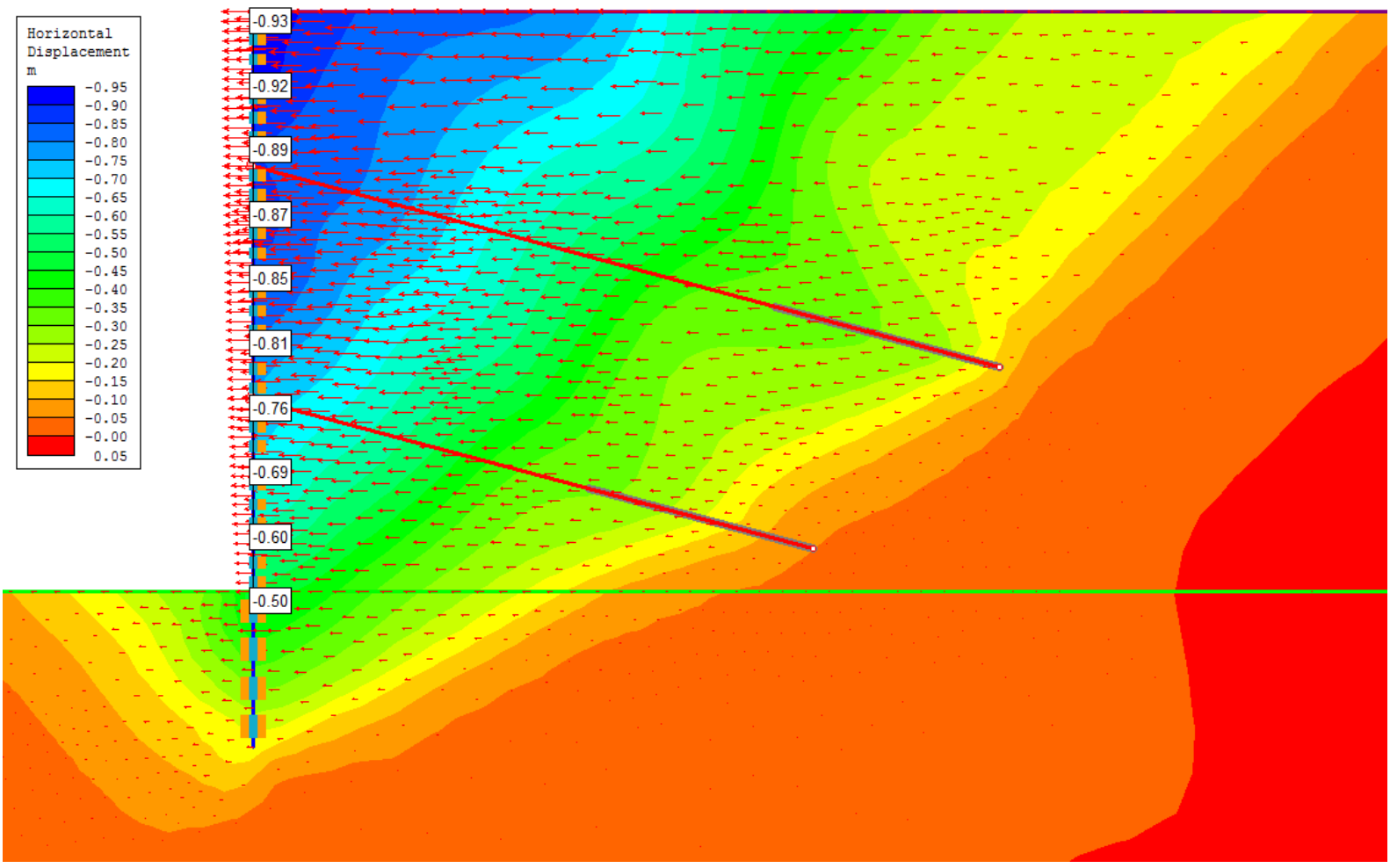

Figura 110 - Acréscimo de deslocamentos horizontais FS = 2 - Modelo 1.2

Critical SRF: 2
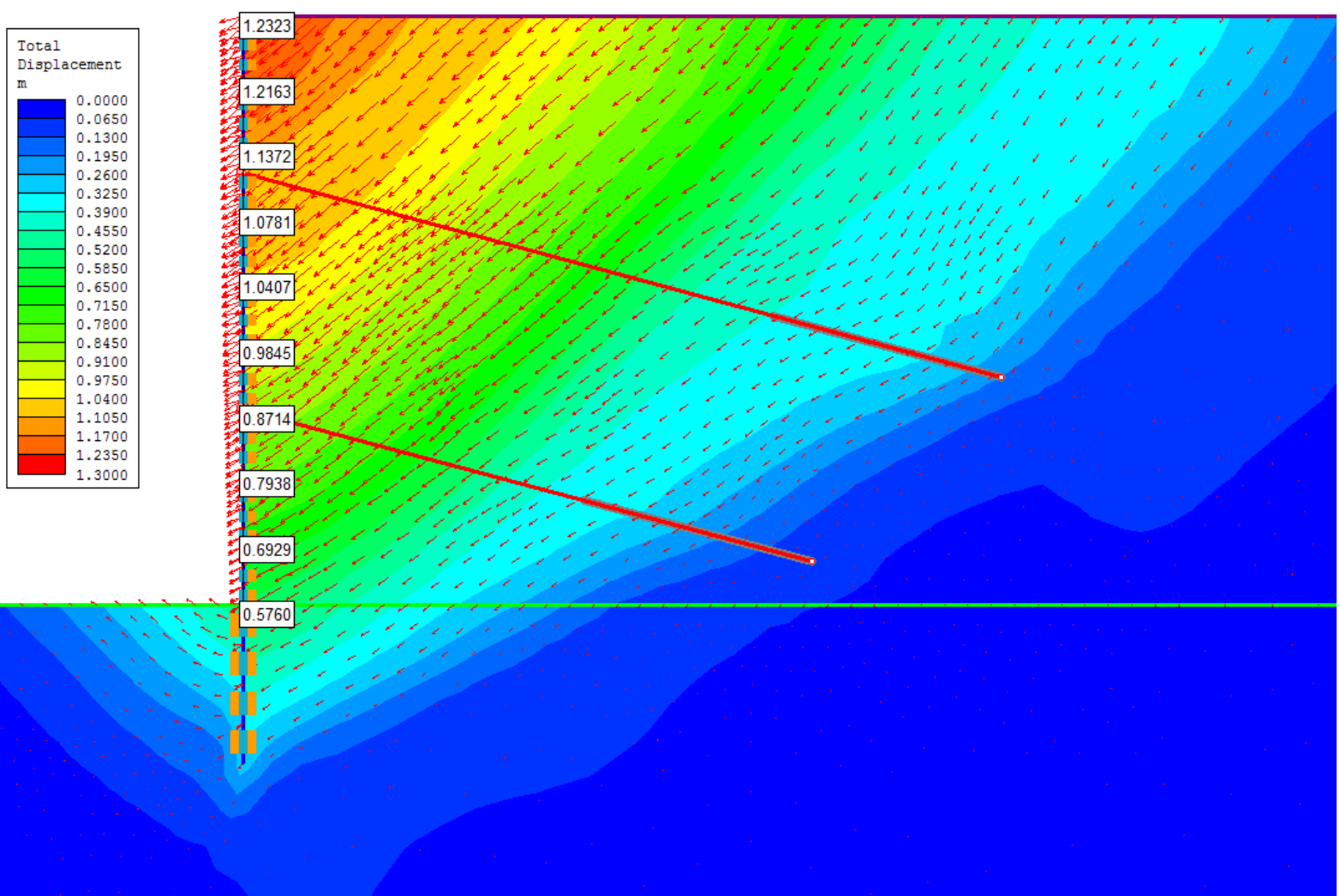

Figura 111 - Acréscimo de deslocamentos totais FS = 2 - Modelo 1.2 
Pela figura 111, observa-se que no estado crítico o acréscimo de deslocamentos chega a aproximadamente $10 \%$ da altura da parede.

Os tirantes não fazem parte do escopo deste trabalho, no entanto pelo grande acréscimo de deslocamentos na parede, na análise de estabilidade foram verificados os efeitos nos tirantes:

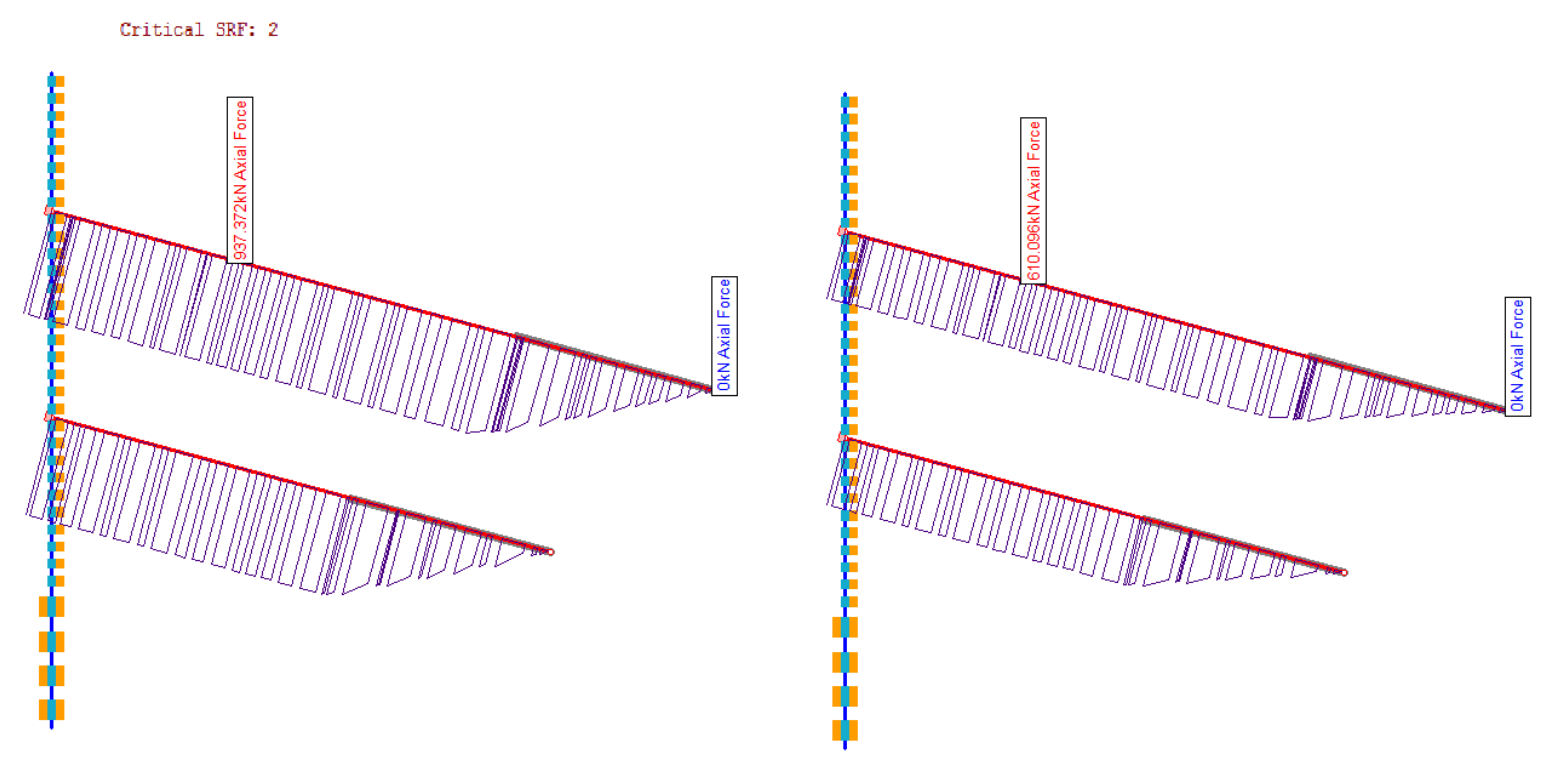

Figura 112 - Esforços nos tirantes - Modelo 1.2

Os tirantes sofreram acréscimo de esforços na fase final de escavação, $2 \%$ e na análise limite, 56\%, no entanto a condição última não foi alcançada, 1050 kN.

Os diagramas de força normal e momento fletor são apresentados abaixo: 

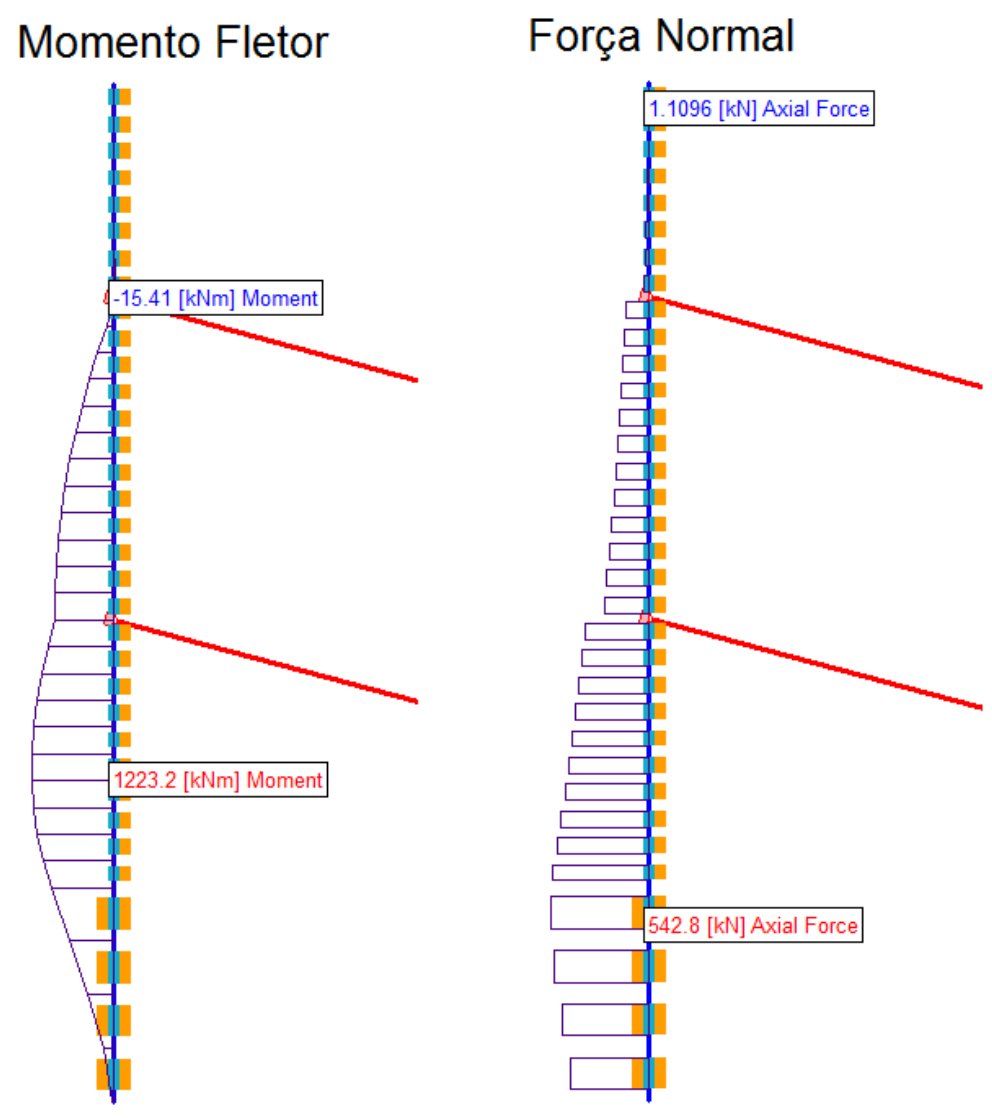

Figura 113 - Esforços na parede no limte da estabilidade, FS = 2

Observa-se que o momento fletor aumentou 6 vezes quando comparado ao esforço obtido no final da escavação, apresentado na figura 107, e a força normal aproximadamente 2 vezes. Se fosse adotado este esforço para armar a parede:

$k_{c}=\frac{b \cdot d^{2}}{M_{d}}=\frac{100 \cdot 35^{2}}{1,4 \cdot 100 \cdot 1223}=0,71 \Rightarrow$ Não é possível armar

Mesmo desconsiderando o coeficiente de majoração dos esforços, ou a força normal atuante, não haveria solução possível, como mostrado abaixo: 


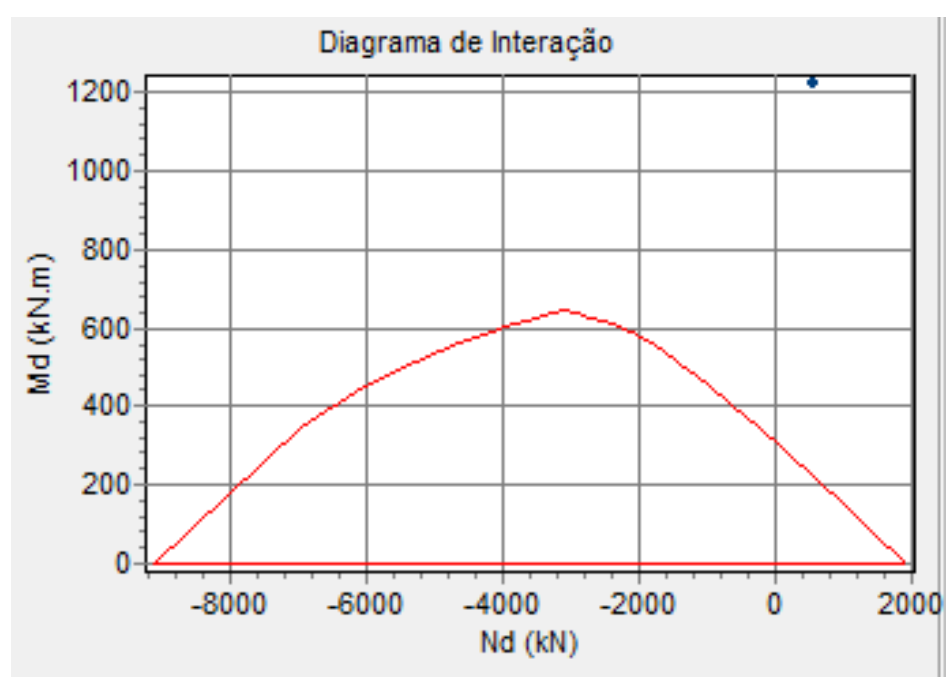

Figura 114 - Diagrama de interação - Nd $=540$ kN

Portanto observa-se que, para a parede com modelo constitutivo elástico linear, na verificação da estabilidade, não é possível atender as condições de compatibilidade entre tensões e deformações. Ressalta-se que nos métodos tradicionais (equilíbrio limite) de verificação da estabilidade, não é considerada a rigidez da parede, no entanto pela prática da engenharia os valores dos fatores de segurança adotados como mínimo, neste tipo de análise (equilíbrio limite), indiretamente proporcionam alguma segurança. O termo "alguma segurança" é usado no sentido de que se desconhece o quão seguro é, pois não é conhecida, plenamente, a variabilidade de todos os agentes envolvidos no problema, a começar pelo solo que é um material muito heterogêneo e chegando até o método construtivo.

No projeto de revisão da ABNT NBR6118 (2011) está previsto o aumento do módulo de elasticidade para análises lineares do concreto armado, o que fará com que o valor do fator de segurança neste tipo de análise aumente. 


\subsection{ANÁLISE DE ESTABILIDADE COM MODELO ELASTOPLÁSTICO PERFEITO PARA A RIGIDEZ DA PAREDE}

Neste caso foram feitas as seguintes considerações:

- Diagrama tensão-deformação bilinear, de acordo com o indicado pelo CEB-FIB 2010;

- Deformação limite para plastificação do concreto, $\varepsilon_{c 3}=0,00175$;

- Resistência a compressão para o concreto: Para o modelo 1.3-1: $0,789 f_{c k}=23,67 \mathrm{MPa}$ e ELU pela ABNT NBR6118:2007; Para o Modelo 1.3-2 $0,85 f_{c k}=25,5 \mathrm{MPa}$ e ELU pelo CEB-FIB 2010;

- Resistência ao escoamento do aço: Para o modelo 1.3-1: $f_{y d}=435 \mathrm{MPa} ;$ Para o Modelo 1.3-2 e 1,1 $f_{y k}=550 \mathrm{MPa}$.

\section{MODELO 1.3-1}

O fator de segurança obtido é apresentado abaixo, juntamente ao gráfico de convergência fornecido pelo programa: 
Shear Strength Reduction - Critical SRF: 1.78 at Displacement: $3.569 \mathrm{~m}$

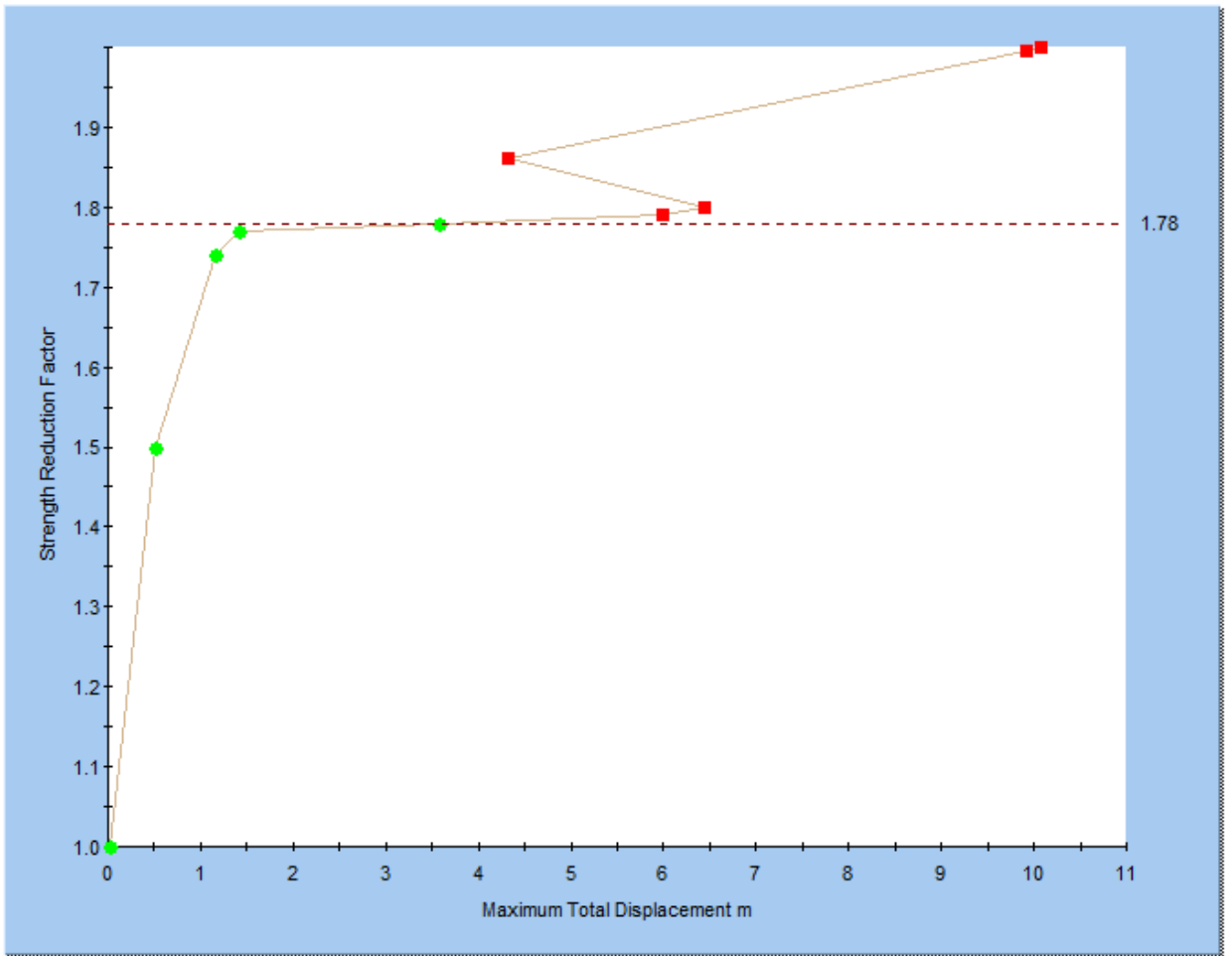

Failed to Converge Converged Critical SRF

Figura 115 - SSR - Gráfico de convergência, parede com material elastoplástico - $(\mathrm{FS}=1,78)$ Modelo 1.3-1

O resultado da análise mostrou que o fator de segurança para o modelo analisado foi $\mathrm{FS}=1,78$. Observa-se que a curva obtida, segue praticamente sem alteração até a instabilidade.

Observou-se que o número de iterações neste tipo de análise (análise de estabilidade considerando a não linearidade física do paramento de concreto) é fundamental para obtenção de valores adequados para o fator de segurança. Os resultados são apresentados abaixo:

Tabela 24 - Número de iterações x Fator de segurança

\begin{tabular}{|c|c|}
\hline $\begin{array}{c}\text { № } \\
\text { Iterações }\end{array}$ & FS \\
\hline 500 & 1,23 \\
\hline 1000 & 1,80 \\
\hline 1500 & 1,78 \\
\hline 2500 & 1,78 \\
\hline 3500 & 1,78 \\
\hline
\end{tabular}

Fonte: Elaborado pelo autor 
Abaixo são mostrados os deslocamentos horizontais para FS $=1$ e 0 acréscimo que ocorre com $\mathrm{FS}=1,78$ :

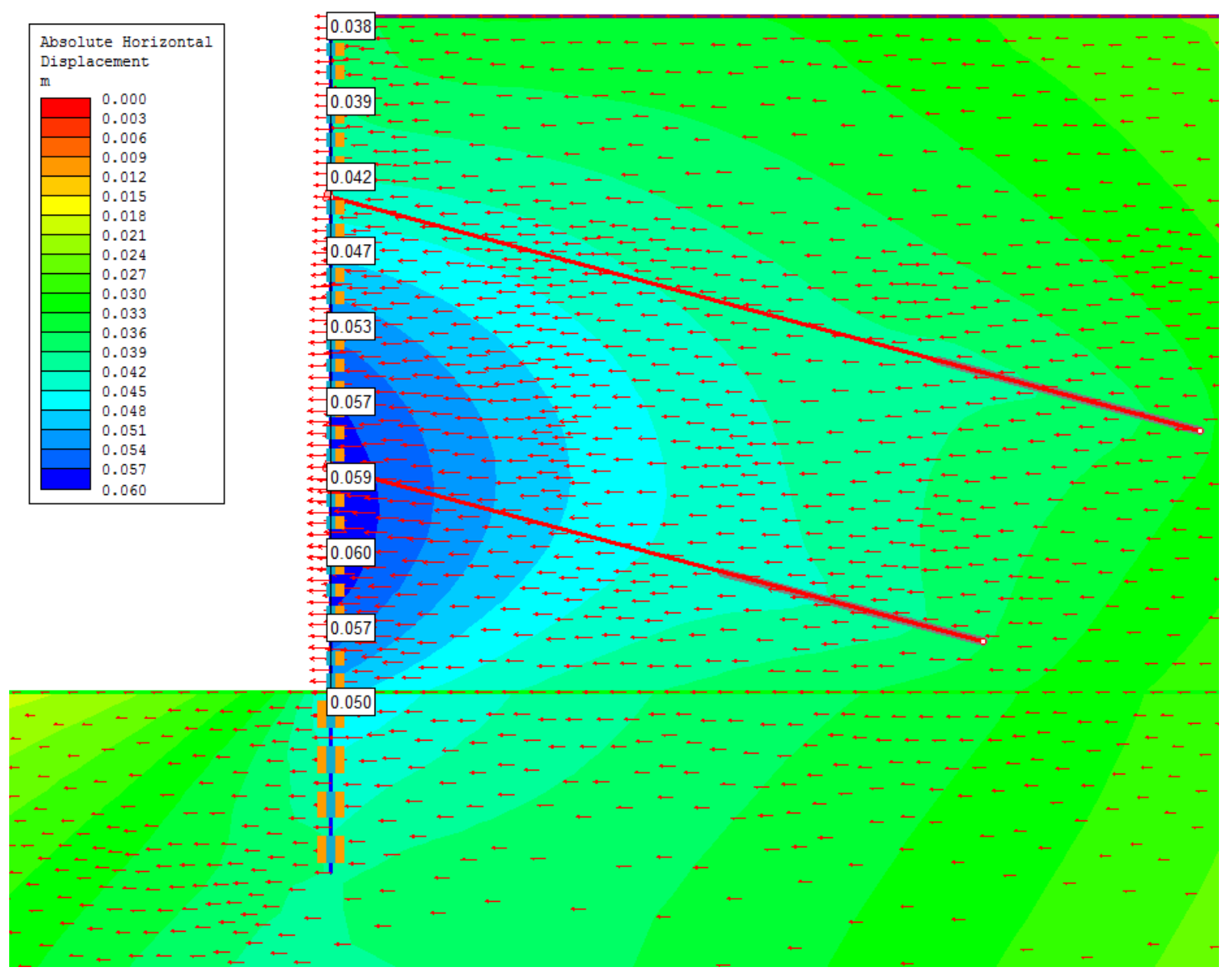

Figura 116 - Deslocamentos horizontais FS = 1 - Modelo 1.3-1 


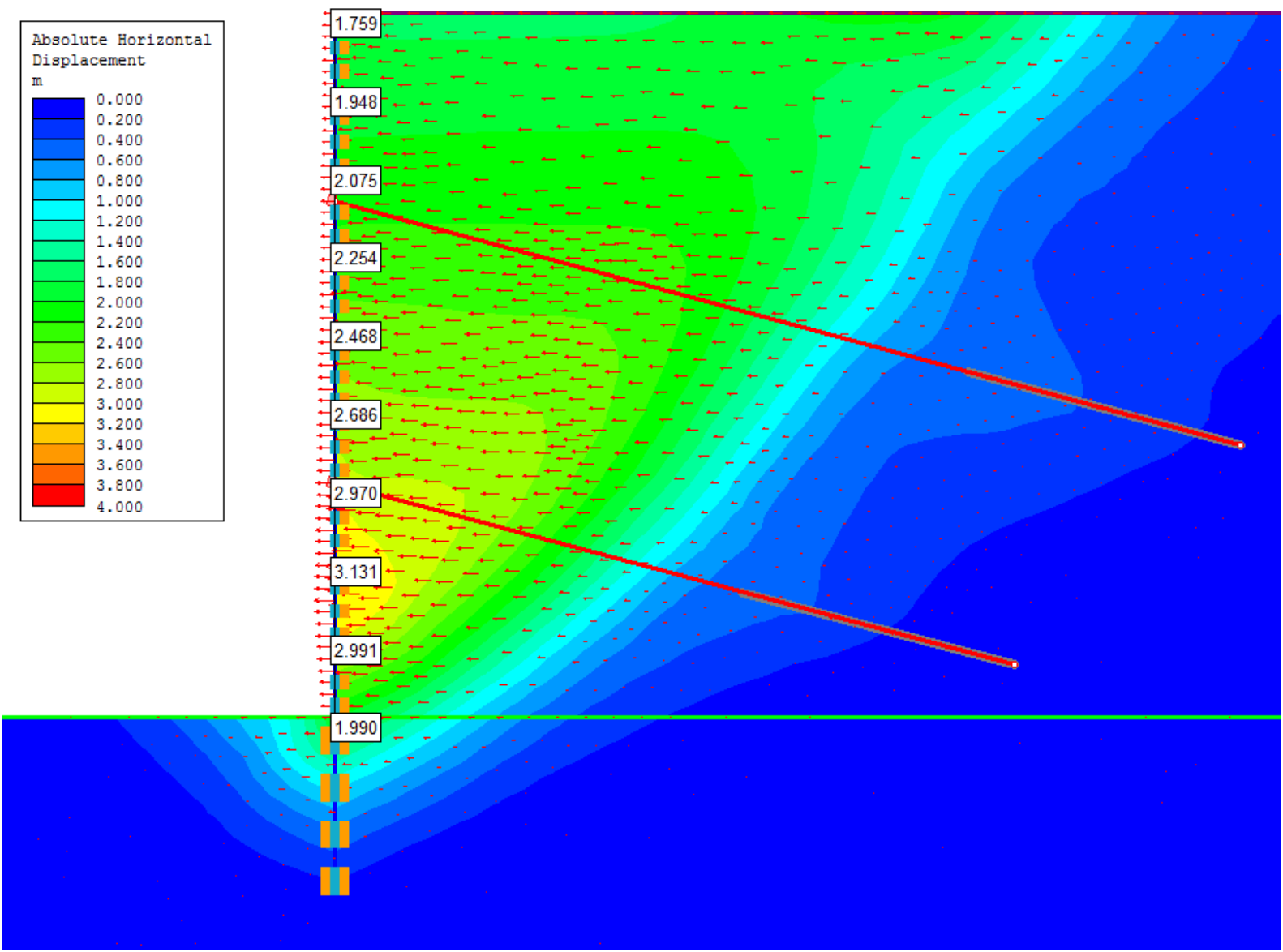

Figura 117 - Acréscimo de deslocamentos horizontais FS = 1,78 - Modelo 1.3-1

Abaixo são mostrados os deslocamentos totais para FS $=1$ e o acréscimo que ocorre com FS = 1,78: 


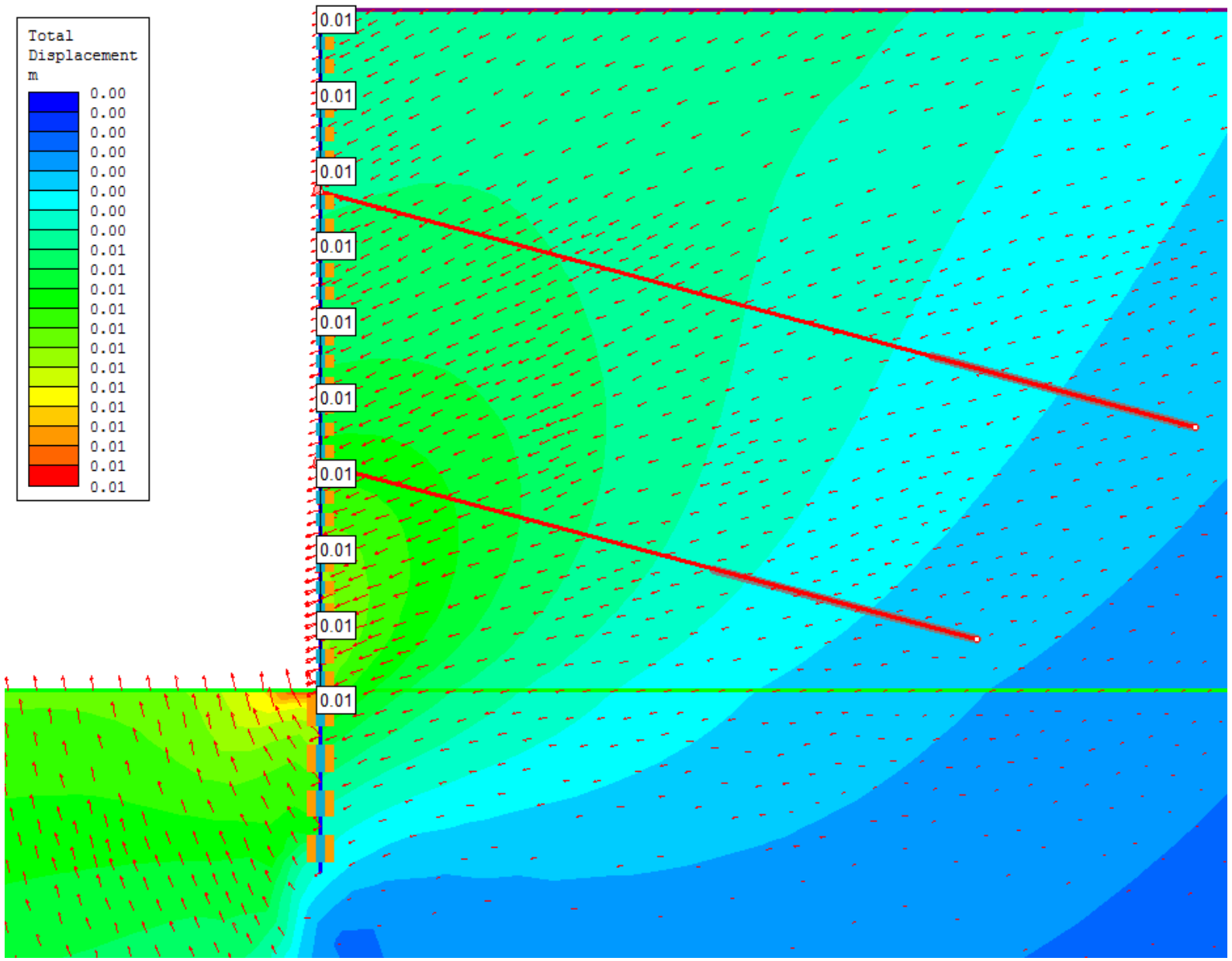

Figura 118 - Deslocamentos totais FS $=1$ - Modelo 1.3-1 

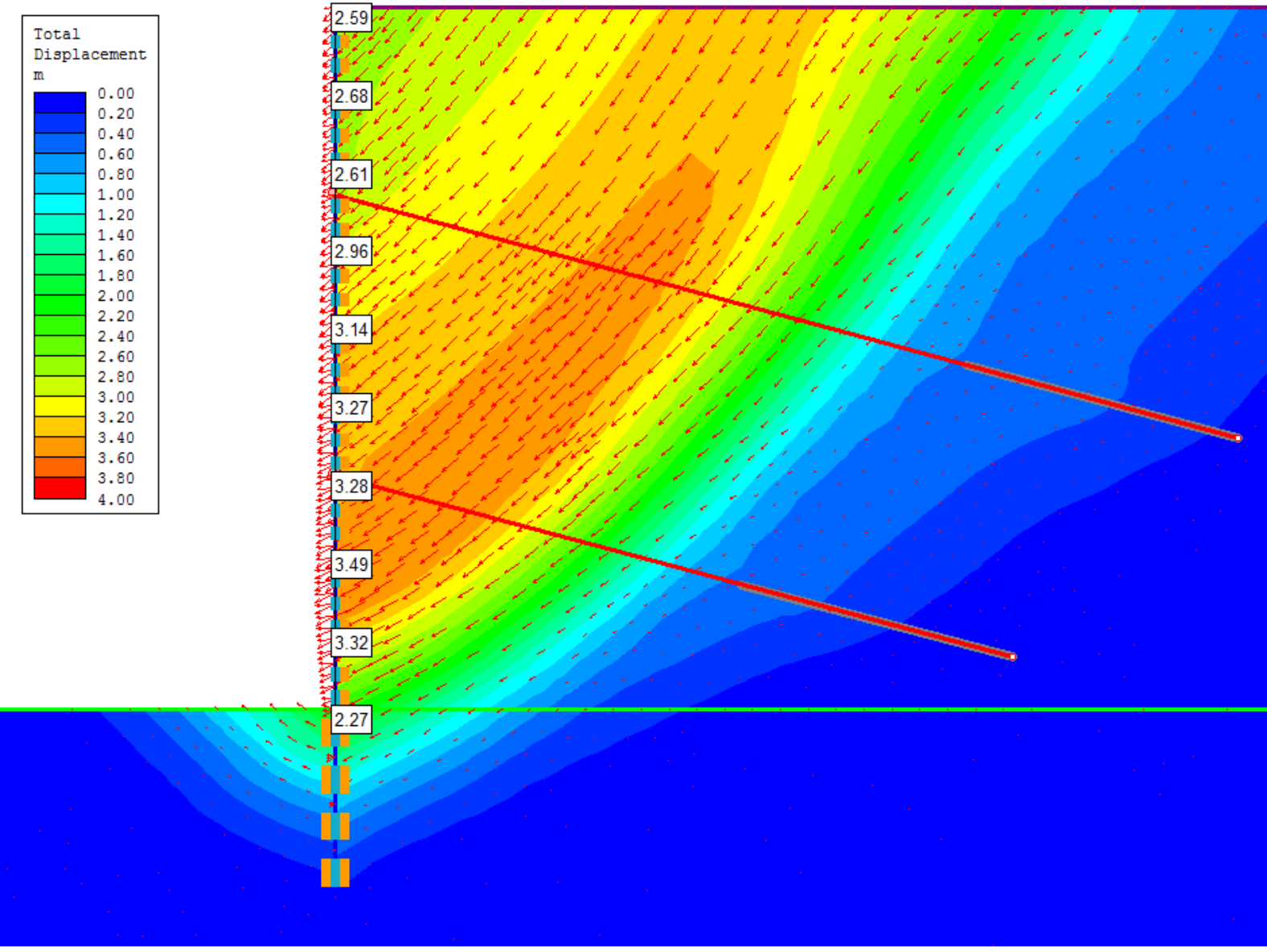

Figura 119 - Acréscimo de deslocamentos totais FS = 1,78 - Modelo 1.3-2

Pela figura 119, observa-se que no estado crítico o acréscimo de deslocamentos totais foi grande, da ordem de metros. Os diagramas de força normal, momento fletor e pontos de plastificação são apresentados abaixo: 


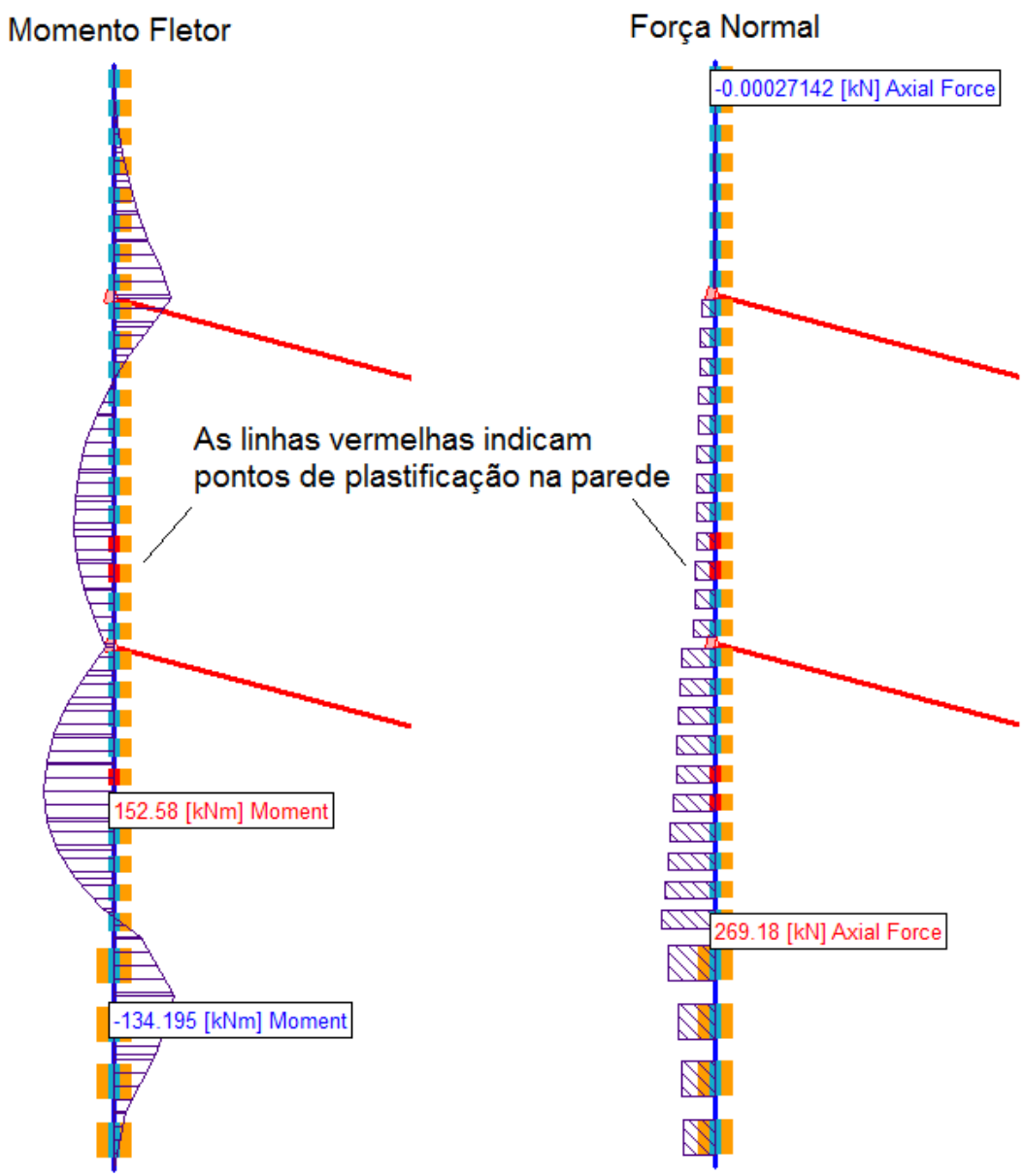

Figura 120 - Esforços na parede no final da escavação - FS = 1,0 - Modelo 1.3-1 


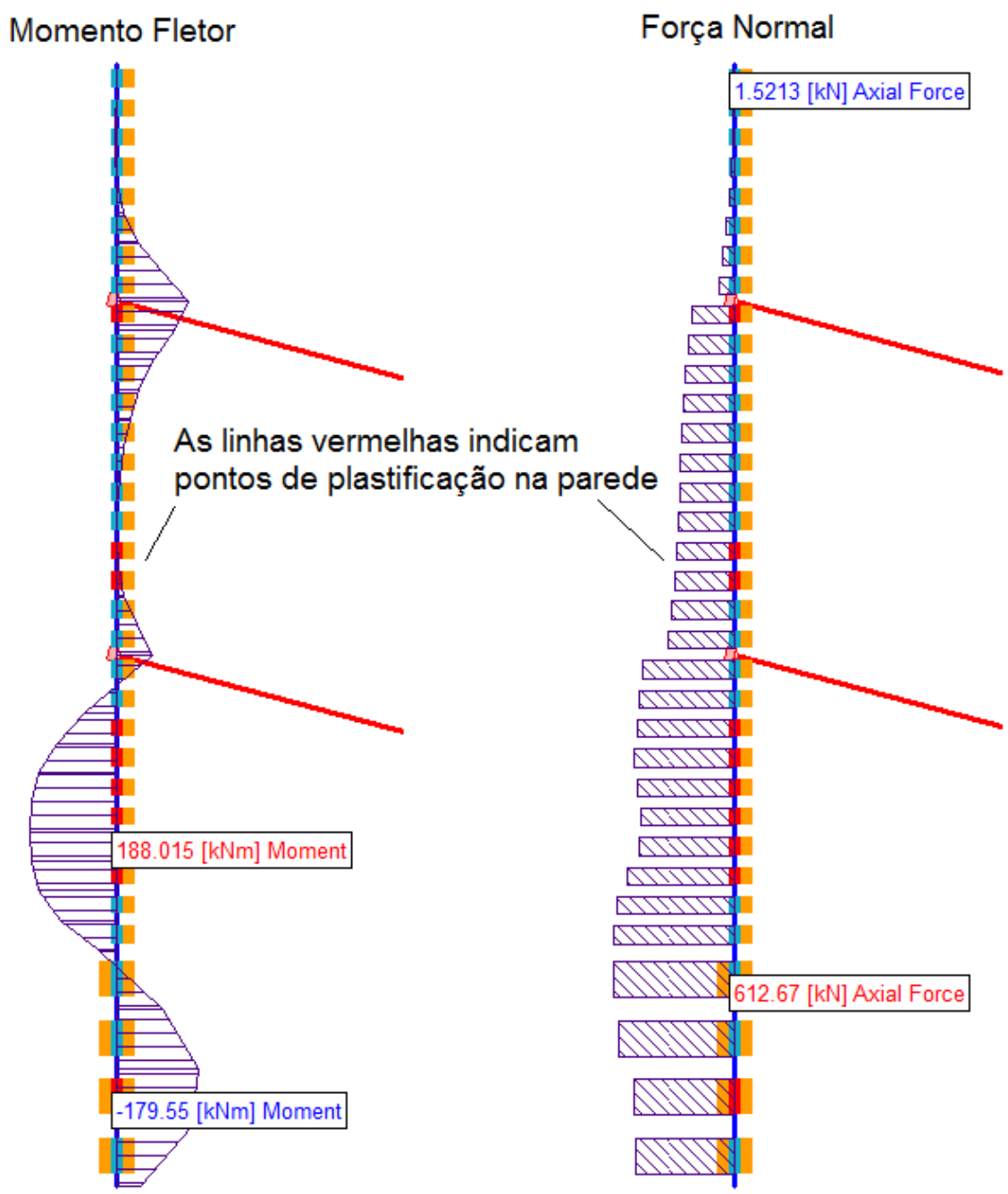

Figura 121 - Esforços na parede no limte da estabilidade - FS = 1,78 - Modelo 1.3-1

Pela figura 121, observa-se um decréscimo no momento fletor, comparado ao modelo 1.2, causado pela menor rigidez da parede e também na força normal.

Entre o final da escavação, $F S=1$, e o limite da estabilidade, $F S=1,78$, houve aumento nos esforços da parede, observa-se que enquanto o momento fletor aumentou $23 \%$, a força normal aumentou $128 \%$. Este aumento na força normal deve-se a direção do deslocamento do maciço contido no limite da estabilidade, como se observa pela figura 119 , pois a massa instável do maciço empurra a parede de concreto para baixo, aumentando a tensão de cisalhamento na interface soloparede.

O programa PHASE2 não indica em qual material (concreto ou aço) ocorreu a plastificação, diz apenas se é de tração ou compressão, assim é necessário verificar se a plastificação corresponde a uma rótula plástica. 
Partindo da força normal, $481,38 \mathrm{kN}$, concomitante ao momento máximo, $188,015 \mathrm{kNm}$, no limite da estabilidade, foi elaborado um diagrama $\mathrm{M}-\mathrm{N}-1 / \mathrm{r}$ verificouse que os esforços estão longe do momento resistente último:

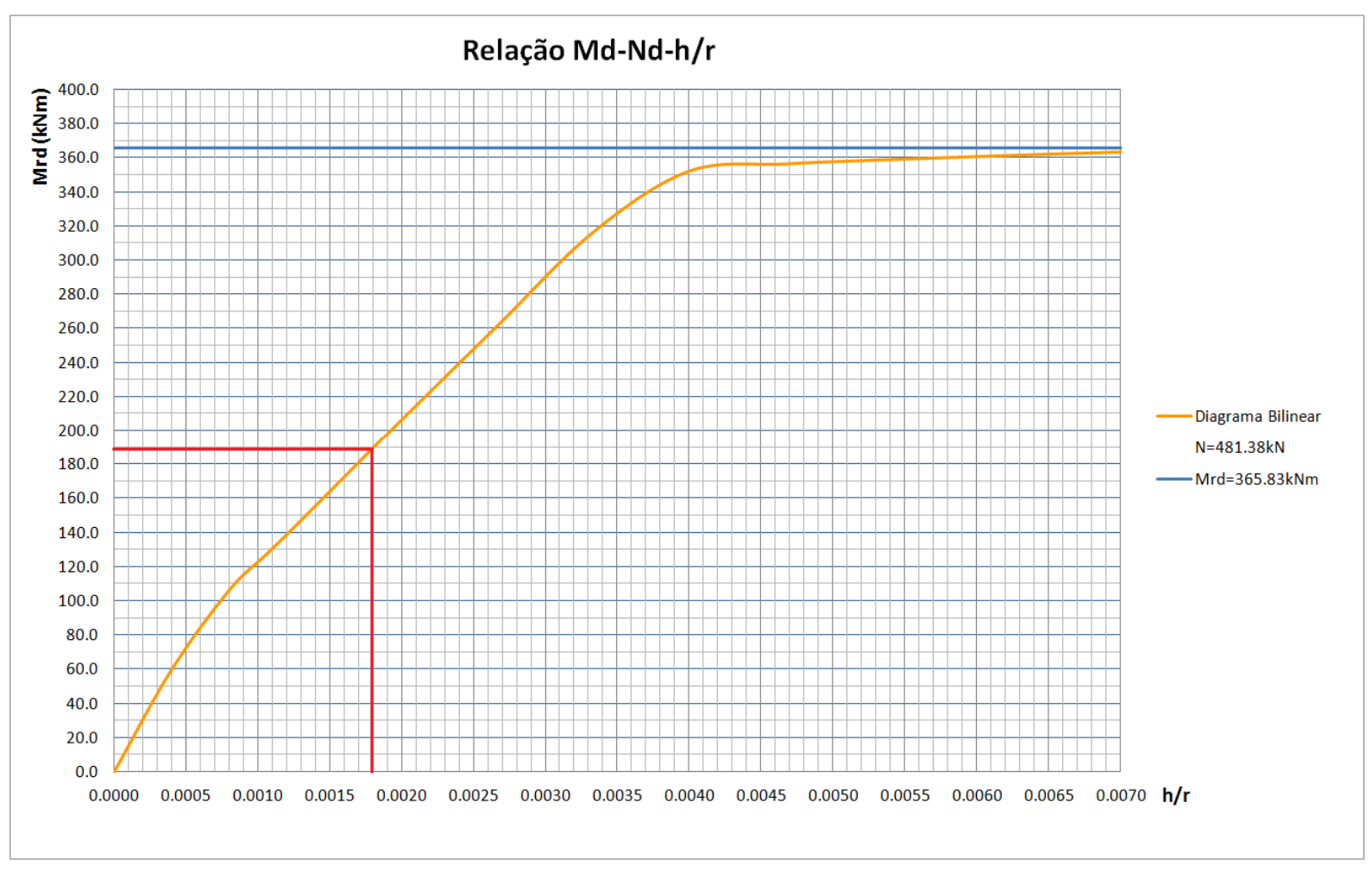

Figura 122 - Diagrama M-N-1/r - Modelo 1.3-1

O diagrama de interação para a seção: 


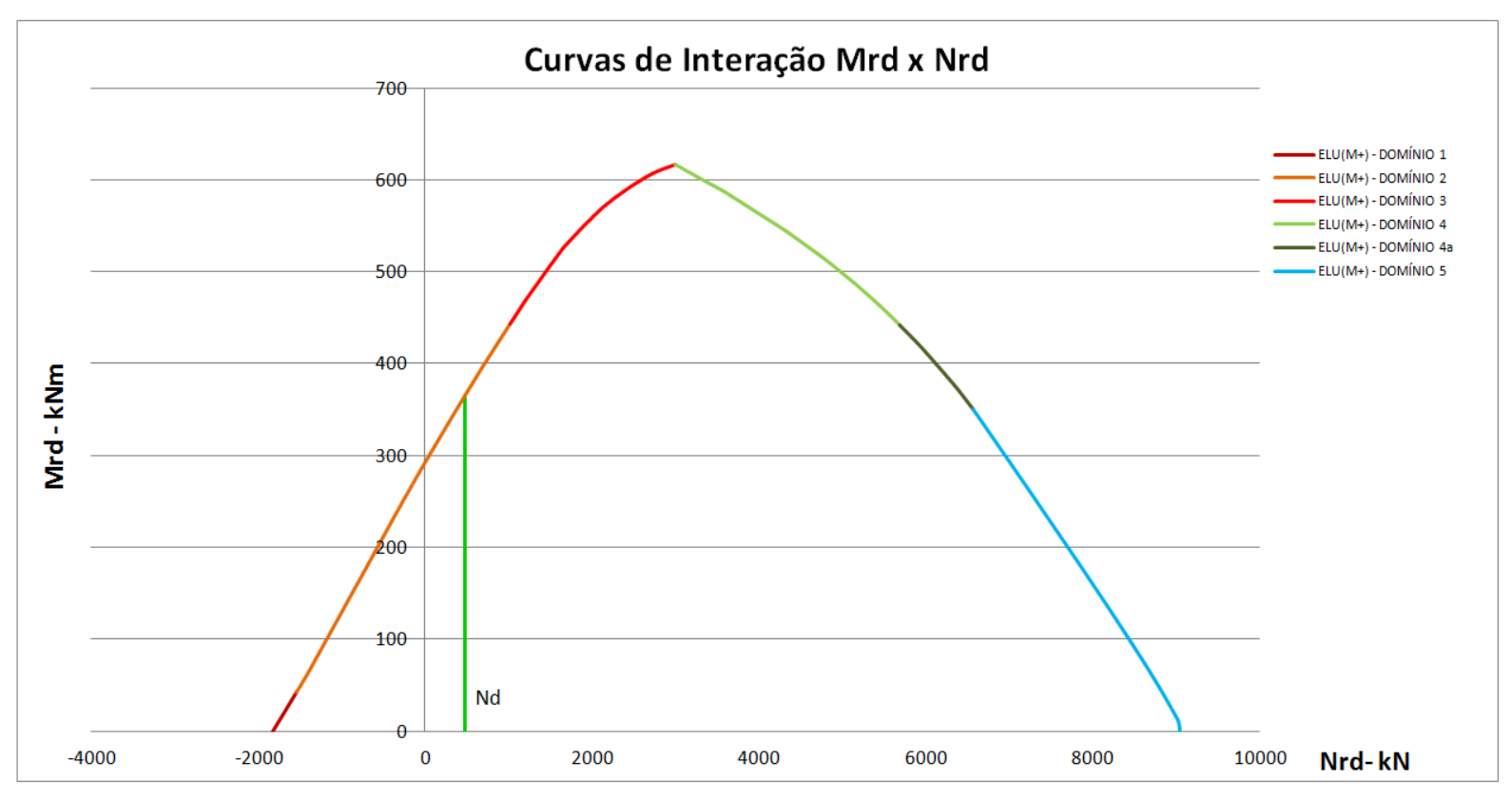

Figura 123 - Diagrama de interação - diagrama tensão deformação bilinear - Modelo 1.3-1

O momento resistente no ELU para normal $\mathrm{Nd}=481,38 \mathrm{kN}\left(\gamma_{f}=1,0\right.$, favor da segurança neste caso, por ser pequena para a seção), é $\mathrm{Mrd}=365,83 \mathrm{kNm}$, considerando o diagrama tensão deformação bilinear para o concreto.

Analisaram-se também as deformações e as tensões na seção, para os esforços obtidos, considerando o diagrama tensão deformação parabólico-retangular para efeito de comparação com o bilinear.

Por meio do programa nFOCCA (MEDEIROS, 2004), obteve-se a deformação na seção para os esforços. Faz-se a observação de que o programa utiliza um diagrama parabólico-retangular para o concreto e que o valor 0,786, na figura 124 não é efeito Rüsh, mas apenas um multiplicador. 


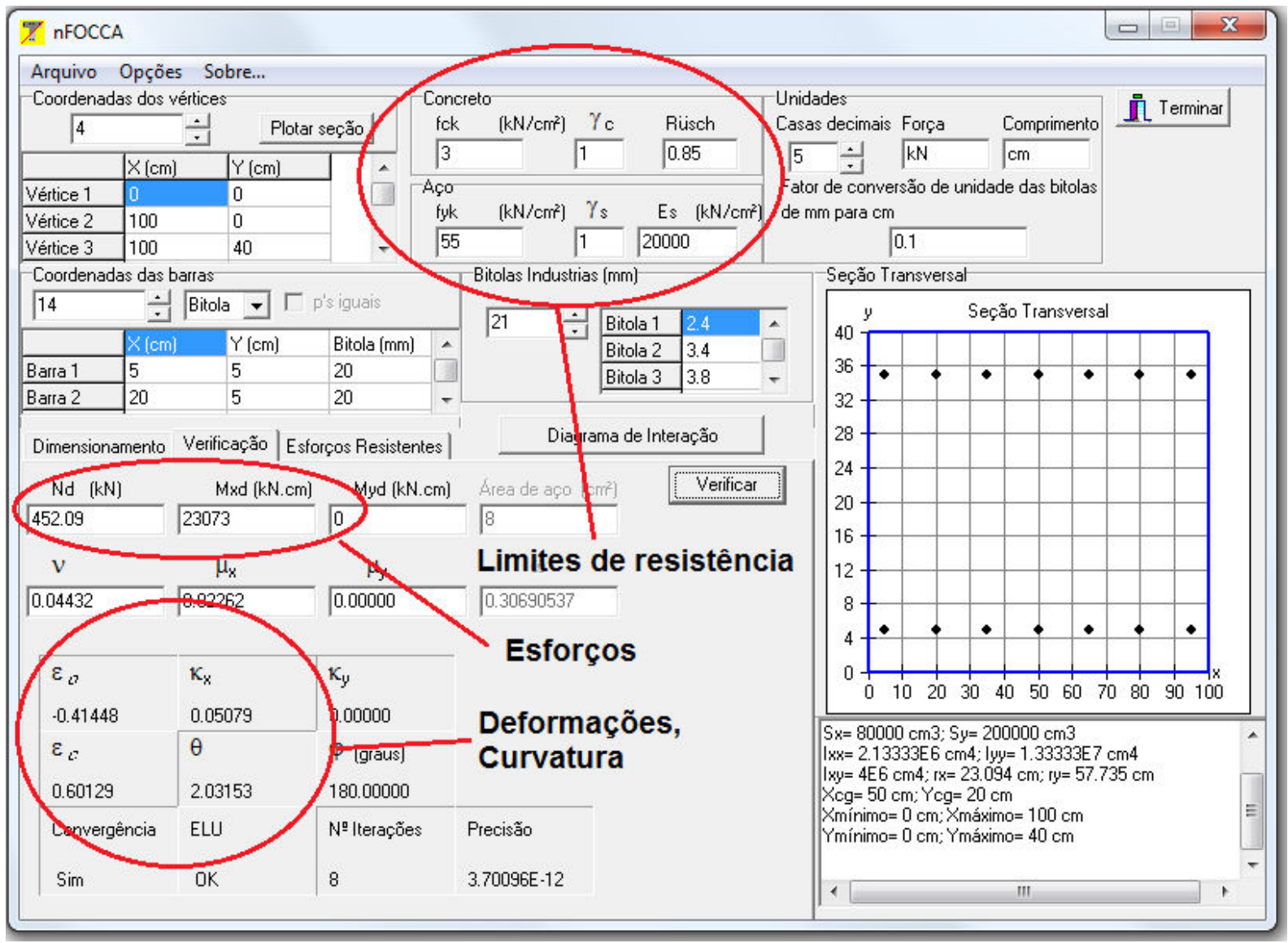

Figura 124 - Deformações na seção de momento fletor máximo - Modelo 1.3-1

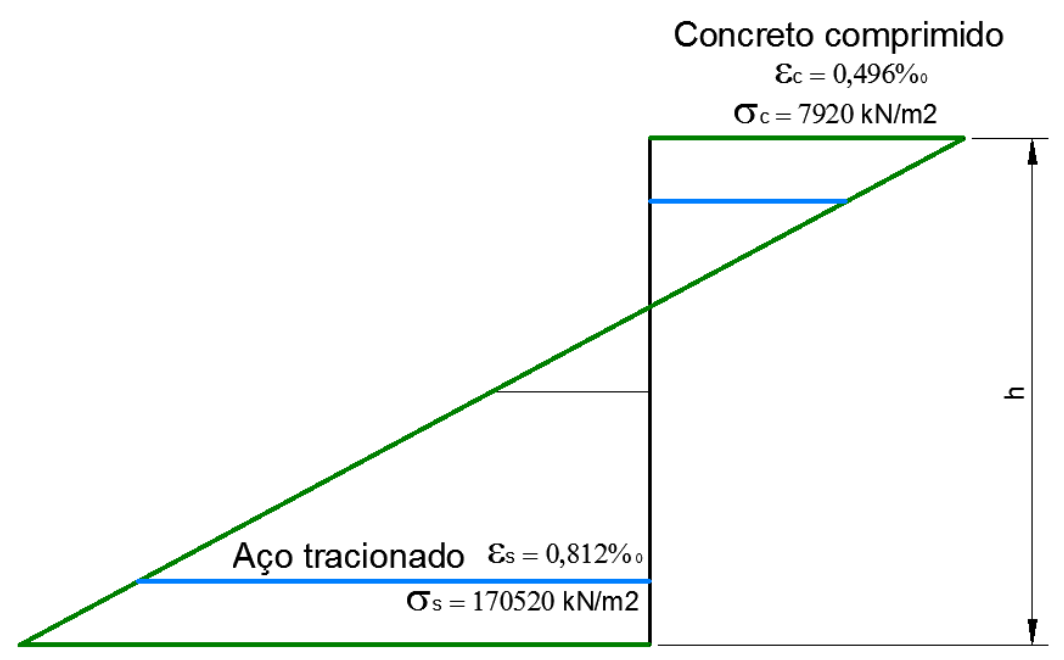

Figura 125 - Deformação na seção de momento máximo - Modelo 1.3-1

Pelo diagrama acima se observa que a plastificação mostrada pelo programa na figura 121, corresponde à tração no concreto, que foi considerada 
nula $^{11}$ no modelo e que a seção encontra-se no estádio II. Para o diagrama parabólico-retangular o momento resistente é, $386,41 \mathrm{kNm}$ ou seja $5,6 \%$ maior que o apresentado na figura 122. Isto demonstra que o dimensionamento com o diagrama bilinear está a favor da segurança. Faz-se a observação de que nesta análise considerou-se que o coeficiente majorador dos esforços foi levado em conta de forma indireta pela aplicação do fator de segurança no maciço, consequentemente aplicando um fator global. A norma ABNT NBR 8681:2003 não trata de um caso específico como este (análise de estabilidade de contenções), pois o coeficiente que seria aplicado dependeria da variabilidade das propriedades do solo, no entanto para situações de projeto recomenda-se cautela, neste caso seria prudente aplicar os coeficientes da combinação normal ou excepcional.

$\mathrm{Na}$ análise de estabilidade o fator de segurança obtido é menor que o do modelo 1.2 (11\% menor), no entanto as condições de compatibilidade de tensões e deformações para a parede foram observadas.

\section{MODELO 1.3-2}

O fator de segurança obtido é apresentado abaixo, juntamente ao gráfico de convergência fornecido pelo programa:

${ }^{11}$ O programa Phase2 não permite que se atribua o valor "0", assim adotou-se um valor muito pequeno, $0,1 \mathrm{kN}$. 
Shear Strength Reduction - Critical SRF: 1.86 at Displacement: $2.243 \mathrm{~m}$

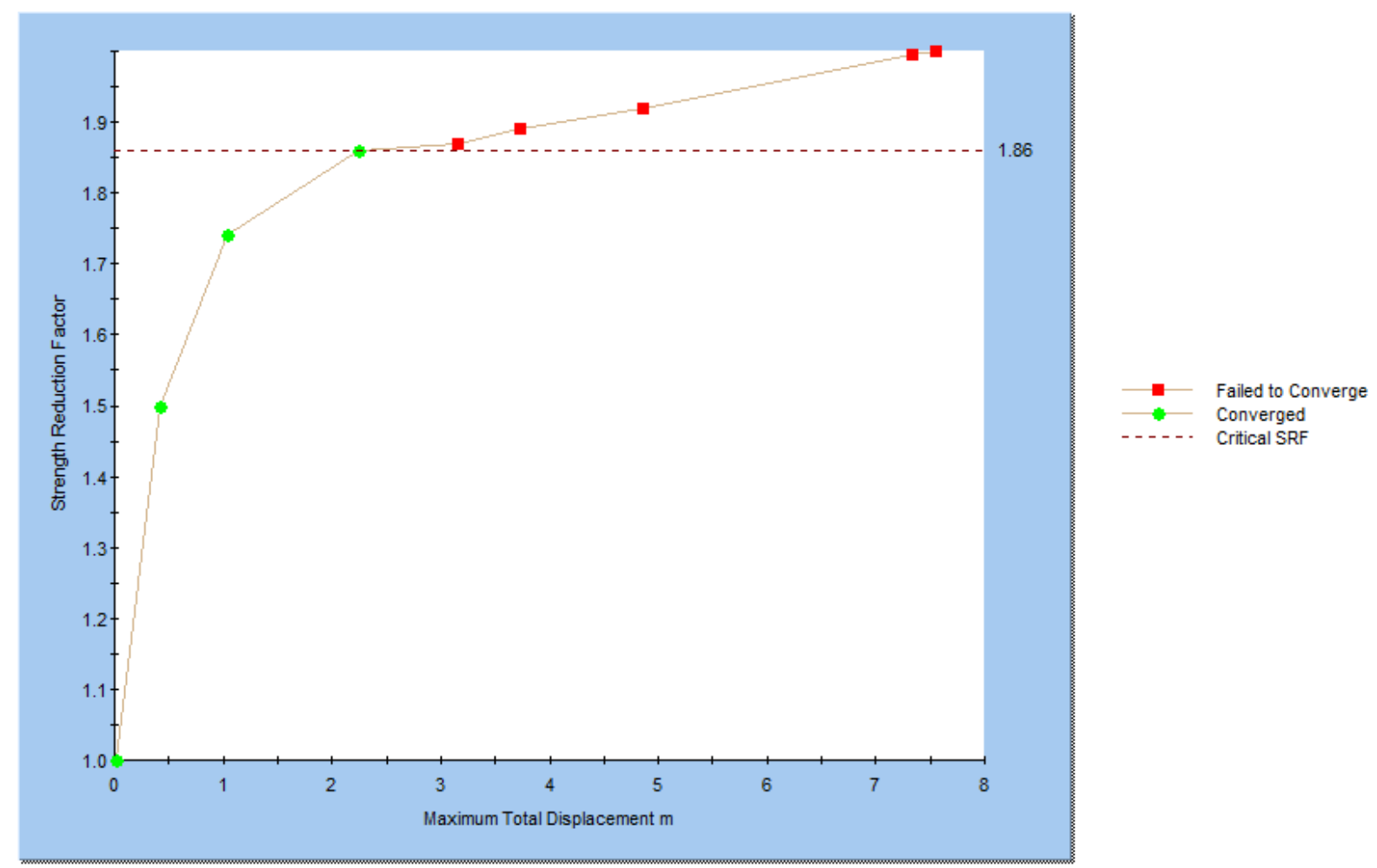

Figura 126 - SSR - Gráfico de convergência, parede com material elastoplástico - $(F S=1,86)$ Modelo 1.3-2

O resultado da análise mostrou que o fator de segurança para o modelo analisado foi $F S=1,86$. Observa-se que a partir de $F S=1,75$, há um rápido acréscimo nas deformações, mas ainda com resultados convergentes, até o FS = 1,86 .

Observou-se, como no modelo anterior, que o número de iterações neste tipo de análise (análise de estabilidade considerando a não linearidade física do paramento de concreto) influencia nos resultados dos valores do fator de segurança:

Tabela 25 - Número de iterações x Fator de segurança

\begin{tabular}{|c|c|}
\hline $\begin{array}{c}\text { № } \\
\text { Iterações }\end{array}$ & FS \\
\hline 500 & 1,44 \\
\hline 1000 & 1,78 \\
\hline 1500 & 1,78 \\
\hline 2500 & 1,86 \\
\hline 3500 & 1,86 \\
\hline 4500 & 1,86 \\
\hline
\end{tabular}

Fonte: Elaborado pelo autor 
Abaixo são mostrados os deslocamentos horizontais para FS $=1$ e 0 acréscimo que ocorre com $\mathrm{FS}=1,86$ :

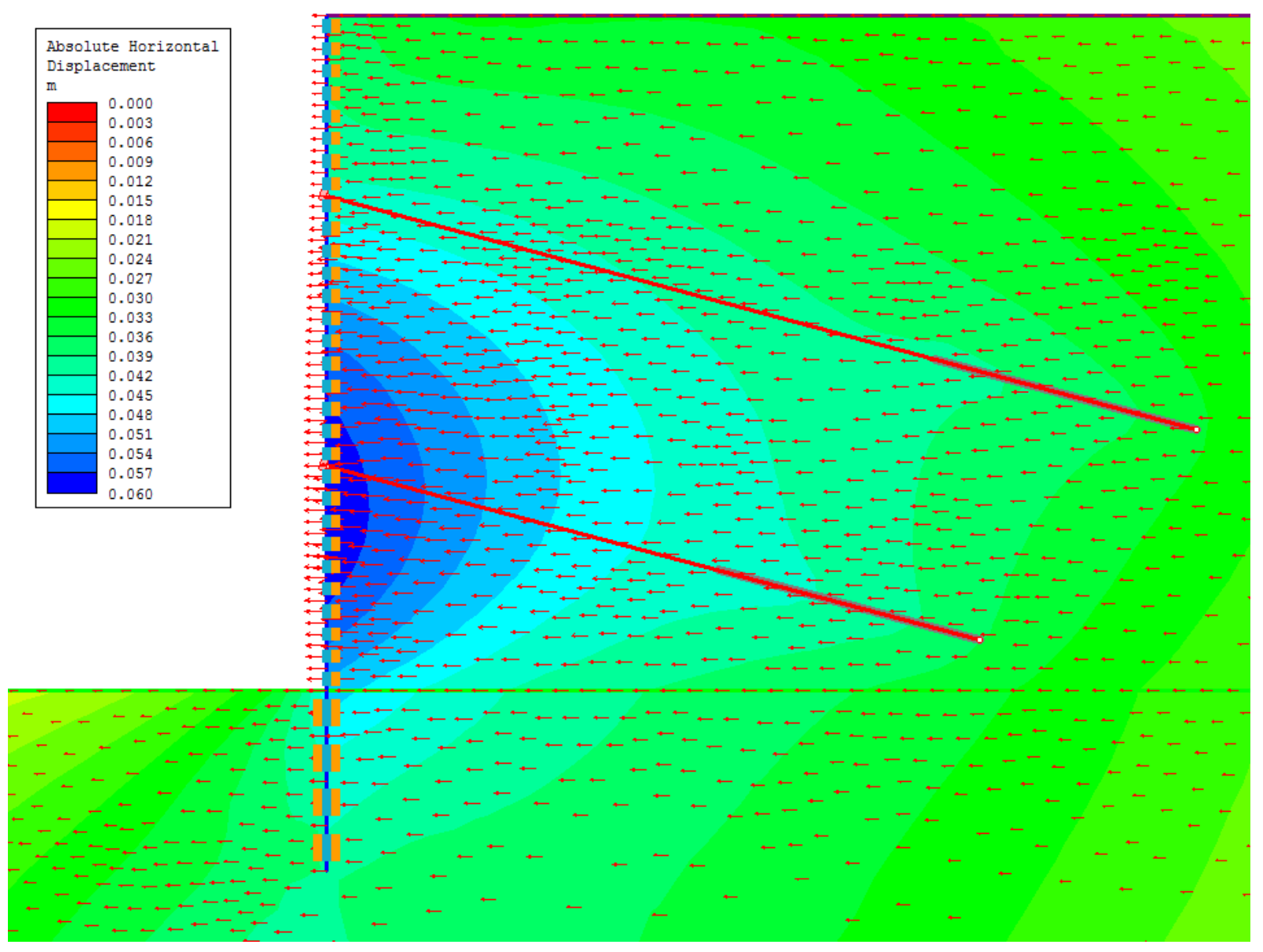

Figura 127 - Deslocamentos horizontais FS = 1 - Modelo 1.3-2 


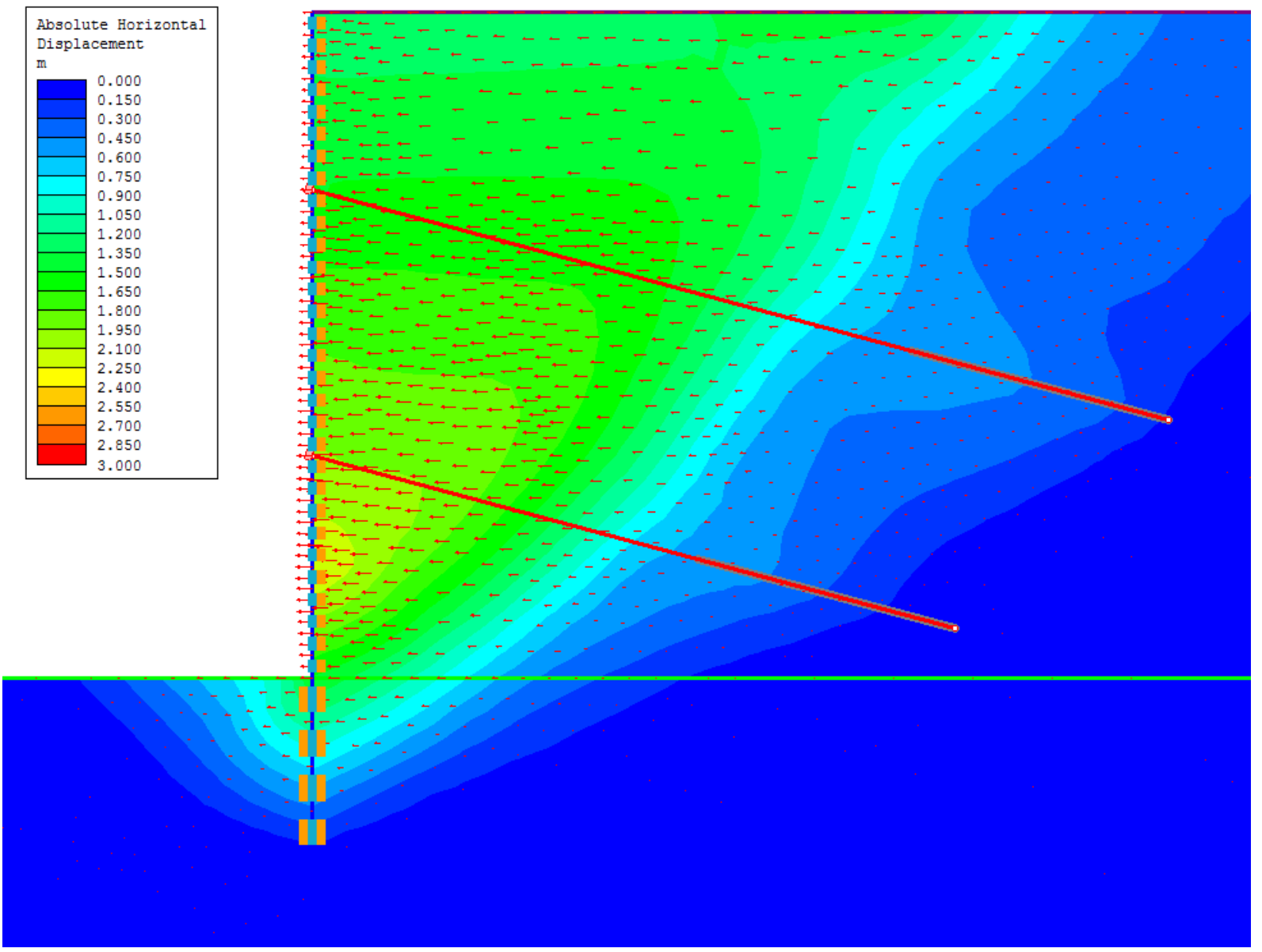

Figura 128 - Acréscimo de deslocamentos horizontais FS = 1,86 - Modelo 1.3-2

Abaixo são mostrados os deslocamentos totais para $F S=1$ e o acréscimo que ocorre com FS = 1,86: 


\begin{tabular}{|l|l|}
\hline \multicolumn{2}{|l|}{ Total } \\
Displacement \\
m \\
\hline \\
0.00 \\
0.00 \\
0.00 \\
0.00 \\
0.00 \\
0.00 \\
0.00 \\
0.00 \\
0.01 \\
0.01 \\
0.01 \\
0.01 \\
0.01 \\
0.01 \\
0.01 \\
0.01 \\
0.01 \\
0.01 \\
\hline 0.01 \\
0.01 \\
0.01 \\
\hline
\end{tabular}

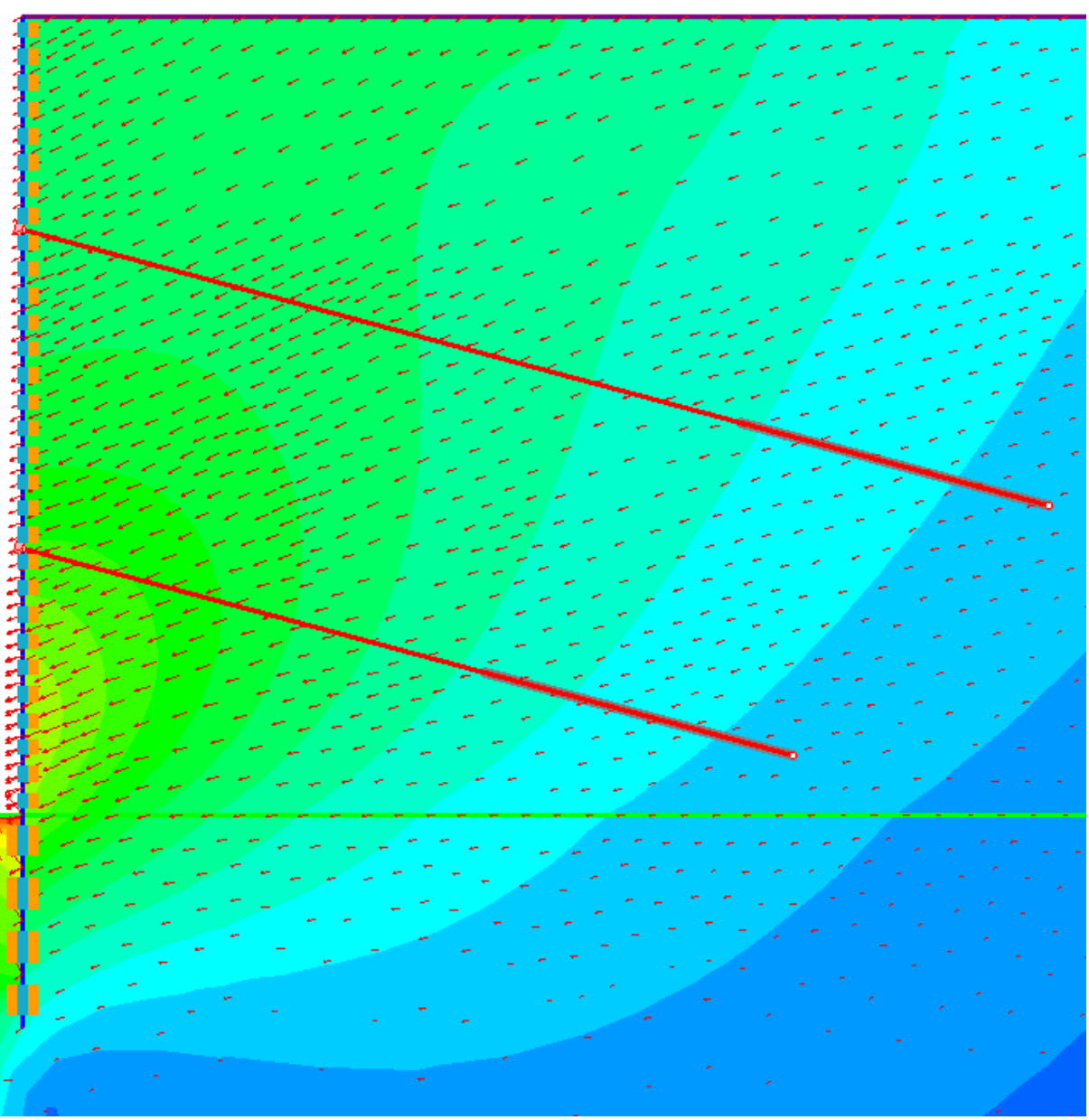

Figura 129 - Deslocamentos totais FS = 1 - Modelo 1.3-2 


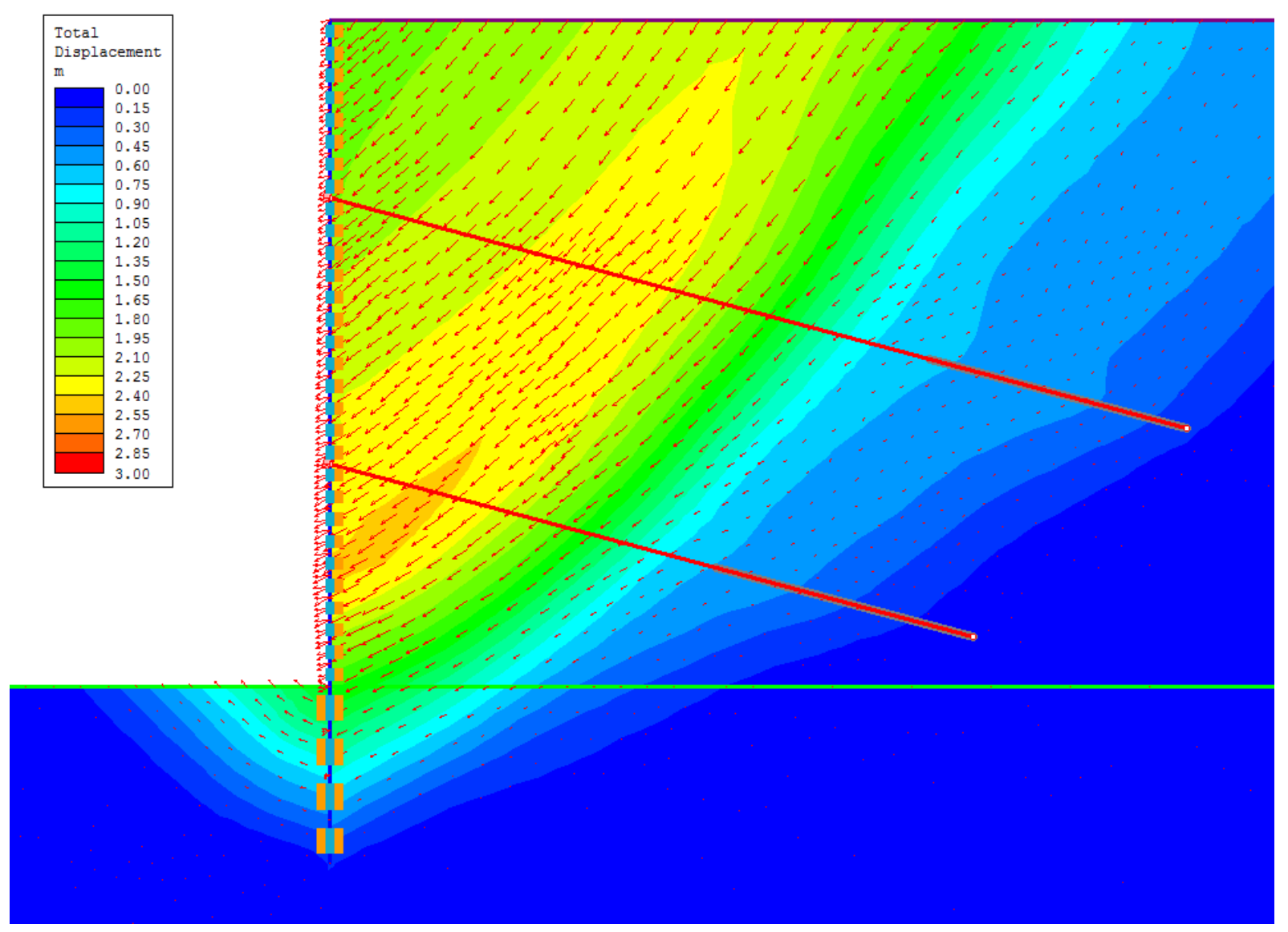

Figura 130 - Acréscimo de deslocamentos totais FS = 1,86 - Modelo 1.3-2

Pela figura 130, observa-se que no estado crítico o acréscimo de deslocamentos totais foi grande, da ordem de metros, como no modelo anterior. Os diagramas de força normal, momento fletor e pontos de plastificação são apresentados abaixo: 
Momento Fletor

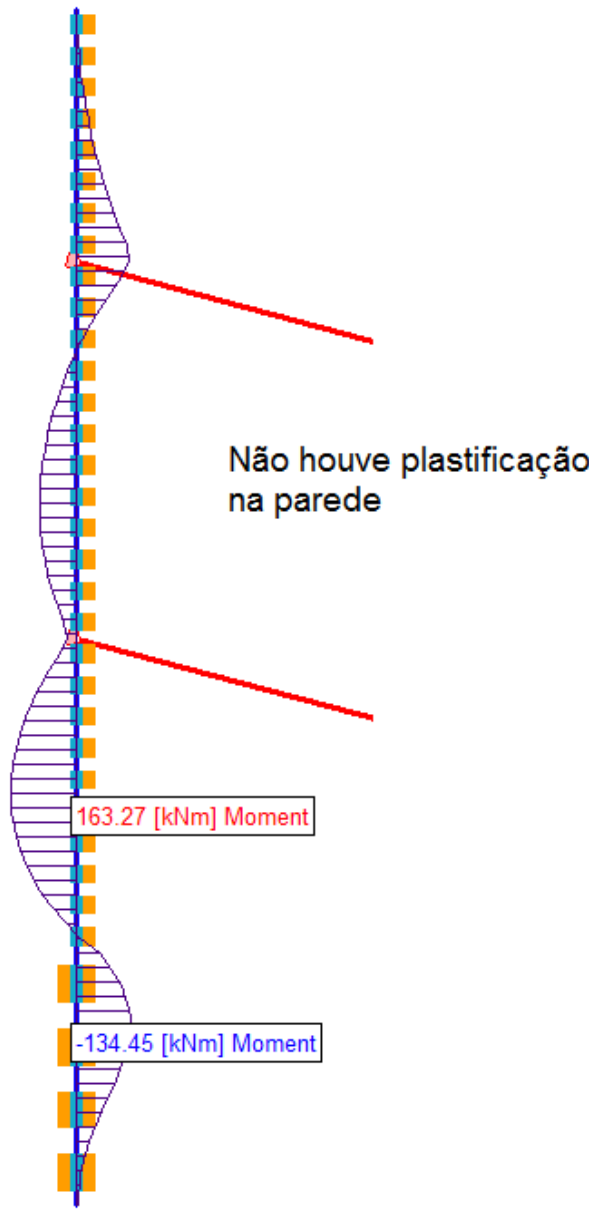

Força Normal

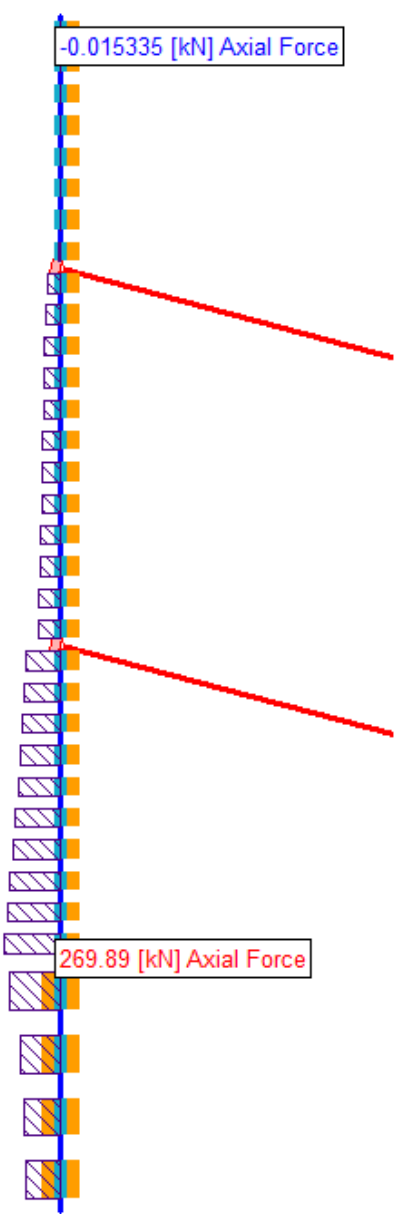

Figura 131 - Esforços na parede na final da escavação - FS = 1,0 - Modelo 1.3-2 


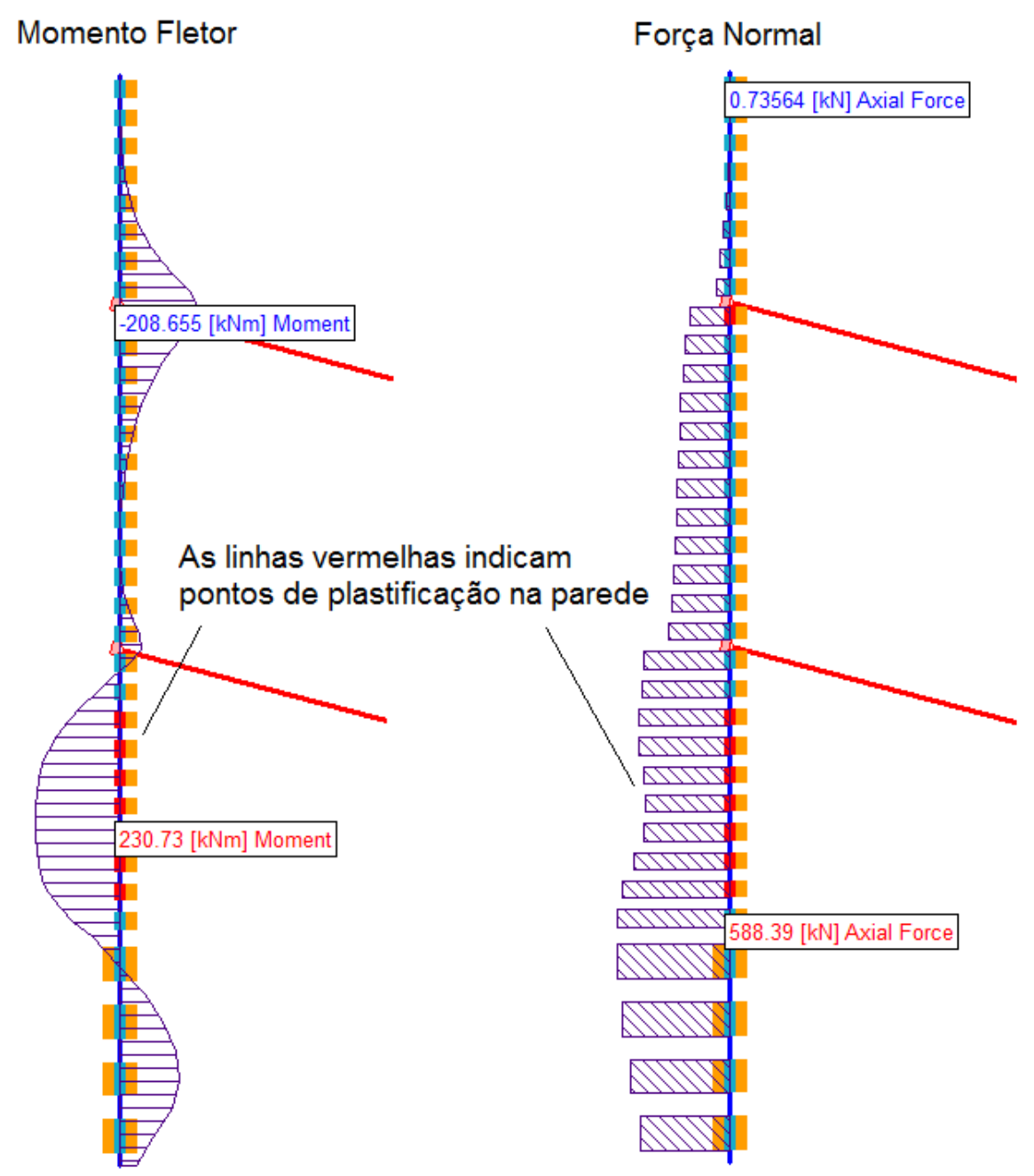

Figura 132 - Esforços na parede no limte da estabilidade - FS = 1,86 - Modelo 1.3-2

As mesmas observações feitas para o modelo 1.3-1 valem para o modelo 1.3-2. A diferença entre os dois modelos é que este é mais rígido devido ao limite de compressão do concreto e de escoamento do aço ser maior que o do modelo 1.3-1, o que faz com que os esforços, neste modelo, fiquem maiores também.

Abaixo é apresentada a verificação da ocorrência de rótula plástica.

Partindo da força normal, 452,09 kN, concomitante ao momento máximo, $230,73 \mathrm{kNm}$, no limite da estabilidade, foi elaborado um diagrama $\mathrm{M}-\mathrm{N}-1 / \mathrm{r}$ verificouse que os esforços estão longe do momento resistente último: 


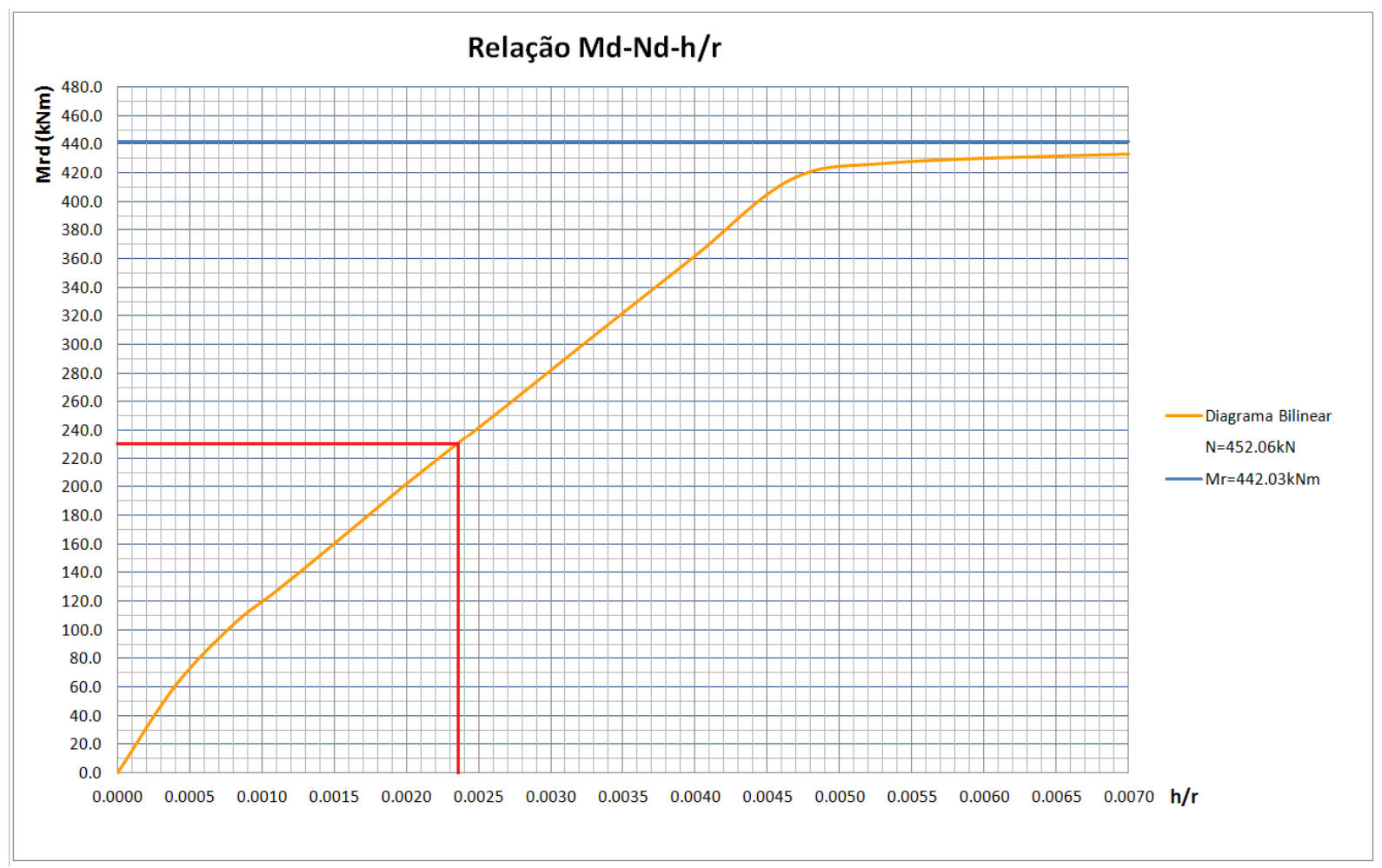

Figura 133 - Diagrama M-N-1/r - Modelo 1.3-2

O momento resistente no ELU para normal $\mathrm{Nd}=452,09 \mathrm{kN}\left(\gamma_{f}=1,0\right.$, favor da segurança neste caso, por ser pequena para a seção), é:

$$
R_{d}=\frac{r\left(f_{m, \ldots}\right)}{\gamma_{R} \cdot \gamma_{R d}}=\frac{M_{R}}{1,2 \cdot 1,1}=\frac{M_{R}}{1,32}=\frac{442,03}{1,32}=334,87 \mathrm{kNm}
$$

O diagrama de interação para a seção: 


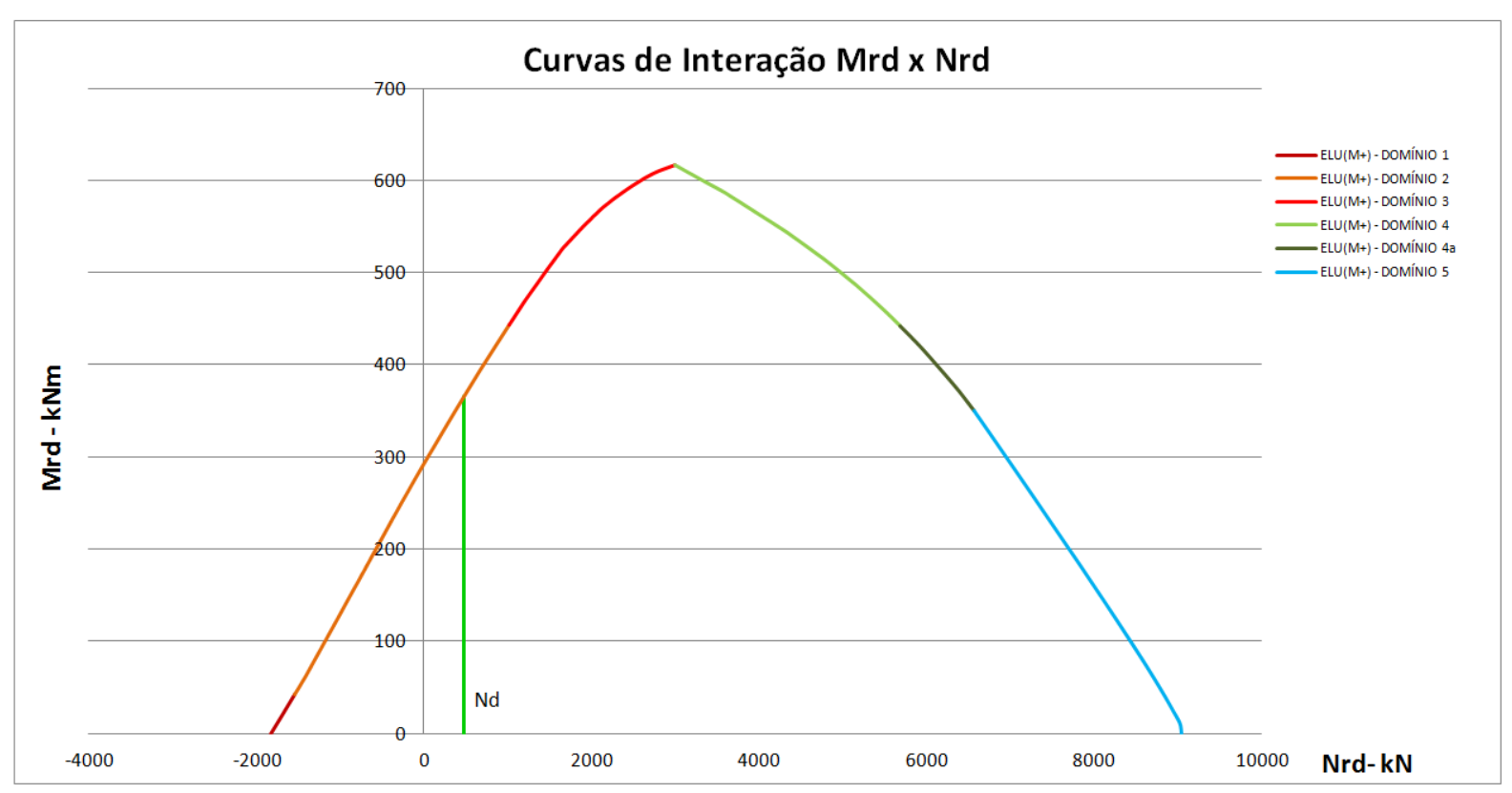

Figura 134 - Diagrama de interação - diagrama tensão deformação bilinear - Modelo 1.3-1

Da mesma forma que no modelo 1.3-1, analisaram-se também as deformações e as tensões na seção, para os esforços obtidos, considerando o diagrama tensão deformação parabólico-retangular para efeito de comparação com o bilinear. Faz-se a observação de que o valor 0,85 , não é efeito Rüsh, mas apenas um multiplicador. 


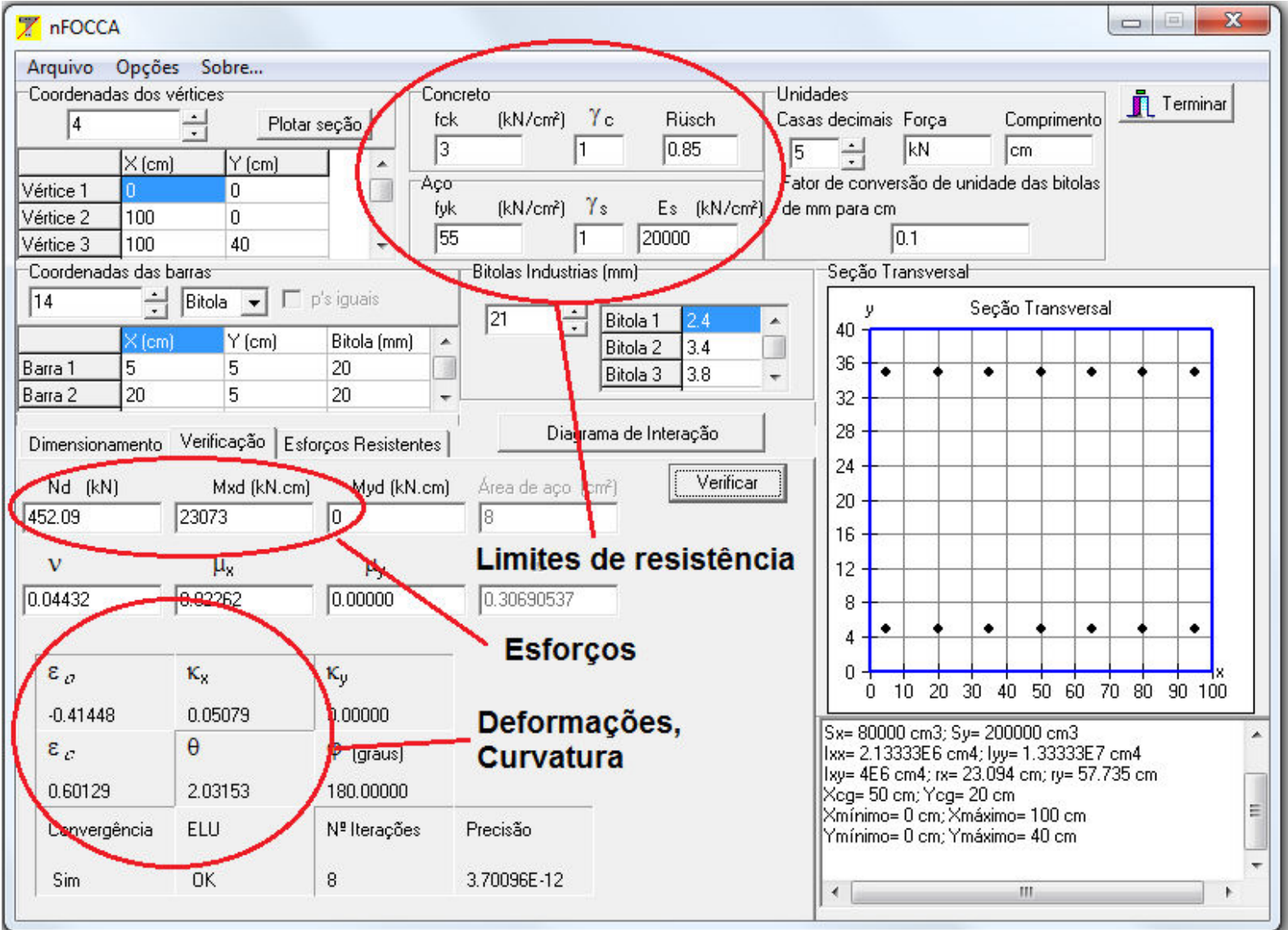

Figura 135 - Deformações na seção de momento fletor máximo - Modelo 1.3-2

Faz-se a observação de que o valor 0,85, na figura 135 não é efeito Rüsh, mas está apenas um multiplicador.

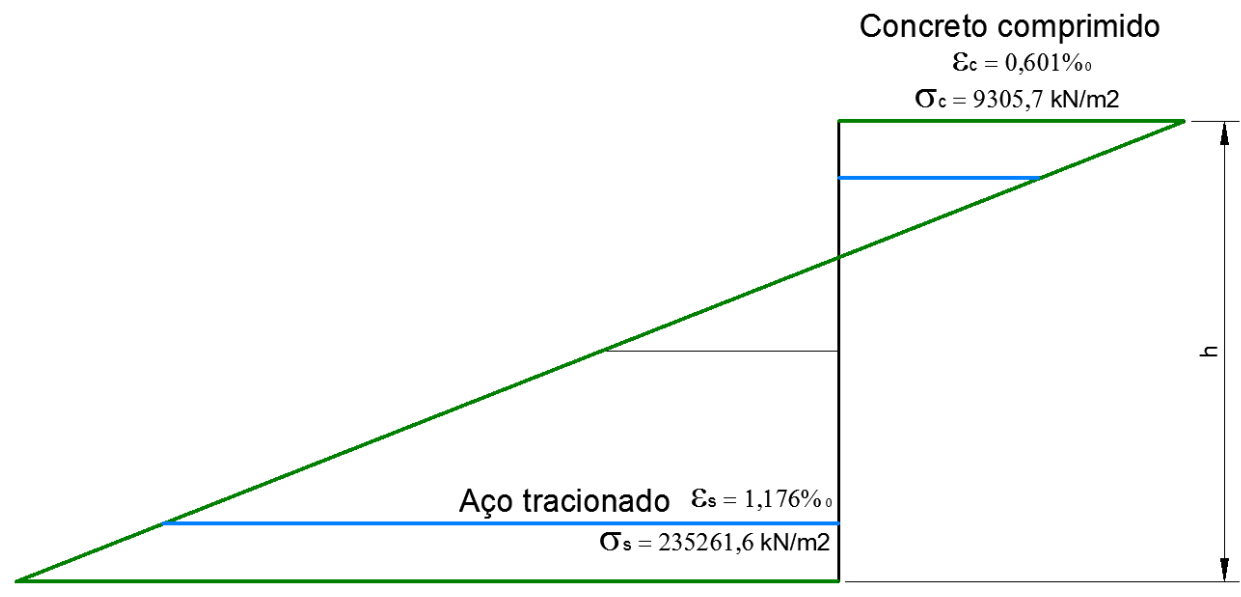

Figura 136 - Deformação na seção de momento máximo - Modelo 1.3-2 
Pelo diagrama acima se observa que a plastificação mostrada pelo programa corresponde à tração no concreto e que a seção encontra-se no estádio II. O momento resistente no ELU considerando o diagrama parabólico retangular é:

$$
R_{d}=\frac{r\left(f_{m, \ldots}\right)}{\gamma_{R} \cdot \gamma_{R d}}=\frac{M_{R}}{1,2 \cdot 1,1}=\frac{M_{R}}{1,32}=\frac{460,27}{1,32}=348,7 \mathrm{kNm}
$$

As mesmas conclusões do modelo 1.3-1 são válidas aqui.

$\mathrm{Na}$ análise de estabilidade o fator de segurança obtido é, igualmente ao modelo 1.3-1, menor que o do modelo 1.2, no entanto as condições de compatibilidade de tensões e deformações para a parede foram observadas. Notase o aumento do fator de segurança deste modelo com relação ao 1.3-1 (4,5\% maior), devido ao aumento na rigidez. 


\subsection{ANÁLISE DE ESTABILIDADE CONSIDERANDO A RIGIDEZ TANGENTE DO DIAGRAMA M-N-1/R, COM DIAGRAMA TENSÃO DEFORMAÇÃO PARABÓLICO-RETANGULAR E OS LIMITES DA ABNT NBR6118:2007}

O intuito desta aplicação do diagrama $\mathrm{M}-\mathrm{N}-1 / \mathrm{r}$ não é resolver o problema da compatibilidade de tensões e deformações, (para isso seria necessário elaborar um novo programa ou implementar algum existente com a formulação adequada), mas atribuir uma rigidez mais adequada, com algum critério, para a parede da contenção, somente para análise de estabilidade.

Os diagramas $\mathrm{M}-\mathrm{N}-1 / \mathrm{r}$, como apresentado no capítulo 5 , foram obtidos pela discretização da seção transversal da parede (com largura unitária), em 22 lamelas em são aplicadas as deformações impostas pela curvatura, foram utilizadas 575 variações de curvatura $\left(23 \varepsilon_{0} \times 25 h / r\right)$. Abaixo é apresentado o gráfico gerado para obtenção das relações $\mathrm{M}-\mathrm{N}-1 / \mathrm{r}$ :

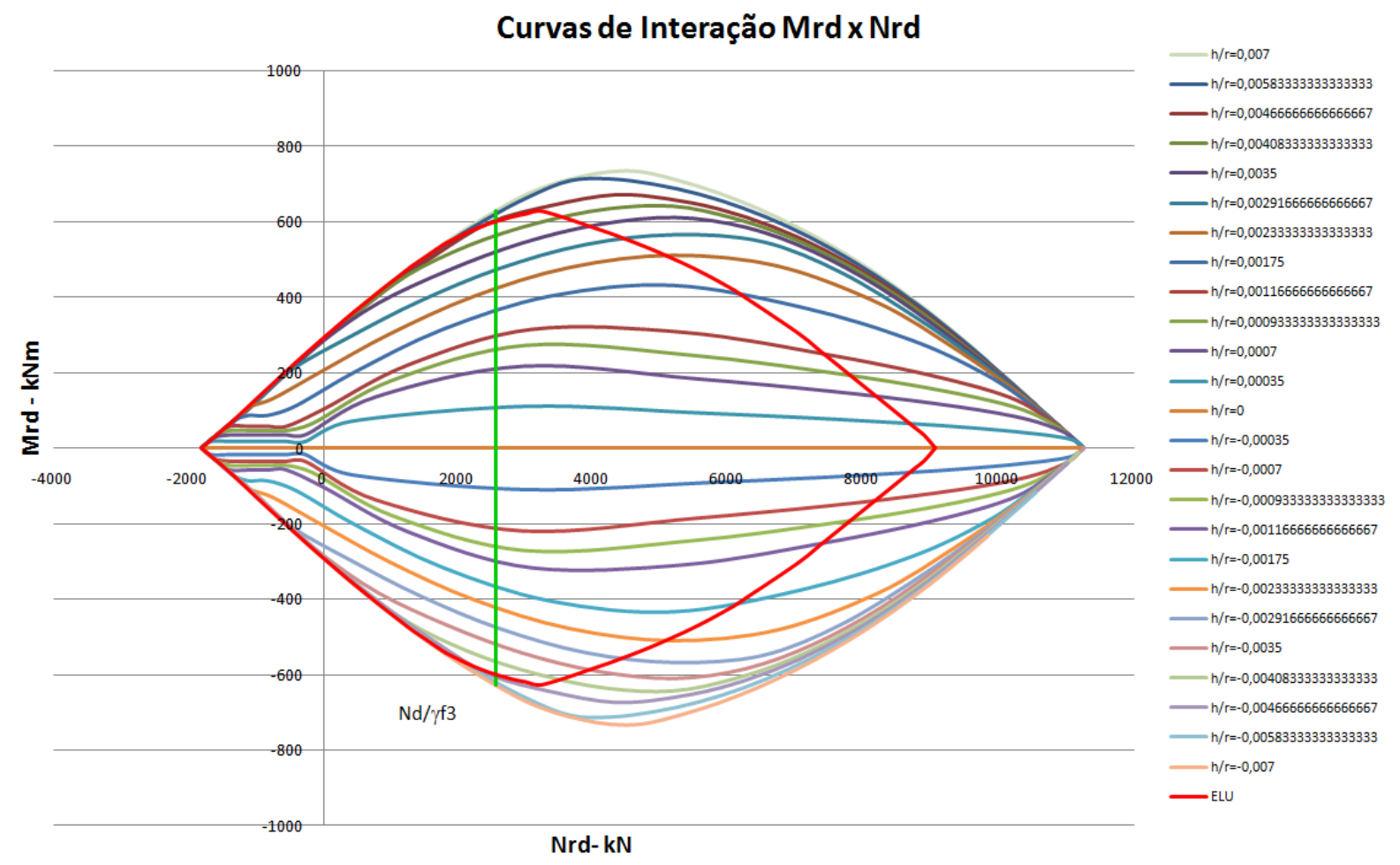

Figura 137 - Curvas de interação Mrd x Nrd

Para construção do diagrama acima foi utilizado o diagrama tensãodeformação parabólico-retangular, com:

- $0,789 f_{c k}=23,67 M P a$; 
- $f_{y d}=435 \mathrm{MPa}$;

- ELU (do diagrama M-N-1/r) de acordo com a ABNT NBR6118:2007. Com os valores conjugados de $\mathrm{M}-\mathrm{N}-\mathrm{h} / \mathrm{r}$, pode-se obter o gráfico abaixo:

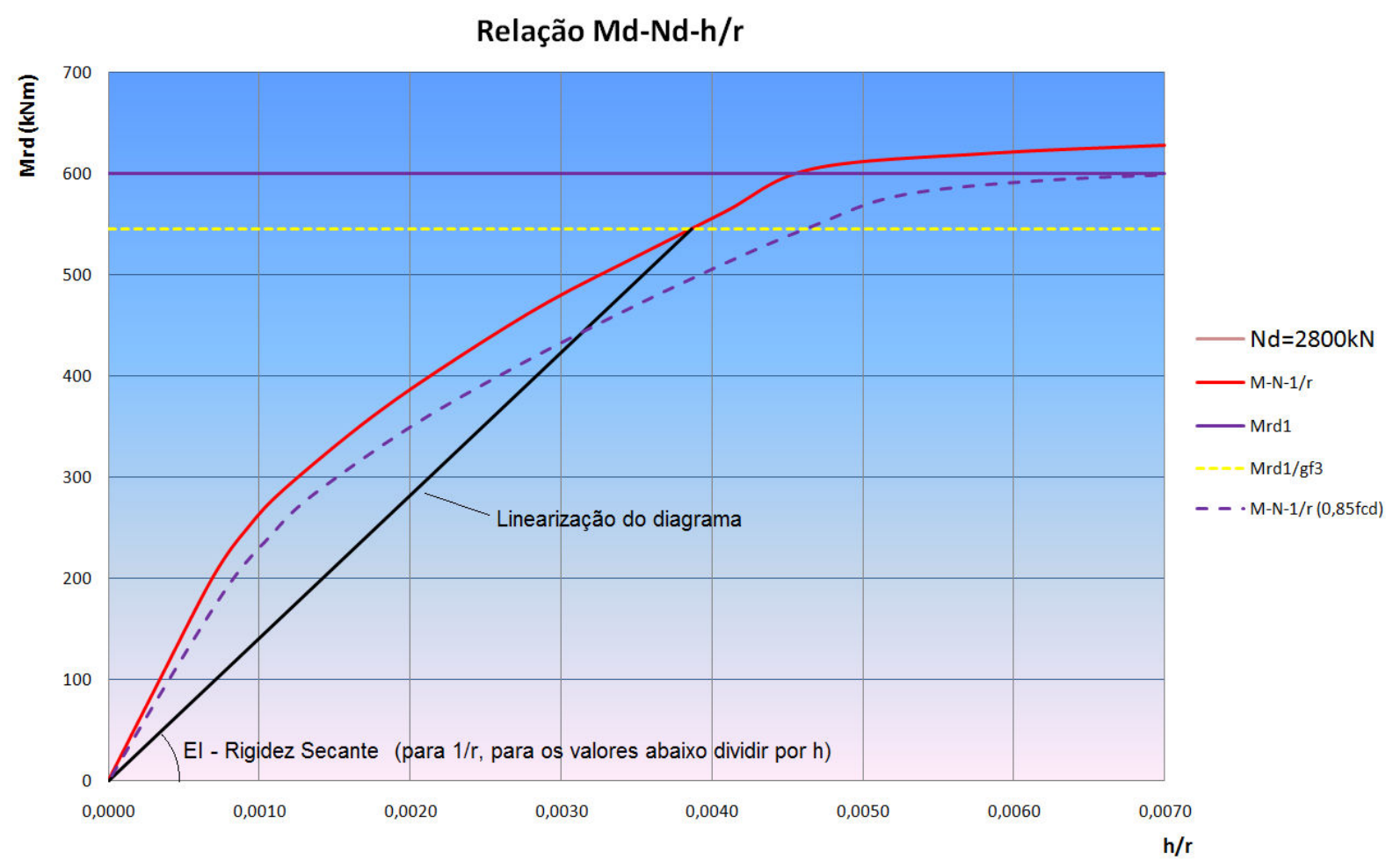

Figura 138 - Diagrama M-N-h/r

O diagrama da figura 138 está de acordo com o apresentado no item 15.3.1 da ABNT NBR6118:2007.

A análise é feita em etapas, a primeira consiste em dividir a parede em trechos para aplicar, posteriormente, as rigidezes: 


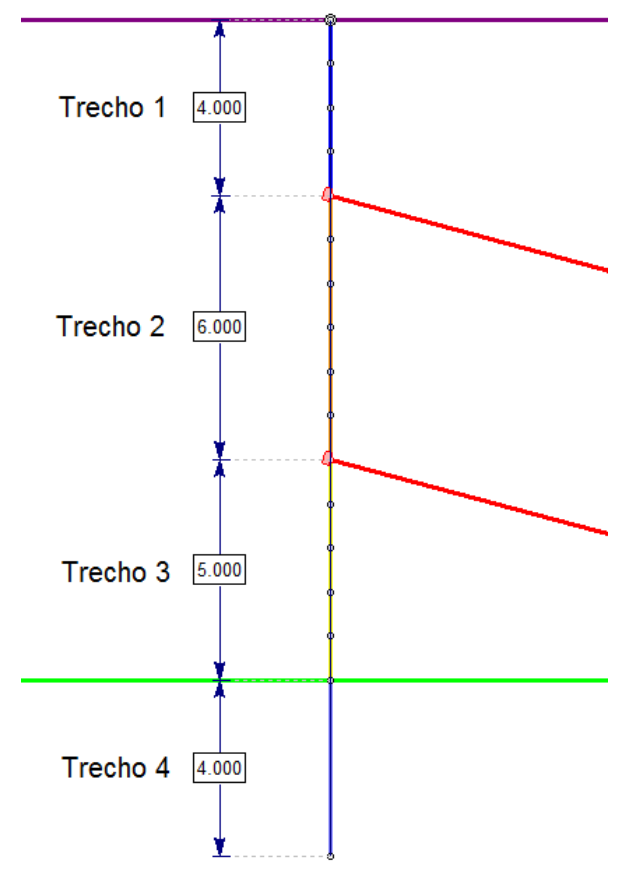

Figura 139 - Divisão da parede para aplicação das rigidezes - Modelo 1.4

A divisão acima foi adotada considerando o diagrama de força normal, em que após a aplicação dos tirantes, que tem uma determinada inclinação com a horizontal, ocorre acréscimo de força normal relativamente significativo (comparativamente entre todos os trechos), assim a rigidez a ser aplicada é correspondente a força atuante média do trecho.

A segunda etapa consiste na obtenção da força normal. Esta análise é feita com a rigidez total, assim partindo dos esforços obtidos na análise elástica linear, mostrada na figura 107 :

Tabela 26 - Rigidezes, de acordo com a força normal média de cada trecho - Modelo 1.4

\begin{tabular}{|c|c|c|}
\cline { 2 - 3 } \multicolumn{1}{c|}{} & Normal média $(\mathrm{kN})$ & El secante $\left(\mathrm{kNm}^{2}\right)$ \\
\hline Trecho 1 & 3,5 & 34434,78 \\
\hline Trecho 2 & 51 & 35093,32 \\
\hline Trecho 3 & 196 & 37250,05 \\
\hline Trecho 4 & 224 & 37682,54 \\
\hline
\end{tabular}

Fonte: Elaborada pelo autor

$\mathrm{Na}$ terceira etapa aplicam-se estas novas rigidezes ao modelo. os resultados são apresentados abaixo: 
Shear Strength Reduction - Critical SRF: 1.8 at Displacement: $0.728 \mathrm{~m}$

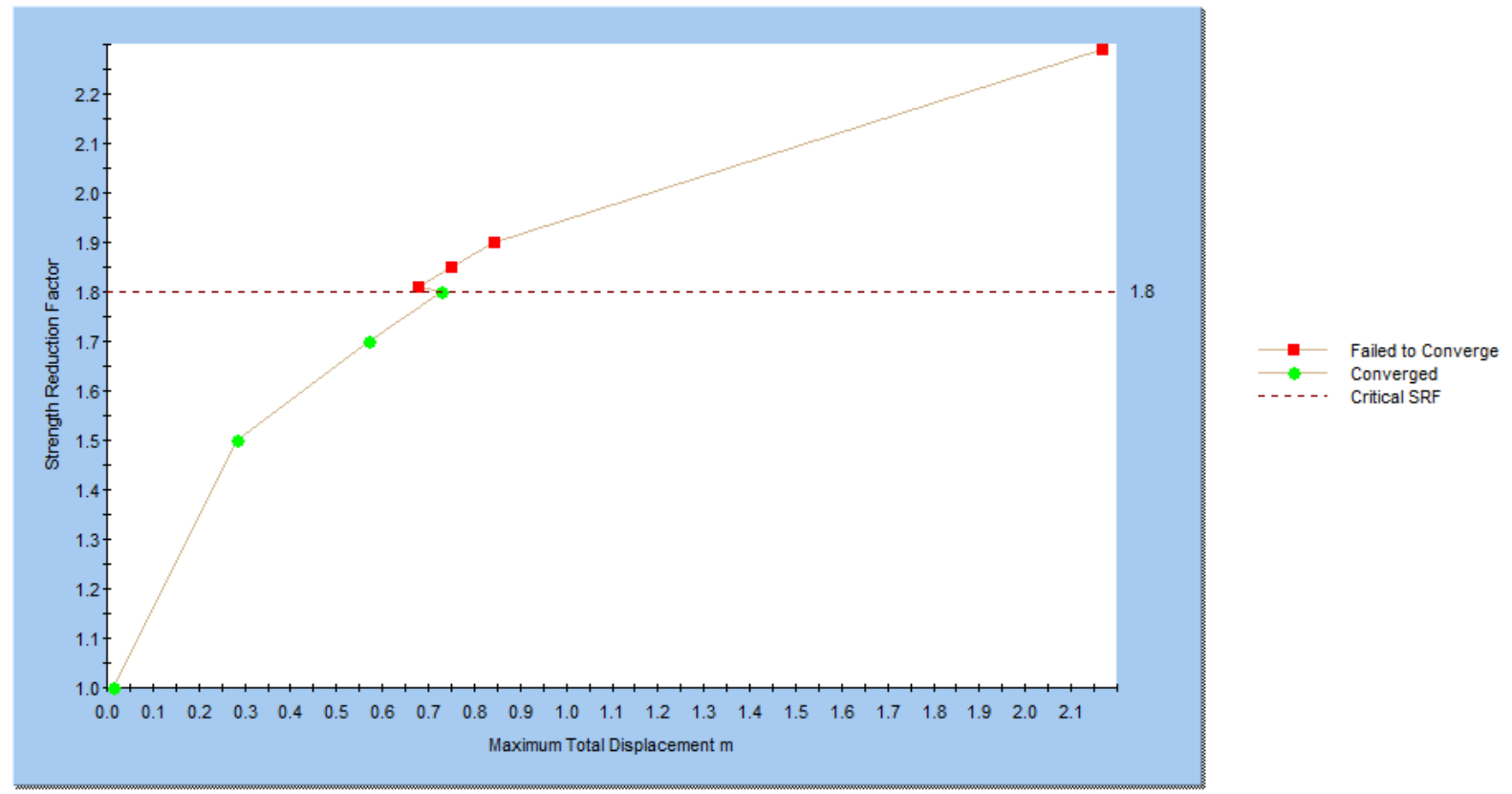

Figura 140 - SSR - Gráfico de convergência, parede com redução de rigidez - $(F S=1,8)$ - Modelo 1.4

Observa-se uma diminuição de $11,1 \%$ no fator de segurança, comparado ao modelo elástico linear. Os esforços atuantes são apresentados abaixo:
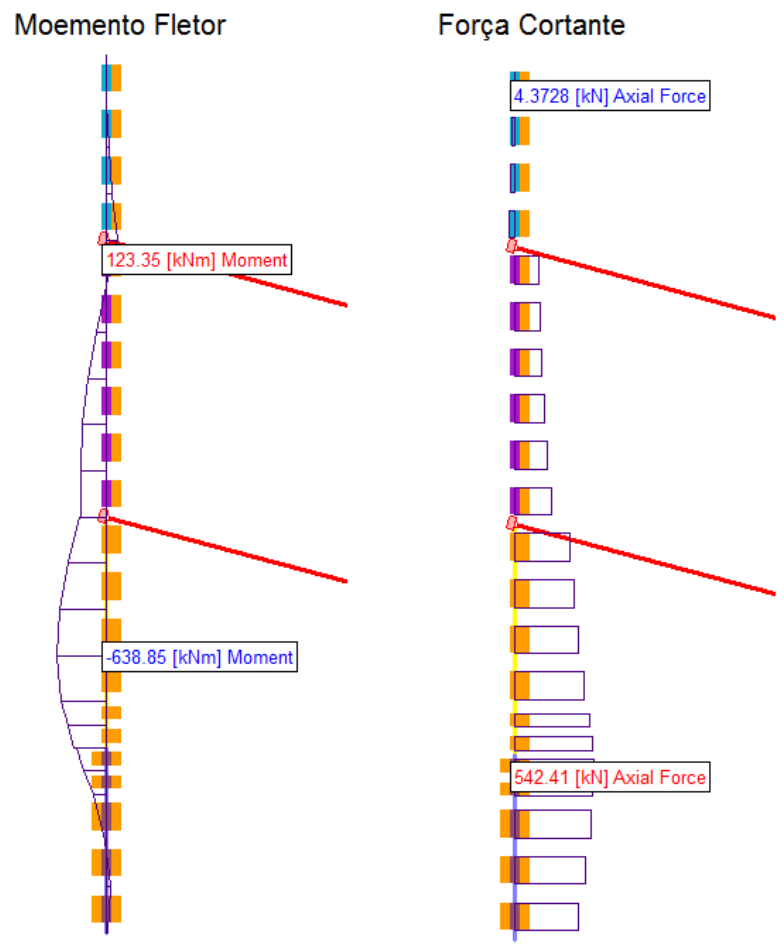

Figura 141 - Esforços na parede no limte da estabilidade - Modelo 1.4 
Houve uma diminuição de $50 \%$ no momento fletor máximo, e um aumento de $93 \%$ na força normal máxima. Dentro do procedimento adotado, somente, podese dizer que a rigidez aplicada tende a ser um limite inferior (considerando os mesmos parâmetros para as propriedades do solo e interface), pois a tendência da força normal é aumentar com o descarregamento do maciço dobre a parede. 
8.5 ANÁLISE DE ESTABILIDADE CONSIDERANDO A RIGIDEZ TANGENTE DO DIAGRAMA M-N-1/R, COM DIAGRAMA TENSÃO DEFORMAÇÃO PARABÓLICO-RETANGULAR E OS LIMITES DO CEB-FIB 2010

O procedimento adotado nesta seção é análogo ao anterior, com a diferença de diagrama tensão-deformação para o concreto, em que foi adotado o de Grasser e para o aço, em que foi adotado o diagrama com endurecimento, de acordo com o apresentado no capítulo 5. Os limites são apresentados abaixo

- $0,85 f_{c k}=25,5 M P a$;

- $\varepsilon_{c 1}=2,3 \%$;

- $\varepsilon_{c u 1}=3,5 \%$;

- $1,1 f_{\text {yd }}=550 \mathrm{MPa}$;

- ELU (do diagrama M-N-1/r) de acordo com o CEB-FIB 2010.

$\mathrm{Na}$ aplicação do diagrama $\mathrm{M}-\mathrm{N}-1 / \mathrm{r}$ é necessário obtermos o momento resistente, dada uma normal, para possa ser obter a rigidez secante, neste caso o momento resistente foi calculado com os valores acima e posteriormente foi aplicado o fator de redução:

$$
R_{d}=\frac{r\left(f_{m, \ldots}\right)}{\gamma_{R} \cdot \gamma_{R d}}=\frac{M_{R}}{1,2 \cdot 1,1}=\frac{M_{R}}{1,32}
$$

Como exemplo para comparação, considerando a seção de concreto e armadura da parede e uma força normal de $1000 \mathrm{kN}$ : 
Relação Md-Nd-h/r NBR6118 (2007)

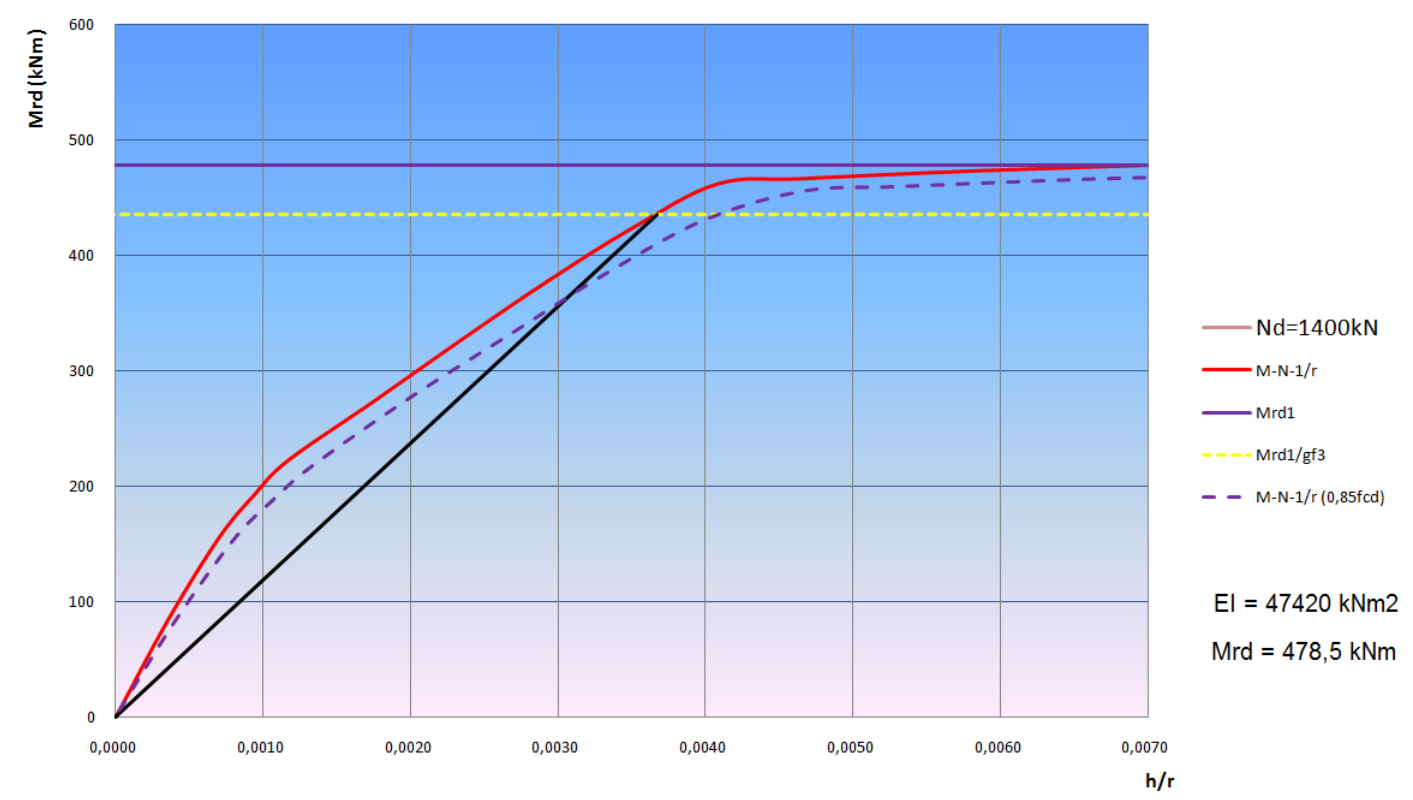

Relação Md-Nd-h/r CEB-FIB 2010 (2010)
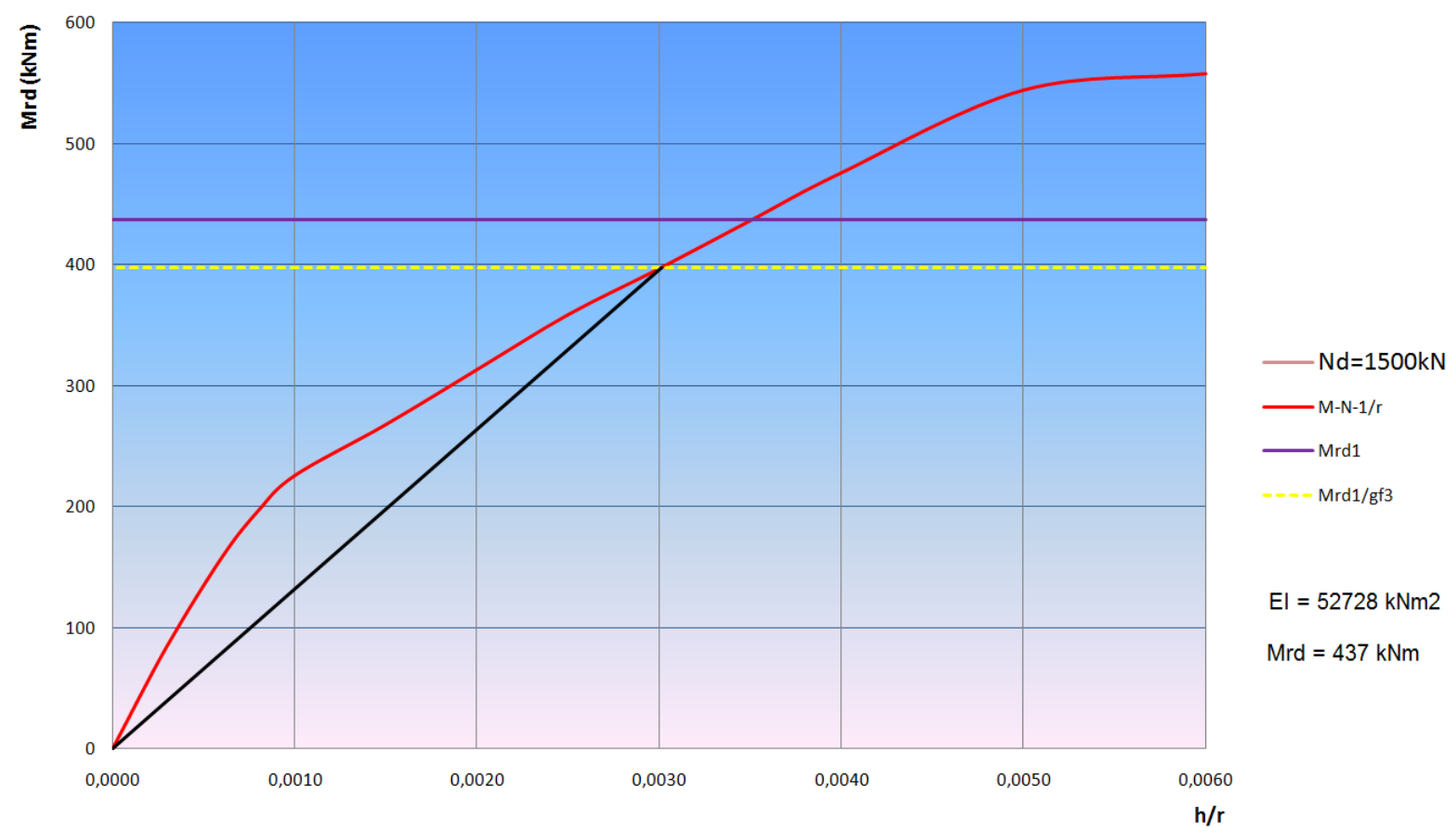

$\mathrm{El}=52728 \mathrm{kNm} 2$ Mrd $=437 \mathrm{kNm}$

Figura 142 - Comparação entre diagramas M-N-1/r

Observa-se que a diferença entre rigidezes foi de 11\% para o CEB-FIB 2010 e entre os momentos resistentes foi de 9,5\% para a ABNT NBR6118:2007.

Partindo da segunda etapa do item anterior, obtêm-se as rigidezes de acordo com a força normal da última etapa de escavação do modelo elástico linear: 
Tabela 27 - Rigidezes, de acordo com a força normal de cada trecho - Modelo 1.5

\begin{tabular}{|l|c|c|}
\cline { 2 - 3 } \multicolumn{1}{c|}{} & Normal média $(\mathrm{kN})$ & El secante $\left(\mathrm{kNm}^{2}\right)$ \\
\hline Trecho 1 & 3,5 & 35187,71 \\
\hline Trecho 2 & 51 & 36100,95 \\
\hline Trecho 3 & 196 & 38885,9 \\
\hline Trecho 4 & 224 & 39421,73 \\
\hline
\end{tabular}

Fonte: Elaborada pelo autor

Os resultados são apresentados abaixo:

Shear Strength Reduction - Critical SRF: 1.81 at Displacement: $0.742 \mathrm{~m}$

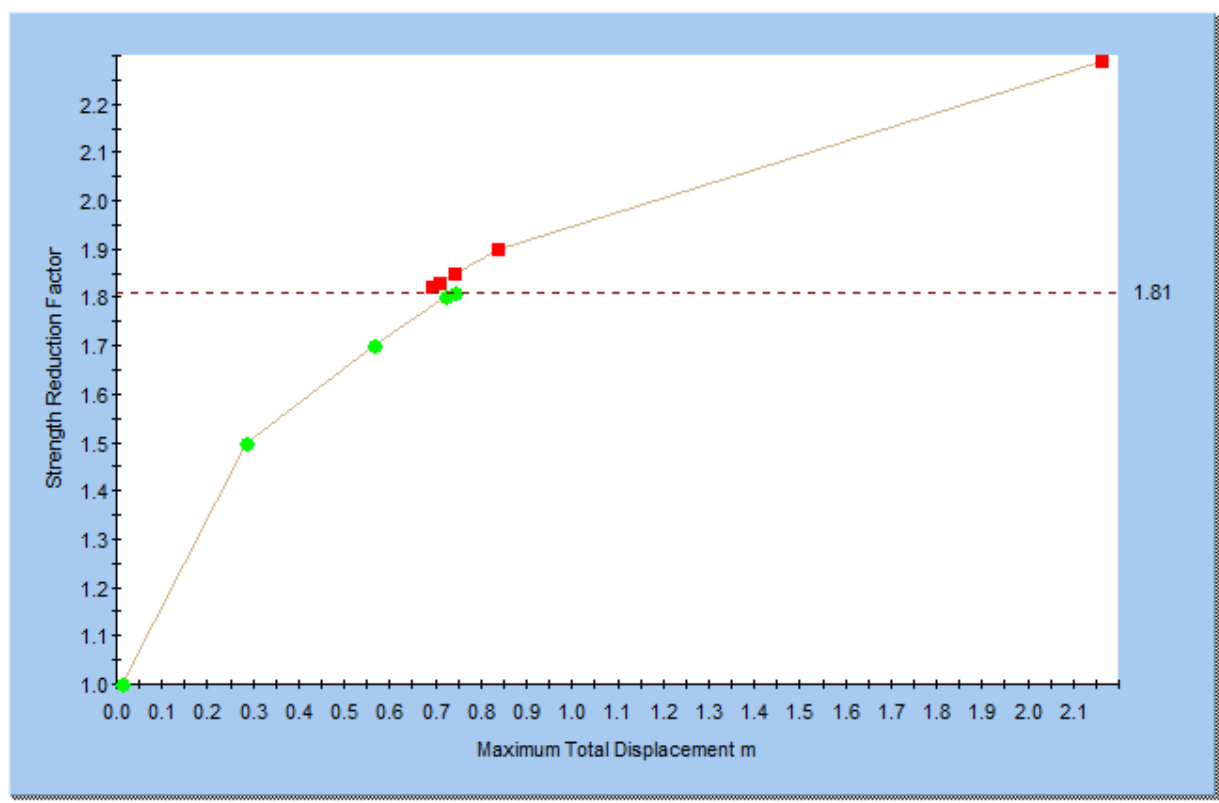

Failed to Converge Converged Critical SRF

Figura 143 - SSR - Gráfico de convergência, parede com redução de rigidez - (FS = 1,81) - Modelo 1.5 

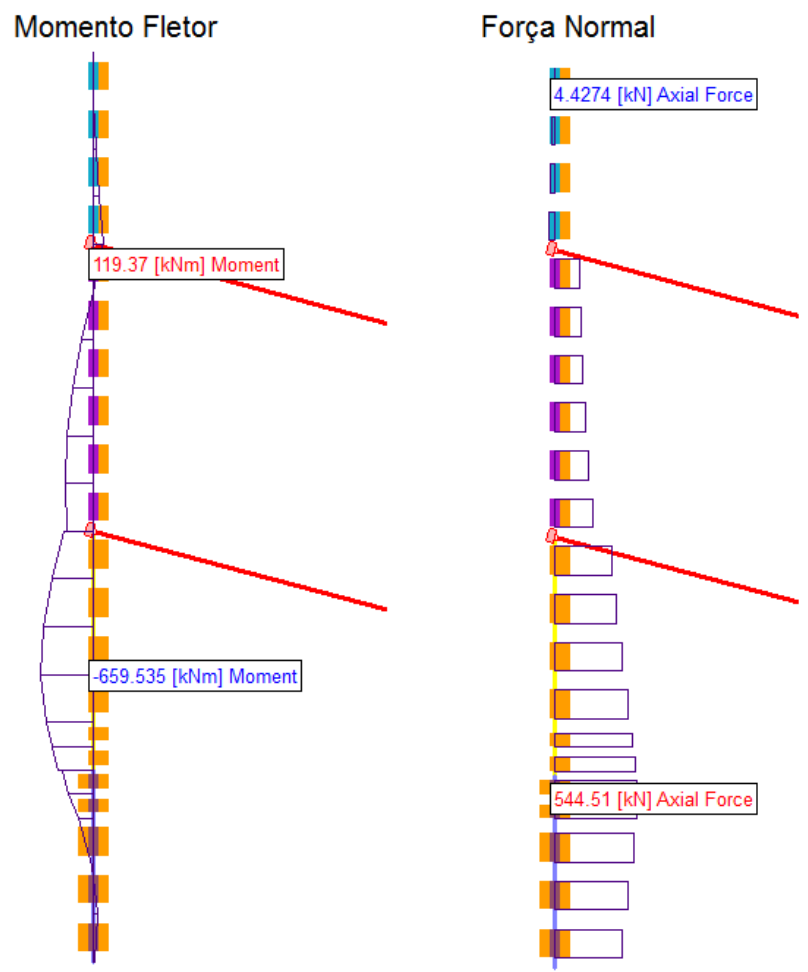

Figura 144 - Esforços na parede no limte da estabilidade - Modelo 1.5

Observa-se que os resultados do modelo 1.4 e do modelo 1.5, a despeito dos diagramas, foram praticamente coincidentes. 


\subsection{ANÁLISE DE ESTABILIDADE COM MODELO ELÁSTICO LINEAR PARA A RIGIDEZ DA PAREDE, CONSIDERANDO A VARIAÇÃO DOS PARÂMETROS DO SOLO (ANÁLISE ESTATÍSTICA)}

Para a análise estatística dos fatores de segurança elaborados três modelos:

\section{MODELO 1.6-1}

Neste modelo foi adotado o método de Monte Carlo com a técnica de amostragem LHS com 256 amostragens para cada variável. Foram utilizados como variáveis os parâmetros coesão e ângulo de atrito interno das duas camadas de solo. As amostragens foram combinadas aleatoriamente para aplicação em 256 análises.

As amostras e as combinações foram obtidas por meio do programa Slide 6.0 da Rocscience.

Foi considerado o modelo de distribuição normal de probabilidades para geração das amostras com os valores de coesão e ângulo de atrito interno do modelo base (figura 85), adotados como médio.

Observando os valores indicados para o desvio padrão das propriedades dos solos disponíveis na literatura, como apresentado no capítulo 6, foram adotados:

- Desvio padrão $\bar{\sigma}_{\phi}=5^{\circ}$, para 0 atrito interno nas duas camadas de solo;

- Desvio padrão $\bar{\sigma}_{c}=10 \mathrm{kPa}$, para a coesão nas duas camadas de solo.

Abaixo são apresentados os histogramas das amostras obtidas: 


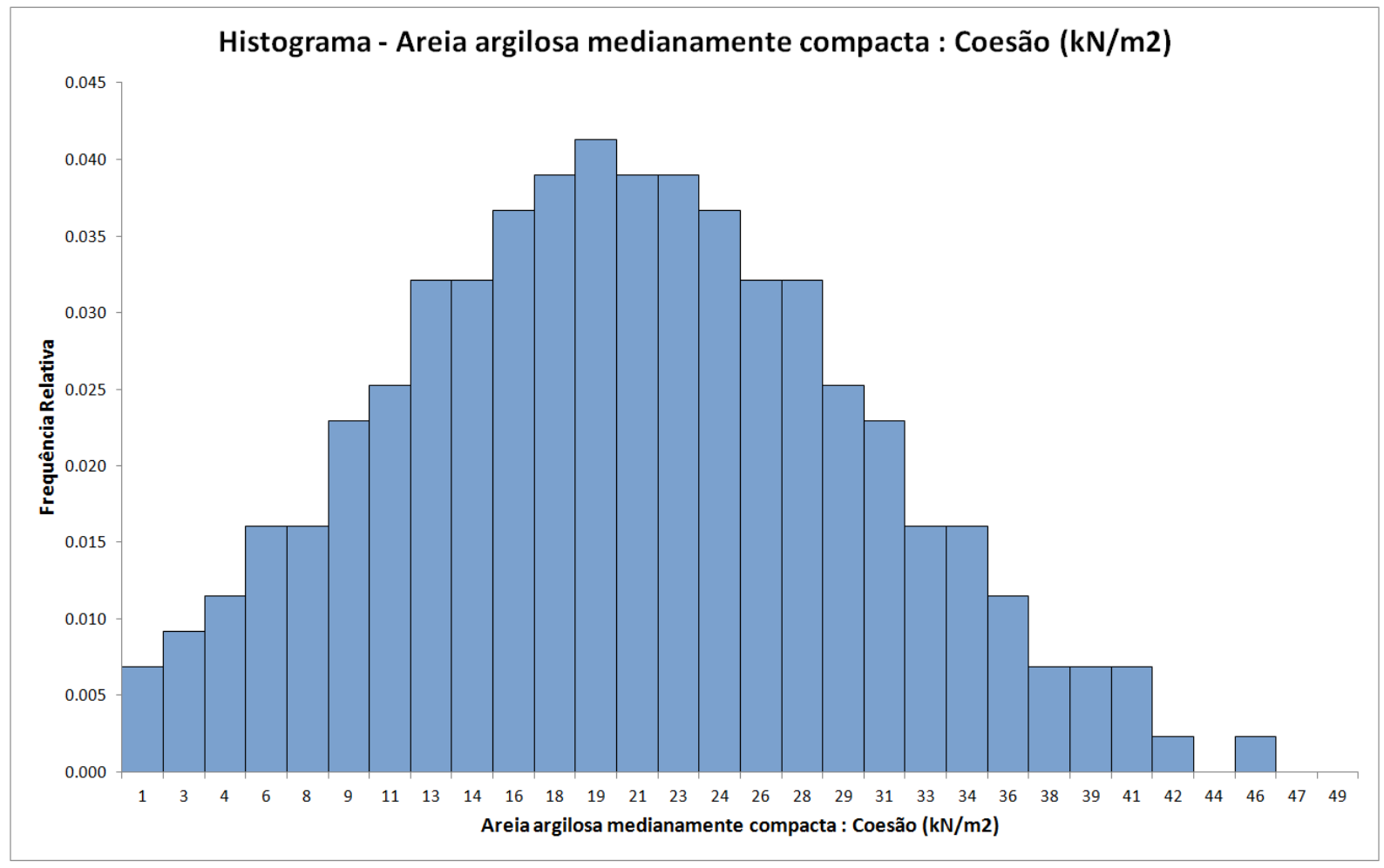

Figura 145 - Histograma de amostragem para a coesão da areia argilosa medianamente compacta (camada 1)

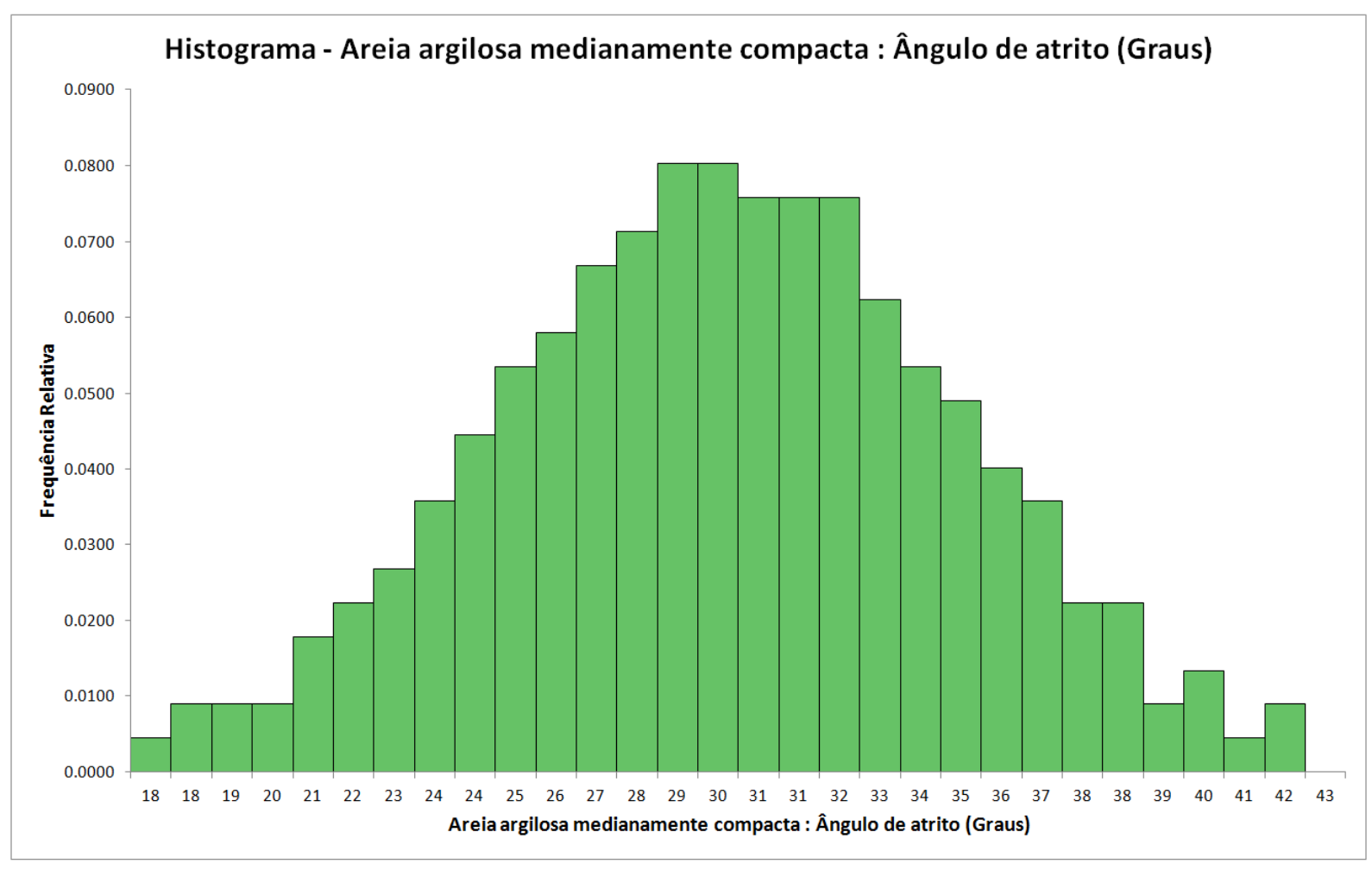

Figura 146 - Histograma de amostragem para o ângulo de atrito da areia argilosa medianamente compacta (camada 1) 


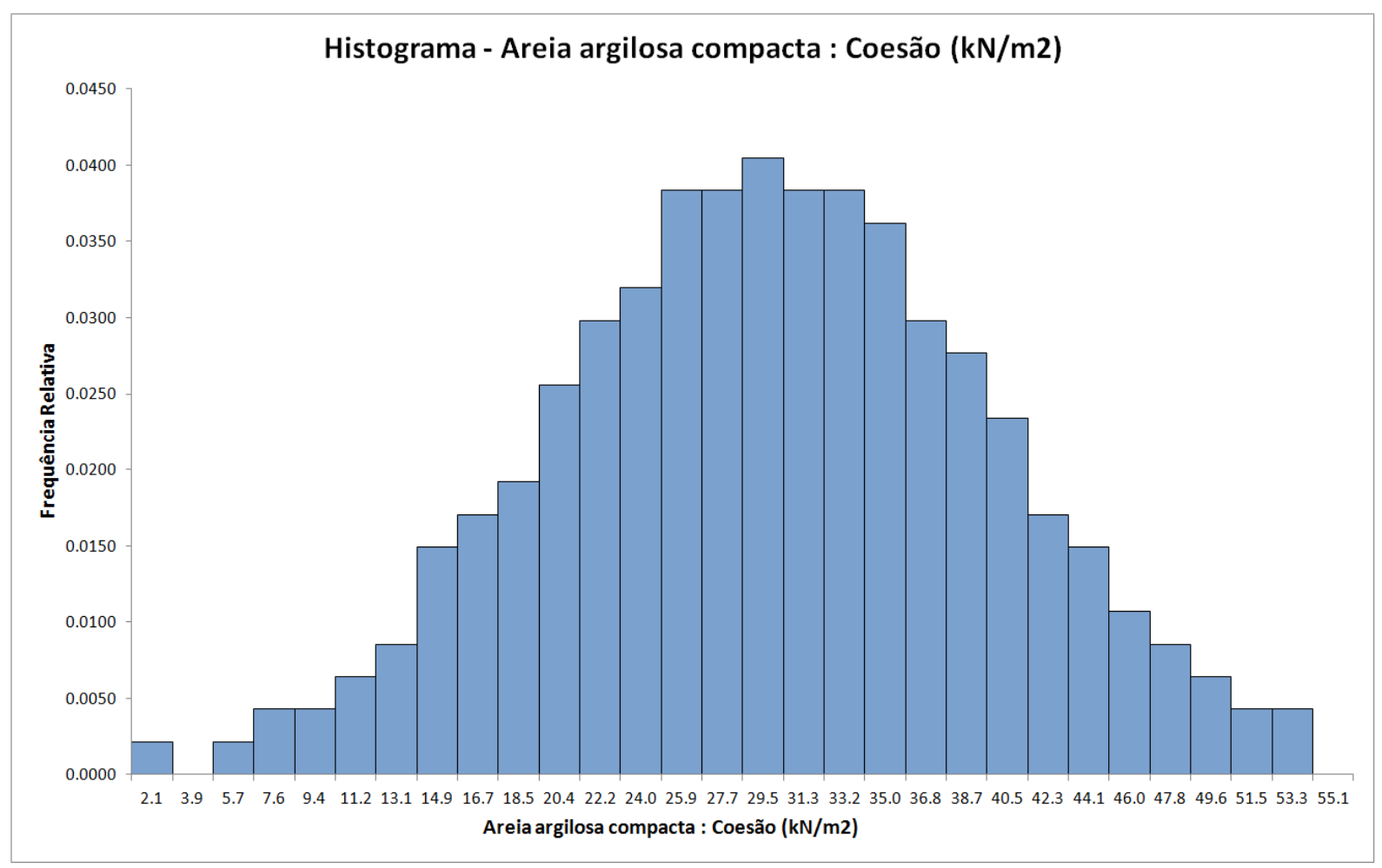

Figura 147 - Histograma de amostragem para a coesão da areia argilosa medianamente compacta (camada 2)

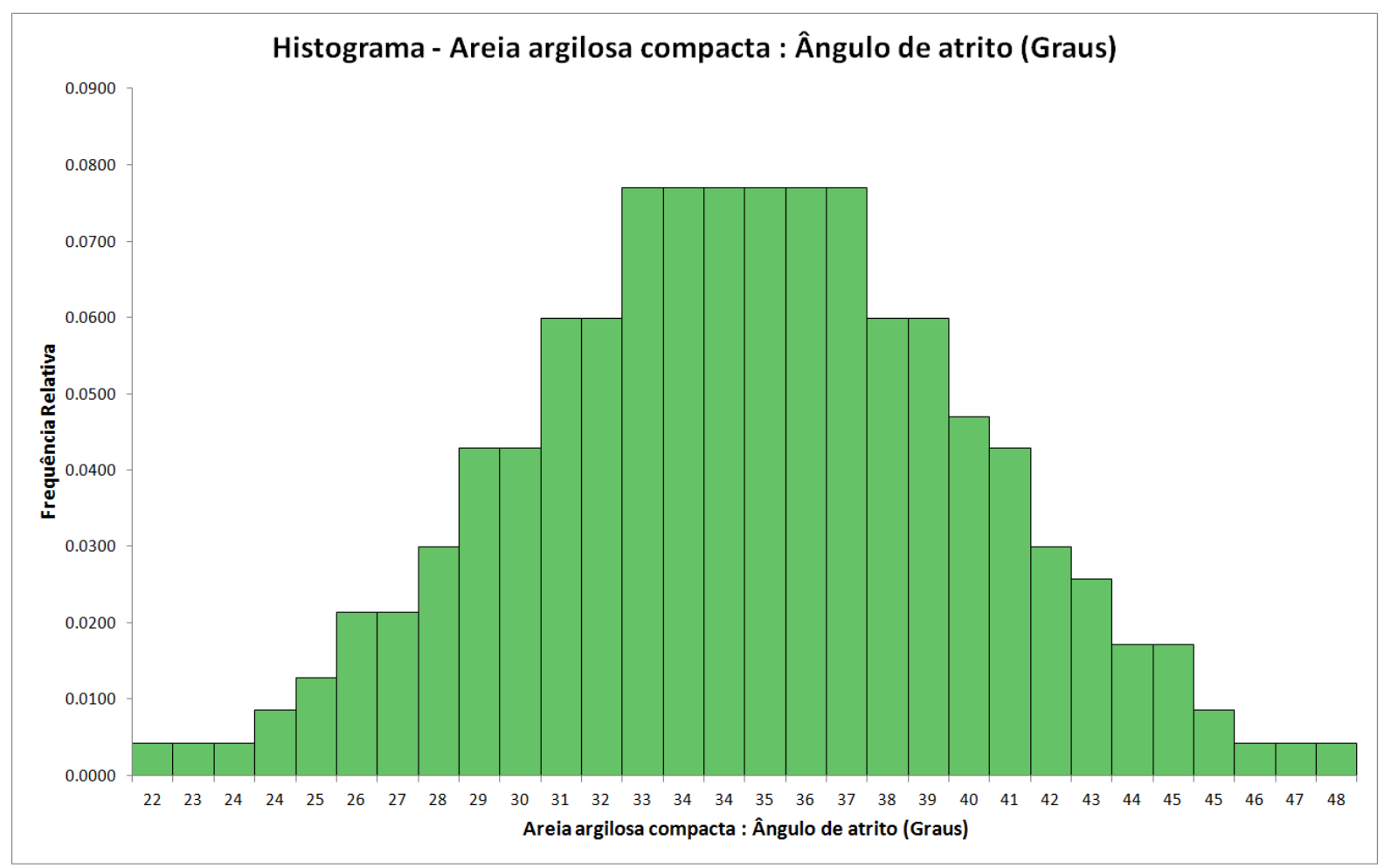

Figura 148 - Histograma de amostragem para o ângulo de atrito da areia argilosa medianamente compacta (camada 2) 
As amostras dos parâmetros e as combinações geradas a partir delas para cada modelo são apresentadas no Apêndice A.

A parede foi considerado o modelo elástico linear com os parâmetros da ABNT NBR6118:2007 e atrito na interface conforme modelo básico.

Para realização das análises os parâmetros foram aplicados manualmente nos modelos, ou seja, sem um procedimento automatizado, pois o programa utilizado (Phase 2) não tem interface com outros programas. As análises foram do tipo determinística e os fatores de segurança para a estabilidade foram determinados por meio do SSR.

Foram utilizados três computadores com processador intel core i5 e $4 \mathrm{~Gb}$ de memória RAM e em cada um foram realizadas em média duas análises por vez. Para completar as análises foram necessárias mais de 8 horas de trabalho entre as etapas de carregar os modelos e fazer os processamentos, considerando o tempo ininterrupto, além disso, foram necessárias mais 2 horas para tratamento dos dados, com total de 10 horas. O tempo médio por modelo considerando as etapas de carregamento e processamento foi de 1,875 minutos (0'1'53"). Para este tipo trabalho ressalta-se a importância do algoritmo de análise estatística estar incorporado ao programa de análise mecânica para ser possível a elaboração de estudos considerando mais dados e outros tipos de modelos de distribuição.

\section{RESULTADOS DO MODELO 1.6-1:}

Os fatores de segurança gerados em cada análise para cada modelo são apresentados no Apêndice A. Abaixo são apresentados os resultados das análises:

Média e desvio padrão:

$$
\begin{aligned}
& \mu=1,89 \\
& \sigma=0,3165
\end{aligned}
$$

Probabilidade de falha (Probabilidade de FS $\leq 1$ ):

$$
P_{f}\{F S \leq 1\}=0,25 \% \text { (1 em 400) }
$$

Índice de confiabilidade: 


$$
\beta=\frac{1,89-1}{0,3165}=2,81
$$

Histograma dos valores do fator de segurança, curva normal de densidade de probabilidade e probabilidade acumulada: 


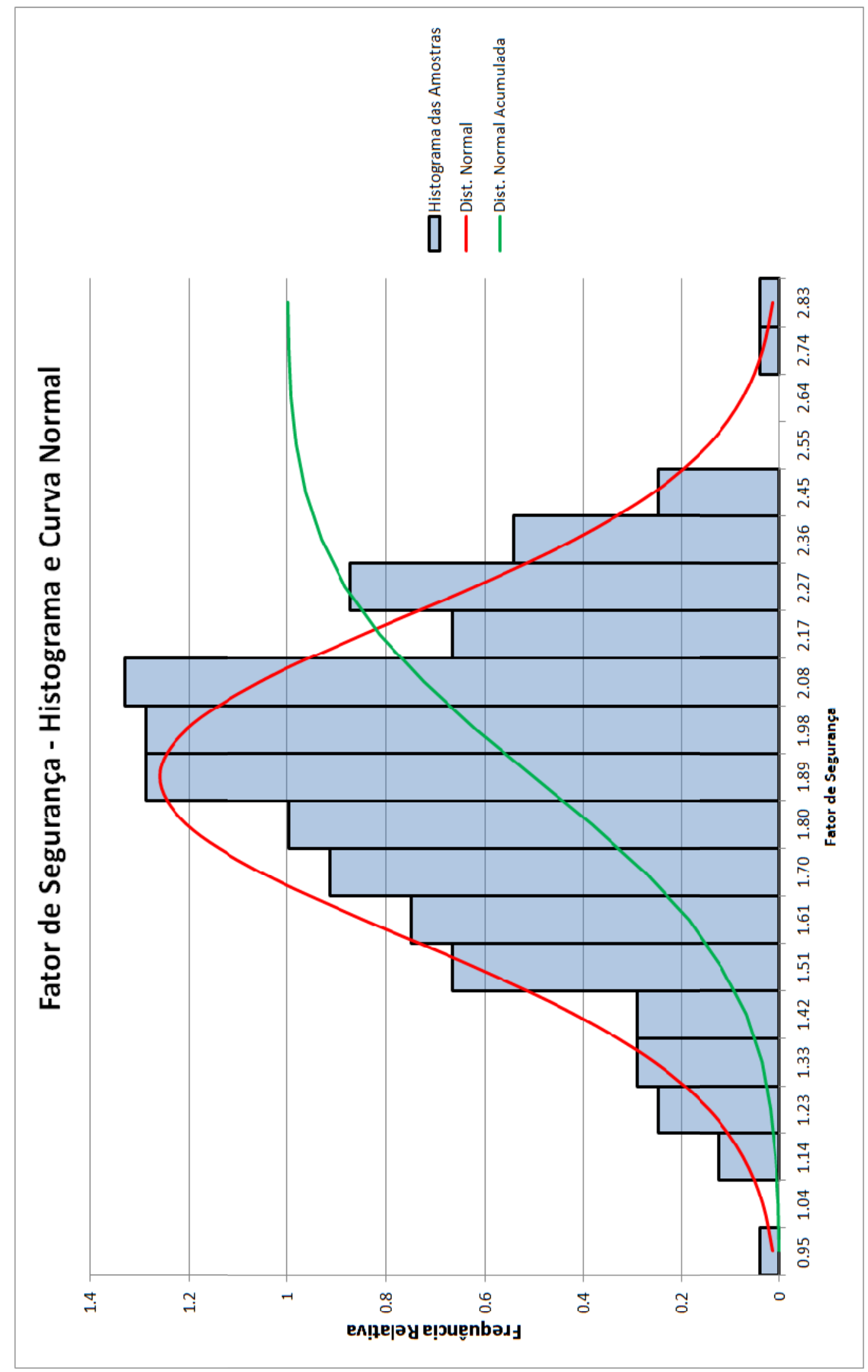

Figura 149 - Histograma e Curva de densidade de probabilidade e probabilidade acumulada do Fator de Segurança 
Observa-se pela figura 149 que a curva normal é um modelo de distribuição de probabilidades satisfatório para o histograma de resultados.

\section{MODELO 1.6-2}

Neste modelo foi utilizado o PEM considerando os mesmos dados e parâmetros do modelo 1.6-1. As combinações de variáveis aplicadas resultaram em $2^{4}=16$ modelos para obtenção dos resultados. Neste caso como programa Phase2 tem o PEM incorporado, é necessário apenas o fornecimento de um modelo e dos parâmetros. $O$ tempo de processamento foi de 4 horas com apenas um computador e apenas uma fase de entrada de dados, portanto mais eficiente que o modelo 1.6-1.

\section{RESULTADOS DO MODELO 1.6-2:}

A figura 150 apresenta os valores obtidos para o fator de segurança médio, desvio padrão e probabilidade de falha (Probabilidade de FS $\leq 1$ ):

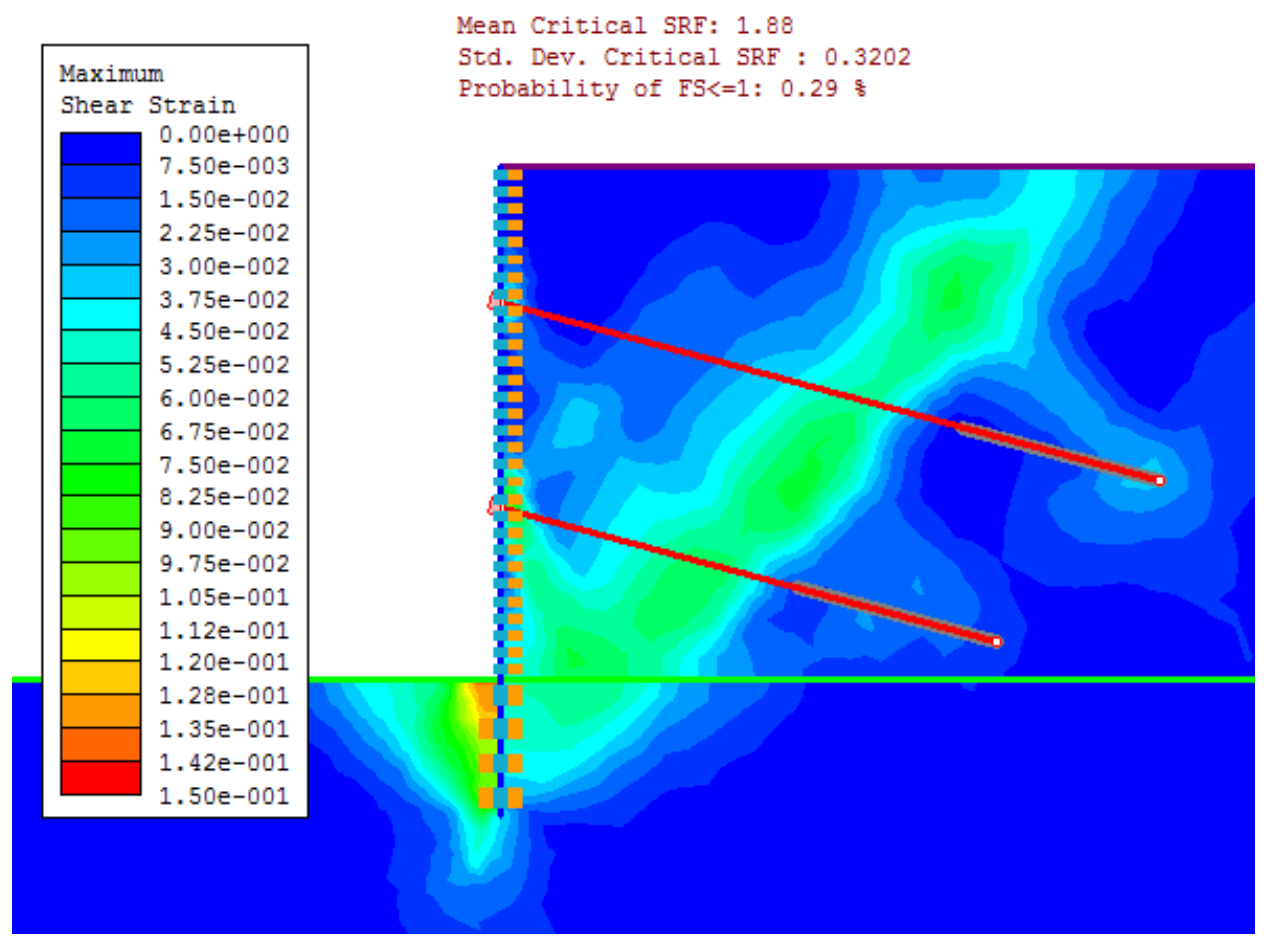

Figura 150 - Resultado da análise de estabilidade com variação probabilística das propriedades do solo - Modelo 1.6-2

Média e desvio padrão: 


$$
\begin{aligned}
& \mu=1,88 \\
& \sigma=0,3202
\end{aligned}
$$

Probabilidade de falha (Probabilidade de FS $\leq 1$ ):

$$
P_{f}\{F S \leq 1\}=0,29 \%(1 \mathrm{em} 344,8)
$$

Índice de confiabilidade:

$$
\beta=\frac{1,88-1}{0,3202}=2,75
$$

Na figura 150 é apresentada a deformação cisalhante máxima que ocorre na condição de instabilidade para o valor médio do fator de segurança. Nota-se que é formado um plano médio de falha entre o paramento de concreto e os tirantes para o valor médio do fator de segurança.

Ao compararmos os modelos 1.6-1 e 1.6-2 observa-se que houve uma excelente aproximação entre os valores dos resultados, principalmente o fator se segurança médio em que a diferença foi de $0,5 \%$.

O método de Monte Carlo é mais robusto que PEM, pois não há a imposição de que as variáveis de entrada e os resultados obedeçam à distribuição normal de densidade de probabilidade. Pelo modelo 1.6-1 foi verificado que a curva normal apresentou uma aproximação satisfatória para a distribuição de probabilidades do fator de segurança, considerando este fato como indício de que a distribuição normal de probabilidades seja adequada para representar o fator de segurança no tipo de análise realizada. Neste caso o PEM apresenta-se como alternativa eficiente e com possibilidade de uso em problemas práticos de engenharia.

Quanto ao índice de confiabilidade, ressalta-se que o valor indicado pelo Eurocode 0 (2004), para estado limite último em 50 anos é 3,5 e que tanto o modelo 1.6-1 quanto o modelo 1.6-2 apresentaram valores que são aproximadamente $20 \%$ inferior. 
Neste modelo foi utilizado o PEM considerando os mesmos dados e parâmetros do modelo 1.6-2, no entanto foi adicionada uma variação no ângulo de atrito na interface entre o solo e o paramento de concreto.

Considerando-se:

$\delta=0,6 a 0,8 \cdot \phi$, e a variação do ângulo de atrito do solo:

$$
\begin{aligned}
& \delta_{\text {máx }}=0,8 \cdot(30+5)=28^{\circ} \\
& \delta_{\text {min }}=0,6 \cdot(30-5)=15^{\circ} \\
& \delta_{\text {médio }}=0,7 \cdot(30)=21^{\circ} \\
& \bar{\sigma}_{\delta}=6,5^{\circ}
\end{aligned}
$$

As combinações de variáveis aplicadas resultaram em $2^{5}=32$ modelos para obtenção dos resultados.

\section{RESULTADOS DO MODELO 1.6-3:}

A figura 151 apresenta os valores obtidos para o fator de segurança médio, desvio padrão e probabilidade de falha (Probabilidade de FS $\leq 1$ ):

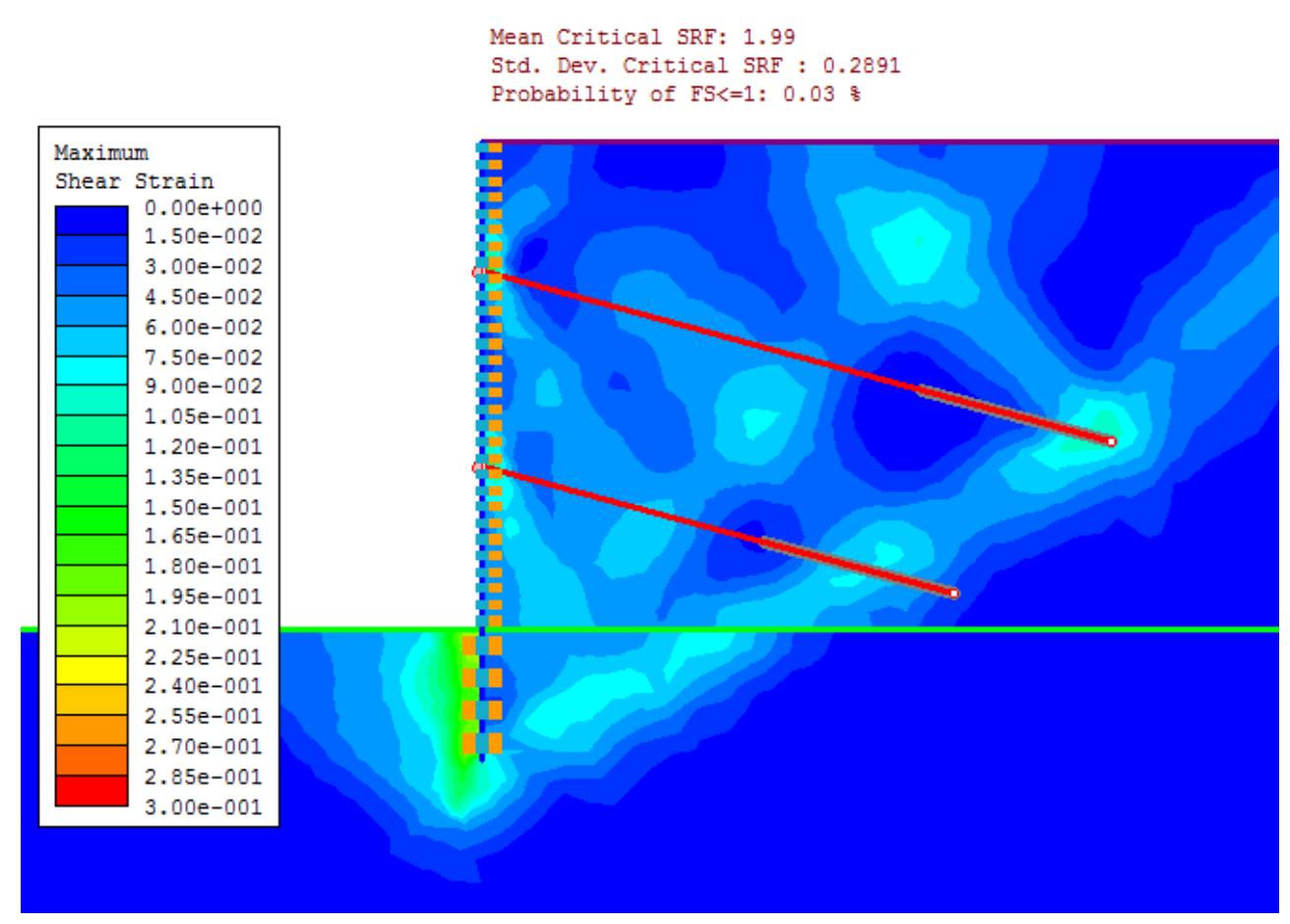

Figura 151 - Resultado da análise de estabilidade com variação probabilística das propriedades do solo - Modelo 1.6-3 
Média e desvio padrão:

$$
\begin{aligned}
& \mu=1,99 \\
& \sigma=0,2891
\end{aligned}
$$

Probabilidade de falha (Probabilidade de FS $\leq 1$ ):

$$
P_{f}\{F S \leq 1\}=0,03 \%(1 \mathrm{em} \mathrm{3333)}
$$

Índice de confiabilidade:

$$
\beta=\frac{1,99-1}{0,2891}=3,42
$$

Na figura 151 é apresentada a deformação cisalhante máxima que ocorre na condição de instabilidade para o valor médio do fator de segurança. Nota-se que é formado um plano médio de falha no alinhamento dos tirantes.

O fator de segurança médio obtido neste modelo é $5,9 \%$ maior que o modelo 1.6-2 e o valor da probabilidade de falha teve uma diminuição significativa de quase 10 vezes.

O índice acima, assim como o anterior é menor que o valor indicado pelo Eurocode 0 (2004), para estado limite último em 50 anos, 3,5.

Para investigar a diminuição na probabilidade de ruína deste modelo perante os anteriores, foram elaborados mais três modelos com alterações no ângulo de atrito na interface entre solo e o concreto.

Reis (2006) estudou o modelo de atrito estático na interface de concreto e areia. De acordo com a bibliografia estudada e os resultados dos ensaios foram encontrados valores para a relação ângulo de atrito residual na interface areiaconcreto e ângulo de atrito de pico da ordem de 0,8 a 1. A partir destes valores foram elaborados modelos com as variações de ângulo de atrito na interface mostradas na tabela 28 . 
Tabela 28 - Valores adotados para o ângulo de atrito na interface solo-concreto

\begin{tabular}{|c|c|c|c|c|}
\cline { 2 - 5 } \multicolumn{1}{c|}{} & \multicolumn{4}{|c|}{ Relação $\delta_{\text {RES }} / \delta$} \\
\hline \multirow{2}{*}{$\delta$} & \multicolumn{2}{|c|}{0,8} & \multicolumn{2}{c|}{1,0} \\
\cline { 2 - 5 } & $\delta_{\text {RES }}$ & Modelo & $\delta_{\text {RES }}$ & Modelo \\
\hline 21 & 16,8 & Modelo 1.6-5 & 21,0 & Modelo 1.6-3 \\
\hline 30 & 24,0 & Modelo 1.6-6 & 30,0 & Modelo 1.6-4 \\
\hline
\end{tabular}

Fonte: Elaborado pelo autor

Faz-se a observação de que nos modelos 1.6-4 e 1.6-6 o ângulo de atrito de pico na interface tem o mesmo valor do ângulo de atrito da camada 1.

Os resultados são apresentados na tabela 29:

Tabela 29 - Resultados dos modelos com variação o ângulo de atrito na interface solo-concreto

\begin{tabular}{|c|c|c|c|c|}
\hline Modelo & $\boldsymbol{\mu}_{\mathrm{FS}}$ & $\boldsymbol{\sigma}_{\mathrm{Fs}}$ & $\mathbf{P}_{\mathbf{f}}(\%)$ & $\boldsymbol{\beta}$ \\
\hline Modelo 1.6-3 & 1,99 & 0,2891 & 0,03 & 3,42 \\
\hline Modelo 1.6-4 & 2,05 & 0,2923 & 0,02 & 3,59 \\
\hline Modelo 1.6-5 & 1,96 & 0,2731 & 0,02 & 3,52 \\
\hline Modelo 1.6-6 & 2,02 & 0,2877 & 0,02 & 3,55 \\
\hline
\end{tabular}

Fonte: Elaborado pelo autor

Observa-se que há tendência de diminuição do fator de segurança médio e do índice de confiabilidade e aumento da probabilidade de falha para valores menores, em geral, do ângulo de atrito na interface. Em geral, a diminuição o ângulo de atrito residual em relação ao de pico trouxe uma diminuição no fator de segurança médio, no entanto a variação da probabilidade de falha e índice de confiabilidade foi pequena.

Explica-se o aumento do fator de segurança médio, do modelo 1.6-3 em relação ao 1.6-2 pelo fato do ângulo de atrito, no modelo 1.6-3, ter sido considerado como variável aleatória independente, quando de fato ele está correlacionado com o ângulo de atrito do solo. Julga-se, portanto, que esta consideração é inadequada.

Para deixar isto mais explícito apresenta-se a seguir os resultados de outros dois modelos, baseados no modelo 1.6-2, mas calculados de forma determinística, em que foi aplicada uma redução de $2 \times \sigma$ no ângulo de atrito da camada 1. Em um 
dos modelos, o modelo 1 , o ângulo de atrito da interface foi correlacionado ao ângulo de atrito da camada 1 pelo fator 0,7 e no modelo 2 foi utilizado o ângulo de atrito da interface original acrescido de $1 \times \sigma$.

Tabela 30 - Valores adotados para o ângulo de atrito na interface solo-concreto e resultados

\begin{tabular}{|c|c|c|c|}
\hline Modelo & $\boldsymbol{\phi}$ & $\boldsymbol{\delta}$ & FS \\
\hline Modelo 1 & 20 & 14 & 1,58 \\
\hline Modelo 2 & 20 & 27,5 & 1,71 \\
\hline
\end{tabular}

Fonte: Elaborado pelo autor

Pelos resultados apresentados na tabela 30 fica evidenciada a influência do ângulo de atrito na interface. 
8.7 ANÁLISE DE ESTABILIDADE COM MODELO ELASTOPLÁSTICO PERFEITO PARA A RIGIDEZ DA PAREDE, CONSIDERANDO O DIAGRAMA BILINEAR INDICADO PELO CEB-FIB 2010 E A VARIAÇÃO DOS PARÂMETROS DO SOLO (ANÁLISE ESTATÍSTICA)

Foram elaborados dois modelos para análise estatística dos fatores de segurança, considerando a não linearidade física do paramento de concreto. Estes modelos foram baseados nos modelos 1.6-1 e 2, em foi utilizado o PEM.

\section{MODELO 1.7-1}

Foram adotados os seguintes parâmetros:

Solo: Foram adotados os mesmos valores para os parâmetros do solo (média e desvio padrão) do modelo 1.6-2.

Interface: Foi adotado o mesmo valor de ângulo de atrito do modelo 1.6-2, sem variação estatística.

Parede: Foram adotados os mesmos valores do modelo 1.3-2 (parâmetros do CEB-FIB 2010).

As combinações de variáveis aplicadas resultaram em $2^{4}=16$ modelos para obtenção dos resultados. $\mathrm{O}$ tempo de processamento foi de 4 horas.

\section{RESULTADOS DO MODELO 1.7-1:}

A figura 152 apresenta os valores obtidos para o fator de segurança médio, desvio padrão e probabilidade de falha (Probabilidade de FS $\leq 1$ ): 


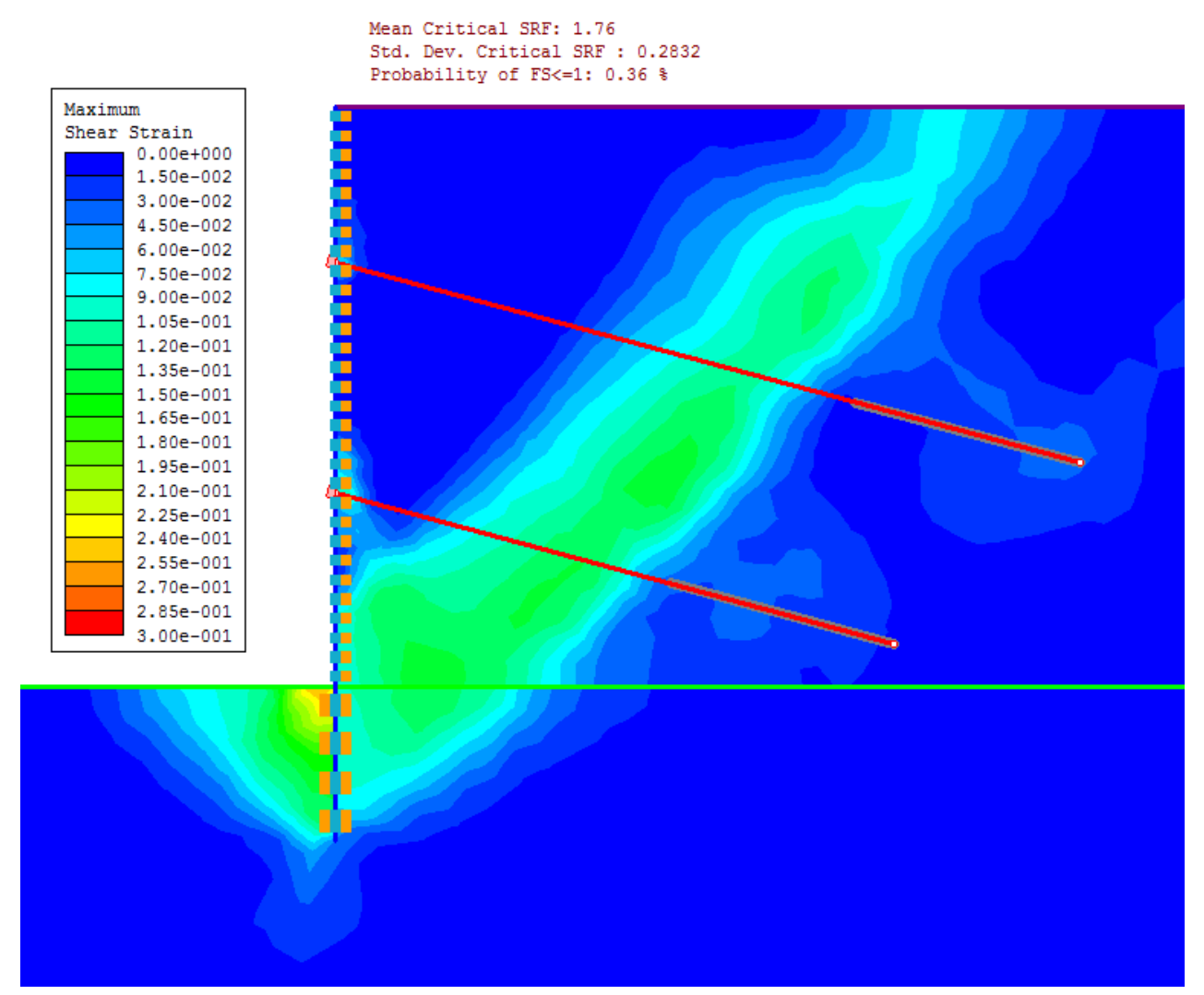

Figura 152 - Resultado da análise de estabilidade com variação probabilística das propriedades do solo e paramento de concreto não linear - Modelo 1.7-1

Média e desvio padrão:

$$
\begin{aligned}
& \mu=1,76 \\
& \sigma=0,2832
\end{aligned}
$$

Probabilidade de falha (Probabilidade de FS $\leq 1$ ):

$$
P_{f}\{F S \leq 1\}=0,36 \%(1 \mathrm{em} 278)
$$

Índice de confiabilidade:

$$
\beta=\frac{1,76-1}{0,2832}=2,68
$$

Para verificar se os modelos gerados pelo PEM atendem aos requisitos de plastificação para o concreto armado foram analisados os 16 modelos gerados para obtenção do momento fletor máximo com a força normal concomitante. 
Dos modelos analisados o que apresentou o maior valor de momento fletor foi o modelo com fator de segurança $F S=1,93$, e com as propriedades:

Areia argilosa medianamente compacta:

Coesão $=30 \mathrm{kPa}(+1 \sigma)$

Angulo de atrito $=25^{\circ}(-1 \sigma)$

Areia argilosa compacta:

Coesão $=40 \mathrm{kPa}(+1 \sigma)$

Angulo de atrito $=25^{\circ}(-2 \sigma)$

O momento fletor máximo foi de $229,9 \mathrm{kNm}$ com força normal concomitante de $454,5 \mathrm{kN}$.

Observou-se que a diferença relativa entre os valores de momento fletor dos modelos foi pequena, da ordem de $\pm 5 \%$, para os valores máximos de força normal a diferença relativa foi pouco maior, da ordem de $\pm 10 \%$. Nota-se que os valores para momento fletor máximo e força normal concomitante encontrado, são próximos dos valores obtidos no modelo 1.3-2, que é a análise com os valores médios para os parâmetros do solo, portanto será desnecessário verificar se há formação de rótulas plásticas.

Ao se comparar os modelos similares 1.7-1 (concreto não linear) e 1.6-2 (concreto linear), observa-se que houve um aumento na probabilidade de falha e diminuição do fator de segurança médio, do modelo 1.7-1. Isso ocorre pelo fato do paramento de concreto do modelo $1.7-1$ ser menos rígido que o do modelo 1.6-2. No entanto o índice de confiabilidade dos dois modelos é menor que o valor indicado pelo Eurocode 0 (2004), para estado limite último em 50 anos, 3,5.

\section{MODELO 1.7-2}

Foram adotados os seguintes parâmetros:

Solo: Foram adotados os mesmos valores para os parâmetros do solo (média e desvio padrão) do modelo 1.6-3.

Interface: Foi adotado o mesmo valor de ângulo de atrito do modelo 1.6-3 (média e desvio padrão). 
Parede: Foram adotados os mesmos valores do modelo 1.3-2 (parâmetros do CEB-FIB 2010).

As combinações de variáveis aplicadas resultaram em $2^{5}=32$ modelos para obtenção dos resultados. O tempo de processamento foi de 4 horas.

\section{RESULTADOS DO MODELO 1.7-2:}

A figura 153 apresenta os valores obtidos para o fator de segurança médio, desvio padrão e probabilidade de falha (Probabilidade de $\mathrm{FS} \leq 1$ ):

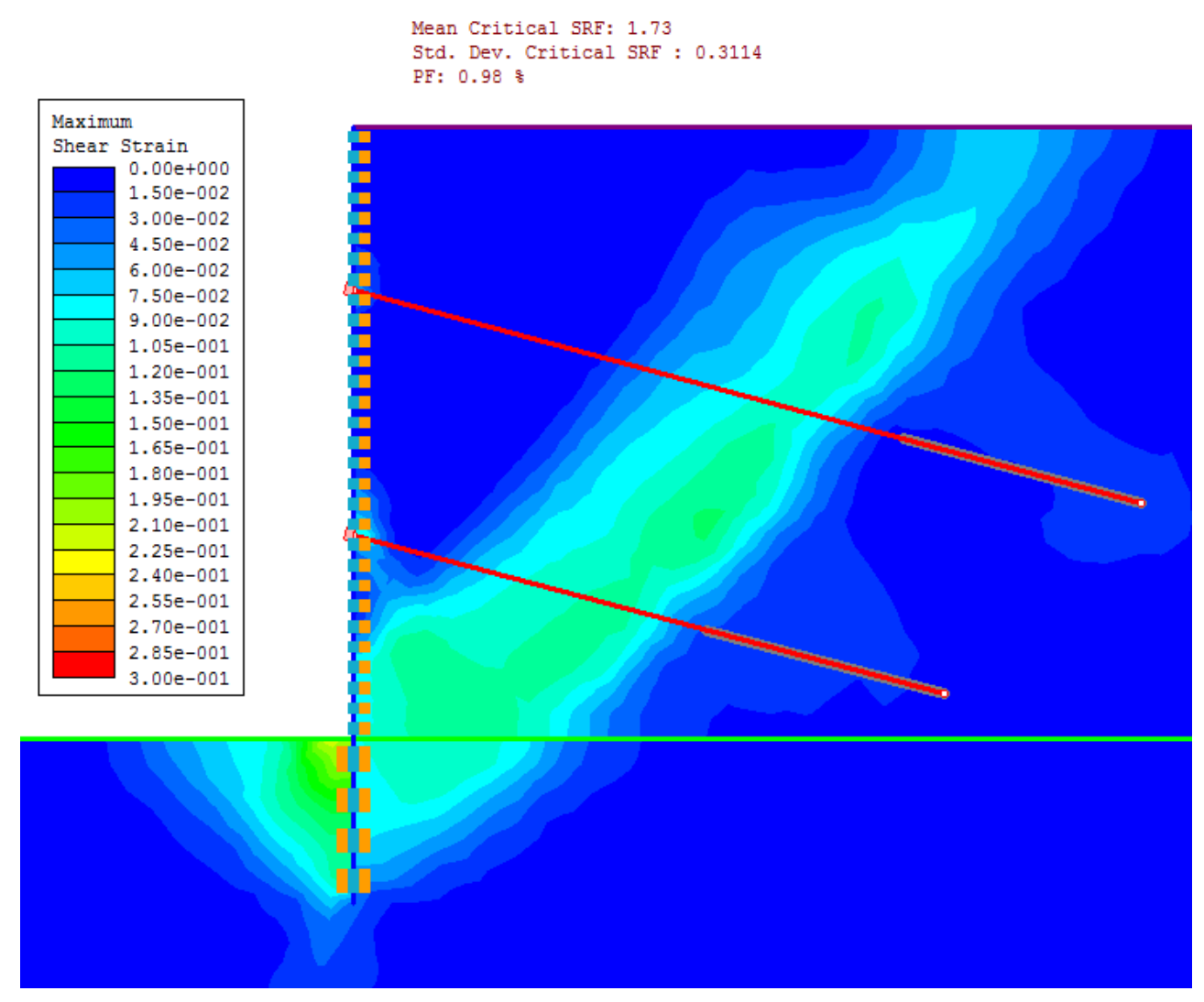

Figura 153 - Resultado da análise de estabilidade com variação probabilística das propriedades do solo e interface e paramento de concreto não linear - Modelo 1.7-2

Média e desvio padrão:

$$
\begin{aligned}
& \mu=1,73 \\
& \sigma=0,3114
\end{aligned}
$$

Probabilidade de falha (Probabilidade de FS $\leq 1$ ): 


$$
P_{f}\{F S \leq 1\}=0,98 \%(1 \mathrm{em} \mathrm{102})
$$

Índice de confiabilidade:

$$
\beta=\frac{1,73-1}{0,3114}=2,34
$$

Observa-se um aumento na probabilidade de falha e uma diminuição no fator de segurança médio ao compararmos os resultados obtidos com os do modelo 1.7-1. Estes resultados são coerentes, pois à medida que se aumentam as variáveis, aumentam as incertezas, e com isto aumenta também a probabilidade de falha.

Para verificar se os modelos gerados pelo PEM atendem aos requisitos de plastificação para o concreto armado foram analisados os 32 modelos gerados para obtenção do momento fletor máximo com a força normal concomitante.

Dos modelos analisados o que apresentou o maior valor de momento fletor foi o modelo com fator de segurança $F S=2,0$, e com as propriedades:

Areia argilosa medianamente compacta:

Coesão $=10 \mathrm{kPa}(-1 \sigma)$

Angulo de atrito $=35^{\circ}(+1 \sigma)$

Areia argilosa compacta:

Coesão $=40 \mathrm{kPa}(+1 \sigma)$

Angulo de atrito $=30^{\circ}(-1 \sigma)$

O momento fletor máximo foi de $241,7 \mathrm{kNm}$ com força normal concomitante de $472,23 \mathrm{kN}$.

Observou-se que a diferença relativa entre os valores de momento fletor dos modelos foi da ordem de $\pm 10 \%$, para os valores máximos de força normal a diferença relativa foi pouco maior, da ordem de $\pm 20 \%$. Estes valores sugerem que proceder a verificação estrutural do paramento de concreto com os esforços resultantes da análise com fator de segurança médio é razoável considerando o efeito dos fatores parciais de segurança que promovem o afastamento das curvas de resistência e solicitação, no entanto seria necessária uma calibração do fator de segurança considerando a dispersão dos resultados para que os fatores de segurança conduzam a uma probabilidade de falha admitida. 
Nota-se que os valores para momento fletor máximo e força normal concomitante encontrado, são pouco maiores que no modelo 1.7-1, portanto será desnecessário verificar se há formação de rótulas plásticas.

Foi elaborado mais um modelo em que foi realizada a variação de ângulo de atrito na interface mostrada na tabela 31 .

Tabela 31 - Valores adotados para o ângulo de atrito na interface solo-concreto

\begin{tabular}{|c|c|c|}
\cline { 2 - 3 } \multicolumn{1}{c|}{} & \multicolumn{2}{c|}{ Relação $\delta_{\text {RES }} / \delta$} \\
\hline \multirow{2}{*}{$\delta$} & \multicolumn{2}{|c|}{1,0} \\
\cline { 2 - 3 } & $\delta_{\text {RES }}$ & Modelo \\
\hline 21 & 21,0 & Modelo 1.7-2 \\
\hline 30 & 30,0 & Modelo 1.7-3 \\
\hline
\end{tabular}

Fonte: Elaborado pelo autor

Optou-se por não elaborar modelos com uma relação entre ângulo de atrito residual na interface versus ângulo de atrito de pico na interface menor que 1, face a pequena diferença apresentada no capitulo 8.6.

Faz-se a observação de que no modelo 1.7-3 o ângulo de atrito de pico na interface tem o mesmo valor do ângulo de atrito da camada 1.

Os resultados são apresentados na tabela 32 :

Tabela 32 - Resultados dos modelos com variação o ângulo de atrito na interface solo-concreto

\begin{tabular}{|c|c|c|c|c|}
\hline Modelo & $\mu_{\mathrm{FS}}$ & $\sigma_{\mathrm{FS}}$ & $\mathbf{P}_{\mathbf{f}}(\%)$ & $\boldsymbol{\beta}$ \\
\hline Modelo 1.7-2 & 1,73 & 0,3114 & 0,98 & 2,34 \\
\hline Modelo 1.7-3 & 1,84 & 0,2850 & 0,17 & 2,95 \\
\hline
\end{tabular}

Fonte: Elaborado pelo autor

Observa-se que, assim como nos modelos com paramento elástico linear para a rigidez da parede, há tendência de diminuição do fator de segurança médio e do índice de confiabilidade e aumento da probabilidade de falha para valores menores, em geral, do ângulo de atrito na interface.

Os modelos com modelo reológico elastoplástico perfeito para a parede, 1.71 e 1.7-2, apresentaram situações opostas as dos modelos 1.6-2 e 1.6-3. Neste caso a consideração do ângulo de atrito na interface como variável aleatória independente 
fez com que fosse obtido um fator de segurança e índice de confiabilidade, menores para o modelo com variação estatística do ângulo de atrito na interface.

Explica-se isto devido ao fato de que, de forma geral, quanto maior o ângulo de atrito na interface, maior a rigidez do sistema e, portanto, maior a parcela de esforço absorvida pela parede. Como, neste caso, a rigidez da parede varia com a solicitação, há uma menor a rigidez do sistema que faz com que haja maiores deslocamentos e assim menos estabilidade. No entanto, pelos mesmos motivos apresentados no capítulo 8.6, julga-se que a consideração do ângulo de atrito na interface como variável aleatória independente é inadequada. 


\subsection{RESUMO DAS ANÁLISES}

Foi elaborada uma tabela com resumo dos resultados das análises realizadas:

Tabela 33 - Resumo dos resultados das análises

\begin{tabular}{|c|c|c|c|c|c|c|c|}
\hline MODELO & $\begin{array}{l}\text { PARAMENTO } \\
\text { DE CONCRETO }\end{array}$ & $\begin{array}{c}\text { NORMA PARA O } \\
\text { CONCRETO }\end{array}$ & $\begin{array}{c}\text { ANÁLISE } \\
\text { ESTATÍSTICA } \\
\text { - SOLO }\end{array}$ & $\begin{array}{c}\text { ANÁLISE } \\
\text { ESTATÍSTICA - } \\
\text { SOLO E } \\
\text { INTERFACE } \\
\end{array}$ & $\begin{array}{c}\text { FATOR DE } \\
\text { SEGURANÇA }\end{array}$ & $\begin{array}{c}\text { PROBABILIDADE } \\
\text { DE FALHA }\end{array}$ & $\begin{array}{c}\text { ÍNDICE DE } \\
\text { CONFIABILIDADE }\end{array}$ \\
\hline 1,2 & Elastico linear & ABNT NBR6118:2007 & - & - & 2,00 & - & - \\
\hline $1.3-1$ & Elastico não linear & ABNT NBR6118:2007 & - & - & 1,78 & - & - \\
\hline $1.3-2$ & Elastico não linear & CEB-FIB 2010 & - & - & 1,86 & - & - \\
\hline 1,4 & $\mathrm{M}-\mathrm{N}-1 / \mathrm{r}$ & ABNT NBR6118:2007 & - & - & 1,80 & - & - \\
\hline 1,5 & $\mathrm{M}-\mathrm{N}-1 / \mathrm{r}$ & CEB-FIB 2010 & - & - & 1,81 & - & - \\
\hline $1.6-1$ & Elastico linear & ABNT NBR6118:2007 & Monte Carlo & - & 1,89 & $0,25 \%$ & 2,81 \\
\hline $1.6-2$ & Elastico linear & ABNT NBR6118:2007 & PEM & - & 1,88 & $0,29 \%$ & 2,75 \\
\hline $1.6-3$ & Elastico linear & ABNT NBR6118:2007 & - & $\operatorname{PEM}\left(\delta_{\mathrm{RES}} / \delta=1\right)$ & 1,99 & $0,03 \%$ & 3,42 \\
\hline $1.6-5$ & Elastico linear & ABNT NBR6118:2007 & - & $\operatorname{PEM}\left(\delta_{\mathrm{RES}} / \delta=0,8\right)$ & 1,96 & $0,02 \%$ & 3,52 \\
\hline $1.7-1$ & Elastico não linear & CEB-FIB 2010 & PEM & - & 1,76 & $0,36 \%$ & 2,68 \\
\hline $1.7-2$ & Elastico não linear & CEB-FIB 2010 & - & $\operatorname{PEM}\left(\delta_{\mathrm{RES}} / \delta=1\right)$ & 1,73 & $0,98 \%$ & 2,34 \\
\hline
\end{tabular}

Fonte: Elaborado pelo autor.

Nota: Os modelos 1.6-4, 1.6-6 e 1.7-3 não foram incluídos no resumo por terem característica básica (ângulo de atrito na interface maior) diferente dos demais.

Pela tabela acima, observa-se de forma geral que os valores do fator de segurança são menores que o do modelo 1.2. Os resultados, em termos de fator de segurança, dos modelos 1.4 e 1.5 estão coerentes com os resultados dos modelos 1.3-1 e 2. Nas análises estatísticas destacam-se os valores da probabilidade de falha e índice de confiabilidade, que apresentaram valores muito diferentes do indicado pelo Eurocode 0 (2004), para durabilidade de 50 anos, a não ser pelos modelos 1.6-3 e 1.6-5. A probabilidade de falha apresentou valores maiores em relação aos apresentados como admissíveis por Munaiar Neto et al. $\left(2005\right.$, p.60) ( $P_{f}$ entre $0,1 \%$ e $0,0001 \%)$ e Meyerhof $(1982)\left(P_{f}=0,1 \%\right)$, no entanto está na faixa dos valores apresentados na figura 75, para taludes. Apesar dos valores da probabilidade de falha serem altos, os fatores de segurança médios apresentaram valores razoáveis, compatíveis com o que se adota na prática (FS entre 1,5 e 2), o que evidencia que os fatores de segurança analisados isoladamente não indicam qual o grau de segurança envolvido. Como exposto no capítulo sobre risco, para 
projetos o grau de segurança a ser adotado deveria ser analisado para cada tipo de obra. Nos modelos 1.6-3 e 1.6-5 a consideração do ângulo de atrito da interface como variável aleatória independente levou a valores de fator de segurança, probabilidade de falha e índice de confiabilidade incoerentes e como exposto anteriormente julga-se inadequada. 


\section{CONCLUSÕES}

Por meio de modelos simples como o de uma viga em balanço, que foi baseado em revisões bibliográficas, verificou-se que o resultado das análises numéricas, via MEF, em elementos com função de interpolação quadrática convergem mais rapidamente (com menor número de elementos) para o resultado correto do que os elementos com função de interpolação linear, pois os modelos com função de interpolação quadrática apresentaram resultados melhores mesmo nos modelos menos discretizados. Os resultados entre o modelo analítico e os numéricos, com função de interpolação quadrática, diferiram pouco. Houve diferença nas tensões apresentadas pelos modelos lineares, que mesmo com o aumento do número de elementos apresentaram diferenças significativas indicando que a convergência para os resultados esperados demandaria um aumento maior na discretização. Os modelos quadráticos com elementos triangulares e quadrilaterais mostraram resultados parecidos para quantidades de elementos semelhantes.

$\mathrm{Na}$ análise de estabilidade, via MEF, dependendo da implementação do programa adotado, as verificações de estabilidade e dimensionamentos, podem ser feitos em um único modelo com a vantagem de se obter os campos de tensões e deslocamentos do maciço.

Como resultado deste tipo de análise, é obtido um fator de segurança global que está ligado ao mecanismo de ruptura em que este fator é menor. Desta forma, como vantagem do método, não é necessário impor uma superfície de deslizamento, pois a medida que ocorre a plastificação aparece naturalmente uma região plastificada cujo plano médio é a superfície de plastificação. Isto se torna interessante em casos complexos de contenções, barragens e taludamentos em que seria necessário fazer um grande número de análises e ainda assim sem a garantia, que de acordo com o método adotado, da obtenção do menor fator de segurança.

Uma desvantagem do método é a necessidade de parâmetros para os modelos, que nem sempre são possíveis de se obter nas obras correntes, como o módulo de deformabilidade e o coeficiente de poisson, e para utilizar o método, recorre-se a correlações com os resultados das investigações disponíveis, normalmente o SPT. 
No entanto os resultados em modelos de análise numérica, indicados pelas revisões bibliográficas, mostraram que mesmo para grandes variações do módulo do deformabilidade, da ordem de $10^{3}$, as diferenças com relação ao fator de segurança foram pequenas, o mesmo foi observado para o coeficiente de poisson. Ressalta-se que os resultados observados são válidos para modelos mais simples e que não foi considerado nenhum tipo de intervenção no maciço, como escavação ou introdução de reforços.

A aplicação do fator de segurança por meio da redução da resistência ao cisalhamento, shear strength reduction (SSR), é similar a aplicação de fator de segurança para materiais como aço e concreto, pois ele é aplicado diretamente sobre a os agentes que geram incerteza na resistência enquanto o método do fator de carga é uma medida indireta da segurança.

Uma forma de se conhecer a segurança em um problema de estabilidade é fazer uma análise de estabilidade utilizando um método estatístico. Desta forma pode-se obter como resultado a probabilidade de ruína e o fator de segurança médio. Para isso é necessário conhecer a propriedades dos materiais em seus valores médios e também sua variação.

Existem na literatura técnica algumas publicações que indicam os valores para o desvio padrão ou a variação dos parâmetros do solo. Porém, devido a heterogeneidade do solo, ainda é muito pouco para que possa ser utilizado em todas as análises de projeto. A maior parte dos estudos e ensaios para obtenção destes parâmetros são em países do hemisfério norte e sabe-se que devido ao intemperismo mais intenso o comportamento mecânico do solo na região dos trópicos é diferente.

No capítulo 5 há uma apresentação dos modelos reológicos adotados pelo o CEB-FIP 1990, CEB-FIB 2010 e ABNT NBR6118:2007 para análises não lineares. Foi analisado também o Eurocode 2 (2004) e constatou-se que as relações constitutivas para o concreto e o aço são similares ao CEB-FIB 2010, assim optouse por não se apresentar o Eurocode 2 (2004).

Ao compararmos a norma ABNT NBR6118:2007 com os códigos modelos CEB-FIP 1990 e CEB-FIB 2010 a primeira diferença está no tipo de diagrama adotado para os diversos fins, que pela norma é o parabólico-retangular para análises não-lineares e dimensionamentos (verificação de estado limite último, ELU), 
nos códigos modelos é indicado um diagrama mais sofisticado para análises nãolineares. O equacionamento do diagrama parabólico-retangular entre os três é o mesmo para classes de concreto até C50, o que indica que tenham a mesma origem. A vantagem no uso deste diagrama está na sua simplicidade pois ele depende apenas da resistência a compressão.

As equações indicadas para análise não-linear pelos códigos modelos são iguais, a não ser pela obtenção dos coeficientes, em que se destaca que no CEBFIB 2010 a deformação correspondente a tensão máxima de compressão, $\varepsilon_{c l}$, não é constante e varia em função da resistência a compressão. O CEB-FIP 1990 apresenta uma formulação específica para o trecho decrescente do diagrama tensão-deformação, além da deformação limite convencionada. Entende-se que sua aplicação seja feita em casos de verificação de estruturas existentes ou que entraram em colapso, pois sua consideração levaria a grandes deformações.

Quanto a resistência média a compressão, a ABNT NBR6118:2007 não indica o valor a ser adotado em projeto. O CEB-FIP 1990 e CEB-FIB 2010 fornecem os mesmos valores para obtenção da resistência média a compressão a ser adotada em projeto. Para a realidade brasileira atual existem dúvidas quantos aos valores a serem adotados para $\Delta f$ e consequentemente para o desvio padrão, que podem ser sensivelmente menores.

Quanto ao aço tanto a norma quanto os códigos modelos indicam o diagrama idealizado elastoplástico perfeito projeto, independentemente do tipo de análise. O CEB-FIB 2010, além do elastoplástico perfeito indica um diagrama elastoplástico com endurecimento, ou encruamento. Os diagramas indicados independem do processo de fabricação do aço. No caso da norma os limites de deformações a serem usados em projeto ficam determinados pelos domínios de deformação, no CEB-FIP 1990 podem ser usados os domínios de deformação e no CEB-FIB 2010 não há indicação dos limites a serem adotados em projeto, a não ser o alongamento máximo de acordo com a classe do aço e no caso das deformações plásticas da estrutura terem relevância.

Tanto o CEB-FIP 1990, quanto o CEB-FIB 2010 classificam o aço por classes que são determinadas pelo alongamento total característico para a carga máxima e, como pode-se chamar, pela razão de encruamento a relação $\left(f_{t} \mid f_{y}\right)_{k}$. 
Observa-se que os valores para o alongamento total característico para a carga máxima e a razão de encruamento, determinados pela norma ABNT NBR7480 (2007) para o aço CA-50 são os mesmos que para o aço da classe A no CEB-FIP 1990 e para o aço da classe B no CEB-FIB 2010.

Quanto aos riscos envolvidos na estabilidade de contenções pode-se considerar quatro tipos de obras quanto ao risco de perda de vidas e custo financeiro:

1. Contenção provisória de taludes fora de áreas urbanas;

2. Contenção definitiva de taludes fora de áreas urbanas;

3. Contenção provisória de taludes em áreas urbanas;

4. Contenção definitiva de taludes em áreas urbanas;

Para contenções um sistema de avaliação como 0 da ABNT NBR11682:2009 poderia ser adotado, neste caso os fatores de segurança a serem considerados deveriam ser calibrados para este tipo de obra.

Quanto aos modelos elaborados para análise de estabilidade, foi realizado um teste de malha em que foram feitos 12 modelos, 6 com o elemento tipo T6 (triângular de 6 nós) e 6 com o elemento tipo Q8 (quadrilateral de 8 nós), com aumento gradativo do número de elementos para verificação da convergência de resultados. A melhor forma de fazer esta verificação seria dividir os elementos progressivamente, no entanto isto não é possível no programa PHASE2, a não ser modelos com geometria muito simples, assim a verificação foi feita gerando uma nova malha, mais refinada, em cada etapa. Foi escolhido, como resultado, o deslocamento horizontal da parede diafragma em que criou-se um gráfico deslocamento versus altura da parede para cada modelo e reuniu-se para cada grupo de elementos.

Como resultados para os modelos com elementos do tipo T6, observou-se que a diferença absoluta entre os deslocamentos foi pequena, e também que a convergência foi alcançada a partir do modelo com 5317 elementos.

Adicionalmente fez-se um modelo em que a malha foi adensada somente na região de influência da parede e dos tirantes, adotou-se, igualmente aos anteriores o elemento T6, com 2918 elementos. Este modelo gerou resultados próximos aos dos modelos com mais de 5000 elementos. 
Quanto aos modelos com elementos do tipo Q8 diferença absoluta entre os deslocamentos foi grande para os modelos com menos de 2000 elementos, e a convergência foi alcançada a partir do modelo com 5817 elementos. Foram comparados os resultados dos modelos com elementos T6 e Q8 e constatou-se um comportamento mais rígido do modelo com elementos triangulares.

Pelo observado nas comparações, os modelos com elemento T6 apresentam resultados satisfatórios, tomando-se os cuidados com a discretização da malha na região da parede.

Quanto a análise de estabilidade para a parede com modelo constitutivo elástico linear não foi possível atender as condições de compatibilidade entre tensões e deformações para o concreto armado na condição limite de estabilidade. Ressalta-se que nos métodos tradicionais (equilíbrio limite) de verificação da estabilidade, não é considerada a rigidez da parede, no entanto pela prática da engenharia os valores dos fatores de segurança adotados como mínimo, neste tipo de análise (equilíbrio limite), indiretamente proporcionam alguma segurança. $O$ termo "alguma segurança" é usado no sentido de que se desconhece o quão seguro é, pois não é conhecida plenamente a variabilidade de todos os agentes envolvidos no problema, a começar pelo solo que é um material heterogêneo e chegando até o método construtivo. $\mathrm{O}$ fator de segurança obtido foi $\mathrm{FS}=2,0$.

Quanto aos modelos com modelo constitutivo elastoplástico perfeito para o paramento de concreto foram obtidos os fatores de segurança $F S=1,78$, para os modelos com os limites indicados por França (R., 1991) e FS $=1,86$ para os modelos com os limites indicados pelo CEB-FIB 2010. Foi possível, com estes modelos, atender as condições de compatibilidade entre tensões e deformações na parede de concreto armado, no entanto com a diminuição de rigidez da parede, houve também diminuição do fator de segurança, comparado ao obtido na análise elástica linear. Observou-se que o número de iterações neste tipo de análise (análise de estabilidade considerando a não linearidade física do paramento de concreto) é fundamental para obtenção de valores adequados para o fator de segurança.

Nessa análise considerou-se que o coeficiente majorador dos esforços foi levado em conta de forma indireta pela aplicação do fator de segurança no maciço, consequentemente aplicando um fator global. A norma ABNT NBR 8681:2003 não 
trata de um caso específico como este (análise de estabilidade de contenções), pois o coeficiente que seria aplicado dependeria da variabilidade das propriedades do solo, no entanto para situações de projeto recomenda-se cautela, neste caso seria prudente aplicar os coeficientes da combinação normal ou excepcional.

$\mathrm{Na}$ análise de estabilidade considerando a rigidez tangente do diagrama M$\mathrm{N}-1 / \mathrm{r}$, com os diagramas tensão-deformação parabólico-retangular e os limites da ABNT NBR6118:2007 e de Grasser e os limites do CEB-FIB 2010, a intenção desta aplicação do diagrama de interação não foi resolver o problema da compatibilidade de tensões e deformações, (para isso seria necessário elaborar um novo programa ou implementar algum existente com a formulação adequada), mas atribuir uma rigidez mais adequada, com algum critério, para a parede da contenção, somente no caso da análise de estabilidade. Obtiveram-se nesta aplicação os fatores de segurança FS = 1,8 e FS = 1,81, com os diagramas tensão-deformação parabólicoretangular e de Grasser respectivamente.

$\mathrm{Na}$ análise de estabilidade com modelo elástico linear e não linear para a rigidez do paramento de concreto, considerando a variação dos parâmetros do solo (análise estatística) foram utilizados dois métodos para análise estatística, o método de Monte Carlo com a técnica de amostragem LHS e o PEM.

Para completar as análises, pelo Método de Carlo foram necessárias mais de 8 horas de trabalho entre as etapas de carregar os modelos e fazer os processamentos, considerando o tempo ininterrupto, além disso, foram necessárias mais 2 horas para tratamento dos dados, com total de 10 horas. Para este tipo trabalho ressalta-se a importância do algoritmo de análise estatística estar incorporado ao programa de análise mecânica para ser possível a elaboração de estudos considerando mais dados e outros tipos de modelos de distribuição.

O método de Monte Carlo é mais robusto que PEM, pois não há a imposição de que as variáveis de entrada e os resultados obedeçam à distribuição normal de densidade de probabilidade. Pelo modelo 1.6-1 foi verificado que a curva normal apresentou uma aproximação satisfatória para a distribuição de probabilidades do fator de segurança, considerando este fato como indício de que a distribuição normal de probabilidades seja adequada para representar o fator de segurança no tipo de análise realizada. Neste caso o PEM apresenta-se como alternativa eficiente e com possibilidade de uso em problemas práticos de engenharia. 
Observa-se de forma geral que os valores do fator de segurança são menores que o do modelo 1.2. Os resultados, em termos de fator de segurança, dos modelos 1.4 e 1.5 estão coerentes com os resultados dos modelos $1.3-1$ e 2 . Nas análises estatísticas destacam-se os valores da probabilidade de falha e índice de confiabilidade, em que último apresentou valores muito diferentes do indicado pelo Eurocode 0 (2004), para durabilidade de 50 anos. A probabilidade de falha apresentou valores maiores em relação aos considerados admissíveis por Munaiar Neto et al. (2005, p.60) ( $P_{f}$ entre $0,1 \%$ e $\left.0,0001 \%\right)$ e Meyerhof $(1982)\left(P_{f}=0,1 \%\right)$, no entanto está na faixa dos valores apresentados na figura 75 , para taludes. Apesar dos valores da probabilidade de falha serem altos, os fatores de segurança médios apresentaram valores razoáveis, compatíveis com o que se adota na prática (FS entre 1,5 e 2), o que evidencia que os fatores de segurança analisados isoladamente não indicam qual o grau de segurança envolvido. Como exposto no capítulo sobre risco, para projetos o grau de segurança envolvida deveria ser analisada para cada tipo de obra. Nos modelos 1.6-3 a 1.6-6 a consideração do ângulo de atrito da interface como variável aleatória independente levou a valores de fator de segurança, probabilidade de falha e índice de confiabilidade incoerentes e como exposto anteriormente julga-se inadequada. Esta observação também é válida para os modelos 1.7-2 e 1.7-3.

O objetivo central deste trabalho foi contribuir, seja com os modelos realizados ou com a bibliografia juntada, para a compreensão da análise de estabilidade do ponto de vista estrito da parede de concreto, pois tradicionalmente este item não é visto com rigor.

Cita-se por fim o dogma do fator de segurança:

"Fator de segurança maior que um é o dogma. O fator de segurança do projeto ótimo deve atender três aspectos de engenharia: a) o técnico que considera a fórmula que associa o fator de segurança à probabilidade de ruína; b) o legal de ter que adotar o valor mínimo das normas vigentes e, c) ao mercado que comanda o custo total incluindo o custo do risco das conseqüências econômico financeiras da ruína. $O$ valor do fator de segurança da alternativa ótima de projeto é o fator de segurança que atende o dogma." (AOKI, 2008). 


\section{SUGESTÕES PARA TRABALHOS FUTUROS}

Como sugestões para trabalhos futuros sobre o tema faz-se as seguintes indicações quanto a análises numéricas:

Paramento de concreto:

Variar os modelos reológicos para o concreto, alterar espessuras e resistências e estabelecer relações paramétricas, considerar a variabilidade das propriedades mecânicas do concreto por meio de uma análise estatística, juntamente com a variabilidade dos demais elementos que compõe a contenção;

Tirantes:

Estudar os efeitos da variabilidade dos tirantes, os efeitos das variações de rigidez, de acordo com o tipo de tirante usado. Este estudo seria importante para complementar o presente trabalho. Pode-se ainda considerar a variabilidade das propriedades mecânicas do tirante por meio de uma análise estatística,

Solo:

Variar os modelos constitutivos, critérios de resistência, estudar os efeitos do endurecimento com o descarregamento principalmente na estabilidade e distribuição de empuxos no paramento. Considerar a variabilidade das propriedades mecânicas do solo com diversos tipos de funções densidade de probabilidade (desde que respaldado em pesquisas), a variabilidade espacial, tanto horizontal quanto vertical e as correlações entre parâmetros.

Todos estes estudos podem ser realizados por meio de modelos em estado plano de deformação e modelos tridimensionais. No caso deste último acrescenta-se o estudo do efeito tridimensional para valas, em que as relações altura de escavação e comprimento da parede são pequenas (menores que 5) e também a possibilidade de se realizar um estudo de robustez em que se considera a eventual falha de um ou mais tirantes e seus efeitos na estabilidade.

Quanto a pesquisas de campo, faltam dados de instrumentação, não só de deslocamentos, mas de esforços atuantes em serviço. A instrumentação seria importante para poder comparar os efeitos dos diversos métodos construtivos com os respectivos desempenhos em serviço e também para validar os modelos desenvolvidos. 


\section{REFERÊNCIAS}

ALMEIDA NETO, E. S. (2008). PEF5741-Fundamentos da mecânica das estruturas I. Notas de aula . São Paulo.

AOKI, N. (2008). Dogma do fator de segurança. v. 1 , p. 9-42. São Paulo: SEFE VI Seminário de Engenharia de Fundações e Geotecnia.

Associação Brasileira de Normas Técnicas. (2009). NBR11682: Estabilidade de encostas. Rio de Janeiro.

Associação Brasileira de Normas Técnicas. (2007). NBR6118: Projeto de estruturas de concreto - Procedimento. Rio de Janeiro.

Associação Brasileira de Normas Técnicas. (2007). NBR7480: Aço destinado a armaduras para estruturas de concreto armado - Especificação. Rio de Janeiro.

Associação Brasileira de Normas Técnicas. (2003). NBR8681: Ações e segurança nas estruturas - Procedimento. Rio de Janeiro.

Associação Brasileira de Normas Técnicas. (2008). NBR8800: Projeto de estruturas de aço e de estruturas mistas de aço e concreto de edifícios. Rio de Janeiro.

AUN, G. V. (2004). A influência da largura de uma vala na determinação do empuxo passivo. Dissertação de Mestrado . São Paulo: Escola Politécnica da Universidade de São Paulo.

AZEVEDO, Á. F. (2003). Método dos elementos finitos. Porto, Portugal: Faculdade de Engenharia da Universidade do Porto.

BATHE, K. J. (1996). Finite element procedure. Nova Jersey: Prentice-Hall.

BECK, A. T. (2011). Confiabilidade estrutural. Apostila do curso SET5915Confiabilidade estrutural . São Carlos: Escola de Engenharia de São Carlos Universidade de São Paulo.

BILGIN, Ö. (2010). Numerical studies of anchored sheet pile wall behavior constructed in cut and fill conditions. Computers and Geotechnics , p. 399-407.

BOWLES, J. E. (1996). Foundation analysis and design (5th ed.). Nova lorque: McGraw-Hill.

BREBBIA, C. A.; Connor, J. J. (1973). Fundamentals of finite element techniques: for structural engineers. Londres: Butterworth.

BRINKGREVE, R. B.; BAKKER, H. L. (1991). Non-linear finite element analysis of safety factor. Computer Methods and Advances in Geomechanics . Rotterdam: Proceedings of the seventh international conference on computer method and advances en geomechanics.

BUCHAIM, R. (2001). A influência do não-linearidade física do concreto armado na rigidez a flexão e na capacidade de rotação plástica. Tese de doutorado, 260p. São Paulo: Escola Politécnica da Universidade de São Paulo. 
BUENO, B. S.; VILAR, O. M. (2004). Mecânica dos solos. Apostila . São Carlos: Serviço Gráfico-Escola de Engenharia de São Carlos.

CAMPOS FILHO, A. (2003). Fundamentos da análise de estruturas de concreto pelo método dos elementos finitos. Apostila . Porto Alegre: Universidade Federal do Rio Grande do Sul.

CAPUTO, H. P. (2011). Mecânica dos solos e suas aplicações-Fundamentos (Vol. 1). Rio de Janeiro: LTC.

CHERUBINI, C.; GARRASI, A.; PETROLLA, C. (Junho de 1992). The reliability of an anchored sheet-pile wall embedded in cohesionless soil. Canadian Geotechnical Journal, Volume 29 - número 3, pp. 426-435.

Cia do Metropolitano de São Paulo - METRÔ. (1980). NC 03. Normas técnicas complementares . São Paulo: Departamento de Projeto Civil.

CLOUGH, G. W.; O'ROURKE, T. D. (1990). Construction Induces Movements of insitu walls. Special publication No 25 - Design and performance of earth retaining structures. ASCE.

Comité Euro-Internacional du Beton. (1993). CEB-FIP. Model Code 1990-Design Code . Londres: Tomas Telford.

COST Action C7. (2002). Guidelines for the use of advanced numerical analysis. Londres: Thomas Telford.

COSTA, H. B. (2008). PEF5762-Método dos elementos finitos. Notas de aula .

DHILLON, B. S. (1999). Design Reliability: Fundamentals and Applications. Londres: CRC Press.

DUNCAN, M. J. (Abril de 2000). Factors of safety and reliability in geotechnical engineering. Journal of Geotechnical and Geoenvironmental Engineering, pp. p. 307-316.

European Committee for Standardization. (2004). Eurocode 2: Design of concrete structures. Reino Unido.

European Committee for Standardization. (2004). Eurocode 7: Geotechinical design. Reino Unido.

European Committee for Standardization. (2004). Eurocode EN 1990 (Eurocode 0) Basis of structural design. Reino Unido.

FABRÍCIO, J. V. (2006). Análises probabilísticas da estabilidade de taludes e contenções. Dissertação de Mestrado . Rio de Janeiro: Pontífícia Universidade Católica do Rio de Janeiro.

FERREIRA, J. C.; FARFÁN, A. D. (2006). Análise comparativa da estabilidade de taludes utilizando os métodos de equilíbrio limite, elementos finitos e análise limite numérica. Campos de Goytacazes: Anais do II Workshop de Computação Científica da UENF. 
FLORES, E. A. (2008). Análises probabilísticas da estabilidade de taludes considerando a variabilidade espacial do solo. Dissertação de Mestrado . Rio de Janeiro: Pontifícia Universidade Católica do Rio de Janeiro.

FRANÇA, P. T. (2009). Estudo do comportamento de túneis-Análise numérica tridimensional com modelos elasto-plásticos. Dissertação de Mestrado, 185p. São Paulo: Escola Politécnica da Universidade de São Paulo.

FRANÇA, R. L. (1991). Contribuição aos efeitos de segunda ordem em pilares de concreto armado. Tese de Doutorado. São Paulo: Escola Politécnica da Universidade de São Paulo.

FRANÇA, R. L. (2009). PEF5746-Concreto estrutural II-Análise de estabilidade. Notas de aula . São Paulo.

FRANÇOIS, M. (2008). A new yield criterion for the concrete materials. Comptes Rendus Mécanique 336 , p. 417 à 421.

FUSCO, P. B. (1981). Estruturas de concreto-Solicitações normais. Rio de Janeiro: Guanabara Dois.

FUSCO, P. B. (1995). Técnica de armar as estruturas de concreto. São Paulo: Pini.

FUSCO, P. B. (2008). Tecnologia do concreto estrutural. São Paulo: Pini.

GIMENES, E. Á. (1988). Contribuição à obtenção de parâmetros estatísticos de medições geotécnicas irregularmente espaçadas. Dissertação de Mestrado . São Paulo: Escola Politécnica da Universidade de São Paulo.

GUIDICINI, G.; NIEBLE, C. M. (1983). Estabilidade de taludes naturais e de escavação. São Paulo: Blucher.

HACHICH, W. C. (1978). Sobre a segurança nos projetos de geotecnia. Dissertação de Mestrado . São Paulo: Escola Politécnica da Universidade de São Paulo.

HAMMAH, R.; YACOUB, T.; CORKUM, B.; CURRAN, J. (Setembro de 2005). A comparison of finite element slope stability analisys with conventional limitequilibrium investigation. 6th Joint IAH-CNC and CGS Groundwater Specialty Conferences . Canda.

IBRACON. (2007). Comentários técnicos e exemplos de aplicação da NB-1. São Paulo.

International Federation for Structural Concrete. (2010). CEB-FIB. Model Code 2010First Complete Draft , I e II . Lausanne, Suiça.

Joint Committe on Structural Fafety. (2006). Section3.7: Soil Properties. JCSS Probabilistic Model Code .

LANGENDONK, T. v. (1959). Cálculo de concreto armado. Rio de Janeiro: Editora Científica.

LEONHARDT, F.; MÖNNING, E. (1977). Construções de concreto (Vol. I). (D. Fridman, Trad.) Rio de Janeiro: Interciência. 
MAGALHÃES, M. N.; LIMA, A. C. (2002). Noções de probabilidade e estatística (4 ed.). São Paulo: Edusp.

MARTINS, P. A. (2008). Análise numérica de escavações subterrâneas com ênfase na interação entre o maciço e o suporte em concreto projetado a baixas idades. Tese de Doutorado , 194. Brasília: Universidade de Brasília.

MARZIONNA, J. D. (1979). Sobre o cálculo estático de valas. Dissertação de Mestrado . São Paulo: Escola Politécnica da Universidade de São Paulo.

MASSAD, F. (2003). Obras de terra - Curso básico de geotecnia. São Paulo: Oficina de textos.

MEDEIROS, G. A. (2004). Programa para análise e dimensionamento da área de armadura de seções de concreto armado submetidas a flexão oblíqua composta. Trabalho de Graduação . São José dos Campos: Instituto Tecnológico de Aeronáutica.

MENDES NETO, F. Acesso em 05 de Junho de 2011, disponível em Páginas do Flávio Mendes : <http://www.civil.ita.br/ mendes/>

MENDONÇA, H. M. (2005). Sobre a modelagem de problemas da engenharia geotecnica pelo método dos elementos finitos. Dissertação de Mestrado , 157p. São Paulo: Escola Politécnica da Universidade de São Paulo.

MEYERHOF, G. G. (1982). Limit states design in geotechnical engineering. Structural Safety, pp. 67-71.

MORE, J. Z. (2003). Análise numérica do comportamento de cortinas atirantadas em solos. Dissertação de Mestrado . Rio de Janeiro: Pontifícia Universidade Católica do Rio de Janeiro.

MUNAIAR NETO, J.; SALES, J. J.; GONÇALVES, R. M.; MALITE, M. (2005). Segurança nas estruturas. São Carlos: SET-EESC-USP.

NIAN, T. K.; CHEN, G. Q.; WAN, S. S.; LUAN, M. T. (Maio de 2011). Nonconvergence criterion on slope stability FE analysis by strength reduction method. Journal of Convergence Information Tecnology .

NIMIR, W. A. (1979). Sobre o calculo de paredes diafragma em valas de metrôs. Tese de Doutorado. São Carlos: Escola de Engenharia de São Carlos Universidade de São Paulo.

NOGUEIRA, C. L. (1998). Análise não linear de escavações e aterros. Tese de Doutorado , 281p. Rio de Janeiro: Pontifícia Universidade Católica do Rio de Janeiro.

OLIVEIRA, R. M.; FRANÇA, R. L. (2000). Contribuição ao estudo da rigidez de pilares e vigas de concreto armado em análises de $2^{\circ}$ ordem. São Paulo: Escola Politécnica da Universidade de São Paulo.

OU, C. (2006). Deep Excavation - Theory and Pratice. Londres: Taylor \& Francis. 
PACHÁS, M. A. (2009). Análise limite com otimizador de grande escala e análise de confiabilidade. Tese de doutorado, 188p. Rio de Janeiro: Pontífica Universidade Católica do Rio de Janeiro.

PIMENTA, P. M. (2007). Fundamentos da mecânica dos sólidos e das estruturas. Apostila curso PEF5742-Fundamentos da mecânica das estruturas II , 386. São Paulo.

PINHEIRO, L. M. (2005). Estruturas de concreto. Apostila do curso SET404Estruturas de concreto $A$. São Carlos.

PINHEIRO, L. M.; NASCIMENTO, A. L.; MOREIRA, M. V. (2006). Flexão simples em seção retangular. Tabelas gerais . São Carlos.

PINTO, C. S. (2002). Curso básico de mecânica dos solos. São Paulo: Oficina de textos.

POTTS, D. M.; ZDRAVKOVIC, L. (1999). Finite element analysis in geotechnical engineering Theory, Application. London: Thomas Telford.

PROENÇA, S. P. (2001). Curso de resistência dos materiais. Apostila , I e II . Serviço Gráfico-Escola de Engenharia de São Carlos.

REIS, J. H. (2006). Modelo de atrito estático em interfaces de contato entre concreto e areia. Tese de Doutorado . São Carlos: Escola de Engenharia de São Carlos.

RIBEIRO JÚNIOR, A. S.; SANTOS, G. J. (2007). Apostila-Curso de introdução ao método dos elementos finitos. Salvador.

RIBEIRO, R. C. (2008). Aplicações de probabilidade e estatística em análises geotécnicas. Tese de Doutorado . Rio de Janeiro: Pontifícia Universidade Católica do Rio de Janeiro.

Rocscience Inc. (s.d.). Manual teórico do Phase2. Toronto.

Rocscience Inc. (s.d.). Slide 6.0 - Probabilistic Analysis. Toronto.

ROSENBLUETH, E. (Outubro de 1975). Point estimates for probability moments. Proceedings of National Academy of Sciences, Vol. 72 , p. 3812-3814.

ROSENBLUETH, E. (Outubro de 1981). Two-point estimates in probabilities. Applied Mathematical Modelling, Vol. 5 , p. 329-335.

RÜSH, H. (1981). Concreto armado e protendido - Propriedades dos materiais e dimensionamento. (Y. P. Melichar, Trad.) Rio de Janeiro: Editora Campus.

SALIBY, E. (1997). Descriptive sampling: An improvement over Latin Hipercube Sampling. Atlanta: Proceedings of the 1997 Winter Simulation Conference.

SÁNCHEZ, E. (2011). Cálculo tensorial (Vol. II). Rio de Janeiro: Editora Interciência.

SÁNCHEZ, E. (2000). Elementos de mecânica dos sólidos. Rio de Janeiro: Interciência.

SÁNCHEZ, E. (2007). Tensores (Vol. I). Rio de Janeiro: Editora Interciência. 
Sandia's Latin Hypercube Sampling Software. (1998). A User's Guide to LHS. Albuquerque: Risk Assessment and Systems Modeling Department.

Savassi, W. (1996). Introdução ao método dos elementos finitos em análise linear de estruturas. São Carlos: Serviço Gráfico EESC.

SAVASSI, W. (1996). Introdução ao método dos elementos finitos em análise linear de estruturas. São Carlos: Serviço Gráfico EESC.

SILVA, F. C. (2003). Análise de segurança e confiabilidade de fundações profundas em estacas. Dissertação de Mestrado . São Carlos: Escola de Engenharia de São Carlos - Universidade de São Paulo.

SORIANO, H. L. (2003). Método de elementos finitos em análise de estruturas. São Paulo: EDUSP.

TACITANO, M. (2006). Análise de paredes de contenção através de método unidimensional evolutivo. Tese de Doutorado . Campinas: Universidade Estadual de Campinas.

TIMOSHENKO, S. P.; GOODIER, J. N. (1970). Theory of elasticity. Nova lorque: McGraw-Hill.

TRONDI, R. R. (1993). Cálculo evolutivo de paredes de contenção. Dissertação de Mestrado . São Carlos: Escola de Engenharia de São Carlos - Universidade de São Paulo.

US Army Corps of Engineers. (1994). Design of sheet pile walls. EM 1110-2-2504 . Washington: Department of the army.

VALLEY, B.; DUFF, D. (01 de Junho de 2011). Probabilistic analyses in Phase2 8.0. http://www.rocscience.com/about/news/article/146.

VELLOSO, D. A.; MARIA, P. E.; LOPES, F. R. (1998). Princípios e modelos básicos de análise. In: V. Autores, Fundações: Teoria e Prática. São Paulo: Pini.

VUOLO, J. H. (1999). Introdução à teoria de erros. Apostila . São Paulo: Instituto de Física - Universidade de São Paulo.

YASSUDA, C. T.; DIAS, H. V. (1998). Tirantes. In: V. Autores, Fundações: Teoria e Prática. São Paulo: Pini.

ZEVGOLIS, I. E.; BOURDEAU, P. L. (2010). Probabilistic analysis of retaining walls. Computer and Geotechnics, p. 359-373. 


\section{APÊNDICE A - TABELA DE AMOSTRAGEM}

Tabela 34 - Amostragem e combinação aleatória das amostras de coesão e ângulo de atrito para os modelos

\begin{tabular}{|c|c|c|c|c|c|}
\hline $\begin{array}{c}\text { Areia argilosa } \\
\text { medianamente compacta } \\
\text { : Coesão }(\mathrm{kN} / \mathrm{m} 2)\end{array}$ & $\begin{array}{c}\text { Areia argilosa } \\
\text { medianamente compacta } \\
\text { : Ângulo de atrito (Graus) }\end{array}$ & $\begin{array}{l}\text { Areia argilosa compacta : } \\
\text { Coesão }(\mathrm{kN} / \mathrm{m} 2)\end{array}$ & $\begin{array}{l}\text { Areia argilosa compacta : } \\
\text { Ângulo de atrito (Graus) }\end{array}$ & Modelo & $\begin{array}{l}\text { Fator de } \\
\text { Segurança }\end{array}$ \\
\hline 18.9999 & 27.5417 & 20.2260 & 35.1159 & 001 & 1.85 \\
\hline 28.1200 & 30.5656 & 16.3698 & 33.5113 & 002 & 1.91 \\
\hline 21.8298 & 36.6521 & 1.1635 & 33.9526 & 003 & 1.71 \\
\hline 20.0152 & 30.2921 & 45.3259 & 32.0489 & 004 & 2.05 \\
\hline 16.2662 & 28.4090 & 42.2997 & 41.9431 & 005 & 1.89 \\
\hline 22.2031 & 24.5141 & 23.3153 & 36.2462 & 006 & 1.77 \\
\hline 13.1984 & 22.7568 & 39.2328 & 31.6005 & 007 & 1.45 \\
\hline 18.0080 & 28.6356 & 44.3879 & 32.3803 & 008 & 1.93 \\
\hline 35.6493 & 29.4707 & 41.1521 & 32.6515 & 009 & 2.23 \\
\hline 14.8730 & 29.5966 & 16.0220 & 41.3426 & 010 & 1.69 \\
\hline 11.5086 & 30.3534 & 14.0128 & 31.7735 & 011 & 1.68 \\
\hline 23.6071 & 29.5380 & 36.2191 & 31.2222 & 012 & 1.99 \\
\hline 23.2448 & 27.6487 & 43.3510 & 39.4006 & 013 & 2.09 \\
\hline 23.3031 & 24.8485 & 45.8018 & 34.9254 & 014 & 2.00 \\
\hline 12.5919 & 28.9136 & 21.8426 & 33.7999 & 015 & 1.60 \\
\hline 25.2695 & 36.0791 & 26.3706 & 30.8829 & 016 & 2.00 \\
\hline 34.0410 & 32.6026 & 24.0019 & 28.6771 & 017 & 1.86 \\
\hline 9.7249 & 35.4533 & 31.3104 & 27.4005 & 018 & 1.85 \\
\hline 29.0302 & 21.6552 & 30.4221 & 43.2680 & 019 & 2.01 \\
\hline 37.7741 & 28.7530 & 31.2214 & 38.6796 & 020 & 2.35 \\
\hline 20.8775 & 33.2293 & 33.9220 & 35.5803 & 021 & 2.18 \\
\hline 5.9129 & 31.9632 & 44.7263 & 35.7370 & 022 & 1.55 \\
\hline 8.8491 & 30.0447 & 38.5269 & 42.5795 & 023 & 1.60 \\
\hline 12.7620 & 29.3199 & 42.5568 & 35.3879 & 024 & 1.75 \\
\hline 8.1200 & 32.3071 & 30.2067 & 31.4070 & 025 & 1.56 \\
\hline 22.8385 & 30.1234 & 37.6262 & 26.6864 & 026 & 1.86 \\
\hline 27.9641 & 31.1365 & 41.6548 & 43.1221 & 027 & 2.41 \\
\hline 25.1376 & 33.0343 & 29.9673 & 33.0323 & 028 & 2.11 \\
\hline 26.1194 & 24.1441 & 54.1404 & 34.1073 & 029 & 2.08 \\
\hline 7.4779 & 31.5778 & 39.0536 & 29.4034 & 030 & 1.55 \\
\hline 35.0626 & 23.9016 & 40.3466 & 31.5708 & 031 & 2.02 \\
\hline 15.6471 & 25.5844 & 8.8616 & 29.0101 & 032 & 1.51 \\
\hline 18.1746 & 25.3874 & 13.7254 & 37.8359 & 033 & 1.61 \\
\hline 9.5608 & 20.7120 & 26.7592 & 32.5779 & 034 & 1.25 \\
\hline 7.8929 & 31.5317 & 26.4717 & 29.1974 & 035 & 1.50 \\
\hline 31.6203 & 23.0953 & 19.3632 & 35.0912 & 036 & 1.89 \\
\hline 16.9218 & 30.7432 & 46.0853 & 39.1192 & 037 & 2.04 \\
\hline
\end{tabular}




\begin{tabular}{|c|c|c|c|c|c|}
\hline $\begin{array}{c}\text { Areia argilosa } \\
\text { medianamente compacta } \\
\text { : Coesão }(\mathrm{kN} / \mathrm{m} 2)\end{array}$ & $\begin{array}{l}\text { Areia argilosa } \\
\text { medianamente compacta } \\
\text { : Ângulo de atrito (Graus) }\end{array}$ & $\begin{array}{l}\text { Areia argilosa compacta : } \\
\text { Coesão (kN/m2) }\end{array}$ & $\begin{array}{l}\text { Areia argilosa compacta : } \\
\text { Ângulo de atrito (Graus) }\end{array}$ & Modelo & $\begin{array}{l}\text { Fator de } \\
\text { Segurança }\end{array}$ \\
\hline 11.7701 & 34.4914 & 23.9381 & 44.3904 & 038 & 1.91 \\
\hline 13.0772 & 37.8970 & 31.7914 & 34.0231 & 039 & 2.14 \\
\hline 22.0498 & 17.0706 & 33.3471 & 42.2348 & 040 & 1.63 \\
\hline 5.1814 & 35.9472 & 27.0849 & 38.3012 & 041 & 1.59 \\
\hline 1.6294 & 30.9723 & 29.3442 & 40.2830 & 042 & 1.40 \\
\hline 32.0341 & 33.0933 & 26.1425 & 32.8985 & 043 & 2.04 \\
\hline 19.7067 & 29.2887 & 30.1680 & 38.7381 & 044 & 1.96 \\
\hline 15.1070 & 31.0803 & 20.2932 & 39.4241 & 045 & 1.79 \\
\hline 20.3458 & 28.8555 & 18.4253 & 25.4532 & 046 & 1.54 \\
\hline 8.1560 & 26.3734 & 29.2418 & 29.6364 & 047 & 1.33 \\
\hline 35.7321 & 33.3215 & 21.2070 & 27.8629 & 048 & 1.83 \\
\hline 32.6847 & 40.4839 & 36.1131 & 44.9047 & 049 & 3.00 \\
\hline 36.9682 & 27.2393 & 12.9986 & 32.2232 & 050 & 1.80 \\
\hline 11.3303 & 39.9430 & 30.0909 & 33.4451 & 051 & 2.14 \\
\hline 13.8871 & 22.1392 & 40.1749 & 41.5985 & 052 & 1.57 \\
\hline 25.2925 & 38.4983 & 48.1719 & 31.8857 & 053 & 2.35 \\
\hline 26.8677 & 20.3613 & 26.0532 & 46.3515 & 054 & 1.85 \\
\hline 12.9788 & 26.7297 & 29.0152 & 30.0917 & 055 & 1.52 \\
\hline 14.4179 & 28.4864 & 47.1487 & 35.3940 & 056 & 1.82 \\
\hline 36.2033 & 38.1034 & 28.1946 & 38.2019 & 057 & 2.45 \\
\hline 0.7674 & 29.6191 & 29.5762 & 42.7377 & 058 & 1.69 \\
\hline 25.0053 & 25.7910 & 40.0444 & 32.4077 & 059 & 1.96 \\
\hline 22.4814 & 37.0245 & 27.6020 & 35.6860 & 060 & 2.25 \\
\hline 16.3314 & 36.7269 & 23.5170 & 22.5051 & 061 & 1.59 \\
\hline 34.7022 & 29.2216 & 43.6190 & 36.4471 & 062 & 2.34 \\
\hline 31.9658 & 26.4377 & 21.3984 & 39.3263 & 063 & 2.12 \\
\hline 45.4859 & 33.1503 & 30.6909 & 29.8206 & 064 & 2.06 \\
\hline 34.4736 & 27.3308 & 35.8462 & 41.0587 & 065 & 2.36 \\
\hline 12.2138 & 32.9566 & 22.0941 & 29.7626 & 066 & 1.77 \\
\hline 19.9201 & 27.4105 & 25.6191 & 32.9758 & 067 & 1.84 \\
\hline 23.7875 & 33.4500 & 12.8987 & 40.2412 & 068 & 2.27 \\
\hline 3.2871 & 35.2142 & 4.8484 & 33.3595 & 069 & 1.24 \\
\hline 17.4174 & 28.7956 & 38.2810 & 38.2808 & 070 & 1.91 \\
\hline 25.6400 & 23.3664 & 42.6726 & 33.2980 & 071 & 1.96 \\
\hline 21.1249 & 35.5962 & 30.5297 & 37.5622 & 072 & 2.30 \\
\hline 13.3455 & 19.9556 & 15.3945 & 44.6012 & 073 & 1.36 \\
\hline 41.0982 & 25.6973 & 20.5608 & 34.3704 & 074 & 1.98 \\
\hline 21.3619 & 32.3310 & 38.6518 & 26.0050 & 075 & 1.84 \\
\hline 15.7631 & 34.1905 & 39.2907 & 37.0715 & 076 & 2.08 \\
\hline 14.6309 & 30.4235 & 37.8189 & 31.9764 & 077 & 1.82 \\
\hline 7.1805 & 24.9226 & 25.5089 & 36.9975 & 078 & 1.28 \\
\hline 27.3635 & 26.7980 & 10.5356 & 38.6437 & 079 & 1.98 \\
\hline 36.6470 & 28.0381 & 31.0220 & 37.4120 & 080 & 2.25 \\
\hline
\end{tabular}




\begin{tabular}{|c|c|c|c|c|c|}
\hline $\begin{array}{c}\text { Areia argilosa } \\
\text { medianamente compacta } \\
\text { : Coesão }(\mathrm{kN} / \mathrm{m} 2)\end{array}$ & $\begin{array}{l}\text { Areia argilosa } \\
\text { medianamente compacta } \\
\text { : Ângulo de atrito (Graus) }\end{array}$ & $\begin{array}{c}\text { Areia argilosa compacta : } \\
\text { Coesão (kN/m2) }\end{array}$ & $\begin{array}{l}\text { Areia argilosa compacta : } \\
\text { Ângulo de atrito (Graus) }\end{array}$ & Modelo & $\begin{array}{l}\text { Fator de } \\
\text { Segurança }\end{array}$ \\
\hline 16.5273 & 26.9849 & 22.9319 & 45.6294 & 081 & 1.75 \\
\hline 17.7523 & 24.2418 & 42.9499 & 29.3548 & 082 & 1.69 \\
\hline 15.0069 & 19.1621 & 27.1983 & 37.0347 & 083 & 1.39 \\
\hline 17.2435 & 36.8392 & 25.6746 & 38.4542 & 084 & 2.27 \\
\hline 17.6326 & 33.6649 & 28.7499 & 34.5960 & 085 & 2.08 \\
\hline 33.5831 & 32.1059 & 19.8505 & 37.4731 & 086 & 2.22 \\
\hline 26.7316 & 28.2249 & 23.0894 & 41.4607 & 087 & 2.21 \\
\hline 38.7316 & 27.1183 & 21.6350 & 33.8463 & 088 & 1.98 \\
\hline 7.0731 & 30.5320 & 32.6188 & 39.5341 & 089 & 1.53 \\
\hline 11.0424 & 37.4561 & 18.5955 & 40.4132 & 090 & 1.89 \\
\hline 0.1213 & 29.8666 & 14.3225 & 35.2481 & 091 & 1.40 \\
\hline 16.7708 & 23.6999 & 48.9091 & 33.5697 & 092 & 1.69 \\
\hline 26.2320 & 27.6952 & 25.0504 & 31.6935 & 093 & 1.90 \\
\hline 20.6477 & 30.8156 & 21.4653 & 43.6066 & 094 & 2.04 \\
\hline 19.5725 & 27.8975 & 39.8315 & 32.8652 & 095 & 1.95 \\
\hline 13.8952 & 29.0633 & 22.7726 & 40.5099 & 096 & 1.69 \\
\hline 22.9047 & 30.7286 & 17.8481 & 30.5636 & 097 & 1.77 \\
\hline 30.6676 & 26.1402 & 40.5021 & 38.8634 & 098 & 2.09 \\
\hline 42.8430 & 31.1293 & 29.6867 & 30.4966 & 099 & 2.03 \\
\hline 39.2128 & 32.2690 & 27.5004 & 37.2312 & 100 & 2.33 \\
\hline 8.9894 & 27.7440 & 12.4025 & 39.7951 & 101 & 1.36 \\
\hline 26.0342 & 31.2382 & 22.8940 & 40.5931 & 102 & 2.24 \\
\hline 29.3102 & 32.5372 & 36.9641 & 39.7735 & 103 & 2.41 \\
\hline 41.4000 & 19.5942 & 27.6651 & 36.1208 & 104 & 1.97 \\
\hline 15.1727 & 28.2816 & 14.7688 & 32.4889 & 105 & 1.71 \\
\hline 29.8108 & 30.1648 & 36.8253 & 37.6703 & 106 & 2.28 \\
\hline 5.5957 & 26.4940 & 32.0254 & 36.6297 & 107 & 1.30 \\
\hline 11.5754 & 22.5874 & 24.5604 & 40.8152 & 108 & 1.37 \\
\hline 4.9738 & 32.4482 & 37.0372 & 39.2586 & 109 & 1.50 \\
\hline 27.5387 & 33.2992 & 17.2591 & 37.1807 & 110 & 2.15 \\
\hline 18.4100 & 33.5840 & 47.7571 & 44.2194 & 111 & 2.23 \\
\hline 18.7845 & 39.0816 & 34.1375 & 37.1284 & 112 & 2.38 \\
\hline 12.3167 & 32.0534 & 16.4987 & 27.9758 & 113 & 1.63 \\
\hline 18.6612 & 21.9228 & 35.4757 & 35.9467 & 114 & 1.66 \\
\hline 24.8638 & 28.3292 & 23.5646 & 25.7674 & 115 & 1.63 \\
\hline 13.7413 & 31.8082 & 39.5365 & 34.7284 & 116 & 1.91 \\
\hline 27.1468 & 40.7817 & 18.0353 & 31.8318 & 117 & 2.05 \\
\hline 19.3923 & 35.4802 & 19.9834 & 31.4874 & 118 & 1.91 \\
\hline 31.5279 & 28.9486 & 34.5826 & 33.1100 & 119 & 2.11 \\
\hline 16.8162 & 18.1906 & 49.2304 & 35.5059 & 120 & 1.51 \\
\hline 18.4848 & 28.9884 & 29.0263 & 33.2022 & 121 & 1.90 \\
\hline 19.8808 & 24.9908 & 24.1461 & 34.8245 & 122 & 1.73 \\
\hline 26.4901 & 21.8543 & 40.6438 & 36.7178 & 123 & 1.95 \\
\hline
\end{tabular}




\begin{tabular}{|c|c|c|c|c|c|}
\hline $\begin{array}{c}\text { Areia argilosa } \\
\text { medianamente compacta } \\
\text { : Coesão }(\mathrm{kN} / \mathrm{m} 2)\end{array}$ & $\begin{array}{l}\text { Areia argilosa } \\
\text { medianamente compacta } \\
\text { : Ângulo de atrito (Graus) }\end{array}$ & $\begin{array}{c}\text { Areia argilosa compacta : } \\
\text { Coesão (kN/m2) }\end{array}$ & $\begin{array}{l}\text { Areia argilosa compacta : } \\
\text { Ângulo de atrito (Graus) }\end{array}$ & Modelo & $\begin{array}{l}\text { Fator de } \\
\text { Segurança }\end{array}$ \\
\hline 12.0399 & 36.5270 & 34.0209 & 40.6953 & 124 & 2.03 \\
\hline 28.2338 & 28.1193 & 31.4687 & 48.6033 & 125 & 2.28 \\
\hline 23.9540 & 41.7545 & 30.3757 & 36.8738 & 126 & 2.39 \\
\hline 27.3976 & 32.8706 & 11.7394 & 31.7392 & 127 & 1.83 \\
\hline 29.5186 & 32.7906 & 23.8614 & 37.3068 & 128 & 2.25 \\
\hline 8.4400 & 31.9311 & 27.3970 & 37.6186 & 129 & 1.59 \\
\hline 17.2775 & 32.1260 & 31.9385 & 35.8722 & 130 & 1.96 \\
\hline 20.2646 & 38.5692 & 24.5835 & 37.3516 & 131 & 2.32 \\
\hline 20.5437 & 23.5539 & 22.5840 & 33.6721 & 132 & 1.67 \\
\hline 28.8138 & 34.0023 & 26.5545 & 29.8955 & 133 & 1.95 \\
\hline 15.2733 & 33.5120 & 24.3321 & 34.9995 & 134 & 2.02 \\
\hline 31.0532 & 38.1700 & 32.9401 & 30.0279 & 135 & 2.09 \\
\hline 15.9626 & 25.9771 & 35.5482 & 37.9365 & 136 & 1.71 \\
\hline 21.0039 & 30.2224 & 46.5140 & 35.4846 & 137 & 2.10 \\
\hline 6.7439 & 28.4511 & 52.6685 & 32.3280 & 138 & 1.50 \\
\hline 17.8949 & 25.5048 & 34.2910 & 30.4334 & 139 & 1.76 \\
\hline 27.7957 & 31.8950 & 45.2016 & 40.9228 & 140 & 2.43 \\
\hline 10.2197 & 31.4052 & 28.7268 & 38.4970 & 141 & 1.68 \\
\hline 2.8551 & 38.8733 & 14.5118 & 32.1306 & 142 & 1.50 \\
\hline 31.3483 & 39.8137 & 33.1079 & 42.3407 & 143 & 2.75 \\
\hline 9.1410 & 30.0493 & 21.0903 & 27.5918 & 144 & 1.60 \\
\hline 37.3455 & 20.7794 & 25.9193 & 39.9414 & 145 & 2.03 \\
\hline 4.1465 & 23.6357 & 25.8165 & 27.0991 & 146 & 1.10 \\
\hline 30.8328 & 28.1711 & 41.8909 & 32.5464 & 147 & 2.12 \\
\hline 19.2198 & 25.2422 & 29.7516 & 37.9629 & 148 & 1.77 \\
\hline 6.0932 & 21.4157 & 11.5416 & 36.3944 & 149 & 1.10 \\
\hline 19.1002 & 32.3808 & 33.8020 & 35.3388 & 150 & 2.11 \\
\hline 24.3239 & 31.1877 & 19.2534 & 28.7865 & 151 & 1.72 \\
\hline 18.1031 & 25.1968 & 17.6228 & 47.4558 & 152 & 1.72 \\
\hline 10.9212 & 34.9546 & 41.0199 & 35.2048 & 153 & 1.91 \\
\hline 20.7599 & 26.0001 & 37.8878 & 27.0015 & 154 & 1.74 \\
\hline 49.9735 & 27.0151 & 39.7006 & 34.3134 & 155 & 2.27 \\
\hline 30.9342 & 30.6143 & 28.8527 & 39.1419 & 156 & 2.28 \\
\hline 10.0215 & 36.3368 & 28.4226 & 38.8821 & 157 & 1.86 \\
\hline 10.6423 & 29.7549 & 33.1866 & 34.1536 & 158 & 1.65 \\
\hline 14.0488 & 33.9478 & 29.4359 & 34.7714 & 159 & 2.05 \\
\hline 22.5933 & 34.2347 & 34.8590 & 32.7476 & 160 & 2.15 \\
\hline 20.6958 & 34.8437 & 28.5345 & 28.5230 & 161 & 1.86 \\
\hline 22.3822 & 29.1255 & 36.3276 & 23.3091 & 162 & 1.68 \\
\hline 19.6469 & 22.4528 & 26.9073 & 21.2729 & 163 & 1.39 \\
\hline 25.5981 & 27.5981 & 40.7759 & 30.5872 & 164 & 1.98 \\
\hline 30.4370 & 25.3065 & 33.4330 & 35.0269 & 165 & 2.05 \\
\hline 24.5975 & 35.3434 & 27.8520 & 35.9954 & 166 & 2.25 \\
\hline
\end{tabular}




\begin{tabular}{|c|c|c|c|c|c|}
\hline $\begin{array}{c}\text { Areia argilosa } \\
\text { medianamente compacta } \\
\text { : Coesão }(\mathrm{kN} / \mathrm{m} 2)\end{array}$ & $\begin{array}{c}\text { Areia argilosa } \\
\text { medianamente compacta } \\
\text { : Ângulo de atrito (Graus) }\end{array}$ & $\begin{array}{c}\text { Areia argilosa compacta : } \\
\text { Coesão }(\mathrm{kN} / \mathrm{m} 2)\end{array}$ & $\begin{array}{l}\text { Areia argilosa compacta : } \\
\text { Ângulo de atrito (Graus) }\end{array}$ & Modelo & $\begin{array}{l}\text { Fator de } \\
\text { Segurança }\end{array}$ \\
\hline 21.5228 & 29.8158 & 51.1826 & 36.8027 & 167 & 2.14 \\
\hline 12.1470 & 26.5799 & 36.6913 & 31.0076 & 168 & 1.56 \\
\hline 11.8866 & 42.1163 & 43.4267 & 32.7039 & 169 & 2.30 \\
\hline 21.7530 & 30.4475 & 27.7404 & 27.7303 & 170 & 1.76 \\
\hline 29.6599 & 25.8037 & 10.1364 & 39.5706 & 171 & 1.99 \\
\hline 15.7010 & 33.7989 & 41.3868 & 38.1683 & 172 & 2.08 \\
\hline 30.0216 & 35.9086 & 32.4896 & 37.5152 & 173 & 2.44 \\
\hline 28.5292 & 26.0939 & 50.3016 & 30.9363 & 174 & 2.05 \\
\hline 33.7964 & 27.8522 & 18.9598 & 45.2639 & 175 & 2.37 \\
\hline 18.8857 & 26.8443 & 18.8294 & 30.7723 & 176 & 1.70 \\
\hline 12.4986 & 32.8985 & 56.0283 & 36.0393 & 177 & 1.94 \\
\hline 21.6419 & 31.7452 & 30.6169 & 33.7505 & 178 & 2.07 \\
\hline 23.8647 & 34.5579 & 34.5052 & 32.8146 & 179 & 2.16 \\
\hline 17.0629 & 37.5548 & 43.9573 & 30.1377 & 180 & 2.16 \\
\hline 30.3507 & 35.1363 & 35.1000 & 24.0880 & 181 & 1.79 \\
\hline 21.9304 & 34.9412 & 32.2476 & 28.3333 & 182 & 1.90 \\
\hline 13.5513 & 24.4420 & 22.5126 & 28.1132 & 183 & 1.37 \\
\hline 4.7254 & 27.0587 & 8.3188 & 41.7054 & 184 & 1.18 \\
\hline 32.5646 & 24.0596 & 38.0764 & 27.2364 & 185 & 1.79 \\
\hline 21.1599 & 34.1342 & 37.4939 & 36.3619 & 186 & 2.27 \\
\hline 16.6542 & 32.5716 & 19.6171 & 41.8309 & 187 & 1.95 \\
\hline 20.4287 & 30.8417 & 41.5726 & 34.1936 & 188 & 2.11 \\
\hline 26.3183 & 26.2168 & 17.3656 & 35.6424 & 189 & 1.91 \\
\hline 24.5074 & 29.7611 & 33.7454 & 34.6601 & 190 & 2.10 \\
\hline 27.1126 & 26.3200 & 38.7148 & 42.0984 & 191 & 2.12 \\
\hline 27.6569 & 31.0098 & 20.7580 & 36.7769 & 192 & 2.15 \\
\hline 6.2140 & 25.8912 & 26.2872 & 26.2873 & 193 & 1.22 \\
\hline 24.1498 & 23.8643 & 34.9139 & 35.8203 & 194 & 1.89 \\
\hline 6.6037 & 22.3120 & 31.7360 & 33.2576 & 195 & 1.22 \\
\hline 23.4554 & 33.7152 & 38.9178 & 25.1008 & 196 & 1.87 \\
\hline 20.1160 & 25.5223 & 36.4805 & 31.1080 & 197 & 1.81 \\
\hline 11.1814 & 34.4160 & 6.8821 & 39.0570 & 198 & 1.64 \\
\hline 34.9326 & 26.6402 & 51.7554 & 30.3252 & 199 & 2.13 \\
\hline 28.6881 & 31.3393 & 31.4529 & 39.7036 & 200 & 2.32 \\
\hline 32.1693 & 27.1895 & 28.4772 & 35.6017 & 201 & 2.08 \\
\hline 17.1286 & 31.4558 & 30.9627 & 36.6620 & 202 & 1.94 \\
\hline 15.9289 & 35.7628 & 23.2269 & 36.2143 & 203 & 2.12 \\
\hline 10.5071 & 29.0857 & 32.7717 & 38.9972 & 204 & 1.65 \\
\hline 24.7311 & 25.0942 & 32.6666 & 40.8918 & 205 & 1.98 \\
\hline 3.8182 & 31.3109 & 33.6418 & 39.9731 & 206 & 1.50 \\
\hline 28.3347 & 31.6125 & 44.1126 & 28.6285 & 207 & 2.07 \\
\hline 14.2367 & 29.9210 & 32.2944 & 34.4609 & 208 & 1.77 \\
\hline 18.6383 & 33.8168 & 22.2286 & 28.2107 & 209 & 1.75 \\
\hline
\end{tabular}




\begin{tabular}{|c|c|c|c|c|c|}
\hline $\begin{array}{c}\text { Areia argilosa } \\
\text { medianamente compacta } \\
\text { : Coesão }(\mathrm{kN} / \mathrm{m} 2)\end{array}$ & $\begin{array}{c}\text { Areia argilosa } \\
\text { medianamente compacta } \\
\text { : Ângulo de atrito (Graus) }\end{array}$ & $\begin{array}{c}\text { Areia argilosa compacta : } \\
\text { Coesão }(\mathrm{kN} / \mathrm{m} 2)\end{array}$ & $\begin{array}{l}\text { Areia argilosa compacta : } \\
\text { Ângulo de atrito (Graus) }\end{array}$ & Modelo & $\begin{array}{l}\text { Fator de } \\
\text { Segurança }\end{array}$ \\
\hline 21.4629 & 34.3216 & 29.1319 & 36.9129 & 210 & 2.22 \\
\hline 24.0781 & 32.2107 & 26.7226 & 43.3420 & 211 & 2.25 \\
\hline 8.6839 & 27.8001 & 23.7601 & 32.2471 & 212 & 1.39 \\
\hline 7.6965 & 30.9120 & 19.4849 & 33.6486 & 213 & 1.50 \\
\hline 22.7119 & 30.6635 & 47.0174 & 34.2547 & 214 & 2.18 \\
\hline 22.1373 & 43.2852 & 16.8341 & 40.0940 & 215 & 2.39 \\
\hline 22.5843 & 29.4061 & 24.9055 & 36.5742 & 216 & 2.03 \\
\hline 26.5869 & 29.1986 & 35.9012 & 29.4641 & 217 & 1.96 \\
\hline 10.7688 & 34.5943 & 26.9778 & 31.2760 & 218 & 1.89 \\
\hline 28.9815 & 28.7022 & 27.2785 & 28.9752 & 219 & 1.81 \\
\hline 14.1373 & 24.2769 & 34.7320 & 33.5662 & 220 & 1.57 \\
\hline 38.4589 & 29.9788 & 35.4175 & 34.6307 & 221 & 2.27 \\
\hline 17.5381 & 26.9390 & 31.1591 & 33.8940 & 222 & 1.75 \\
\hline 16.3766 & 36.3046 & 37.2609 & 43.8302 & 223 & 2.22 \\
\hline 25.8520 & 24.5812 & 35.2963 & 38.5999 & 224 & 2.04 \\
\hline 10.1349 & 30.3351 & 37.3484 & 30.8400 & 225 & 1.64 \\
\hline 17.7762 & 39.4404 & 42.0965 & 34.3183 & 226 & 2.35 \\
\hline 15.5272 & 29.4265 & 24.3880 & 36.1692 & 227 & 1.74 \\
\hline 33.3679 & 28.5569 & 28.2916 & 34.5214 & 228 & 2.11 \\
\hline 32.9873 & 35.0979 & 15.1551 & 31.1533 & 229 & 1.91 \\
\hline 26.9646 & 23.0044 & 34.3711 & 33.0505 & 230 & 1.88 \\
\hline 25.7823 & 28.6055 & 35.0518 & 36.3137 & 231 & 2.13 \\
\hline 25.4959 & 28.0930 & 36.4005 & 30.6731 & 232 & 1.97 \\
\hline 19.4685 & 34.7512 & 22.3285 & 26.4883 & 233 & 1.72 \\
\hline 1.8440 & 32.6736 & 25.2446 & 29.5587 & 234 & 0.96 \\
\hline 24.7976 & 36.1859 & 29.8536 & 24.4935 & 235 & 1.76 \\
\hline 9.2874 & 37.7460 & 33.0146 & 36.4942 & 236 & 1.89 \\
\hline 40.1782 & 21.2138 & 32.1362 & 29.1228 & 237 & 1.86 \\
\hline 2.6468 & 27.4709 & 25.4176 & 34.5105 & 238 & 1.21 \\
\hline 14.5438 & 18.4124 & 15.7551 & 32.0995 & 239 & 1.27 \\
\hline 21.2925 & 37.0704 & 38.2469 & 38.1100 & 240 & 2.41 \\
\hline 9.7677 & 24.6629 & 32.4291 & 35.8942 & 241 & 1.42 \\
\hline 24.2876 & 27.9589 & 18.2094 & 38.3919 & 242 & 2.03 \\
\hline 33.0795 & 37.2115 & 25.2326 & 37.7140 & 243 & 2.33 \\
\hline 15.4008 & 22.8980 & 30.8256 & 41.2299 & 244 & 1.63 \\
\hline 4.4389 & 33.4120 & 20.6714 & 33.3650 & 245 & 1.50 \\
\hline 23.5878 & 26.5519 & 20.9078 & 42.8232 & 246 & 1.93 \\
\hline 18.3069 & 24.7407 & 28.0034 & 41.1813 & 247 & 1.73 \\
\hline 16.1666 & 31.6418 & 35.7081 & 38.0192 & 248 & 1.96 \\
\hline 19.1620 & 34.7014 & 33.5370 & 34.8819 & 249 & 2.16 \\
\hline 13.4244 & 33.8965 & 21.8965 & 40.1770 & 250 & 1.86 \\
\hline 12.8891 & 29.6650 & 24.9879 & 31.3894 & 251 & 1.67 \\
\hline 30.1159 & 31.7368 & 24.7633 & 30.2494 & 252 & 1.88 \\
\hline
\end{tabular}




\begin{tabular}{|c|c|c|c|c|c|}
\hline $\begin{array}{c}\text { Areia argilosa } \\
\text { medianamente compacta } \\
\text { : Coesão (kN/m2) }\end{array}$ & $\begin{array}{c}\text { Areia argilosa } \\
\text { medianamente compacta } \\
\text { :Ângulo de atrito (Graus) }\end{array}$ & $\begin{array}{c}\text { Areia argilosa compacta : } \\
\text { Coesão (kN/m2) }\end{array}$ & $\begin{array}{c}\text { Areia argilosa compacta : } \\
\text { Ângulo de atrito (Graus) }\end{array}$ & Modelo & $\begin{array}{c}\text { Fator de } \\
\text { Segurança }\end{array}$ \\
\hline 23.0046 & 23.2191 & 31.6581 & 26.0321 & 253 & 1.62 \\
\hline 14.6987 & 35.6976 & 37.1552 & 34.0130 & 254 & 2.14 \\
\hline 29.1759 & 27.3790 & 28.0588 & 35.1695 & 255 & 2.05 \\
\hline 23.1695 & 32.7209 & 16.9255 & 37.8184 & 256 & 2.13 \\
\hline
\end{tabular}

Fonte: Elaborado pelo autor. 